Bibliothek der Brandenburgischen und Preußischen Geschichte

Oliver Werner, Detlef Kotsch, Harald Engler (Hrsg.)

\title{
Bildung und Etablierung \\ der DDR-Bezirke in Brandenburg
}

Verwaltung und Parteien in den Bezirken Potsdam, Frankfurt/Oder und Cottbus 1952-1960 

Oliver Werner, Detlef Kotsch, Harald Engler (Hrsg.)

Bildung und Etablierung

der DDR-Bezirke in Brandenburg 


\section{BIBLIOTHEK DER BRANDENBURGISCHEN UND PREUSSISCHEN GESCHICHTE}

Herausgegeben

im Auftrag des Brandenburgischen Landeshauptarchivs und der Historischen Kommission zu Berlin

von Klaus Neitmann und Michael Wildt

Band 16 
Oliver Werner, Detlef Kotsch, Harald Engler (Hrsg.)

\section{Bildung und Etablierung der DDR-Bezirke in Brandenburg}

Verwaltung und Parteien in den Bezirken Potsdam, Frankfurt/Oder und Cottbus 1952-1960 
Bibliografische Informationen der Deutschen Nationalbibliothek

Die Deutsche Nationalbibliothek verzeichnet diese Publikation in der Deutschen Nationalbibliografie; detaillierte bibliografische Daten sind im Internet über http://dnb.d-nb.de abrufbar.

ISBN 978-3-8305-2209-6

Bibliothek der brandenburgischen und preußischen Geschichte (Print) ISSN 2366-858X Bibliothek der brandenburgischen und preußischen Geschichte (Online) ISSN 2366-8598

(C) 2017

BWV • BERLINER WISSENSCHAFTS-VERLAG GmbH

Markgrafenstraße 12-14, 10969 Berlin

E-Mail: bwv@bwv-verlag.de, Internet: http://www.bwv-verlag.de

Alle Rechte, auch die des

Nachdrucks von Auszügen, der fotomechanischen

Wiedergabe und der Übersetzung, vorbehalten. 


\section{Inhalt}

Zum Geleit

KLAus NeitmanN

Editorische Vorbemerkung

OLIVER Werner

Staat und Staatspartei. Die Verwaltungsreform der SED

in Brandenburg 1952-1960

Detlef Kotsch \& Harald Engler

Die Etablierung der staatlichen Bezirksverwaltungen in Brandenburg und der übrigen DDR. Forschungsstand und Forschungsperspektiven

OLIVER WeRnER

Verzeichnis der Dokumente

Dokumente 1952-1960

Literaturverzeichnis

Abkürzungsverzeichnis

Personenregister

Ortsregister 



\section{Zum Geleit}

Die DDR-Verwaltungsreform vom 23. Juli 1952, wie sie im „Gesetz über die weitere Demokratisierung des Aufbaus und der Arbeitsweise der staatlichen Organe in den Ländern der Deutschen Demokratischen Republik“ niedergelegt war, beinhaltete den tiefgreifendsten Umbau der Staatsorganisation und der Staatsverwaltung, der sich zwischen 1945 und 1990 in der Sowjetischen Besatzungszone und der Deutschen Demokratischen Republik vollzog. Die 1945 geschaffenen fünf Länder wurden faktisch, wenn auch (noch) nicht formal, aufgelöst und durch 14 Bezirke ersetzt, die Zahl der Kreise durch die Aufgliederung der bislang bestehenden (Groß-)Kreise erheblich vermehrt, und die Über- und Unterordnungsverhältnisse zwischen den verschiedenen Verwaltungsebenen, der zentralen (Ministerien), der regionalen (Räte der Bezirke) und der lokalen (Räte der Kreise) Ebene, wurden neu geordnet.

Mit den Beschlüssen vom Juli 1952 und deren nachfolgender Umsetzung hatte die DDR knapp drei Jahre nach ihrer Gründung die Form ihres Staatsaufbaues geschaffen, die bis zu ihrem Untergang in der friedlichen Revolution von 1989/90 nahezu unverändert bestehen blieb. Die Bezirke wurden so sehr mit der DDR identifiziert, dass ihre Fortexistenz in den politischen Debatten der ,Wendezeit“ über die Beseitigung des SEDStaates von Anfang an ausgeschlossen war und ihre Tätigkeit spätestens mit dem Beitritt der DDR zur Bundesrepublik Deutschland am 3. Oktober 1990 beendet wurde. Sie verschwanden geradezu geräusch- und folgenlos in der Geschichte, fast ist man geneigt zu sagen, sie landeten auf deren Kehrrichthaufen, da sie sich nie im Bewusstsein der breiten Bevölkerung mit einer eigenen Identität verankert hatten - im Gegensatz zu den Ländern, an deren Stelle sie 1952 gesetzt worden waren und die 1990 wiederauferstanden und ihre Nachfolge antraten.

Es wäre freilich verfehlt, in einem weitgespannten Rückblick auf die politische Verfassungs- und Verwaltungsgeschichte Deutschlands mit seinen vorwaltenden föderativen Traditionen die Bezirke zu vernachlässigen. Denn die Beseitigung der Länder und ihre Ersetzung durch Bezirke 1952 war keine minderrangige Reform der DDR/SED-Staatsund Parteiführung, sondern in diesen Maßnahmen gipfelten schließlich die seit 1945/46 unter wechselnden politischen Bedingungen verfolgten Pläne der SED zu der ihrem Machtanspruch und ihrer Machtausübung geeigneten Gestaltung des „Staatsapparates“. Die Bezirke wurden an Stelle der Länder geschaffen, um dem „demokratischen Zentralismus“ zum endgültigen Durchbruch zu verhelfen. Es galt, im Rahmen des verkündeten „Aufbaus des Sozialismus“ eine ununterbrochene Befehls- und Kontrollkette von oben nach unten zu schmieden; es galt zu gewährleisten, dass die Vorgaben und Anweisungen der Berliner Zentrale direkt den untergeordneten Verwaltungsinstanzen ohne eigenständige verfassungsrechtliche Legitimation zur Ausführung unter regelmäßiger Überprüfung vermittelt wurden. „Aufbau des Sozialismus unter den Bedingungen des gespaltenen 
Deutschlands bedeutet zusätzliche Schwierigkeiten, bedeutet Erhöhung der Wachsamkeit, Schaffung der Voraussetzungen zur Verteidigung unserer Errungenschaften. Das ist alles nicht so einfach, und deshalb ist es notwendig, dass der Staat straff geleitet wird" (Werner Eggerath am 15. August 1952, siehe Dok. 29). „Die Einheitlichkeit der Staatsführung“, die „straffe Gliederung des Staatsaufbaues“ waren erst dann gesichert, wenn nicht mehr wie zuvor „die verschiedensten Probleme in jedem Land anders behandelt wurden“, wie an den von den Landtagen verabschiedeten Gesetzen abzulesen gewesen sei (Willi Barth am 21. Oktober 1952, Dok. 50). Ein knappes Jahrzehnt später ermahnte Ministerpräsident Otto Grotewohl die Vorsitzenden der Räte der Bezirke mit allem Nachdruck: „Jeder Staatsfunktionär muss sich Klarheit schaffen über das Verhältnis Regierung, Bezirk, Kreis, Gemeinde von der Seite des Wesenszuges des demokratischen Zentralismus. Es kann keinem Organ gestattet werden, Weisungen nicht durchzuführen“" (Dok. 61).

Kein Einzelelement der Verwaltungsreform von 1952 verrät über ihren Geist und ihre Absichten mehr als das von ihr eingeführte Prinzip der ,doppelten Unterstellung“: Die Fachabteilungen der Räte der Bezirke waren demnach sowohl dem Rat des Bezirkes als auch den zuständigen Fachministerien der DDR-Regierung unterstellt, weiterhin die Fachabteilungen der Räte der Kreise sowohl dem Rat des Kreises als auch der Fachabteilung des Rates des Bezirkes. Gerechtfertigt wurde das Prinzip damit, „dass es die Zentralisation der staatlichen Leitung mit einer maximalen Entwicklung der Initiative der örtlichen Organe und der schöpferischen Tätigkeit der werktätigen Massen verbindet" (Dok. 50) - der überhöhte Anspruch verdeckt in Verbindung mit anderen Aussagen nicht, dass in erster Linie die Direktive von oben widerspruchslos und widerstandslos unten empfangen und verwirklicht und dazu den Befehlsgebern in der Zentrale der unmittelbare Zugriff auf die Befehlsempfänger in den Regionen ermöglicht werden sollte. Zu den von vornherein angestrebten Nebeneffekten der Reform gehörte es, den maßgeblichen Einfluss der SED auf den Staatsapparat durch die vermehrte Besetzung der Leitungsstellen in den neuen „Organen“ mit eigenen Parteimitgliedern und durch die betonte Zurückdrängung und Kontrolle der bürgerlichen Blockparteien noch auszubauen. Nachdem der SED in den ersten Nachkriegsjahren die Machteroberung auf dem Gebiet der Sowjetischen Besatzungszone mit entscheidender Unterstützung der Besatzungsmacht gelungen war, zementierte sie mit der Reform von 1952 endgültig ihre Machtbehauptung.

Die hier vorgelegte Quellenedition will die Vorgänge um die Bildung der Bezirke erhellen, indem sie besonders aussagekräftige Dokumente zu den Motiven und Absichten der zentralen bzw. zentralstaatlichen Initiatoren für den Übergang von der Länder- zur Bezirksstruktur, zu der Vorbereitung und Durchführung der neuen Verwaltungsorganisation und den dabei auftretenden Problemen und zum inneren Aufbau und zur Arbeitsweise der neuen Verwaltungsorgane veröffentlicht. Es versteht sich dabei für den kritischen Historiker von selbst, dass er die Äußerungen in ihrem sachlichen Gewicht, in ihrer argumentativen Stichhaltigkeit und inneren Folgerichtigkeit und Überzeugungskraft zu beurteilen hat, um etwa bestimmende politische Antriebe von nachrangigen Begründungsmustern zu sondern. So bleibt beispielsweise die angebliche Orientierung der Bezirksbildungen an regionalen wirtschaftlichen Verhältnisse fragwürdig, wenn dafür wiederholt (nur) der Bezirk Cottbus angeführt wird und weitere vergleichbare Fälle ausbleiben. Die ausge- 
wählten 62 Dokumente, die teils in vollem Umfange, teils in Auszügen, aber oftmals in erheblicher Länge abgedruckt werden, sind größtenteils im Jahr 1952 entstanden. Sie ermöglichen es, sehr genau die verschiedenen Stufen des Staats- und Verwaltungsumbaues von den ersten Überlegungen und Planungen bis zum Vollzug der Maßnahmen sowie die ersten Erfahrungen mit den neuen Organen nachzuvollziehen. Eine kleinere Anzahl von Dokumenten befasst sich mit den politischen Erörterungen der weiteren (vor allem der späten 1950er Jahre) zu Änderungen in den Zuständigkeiten der Räte der Bezirke und zur erwogenen Vergrößerung ihrer Selbstständigkeit, die bezeichnenderweise recht zurückhaltend behandelt wurde.

Die Quellen entstammen Beständen des Brandenburgischen Landeshauptarchivs und des Bundesarchivs in Berlin. Sie spiegeln infolgedessen die Debatten und Vorgänge um die Reform auf der zentralen Ebene in der DDR-Hauptstadt (Ost-)Berlin, deren Umsetzung in Brandenburg sowie die Ablösung der brandenburgischen Landesregierung und Landesverwaltung durch die Räte der drei Bezirke Potsdam, Frankfurt (Oder) und Cottbus wider. Dabei dient Brandenburg als pars pro toto, soll sein Beispiel die grundsätzlichen Fragen und Dimensionen des Gegenstandes verdeutlichen und veranschaulichen, welche Absicht dadurch erleichtert und befördert wird, dass sich etliche Zeugnisse auf Grund ihrer jeweiligen Themen und ihrer Verfasser nicht nur auf Brandenburg beziehen, sondern Schlaglichter auf den Verwaltungsumbruch in anderen Bezirken und in der gesamten DDR werfen.

Auch wenn die Edition wegen ihres territorialen Schwergewichtes als Beitrag zur brandenburgischen Landesgeschichte verstanden werden kann (und soll), liegt ihr Augenmerk in erster Linie auf der Umgestaltung der staatlichen Verwaltung in der DDR als einem (bedeutsamen) Teil der umfassenderen gesellschaftlichen Umwälzung in der DDR. Die publizierten Quellen konzentrieren sich zwar auf die Verwaltung, aber sie beschränken sich nicht auf sie, da sie eindrucksvolle Einblicke in die grundsätzlichen Überlegungen der SED- und DDR-Führung zur sozialistischen Umgestaltung von Staat und Gesellschaft gewähren. In ihren Verlautbarungen reicht der Bogen von den hohen ideologischen Vorgaben und Perspektiven bis hin zur zuweilen sperrigen, widerspenstigen Realität des Verwaltungsalltages, der den hochgespannten Erwartungen der Planziele zu oft nicht gerecht wurde und sie nicht erfüllte. Der historische Gehalt der ausgesuchten Texte offenbart sich dabei über ihren unmittelbaren Gegenstand, die Verwaltungsreform, hinaus dadurch, dass sie die Denk- und Argumentationsweise der leitenden SED-Funktionärsschicht auf ihrem proklamierten Weg zum Sozialismus und zur Planwirtschaft enthüllen. Wie dieser Weg beschritten werden sollte, von welchen Vorbildern und Gegnern man sich dabei begleitet sah, in welcher Weise mit Problemen umgegangen wurde, all das wird immer wieder oder wenigstens gelegentlich angesprochen und angedeutet. Wenige Beispiele mögen eine Ahnung von der „Mentalität“ der entscheidenden SED-Kader in den frühen 1950er Jahren vermitteln.

Den instrumentellen Umgang der SED mit der Verfassung und dem Verfassungsrecht ihres Staates gibt wohl am besten die Vorlage Willi Barths für das Politbüro der SED über die „Grundsätze der Gesetzesvorlage über die Neuorganisation im Staatsapparat“ vom 5. Juli 1952 (Dok. 10) wieder, in der störende Verfassungsbestimmungen, die den ange- 
strebten Änderungen der Staatsorganisation entgegenstehen, mit leichter Hand beiseite geschoben und für belanglos und unverbindlich erklärt werden, ohne dass die Verfassung geändert werden müsse. „Die Tatsache, dass gewisse Teile der Verfassung (Art. 109ff. ,Republik und Länder') nicht mehr den mit der Neuorganisation erreichten Zustand unserer Staatsstruktur widerspiegeln, macht eine Aufhebung dieses Teiles der Verfassung nicht notwendig“, bemerkt Barth apodiktisch ohne weitere Begründung. „Es wird empfohlen, die Länderverfassungen formell nicht aufzuheben. Es lässt sich juristisch der Standpunkt vertreten, sie seien gegenstandslos geworden. “ Irgendein höherwertiger Rang der Verfassung, ein tiefer Respekt vor ihren unverrückbaren Bestimmungen wegen ihres legitimatorischen Charakters sind in diesen Worten nicht mehr zu erkennen, die in ihr verbindlich beschriebene Rechtsordnung wird ohne Weiteres für irrelevant erklärt, wenn sie nicht mehr zu den aktuellen politischen Zielstellungen passt, und geradezu mit einem Federstrich beiseite gefegt.

Die verfassungsrechtliche Beurteilung Barths wird einige Wochen später vom Leiter der DDR-Regierungskanzlei gewissermaßen in das Kleingedruckte des Verwaltungsformulars umgesetzt, indem er in einer Debatte über die Bezeichnung der neuen Organe bemerkt: „Es soll heißen: Bezirk Dresden, in Klammern Land Sachsen. Nicht etwa ein Briefkopf, wo oben steht ,Land Sachsen“ und darunter Bezirk Dresden. ,Land Sachsen“ kommt nur in Klammern. Es ist ja ein absterbender Körperteil“" (Dok. 29). Es überrascht nicht, wenn die Reform auch mit dem Vorbild der Sowjetunion gerechtfertigt wird, wenn dazu aufgerufen wird, ,die Erfahrungen aus der Sowjetunion, welche von der Studienkommission gesammelt wurden, zu verallgemeinern, die Weisung des Genossen Stalin bei uns zu verwirklichen“ (Dok. 50). Da die fragliche Studienkommission freilich von ihrer Reise in die Sowjetunion zu einem Zeitpunkt zurückkehrte, zu dem Grundlinien und Detailregelungen der Verwaltungsreform bereits in den maßgeblichen SED-Gremien festgelegt waren, dürfte die Bemerkung eher dazu gedient haben, die Verwaltungsreform durch ihre angebliche sowjetische Ableitung unangreifbar zu machen, nicht aber für die tatsächliche Übernahme sowjetischer Organisationsformen sprechen.

In vielleicht für den Leser unerwarteter Weise wurden ,sowjetische Erfahrungen“ überprüft, als die Mitarbeiterschaft der neuen Räte der Bezirke gebildet wurde: Ehemalige Kriegsgefangene der Sowjetunion galten wegen ihrer dortigen ideologischen Unterweisung als verlässliche und vertrauenswürdige Kräfte, während ehemalige Kriegsgefangene der Westalliierten wegen ihrer Bekanntschaft mit kapitalistischen Lebensverhältnissen für verdächtig erklärt wurden und zurückgedrängt werden sollten. Für die Kaderabteilung des Rates des Bezirkes Potsdam lautete die Parole für die Zusammenstellung des Personals im Oktober 1952: „Es gilt vor allen Dingen, auch den Anteil der SED-Mitglieder zu heben und der Mitarbeiter, die in sowjetischer Kriegsgefangenschaft waren. Dagegen muss ein konsequenter Kampf geführt werden gegen das Ansteigen der Mitarbeiter, die in den kapitalistischen Ländern in Kriegsgefangenschaft waren“ (Dok. 47). Die unhinterfragbaren ideologischen Frontstellungen, die Schemata des Klassenkampfgedankens werden immer wieder beschworen, die Aufmerksamkeit der Verwaltungsorgane und ihrer Mitarbeiter soll für die ständige Auseinandersetzung mit dem Klassengegner geweckt werden, 
zu dem sowohl ausländische, westliche Agenten als auch die Kirche und die Großbauern im eigenen Lande gezählt wurden.

Die Texte erschließen sich dem Leser nicht einfach und leicht. Sie sind durchdrungen von der Ideologie der kommunistischen Staatspartei, von Formeln und Phrasen einer eigenen politischen Sprache, eines in sich geschlossenen Weltbildes, hinter denen die Wirklichkeit, die entscheidenden Antriebe und Ziele der Handelnden nicht leicht ausfindig zu machen sind. Mit großem, zuweilen geradezu unerträglichem Pathos wird der angeblich von der Bevölkerung verlangte Aufbruch zu neuen Ufern, der Übergang in eine bessere „demokratisierte“ Staatsordnung verkündet, mit neuen Formen der Zusammenarbeit zwischen Regierung, Verwaltungsmitarbeitern, Abgeordneten und Arbeitern: „So wird unsere demokratische Entwicklung in ein höheres Stadium treten“ (Dok. 10). Der bisherige parlamentarische Betrieb, die Trennung von Exekutive und Legislative werden mit allem Nachdruck verworfen, stattdessen wird mit großer Rhetorik die Vision der „Volksdemokratie“ an die Wand gemalt: „Wir müssen erkennen, dass es jetzt darum geht, diese neuen Organe, die die höchsten Organe der Staatsgewalt darstellen, die außerordentliche Vollmachten haben, und die praktisch zum Ausdruck bringen, dass die Werktätigen die Leitung des Staates in die Hand nehmen, zu solchen arbeitenden Körperschaften zu machen, dass sich in ihnen der Wille der Werktätigen widerspiegelt und sie den Willen der Werktätigen durchführen“ (Dok. 29). Von den Abgeordneten des Bezirkstages wurde verlangt, „dass mit der bisherigen Tätigkeit der Abgeordneten Schluss gemacht werden soll und dass die Abgeordneten eine ständige Verbindung mit den schaffenden Menschen herbeiführen werden“ (Dok. 26). Die Verantwortlichen mussten freilich bald zugeben, dass die neuen Organe nicht von heute auf morgen die hochgespannten Leitbilder in ihrem Arbeitsalltag umsetzten: Es ,,verläuft die Arbeit noch stark im Stil der Landesregierung. Es wird administrativ gearbeitet und nicht schöpferisch geleitet. ... Das Prinzip der Einbeziehung der Massen in die Lösung der staatlichen Aufgaben wird fast ebenso wenig angewandt wie die Aufklärung der Bevölkerung über die getroffenen Maßnahmen“ (Dok. 48). Wie man diesen Zitaten ablesen kann, ist der Gegenstand dieses Werkes nicht nur ein gewichtiger verwaltungsgeschichtlicher Einschnitt, sondern es enthält darüber hinaus bedenkenswerte Lektionen über Sein und Schein im Umgang von Regierenden mit Regierten und verdient daher eine aufmerksame Lektüre.

Die vorliegende Edition von Schriftzeugnissen zur Bildung und Etablierung der Bezirke in der DDR und in Brandenburg aus den Jahren 1952 bis 1960 hat eine längere verwickelte Vorgeschichte, die das Endprodukt in besonderer Weise geprägt hat. Das ursprüngliche Vorhaben war in ein umfassendes geplantes Projekt zu ,Wirtschaft und Gesellschaft in Brandenburg 1945-1955“ eingegliedert, das Detlef Kotsch nach der Vollendung des Manuskriptes zu seinem 2001 erschienenen Buch „Das Land Brandenburg zwischen Auflösung und Wiederbegründung. Politik, Wirtschaft und soziale Verhältnisse in den Bezirken Potsdam, Frankfurt (Oder) und Cottbus in der DDR (1952 bis 1990)“ Ende der 1990er Jahre konzipiert hatte. Seine von der Fritz Thyssen Stiftung auf Antrag des 
Brandenburgischen Landeshauptarchivs und der Historischen Kommission zu Berlin geförderte Forschung zielte auf eine mehrbändige Aktenedition, in der in einem Teil neben der staatlichen auch die Entwicklung der Parteien sowie die wirtschaftlichen und gesellschaftlichen Folgen der Verwaltungsreform bis 1961 dokumentiert werden sollten. Detlef Kotsch nahm die Arbeiten an der Edition mit Sichtung und Auswertung von Archivbeständen und mit vorläufigen darstellerischen Entwürfen nachdrücklich auf, vermochte aber nur erste Teilergebnisse vorzulegen, bis er aus persönlichen Gründen 2000 ausschied. Ihm folgte Harald Engler nach; in die Zeit seines bis 2002 reichenden Einsatzes fielen weitere Detailrecherchen, eine Überarbeitung der Einleitung und eine konzeptionelle Konzentration des Editionsprojektes auf die Entwicklung der staatlichen Verwaltungspraxis und der in der DDR tätigen politischen Parteien.

Mit Ablauf der Projektlaufzeit lag ein Manuskript vor, in dem sich verschiedene konzeptionelle Vorstellungen mit unterschiedlichen Arbeitsständen überlagerten und eine rasche Veröffentlichung verhinderten. In den folgenden Jahren blieb es unbearbeitet, da sich die anfänglichen Hoffnungen auf seine Vollendung durch Harald Engler wegen dessen anderweitiger beruflicher Tätigkeit zerschlugen. Erst 2014 sah sich der unterzeichnende Reihenherausgeber in der Lage, mit Mitteln des Brandenburgischen Landeshauptarchivs das unvergessene Vorhaben ,wiederzubeleben“, und er fand glücklicherweise für den Abschluss mit Oliver Werner einen Zeithistoriker, der durch seine damals weitgediehenen Forschungen zur Geschichte der DDR-Bezirke mit der Materie bestens vertraut war. Ihm ist es, von Harald Engler beratend unterstützt, nicht einmal innerhalb eines knappen Jahres gelungen, die vorliegenden Fragmente zu einem ansehnlichen Körper umzuformen und ein in sich geschlossenes Werk fertigzustellen. Dabei wurde ihm konzeptionell und inhaltlich freie Hand gelassen. Der Reihenherausgeber ist ihm dafür besonders zu Dank verbunden, dass er die schwierige Aufgabe so überzeugend bewältigt und die drohende Gefahr einer „Forschungsruine“ beseitigt hat. Schließlich soll nicht unerwähnt bleiben, dass das angesprochene ursprüngliche Projekt in der Antrags- und ersten Bearbeitungsphase von Wolfgang Ribbe, dem damaligen Vorsitzenden der Historischen Kommission zu Berlin, mit Rat und Tat nachhaltig begleitet worden ist. Nicht zufällig erscheint daher das jetzt erreichte Ergebnis in der gemeinsam von Historischer Kommission und Brandenburgischem Landeshauptarchiv herausgegebenen Schriftenreihe.

Potsdam, im Juni 2016

Prof. Dr. Klaus Neitmann

Direktor des Brandenburgischen Landeshauptarchivs 


\title{
Editorische Vorbemerkung
}

\author{
OLIVER WeRner
}

Das Ergebnis der im Geleitwort skizzierten letzten Projektphase liegt hier als Dokumentenedition vor, die sich auf die staatliche Entwicklung der regionalen Mittelinstanzen in Brandenburg zwischen 1952 und 1960 konzentriert, mit einem deutlichen Schwerpunkt auf dem konstituierenden Jahr 1952. Diese Fokussierung ermöglicht es, formale und informelle Faktoren der administrativen Veränderungen ab 1952 gleichermaßen einzubeziehen. Nicht nur die strukturellen Vorgaben der zentralen Partei- und Staatsinstanzen werden umfassend dokumentiert, sondern gerade auch die oftmals sehr viel schwerer zu fassenden Rückmeldungen der Verwaltungsbasis.

Mithin werden in erster Linie nicht die brandenburgischen Verwaltungsstrukturen dokumentiert, sondern die Beziehungen zwischen den Instanzen, die sich in Kontrollberichten, Verhandlungsprotokollen, intern gehaltenen Einschätzungen und nicht zuletzt in Erfahrungsberichten von Partei- und Staatsfunktionären niederschlugen. Die hier präsentierten Unterlagen aus dem Brandenburgischen Landeshauptarchiv und dem Bundesarchiv Berlin dokumentieren auf diese Weise das Nebeneinander von administrativer Improvisation in den brandenburgischen Bezirken und lautstark behaupteter Schlüssigkeit und Folgerichtigkeit der zentral dirigierten Maßnahmen.

Daher sprechen diese Quellen keineswegs „für sich selbst“, sondern müssen immer im politischen Kontext der gesellschaftlichen Umgestaltung der frühen DDR interpretiert werden. Die vorliegende Dokumentation trägt diesem Umstand auch dadurch Rechnung, dass sie sich widersprechende Quellen nebeneinanderstellt. So wurden Anfang Juli 1952 per Beschluss des Sekretariats des ZK der SED auf regionaler Ebene „Bezirkskommissionen " mit umfangreichem Aufgabengebiet geschaffen, ${ }^{1}$ deren praktische Tätigkeit indes nur schleppend anlief, ${ }^{2}$ während ihre fundamentale Bedeutung für die administrative Umgestaltung auf der Bezirksebene vom zuständigen Staatssekretär Werner Eggerath hervorgehoben wurde. ${ }^{3}$ Eggerath erntete dafür Mitte August 1952 bei den verantwortlichen regionalen Verwaltungsfunktionären weitgehendes Unverständnis, ${ }^{4}$ verteidigte die neuen Kommissionen aber hartnäckig, um sie dann bereits 14 Tage später durch ein knappes Schreiben für obsolet zu erklären. ${ }^{5}$

Die Auswahl der Edition konzentriert sich ganz überwiegend auf Dokumente staatlicher Provenienz aus den Bezirken Potsdam, Cottbus und Frankfurt (Oder) sowie auf Un-

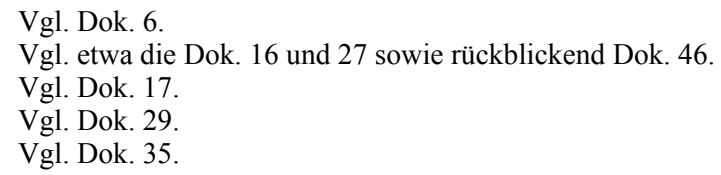


terlagen der SED und der Nationalen Front zur Bezirksbildung und zur Stellung der ,bürgerlichen “ Parteien. ${ }^{6}$ Die Dokumente werden in chronologischer Reihenfolge präsentiert. Quellen mit informellem oder internem Charakter wurden besonders berücksichtigt, ${ }^{7}$ verzichtet wurde allerdings grundsätzlich auf die Aufnahme von Dokumenten, die über andere Editionen bzw. über das Gesetzblatt der DDR leicht zugänglich sind. ${ }^{8}$

Eine besondere Entscheidung betraf die von Detlef Kotsch in Anlehnung an seine Monografie verfasste und von Harald Engler überarbeitete Einleitung. Der Text stützt sich auf die 2001 erschienene Arbeit über Brandenburg zwischen 1952 und 1990, ${ }^{9}$ führt aber die Darlegungen zur Bezirksbildung prägnant auf die Dokumente zu. Wir haben uns daher entschieden, den Text in einer gestrafften, leicht aktualisierten und um die Ausführungen zu den „,bürgerlichen“ Parteien gekürzten Form in die Edition aufzunehmen. Der aktuelle Forschungsstand und perspektivische Forschungsfragen zur Entwicklung der Bezirke in Brandenburg und der übrigen DDR werden in einem separaten Aufsatz von Oliver Werner erörtert.

Bei der Wiedergabe der Dokumente werden Anreden, Grußformeln, Sachbetreffe, Aktenzeichen und Verteiler weggelassen. Ziffern werden bis einschließlich ,zwölf“" grundsätzlich ausgeschrieben, ${ }^{10}$ offensichtliche Rechtschreibfehler sind stillschweigend nach der neuen Rechtschreibung korrigiert worden. ${ }^{11}$ Auslassungen entstellen selbstverständlich nicht den Sinn des Textes und werden mit dem Auslassungszeichen ,,[...]“ kenntlich gemacht. Unterschiedliche Hervorhebungen in den Originaltyposkripten werden grundsätzlich durch eine Fettsetzung der entsprechenden Passagen wiedergegeben.

$6 \quad$ Vgl. etwa Dok. 7, 8 und 9.

7 Vgl. insbesondere die Dok. 10, 15, 29 und 50.

8 Neben Dokumente 1945-1949 und Dokumente 1949-1961 etwa auch Hoffmann, DDR und Judt, DDR-Geschichte.

9 Vgl. Kotsch, Brandenburg.

10 Ausnahmen bilden Datums- und Prozentangaben, statistische Aufstellungen sowie Aufzählungen. Datumsangaben wurden innerhalb der einzelnen Dokumente vereinheitlicht.

11 Unklare Fehler wurden beibehalten und mit dem Vermerk ,[sic!]“ versehen; so kann etwa „Kartoffelbersorgung“ als „Kartoffelversorgung“ oder als „Kartoffelbesorgung“ gelesen werden; vgl. Dok. 29. Der durchaus unterschiedliche Ausdruck des Genitivs (,des Bezirkes“ oder „des Bezirks“) wurde beibehalten. 


\title{
Staat und Staatspartei. Die Verwaltungsreform der SED in Brandenburg 1952-1960
}

\author{
Detlef Kotsch \& Harald Engler
}

$I$.

Am 25. Juli 1952 beschloss der Landtag in Potsdam seine Selbstauflösung und die Beendigung der Tätigkeit der Landesregierung zum 31. Juli 1952. Vier Tage später bestätigte das Präsidium des Landesausschusses der Nationalen Front, das im Potsdamer Kulturbundhaus „Bernhard Kellermann“ tagte, die Abgeordnetenlisten für die Bezirkstage in Potsdam, Frankfurt (Oder) und Cottbus. Auf ihren konstituierenden Sitzungen - am 8. August in Potsdam und in Frankfurt (Oder), am 11. August in Cottbus - wählten die Abgeordneten den Vorsitzenden des Rates des Bezirkes, seine Stellvertreter, den Sekretär und weitere Mitglieder des Rates, womit der Rat als staatliches Verwaltungsorgan in jedem Bezirk seine Tätigkeit aufnehmen konnte. ${ }^{12}$

Mit den Verwaltungsbezirken von 1952 entstand ein Typus von territorialen Verwaltungs- und Gliederungseinheiten, den es zuvor so nicht gab und der auf eigene Weise die Entwicklung des Landesterritoriums prägte. Diese Bezirke hatten mit den Regierungsbezirken der alten preußischen Provinzen ${ }^{13}$ in den Grundsätzen nichts gemein, sie waren vielmehr wesentlicher Bestandteil des zentralisierten Staatswesens der 1949 geschaffenen DDR. Mit der faktischen Auflösung des Landes Brandenburg wie auch der Länder Sachsen, Sachsen-Anhalt, Thüringen und Mecklenburg-Vorpommern sollten die Reste des Föderalismus in der DDR, die zu diesem Zeitpunkt noch existierten, beseitigt und der Übergang zum zentralisierten Staat vollendet werden. 38 Jahre lang prägte die neue staatliche Verwaltungsstruktur die Entwicklung der Länderterritorien im Osten Deutschlands - für die historische Forschung Grund genug, sich den Bezirken als Verwaltungstypus zuzuwenden.

Wenngleich die Prozesse beim Übergang von der Länder- zur Bezirksstruktur in der gesamten DDR sehr ähnlich verliefen, werden mit der vorliegenden Quellensammlung bewusst ganz singulär das Land Brandenburg bzw. die aus dem Land hervorgegangenen Bezirke dargestellt. Gründe hierfür gibt es mehrere: Erstens lassen sich so sehr kompakt und konkret die Prozesse in einem Land darstellen. Zweitens wird das Ausmaß von Unterschieden und Ähnlichkeiten zwischen den fünf Ländern erst dann erkennbar, wenn die Einzelvorgänge dargestellt und untersucht wurden. Drittens schließlich ordnet sich die vorliegende Quellenauswahl in eine ganze Reihe landesgeschichtlicher Arbeiten zu Brandenburg ein, weshalb sich schon hieraus allein ein ganz besonderes Interesse für diese Schwerpunktsetzung ergibt.

12 Vgl. grundsätzlich Kotsch, Brandenburg, S. 31-83.

13 Vgl. Vogel, Brandenburg, S. 55-187. 
Die Fragestellungen, auf die mit der vorliegenden Quellenedition eingegangen wird, sind die nach den zentralstaatlichen Motiven und Zielen für den Übergang von der Länder- zur Bezirksstruktur, nach den zeitlichen Abläufen und dem Charakter dieses Überganges sowie nach der Struktur, den Zuständigkeiten und der inneren Verfasstheit der neuen Verwaltungsbehörden. Dabei wird sich zeigen, dass die Ursachen und Zielstellungen aus übergeordneten Interessen abgeleitet waren und sich aus dem Charakter der Staatsverfassung der DDR und der internationalen Einbindung des östlichen deutschen Teilstaats in den sowjetischen Machtbereich ergaben. Die neue territoriale Verwaltungsstruktur hatte ganz konkrete Konsequenzen für die einzelnen historischen Landschaften und Länder, somit für Brandenburg bzw. die drei 1952 aus diesem Kernland Preußens hervorgegangenen neuen Verwaltungsbezirke Potsdam, Frankfurt (Oder) und Cottbus.

Zeitlich setzt die Quellenedition im Frühjahr 1952 ein und erstreckt sich bis 1960, also bis zu dem Zeitpunkt, zu dem die neue Verwaltungsstruktur jene Formen angenommen hatte, die bis zum Zusammenbruch des politischen Systems und zur Revolution 1989/90 existierten. Hierin eingeschlossen sind zum einen die Vorbereitung und Durchführung der Verwaltungsreform vom Sommer 1952. Zum anderen werden einzelne Aspekte der Veränderungen im Zuge der „Vervollkommnung und Vereinfachung des Staatsapparates" ${ }^{\text {"14 }}$ $1957 / 58$ dokumentiert.

Die Einrichtung der Verwaltungsbezirke im Jahr 1952 bildete einen herausragenden und spektakulären Vorgang bei der Formung der DDR zum zentralistischen Einheitsstaat. Die Verwaltungsreform von 1952 steht dabei jedoch nicht allein als singuläres Ereignis im historischen Raum. In strikter Ablehnung des extrem zentralisierten nationalsozialistischen Staatswesens aus der Zeit vor 1945 hatte die sowjetischen Besatzungsmacht nach Kriegsende in Ostdeutschland zunächst föderale Strukturen wiederbelebt und ihre Besatzungszone sehr rasch in fünf Länder gegliedert. Selbst die Gründungsverfassung von 1949 definierte die DDR als Bundesstaat. Die Verfassungen der Länder aus den Jahren 1946/47 blieben in Kraft, Landtage und Landesregierungen behielten weitgehend ihre Kompetenzen. ${ }^{15}$

Jedoch kollidierte diese Entwicklung mit der sich im Verlauf der zweiten Hälfte der 1940er Jahre herausgebildeten offiziellen Staatstheorie, die auf die Herrschaftssicherung einer kleinen bürokratischen Elite an der Spitze der Partei und des Staates gerichtet war. Als grundlegendes Organisationsprinzip des gesamten politischen Systems in seinen drei Subsystemen - der eigenen, hegemonialen Partei (SED), der staatlichen Verwaltung (in der DDR „Staatsapparat“ genannt) sowie in den übrigen Massenorganisationen und den sogenannten Blockparteien - galt der „Demokratische Zentralismus“. Danach waren alle Stellen und Personen innerhalb des politischen Systems zur widerspruchslosen Umsetzung der Beschlüsse und Anordnungen der übergeordneten Organe verpflichtet. Zur Legitimierung der Führungsorgane wurden Wahlen „von unten nach oben“ durchgeführt, allerdings mit pseudodemokratischem Charakter: Da die Kandidaten nach ihrer Wahl,

14 Vgl. Kotsch, Brandenburg, S. 91-98.

15 Vgl. Foitzik, Sowjetische Kommandanturen. 
teilweise sogar schon vor ihrer Aufstellung, durch die übergeordneten Organe zu bestätigen waren, kontrollierten diese Instanzen praktisch den gesamten Wahlvorgang und sicherten damit ihre Führungsrolle.

Während diese Entwicklung für die SED bereits seit 1948/49 abgeschlossen war, verlief dieser Prozess im Bereich der staatlichen Verwaltung erheblich langsamer und zurückhaltender. Der Verwaltungsaufbau vollzog sich zunächst vor allem auf der Ebene der Länder bzw. Provinzen, deren Grenzen die Sowjetische Militäradministration durch Befehl Nr. 5 vom 9. Juli 1945 festgelegt hatte. ${ }^{16}$ Den regionalen SMA-Chefs ${ }^{17}$ nachgeordnet waren deutsche Landes- bzw. Provinzialverwaltungen, denen mit SMAD-Befehl Nr. 110 vom 22. Oktober 1945 unter Vorrang der Kontrollratsgesetze und SMAD-Befehle die Befugnis zum Erlassen von Gesetzen und Verordnungen mit Gesetzeskraft eingeräumt wurde. ${ }^{18}$ Deren Geltungsbereich erstreckte sich auch auf die Bereiche, die früher in die Gesetzgebungskompetenz des Reiches gefallen waren. ${ }^{19}$

Parallel dazu entstanden Behörden auf gesamtzonaler Ebene. Eingeleitet wurde diese Entwicklung mit dem SMAD-Befehl Nr. 17 vom 27. Juli 1945, der die Errichtung von elf Zentralverwaltungen sanktionierte. ${ }^{20}$ Die Zentralverwaltungen unterstanden direkt den entsprechenden Abteilungen der Sowjetischen Militäradministration und hatten lediglich deren Anordnungen auszuführen. Bereits im Jahr 1946 erhielten sie erste gestaltende Kompetenzen. Am 4. Juni 1947 wurde mit dem SMAD-Befehl Nr. 138 die Deutsche Wirtschaftskommission (DWK) als zentrale Zonenverwaltung für die vier Ressorts Industrie, Brennstoff und Energie, Handel und Versorgung sowie Land- und Fortwirtschaft gebildet. ${ }^{21}$ Schrittweise wurden ihr gegenüber den Ländern Planungs-, Anordnungs- und Kontrollbefugnisse eingeräumt, und der SMAD-Befehl Nr. 32 vom 12. Februar 1948 stattete die DWK mit Rechtssetzungsbefugnissen aus. ${ }^{22}$ Mit ihren Kontrollkommissionen auf gesamtzonaler Ebene, in den Ländern und Kreisen sowie den örtlichen Volkskontrollausschüssen schuf die DWK 1948/49 wichtige Institutionen für die sich anbahnende Zentralverwaltungswirtschaft sowjetischen Typs. ${ }^{23}$

Dennoch war die staatliche Verwaltung noch nicht durchgängig zentralistisch organisiert. Die Fortexistenz der Landtage und Landesregierungen sowie der Länderkammer in der SBZ bildete einen erheblichen Widerspruch zum totalitären Herrschaftsanspruch der Parteiführung, der nicht nur darin bestand, alle wichtigen Stellen mit den eigenen Vertretern besetzt zu haben, sondern auch durch zentralistische Strukturen jederzeit den direkten Zugriff auf alle Bereiche der Gesellschaft zu besitzen. Gerade dieser Anspruch war durch die föderale Organisation der staatlichen Organe nicht unumschränkt gegeben. Dieser Zustand wurde auch nicht durch die ostdeutsche Staatsgründung am 7. Oktober 1949

16 Der Befehl Nr. 5 ist abgedruckt in Dokumente 1945-1949, S. 33.

17 Vgl. Geßner/Sacharow, Inventar.

18 Der Befehl Nr. 110 ist abgedruckt in Dokumente 1945-1949, S. 71-72.

19 Vgl. dazu grundsätzlich Foitzik, SMAD.

20 Der Befehl Nr. 17 ist auszugsweise abgedruckt in Dokumente 1945-1949, S. 69-70.

21 Der Befehl Nr. 138 ist abgedruckt in Dokumente 1945-1949, S. 140-141.

22 Der Befehl Nr. 32 ist abgedruckt in ebd., S. 149.

23 Vgl. Horstmann, Logik. 
beseitigt, so unvollkommen und funktionsuntüchtig sich das föderale Staatswesen der DDR in den ersten Jahren auch präsentierte.

Die DDR wurde zunächst als Bundesstaat definiert und in wichtigen Bereichen auch als Bundesstaat organisiert. Damit stellen sich zwei Fragen: erstens die nach den Gründen, die DDR als Bundesstaat zu konstituieren, und zweitens, warum nur knapp drei Jahre später die föderalen Elemente im Staatsaufbau der DDR wieder beseitigt wurden. ${ }^{24} \mathrm{Al}-$ lein der Hinweis auf die II. Parteikonferenz (9.-12. Juli 1952), auf der der „Aufbau des Sozialismus zur grundlegenden Aufgabe in der Deutschen Demokratischen Republik“"25 erklärt und damit die Gesellschaftsprogrammatik der SED nun klar benannt wurde, reicht als Erklärungsmuster nicht aus. Der Verweis liefert keine Antwort auf die Frage, warum mit der Auflösung der Verfassungsorgane der Länder nach nur drei Jahren die DDR-Verfassung in einem wichtigen Punkt ausgehöhlt und 15 Jahre lang gegen bestehendes Verfassungsrecht verstoßen wurde, bis 1968 die zentralistische Staatsgliederung Eingang in den Verfassungstext fand. Damit eng verbunden ist die Frage, warum die SED-Führung ausgerechnet im Sommer 1952 den „Aufbau des Sozialismus“ in den Mittelpunkt ihrer Gesellschaftsprogrammatik stellte.

Die Entscheidung, die DDR zunächst föderal zu organisieren, und die Revision dieser Entscheidung knapp drei Jahre später waren nur bedingt ein Ergebnis der Entwicklungen in der SBZ bzw. in der DDR selbst. Wäre es nach dem Willen der SED-Führung um Walter Ulbricht gegangen, der im Auftrag Moskaus schon unmittelbar bei Kriegsende die örtliche Verwaltung in der Region Berlin-Brandenburg zu organisieren begann und dabei nach dem viel zitierten Grundsatz handelte, dass alles demokratisch auszusehen habe, doch er und seine Genossen alles in der Hand haben müssten, ${ }^{26}$ hätte es kaum einen langen föderalen Umweg auf dem Weg zum zentralistischen Staat gegeben. In dem „Entwurf einer Verfassung für die deutsche demokratische Republik“, der als gesamtdeutscher Verfassungsentwurf am 14. November 1946 vom Parteivorstand der SED beraten und beschlossen wurde, sprach sich die SED-Führung klar gegen einen föderativen Staatsaufbau aus. ${ }^{27}$

Dafür gab es zwei wesentliche Gründe: Zum einen widersprach der Föderalismus prinzipiell dem kommunistischen Verständnis von Machtausübung, weil dadurch die Herrschaft der Zentrale nicht gesichert werden konnte. Zum anderen war die strikte Ablehnung des Föderalismus auch der Situation im Nachkriegsdeutschland geschuldet. Die Länder in den Westzonen erwiesen sich, kaum dass sie gebildet waren, als Betätigungsfeld jener politischen Kräfte, die in der Ostzone bekämpft wurden: Sozialdemokraten

24 Die offizielle Geschichtsschreibung der SED formulierte, dass , die historisch entstandenen Länder und deren beträchtliche Kompetenzen“ es erschwert hätten, „die sozialistische Umgestaltung einheitlich zu leiten“. Die „Reorganisation der staatlichen Organe“ habe „die führende Rolle der Arbeiterklasse“ gestärkt und „,ihr Bündnis mit den werktätigen Bauern und der Intelligenz“ gefestigt; Geschichte der SED, S. 281.

25 Protokoll der II. Parteikonferenz, S. 492.

26 Vgl. Leonhard, Revolution, S. 358.

27 Vgl. die Stellungnahme der Abteilung Staats- und Rechtsfragen des ZK der SED zur Frage der Länderkammer aus dem Jahr 1958, S. 1, in: BArch, DY 30/IV 2/13/258. 
und antikommunistische bzw. prowestliche Politiker der CDU und der liberalen Parteien. Wenn sich die SED-Führung gegen den Föderalismus aussprach, vermischten sich alte Ressentiments gegen den traditionellen süddeutschen Liberalismus und den westrheinischen Separatismus mit der antiwestlichen Haltung in dem sich abzeichnenden bzw. beginnenden Kalten Krieg. Die Forderung nach Errichtung eines zentralisierten Einheitsstaates bedeutete somit auch eine Abwehrhaltung gegen die politischen Gegner in Deutschland. Die Mehrzahl der Politiker in den Westzonen trat ihrerseits für einen starken Föderalismus ein und wussten sich dabei eins mit den westlichen Besatzungsmächten. Besonders die USA und Frankreich förderten schon bald nach Kriegsende die Herausbildung starker Länder - die Amerikaner, weil sie lebensfähige und mit eigener Kompetenz ausgestattete Einzelstaaten, die sich zu einem Bundesstaat vereinigten, als wesentliche Voraussetzung eines demokratischen Systems betrachteten, und die Franzosen, weil sie aus Gründen der Machtpolitik und gesamteuropäischer Interessen ohnehin lieber einen Deutschen Bund sahen. ${ }^{28}$

Dennoch blieb die SED-Führung in der Frage des Staatsaufbaus jahrelang zur Zurückhaltung gezwungen. Der Grund dafür lag in den Prioritäten der sowjetischen Deutschlandpolitik, die eine Schlüsselrolle in den europa- und weltpolitischen Strategien der Kreml-Führung spielte. Auch wenn bis heute die sowjetische Deutschland- und Europapolitik in der Forschung kontrovers diskutiert wird, war der SBZ (und unmittelbar nach ihrer Gründung auch der DDR) zunächst offenbar die Rolle eines strategischen Spielballs zugedacht, der zugleich einen militärischen Aufmarschraum gegenüber dem Westen und ein wirtschaftlich auszubeutendes Objekt darstellte. ${ }^{29}$ Allzu rasche politische Weichenstellungen wie in den ostmittel- und südosteuropäischen Ländern des sowjetischen Machtbereiches vermied man hier zunächst. ${ }^{30}$

Dieser Umstand wirkte sich auch auf die Frage nach den Formen des Staatsaufbaus bzw. der öffentlichen Verwaltung in der SBZ aus. Auf der Potsdamer Konferenz (17. Juli bis 2. August 1945) hatte die UdSSR einer „Dezentralisation der politischen Struktur“631 zugestimmt und anschließend in ihrer Besatzungszone am schnellsten Länderverwaltungen aufgebaut. Doch war aus sowjetischer Sicht damit keine föderale Struktur des Staatswesens in Deutschland auf Dauer festgelegt, sondern nur für eine Übergangszeit. Schon bald konfrontierte sie die Westmächte mit der Forderung nach einem deutschen Einheitsstaat mit starker Zentralregierung - wovon sich die sowjetische Führung, die schon bald ihre Ohnmacht gegenüber den Entwicklungen in den Westzonen erkannte, mehr Einfluss auch dort versprach - und der Forderung nach drastischer Einschränkung der Rechte der Länder, konnte sich aber damit auf den Außenministerkonferenzen 1946/47 nicht durchsetzen. Nach der Londoner Sechsmächtekonferenz im Frühjahr und Sommer 1948 musste die sowjetische Führung zur Kenntnis nehmen, dass sie über keine Möglichkeiten verfügte, den föderalen Staatsaufbau im Westen Deutschlands zu verhindern. Die separate

28 Vgl. Henke, Politik.

29 Vgl. Foitzik, Sowjetische Interessenpolitik.

30 Vgl. O'Sullivan, Stalins „Cordon sanitaire“.

31 Zitiert nach Benz, Potsdam, S. 213. 
westdeutsche Staatsbildung, auf die die Entwicklung nunmehr zusteuerte, durchkreuzte das gesamte sowjetische Machtkalkül für Mittel- und Westeuropa. Wenn überhaupt, so blieb Moskau ein nennenswerter Einfluss auf Deutschland und die deutsche Frage nur dann erhalten, wenn sich der Kreml in der Frage des Staatsaufbaus kompromissbereit gab, also Abschied nahm von der starren Forderung nach einer Zentralregierung, und den Föderalismus als legitimer Form der Staatlichkeit in Deutschland anerkannte.

Bereits Anfang 1948 deutete sich ein sowjetischer Stimmungswandel in Bezug auf die staatliche Organisation an. Er kam jedoch zu spät und wirkte wenig glaubhaft, um noch auf westlicher Seite Veränderungen bewirken zu können. Dieser Stimmungsumschwung äußerte sich in dem Entwurf für eine gesamtdeutsche Verfassung, den der von der SED organisierte „2. Volkskongress für Einheit und gerechten Frieden“ im März 1948 vorlegte: Er enthielt ein Bekenntnis zum Föderalismus und sah die Schaffung entsprechender staatlicher Strukturen vor. Vieles deutet darauf hin, dass diese Orientierung aus Moskau stammte und sich aus übergeordneten strategischen Interessen der Sowjetunion ergab. Schon während des Krieges hatte sich eine Planungsgruppe im sowjetischen Außenministerium unter Leitung des stellvertretenden Ministers Maxim Litwinow mit Fragen der Organisation des Staatswesens im Nachkriegsdeutschland beschäftigt und einer Föderalisierung des Staatswesens durchaus Vorteile abgewonnen, allerdings vorrangig als Alternative zum zentralistischen NS-Staat. ${ }^{32}$ Insofern war diese Fragestellung für Moskau nicht neu.

Verändert hatte sich jetzt jedoch die Zielstellung. Es ging nun nicht mehr vorrangig darum, Deutschland niederzuhalten. Stattdessen erwies sich die Debatte um die Organisation des Staatswesens als ein wichtiger Punkt in der Auseinandersetzung mit den Westmächten um den künftigen Einfluss auf Deutschland und um die Stellung Deutschlands in Europa, was Grundfragen der sowjetischen Außenpolitik tangierte. Während die Planer und Entscheidungsträger in Moskau die Fragen der staatlichen Organisation in Deutschland vor allem unter strategischem Blickwinkel sahen, betrachtete die Führung der Sowjetischen Militäradministration in Deutschland diese Fragen viel unmittelbarer, woraus sich auch Unterschiede ergaben. In der SMAD favorisierte man die zonale Zentralverwaltung, die sich leichter und effektiver als die einzelnen Landesregierungen lenken lassen würde. Die im Juni 1947 verfügte Errichtung der Deutschen Wirtschaftskommission als zentrale Zonenverwaltung mit Planungs-, Anordnungs- und Kontrollbefugnissen entsprang einer eigenmächtigen Entscheidung der SMAD, die ihrem Chef, Marschall Wassili D. Sokolowski, herbe Kritik aus Moskau eintrug und offenbar nur geduldet wurde, um das Gesicht gegenüber den Westmächten zu wahren. ${ }^{33}$ Zugleich erachtete es die SMADLeitung für notwendig, der Führung in Moskau das mögliche Erstarken des Föderalismus in der sowjetischen Besatzungszone als unerwünschte Entwicklung darzustellen. Für die SED-Führung bedeutete das Bekenntnis zum Föderalismus von vornherein nur eine taktische Wendung, die eigentlich ihrem Verständnis von Macht völlig zuwiderlief. Otto Gro-

32 Vgl. Kleßmann, Thesen.

33 Vgl. die Stellungnahme des sowjetischen Außenministeriums in: AVPRF, F. 082, op. 34, p. 150, d. 38, Bl. $6-9$. 
tewohl sprach im Februar 1948 von der Notwendigkeit, ,die bisher auf einer zu engen Länderbasis geführte Wirtschaft für die ganze sowjetische Besatzungszone auf einer höheren Ebene zu planen“. ${ }^{34}$

In der Praxis hat die DDR nicht einen einzigen Tag als wirklicher Bundesstaat funktioniert. Die Entscheidungskompetenz lag in den wichtigen Fragen nach wie vor bei der sowjetischen Führung, auch wenn sie im Zuge der ostdeutschen Staatsgründung die Verwaltungsfunktion an die Behörden der DDR übergab und die SMAD in die Sowjetische Kontrollkommission (SKK) umwandelte. ${ }^{35}$ Auf deutscher Seite, die zwar größere Vollmachten und Gestaltungsmöglichkeiten erhielt, aber dennoch weiter von der sowjetischen Führung abhängig blieb, wuchs der Einfluss des im Januar 1949 gebildeten Politbüros der SED als Quasi-Regierung. Sowohl die Provisorische Regierung als auch die auf die ersten Volkskammerwahlen vom 15. Oktober 1950 folgende Regierung - bald Ministerrat genannt - beschränkte sich in wichtigen Fragen auf die Ausführung von Politbürobeschlüssen. ${ }^{36}$

Wenig gestaltende Energie kam aus den Ländern selbst, die wegen ihrer mangelhaften Gesetzgebungsarbeit wiederholt von der sowjetischen Besatzungsmacht gerügt wurden. Von Anfang an waren durch die Personalpolitik der SMAD Kommunisten in die Schlüsselämter der Länderverwaltungen gebracht worden, deren politisches Selbstverständnis keine Instrumentalisierung föderaler Mechanismen gegen den Führungsanspruch der Zentrale befürchten ließ. Von vielen als unzuverlässig und unsicher geltenden Sozialdemokraten und bürgerlichen Politikern hatte man sich bereits wieder getrennt. Die Ministerpräsidenten und Minister der seit der Staatsgründung im Amt befindlichen Landesregierungen verliehen ihren Ämtern noch weniger Eigenständigkeit als die meist auch schon angepassten Amtsinhaber der ersten Jahre. Als wirksames Mittel zur Durchsetzung von SED-Interessen erwies sich gegenüber den SED-Mitgliedern, die die meisten Leitungsfunktionen innehatten, das Institut der Parteidisziplin. ${ }^{37}$ Schließlich nahm die Regierung der DDR über die Organisations- und Instrukteur-Abteilung (bald nur noch „Org.Instrukteur-Abteilung“ genannt) des Ministeriums des Innern bereits sehr unmittelbaren Einfluss auf die Tätigkeit der Landesregierungen, ohne dass es dafür eine staatsrechtliche Grundlage gab. ${ }^{38}$

34 Vgl. „Neues Deutschland“ vom 10. Februar 1948, S. 1: „Was müssen wir tun? Auf diese Frage antwortet Otto Grotewohl".

35 Vgl. Scherstjanoi, SKK-Statut.

36 Vgl. Lapp, Ministerrat, S. 10-22.

37 Vgl. etwa die im Frühjahr 1951 im ZK der SED entstandene Analyse „Lehren aus der Konferenz von Staatsfunktionären am 24./25. Februar 1951“ in: BArch, DO 1 (Ministerium des Innern), Nr. 26084, B1. 252-268; generell vgl. Schwarzenbach, Kaderpolitik, S. 62-83.

38 Diese Abteilung war nach § 25 der Dienstordnung der Regierung der DDR vom 3. November 1949 im Ministerium des Innern der DDR, Hauptabteilung Staatliche Verwaltung, errichtet worden. Sie hatte die Durchsetzung der Regierungspolitik zu sichern und deren Umsetzung zu kontrollieren, wozu in allen zentralen Regierungsstellen sowie in den Behörden auf Landes-, Kreis- und kommunaler Ebene Org.-Instrukteur-Abteilungen geschaffen wurden, die wiederum einer zentralen Org.Instrukteur-Abteilung des MdI unterstanden; vgl. deren Berichte wie z. B. „Über die Maßnahmen 
Dennoch erwies sich die verbleibende föderale Struktur für die Zentrale als Hindernis bei der Machtausübung. Eine straffe zentrale Leitung und Kontrolle war angesichts der Existenz von Ländern nur begrenzt möglich. Vor allem erwies es sich immer wieder als schwierig, die Landesparlamente und -regierungen untereinander zu einem abgestimmten Handeln zu bewegen, was den Verwaltungsaufwand der Zentrale ins Unermessliche steigerte und die Effizienz einschränkte, weshalb die SED-Führung bereits auf dem III. Parteitag 1950 eine Stärkung der zentralen Leitungsorgane in Aussicht stellte. ${ }^{39}$

So begann man nach der Staatsgründung, den Ländern und auch den kommunalen Selbstverwaltungsorganen Kompetenzen zu entziehen und diese auf die Zentrale zu verlagern. Schon wenige Monate nach der Staatsgründung wurden die Länder und Kommunen ihrer Finanzhoheit beraubt, die in der SBZ durch ein auf SMAD-Befehlen beruhendes System gegenseitiger Ab- und Zuführungen sowie die Anfänge der zentralen Planwirtschaft bereits stark eingeschränkt gewesen war. ${ }^{40}$ Mit dem Haushaltsgesetz für 1950 wurden die Länder-, Kreis- und Gemeindehaushalte in den zentralen Haushalt eingegliedert, worauf am 15. Dezember 1950 mit dem Gesetz über die Reform des öffentlichen Haushaltswesens das Prinzip der Einheitlichkeit des Staatshaushaltes zur Einführung gelangte. Fortan gab es nur noch einen Haushaltsplan der DDR, dem der Volkswirtschaftsplan der Republik zugrunde lag und der die Haushalte aller Staatsorgane und Gebietseinheiten umfasste. ${ }^{41}$

Doch auch nach dieser Einschränkung, so fundamental sie war, existierte immer noch kein vollständig zentralisiertes Staatswesen. Der stärker hervortretende Herrschaftsanspruch der SED-Führung und die inzwischen etablierte zentrale Planwirtschaft verlangten hingegen regelrecht eine Reform der staatlichen Strukturen in der DDR. Die sich aufdrängende Alternative hieß: entweder Zentralisierung des Staatswesens oder Relativierung der Planwirtschaft, entweder Festigung der Herrschaft der SED-Führung oder Erosion der gerade etablierten politischen Ordnung in der DDR. Die sowjetische Besatzungsmacht sah aus übergeordneten Erwägungen zunächst keinen Handlungsbedarf. Erst 1952, als es der Führung in Moskau aufgrund der deutschlandpolitischen Situation - inzwischen waren mit der fortschreitenden Westintegration der Bundesrepublik und ihrer inneren Konsolidierung wichtige Entscheidungen gefallen - kaum noch als aussichtsreich erschien, weiterhin an ihrem deutschlandpolitischen Neutralitätskonzept festzuhalten, gab sie der schon lange drängenden SED-Führung den Weg frei. Frühere Zurückhaltung in Bezug auf die politische Umgestaltung der DDR hin zur kommunistischen Parteidiktatur war nur noch aus untergeordneten Gründen notwendig, etwa der propagandistischen Selbstdarstellung der DDR; die grundsätzlichen Erwägungen waren entfallen.

Die Stalin-Note vom 10. März 1952 an die Westmächte, die den Vorschlag einer Wiedervereinigung Deutschlands zu einem neutralen Staat enthielt, markierte das definitive

zur Entwicklung des demokratischen Staatsbewusstseins der Angestellten des Staatsapparates" von 1951 in: BArch, DO 1 (Ministerium des Innern), Nr. 26084, B1. 63-70.

39 Vgl. Protokoll des III. Parteitages, S. 64.

40 Vgl. Türke, Demokratischer Zentralismus, S. 66.

41 Vgl. Buck, Finanzhaushalte. 
Ende derartiger sowjetischer Deutschlandpolitik - egal, ob das Angebot nun ehrlich gemeint war - dann hat die ablehnende Antwort Moskau endgültig die Nichtigkeit weiterer Hoffnungen in dieser Angelegenheit klargemacht - oder durch das Anfachen einer Kontroverse auf westlicher Seite lediglich das Projekt der Europäischen Verteidigungsgemeinschaft verzögern bzw. verhindern sollte - in diesem Fall hätte sich Moskau tatsächlich schon zuvor von diesem Konzept verabschiedet. In dieser Konstellation ließ Moskau der SED-Führung nun freie Hand, ihre Parteiherrschaft durch neue Strukturen und klare Aufgabenstellungen auszubauen. ${ }^{42}$

Mit der Vorbereitung und den Planungsarbeiten für die Verwaltungsreform waren zunächst zwei Dienststellen befasst: die Abteilung Staatliche Verwaltung im Zentralkomitee der SED (Leiter: Anton Plenikowski, Stellvertreter: Willi Barth) und die Hauptabteilung Staatliche Verwaltung im Ministerium des Innern (Leiter: Klaus Sorgenicht). Der exakte Zeitpunkt, an dem die Planungen begannen, ist schwer zu bezeichnen und zu belegen. Da bereits im April 1952 erste Planungspapiere vorlagen, müssen die Vorbereitungen aber schon mehrere Wochen, wenn nicht gar Monate zuvor begonnen haben. ${ }^{43}$ Bereits am 27. Februar 1952 hatte sich Ulbricht auf einer Konferenz mit den 1. Sekretären der SEDKreisleitungen konkret zum Plan einer Verwaltungsreform geäußert. Er nutzte die wirtschaftlichen Schwierigkeiten, die sich in der gesamten DDR damals zeigten, um hieraus ein ,bürokratisches Zurückbleiben in großen Teilen des Staatsapparates, der wirtschaftlichen Organe“ abzuleiten. ${ }^{44}$

\section{II.}

Im April 1952 stand die Grundidee der Verwaltungsreform fest. Geplant war die vertikale Neuordnung des Staatsapparates und der Parteibehörden, wozu die Verwaltungsgrenzen in der gesamten DDR radikal geändert werden sollten. Die Planer griffen auf die Idee der früheren Mittelbehörden zurück, also der Regierungsbezirke, in die bis zum Kriegsende z. B. die preußischen Provinzen unterteilt gewesen waren und die es in abgewandelter Form auch einigen Teilen der SBZ gegeben hatte. ${ }^{45}$ Die nun neu zu schaffenden Verwaltungsbezirke ließen sich durch Wegfall der Landesbehörden unkompliziert dem Ministerrat direkt unterstellen.

Auch über die Aufgaben und Kompetenzen der Bezirksverwaltungen, die vor allem ausführende Verwaltungsorgane sein sollten, vorrangig auf der Basis von zentralen Gesetzen, Anweisungen und Direktiven zu handeln hätten und über ihre Tätigkeit gegenüber der Regierung rechenschaftspflichtig wären, wurde schnell Übereinstimmung erzielt. An die Stelle der Länderverwaltungen sollten je zwei bis drei Bezirksverwaltungen treten, wobei die Landesgrenzen, die dann keine Rolle mehr spielten, nicht unbedingt mit den

42 Vgl. Staritz, Gründung, S. 208-218.

43 Vgl. Mielke, Länder, S. 66-75.

44 Zitiert nach Kotsch, Brandenburg, S. 44.

45 Vgl. Schreckenbach, Bezirksverwaltungen. 
Bezirksgrenzen deckungsgleich sein sollten. Die Kreise waren drastisch zu verkleinern, womit deren Anzahl sich fast verdoppeln würde. Längere Debatten, die von einer ganzen Flut neuer Planungspapiere begleitet waren, löste einmal die Frage nach der konkreten territorialen Gestalt der Bezirke aus, was für Brandenburg mit einer lang andauernden Unsicherheit bei der Suche nach dem Sitz der Verwaltungsbehörden verbunden war. Die zweite Frage betraf die Personalauswahl, vor allem die Wahl der Führungskader, womit sich die SED-Führung bis zum unmittelbaren Vollzug der Reform beschäftigte.

Als Anton Plenikowski am 24. April 1952 in einer Beschlussvorlage für das Sekretariat des ZK der SED die ersten Planungsergebnisse seiner Abteilung vorlegte, schlug er die Bildung von 13 Bezirken vor, die in insgesamt 205 Kreise zu untergliedern seien. Bei der exakten Festlegung der Bezirksgrenzen, für die eine Zentrale Kommission nach Konsultation der Innenminister der Länder, der betreffenden Landräte sowie der 2. Landes- und Kreissekretäre der SED eine Vorlage zu unterbreiten habe, sollten „die Grenzen der Bezirke und Kreise entsprechend den politischen, wirtschaftlichen und verkehrstechnischen Zweckmäßigkeiten festgelegt werden“" ${ }^{46}$ Konkrete Kriterien fanden sich in der Vorlage jedoch nicht, obwohl gerade diese für eine effektive Bezirkseinteilung Priorität besessen hätten. Die weitere Entwicklung zeigt, dass mit dieser Planungsvorlage bereits präjudizierend einige Positionen umrissen waren. Erstens spielten die alten Landesgrenzen für die Bezirkseinteilung nur noch eine untergeordnete Rolle. Zweitens sollten die neu entstehenden Bezirke deutlich größer sein als die zeitweilig nach dem Kriegsende existierenden Verwaltungsbezirke. Drittens sollte es auch in den neuen Verwaltungseinheiten sogenannte Volksvertretungen geben, die zunächst nicht gewählt, sondern durch Aufteilung der aufzulösenden Landtage und Kreistage zu bilden seien; die Bezeichnungen lauteten Bezirkstag, Kreistag, Stadtverordnetenversammlung und Gemeindevertretung. Die Verwaltungsorgane sollten sich Rat des Bezirkes, Rat des Kreises, Rat der Stadt und Rat der Gemeinde nennen. Viertens stand fest, dass die staatliche Neugliederung allein in die Kompetenz der Parteiführung fiel und dass ausgewählte Organe der Regierung zur Unterstützung herangezogen würden, während die Länder und Kreise aus der Phase der Planung und Vorbereitung weitgehend ausgeschlossen blieben. Deren Vertreter durften, sofern sie der SED angehörten, nach Aufforderung ihre Ansichten äußern, hatten jedoch keine eigene Planungskompetenz.

Bereits am 29. April 1952 beriet das Politbüro über diese Vorlage, die inzwischen in einigen Punkten verändert worden war. ${ }^{47}$ Die Zahl der Bezirke, deren Bildung nun verbindlich beschlossen wurde, war auf 14 gestiegen. Anstelle von Oranienburg wurde für den geplanten brandenburgischen Nordbezirk nun Neuruppin als Sitz der Verwaltung genannt. Während der Bezirk Frankfurt 16 Kreise umfassen sollte, waren für den Bezirk Potsdam elf Kreise und für den Bezirk Neuruppin sieben Kreise vorgesehen.

In die Zentrale Kommission, die die Federführung für die weiteren Planungen hatte, wurden Anton Plenikowski, Klaus Sorgenicht sowie Hans Warnke (Staatssekretär im In-

46 Vgl. Dok. 2.

47 Vgl. das Protokoll Nr. 109 der Politbüro-Sitzung am 29. April 1952, in: BArch, DY 30/IV 2/2/209, B1. 10. 
nenministerium), Werner Eggerath (als Ministerpräsident von Thüringen bereits mit den Vorbereitungen zur Bildung einer Koordinierungs- und Kontrollstelle des Ministerrates für die Arbeit der örtlichen Verwaltungsorgane betraut) und Ernst Lange (Stellvertretender Vorsitzender der Zentralen Kommission für Staatliche Kontrolle) berufen. Die Bildung weiterer Kommissionen, so für die Erarbeitung der Stellenpläne und für die Auswahl der Gebäude in den künftigen Verwaltungszentren, wurde angekündigt. ${ }^{48}$

Diese Planungen wären ohne Rückkopplung zur sowjetischen Führung undenkbar gewesen. Schon im März verfügte das Politbüro die Entsendung einer Delegation zum Studium der Arbeit der Staatlichen Organe in die UdSSR, der neben Plenikowski, Sorgenicht und Lange auch der sehr talentierte und flexible Herbert Kröger von der Deutschen Verwaltungsakademie angehörte. ${ }^{49}$ In der UdSSR machte sich die Gruppe mit der Struktur und Arbeitsweise regionaler bzw. örtlicher Volksvertretungen (Sowjets) und Staatsorgane (Exekutivkomitees) vertraut. ${ }^{50}$ Ohne größere Beanstandung wurden in Moskau die in der DDR angestrebten Veränderungen akzeptiert. Als Wilhelm Pieck in Vorbereitung der II. Parteikonferenz vom 29. März bis 10. April in Moskau weilte, spielten diese Fragen bei den Besprechungen mit Stalin, Molotow, Malenkow, Mikojan und Bulganin nur eine sehr untergeordnete Rolle. Die sowjetische Seite interessierte sich vorrangig für die möglichen politischen und ideologischen Einflussmöglichkeiten der SED auf die Bundesrepublik, für den Stand der geheimen Aufrüstung in der DDR und für die wirtschaftliche Leistungsfähigkeit jenes Staates, der nach wie vor hohe Reparationen an die UdSSR zu leisten hatte. ${ }^{51}$ Konkreter verliefen die Konsultationen mit der Sowjetischen Kontrollkommission. Am 7. Mai informierte Pieck den Chef der SKK, Marschall Tschuikow, über den Planungsstand der Verwaltungsreform, wobei dieser den Bericht eher uninteressiert entgegennahm, lediglich einige Kreise als zu groß befand und sodann das Gespräch auf Fragen der Grenzsicherung und andere Sicherheitsaspekte überleitete. ${ }^{52}$

Anfang Mai wurde für die Verwaltungsreform eine neue Institution gegründet: die Koordinierungs- und Kontrollstelle für die Arbeit der Verwaltungsorgane. Wohl um der mangelnden Effektivität der Regierungstätigkeit zu begegnen, hatte der Ministerrat insgesamt fünf Koordinierungs- und Kontrollstellen (Ko.-Ko.-Stellen) eingerichtet. ${ }^{53}$ Die Leitung der Ko.-Ko.-Stelle für die Arbeit der Verwaltungsorgane übernahm mit Wirkung vom 16. Mai der gleichzeitig zum Staatssekretär beim Ministerpräsidenten berufene Werner Eggerath, der damit sein Amt als Ministerpräsident von Thüringen aufgab. Personell

$48 \quad$ Vgl. Dok. 2.

49 Vgl. das Protokoll Nr. 104 der Politbüro-Sitzung am 25. März 1952, in: BArch, DY 30/IV 2/2/204, Bl. 19-20.

50 Vgl. Foitzik, Sowjetische Kommandanturen, S. 24, der allerdings auf den späten Reisetermin verweist, der einen Einfluss der Studienerfahrungen auf die Planung in der DDR fraglich erscheinen lässt.

51 Vgl. Badstübner/Loth, Wilhelm Pieck, S. 382-399.

52 Vgl. ebd., S. 403. Hier findet sich auch einer der wenigen Hinweise auf eine direkte Genehmigung der Bezirksbildung durch sowjetische Stellen: „Einteilung der DDR / keine Einwände / einige Kreise zu groß“.

53 Vgl. den Beschluss der Regierung vom 9. Mai 1952, Anlage 6 zum Protokoll der 81. Sitzung, in: BArch, DC 20/1/3/106, Bl. 46-47. 
ging die Ko.-Ko.-Stelle aus der Hauptabteilung Staatliche Verwaltung des MdI hervor, deren Chef Klaus Sorgenicht Leiter der neuen Hauptabteilung Staatliche Organe wurde. Als Vorsitzender der für die weiteren Planungen eingerichteten Zentralen Kommission war Eggerath zum obersten Planungschef und ersten Berater der Partei- und Staatsführung avanciert. In der Praxis wurde die Dualität zwischen Eggerath und Plenikowski, der im zentralen Parteiapparat über die besseren Verbindungen verfügte, nie ausgeräumt. Selbst Willi Barth schob sich mit eigenen Entwürfen, die in das Politbüro gelangten, immer wieder nach vorn.

Der Fortgang der Reform drohte in eine Sackgasse ergebnisloser Betriebsamkeit zu geraten, da immer mehr Kommissionen fortwährend neue Konzepte und Vorschläge hervorbrachten, Entscheidungen aber nicht fielen. In dieser Situation trat Walter Ulbricht, der in der SED-Führung von Anfang an die Zuständigkeit für alle Fragen der Staatsorganisation an sich gezogen hatte, aus seiner auf diesem Gebiet seit der 8. ZK-Tagung im Februar 1952 zu beobachtenden Zurückhaltung heraus. Am 17. Juni 1952 legte er verbindlich fest, dass die neuen Bezirksstrukturen bis zum 1. August $1952 \mathrm{zu}$ schaffen seien und die Verwaltungsapparate spätestens am 15. August ihre Tätigkeit aufzunehmen hatten. ${ }^{54}$ Für die neuen Kreise galten als entsprechende Termine der 1. bzw. 15. September, woraus sich alle anderen Termine herleiteten - Behandlung der Gesetzesvorlage in der Volkskammer bis zum 23. Juli, dazu bis spätestens 17. Juli Beratung und Abstimmung in der Regierung. Um die Parteien und Organisationen des Demokratischen Blocks zu informieren, was durch Franz Dahlem am 7. Juli geschehen sollte, musste der Ministerpräsident die Vorlage bis spätestens zum 5. Juli auf den Tisch bekommen, woraus sich als letzter Tag für die Erarbeitung des Papiers der 3. Juli ergab. Eine kleine Kommission, zu der u. a. Willi Barth, Hans Warnke, Karl Polak ${ }^{55}$ und der ZK-Mitarbeiter Werner Manneberg gehörten, erstellte den Entwurf. Als Termin für die Vorlage im Politbüro wurde der 14. Juli bestimmt, sodass bis zu diesem Termin noch letzte Veränderungen vorgenommen werden konnten. Die Zentrale Kommission unter Werner Eggerath hatte nur noch operative Befugnisse und Koordinierungsfunktionen zwischen allen beteiligten Seiten wahrzunehmen. Zur Struktur der künftigen Räte der Bezirke und Kreise legte Ulbricht fest, dass sie sich aus einem Vorsitzenden und sechs Mitgliedern zusammenzusetzen hätten, wobei als Vorsitzende ausschließlich SED-Mitglieder in Frage kämen und zum Stellvertreter je nach Struktur ein Ratsmitglied einer anderen Partei gewählt werden könne. ${ }^{56}$

Nun erst wurden einige wirkliche brisante Fragen aufgeworfen. Das größte Problem ergab sich aus der bestehenden Verfassungslage, wonach die Existenz von Ländern in der DDR vorgegeben war. Um die Verfassung nicht schon nach weniger als drei Jahren zu revidieren, gelangten die Planer im Zentralkomitee zu der Auffassung, nicht die Länder selbst aufzulösen, sondern nur ihre Organe, also Landtage und Landesregierungen.

54 Vgl. die Aktennotiz von Willi Barth vom 2. Juli 1952, in: BArch, NY 4090/432 (Nachlass Otto Grotewohl), Bl. 63-65.

55 Zu Karl Polak (1905-1963), einem führenden Staatsrechtler der DDR, vgl. Müller-Enbergs, Wer war wer, S. 666.

56 Vgl. BArch, NY 4090/432 (Nachlass Otto Grotewohl), Bl. 65. 
Auch ihre Verfassungen sollten nach dieser Vorstellung nicht suspendiert, sondern zu einem späteren Zeitpunkt für gegenstandslos erklärt werden, was im ZK verfassungsrechtlich für unbedenklich gehalten wurde. Aus dieser Rechtsauffassung heraus sollte auch die Länderkammer, über deren Schicksal bis dahin wohl kaum nachgedacht worden war, bestehen bleiben. ${ }^{57}$

Auch über die Befugnisse und Aufgaben der Bezirkstage und der neu zu bildenden Kreistage wurden die Vorstellungen, die sich sehr stark am sowjetischen Vorbild orientierten, konkreter. Sie sollten vorrangig Agitationsbühnen des sozialistischen Aufbaus sein, was mit den alten Land- und Kreistagen mit ihren aus der Weimarer Republik entlehnten Strukturen und Geschäftsordnungen nicht möglich war. Die Volksvertretungen sollten nicht in konkurrierende Fraktionen zerfallen, die alternative Anträge einbrachten und in kontroversen Debatten um Positionen rangen, Entscheidungen der Verwaltung hinterfragten oder gar kritisierten. Sie sollten vielmehr die Beschlüsse, die in den wirklichen Entscheidungszentren gefallen waren, durch Zustimmung legitimieren und durch Einstimmigkeit ein harmonisches Bild von den politischen Verhältnissen vermitteln. Damit erfüllten die Volksvertretungen eine ideologische Funktion. Zwar wurde auch Kontrolle für angebracht gehalten, doch mussten die Volksvertreter selbst jederzeit kontrollierbar und steuerbar sein..$^{58}$

Eine Schlüsselfunktion kam in diesem Geflecht der Aufgaben und Zuständigkeiten den für die einzelnen Sachgebiete zu bildenden ,ständigen Kommissionen“ zu. Sie sollten kontrollieren und zugleich selbst an der Verwaltungstätigkeit teilnehmen, was einen erheblichen Arbeitsaufwand für deren Mitglieder bedeutete. Die Frage, ob die Abgeordneten, die in ihren Berufen verblieben, zu dieser aufwendigen Tätigkeit zeitlich und fachlich in der Lage überhaupt wären, wurde nicht gestellt. Der SED-Führung gelang es auf diese Weise, die Grenzen zwischen Legislative und Exekutive zu verwischen. ${ }^{59}$

Der weitere Ablauf der Ereignisse entsprach dem von Walter Ulbricht skizzierten Zeitplan. Am 3. Juli verabschiedete das Sekretariat des ZK der SED die „Direktive für die Überleitung der Staatlichen Organe in die neuen Bezirke und Kreise" ${ }^{60}$ Auf der II. Parteikonferenz machte die SED-Führung ab dem 9. Juli die Öffentlichkeit mit dem unmittelbar bevorstehenden Umbau des Staatsapparates in der DDR bekannt. Zwar unterblieb jeder Hinweis auf die staats- und verfassungsrechtliche Dimension dieses Projektes. Dass es sich um eine tiefgreifende Veränderung der staatlichen Grundlagen der ostdeutschen Gesellschaft handelte, wurde hingegen sehr deutlich herausgestellt. Fünf Tage nach Be-

$57 \quad$ Vgl. Dok. 10.

58 Vgl. Kurzweg, Parteiherrschaft.

59 Vgl. Dok. 10. Als Walter Ulbricht vier Jahre später, am 23. April 1956, vor dem Nationalrat der Nationalen Front die Notwendigkeit der Bezirksbildung darlegte, sprach er von „Mammutlandtage[n] und ihre[n] Landesregierungen, die weit von der Bevölkerung entfernt waren, wogegen die Bezirkstage sehr viel operativer die Leitung des wirtschaftlichen und kulturellen Aufbaus durchführen“. Ulbricht propagierte einen ,erforderlich[en] Kampf gegen einen in unserer Tradition tief verankerten Bürokratismus [...], dessen Tendenz es ist, den Staatsapparat über die Parlamente herrschen zu lassen“; BArch, DY 30/IV 2/12/69, B1. 7-8.

60 Vgl. das Dok. 6 sowie die Brandenburg betreffenden Anlagen als Dok. 7, 8 und 9. 
endigung der Konferenz, am 17. Juli, stand auf der Tagesordnung des Ministerrates die Behandlung des Gesetzentwurfes „Über die weitere Demokratisierung des Aufbaus und der Arbeitsweise der staatlichen Organe in den Ländern der Deutschen Demokratischen Republik" ${ }^{61}$ womit sich der enge Terminplan für die Verabschiedung des Gesetzes durch die Volkskammer am 23. Juli einhalten ließ. ${ }^{62}$

In der letzten Julidekade geriet die Verwaltungsreform indes erneut in Turbulenzen, da wichtige Planungsarbeiten noch nicht zum Abschluss gebracht waren und die Sowjetische Kontrollkommission plötzlich ultimative Forderungen stellte. Die Sowjets waren teilweise nicht mit der territorialen Einteilung einverstanden. Innerhalb weniger Tage waren neue Vorstellungen über die Einrichtung von Abteilungen bei den Räten zu entwickeln, deren Zahl nach Auffassung der SKK geringer als geplant sein sollte. Zugleich bestand die SKK auf der Schaffung von ständigen Kommissionen für Justiz- und Polizeiarbeit, was nach deutschen Planungen nicht vorgesehen war. ${ }^{63}$

Als problematisch erwiesen sich die Gewinnung von Personal an den künftigen Verwaltungssitzen und die Bereitstellung von Verwaltungsgebäuden, zumal die SKK die Umwidmung von Wohnraum in Büros für Verwaltungszwecke untersagte. Bis zuletzt wurde um die Verteilung der Führungspositionen in den künftigen Bezirken gerungen. Besonders kompliziert gestalteten sich diese Probleme für Brandenburg, da hier erst sehr spät die Entscheidung über die endgültige Bezirkseinteilung fiel. Bis Anfang Juni bestand der Plan, das Land Brandenburg in einen Nord-, einen Südwest- und einen Südostbezirk aufzuteilen, wobei sowohl Oranienburg als auch Neuruppin als Verwaltungssitz des Nordbezirkes im Gespräch waren. Erst in der letzten Planungsphase entstand die Idee, im Südosten einen Bezirk mit Cottbus als Verwaltungssitz zu schaffen, um dort das künftige Entwicklungszentrum der Kohle- und Energieindustrie zusammenzufassen. Damit gehörte der Bezirk Cottbus zu den wenigen Beispiele einer Bezirksgründung nach tatsächlich wirtschaftlichen Aspekten. ${ }^{64} \mathrm{Ob}$ eine derartige Konzentration einzelner Wirtschaftszweige und deren weiterer Ausbau sinnvoll sind, ist eine andere Frage. Es fällt aber auf, dass weder die Frage einer Konzentration von Wirtschaftszweigen noch die einer sinnvollen Mischung bei der Entscheidungsfindung im Politbüro oder im Sekretariat des ZK behandelt worden wären oder dass dort entsprechende Planungspapiere vorgelegen hätten. „Wirtschaftliche und verkehrstechnische Zweckmäßigkeit“, wie in den ersten Strategiepapieren vom April 1952 formuliert, ${ }^{65}$ wurde in den meisten Fällen der Neugliederung kaum erreicht und wohl auch gar nicht ernsthaft angestrebt. Schon nach rund eineinhalb Jahren fiel die Bilanz in diesen Punkten sehr kritisch aus. So bemerkte Eggeraths Nach-

61 Vgl. das Protokoll der 92. Sitzung der Regierung, 17. Juli 1952, Vorlage Nr. 1373, in: BArch, DC 20/I/118, Bl. 1-3.

62 Das „Gesetz über die weitere Demokratisierung des Aufbaus und der Arbeitsweise der staatlichen Organe in den Ländern der Deutschen Demokratischen Republik" vom 23. Juli 1952 ist abgedruckt in Dokumente 1949-1961, S. 99-101, sowie im Gesetzblatt der DDR, Teil I, 1952, S. 613-614.

63 Vgl. das Protokoll der Sitzung der zentralen Regierungskommission am 19. Juli 1952, in: BArch, DO 1 (Ministerium des Innern), Nr. 26099, B1. 61-65.

64 Vgl. Dok. 15.

65 Vgl. Dok. 2. 
folger Günter Heyden im Februar 1954, bei der Bezirksbildung seien ,ernsthafte Fehler“ begangen worden, indem etwa ,ungünstige Verkehrsverhältnisse [...] entstanden sind, was den berechtigten Unwillen der Bevölkerung" hervorgerufen habe. ${ }^{66}$

Wesentlich blieb aber die politische Zweckmäßigkeit des Verfahrens, weshalb trotz kritischer Bilanz die Bezirksgliederung unverändert blieb. Das betraf die Gliederung in vom Ministerrat direkt geführte Verwaltungseinheiten und deren territoriale Einteilung. Das mit Beschluss vom 17. Juli 1952 geschaffene Präsidium des Ministerrates, das nach den Kompetenzüberschneidungen der Ko.-Ko.-Stellen die Arbeitsfähigkeit des Kabinetts wiederherstellen sollte, bildete somit die notwendige Bedingung für die vertikale Neugliederung des Staates ${ }^{67}$ Doch auch Sicherheitsfragen, auf die in diesem Zusammenhang weder von den Akteuren noch in der späteren Literatur bisher ausreichend hingewiesen wurde, spielten zweifellos eine erhebliche Rolle. Vor allem die Überwachung der Westgrenze und der Umlandgrenze zu den Berliner Westsektoren, für die die bewaffneten Organe ebenso zuständig waren wie die örtlichen Partei- und Staatsorgane, stand dabei im Vordergrund der Überlegungen. Am 26. Mai 1952 war die Einführung einer neuen Grenzordnung beschlossen worden, über die schon seit längerer Zeit diskutiert worden war. ${ }^{68}$ Die gesamte West-Berliner Umlandgrenze befand sich nun im Bezirk Potsdam. Die Länder selbst wurden erst sehr spät in die Verwaltungsreform einbezogen. Ihre Aufgaben erstreckten sich ausschließlich auf die Umsetzung zentraler Direktiven sowie auf die exakte Berichterstattung über den Fortgang der Veränderungen in ihren Territorien. Zwei parallele Prozesse waren zu bewältigen, deren Dimension sich in umgekehrter Proportion zu der zur Verfügung stehenden Zeit verhielt: die Abwicklung der Einrichtungen des Landes und der Aufbau der Behörden der Bezirke. Für beide Prozesse verantwortlich waren die Ministerpräsidenten, die damit ihre letzte große Aufgabe zu erfüllen hatten. Angeleitet wurden sie durch die Koordinierungs- und Kontrollstelle für die Arbeit der Verwaltungsorgane unter Staatssekretär Eggerath; abzustimmen hatten sie sich mit den 1. Landessekretären der SED.

Die Abwicklung der Regierungsstellen regelte in Brandenburg Ministerpräsident Jahn mit den „Genossen Minister[n]“ bzw. mit den „Genossen Hauptabteilungsleitern in den Ministerien mit bürgerlichen Ministern“. ${ }^{69}$ Aus Berlin reiste eine Instrukteursgruppe an, aus der für jedes Ministerium ein Instrukteur zuständig war. Den Instrukteuren waren über alle Vorgänge Mitteilung zu machen; bestimmte Entscheidungen bedurften ihrer Zustimmung. Jeder Instrukteur berichtete für sein Ressort an die Ko.-Ko.-Stelle. Zusam-

66 Schreiben des Leiters der Hauptabteilung Örtliche Organe des Staates beim Ministerpräsidenten, Günter Heyden, an Otto Grotewohl, 17. Februar 1954, in: BArch, NY 4090/432 (Nachlass Otto Grotewohl), Bl. 177-178.

67 Vgl. Lapp, Ministerrat, S. 20.

68 Vgl. Verordnung über Maßnahmen an der Demarkationslinie zwischen der Deutschen Demokratischen Republik und den westlichen Besatzungszonen Deutschlands vom 26. Mai 1952. Anlage 1 zum Protokoll der 84. (außerordentlichen) Sitzung der Regierung vom 26. Mai 1952, in: BArch, DC 20/1/3-109, B1. 78-79. 
menfassende Berichte der Gruppe lieferte zusätzlich der Leitinstrukteur für das Land Brandenburg Schulz. ${ }^{70}$

Der wichtigste und schwierigste Teil der Arbeit bestand im Aufbau der Bezirksbehörden, wozu im Land Brandenburg am 17. Juli 1952 drei Bezirkskommissionen gebildet wurden..$^{71}$ Bis zu zehn Mitglieder stark, vereinten diese Kommissionen das künftige Führungspersonal für die Räte der Bezirke, die Bezirksleitungen der SED sowie von FDGB und FDJ. Daneben fungierte für jeden Bezirk ein Organisationskomitee, das in Personalunion vom Vorsitzenden der Bezirkskommission geleitet wurde und sich in mehrere Unterkommissionen untergliederte, im Einzelnen für territoriale Fragen, für Kaderfragen, für die personelle Zusammensetzung der Bezirks- und Kreistage, für Gebäude und für die grundsätzliche administrative Überleitung. ${ }^{72}$

Damit waren zugleich die bis Ende Juli noch immer nicht geklärten Problemkreise umrissen, mit deren Lösung die Kommissionen z. T. bis Ende August befasst waren. Im Land Brandenburg stellten sich diese Probleme mit besonderer Schärfe, was sich aus der verspäteten Entscheidung zur Bildung des Bezirkes Cottbus ergab. ${ }^{73}$ Die überhasteten Planungen für Cottbus wirkten wiederum auf die Planungen und Entscheidungen in Potsdam und Frankfurt (Oder) zurück, wo sich vor allem die Personalpläne immer wieder als Makulatur erwiesen. Im Einzelnen ging es um Lösungen zu folgenden Punkten:

Territoriale Fragen: Nachdem die Bezirkseinteilung für Brandenburg auf der zentralen Ebene entschieden worden war, oblag den Bezirkskommissionen - nicht ohne die jeweilige Bestätigung durch zentrale Behörden - die Klärung wesentlicher Detailfragen. Hierzu zählten die endgültige Festlegung der Bezirksgrenzen sowie die Kreiseinteilung und Festlegung der Verwaltungssitze. An Mecklenburg und Sachsen-Anhalt waren Unterlagen über die zu den Bezirken Schwerin, Neubrandenburg und Magdeburg wechselnden Kreise zu übergeben, von Sachsen-Anhalt und Sachsen für die zu Potsdam und Cottbus kommenden Kreise zu übernehmen. Die Abstimmungen zwischen Cottbus und Frankfurt (Oder) über die Zugehörigkeit einiger Gemeinden zu dem einen oder anderen Bezirk zogen sich entsprechend in die Länge. ${ }^{74}$

Personalfragen: Um Massenentlassungen zu vermeiden und die Funktionsfähigkeit der Bezirksverwaltungen zu gewährleisten, sollte das Personal der aufzulösenden Landesministerien und der anderen Behörden übernommen werden. Neben den sogenannten kaderpolitischen Aspekten, auf die später eingegangen wird, erwies sich die mangelnde Mobilität der Mitarbeiter als Haupthindernis. Kaum jemand war bereit, seinen Potsdamer Arbeitsplatz gegen einen Schreibtisch in Frankfurt oder Cottbus einzutauschen und damit auch den Wohnort zu wechseln, zumal in den neuen Bezirkszentren kaum Wohnungen

$70 \quad$ Vgl. Dok. 12 und 14.

71 Zur Tätigkeit dieser Kommissionen sind die jeweiligen Berichte über den Stand der Durchführung der Verwaltungsreform aussagekräftig, die regelmäßig an Staatssekretär Eggerath gesandt wurden; vgl. die Dok. 11, 13, 24, 25, 26, 28, 31, 32, 34, 36, 37, 40 und 42.

72 Vgl. Dok. 45.

73 Dieser Zusammenhang wurde auch in der Verwaltung selbst gesehen, vgl. Dok. 49.

74 Vgl. etwa das Protokoll über die Besprechung zum „Stand der Überleitung - Bezirk Cottbus“, 2. August 1952, in: BLHA, Rep. 401, Nr. 58, B1. 16. 
zu bekommen waren. In Potsdam hatten sich viele gerade eingerichtet, nicht wenige Mitarbeiter auch in den meist attraktiven Gemeinden im Umland von Potsdam. ${ }^{75}$ Für zahlreiche Betroffene bildete die geringe Aussicht auf einen angemessenen Arbeitsplatz für den Ehepartner in Frankfurt oder Cottbus ein ebenso gewichtiges Argument gegen einen Wechsel. Während so für die Bezirksbehörden in Potsdam ausreichend Personal zur Verfügung stand, entwickelte sich die Suche nach geeigneten Mitarbeitern für die beiden anderen Bezirksbehörden zu einem längerfristigen Problem, das sowohl die untere Ebene wie auch die mittlere Leitungsebene tangierte. ${ }^{76}$ Am 25. August zählte die Cottbusser Bezirksverwaltung 307 Mitarbeiter $^{77}$ - das entsprach 65 Prozent der zu besetzenden Stellen -, zwei Wochen später waren immerhin 412 der 496 Stellen besetzt. ${ }^{78}$ In Frankfurt entwickelte sich die Situation ähnlich. ${ }^{79}$ Knapp die Hälfte der Mitarbeiter wurde aus den Landesbehörden übernommen, ein Viertel aus der Kreis- und Stadtverwaltung. Die restlichen Beschäftigten hatten zuvor meist in anderen Verwaltungen und Organisationen bzw. in Betrieben gearbeitet.

Gebäudefragen: Von erheblicher Tragweite erwies sich der Mangel an geeigneten Verwaltungsgebäuden in den neuen Bezirksstädten. Vor allem Cottbus, wo es nie eine größere Anzahl von Verwaltungen gegeben hatte und somit auch nie entsprechende Gebäude errichtet worden waren, war davon betroffen. Deshalb entstanden in der noch immer kriegszerstörten Stadt zahlreiche Baracken - eine Methode, nach der auch in Frankfurt und in vielen Kreisstädten der Mangel an Büroflächen behoben wurde. Finanziert wurde das Barackenbauprogramm durch die kurzfristige Bereitstellung von mehreren Millionen DM aus dem zentralen Staatshaushalt und die Freigabe von Kontingentscheinen für das Material durch die Regierung. ${ }^{80}$ Auch Schulen, Wohnheime und Villen, oft bereits von der sowjetischen Besatzungsmacht nach dem Krieg beschlagnahmt und nun teilweise abgegeben, dienten fortan Verwaltungszwecken. ${ }^{81}$

Personelle Zusammensetzung der Bezirks- und Kreistage: Keinesfalls wollte die SED-Führung den Umbau des politischen Systems in der DDR mit dem unkalkulierbaren

$75 \quad$ Vgl. Dok. 39.

76 Vgl. Dok. 24; die zur selben Zeit (Anfang August 1952) aus Cottbus genannte Zahl von 283 übernommenen Mitarbeitern erwies sich in der Praxis als überhöht, da viele Betroffene, die anfangs zum Wechsel bereit waren, am Ende doch nicht nach Cottbus gingen; vgl. BLHA, Rep. 801, Nr. 136, B1. 128.

77 Vgl. ebd., B1. 93.

78 Vgl. das Schreiben des Vorsitzenden des Rates des Bezirkes Cottbus an Staatssekretär Eggerath, 9. September 1952, in: ebd., Bl. 97.

79 Bis zum 15. September 1952 waren 336 Stellen besetzt, was 73,5 Prozent der Sollstärke entsprach; vgl. die Aufstellung der Kaderabteilung des Rates des Bezirkes Frankfurt (Oder), in: BLHA, Rep. 601, Nr. 5990. Zur Weigerung von Landesbediensteten, nach Frankfurt zu wechseln, vgl. auch den Abschlussbericht der Zentralen Kommission für Staatliche Kontrolle, Bezirksinspektion Frankfurt (Oder) vom 3. Oktober 1952, in: BArch, DO 1 (Ministerium des Innern), Nr. 26100, B1. 261-262, sowie Dok. 47.

80 Vgl. Dok. 27.

81 Vgl. den Vorschlag der Gebäudekommission des Kreises Frankfurt (Oder) vom 6. Juli 1952, in: BLHA, Rep. 601, Nr. 29, B1. 16-20, sowie das entsprechende Schreiben der Stadt Potsdam vom 20. Juli 1952, in: BLHA, Rep.401, Nr. 58, Bl. 147-155. 
Risiko von Wahlen verbinden. Daraus ergab sich die Entscheidung, die Landtagsabgeordneten nach dem Wohnortprinzip auf die Bezirkstage aufzuteilen und für die freien Sitze Kandidaten auszuwählen, die das Präsidium des Landesausschusses der Nationalen Front zu bestätigen hatte. Die Zusammensetzung der Bezirkstage war das Ergebnis minuziöser Berechnungen im Zentralkomitee. Zwei Ziele wurden verfolgt: erstens die unbedingte Sicherung der SED-Mehrheit und zweitens eine weitere Schwächung der Positionen von CDU und LDP, die immer noch als Unsicherheitsfaktoren galten.

Am 24. Juli 1952 legte der Ministerrat die Stärke der Bezirkstage fest: 60 Abgeordnete für bis zu 500.000 Einwohner, für jeweils weitere 35.000 Einwohner ein weiterer Abgeordneter bis zu maximal 90. ${ }^{82}$ Daraus ergaben sich für den Bezirkstag Potsdam $82 \mathrm{Ab}-$ geordnete, für den Bezirkstag Cottbus 66 Abgeordnete und für den Bezirkstag Frankfurt (Oder) 64 Abgeordnete. Bereits am 3. Juli stand ZK-intern die künftige Sitzverteilung fest. Dazu wurde der Schlüssel, der nach den Einheitslisten-Wahlen von 1950 die Sitzverteilung im Landtag geregelt hatte, verändert. Einmal erhöhte sich in allen Bezirkstagen die Anzahl der Sitze für die SED um jeweils einen. „Die absolute Mehrheit ist gegeben“, lautete das Fazit: im Bezirk Potsdam mit 44 Genossen (bei 16 direkten Mandaten für die SED), im Bezirk Cottbus mit 37 Genossen (13 direkte Mandate) und im Bezirk Frankfurt (Oder) mit 39 Genossen (13 direkte Mandate). Zum anderen mussten sich CDU und LDP mit jeweils bis zu drei bzw. zwei Sitzen weniger pro Bezirkstag begnügen, wogegen NDPD und DBD bis zu drei bzw. zwei Sitze mehr erhielten. ${ }^{83}$ Als Vorwand diente die angeblich gesunkene oder gewachsene Bedeutung der betroffenen Parteien. In den Vordergrund gestellt wurde die als gesellschaftliche Notwendigkeit bezeichnete Erhöhung des Anteils der Arbeiterklasse und anderer werktätiger Schichten in den neuen Volksvertretungen. Die zuständige Unterkommission hatte den künftigen Abgeordneten ihre neue Funktion und die Arbeitsweise der Bezirkstage mit ihren ständigen Kommissionen zu vermitteln, wozu ein enges Netz von Schulungen und anderen Unterweisungen geknüpft wurde.

Unklar bis zum Schluss blieb die Frage, wer die Spitzenfunktionen in den Bezirken besetzen würde, wozu sich die SED-Führung in Berlin allein die Entscheidung vorbehielt. Vorrangig um vier Ämter ging es in den Planungen: der Vorsitzende des Rates des Bezirkes, der in der damaligen Phase offenbar als die wichtigste Person in den neuen Verwaltungsgebieten betrachtet wurde, der Sekretär des Rates sowie der 1. und der 2. Sekretär der SED-Bezirksleitungen. ${ }^{84}$

82 Vgl. die Anlage A zum Beschluss des Ministerrates vom 24. Juli 1952, in: BArch, DC 20/1/3-119, Bl. $99-100$.

83 Vgl. die Dok. 6, 7, 8 und 9; nach Auskunft von Plenikowski war bei Besprechungen, die er und Warnke bei der Sowjetischen Kontrollkommission zu führen hatten, sogar über einen Stimmenanteil von 60 Prozent für die SED geredet worden; vgl. das Protokoll der Sitzung der zentralen Regierungskommission am 19. Juli 1952, in: BArch, DO 1 (Ministerium des Innern), Nr. 26099, Bl. 61-65.

84 Vgl. Kotsch, Brandenburg, S. 59-61. 


\section{III.}

Der offizielle Übergang vom Land Brandenburg zu den drei Bezirken vollzog sich innerhalb von zwei Wochen. Am 25. Juli 1952 stimmte der Landtag in Potsdam unter Bezug auf das von der Volkskammer zwei Tage zuvor verabschiedete Gesetz seiner Selbstauflösung und der Beendigung der Tätigkeit der Landesregierung zum 31. Juli $1952 \mathrm{zu}^{85} \mathrm{Da}$ sich die Räte der Bezirke am 1. August noch nicht im Amt befanden - sie waren von den Bezirkstagen zu wählen, die sich aber noch nicht konstituiert hatten -, beauftragte die Regierung der DDR die Organisationskomitees der Bezirke mit der provisorischen Ausübung der Befugnisse der Räte der Bezirke. ${ }^{86}$ Die Mandatsverteilung in den Bezirkstagen erfolgte durch Absprache zwischen den Parteien und den Massenorganisationen, die ebenfalls Abgeordnete in die Bezirkstage entsenden durften. Der SED stand die relative Mehrheit der Mandate zu, die sich durch die SED-Mitglieder unter den Abgeordneten der Massenorganisationen schnell in eine absolute Mehrheit verwandeln ließ. Mit starken Gruppen waren die neuen Parteien (NDPD und DBD) sowie die Einheitsgewerkschaft FDGB in den Bezirkstagen vertreten, während die ,altbürgerlichen“" Parteien CDU und LDP eine weitere Schwächung gegenüber ihren Positionen in den Landtagen hinnehmen mussten. In bewusster Abkehr von traditioneller parlamentarischer Praxis bildeten die Abgeordneten keine Fraktionen und wählten keine Präsidien. Stattdessen wählte der Bezirkstag zu jeder Sitzung von neuem einen Tagungsvorsitzenden und zwei Stellvertreter. Mit der Auflösung der Bezirkskommissionen, von der Zentralen Regierungskommission am 27. August 1952 mit sofortiger Wirkung dekretiert, befanden sich alle staatlichen Verwaltungsfunktionen für die Bezirke bei den Räten. ${ }^{87}$

Mitte August begann die zweite Etappe beim Umbau des Staatsapparates, die die Auflösung der Großkreise und die Bildung der kleineren Verwaltungskreise zum Ziel hatte. An die Stelle der 23 Kreise des Landes Brandenburg traten 41 Kreise, von denen $17 \mathrm{im}$ Bezirk Potsdam, 14 im Bezirk Cottbus und zehn im Bezirk Frankfurt (Oder) lagen. Die Planung, bis Ende August alle Räte der Kreise ins Amt zu bringen, erwies sich als unrealistisch, obwohl die wichtigsten Personalentscheidungen bis Ende August gefallen waren. ${ }^{88}$ Die Verzögerung bei der Besetzung der Ämter betrug fast einen Monat. Auch gab es Widerspruch gegen die Neuorganisation der Kreise, etwa in Bernau, wo der Landrat die Übergabe von Gegenständen aus dem Landratsamt an die Kreise Oranienburg und Gransee verweigerte, da nach seiner Auffassung der gesamte Kreis Niederbarnim zum Bezirk Frankfurt (Oder) gehört hätte. ${ }^{89}$

Die Größe der Kreistage hing von der Einwohnerzahl ab. In Kreisen mit weniger als 50.000 Einwohnern zählten die Kreistage 30 Abgeordnete, die sich in Kreisen mit bis

85 Vgl. das Gesetz- und Verordnungsblatt des Landes Brandenburg, Teil I (1952), S. 15-16.

86 Vgl. das Protokoll der 94. Sitzung der Regierung, 31. Juli 1952, in: BArch, DC 20/1/3-121, Bl. 6.

87 Vgl. Dok. 35.

88 Vgl. Dok. 30.

89 Vgl. Dok. 36; größere Gebietsteile des aufgelösten Kreises Niederbarnim wurden 1952 dem neugebildeten Kreis Oranienburg im Westen, kleinere dem neuen Kreis Gransee im Osten zugeschlagen. 
zu 70.000 Einwohnern auf 40, mit bis zu 100.000 Einwohnern auf 50 und danach für je 20.000 Einwohner um jeweils einen weiteren Abgeordneten erhöhten. ${ }^{90}$ Sieben ständige Kommissionen konstituierten sich in den Kreistagen: Haushalt, Landwirtschaft und ländliches Bauwesen, Gesundheitswesen und Sozialfürsorge, Volksbildung und kulturelle Massenarbeit, Handel und Versorgung, Örtliche Industrie, kommunale Wirtschaft und Wohnungswesen sowie Örtliche Volkspolizei und Justiz. ${ }^{91}$

Die dritte und letzte Etappe des vertikalen Umbaus des Staatsapparates (Dezember 1952 bis Januar 1953) erfasste die kreisfreien Städte. Im ehemaligen Land Brandenburg betraf das zwei Städte: Potsdam und Brandenburg/Havel. Cottbus, Eberswalde, Forst, Frankfurt (Oder), Guben, Rathenow und Wittenberge (das mit der Bezirksbildung zu Schwerin gelangte) hatten den Stadtkreisstatus bereits 1950 verloren. ${ }^{92}$ Mit den Veränderungen zum Jahreswechsel 1952/53 unterschieden sich die kreisfreien Städte in ihrer Verwaltung kaum mehr von den Flächenkreisen. Im Gegensatz zu den neuen Kreis- und Bezirkstagen blieb die im Ergebnis der Wahlen vom 15. Oktober 1950 entstandene Zusammensetzung der Stadtverordnetenversammlungen, die einen ständigen Vorsitzenden hatte, erhalten. ${ }^{93}$ Die Potsdamer Stadtverordnetenversammlung zählte 60 Abgeordnete, die Brandenburger 55 Abgeordnete. Für eine kurze Übergangszeit gab es in Potsdam auch drei Stadtbezirksversammlungen (Potsdam I mit 40 Abgeordneten, Potsdam II mit 45 Abgeordneten und Potsdam III mit 50 Abgeordneten), wenngleich die Verordnung über die Bildung von Stadtbezirksversammlungen nur für Städte mit mehr als 250.000 Einwohnern Gültigkeit besitzen sollte. ${ }^{94}$ Die Stadtverordnetenversammlung wählte die Mitglieder des Rates der Stadt und als Vorsitzenden den Oberbürgermeister. Seine Stellung entsprach der eines Vorsitzenden des Rates des Kreises; ebenso wie die Räte der Kreise unterstanden die Räte der Städte direkt dem Rat des Bezirkes.

In den kreisangehörigen Städten wählten die Stadtverordnetenversammlungen ebenfalls die Mitglieder der Räte der Städte und als Vorsitzenden die Bürgermeister oder Oberbürgermeister. Allerdings waren diese den Räten der Kreise unterstellt, ebenso wie die Bürgermeister und Gemeinderäte, die von den Gemeindevertretungen gewählt wurden.

Damit war in der gesamten DDR ein dreistufig gegliedertes System der „örtlichen Organe der Staatsmacht“ geschaffen worden. Gemeinden, Kreise und Bezirke waren einan-

90 Vgl. die Direktive der Koordinierungs- und Kontrollstelle für die Arbeit der Verwaltungsorgane ,über die Vorbereitung der Arbeit der staatlichen Organe in den Kreisen“, o. D., in: BLHA, Rep. 401, Nr. 71, B1. 224.

91 Vgl. die vorläufige Direktive der Koordinierungs- und Kontrollstelle für die Arbeit der Verwaltungsorgane ,über die Aufgaben und Arbeit der ständigen Kommissionen der Bezirkstage und Kreistage" vom 18. September 1952, abgedruckt in Dokumente 1949-1961, S. 107-109.

92 Später wurden (wieder) kreisfrei: Frankfurt (Oder) und Eisenhüttenstadt (1953), Cottbus (1955) sowie Schwedt (1961); vgl. Grimm, Geographische Aspekte.

93 Vgl. die Richtlinie der Koordinierungs- und Kontrollstelle für die Arbeit der Verwaltungsorgane „für die Bildung der Stadtverordnetenversammlungen und ihrer Organe" vom 10. Dezember 1952, in: BLHA, Rep. 401, Nr. 294, B1. 52-59.

94 Vgl. die Richtlinie der Koordinierungs- und Kontrollstelle für die Arbeit der Verwaltungsorgane „für die Bildung der Stadtbezirksversammlungen und ihrer Organe“ vom 10. Dezember 1952, in: ebd., Bl. 9-37. 
der unterstellt und wurden zentral durch die Regierung angeleitet und kontrolliert. Der Begriff der „örtlichen Organe der Staatsmacht“ hob zugleich die Zweiteilung im staatlichen Aufbau der DDR hervor. Die Gesetzgebungskompetenz lag allein bei der Zentrale: Den örtlichen Organen - egal ob Bezirk, Kreis oder Gemeinde - war lediglich die Umsetzung zentraler Vorgaben nach örtlichen Erwägungen überantwortet. Selbst diese Möglichkeit engte ein Netz von Vorschriften (wie die verbindlichen Kennziffern über die Verwendung finanzieller und materieller Fonds) und die Pflicht zur ständigen Rechenschaft ein. Hinzu kam die doppelte Unterstellung der Fachorgane bei den örtlichen Räten: zum einen dem Ratsvorsitzenden und zum anderen dem entsprechenden Fachorgan auf der übergeordneten Stufe. ${ }^{95}$ Der zentralistische Staatsaufbau war in seiner Grundstruktur vollendet, das Ziel der als „Verwaltungsreform“ bezeichneten Veränderungen erreicht.

Die Bildung der Verwaltungsbezirke und die neue Kreiseinteilung bewirkten eine tiefgreifende Veränderung der territorialen Strukturen Ostdeutschlands. Geradezu radikal gestalteten sich diese Veränderungen für Brandenburg. Die ehemalige preußische Provinz Brandenburg hatte bereits sieben Jahre zuvor, am Ende des Zweiten Weltkrieges, mit dem Verlust der Neumark und anderer Gebiete östlich von Oder und Neiße rund ein Drittel ihres Territoriums eingebüßt. Durch die Neugliederung von 1952 gingen weitere brandenburgische Gebiete an Bezirke, die hauptsächlich mecklenburgisches und pommersches Gebiet umfassten: Der Bezirk Schwerin erhielt die Westprignitz und Teile der Ostprignitz, Neubrandenburg den Kreis Prenzlau, fast den gesamten Kreis Templin und Teile des Kreises Angermünde. Havelberg ging an den Bezirk Magdeburg und fand auf diese Weise Anschluss an die Altmark, von der im Mittelalter die deutsche Eroberung und Besiedlung der späteren Mark Brandenburg ausgegangen war. Sofern in den neu gebildeten Verwaltungsbezirken Potsdam, Frankfurt (Oder) und Cottbus die historische Nachfolge der 1947 von der Provinz zum Land umgewandelten Mark Brandenburg gesehen wird, hat sich im Jahre 1952 für Brandenburg eine Südverschiebung vollzogen.

Um einen bemerkenswerten Vorgang handelte es sich bei den südwestlichen Gebietsgewinnen. Denn obwohl diese im Jahr 1952 in den Bezirk Cottbus inkorporierten Territorien vom Land Sachsen kamen, hatten sie als ehemalige Kreise der bis 1945 bestehenden Provinz Schlesien eine preußische Vergangenheit. ${ }^{96}$ Somit kamen fünf Jahre nach der amtlich verfügten Auflösung Preußens durch die Alliierten Gebiete der einen ehemaligen preußischen Provinz mit Gebieten einer anderen ehemaligen preußischen Provinz zusammen. $^{97}$

Der neu gebildete Bezirk Potsdam umfasste ein Territorium von $12.568 \mathrm{~km}^{2}$ und war damit größter Flächenbezirk in der DDR. Bei seiner Gründung lebten dort rund 1.274.300

95 Die „doppelte Unterstellung“ bot indes in der Folge Anlass für vielfältige Unklarheiten und Missverständnisse über die tatsächlichen Unterstellungsverhältnisse; vgl. Foitzik, Sowjetische Kommandanturen, S. 24-25, sowie Dok. 56.

96 Die westlich der Neiße gelegenen Teile Schlesiens (die Gebiete um Hoyerswerda, Rothenburg, Görlitz) wurden von der sowjetischen Besatzungsmacht im Sommer 1945 in das Land Sachsen eingegliedert.

97 Vgl. Vogel, Brandenburg. 
Menschen. ${ }^{98}$ Der Bezirk, dessen Territorium aus den Landkreisen Ostprignitz, Ruppin, Westhavelland, Osthavelland, Zauch-Belzig, Teltow und Luckenwalde, Teilen der brandenburgischen Kreise Templin, Niederbarnim, Beeskow-Storkow und Luckau, der sächsisch-anhaltinischen Kreise Jerichow I und II, Wittenberg und Schweinitz sowie den Stadtkreisen Potsdam und Brandenburg/Havel hervorging, gliederte sich in die neuen Landkreise Pritzwalk, Wittstock, Kyritz, Neuruppin, Gransee, Oranienburg, Nauen, Rathenow, Brandenburg/Havel, Potsdam, Belzig, Jüterbog, Luckenwalde, Zossen und Königs Wusterhausen sowie in die Stadtkreise Potsdam und Brandenburg/Havel. Städte, in denen sich bereits Landratsämter der aufgelösten Großkreise befanden, blieben Kreissitz. In sechs weiteren Städten waren hingegen Kreisverwaltungen erst aufzubauen: in Pritzwalk, Wittstock, Gransee, Oranienburg, Zossen und Königs Wusterhausen. Die kreisfreien Städte Potsdam und Brandenburg/Havel, die zugleich auch Verwaltungssitz der umliegenden Landkreise waren, mussten je zwei Kreisverwaltungen aufnehmen.

Mit einer Fläche von $7.186 \mathrm{~km}^{2}$ bedeutend kleiner war der Bezirk Frankfurt (Oder) im Osten, der eine auffällige Nord-Süd-Ausdehnung aufwies. 642.000 Einwohner lebten dort. ${ }^{99}$ Zwei der aufgelösten Landkreise, Oberbarnim und Lebus, gingen vollständig im Bezirk Frankfurt (Oder) auf. Hinzu kamen die Kreise Angermünde, Niederbarnim und Beeskow-Storkow, von denen die überwiegenden Teile in den neuen ostbrandenburgischen Verwaltungsbezirk integriert wurden. Teile der Kreise Lübben und Guben und des mecklenburgisch-pommerschen Kreises Randow rundeten das Bezirksterritorium im Süden und im Norden ab. Daraus wurden die Kreise Angermünde, Eberswalde, Bernau, Bad Freienwalde, Strausberg, Fürstenwalde, Seelow, Frankfurt (Oder), Beeskow und Fürstenberg gebildet, wozu neue Kreisverwaltungen in Bad Freienwalde, Strausberg, Beeskow und Fürstenberg einzurichten waren.

Der $8.262 \mathrm{~km}^{2}$ umfassende Bezirk Cottbus setzte sich zu einem Drittel aus vorher nicht zum Land Brandenburg gehörenden Gebieten zusammen. 1952 wurden im Bezirk 705.000 Einwohner gezählt. ${ }^{100}$ Die Großkreise Lübben und Guben, die einige Gebiete an den Bezirk Frankfurt (Oder) gegeben hatten, der Großkreis Luckau mit seinen Gebietsabgaben an Potsdam sowie die Großkreise Calau, Cottbus und Spremberg machten den ursprünglich brandenburgischen Teil des neuen Verwaltungsbezirkes aus. Von SachsenAnhalt kamen der Kreis Liebenwerda sowie Teile der Kreise Schweinitz und Torgau, während aus Sachsen der ursprünglich schlesische Kreis Hoyerswerda und der Norden des Kreises Niesky (des ehemaligen schlesischen Kreises Rothenburg) hinzutraten. ${ }^{101}$ Neue Kreisverwaltungen waren im Zuge dieses Verwaltungsumbaus in Jessen, Herzberg, Finsterwalde, Senftenberg, Forst und Weißwasser aufzubauen.

98 Vgl. Dok. 7.

99 Vgl. Dok. 9.

100 Vgl. Dok. 8.

101 Beide Kreise gehörten bis 1945 zum schlesischen Verwaltungsbezirk Liegnitz, die Herrschaft Hoyerswerda war 1925 von Brandenburg zum schlesischen Provinzialverband gewechselt; vgl. Stüttgen, Schlesien, S. 119. 


\section{$I V$.}

Die in Vorbereitung und bei Durchführung der Verwaltungsreform von 1952 besonders in Erscheinung getretenen zentralen Partei- und Regierungsstellen behielten weiterhin ihre Zuständigkeit für die neuen Verwaltungsterritorien und die örtlichen Verwaltungsorgane. Im ZK der SED war es die Abteilung Staatliche Verwaltung, deren Struktur sich bis Ende 1955 nicht veränderte. ${ }^{102}$ Bereits im Jahr 1954 folgte Anton Plenikowski, der zunächst zum stellvertretenden Leiter und ab 1956 als Staatssekretär zum Leiter des Büros des Ministerrates avancierte, Willi Barth im Amt des Abteilungsleiters. Da Barth noch im selben Jahr die Leitung der nun selbständigen Abteilung Kirchenfragen im ZK übertragen bekam, fand die Abteilung sodann in Klaus Sorgenicht einen Leiter, der in dieser Funktion bis 1989 verblieb. Ende 1955 erhielt die Abteilung eine neue Struktur und gliederte sich in die Sektoren Leitende Staatsorgane, Örtliche Organe, Staatsaufbau, Staats- und rechtswissenschaftliche Ausbildung, Justiz und Westdeutsche Staatsfragen. Im Ergebnis weiterer Veränderungen in den örtlichen Organen des Staatsapparates in den Jahren 1957 und 1958 wurden die Aufgaben der Abteilung fester umrissen. Unterstellt war die Abteilung einem Sekretär des ZK der SED, der in der Regel Mitglied oder Kandidat des Politbüros war.

Während die Tätigkeit der ZK-Abteilung somit vorrangig die Vorbereitung und Umsetzung zentraler Weichenstellungen umfasste, fiel die Detailarbeit seit April 1953 in die Zuständigkeit der „Koordinierungs- und Kontrollstelle für die Arbeit der Verwaltungsorgane beim Ministerpräsidenten der DDR“. Bereits mit Wirkung vom 1. Oktober 1953 ging aus dieser Ko.-Ko.-Stelle allerdings die „Hauptabteilung für örtliche Organe des Staates beim Ministerpräsidenten der DDR“ hervor. Damit blieb sie dem Regierungschef direkt unterstellt, mit dem Status als Hauptabteilung für die gesamte Dienststelle jedoch mit deutlich herabgestuftem Rang, wenngleich der Leiter der selbständigen Hauptabteilung, Günter Heyden, am Tisch des Ministerrates Platz nehmen durfte. Erst 1957 wurde die Position eines Stellvertreters des Ministers des Innern und Staatssekretärs für die Anleitung der örtlichen Räte eingerichtet. Erster Inhaber dieser Position war Franz Peplinski, der zuvor ausschließlich im örtlichen Staatsapparat bzw. auf Landesebene tätig gewesen war. ${ }^{103}$ Bereits im Juli 1960 entfiel die Position des Staatssekretärs für die Anleitung der örtlichen Räte wieder, dessen Aufgaben nun der stellvertretende Ministerpräsident Willi Stoph wahrnahm.

Von untergeordneter Bedeutung und zeitlich auf eine Übergangsperiode begrenzt war die Zuständigkeit, die der Volkskammer für die örtlichen Staatsorgane eingeräumt wurde. In Ausführung des „Gesetzes über die örtlichen Organe der Staatsmacht“ von 17. Januar $1957^{104}$ hatte die Volkskammer einen ständigen Ausschuss für die örtlichen Volksver-

102 Vgl. Amos, Politik, S. 368-370.

103 Vgl. Kotsch, Karrierewege, S. 183-187.

104 Das „Gesetz über die örtlichen Organe der Staatsmacht“ ist auszugsweise abgedruckt in Dokumente 1949-1961, S. 117-123, sowie, dort allerdings unter dem Datum 18. Januar 1957, im Gesetzblatt der DDR, Teil I, 1957, S. 65-72. 
tretungen einzurichten. ${ }^{105}$ Der Ausschussvorsitz war einem hochrangigen SED-Funktionär vorbehalten, dem Politbüromitglied und Vorsitzenden der Zentralen Parteikontrollkommission Hermann Matern. Weitere Mitglieder aus der SED-Fraktion waren Friedrich Ebert, Anton Plenikowski, Hans Warnke, Herbert Kröger und Hans Seigewasser, der Vorsitzende des Büros des Präsidiums des Nationalrates der Nationalen Front. Die anderen Parteien und Massenorganisationen waren im Ausschuss mit je einem Abgeordneten vertreten. Bereits 1961 verlor die Volkskammer indes ihre ohnehin nur formale Zuständigkeit für die örtlichen Organe wieder, die nun offiziell auf den Staatsrat überging. ${ }^{106}$

Das einzige Verfassungsorgan, das als föderale Einrichtung den Veränderungen des Jahres 1952 nicht sofort zum Opfer fiel, war die Länderkammer. ${ }^{107}$ Bei ihr handelte es sich um ein Staatsorgan, das den Ländern Einfluss auf die Gesetzgebung und bei der Wahl des Präsidenten der Republik sichern sollte, wenngleich ihr Mitbestimmungsrecht schon nach dem Verfassungstext gering bemessen war. Ihre wichtigsten Befugnisse bestanden in ihrem Einspruchsrecht bei der Gesetzgebung durch die Volkskammer und in dem Recht zum Einbringen von Gesetzesvorlagen bei der Volkskammer.

Der Fortbestand der Länderkammer über das Datum der Auflösung der Landtage hinaus war ursprünglich nicht beabsichtigt und ergab sich aus dem Entschluss, mit der Verwaltungsreform von 1952 die Existenz der Länder streng formal nicht anzutasten. Auf ihrer 9. Vollsitzung am 3. Oktober 1952 bestätigte die Länderkammer das Neugliederungsgesetz vom 23. Juli 1952 und stimmte gleichzeitig der Begründung durch Staatssekretär Fritz Geyer von der Regierungskanzlei zu, wonach die Länder und damit die Länderkammer weiterbestünden und ihre Verfassungsrechte behielten. ${ }^{108}$ Auf der 13. Sitzung des Präsidiums der Länderkammer mit den Fraktionsvorsitzenden wurde am 8. Oktober 1952 nochmals bestätigt, die Länderkammer über den 31 . Juli 1952 hinaus wirken zu lassen, nachdem es im Demokratischen Block doch noch Bedenken wegen der Verfassungskonformität der Veränderungen in Bezug auf die Länder und ihre Organe gegeben hatte. ${ }^{109}$ Um dem Dilemma zu entgehen, dass den Vertretern der Länder die sie entsendenden Landtage ja abhandengekommen waren, gruppierten sich die Abgeordneten der Länderkammer fortan nach einem sogenannten Bezirksschlüssel, der die Abgeordneten praktisch zu Vertretern der Bezirke machte, was insofern anachronistisch war, als für die Bezirkstage keine Vertretung in einer zweiten Parlamentskammer vorgesehen war. Dies warf ein bezeichnendes Licht auf die Länderkammer und den Umgang der Staatspartei mit dem geschriebenen Verfassungstext des östlichen Teilstaates.

1958 hielt die SED-Führung den Zeitpunkt für gekommen, die Länderkammer, deren Existenz angesichts der staatlichen Realität des Grotesken nicht entbehrte, abzuschaf-

105 Vgl. BArch, DY 30/IV 2/13/252.

106 Vgl. das „Gesetz zur Änderung des Gesetzes vom 17. Januar 1957 über die Rechte und Pflichten der Volkskammer gegenüber den örtlichen Volksvertretungen" vom 20. September 1961, abgedruckt in Dokumente 1949-1961, S. 143-144, sowie im Gesetzblatt der DDR, Teil I, 1961, S. 178; vgl. generell Lapp, Staatsrat.

107 Vgl. Thiem, Länderkammer.

108 Vgl. Kotsch, Brandenburg, S. 79.

109 Vgl. BArch, LK 3184, Bl. 39. 
fen. ${ }^{110}$ Als Anlass nutzte man das „Gesetz über die örtlichen Organe der Staatsmacht“ und das „Gesetz über die Rechte und Pflichten der Volkskammer gegenüber den örtlichen Volksvertretungen“ vom 17. Januar 1957, ${ }^{111}$ vor allem aber das „Gesetz über die Vervollkommnung und Vereinfachung der Arbeit des Staatsapparates“ vom 11. Februar 1958. ${ }^{112}$ Die Länderkammer, so die offizielle Begründung, sei in dieser neuen Situation überflüssig geworden. Als die Länderkammer am 10. Dezember 1958 zu ihrer 1. Sitzung der 3. Wahlperiode zusammentrat, stimmte sie daher - nach der Ansprache des Alterspräsidenten und der Wahl des Präsidenten sowie des Präsidiums - dem Gesetz zu ihrer eigenen Auflösung zu.

Für die SED-Führung war die Ländervertretung von Anfang an ein störendes Element im Staatsaufbau der DDR gewesen. Indem sie als Symbol des Föderalismus galt, wollte man sich ihr so rasch wie möglich entledigen. So wie allein deutschlandpolitische Erwägungen den Grund für die formale Weiterexistenz der Länderkammer gebildet hatten, war aus Sicht der SED-Führung die Länderkammer ersatzlos aufzulösen, als diese Gründe nicht mehr bestanden. Nachdem dieser Zeitpunkt weder 1952 noch - mit Blick auf die Berliner Außenministerkonferenz von Januar/Februar 1954 - nach der Volkskammerwahl vom 17. Oktober 1954 als gegeben betrachtet wurde, hatte sich die Einschätzung im Ergebnis der bündnis- und militärpolitischen Weichenstellungen ab 1956 radikal geändert. Mit Blick auf die innenpolitische Situation sollte die Länderkammer jedoch möglichst unspektakulär aufgelöst werden. Zugleich durfte dieser Akt nicht als Verstoß gegen das Potsdamer Abkommen interpretierbar sein. Deshalb wurde die Auflösung der Länderkammer in einer Regierungserklärung von Ministerpräsident Grotewohl im Dezember 1958 der Öffentlichkeit ,,als eine aus der Entwicklung des Staatsapparates natürlich und notwendig sich ergebende staatsorganisatorische Maßnahme" ohne prinzipielle politische Bedeutung vermittelt. ${ }^{113}$

Tatsächlich hatte die Auflösung der Länderkammer weder innenpolitische Debatten noch außenpolitische Komplikationen zur Folge. Es war wohl der schon im Vorfeld der Auflösung erreichte Grad ihrer Bedeutungslosigkeit, der ihre lautlose Liquidation ermöglichte. Bemerkenswert war ihre Auflösung dennoch, war doch mit diesem Akt die zweite Verfassungsänderung in der Geschichte der DDR verbunden. Sämtliche Artikel und Passagen, die die Länderkammer betrafen - die Artikel 71 bis 80 und 84 sowie Teile der Artikel 101, 102 und 103 -, wurden ersatzlos aus der Verfassung gestrichen.

110 Vgl. die Stellungnahme der Abteilung Staats- und Rechtsfragen des ZK der SED zur Frage der Länderkammer aus dem Jahr 1958, in: BArch, DY 30/IV 2/13/258.

111 Vgl. Gesetzblatt der DDR, Teil I, 1957, S. 72-73.

112 Vgl. Gesetzblatt der DDR, Teil I, 1958, S. 117-120.

113 „Die Länderkammer im Verfassungssystem der Deutschen Demokratischen Republik“, Entwurf des ZK der SED vom 13. November 1958, S. 13-14, in: BArch, DY 30/IV 2/13/258. 
Die mit der Gebietsreform von 1952 verbundene vertikale Strukturreform hatte eine streng hierarchisch gestufte und zentralistisch geleitete Organisation der Staatsverwaltung entstehen lassen. Unter den örtlichen Organen der Staatsgewalt, die eine dreistufige Gliederung aufwiesen, nahmen die Räte der Bezirke eine herausgehobene Stellung ein. Sie bildeten unterhalb der Regierung der DDR die oberste Stufe und waren dem Ministerrat direkt unterstellt. Auch fielen in ihre Zuständigkeit Sachbereiche, die es auf den nachgeordneten Ebenen, den Kreisen bzw. kreisfreien Städten und den Gemeinden bzw. kreiszugehörigen Städten, z. T. nicht oder nur in begrenzter Form gab. Das hatte Rückwirkungen auf deren personelle Ausstattung und funktionale Zusammensetzung, aber auch auf das Selbstverständnis der Mitarbeiter als wichtige Repräsentanten der Staatsmacht. Als Rat des Bezirkes bezeichnet wurde zum einen das durch gewählte Abgeordnete des Bezirkstages gebildete kollegiale Vollzugsorgan der Volksvertretung, das für die Dauer der Wahlperiode im Amt war. Die Räte setzten sich aus einem Vorsitzenden, fünf Stellvertretern, fünf bis acht ehrenamtlichen Mitgliedern und einem Sekretär des Rates zusammen. ${ }^{14}$ Sie bildeten die Leitung der gesamten Bezirksverwaltung mit ihren Fachorganen (in der Regel als Abteilung, Amt, Kommission oder Rat bezeichnet), die sich als Behörde ebenfalls Rat des Bezirkes nannte. Der Vorsitzende war gegenüber den Ratsmitgliedern weisungs- und disziplinarbefugt, was ein praktisches Vorgesetzten-Untergebenen-Verhältnis zur Folge hatte. Damit wurde das häufig apostrophierte „Kollegialitätsprinzip“ bereits im Ansatz durchbrochen und funktionierte in der Praxis nie. Auch die herausgehobene Funktion des Sekretärs, die er in späteren Jahren allerdings einbüßte, stand dem Kollegialitätsprinzip entgegen. Der Sekretär galt besonders in den ersten Jahren, als die SED-Funktionäre den Block-Parteien noch mit einem gewissen Misstrauen begegneten, als politischer Vertrauensmann des SED-Apparates. ${ }^{115}$

Der Vorsitzende, der Sekretär, die Stellvertreter des Vorsitzenden und die Mitglieder des Rates hatten auf den Ratssitzungen, die mehrmals monatlich stattfanden, kollektive Entscheidungen zu grundsätzlichen Fragen zu treffen. Der Vorsitzende, der Sekretär und die Stellvertreter waren zugleich für einzelne Fachressorts zuständig. Die Mehrzahl der Ressorts war beim Vorsitzenden und dem Sekretär angesiedelt. In einigen Fällen standen die Stellvertreter einem Fachressort als Abteilungsleiter direkt vor. Ehrenamtliche Mitglieder, die aus dem Kreis „,verdienstvoller Werktätiger“ - Nationalpreisträger, Helden der Arbeit, Meisterbauern „,oder anderer im gesellschaftlichen Aufbau erfahrener Mitglieder des Bezirkstages“ - zu wählen waren und nur in den ersten Jahren in den Räten vertreten waren, blieben ohne Ressortverantwortlichkeit. ${ }^{116}$

114 Vgl. die „Ordnung über den Aufbau und die Arbeitsweise der staatlichen Organe der Bezirke“ vom 24. Juli 1952, abgedruckt in Dokumente 1949-1961, S. 101-104, sowie im Gesetzblatt der DDR, Teil I, 1952, S. 621-623.

115 Vgl. Scheller, Staatsmacht, S. 105-109.

116 Dokumente 1949-1961, S. 102. 
Bewusst unübersichtlich waren von Anfang an die Unterstellungsverhältnisse gestaltet, aus denen sich die Struktur von Weisungsbefugnissen sowie Anleitungs- und Kontrollkompetenzen ergab. Diese Unübersichtlichkeit eröffnete die Möglichkeit zur Einflussnahme von außen, vor allem durch den Apparat der SED. Als offizielles Organisationsprinzip galt das „Prinzip der doppelten Unterstellung“, wonach die Räte zugleich ihrer Volksvertretung und dem übergeordneten Rat bzw. Ministerrat, der die Beschlüsse des unterstellten Rates aufheben konnte, rechenschaftspflichtig waren. ${ }^{117}$ Von praktischer Bedeutung war indes die sogenannte Anleitungs- und Kontrollkompetenz der jeweils übergeordneten Räte. Damit entstand eine lückenlose Kette von Weisungsbefugnissen, die ihren Ausgang beim Ministerpräsidenten nahm und in der vertikalen Hierarchie die Ratsvorsitzenden erfasste, über die die Weisungen an die Fachorgane weitergeleitet wurden. Da aber auch die Fachorgane vertikal miteinander verknüpft waren, wodurch Weisungen an den Ratsvorsitzenden vorbei ,nach unten“ gelangten, ${ }^{118}$ war der Begriff der „,doppelten Unterstellung“ viel zutreffender für dieses Problem, da er die Parallelität von horizontaler und vertikaler Unterstellung der Fachorgane erfasste. Die Fachorgane der Räte der Bezirke waren zugleich an die Weisungen ihres Rates bzw. des Vorsitzenden des Rates und an die Weisungen des übergeordneten Fachorgans - in der Regel das zuständige Ministerium - gebunden, was zu widersprüchlichen Anweisungen und enormen Reibungsverlusten führte. ${ }^{119}$ Versuche, dieses Dilemma zu überwinden, setzen erst zu Beginn der 1960er Jahre ein, ${ }^{120}$ als im Zuge der Wirtschaftsreformen des „,Neuen Ökonomischen Systems“ (NÖS) auch die staatlichen Lenkungsmechanismen dezentralisiert werden sollten. Seit den 1970er Jahren erfuhr die vertikale Weisung wieder eine deutliche Stärkung. ${ }^{121}$

Von den sieben hauptamtlichen Mitgliedern des kollegialen Leitungsorgans gehörten der Vorsitzende, der Sekretär und zwei Stellvertreter der SED an, drei Stellvertreter kamen aus den anderen Parteien - in Potsdam und Cottbus aus CDU, NDPD und DBD, in Frankfurt (Oder) aus LDP, NDPD und DBD. Hingegen waren die Abteilungsleiter, 19 in

117 Vgl. Brunner, Verwaltung, S. 1250-1252.

118 Vgl. Ziff. 3 des Beschlusses des Ministerrates, ,über die Anleitung und Kontrolle der Fachabteilungen bei den Räten der Bezirke und Kreise durch die Ministerien und Staatssekretariate mit eigenem Geschäftsbereich“vom 3.2.1955, im Gesetzblatt der DDR, Teil II, 1955, S. 66-67.

119 Vgl. Dok. 56.

120 Während das Gesetz über die örtlichen Organe der Staatsmacht von 1957 auf eine vorsichtige Schwächung der vertikalen Weisungsbefugnisse gerichtet war, enthielten die vom Staatsrat erlassenen Ordnungen über die Aufgaben und die Arbeitsweise der örtlichen Volksvertretungen und Staatsorgane klare Eingrenzungen; vgl. etwa den „Erlass des Staatsrates der Deutschen Demokratischen Republik zu den Ordnungen über die Aufgaben und die Arbeitsweise der örtlichen Volksvertretungen und ihrer Organe" vom 28. Juni 1961, im Gesetzblatt der DDR, Teil I, 1961, S. 51, sowie die dazugehörigen Ordnung in: ebd., S. 52-73.

121 Vgl. das „Gesetz über die örtlichen Volksvertretungen und ihre Organe in der Deutschen Demokratischen Republik“"vom 17. Juli 1973, im Gesetzblatt der DDR, Teil I, 1973, S. 313-335. 
jedem Rat, fast ausschließlich Mitglieder der SED, unter den Referatsleitern fanden sich mehrere Parteilose, aber kaum Angehörige der anderen Parteien. ${ }^{122}$

Die Zuständigkeit der örtlichen Staatsorgane erstreckte sich auf wesentliche Bereiche des Lebens. ${ }^{123}$ Im Mittelpunkt standen Wirtschaftsfragen, allerdings immer in abgestufter Verantwortlichkeit gegenüber den zentralen Regierungsstellen. Gleiches traf auf die Landesplanung und Siedlungsentwicklung, Volksbildung, Kultur und Sport sowie Soziales und Gesundheit zu. Zwei Ressorts wiesen eine besondere Bedeutung auf: die Plankommission und die bereits erwähnte Org.-Instrukteur-Abteilung. In beiden Fällen handelte es sich nicht um Fachorgane, die für einen Lebensbereich zuständig waren. Die dem Ratsvorsitzenden direkt unterstellte Plankommission präsentierte sich als Funktionalorgan mit Querschnittsaufgaben, das im Verhältnis zu den Fachorganen und nachgeordneten örtlichen Organen mit einer partiellen Weisungsbefugnis ausgestattet war. Laut Statut war sie zuständig für die Planung der wirtschaftlichen und kulturellen Entwicklung im Bezirk; sie arbeitete im Auftrag des Rates und der Staatlichen Plankommission der DDR. ${ }^{124}$

Die Org.-Instrukteur-Abteilungen waren Stabsorgane ohne Weisungsbefugnis, hingegen mit ausgesprochenen Kontrollrechten ausgestattet, die der Informationsbeschaffung für vorgesetzte Stellen in der Absicherung der horizontalen und vertikalen Hierarchie dienten. ${ }^{125}$ Sie waren für die Bezirksräte und Bezirkstage zuständig und hatten sowohl die Bezirkstage als auch deren ständige Kommissionen in ihrer Tätigkeit zu unterstützen. Die Priorität lag jedoch bei der Kontrolltätigkeit, die sich auf alle Ebenen der örtlichen Verwaltung erstreckte und sich in der Regel nach bestätigten Arbeitsplänen vollzog. Sowohl die ständigen Kommissionen als auch die Abteilungen der Räte aller Ebenen hatten der Org.-Instrukteur-Abteilung alle verlangten Auskünfte über Planungen und Arbeitsabläufe zu erteilen. ${ }^{126}$ Auch die Schulung der Abgeordneten und die Gestaltung des sozialistischen Wettbewerbes im kommunalen Bereich gehörte zu den Aufgaben dieser Abteilungen, deren Leiter von den Räten der Bezirke bzw. der Kreise vorgeschlagen und von den Bezirks- bzw. Kreistagen zu bestätigen waren.

Obwohl die Räte der Bezirke in ihrem Ressortzuschnitt viele Ähnlichkeiten mit den aufgelösten Landesregierungen aufwiesen, gab es auch wichtige Unterschiede. Besonders auffällig war der Wegfall des Innenressorts. Die im ehemaligen Innenministerium des Landes Brandenburg zusammengefassten Zuständigkeiten wurden aufgeteilt und neu geordnet, wobei den Räten der Bezirke nur einzelne Bereiche zufielen, die beim Ratsvorsitzenden und beim Sekretär angesiedelt waren. Ein selbständiges Innenressort hingegen fehlte, wo-

122 In Potsdam bekleidete der Bezirksvorsitzende der LDP, Erwin Steffen, die Positionen eines Abteilungsleiters beim Rat des Bezirkes. Damit war jene Partei, die im Rat keinen Platz gefunden hatte, dennoch in der Leitung vertreten. In Frankfurt kam diese Praxis nicht zur Anwendung, dort gehörten alle Abteilungsleiter des Rates der SED an.

123 Vgl. Dok. 43.

124 Vgl. Kotsch, Brandenburg, S. 85-91.

125 Vgl. die Ausführungen Werner Eggeraths in Dok. 29 sowie die Direktive „für die Arbeit der Organisations-Instrukteur-Abteilungen bei den Räten der Bezirke und Kreise" vom 18. September 1952 in Dokumente 1949-1961, S. 110-111, und im Gesetzblatt der DDR, Teil I, 1952, S. 875-876.

126 Vgl. Dok. 55. 
für es verschiedene Gründe gab. Erstens befand sich die oberste Innenbehörde, das Ministerium des Innern der DDR, Anfang der 1950er Jahre in einem Prozess der völligen Neuorganisation. Seit dem Sommer 1952 fungierte das MdI als zentrale Aufrüstungsbehörde, weshalb die genuinen Innenaufgaben ausgegliedert und auf andere Ministerien aufgeteilt bzw. in selbständigen Unterbehörden angesiedelt werden sollten. Bereits im Februar 1953 wurde diese Entscheidung allerdings revidiert. Als zentrale Innenbehörde der DDR entstand am 1. März 1953 ein Staatssekretariat für Innere Angelegenheiten im Ministerium des Innern. ${ }^{127}$ Daraufhin wurden in den örtlichen Staatsorganen die Abteilung Kataster sowie die Referate Bevölkerungspolitik, Staatliches Eigentum und Verschlusssachen zu Abteilungen für Inneres zusammengefasst. Zusammen mit der selbständigen Abteilung Kader und dem Referat Religionsgemeinschaften unterstanden sie dem Stellvertreter des Ratsvorsitzenden für Inneres, dessen Position in den örtlichen Staatsorganen aus diesem Anlass eingerichtet wurde. Zweitens wurde auf Dauer die Polizei von den örtlichen Staatsorganen getrennt, woraus sich ebenfalls Unsicherheiten in Bezug auf die Behördenstruktur in den Bezirken und Kreisen ergaben. ${ }^{128}$ Zuvor als Länderpolizei organisiert, war sie nun einheitlich dem Ministerium des Innern der DDR unterstellt und streng zentralistisch gegliedert. In ihrer regionalen Struktur folgte sie der neuen Verwaltungsgliederung der DDR. Oberstes Führungsorgan im Bezirk war die Bezirksbehörde der Volkspolizei (BdVP), wogegen sich in den Kreisen Volkspolizeikreisämter (VPKA) fanden. Zwischen dem Chef der BdVP und dem Vorsitzenden des Rates des Bezirkes gab es lediglich informelle Kontakte, ebenso zwischen den Leitern der VPKA und den Ratsvorsitzenden in den Kreisen. Die Aufgaben des „Amtes zum Schutz des Volkseigentums“ gingen vollständig auf das 1950 entstandene Ministerium für Staatssicherheit über, das nun seinerseits Bezirksverwaltungen bildete.

Weitgehend ungeregelt war anfangs das Verhältnis zwischen den regionalen Sicherheitsbehörden, den staatlichen Verwaltungsbehörden und dem Apparat der SED, woraus sich ein hohes Maß an Handlungsunfähigkeit ergab. Deutlich trat dieser Zustand schon ein Jahr später bei den Massenprotesten, Streiks und gewaltsamen Aktionen zum Sturz der politischen Ordnung am 17. Juni 1953 hervor. Im Juli 1953 entstand daraufhin die Bezirkseinsatzleitung (BEL), die sich aus dem Vorsitzenden des Rates, dem 1. Sekretär der SED-Bezirksleitung, dem Leiter der Bezirksverwaltung des Staatsicherheitsdienstes, dem Chef der BdVP und einem beauftragten Offizier der Kasernierten Volkspolizei - ab 1956 dem Chef des Wehrbezirkskommandos - zusammensetzte. ${ }^{129}$ Die BEL hatte zusammenzutreten, „wenn eine Gefährdung der öffentlichen Sicherheit angenommen“ wurde. ${ }^{130}$ Die

127 Im Staatssekretariat wurden die Hauptverwaltungen Deutsche Volkspolizei, Strafvollzug, Feuerschutz, Kader sowie Vermessung und Kartenwesen, die Staatliche Archivverwaltung und die Abteilungen Staatliches Eigentum und Bevölkerungspolitik zusammengefasst; vgl. Anlage 11 zum Protokoll der 117. Sitzung des Ministerrates vom 19. Februar 1952, in: BArch, DC 20/1/3-174, B1. 81-82.

128 Vgl. Arlt, Aufstellung.

129 Vgl. Kaiser, Herrschaftsinstrumente.

130 Schreiben der Koordinierungs- und Kontrollstelle für die Arbeit der Verwaltungsorgane an den Minister des Innern und an die Vorsitzenden der Räte der Bezirke vom 16. Juli 1953, in: BLHA, Rep. 401, Nr. 1395. 
Leitung lag zunächst beim Ratsvorsitzenden, was eine deutliche Stärkung dieser Position gegenüber dem regionalen SED-Apparat signalisierte. Schon kurze Zeit später ging die Leitung allerdings an den 1. Sekretär der Bezirksleitung über, womit sich die Suprematie der SED-Führung in den Sicherheitsfragen auch auf dieser Ebene durchsetzte.

Verzichtet wurde bei den Räten der Bezirke auch auf die Bildung eines Justizressorts. Veränderungen in diesem Bereich hatten sich schon vorher angekündigt. Bereits die Regierungsumbildung nach den Wahlen vom Oktober 1950 diente als Anlass, das Landes-Justizministerium aufzulösen. Im Gegenzug entstand beim Ministerpräsidenten eine Hauptabteilung Justiz. Im Ergebnis der Verwaltungsreform vom Sommer 1952 wurde der Justizbereich ebenso wie die Polizei von der örtlichen Staatsverwaltung getrennt und ausschließlich dem Justizministerium der DDR unterstellt, was eine straffe Zentralisierung ermöglichte. Der gesamte Justizbereich hatte parallel zu den Veränderungen im Verwaltungsapparat eine neue Struktur erhalten. Auf der II. Parteikonferenz der SED waren diese Veränderungen in ihrer Bedeutung mit der Verwaltungsreform auf eine Stufe gestellt worden, was durchaus dem Stellenwert dieser Veränderungen entsprach. Die Verbindungen zwischen dem Justizbereich und den örtlichen Staatsorganen war ausschließlich informeller Natur, die der Ratsvorsitzende mit dem Bezirksgericht und dem Bezirksstaatsanwalt unterhielt.

\section{$V I$.}

Schon nach wenigen Jahren zeigten sich in der Tätigkeit der örtlichen Staatsorgane Defizite, was Korrekturen zwingend nötig machte. Nur unzureichend kamen die örtlichen Räte den ihnen übertragenen Aufgaben nach, was besonders bei der Leitung der ökonomischen Prozesse in den Verwaltungsterritorien sichtbar wurde. Es zeugt immerhin von einer gewissen Beweglichkeit innerhalb des politischen Systems, dass dieses Defizit erkannt und dass eine Lösung gesucht wurde.

Der Zustand der Wirtschaft ließ Mitte der 1950er Jahre jedoch auch keinen weiteren Zeitverzug geboten erscheinen. Um die zentralen Planungs- und Leitungsgremien zugunsten der großen und z. T. sehr ehrgeizigen Industrialisierungsprojekte - hier ist nicht zuletzt der Aufbau der Schwerindustrie im Bezirk Frankfurt (Oder) zu nennen - partiell zu entlasten, sollte den örtlichen Organen ein höheres Maß an Planungs-, Leitungs- und Kontrollkompetenz zugebilligt werden. Angestrebt wurde eine begrenzte und kontrollierte Dezentralisierung, jedoch bei einer prinzipiellen Wahrung der Allmacht der Zentrale.

Eine wichtige Voraussetzung für die angestrebte Dezentralisierung bildete die vorsichtige Entstalinisierung, die in der UdSSR auf dem XX. Parteitag der KPdSU im Februar 1956 eingeleitet wurde und der sich die SED-Führung auf ihrer III. Parteikonferenz Ende März 1956, allerdings mit deutlichen Abstrichen, anschloss. Die ersten Vorbereitungen für die Veränderungen im ostdeutschen Staatsapparat hatten im zentralen Parteiapparat der SED indes schon erheblich früher begonnen, nämlich in der ersten Jahreshälfte 
1955. Vollständige Entwürfe für die Veränderungen in der staatlichen Verwaltung der Bezirke wurden in der SED schon im Sommer 1955 intern besprochen. ${ }^{131}$

Die Dezentralisierung fiel den Verantwortlichen offensichtlich schwerer als die Zentralisierung des Staates, die sich seit den späten 1940er Jahren kontinuierlich durchgesetzt hatte. Davon zeugt das langsame Tempo der Planungen, die auch als mangelnde Bereitschaft zur Dezentralisierung bei vielen Verantwortlichen zu interpretieren ist. Den jahrelang mit Lenins und Stalins Theorien geschulten Führungskadern und Funktionären musste jede Variante von Dezentralisierung als dem Sozialismus artfremder Gedanke erscheinen. So geriet die Reform am Ende doch nur halbherzig. Der Zentralismus obsiegte und blieb das bestimmende Moment. ${ }^{132}$

Als die Veränderungen auf der III. Parteikonferenz der SED angekündigt wurden, befanden sich die Planungen noch im Anfangsstadium. Erst zu Beginn des Jahres 1957 konnte die Volkskammer das „Gesetz über die Örtlichen Organe der Staatsmacht“ verabschieden, das einen ambivalenten Charakter aufwies und in seinen Bestimmungen noch unfertig wirkte. Die auseinanderstrebenden Zwänge und Interessen erwiesen sich als ein nur schwer überwindbares Hindernis. So unterstrich das Gesetz einerseits die Zentralisierung des Staates, indem der demokratische Zentralismus erstmals in rechtsnormativer Weise zum grundlegenden Organisationsprinzip des Staatsaufbaus erklärte wurde, was Dekonzentrationsmaßnahmen nur in begrenztem Ausmaß zuließ. Die Kreis- und Gemeindeordnungen von 1946/47, die eine kommunale Selbstverwaltung ermöglichten, wurden offiziell außer Kraft gesetzt, nachdem sie praktisch schon lange zuvor ausgehöhlt worden waren. Unverändert erhalten blieb das Prinzip der doppelten Unterstellung. ${ }^{133}$

Zugleich wuchs die wirtschaftsleitende Kompetenz der örtlichen Staatsorgane. Zusätzlich zu den Betrieben des öffentlichen Personennahverkehrs und den örtlichen Baubetrieben, für die die Räte der Bezirke bereits zuvor zuständig waren, erhielten sie nun auch die Verantwortung für die Lebensmittelindustrie, die Leicht- und Grundstoffindustrie sowie die Energie- und Wasserbetriebe übertragen; in abgestufter Form erfasste dieser Prozess auch die Räte der Kreise. In Umsetzung dieser Maßnahmen wurde bei den Räten das Ressort eines Stellvertreters für Wirtschaft und Verkehr eingerichtet. Gestärkt aus den Veränderungen ging auch die Plankommission hervor, deren Vorsitzender nun in den Rang eines Stellvertreters des Ratsvorsitzenden erhoben wurde. In die Plankommission eingegliedert wurden die Abteilung Finanzen und die Bezirksaußenstelle des Statistischen Zentralamtes. Die Abteilung Industrie entfiel ersatzlos.

Die Neuordnung der Ratsbereiche ging mit einem Anwachsen der Zahl der Stellvertreter der Vorsitzenden einher. Bei den Räten der Bezirke erhöhte sie sich auf sechs, bei den Räten der Kreise auf vier, bei den Räten der kreisangehörigen und kreisfreien Städte auf drei Stellen. Als neues Ressort entstand der Ratsbereich für Inneres. Dem Leiter, der

131 Vgl. den „Entwurf zum Gesetz über die örtlichen Organe der Staatsmacht“, der Ende Juli 1955 vom ZK in zwei Exemplaren persönlich an den Vorsitzenden des Rates des Bezirkes Potsdam, Josef Stadler, mit der Bitte um Stellungnahme geschickt wurde, in: BLHA, Rep. 401, Nr. 412.

132 Vgl. Scheller, Staatsmacht, S. 329-346.

133 Vgl. Gesetzblatt der DDR, Teil I, 1957, S. 65-72. 
den Rang eines 1. Stellvertreters erhielt, unterstanden die Abteilung Inneres mit den Referaten Bevölkerungspolitik, Personenstandswesen, Kataster und Archiv, die Abteilung Kader, das Referat Kirchenfragen und der neu gebildete Stab Luftschutz. Klar abgegrenzt waren die Kompetenzen gegenüber der Polizei. ${ }^{134}$

Volle Zufriedenheit lösten diese Veränderungen bei den Verantwortlichen nicht aus. Die neuen Regelungen sah man als noch unzureichend an. Schon ein halbes Jahr später verkündete Walter Ulbricht im Sommer 1957 auf der 32. Tagung des SED-Zentralkomitees seine ,Thesen über die Vereinfachung des Staatsapparates und die Änderung der Arbeitsweise der Mitarbeiter des Staatsapparates“. ${ }^{135}$ Sie enthielten indirekt das Eingeständnis eines teilweisen Scheiterns der Reform von Anfang 1957, die offensichtlich nicht genügend vorbereitet gewesen war. Praktisch in einer zweiten Etappe - offiziell als solche jedoch nicht bezeichnet - sollte verwirklicht werden, was in der ersten Etappe Anfang 1957 nicht gelungen war: eine spürbare Verlagerung von Kompetenzen der Zentrale auf die örtlichen Staatsorgane. Das Politbüro berief eine von Ulbricht geleitete Kommission, der 23 Arbeitsgruppen des ZK zuzuarbeiten hatten, u. a eine Arbeitsgruppe „Bezirke und Kreise“ und „Örtliche Wirtschaft" (beide unter Vorsitz von Franz Peplinski). ${ }^{136}$

Drei Hauptziele wurden mit der Fortschreibung der Reform verfolgt: erstens die weitere Stärkung der Kompetenz der Räte in Wirtschaftsangelegenheiten, zweitens eine zusätzliche personelle Ausstattung der Räte und drittens eine Überprüfung der Ressorteinteilung in den örtlichen Räten. Beklagt wurde noch immer die Trennung von Planung und operativer Tätigkeit im Bereich der Wirtschaft, weshalb der Gedanke entstand, bei den örtlichen Staatsorganen eine Wirtschaftskommission als selbständiges Organ einzurichten, die branchen- und territorialbezogen operieren sollte. ${ }^{137}$ Die Lösung des Personalproblems in den örtlichen Räten betrachtete die SED-Führung als Teil eines größeren personellen Revirements auf allen Leitungspositionen, einschließlich der Ministerien, der Staatlichen Plankommission und der großen Wirtschaftsbetriebe. Das Politbüro berief eine Zentrale Kaderkommission unter Vorsitz von Bruno Leuschner, Kandidat des Politbüros und Vorsitzender der Staatlichen Plankommission. Viele zentrale Wirtschaftsorgane, vor allem in Berlin und in den südlichen Bezirken angesiedelte Hauptverwaltungen von Wirtschaftsministerien, wurden aufgelöst. Den freigesetzten Mitarbeitern, insgesamt rund eintausend, davon etwa 200 vormals in Leitungspositionen, wurden Stellen in den örtlichen Staatsorganen angeboten, vor allem als leitende Funktionäre in den neuen Wirtschaftskommissionen und in den Kreisplankommissionen, was viele von ihnen trotz Parteistrafen ablehnten. Auf besonderen Widerstand stieß der mit den Versetzungen häufig verbundene Ortswechsel in die als unattraktiv angesehenen mittleren und nördlichen Bezirke der DDR. ${ }^{138}$

134 Vgl. die Strukturpläne „Bezirks- und Kreistag mit Räten“, in: BArch, DO 1 (Ministerium des Innern), Nr. 26027, Bl. 1-2.

135 Auszugsweise abgedruckt in Dokumente 1949-1961, S. 41-45.

136 Vgl. die entsprechenden Unterlagen in BArch, DY 30 (Büro Walter Ulbricht), Nr. 3301 und 3302.

137 Vgl. Dok. 58.

138 Vgl. die entsprechenden Unterlagen der Kaderkommission, in: BArch, DY 30/IV 2/13/84. 
Unterschiedliche Vorstellungen wurden in Bezug auf die Struktur der Verwaltungsorgane entwickelt. Von Ulbricht stammte der Vorschlag, die Anzahl der Stellvertreter der Vorsitzenden der Bezirksräte auf vier zu begrenzen und ihnen die Bereiche Inneres, Wirtschaftskommission, Landwirtschaft, Handel und Versorgung sowie Volksbildung und Kultur zu unterstellen. Herbert Grünstein, 1. Stellvertreter des Innenministers, plädierte für die Bildung von Bezirksverwaltungen für Innere Angelegenheiten, die durch einen Stellvertreter des Ratsvorsitzenden zu leiten gewesen wären, was einer Wiederbelebung des alten Innenressorts entsprochen hätte. In drei Abteilungen wollte er die Bezirksverwaltung gegliedert sehen: Militärische Fragen mit den Unterabteilungen bzw. Referaten Einsatz (der Bereitschaftspolizei), Ausbildung, Technik und Kampfgruppen; Polizei, Feuerwehr und Luftschutz; Inneres mit den Unterabteilungen bzw. Referaten Bevölkerungspolitik, Personenstandswesen, Kataster und Archive. Das Referat Kirchenfragen sollte nach dieser Idee zum Bereich des Ratsvorsitzenden zurückkehren. Grünsteins Vorstoß hatte von vornherein keine Chance auf Verwirklichung, war doch die SED-Führung in Übereinstimmung mit allen anderen Ostblockländern entschlossen, den gesamten Sicherheitsbereich ausschließlich zentral zu leiten. Gefolgt wurde jedoch dem Gedanken, das Referat Kirchenfragen vom Bereich des Ratsvorsitzenden zu trennen und in den Bereich Inneres einzugliedern. ${ }^{139}$

Bis zum Jahresende 1957 waren die Vorbereitungen für die Umstrukturierungen in der staatlichen Verwaltung abgeschlossen, im Dezember fiel die zustimmende Entscheidung im SED-Politbüro, und am 11. Februar 1958 verabschiedete die Volkskammer das „Gesetz über die Vervollkommnung und Vereinfachung der Arbeit des Staatsapparates““.140

Der Schwerpunkt der Neuregelungen bildete die Einrichtung der Wirtschaftskommissionen bzw. Wirtschaftsräte, wie die endgültige Bezeichnung lautete. ${ }^{141}$ Nach den ersten Planungen sollten sie sowohl auf der Ebene der Bezirke als auch der Kreise eingerichtet werden, ${ }^{142}$ wovon jedoch Abstand genommen wurde. Wirtschaftsräte entstanden ausschließlich auf der Ebene von Bezirken, womit diese nun zur entscheidenden regionalen Verwaltungsebene avancierten, auf der in dem sonst zentralistisch organisierten Staat eine begrenzte Gestaltung gegeben war. Die Kreise wurden hingegen auf Dauer jeder Eigenständigkeit beraubt, und deren Räte hatten ausschließlich ausführende Funktionen gegenüber den Bezirken auszuüben.

Der dem Rat des Bezirkes unterstellte Wirtschaftsrat wurde als Kollegialorgan konzipiert. Der Vorsitzende war zugleich Stellvertreter des Vorsitzenden des Rates des Bezirkes. Als Mitglieder gehörten dem Wirtschaftsrat der Leiter der Abteilung Planung als Stellvertreter des Vorsitzenden des Wirtschaftsrates, die Leiter der wichtigsten Abteilun-

139 Vgl. das Protokoll der Sitzung der Kommission des Politbüros am 24. Juni 1957, in: BArch, DY 30 (Büro Walter Ulbricht), Nr. 3302, B1. 3-27.

140 Vgl. Gesetzblatt der DDR, Teil I, 1958, S. 117-120.

141 Vgl. Wolf, Arbeitsstil.

142 Vgl. die „Grundsätze für die Bildung von Wirtschaftskommissionen bei den örtlichen Staatsorganen, ihre Aufgaben, Arbeitsweise und Rechtsstellung“ des Ministerium des Innern/Örtliche Organe vom Herbst 1957, in: BArch, DO 1 (Ministerium des Innern), Nr. 26087, Bl. 72. 
gen des Wirtschaftsrates als hauptamtliche Mitglieder sowie Spezialisten aus wichtigen Wirtschaftszweigen des Bezirkes als ehrenamtliche Mitglieder an. Verantwortlich und rechenschaftspflichtig war der Wirtschaftsrat dem Rat des Bezirkes und der Zentralen Plankommission, nicht jedoch dem Bezirkstag, der lediglich den vom Rat des Bezirkes berufenen Vorsitzenden der Wirtschaftskommission zu bestätigen hatte. Zu den Besonderheiten des Wirtschaftsrates gehörte, dass ihm keine unmittelbaren Leitungsbefugnisse gegeben waren. Stattdessen war er als beratendes Organ seines Vorsitzenden eingerichtet, der als Stellvertreter des Ratsvorsitzenden diesem hierarchisch unterstellt war. Zugleich erhielt der Vorsitzende des Wirtschaftsrates eine begrenzte Weisungsbefugnis gegenüber den unterstellten Betrieben und Einrichtungen, die jedoch so gestaltet war, dass sich der Wirtschaftsrat nicht zu einer selbständigen Wirtschaftsverwaltungsbehörde im Bezirk entwickelte. Seine Hauptaufgaben waren u. a. die volkswirtschaftliche Planungstätigkeit für den Bezirk auf der Grundlage der zentralen Volkswirtschaftspläne sowie die operative Anleitung der Betriebe im Bezirk. Gesonderte Fachorgane etwa für Maschinenbau, Leichtindustrie oder Textilindustrie entstanden nur bei entsprechenden Schwerpunkten in der örtlichen Wirtschaft, so beispielsweise für die Leichtindustrie im Bezirk Potsdam und für die Textilindustrie im Bezirk Cottbus. ${ }^{143}$

Die Zahl der Stellvertreter des Vorsitzenden des Rates des Bezirkes blieb ungeachtet der Einrichtung des Wirtschaftsrates gleich, es entfiel nur die Leitung der Plankommission durch einen Stellvertreter. Allerdings verzeichneten die Stellvertreter insgesamt einen Kompetenzzuwachs. Während in den ersten Jahren die wichtigsten Ressorts beim Vorsitzenden und dem Sekretär angesiedelt waren, die alle wichtigen Fragen direkt mit den Abteilungsleitern entschieden, unterstanden dem Vorsitzenden und dem Sekretär nun nur noch wenige Abteilungen direkt. Dagegen gewann der Stellvertreterbereich deutlich an Kontur. Auf diese Weise erhielten auch die von Blockparteien benannten Stellvertreter mehr Kompetenzen übertragen, obwohl ihr spezifisches Gewicht angesichts neuer Ressortzuständigkeiten abnahm. Zwei Stellvertreterfunktionen waren für die Blockparteien reserviert, entweder für den Bereich Landwirtschaft (mit den zwei Abteilungen Landund Fortwirtschaft sowie Erfassung und Aufkauf), Handel und Versorgung oder für Gesundheit und Sozialwesen, zu denen jeweils nur eine Abteilung gehörte. Stets von der SED besetzt waren die Positionen des 1. Stellvertreters für Inneres, des Stellvertreters für Volksbildung, Kultur, Sport und Jugendfragen und des Sekretärs des Rates, der für die Org.-Instrukteur-Abteilung, das Abgeordnetenkabinett ${ }^{144}$ und das Sekretariat des Rates mit der Allgemeinen Verwaltung zuständig war. Dem Vorsitzenden unterstanden direkt nur noch die selbständige Abteilung Finanzen, die entgegen ursprünglichen Planungen nicht zum Wirtschaftsrat kam, und das Bezirksbauamt. Die Abteilung Finanzen, das Bezirksbauamt sowie die Abteilung Handel und Versorgung waren zur Entgegennahme von bestimmten Weisungen des Wirtschaftsrates und umgekehrt zur Auskunftserteilung

143 Vgl. Kotsch, Brandenburg, S. 95-96.

144 Das Abgeordnetenkabinett diente der Vorbereitung von Bezirkstagssitzungen. Es hatte zugleich die Abgeordneten, die über keine eigenen Mitarbeiter verfügten und selten Vorstellungen von ihren Aufgaben besaßen, auf ihre Tätigkeit vorzubereiten. 
verpflichtet. Der Rat des Bezirkes als Kollegialorgan umfasste nun den Vorsitzenden, die Stellvertreter, den Sekretär, den Leiter der Abteilung Planung des Bezirks-Wirtschaftsrates sowie acht bis zehn weitere Mitglieder. ${ }^{145}$

Auch bei den Räten der Kreise wurden weiterhin vier Stellvertreter des Vorsitzenden eingesetzt. Das gelang durch die Zusammenfassung der Abteilungen Land- und Forstwirtschaft, Erfassung und Aufkauf sowie Handel und Versorgung bzw. Volksbildung, Kultur, Sport, Jugendfragen sowie Gesundheits- und Sozialwesen/Wohnungsfragen zu jeweils einem Stellvertreterbereich. Anstelle eines Wirtschaftsrates fand sich lediglich eine Kreisplankommission, die kaum wirtschaftsleitende Kompetenzen besaß; sie unterteilte sich in die Arbeitsgruppen Perspektivplanung, operative Jahresplanung, Koordinierung und materiell-technische Versorgung. Dem Vorsitzenden der Kreisplankommission unterstanden als Stellvertreter des Ratsvorsitzenden zudem die nicht in die Plankommission integrierten Abteilungen Örtliche Industrie und Handwerk, kommunale Wirtschaft, Wasserwirtschaft und Verkehr, Energie, Arbeit sowie Lebensmittelindustrie. ${ }^{146}$

Nur schwerfällig kamen die örtlichen Räte mit ihrer neuen Struktur und in ihren neuen Zuständigkeiten zurecht. Eine Grundintention der Reform, den Stellvertretern des Ratsvorsitzenden mehr Leitungskompetenz für ihre Bereiche zu übertragen und die Tätigkeit des Vorsitzenden auf die Anleitung und Kontrolle des Rates insgesamt zu lenken - weshalb er für immer weniger Ratsbereiche die unmittelbare Verantwortung behielt -, funktionierte anfangs kaum. Dagegen überwog noch lange die Praxis, dass der Vorsitzende die Fachorgane dirigierte und an den Stellvertretern vorbei den direkten Kontakt mit den Abteilungsleitern suchte. ${ }^{147}$ Die Wirtschaftsräte, wichtigste strukturelle Neuerung bei den örtlichen Räten, waren auf ihre Tätigkeit überhaupt nicht vorbereitet und erwiesen sich in den folgenden Jahren als völlig überfordert. Zusätzlich standen in dieser Phase ständige Personalwechsel einer kontinuierlichen Arbeit entgegen. Zudem beklagten die Räte eine schlechte Anleitung durch die Fachminister.

Als hinderlich für die Verwaltung erwies sich insbesondere das System der ständigen Kommissionen. Ihnen war bei der Verwaltung eine Schlüsselrolle zugewiesen worden, der sie praktisch nie zu entsprechen vermochten. Ihre meisten Mitglieder verfügten kaum über die notwendigen Kenntnisse für ihre Tätigkeit, die ihnen die Räte, die für sie zuständig waren, erst zu vermitteln hatten. Da die Kommissionsmitglieder in ihren Berufen verblieben, stand ihnen für die Kommissionsarbeit praktisch kaum Zeit zur Verfügung. So tagten sie meist einmal im Monat und verfassten Schreiben an die örtlichen Räte, worin sie diese beauftragten, die ihnen selbst übertragenen Aufgaben zu erledigen. Die Räte wiederum hatten anschließend den Kommissionen über die Erfüllung der Aufträge zu berichten, was einen gewaltigen Arbeitsaufwand verursachte und von den Räten kritisiert wurde. Änderungen stellten sich nicht ein. Sowohl die Rechtskonstruktion für die ständi-

145 BLHA, Rep. 401, Nr. 216, B1. 235.

146 Vgl. Dok. 60.

147 Vgl. die verschiedenen Stellungnahmen auf einer Arbeitsberatung der ZK-Abteilung für Staats- und Rechtsfragen mit den Vorsitzenden der Räte der Bezirke und den Parteisekretären, 28. Mai 1959, in: BArch, DY 30/IV 2/13/113, Bl. 1-77. 
gen Kommissionen als auch die Praxis der Zusammenarbeit von Kommissionen und Räten blieb erhalten, womit das faktische Übergewicht des Staatsapparates gegenüber den Volksvertretungen gewahrt blieb. ${ }^{148}$

\section{VII.}

Ebenso wie die staatlichen Verwaltungsbehörden waren mit der Neugliederung des politischen Systems von 1952 auch die Parteien betroffen. Nicht alle Entwicklungen, die die Parteien bis zu diesem Zeitpunkt vollzogen hatten, entsprachen den Vorstellungen der obersten politischen Führung. So nutzte man die territoriale Neugliederung auch zur organisatorischen und personellen Neuordnung der Parteien.

Das betraf in erster Linie die Herrschaftspartei selbst, die Sozialistische Einheitspartei Deutschlands. ${ }^{149}$ Drei Prozesse hatte die SED seit ihrer Gründung bis zum Jahr 1952 durchlaufen: erstens die ideologische Vereinheitlichung, zweitens die organisatorische Neuordnung und drittens die Veränderung der Mitgliederstruktur. Die Vereinigung von KPD und SPD hatte zunächst eine hybride Partei entstehen lassen, in der sich unterschiedliche Ansichten über Formen und Inhalte der Parteiarbeit, über den organisatorischen Aufbau der Partei und über die politischen Ziele gegenüberstanden. Sie war in dieser Form nur eingeschränkt geeignet, als Kampfpartei den Führungsanspruch der Kommunisten in der Gesellschaft durchzusetzen. Bis 1948 gelang es, den MarxismusLeninismus als ideologische Basis in der SED zu etablieren und die Anerkennung der führenden Rolle der KPdSU, deren Parteigeschichte zum Pflichtthema der Bildungsarbeit in der SED wurde, von den Funktionären und Mitgliedern einzufordern. Das Schulungssystem der Partei wurde ausgebaut, es entstand ein flächendeckendes Netz von zentralen und regionalen Parteischulen. ${ }^{150}$ An den Kreisparteischulen (in jedem Kreis) fanden zweibis dreiwöchige Kurse statt, an den Landesparteischulen (für Brandenburg auf Schloss Schmerwitz, das die KPD nach dem Krieg von der sowjetischen Militärkommandantur Belzig für Schulungszwecke übereignet bekommen hatte) mindestens sechswöchige Schulungszyklen. Für Sonderlehrgänge wurde 1946 eine Sonderschule in Ludwigsfelde eingerichtet.

Geformt wurde - in Koordination mit den übrigen ostmittel- und osteuropäischen Arbeiterparteien - eine „Partei neuen Typus“. ${ }^{151}$ Neben der ideologischen Ausrichtung ging es um die organisatorische Straffung und die Durchsetzung einer widerspruchslosen Parteidisziplin, wodurch die Führung der Partei nach dem Prinzip des Demokratischen Zentralismus ermöglicht wurde. Um den Befehlsweg von der Zentrale zur Parteibasis kurz zu halten, wurden Mittelinstanzen in der Parteihierarchie wie die (Unter-)Bezirks-

148 Vgl. den Diskussionsbeitrag von Günter Springer, Frankfurt (Oder), in: ebd., Bl. 30-32.

149 Vgl. Malycha, SED.

150 Vgl. Leonhard, Fadenkreuz.

151 So die SED-Führung in einer Resolution im Juli 1948; vgl. Friedrich u. a., Entscheidungen, sowie Malycha, Geschichte. 
leitungen aufgelöst. Auch das Produktionsprinzip, das aus Sicht der Kommunisten den Mobilisierungsgrad der Mitglieder erhöhte, wurde nach einer kurzen Übergangsfrist in der Partei gegenüber dem Wohnortprinzip wieder gestärkt, was eine Aufwertung der Betriebsgruppen - unterteilt in Betriebsparteiorganisationen, Abteilungsparteiorganisationen und Grundeinheiten - zur Folge hatte. Die teilweise sehr großen Ortsgruppen, die zu einem Eigenleben neigten, hatten sich in kleine Wohngebietsgruppen aufzuteilen und spielten fortan nur noch eine untergeordnete Rolle.

Der Parteiaufbau entsprach mit den Landes- und Kreisleitungen der staatlichen Verwaltungsgliederung. 1949 wurde die Führungsstruktur der Partei verändert und die seit 1946 bestehende Parität beseitigt. Der mit Kommunisten und Sozialdemokraten paritätisch besetzte Parteivorstand und das Zentralsekretariat - der geschäftsführende Vorstand - erlitten einen raschen Bedeutungsverlust, ebenso die paritätisch besetzten Landesvorstände und Landessekretariate. $\mathrm{Zu}$ den wichtigsten Führungsgremien entwickelten sich das im Januar 1949 geschaffene Politbüro und das Kleine Sekretariat. Es waren kleine und personell überwiegend identische Führungsgruppen, in denen ehemalige KPD-Funktionäre dominierten. Auch in den Landesvorständen wurden Kleine Sekretariate gebildet, denen jeweils sieben Mitglieder angehörten. Sie präsentierten sich als Kollegialorgane, die gemeinsam der Landesleitung vorstanden. Eine Einzelverantwortung der Sekretäre für Abteilungen oder Bereiche gab es noch nicht. Derartige Ressortzuständigkeiten bildeten sich aber rasch heraus; umgekehrt nahmen einige Abteilungsleiter seit 1951 regelmäBig an den Sekretariatssitzungen teil.

Eine dominante Stellung im Kleinen Sekretariat besaß von Anfang an der Landesvorsitzende, in Brandenburg war dies das frühere KPD-Mitglied Willy Sägebrecht. ${ }^{152}$ Die Überwindung der Parität zog eine weitere Zurückdrängung der Sozialdemokraten in der SED nach sich. Die Spitzenämter, die nur noch von einer Person besetzt wurden, fielen in der Regel an ehemalige Kommunisten oder Funktionäre, die während der Kriegsgefangenschaft in der Sowjetunion auf Antifa-Schulen ausgebildet worden waren und nach ihrer Rückkehr gezielt in den Funktionärsapparat integriert wurden. ${ }^{153}$

Im Juli 1950 wurden der Parteivorstand und das Zentralsekretariat aufgelöst. An ihre Stelle trat ein neuartiges Zentralkomitee, aus dem heraus das Politbüro und das (Kleine) Sekretariat als oberste Führungsgremien zu wählen waren. ${ }^{154}$ Die Wahl Walter Ulbrichts zum Generalsekretär am 25. Juli 1950 vollendete die Umwandlung der SED in eine stalinistische Partei. Auf der Landesebene verloren die Sekretariate ihren Charakter als Kollegialorgane. Sie verwandelten sich in hierarchisch gestufte Führungsorgane mit einem

$152 \mathrm{Zu}$ Willy Sägebrecht vgl. Niemann/Herbst, SED-Kader, S. 415, sowie seine Autobiografie Sägebrecht, Nicht Amboss.

153 Exemplarisch ist hierfür der Karriereweg von Herbert Puchert (1914-1997), der sofort nach seiner Rückkehr aus der Sowjetunion (Ende 1949) als Mitarbeiter in die Kreisleitung Guben kam (3. Januar 1950), obwohl er erst am 10. April 1950 Mitglied der SED wurde. Im März 1951 wurde er 2. Sekretär der Kreisleitung Teltow/Mahlow und im August 1952 1. Sekretär der Kreisleitung Zossen. Von 1962 bis 1971 war er Vorsitzender des Rates des Bezirkes Potsdam; vgl. Niemann/Herbst, SED-Kader, S. 396.

154 Vgl. Malycha, Partei. 
1. und einem 2. Landessekretär sowie vier Sekretären mit folgenden Ressorts: Kultur und Aufklärung; Organisation; Wirtschaft; Finanzen, Revision und Geschäftsleitung.

Zum 1. Januar 1950 zählte die SED 1.603.754 Mitglieder (davon 183.455 in Brandenburg), zum 1. August des Jahres 1.462.509 Mitglieder (159.894 in Brandenburg) und zum 29. Februar 1952 1.202.034 Mitglieder (127.409 in Brandenburg). ${ }^{155}$ Durch den Austausch der Parteibücher erreichte „Säuberungen“ führten allerdings auch zu einigen unbeabsichtigten Ergebnissen. So sank der Anteil der Arbeiter in der Partei auf 39 \%, während sich der Anteil der Hausfrauen und Rentner erhöhte. ${ }^{156}$ Insgesamt wertete die SED-Führung die Veränderungen in der Partei als Erfolg, zumal sich die Mitgliederzahl im ersten und zweiten Quartal des Jahres 1952 zu stabilisieren schien und bei der Kandidatengewinnung die sozialen und politischen Kriterien nahezu eingehalten wurden. ${ }^{157}$ Entschieden kritischer beurteilten die sowjetischen Beobachter die Mitgliederentwicklung in der SED. ${ }^{158} \mathrm{Zu}$ Recht, denn im Juli 1952, unmittelbar nach der II. Parteikonferenz, verlor die SED allein in Brandenburg 15.000 Mitglieder und 1.400 Kandidaten. ${ }^{159}$

Der Schlusspunkt bei der Umgestaltung der SED sollte im Sommer 1952 mit der Anpassung der Parteistrukturen an die veränderte staatliche Verwaltungsgliederung gesetzt werden. Die Einrichtung neuer Organisationsstrukturen vollzog sich ausschließlich als administrativer Akt. Die im Vorfeld der II. Parteikonferenz durchgeführten Wahlen galten ausdrücklich den alten Parteistrukturen, die kurz darauf unwirksam wurden. Am 29. Juni, einen Monat vor der Verwaltungsreform, konstituierte sich noch eine Landesleitung. Am 1. August wurden in Potsdam, Frankfurt (Oder) und Cottbus Bezirksorganisationskomitees tätig, die bis zur Wahl der Bezirksleitungen auf den Bezirksdelegiertenkonferenzen am 27./28. September in Potsdam und Cottbus sowie am 4./5. Oktober in Frankfurt (Oder) im Amt blieben.

Durch die Einrichtung von Bezirksleitungen und die Anpassung der Kreisorganisationen an die neue Verwaltungsstruktur verdoppelte sich die Anzahl der regionalen Parteibehörden, die nun kleiner wurden und damit als besser steuerbar galten. Der Landesverband Brandenburg wurde in Bezirksparteiorganisationen aufgeteilt. 47.400 Mitglieder und 5.380 Kandidaten zählte die Organisation im Bezirk Potsdam, 32.945 Mitglieder und 3.440 Kandidaten in Frankfurt (Oder) sowie 31.255 Mitglieder und 3.387 Kandidaten im Bezirk Cottbus. ${ }^{160}$ Der Anteil der Mitglieder und Kandidaten der SED an der Gesamtbevölkerung betrug im Bezirk Potsdam 4,1 Prozent, im Bezirk Frankfurt (Oder) 5,7 Prozent und im Bezirk Cottbus 4,8 Prozent. Der Rückgang der Mitgliederzahlen setzte sich zunächst fort und erreichte 1954 den Tiefpunkt; danach nahmen die Zahlen langsam wieder zu. 1957/58 war der Mitgliederstand von 1952 erreicht, danach wuchs die Zahl kontinu-

155 Vgl. BArch, DY 30/IV 2/5/1370, Bl. 14.

156 Vgl. Kotsch, Brandenburg, S. 149-150.

157 Vgl. die Analyse der SED-Landesleitung Brandenburg, ,über den Stand der Neuaufnahmen von Kandidaten“ vom 7. Juli 1952, in: BArch, DY 30/IV 2/5/1383, Bl. 163-164.

158 Vgl. den Bericht der Informationsabteilung der SKK an das ZK der KPdSU, 10. März 1952, in: RCChIDNI, 17/137/890, Bl. 1-2, sowie Creuzberger, Besatzungsmacht.

159 Vgl. BArch, DY 30/IV 2/5/1383, Bl. 172.

160 Vgl. BArch, DY 30/IV 2/5/1383, Bl. 173-175. 
ierlich weiter an. Bis Ende der 1970er Jahre verdoppelten sich die Zahlen. Am 31. Oktober 1989 enthielt die aktuelle Mitgliederkartei des Bezirkes Potsdam 104.640 Namen, somit 8,6 \% der gesamten Bevölkerung des Bezirkes. ${ }^{161}$

Die im August/September 1952 gebildeten Parteibehörden wiesen in ihrer Organisationsstruktur und dem Zuschnitt der Abteilungen viele Ähnlichkeiten mit der Landesleitung und den Leitungen der Großkreise auf. An der Spitze der Bezirksleitungen stand weiterhin ein Sekretariat mit sechs hauptamtlichen Sekretären. ${ }^{162}$ Unter Bezirksleitung wurde erstens das kollektive Leitungsgremium verstanden, das auf den Bezirksdelegiertenkonferenzen gewählt wurde. Die Zahl der Mitglieder fiel höher aus als in den ehemaligen Landesvorständen. Als Entscheidungszentrum fungierte weiterhin das Sekretariat, dem als nicht von der Partei besoldetes Mitglied auch der Vorsitzende des Rates des Bezirkes angehörte. Eine überragende Position fiel dem 1. Sekretär zu, dem alle Bereiche und alle Funktionsträger direkt verantwortlich waren. Er hatte zudem die Aufsicht über die Staatsorgane wahrzunehmen. Der 2. Sekretär besaß die Zuständigkeit für die Organisations- und Kaderarbeit.

Zweitens wurde als Bezirksleitung die Parteibehörde bezeichnet, die von den gewählten Sekretären geleitet wurde und die sich aus besoldeten Angestellten der SED zusammensetzte. Die Abteilungsstruktur war in allen Bezirksleitungen einheitlich: Leitende Parteiorgane, Staatliche Verwaltung, Wirtschaft, Landwirtschaft, Propaganda und Agitation, Kultur und Erziehung, Frauen, Kaderregistratur, Finanz- und Geschäftsabteilung sowie das Büro des Sekretariats und die Bezirksparteikontrollkommission. Unterschiedlich fiel hingegen die Anzahl der Mitarbeiter aus: Ende 1952 zählte die Bezirksleitung in Potsdam 178 (102 politische und 76 technische Mitarbeiter), die Bezirksleitung in Cottbus 166 (97/69) und die Bezirksleitung in Frankfurt (Oder) 155 (87/68) Mitarbeiter. ${ }^{163}$

Nach ähnlichen Kriterien wie die Bezirksleitungen waren die Kreisleitungen aufgebaut. Dort setzte sich das Sekretariat aus fünf Mitgliedern zusammen. Nach dem 1. Sekretär, der die Gesamtverantwortung trug und für die ideologische Arbeit und die Anleitung des Staatsapparates zuständig war, und dem für die Anleitung der Instrukteure, für die Kaderangelegenheiten und für Organisationsfragen zuständigen 2. Sekretär arbeiteten hier jeweils die Sekretäre für Wirtschaft, für Landwirtschaft sowie für Propaganda, Agitation und Kultur. ${ }^{164}$ Gegliedert waren die Kreisleitungen in die Abteilungen Partei und Massenorganisationen, Staatliche Organe sowie Wirtschaft und Landwirtschaft, wofür ein Personallimit von 50 Mitarbeitern gesetzt war, darunter bis zu 33 politische Mitarbeiter.

Der Aufbau dieser neuen Parteibehörden war mit einem massiven Personalaustausch verbunden. Er ergab sich nicht nur aus dem gewachsenen Kaderbedarf für die vermehrten Parteieinrichtungen. Die organisatorischen Umstellungen im Parteiapparat boten auch die

\footnotetext{
161 Vgl. BLHA, Rep. 530, Nr. 397.

162 Vgl. Niemann, Bezirksleitungen.

163 Vgl. BArch, DY 30/J IV 2/3/313, B1. 19.

164 Wenn es die Situation im Kreis erlaubte, konnten die Ressorts Wirtschaft und Landwirtschaft in Personalunion geführt werden, wie etwa im stark agrarisch geprägten Kreis Beeskow; vgl. BLHA, Rep. 730, Nr. 856.
} 
Möglichkeit, sich ohne Aufsehen von einer großen Anzahl von Funktionären zu trennen, die zumeist auf unbedeutende Positionen in anderen Einrichtungen abgedrängt wurden. In jedem Fall war eine Abstimmung mit der Sowjetischen Kontrollkommission herbeizuführen, die nicht alle Entscheidungen sanktionierte. So bestand sie beispielsweise darauf, den alten Agrarfunktionär Robert Neddermeyer in die aus ihrer Sicht wichtige Funktion des Bezirksvorsitzenden der VdgB in Potsdam einzusetzen, statt ihn zum Leiter eines Volkseigenen Gutes zu ernennen. ${ }^{165}$

Während der Anteil alter KPD-Kader in den regionalen Parteibehörden auffällig zurückging, gelangten viele junge Funktionäre in Spitzenpositionen, die erst nach dem Krieg zur Partei gekommen waren und oft weder die KPD noch die SPD gekannt hatten. Dabei handelte es sich einmal um ehemalige Kriegsgefangene, die in sowjetischen Antifa-Schulen eine intensive Umerziehung erfahren hatten und sich nach ihrer Rückkehr zuverlässig dem Willen der sowjetischen Besatzungsorgane unterordneten. Zum anderen erhielten nun auch schon die Angehörigen jener Jahrgänge eine Chance, die selbst nicht mehr als Soldaten gekämpft hatten und aus verschiedenen Gründen oft direkt den Schritt von der Hitlerjugend in die FDJ und in die SED gegangen waren. Es waren zumeist geschickte und oftmals ideologisch fanatische Jungkader, die in den ersten Jahren schnell die Parteischulen absolvierten und außerhalb des Konfliktes zwischen Kommunisten und Sozialdemokraten sowie zwischen ehemaligen Moskau-Emigranten, Westemigranten und den in Deutschland verbliebenen Illegalen standen. ${ }^{166}$

Mit der Bildung der Bezirks- und der neuen Kreisleitungen endete eine wichtige Etappe im Prozess der ideologischen und organisatorischen Umgestaltung der SED. Die Bemühungen, die soziale und politische Struktur unter den Parteimitgliedern zu korrigieren, setzte die SED-Führung auch nach 1952 fort. Vor allem der Arbeiteranteil sollte unablässig erhöht werden, was der Legitimierung des Machtanspruches der Parteielite, die Arbeiterschaft zu repräsentieren, zu dienen hatte. ${ }^{167}$ Tatsächlich drängten jedoch Angestellte und zunehmend Angehörige der Intelligenz in die Partei. Völlig unterrepräsentiert war und blieb die Bauernschaft, wodurch die schon früher geübte Kritik der Sowjetischen Kontrollkommission an diesem Zustand andauerte.

Schon kurz nach Bildung der neuen Parteibehörden auf Bezirksebene begann die Suche nach veränderten Führungsstrukturen. Zwei gegenläufige Tendenzen stießen dabei aufeinander: zum einen die Einbeziehung einer wachsenden Zahl von Funktionsträgern ausgewählter Bereiche in die Führungsverantwortung und zum anderen das Bestreben, einen exklusiven, kleinen Kreis von Entscheidungsträgern zu erhalten. Aus diesem Spannungsverhältnis heraus ergaben sich häufige Veränderungen. In den ersten Jahren fanden sich zu den entscheidenden Sekretariatssitzungen die hauptamtlichen Sekretäre und der Ratsvorsitzende sowie der Vorsitzende der Bezirksparteikontrollkommission (BPKK) und der Chef-

165 Vgl. den Bericht des Bezirksorganisationskomitees Potsdam über die Aussprache bei der SKK im August 1952, in: BLHA, Rep. 530, Nr. 1958.

166 Vgl. Kotsch, Brandenburg, S. 153.

167 Vgl. die Kritik des Politbüro-Mitglieds Karl Schirdewan an der Kaderarbeit der Bezirksleitungen, 26. März 1953, in: BArch, DY 30/IV 2/5/1370, B1. 178-184. 
redakteur der Bezirkszeitung der $\mathrm{SED}^{168}$ zusammen. 1955 traten an die Stelle der Sekretariate, die formal nicht aufgelöst wurden, Büros der Bezirksleitungen. Ihnen gehörten als Mitglieder an: die hauptamtlichen Sekretäre, der Vorsitzende der BPKK, der Vorsitzende des Rates des Bezirkes, der Bezirksvorsitzende des FDGB, der Leiter der MfS-Bezirksverwaltung sowie unter Umständen der 1. Sekretär der Kreisleitung eines strukturprägenden Kreises im Bezirk. ${ }^{169}$ Als Kandidaten gehörten dem Büro der 1. Sekretär der FDJ-Bezirksleitung und der Vorsitzende einer Landwirtschaftlichen Produktionsgenossenschaft an, später auch ein Produktionsarbeiter aus einem industriellen Großunternehmen des Bezirkes. Als 1958 die Bezirkswirtschaftsräte entstanden, wurden deren Vorsitzende in die Büros integriert, 1962 auch die Vorsitzenden der Bezirksplankommissionen. Innerhalb der Büros bildeten die hauptamtlichen Sekretäre der Bezirksleitungen jeweils einen engeren Führungszirkel, die Kleinen Sekretariate, die bis Ende 1963 bestanden. ${ }^{170}$

Nur wenige Jahre nach der Bildung der Bezirks- und der neuen Kreisleitungen der SED wurde auch das Verhältnis von Parteiinstanzen und örtlichen Staatsorganen neu überdacht. Die veränderte Rolle der 1952 gebildeten örtlichen Räte, deren straffe Führung durch den Ministerrat und die mit der Bildung der Räte verbundene Kaderauswahl nährte die Auffassung, dass die konkreten Aufgaben der Parteiorgane auf ausgewählte Bereiche begrenzt werden müssten.

Der Dualismus von Staats- und Parteiapparat war ein Grundproblem, das sich aus den Grundkonstanten des politischen Systems aller kommunistischen Staaten ergab. In der DDR wurde dieses Problem mit dem Ausbau der Planwirtschaft akut, d. h. mit der Einführung des ersten langfristigen, nun auf fünf Jahre angelegten Planes im Januar 1951. Nach dem Willen der SED-Führung sollte die wirtschaftsleitende Kompetenz vorrangig im Staatsapparat angesiedelt werden. ${ }^{171}$ Aufgabe der Landes-, Kreis- und Ortsparteileitungen sollte es sein, über die Parteimitglieder im Staatsapparat, vor allem die Genossen mit Führungsaufgaben, eine straffe politische Kontrolle auszuüben, ohne selbst wirtschaftsleitend tätig zu werden. ${ }^{172}$ Das galt auch für die Kaderarbeit im Staatsapparat: Die Parteiorgane sollten umfassend auf die Kadersituation Einfluss nehmen, ohne selbst Personalentscheidungen zu treffen. ${ }^{173}$ In der Praxis funktionierte dieses Modell kaum. Es scheiterte nicht nur am Ehrgeiz der Funktionäre in den Landes-, Kreis- und Ortsparteileitungen, sondern vor allem am umfassenden Führungsanspruch der obersten SED-Führung. Es sollte indes gerade mit der Verwaltungsreform und der Bildung von SED-Be-

168 Es handelte sich in den drei brandenburgischen Bezirken um die „Märkische Volksstimme“ (Potsdam), „Neuer Tag“ (Frankfurt (Oder)) sowie die „Lausitzer Rundschau“ (Cottbus).

169 So war etwa Hans Albrecht, ab 1954 1. Sekretär der SED-Kreisleitung Stalinstadt, zeitgleich auch Mitglied der SED-Bezirksleitung Frankfurt (Oder); vgl. Niemann/Herbst, SED-Kader, S. 88.

170 Die offiziellen Aufgaben der Kleinen Sekretariate umfassten die Durchführung der Bürobeschlüsse, eine straffe Führung des Parteiapparates, Erziehung und Einsatz der Kader, sowie die Vorbereitung der Beschlüsse und der Bürositzungen; vgl. BLHA, Rep. 730, Nr. 497.

171 Vgl. Werner, Demokratisierung.

172 Vgl. das Referat von Otto Schön, Mitglied des Sekretariats des ZK der SED, auf der Zentralen Arbeitstagung am 30. Juni 1950; in: RCChIDNI, 17/137/652.

173 Vgl. die Rede von Paul Hentschel, stellvertretender Leiter der ZK-Abteilung Staatliche Verwaltung, in: ebd. 
zirksleitungen und neuen Kreisleitungen seine Praxiswirksamkeit unter Beweis stellen. In beiden Fällen handelte es sich um deutlich verkleinerte Parteibehörden, deren Gewicht als Führungsinstanzen theoretisch zurückging. Praktisch blieb diese Veränderung ohne Folgen, da ja auch die staatlichen Behörden kleiner geworden waren, womit das Kräfteparallelogramm zwischen staatlichen und Parteibehörden in etwa gleich blieb. ${ }^{174}$

Erst in der Sogwirkung der Reform des örtlichen Staatsapparates 1957/58, als dessen wirtschaftsleitende Kompetenz durch die Einrichtung der Bezirkswirtschaftsräte und durch andere Regelungen gestärkt wurde, vollzog sich ein gradueller Wandel in den Parteibehörden. Schon 1956 war das Wirtschaftsressort in den meisten Kreisleitungen abgeschafft worden. Parallel zu diesem Teilrückzug des Parteiapparates aus der Wirtschaftslenkung wurden andere, vor allem sicherheits- und ideologiesteuernde Bereiche in den Parteibehörden ausgebaut. Am 15. Februar 1962, ein Jahr vor der Verkündung der Wirtschaftsreform auf dem VI. Parteitag der SED, ordnete das Sekretariat des ZK eine Reduzierung der Stellenpläne in den Bezirksleitungen an, von der vor allem die Abteilung Wirtschaftspolitik betroffen war. Sie behielten lediglich jeweils fünf besoldete Instrukteure. In der Bezirksleitung Potsdam waren sie für die Arbeitsgebiete Planung und Finanzen, Metallurgie, Maschinenbau, Bauindustrie und Technischer Fortschritt zuständig; die Bereiche Handel, Verkehr und Gewerkschaftsarbeit wurden ehrenamtlichen Kommissionen übertragen. ${ }^{175}$ Die Abteilung Organisation und Kader verfügte hingegen über 32 Stellen in dem von 114 auf 85 Stellen gekürzten Plan für politische Mitarbeiter der Bezirksleitung. ${ }^{176}$

Von langer Dauer waren diese Veränderungen nicht. Schließlich widersprachen sie dem Führungs- und Kontrollanspruch der Parteibürokratie. 1964 wurde die Reduzierung des Parteiapparates rückgängig gemacht, womit die traditionelle Praxis, Funktionen der örtlichen Staatsorgane in die unmittelbare Zuständigkeit der Partei zu ziehen, eine nun andauernde Wiederbelebung erfuhr. Im wirtschaftlichen Bereich war diesen Ansprüchen durch die gewachsenen und geformten Strukturen der staatlichen Verwaltungsbehörden allerdings Grenzen gesetzt. Das Arbeitsprofil, das die Bezirkswirtschaftsräte und die Bezirksplankommissionen entwickelt hatten, und der Zwang zu moderneren Führungsmethoden in der Wirtschaft erwiesen sich in gewissem Maße als Schild gegen unmittelbare Führungsansprüche der Parteibehörden. Die Bezirksleitungen der SED, in abgestufter Weise auch die Kreisleitungen, fungierten nun hauptsächlich als allgemeine Koordinierungsinstanzen, als Kontrollgremien für die Einhaltung der Volkswirtschaftspläne und als Führungsstellen für die ideologische Arbeit.

174 Vgl. Kotsch, Brandenburg, S. 157.

175 Vgl. BLHA, Rep. 530, Nr. 1960.

176 Die Reduzierung der besoldeten Stellen führte zur Bildung weiterer ehrenamtlicher Kommissionen für Jugend, Frauen, Sport, Schule, Hoch- und Fachschulwesen, Berufsbildung, Film und Theater, Literatur und Bildende Kunst; vgl. BLHA, Rep. 730, Nr. 1074. 


\title{
Die Etablierung der staatlichen Bezirksverwaltungen in Brandenburg und der übrigen DDR. Forschungsstand und Forschungsperspektiven
}

\author{
OLIVER WERNER
}

$I$.

Auch über 25 Jahre nach dem Ende der Deutschen Demokratischen Republik werden unsere Kenntnisse von der regionalen staatlichen Verwaltung der DDR noch immer wesentlich von zwei Studien bestimmt, die in den 1990er Jahren entstanden sind. Die 1995 erschienene Arbeit von Henning Mielke zur „Auflösung der Länder“ untersucht detailliert die politischen Umstände und Beweggründe der Bezirksbildung; sie stützt sich neben Akten zentraler Partei- und Staatsinstanzen wesentlich auf Unterlagen brandenburgischer Provenienz. ${ }^{177}$ Detlef Kotschs umfangreiche Untersuchung der brandenburgischen Bezirke wurde im Sommer 2000 fertiggestellt und arbeitet die enge Verknüpfung politischer, wirtschaftlicher, gesellschaftlicher und nicht zuletzt sicherheitspolitischer Faktoren bei der Bezirksbildung 1952 sowie in der regionalen Verwaltungspraxis der DDR bis 1990 heraus. ${ }^{178}$

Beide Untersuchungen beziehen sich in besonderer Weise auf Brandenburg, und beide Arbeiten präsentieren eine differenzierte Analyse des Verhältnisses zwischen staatlicher Verwaltung und der Staatspartei SED. Die Interaktion zwischen verschiedenen politischen und gesellschaftlichen Kräften prägte die Anfangsjahre der DDR mindestens ebenso sehr wie der umfassende Gestaltungsanspruch der SED. Die Diktatur entfaltete sich nicht allein im politischen Konzept, sondern gerade auch in den gesellschaftlichen Auseinandersetzungen bei dessen praktischer Umsetzung.

Neuere Studien zur regionalen Staatsverwaltung in der DDR trennen deutlich stärker zwischen den Staatsfunktionären auf der einen und den Parteifunktionären auf der anderen Seite. Während Friederike Sattler (2002) die Wirtschaftspolitik der KPD/SED im Land Brandenburg als konflikthafte Durchsetzung kommunistischer Planwirtschaft erfasst, ${ }^{179}$ konzentrieren sich Eva Rickmers am Beispiel des Bezirks Cottbus (2007) und Veit Scheller für Chemnitz/Karl-Marx-Stadt (2009) auf die Strukturen der staatlichen Verwaltung. ${ }^{180}$ Solche Darstellungen sind für die Erschließung der umfangreichen Aktenbestände eine unverzichtbare Voraussetzung. Aber die Ordnungen, Direktiven und Strukturvorgaben für die Bezirke und Kreise bildeten in der DDR nie die Realität der Verwaltungspraxis.

177 Mielke, Auflösung.

178 Kotsch, Brandenburg.

179 Sattler, Wirtschaftsordnung.

180 Rickmers, Bezirkstag, und Scheller, Staatsmacht. 
Die Arbeiten von Heinz Mestrup (2000) und Mario Niemann (2007) analysieren die Stellung der regionalen Parteiorganisationen der SED und die Handlungsspielräume der Parteifunktionäre sowohl gegenüber der staatlichen Verwaltung als auch den übergeordneten Parteiinstanzen. ${ }^{181}$ Aus dieser Perspektive gerät der Kontrollzugriff der SED in den Fokus, und die Fähigkeit staatlicher Funktionäre, regionale Interessen in die Erfüllung zentraler Planvorgaben einzuflechten, wird ganz überwiegend durch Parteiverfahren und andere Sanktionsmaßnahmen aufgespürt. ${ }^{182}$

Die Zugänge zur regionalen Geschichte der DDR allein über die staatliche Verwaltung oder mit einem ausschließlichen Fokus auf die SED bringen bei allem Erkenntnisfortschritt neuerliche Einschränkungen, die nicht zuletzt auf das methodische Grundproblem zurückzuführen sind, wie in einem Geflecht sich überlagernder Kontrollansprüche die Handlungsspielräume einzelner Akteure überhaupt ermittelt werden können. Entsprechend häufig präsentieren die Untersuchungen von Scheller, Mestrup und Niemann interessante Einzelfälle, die sich indes nur bedingt verallgemeinern lassen. Tatsächlich steht die Interaktion von staatlichen und Parteifunktionären erst seit geraumer Zeit im Blick der Forschung. ${ }^{183}$ Dabei geht es darum, Kooperations- und Konfliktbeziehungen etwa zwischen den Sekretären der SED-Bezirksleitung und den Mitgliedern des Rates des Bezirkes aufzuspüren, an denen sich „Herrschaftsdurchsetzung und -aufrechterhaltung in den sozialen Nahräumen der Gesellschaft"'184 untersuchen lassen.

In diesen Nahräumen fiel der regionalen und lokalen Verwaltung eine Schlüsselstellung zu. Zugleich aber bot die Fähigkeit nachgeordneter Funktionäre, sich in ihrem Verantwortungsbereich zu arrangieren, Anlass für die zentrale Partei- und Staatsführung, ihren Anspruch auf umfassende „Anleitung und Kontrolle“ immer wieder zu bekräftigen. Dieser potenziell unbegrenzte Anspruch begünstigte, wie die in der vorliegenden Edition präsentierten Dokumente belegen, dass die ganz verschiedenen Kontrollgremien sich auf der Bezirks- und Kreisebene in den 1950er Jahren eher überlagerten und blockierten, als dass sie den Einfluss der Zentrale auf regionale und lokale Entscheidungen und Entwicklungen verstärkten.

Der Kontrollanspruch der SED gegenüber den staatlichen Instanzen in der Sowjetischen Besatzungszone und der frühen DDR hatte seinen Ursprung in der Verwaltungspraxis der UdSSR und ist bereits in den späten 1940er Jahren explizit formuliert worden. Die praktische Umsetzung dieser Kontrolle war dabei nicht zwingend an eine Reform der Mittelinstanzen oder gar an die Auflösung der eben erst gebildeten Länder gekoppelt. ${ }^{185}$ Die wichtigsten Instrumente dieser Kontrolle bildeten die Kaderpolitik - gegenüber Staatsfunktionären gerade in einer Verbindung aus politischer Schulung und persönlicher Verpflichtung durch Mitgliedschaft in der SED - sowie die durchgängige, enge

181 Mestrup, SED, und Niemann, Sekretäre.

182 Zum aktuellen Forschungsstand über die regionalen Parteiorganisationen der SED vgl. Malycha, Ära Honecker, S. 113-121.

183 Vgl. etwa Kurzweg/Werner, SED, für den Bezirk Leipzig.

184 Bahr, Soziale Wirklichkeit, S. 68.

185 Vgl. Werner, Demokratisierung, S. 304-311, sowie Dok. 1. 
hierarchische Anleitung der regionalen und lokalen Instanzen im Rahmen des ,demokratischen Zentralismus“.

Eine bedeutende Kontrollfunktion sollte der „Sekretär des Rates“ in jedem Bezirk übernehmen. Der Sekretär erhielt mit der „Org.-Instrukteur-Abteilung“ zwar einen eigenen Stab, allerdings wurde seine Aufgabenstellung zunächst nur vage umrissen, um dann ab dem Sommer 1952 immer ausufernder formuliert zu werden. ${ }^{186}$ Hier verschränkte sich der Führungsanspruch der SED mit der bürokratischen Eigendynamik einer immer wieder kampagnenhaft angespornten Regionalverwaltung. Die Feststellung, der Sekretär habe ,,aufgrund seiner politischen Implementierung den größten Einfluss auf die Tätigkeit des Rates des Bezirkes“ besessen, ${ }^{187}$ lässt sich daher nicht verallgemeinern. Der tatsächliche Einfluss eines Sekretärs im Bezirk hing nicht zuletzt von seiner Fähigkeit ab, eine belastbare Arbeitsbeziehung zum Vorsitzenden des Rates aufzubauen und in seiner Berichterstattung die Verantwortung für Fehlentwicklungen im Bezirk so auszubalancieren, dass keine personellen Konsequenzen drohten. ${ }^{188}$

Das Kollegium des Rates eines Bezirkes war nicht nur durch die ,doppelte Unterstellung“ unter den Bezirkstag und den Ministerrat der DDR formal gebunden. Der Vorsitzende des Rates wurde darüber hinaus als Mitglied der SED-Bezirksleitung politisch angeleitet. Das war konzeptionell durchaus eine vorbildliche Umsetzung des umfassenden Kontrollanspruchs der SED. In der Praxis erhielten die Mitglieder des Rates jedoch immer wieder Entscheidungskompetenzen zugesprochen, die ihnen jederzeit von Mitarbeitern der Ministerien streitig gemacht werden konnten oder mit Verantwortlichkeiten kombiniert wurden, die eigenständige Entscheidungen riskant werden ließen. Die aus dieser Dynamik erwachsenden Handlungsoptionen sowie das Ausmaß, in dem neben institutionellen Faktoren gerade auch persönliche Eigenschaften der Ratsmitglieder das praktische Verwaltungshandeln in der DDR geprägt haben, gehört weiterhin zu den Desideraten der DDR-Forschung.

\section{II.}

Die hier präsentierten Dokumente bieten einen differenzierten Zugang zur Verwaltungspraxis der DDR und ermöglichen zugleich, die grundsätzlichen Schwierigkeiten in der Analyse der vielschichtigen Quellen aus kommunistischen Diktaturen zu untersuchen. ${ }^{189}$ Dazu gehört insbesondere die begrenzte Aussagekraft offizieller Berichte innerhalb der Partei- und Staatshierarchie, die in der DDR schon in den frühen 1950er Jahren zu einer eigenwilligen Parteisprache gefunden hatten, deren rückblickende „Dechiffrierung“ nicht ohne weiteres möglich ist, da für das heutige Ohr harmlos klingende Schuldzuschreibun-

186 Vgl. etwa die Dok. 29 und 46.

187 Scheller, Staatsmacht, S. 105.

188 Vgl. Dok. 48.

189 Vgl. dazu grundsätzlich die Beiträge in Lüdtke, Akten. 
gen für die betreffenden Funktionäre schwerwiegende Konsequenzen haben konnten. ${ }^{190}$ Umso schwieriger lassen sich informelle Schilderungen der tatsächlichen Zustände in der regionalen Verwaltungspraxis aufspüren, und selbst bei verhältnismäßig offenen Auseinandersetzungen etwa auf Tagungen des Zentralkomitees der SED waren die beteiligten Funktionäre darauf bedacht, dass die von ihnen angesprochenen Missstände nicht ihnen persönlich angelastet würden. ${ }^{191}$

Eine unnachgiebige Kaderpolitik und die kompromisslose Umsetzung des ,demokratischen Zentralismus “ bildeten die unumstößlichen Rahmenbedingungen für die Tätigkeit der Staatsorgane in der DDR. Das wird schon in der Vorbereitungsphase der Bezirksbildung im Frühjahr und Sommer 1952 deutlich. Nicht nur war die Einrichtung der zuständigen Gremien maximal zentralisiert - selbst das Personal der regional maßgeblichen Bezirkskommissionen wurde vom Sekretariat des ZK bzw. vom Politbüro bestätigt. ${ }^{192}$ Auch der Prozess der Entscheidungsfindung war streng hierarchisiert: Die detaillierten, bis in die Abteilungsstrukturen ausgeführten Vorgaben der zentralen Kommission für den einheitlichen Aufbau der neuen Bezirks- und Kreisverwaltungen waren sakrosankt. ${ }^{193}$ Selbstredend sollten schließlich bereits in dieser Phase die der sowjetischen Praxis entlehnten Nomenklaturprinzipien als allein bestimmender Faktor bei der Rekrutierung von Verwaltungspersonal gelten. ${ }^{194}$

Der Kontrollzugriff wurde in den Monaten unmittelbar nach dem Gesetz vom 23. Juli 1952 noch engmaschiger. Die Koordinierungs- und Kontrollstelle für die Arbeit der Verwaltungsorgane legte per Direktive den genauen Ablauf der ersten Sitzungen jeweils der Bezirkstage und der Räte des Bezirkes fest, ${ }^{195}$ der Einsatz von Instrukteuren sollte die Kontrolle und genaue Anleitung der Staatsfunktionäre in den Bezirken und Kreisen gewährleisten, ${ }^{196}$ und an der Gestaltung der Handlungsspielräume auf Bezirksebene wurden die zentralen Ministerien beteiligt. ${ }^{197}$ Die Blockparteien hatten kaum Einfluss auf die Entwicklung, blieben aber als mobilisierende Kräfte bei der Bewältigung regionaler Schwierigkeiten unverzichtbar. ${ }^{198}$

Es ist beinahe selbstverständlich, dass im Eifer der überstürzten Bezirksbildung mitunter vergessen wurde, die bisher beim Land Brandenburg liegenden Kompetenzen und Aufgaben geordnet an die neuen Bezirksverwaltungen zu übergeben. ${ }^{199}$ Zugleich wird am Umgang mit solchen Fehlern erkennbar, wie schwerfällig die Verantwortlichen in den neuen Strukturen auf die Herausforderungen reagierten: Die Bezirksverwaltungen hatten selbst zu wenig Ressourcen und konnten nur feststellen, dass sie von der Regierung

190 Beispiele hierfür sind etwa die Dok. 47 und 48.

191 Vgl. Dok. 56.

192 Vgl. Dok. 3.

193 Vgl. Dok. 4

194 Vgl. Dok. 5.

195 Vgl. die Dok. 17 und 18.

196 Vgl. die Dok. 20 und 22.

197 Vgl. beispielsweise zum Ministerium für Justiz der DDR Dok. 21.

198 Vgl. die Dok. 19 und 38.

199 Vgl. Dok. 23. 
vernachlässigt würden, während sich die Kreisverwaltungen der Anleitung durch die Bezirksverantwortlichen zu entziehen versuchten. ${ }^{200}$ Zugleich fehlte häufig kompetentes Personal, und wo dieses vorhanden war, schien es durch die unerbittliche Kaderpolitik eher entmutigt als zur weiteren Qualifizierung motiviert zu werden. ${ }^{201}$

Die Expertisen und Überlegungen aus dem zeitlichen Umfeld der Bezirksbildung dokumentieren eine sehr begrenzte Fähigkeit vieler Partei- und Staatsfunktionäre, die administrativen und personellen Probleme nutzbringend zu evaluieren. Staatssekretär Werner Eggerath, der seinerseits ab September 1952 unter politischen Druck geriet, konnte trotz der anfangs relativ offenen Diskussionen mit den Vorsitzenden und Sekretären der Räte der Bezirke ${ }^{202}$ in seinen Äußerungen nur die politischen Prämissen der Bezirksbildung wiederholen und die Staatsfunktionäre zur Disziplin mahnen. ${ }^{203}$ Das Handlungsfeld der regionalen Funktionäre in Partei und Staat blieb entsprechend eng zugeschnitten auf die propagandistische „Popularisierung“ der neuen Staatsorgane, ${ }^{204}$ Schuldzuschreibungen an „schwankende“ oder unzuverlässige politische Kräfte ${ }^{205}$ sowie nicht zuletzt eine Intensivierung der kaderpolitischen Anstrengungen zur Gewinnung qualifizierter und politisch zuverlässiger Staatsfunktionäre. ${ }^{206}$ Zudem wurden die Aufgaben der regionalen Funktionäre immer wieder von dringenden zentralen Kampagnen etwa zur Kollektivierung landwirtschaftlicher Betriebe überlagert. ${ }^{207}$

Diese Konstellation wurde auch in den Reformen der örtlichen Organe der Staatsmacht in den Jahren 1957 und 1958 nicht angetastet. ${ }^{208}$ Während die strukturellen Probleme der Verteilung von Verwaltungskompetenzen im Reformprozess durchaus offen angesprochen wurden, blieben der kontrollierende Einfluss der SED und der hierarchische Aufbau der Verwaltung als grundsätzliche Prämissen unveränderbar. ${ }^{209}$ Selbst die Einrichtung neuer Planungsinstitutionen auf der Bezirks- und Kreisebene, ${ }^{210}$ die in den folgenden Jahren die Fachkompetenz der örtlichen Staatsfunktionäre tatsächlich signifikant erhöhten, schufen keine regionalen Freiräume, sondern wurden von der zentralen Partei- und Staatsführung weiterhin als Verbesserung ihres Kontrollzugriffs empfunden. ${ }^{211}$ Den aus dieser starren Reform neuerlich erwachsenden oder sich verstärkenden Problemen auf regionaler und lokaler Ebene begegnete die SED-Führung mit dem inzwischen erprobten Dreigestirn einer intensivierten Kaderkontrolle, ${ }^{212}$ verschärfter politischer Rhetorik ${ }^{213}$ so-

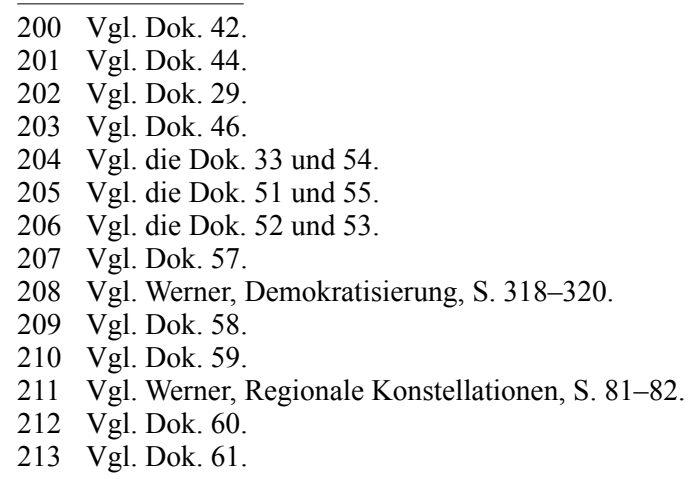


wie einer ausufernden Schulung der Funktionäre - gerade in den an West-Berlin und die Bundesrepublik Deutschland grenzenden Gebieten. ${ }^{214}$

\section{III.}

Der immer wieder bekräftigte Zentralismus der politisch-administrativen Gliederung des DDR-Staatsgebiets hat sehr lange den Blick auf die tatsächlich vorhandenen Handlungsspielräume regionaler und lokaler Funktionsträger verstellt. Tatsächlich spielen die Bezirke in den meisten aktuelleren Gesamtdarstellungen der DDR nur im Zusammenhang der II. Parteikonferenz der SED im Sommer 1952 eine Rolle. ${ }^{215}$ Die mit der Bildung der Bezirke von der SED-Führung angestrebte strenge staatliche Hierarchie wird für die Jahre bis 1989/90 dann als gesetzte politische Größe akzeptiert. ${ }^{216}$

Forschungen zu gesellschaftlichen Teilbereichen der DDR zeigen indes, dass die Dynamik des „demokratischen Zentralismus“ zwischen Mobilisierungserwartungen und Planerfüllung, zwischen strenger Hierarchie und sporadischen Partizipationsoptionen ganz wesentlich von der Anpassungsbereitschaft und der Improvisationsfähigkeit nachgeordneter Staats- und Parteifunktionäre bestimmt worden ist. Diese konstituierende Rolle der Funktionäre in den Bezirken und Kreisen für die Entwicklung der gesamten DDR wird gerade in Politikfeldern wie Stadtplanung und Strukturpolitik augenfällig, in denen die Mitwirkung regionaler und lokaler Planer an zentral gesteuerten Investitionsschwerpunkten unverzichtbar war. ${ }^{217}$ Gerade im Bauwesen sollte sich mit der „Vervollkommnung und Vereinfachung des Staatsapparates“ ab 1958 die von der SED-Führung für die Bezirke postulierte Verbindung aus bereitwilliger Planerfüllung und einer „Mobilisierung örtlicher Reserven“" produktiv entfalten. ${ }^{218}$

Handlungs- und Entscheidungsspielräume auf der Bezirks- und Kreisebene jenseits des erwarteten Planvollzugs waren allerdings keine dauerhaft $\mathrm{zu}$ erreichenden oder gar rechtlich abgesicherten Tatbestände, sondern fragile, durch persönliche Netzwerke und vorsichtiges Taktieren immer wieder neu abzusichernde Möglichkeiten. Diese konnten von der zentralen Führung je nach Sachlage stillschweigend geduldet werden, standen aber jederzeit unter dem Vorbehalt des Planverstoßes: Der schmale Grat zwischen begrüßten „Initiativ-“ und geahndeten „Schwarzbauten“ jenseits des Volkswirtschaftsplans ist hierfür ein anschauliches Beispiel. ${ }^{219}$

Der Anspruch der Partei- und Staatsführung, mit Hilfe einer zentralisierten Wirtschafts- und Territorialplanung die räumlichen Disparitäten in der DDR auszugleichen, 220

214 Vgl. Dok. 62.

215 Vgl. Hoffmann, DDR, S. 43-44.

216 Vgl. zuletzt Scholz, DDR.

217 Vgl. Betker, Einsicht, S. 117-145.

218 Vgl. Werner, Regionale Konstellationen, S. 80.

219 Vgl. Engler, Stadtplanung.

220 Vgl. Bernhardt, Disparitäten. 
bietet auf den ersten Blick nur wenig Anknüpfungspunkte für eine regional ausdifferenzierte Betrachtung der Geschichte der DDR. Indes waren an den Reformvorbereitungen der Jahre 1957 und 1958 Funktionäre aus den brandenburgischen Bezirken überdurchschnittlich beteiligt. ${ }^{221}$ Das war kein Zufall, sondern Ausdruck der Tatsache, dass die drei Bezirke Potsdam, Cottbus und Frankfurt (Oder) die Herausforderungen der DDR-Regionalpolitik in besonderer Weise repräsentierten. Während der Bezirk Potsdam mit dem Einschluss West-Berlins bis 1961 eine exponierte, sicherheitsrelevante Grenzlage aufwies, begannen in den Bezirken Cottbus und Frankfurt (Oder) umfangreiche Investitionsprogramme zum Ausbau der Schwerindustrie, die nicht nur die Sozial- und Wirtschaftsstruktur der Regionen grundlegend veränderten. Sie stellten auch besondere Ansprüche an die fachliche Qualifikation und die politische Zuverlässigkeit der verantwortlichen Funktionäre in den Bezirken und Kreisen. ${ }^{222}$

Die wirtschaftlichen Aufbauprogramme zielten mit Blick auf die gesamte DDR auf eine Verringerung der regionalen Disparitäten, etwa mit der Schaffung industrieller Zentren in der Nordhälfte des Landes. Zugleich aber schufen sie innerhalb einzelner Bezirke neuerliche Ungleichheiten, die etwa in den Bezirken Frankfurt (Oder) mit dem Stahlzentrum Stalinstadt und Cottbus mit einer expandierenden Braunkohlegewinnung das Verhältnis von Stadt und Land noch verschärften. ${ }^{223}$ Den Bezirken standen in der Regel nur die von der zentralen Führung gewährten Ressourcen zur Verfügung, um die neuen Disparitäten in den Griff zu bekommen. Die regionalen Staats- und Parteifunktionäre waren gezwungen, in einer permanenten Improvisation wenigstens die gröbsten Ungleichheiten bei der Verteilung wichtiger Ressourcen und Kapazitäten innerhalb ihres Verantwortungsbereichs zu kompensieren. Auf diese Weise stabilisierten sie auch das Gesamtsystem, und oft genug wirkte die „Mobilisierung örtlicher Reserven“ weit über den lokalen Rahmen hinaus.

Die Untersuchung dieser Dynamik steht erst am Anfang und umfasst mehr als eine Regionalgeschichte Brandenburgs der Jahre 1952 bis $1990 .{ }^{224}$ Vielmehr werden aus dieser Perspektive die regionalen Mittelinstanzen als stabilisierende Ebenen der DDR erkennbar, die die Systemdefekte der Zentralverwaltungswirtschaft wenn nicht ausgleichen, so doch lange kaschieren konnten. Die Untersuchung der Bezirke und Kreise der DDR ist daher keine einfache Sammlung von Regionalgeschichten, sondern ein konstituierender Beitrag zu einer System- und Gesellschaftsgeschichte der DDR, der die integrierenden und die zersetzenden Faktoren, die mobilisierende wie der überlastende Dynamik der DDR in den Blick nimmt. In diesem Sinne bilden die regionalen Mittelinstanzen der DDR durchaus einen Schlüssel zum Verständnis des zweiten deutschen Staates.

221 Vgl. Dok. 58.

222 Vgl. Blöß, Grenzen, S. 75-149, sowie Kotsch, Brandenburg, S. 297-329.

223 Vgl. Kehrer, Abriss.

224 Ein von 2012 bis 2015 am Leibniz-Institut für Raumbezogene Sozialforschung (IRS) in Erkner durchgeführtes Forschungsprojekt, das mit Mitteln der Deutschen Forschungsgemeinschaft (DFG) finanziert wurde, untersuchte die „DDR-Bezirke als Akteure zwischen Macht und Ohnmacht“. Die beiden Bearbeiter Lena Kuhl und Oliver Werner werden ihre Arbeitsergebnisse als Monografien präsentieren. 



\section{Verzeichnis der Dokumente}

Dokument 1: Berichtigter Beschluss des Politbüros der SED über die „Verbesserung der Arbeit des Staatsapparates“, 28. März 1952

Das Politbüro beschließt u. a. die Einsetzung eines Staatssekretär beim Ministerrat, der die Landes-, Kreis- und Kommunalbehörden ,,anleiten und kontrollieren“ solle.

Dokument 2: Beschlussvorlage für das Sekretariat des Zentralkomitees der SED über „Maßnahmen zur Änderung der staatlichen Struktur der Deutschen Demokratischen Republik", 24. April 1952

Das Sekretariat beschließt die Aufteilung des Gebiets der DDR in Bezirke, deren genaue Grenzen von einer ,zentralen Kommission“ festgelegt werden sollten.

Dokument 3: Beschluss des Sekretariats des Zentralkomitees der SED zur Bildung der Bezirke und der neuen Kreise, 30. Mai 1952

Das Sekretariat bestimmt die Aufgaben des ,zentralen Organisationskomitees“ und beschließt die Bildung nachgeordneter Länderkommissionen.

Dokument 4: Protokoll einer Sitzung der Unterkommission Struktur- und Stellenpläne, 4. Juni 1952

Die Unterkommission erörtert die administrativen „Grobstrukturen“ und Aufgabengebiete der zu bildenden Bezirke und Kreise.

Dokument 5: Anlage zum Protokoll einer Sitzung des Sekretariats des Zentralkomitees der SED, 26. Juni 1952

Der Ministerrat erlässt personalpolitische Richtlinien zur „Nomenklatur“, die die politische Zuverlässigkeit und die fachliche Qualifikation der Staatsfunktionäre auf Bezirks- und Kreisebene gewährleisten sollen. Die Verantwortung für die Erfüllung der Richtlinien wird dem Ministerium des Innern übertragen.

Dokument 6: Beschluss des Sekretariats des Zentralkomitees der SED „für die Überleitung der Staatlichen Organe in die neuen Bezirke und Kreise“, 3. Juli 1952

Das Sekretariat beschließt einen detaillierten Zeit- und Ablaufplan für die „Reorganisation des Staatsapparates“, der auf „strengste Sparsamkeit“ und die „strengste Einhaltung von Sicherheitsmaßnahmen" abzielt. 
Dokument 7: Aufstellung für den Bezirk Potsdam, 3. Juli 1952

Die statistische Aufstellung begründet den Zuwachs an politischem Einfluss für die SED und die ihr angeschlossenen politischen Organisationen gegenüber den „bürgerlichen“ Parteien im entstehenden Bezirk Potsdam.

\section{Dokument 8: Aufstellung für den Bezirk Cottbus, 3. Juli 1952}

Die statistische Aufstellung begründet den Zuwachs an politischem Einfluss für die SED und die ihr angeschlossenen politischen Organisationen gegenüber den „bürgerlichen“ Parteien im entstehenden Bezirk Cottbus.

\section{Dokument 9: Aufstellung für den Bezirk Frankfurt (Oder), 3. Juli 1952}

Die statistische Aufstellung begründet den Zuwachs an politischem Einfluss für die SED und die ihr angeschlossenen politischen Organisationen gegenüber den „bürgerlichen“ Parteien im entstehenden Bezirk Frankfurt (Oder).

Dokument 10: Vorlage des stellvertretenden Leiters der Abteilung Staatliche Verwaltung des Zentralkomitees der SED, Willi Barth, für das Politbüro über die „Grundsätze der Gesetzesvorlagen über die Neuorganisation im Staatsapparat", 5. Juli 1952

Willi Barth legt zwei verschiedene Wege für die geplante Bezirksbildung dar, wägt die zukünftige Stellung der Länder ab und erläutert die Notwendigkeit der „,neuen Einteilung und Struktur".

Dokument 11: Erster Bericht des Vorsitzenden des Organisations-Komitees für den Bezirk Potsdam, Rudolf Jahn, über den „Stand der Vorbereitungsarbeiten für die Verwaltungsreform im Bezirk Potsdam“, 17. Juli 1952

Rudolf Jahn berichtet, dass die Vorbereitungsarbeiten nahezu reibungslos verliefen und für die Bereiche der territorialen Struktur, des Personals und der Bereitstellung von Gebäuden keine wesentlichen Probleme bestünden.

Dokument 12: Bericht an den Leitinstrukteur für das Land Brandenburg über den „Instrukteureinsatz Verwaltungsreform im Land Brandenburg“, 18. Juli 1952

Die Aufgabenstellung für die Instrukteure und der Zeitablauf des Übergangs vom Land Brandenburg zu den neuen Bezirken werden mehrfach detailliert durchgesprochen. Zudem erwähnt der Bericht Versäumnisse bei der Zuteilung von Diensträumen.

Dokument 13: Zweiter Bericht des Vorsitzenden des Organisations-Komitees für den Bezirk Potsdam, Rudolf Jahn, ,über den Stand der Durchführung der Verwaltungsreform für die Bezirke Cottbus, Potsdam und Frankfurt (Oder)“, 20. Juli 1952 (Auszug)

Rudolf Jahn berichtet, dass das Verbot, neue Verwaltungen in Wohnräumen unterzubringen, bei zwei Bezirks- und vielen Kreisverwaltungen zu „erheblichen Schwierigkeiten“ führe. Außerdem werden Probleme bei der praktischen Umsetzung der vorgegebenen Strukturpläne benannt. 
Dokument 14: Bericht des Leitinstrukteurs für das Land Brandenburg „über den Stand der Durchführung der Verwaltungsreform für die Bezirke Cottbus, Potsdam und Frankfurt (Oder)“, 21. Juli 1952 (Auszug)

Der Bericht schildert Verlauf und Ergebnisse der ersten Besprechung der für Brandenburg zuständigen Instrukteure der Fachministerien. Es wird bemängelt, dass bisher von den Ministerien nur wenige Direktiven vorlägen, die zudem teilweise widersprüchlich seien. Kritisiert werden auch ,die schlechte Verwaltungsarbeit der Koordinierungs- und Kontrollstelle für die Arbeit der Verwaltungsorgane“ sowie der nachlässige Umgang mit vertraulichen Materialien.

Dokument 15: Aktennotiz des Staatssekretärs im Ministerium des Innern der DDR, Hans Warnke, zur „Begründung für die territoriale Einteilung“, 21. Juli 1952

Hans Warnke begründet die Zuordnung einzelner Kreise zu den verschiedenen Bezirken. Neben verkehrstechnischen und wirtschaftlichen Gründen (Cottbus) seien in erster Linie Sicherheitsfragen wie die Nähe zur „Demarkationslinie“ ausschlaggebend gewesen.

Dokument 16: Protokoll einer Besprechung der Instrukteure der Fachministerien mit den Vorsitzenden der Bezirkskommissionen, 23. Juli 1952

Die Instrukteure berichten von Problemen ihrer Arbeit wie dem Fehlen verbindlicher Strukturpläne, hoher Personalfluktuation oder Eigenmächtigkeiten von Verwaltungsfunktionären. Der anwesende Ministerpräsident resümiert, ,dass eine Besprechung in diesem Rahmen unfruchtbar"sei.

Dokument 17: Direktive der Koordinierungs- und Kontrollstelle für die Arbeit der Verwaltungsorgane beim Ministerpräsidenten der DDR „für die Vorbereitung der Durchführung der konstituierenden Sitzung des Bezirkstages“, 24. Juli 1952

Die Direktive legt den Ablauf der konstituierenden Sitzungen der Bezirkstage in allen Bezirken fest und bestimmt die Tagesordnung bis in die inhaltlichen Details.

Dokument 18: Direktive der Koordinierungs- und Kontrollstelle für die Arbeit der Verwaltungsorgane beim Ministerpräsidenten der DDR ,für die Durchführung der konstituierenden Sitzung des Rates des Bezirkes“, 24. Juli 1952

Die Direktive bestimmt den Verlauf der konstituierenden Sitzungen der Räte der Bezirke in allen Bezirken und hebt noch einmal die „Aufteilung der Aufgabengebiete“ auf der Bezirksebene hervor.

Dokument 19: „Beschlussvorlage für die Präsidiumssitzung der Nationalen Front des demokratischen Deutschland vom 29.7.1952“, 24. Juli 1952

Das Präsidium bestätigt die Abgeordneten der Bezirkstage in den drei brandenburgischen Bezirken und konkretisiert für einige neue Kreise das „Bodenreform-Bauprogramm im Lande Brandenburg“. 
Dokument 20: Bericht an den Leitinstrukteur des Landes Brandenburg über den „Instrukteureinsatz Verwaltungsreform Land Brandenburg“, 28. Juli 1952 (Auszug)

Der Bericht betont die weiterhin drängenden Probleme bei der angemessenen Bereitstellung von Dienstgebäuden und von verbindlichen Stellenplänen für die neuen Verwaltungen. Dies habe ,auch in den Kreisen nunmehr eine gewisse Beunruhigung“ zur Folge.

Dokument 21: Direktive des Ministeriums für Justiz der DDR, über die Überleitung der Justizverwaltung und den neuen Gerichtsaufbau“, 31. Juli 1952

Die Direktive bestimmt den zeitlichen und organisatorischen Ablauf zur Einführung der Justizverwaltungen und Gerichte auf Bezirksebene.

Dokument 22: Nachtrag zur Direktive des Ministeriums für Justiz der DDR vom 31. Juli 1952, ohne Datum

Die Instrukteure des Ministeriums für Justiz für die einzelnen Bezirke werden benannt und Schwerpunkte für den Anlauf ihrer Arbeit bestimmt.

Dokument 23: Schreiben des brandenburgischen Innenministers, Bruno Lentzsch, an den Ministerpräsidenten des Landes Brandenburg, Rudolf Jahn, zur ,Überleitung und Übernahme der Arbeit des Staatsapparates in den Bezirken", 2. August 1952

Bruno Lentzsch mahnt an, dass die Minister der abzuwickelnden Landesregierung noch schnell die „Abteilungsleiter für die ihr Ministerium betreffenden Aufgabengebiete“ versammeln und in ihr Aufgabengebiet einführen.

Dokument 24: Fünfter Bericht des Vorsitzenden des Organisations-Komitees für den Bezirk Potsdam über den Stand der Durchführung der Verwaltungsreform für die neuen Bezirke des ehemaligen Landes Brandenburg, Potsdam, Cottbus und Frankfurt (Oder), 4. August 1952

Der Bericht benennt als hauptsächliches Problem bei der „Überleitung“ die Bereitstellung von Baracken, da die dafür benötigten Gelder noch nicht bewilligt worden seien.

Dokument 25: Sechster Bericht des Vorsitzenden der Bezirkskommission Potsdam, Curt Wach, ,über den Stand der Durchführung der Verwaltungsreform im Bezirk Potsdam“, 7. August 1952 (Auszug)

Curt Wach berichtet von den Schwierigkeiten der Angestellten der neuen Verwaltungen im Bezirk Potsdam bei der Bereitstellung angemessener Diensträume, die zum Teil durch großzügige Urlaubsregelungen gemildert würden. Auch bereiteten „Gerüchte des Gegners“ über die Grenzlage des Bezirks Potsdam Probleme. 
Dokument 26: Siebter Bericht des Vorsitzenden der Bezirkskommission, Curt Wach, ,über den Stand der Durchführung der Verwaltungsreform im Bezirk Potsdam“, 11. August 1952

Curt Wach berichtet von der konstituierenden Sitzung des Bezirkstags in Potsdam, die ,reibungslos“verlaufen sei, von der ersten Sitzung des „Bezirksrats“ sowie von weiteren Sitzungen und Schulungen. Neben Fragen, die die Ernte betrafen, habe die Vermittlung der „Verwaltungsreform" im Mittelpunkt gestanden.

Dokument 27: Sitzungsprotokoll der Bezirkskommission Potsdam, 11. August 1952 Die Bezirkskommission sucht angesichts der anhaltenden Gebäudeprobleme nach Möglichkeiten, bei Baubetrieben im Bezirk Baracken zu erwerben.

Dokument 28: Achter Bericht des Vorsitzenden des Rates des Bezirkes Potsdam, Curt Wach, ,über den Stand der Durchführung der Verwaltungsreform im Bezirk Potsdam", 14. August 1952

Curt Wach berichtet, dass sich die Bereitstellung von Dienstbaracken durch eigene Anstrengungen „,im Lande Brandenburg“ verbessert habe. Die inzwischen vorliegenden Stellenpläne machten indes deutlich, dass der Bedarf an Arbeitsplätzen deutlich höher sei. Es sei weiterhin schwierig, ,die bisherigen Angestellten der Landesregierung zu bewegen, von den alten Arbeitsmethoden abzukommen".

Dokument 29: Stenografisches Protokoll der ersten Besprechung Otto Grotewohls und Werner Eggeraths mit den Vorsitzenden und Sekretären der Räte der Bezirke, 15. August 1952 (Auszug)

Die Referate von Werner Eggerath und Otto Grotewohl spiegeln die Perspektive der zentralen Regierungsinstanzen wider, dass die bestehenden Probleme der „weiteren Demokratisierung“ nun in ersten Linie von den Bezirks- und Kreisfunktionären durch die „Mobilisierung örtlicher Reserven“ gelöst werden müssten. Demgegenüber belegt die weitgehend ungefilterte Diskussion der anwesenden regionalen Staatsfunktionäre die große Diskrepanz zwischen der behaupteten Folgerichtigkeit der Bezirksbildung und der tatsächlich chaotisch verlaufenden ,,Verwaltungsreform“.

Dokument 30: Direktive der Koordinierungs- und Kontrollstelle für die Arbeit der Verwaltungsorgane, ,zur Durchführung des Gesetzes über die weitere Demokratisierung des Aufbaus und der Arbeitsweise der staatlichen Organe in den Ländern der Deutschen Demokratischen Republik vom 23.7.1952“, 16. August 1952

Die Direktive schreibt einen zum Teil überholten Zeitplan vor, nach dem bis zum 30. September 1952 „alle Maßnahmen zur weiteren Demokratisierung des Staatsapparates“ abgeschlossen sein müssten. Die damit verbundenen Maßnahmen beinhalten weitere umfassende Aufgaben für die Bezirks- und Kreisfunktionäre und bekräftigen, dass die Mitglieder des Ministerrats der DDR „für die Reorganisation ihres Fachgebietes voll verantwortlich“ seien. 
Dokument 31: Neunter Bericht des Vorsitzenden des Rates des Bezirkes Potsdam über die Durchführung der Verwaltungsreform im Bezirk Potsdam, 18. August 1952 (Auszug)

Der Bericht schildert umfangreiche Maßnahmen zur Kartoffelrodung und zur Beseitigung von Unwetterschäden in den Kreisen sowie eine Kampagne zum „Nachtdrusch“ zur Gewinnung zusätzlichen Getreides.

Dokument 32: Zehnter Bericht des Vorsitzenden des Rates des Bezirkes Potsdam über die Durchführung der Verwaltungsreform im Bezirk Potsdam, 21. August 1952 (Auszug)

Der Bericht schildert den weiteren Verlauf der Kampagnen zur Einbringung der Ernte und zur Behebung von Unwetterschäden. Zudem wird auf die „ernste Lage“ bei der Treibstoffversorgung hingewiesen.

Dokument 33: Bericht der Abteilung Information des Rates des Bezirkes Potsdam, 21. August 1952

Der Bericht beschreibt die propagandistischen Anstrengungen im Bezirk, mit denen die neuen Verwaltungsorgane und vorbildliche Staatsfunktionäre ,popularisiert“ werden sollen.

Dokument 34: Elfter Bericht des Vorsitzenden des Rates des Bezirkes Potsdam über die Durchführung der Verwaltungsreform im Bezirk Potsdam, 23. August 1952 (Auszug)

Der Bericht schildert erfolgreiche Bemühungen zur Versorgung der Bevölkerung mit Kartoffeln, kritisiert aber auch die willkürliche Einbestellung regionaler Funktionäre nach Berlin, wodurch die Arbeit im Bezirk behindert werde.

Dokument 35: Schreiben der Koordinierungs- und Kontrollstelle für die Arbeit der Verwaltungsorgane an den Vorsitzenden des Rates des Bezirkes Potsdam zur „Auflösung der Bezirks- und Kreiskommissionen“, 27. August 1952

Die zuständige Regierungskommission hat beschlossen, die Bezirks- und Kreiskommissionen sofort aufzulösen und deren Aufgaben den neuen Organen zu überantworten.

Dokument 36: Zwölfter Bericht des Vorsitzenden des Rates des Bezirkes Potsdam über die Durchführung der Verwaltungsreform im Bezirk Potsdam, 27. August 1952 (Auszug)

Der Bericht schildert die Probleme bei der Verwaltungsreform in den Kreisen, die etwa auf der Vernachlässigung des verbindlichen Stellenplans beruhten, und beschreibt die Maßnahmen, die vom Rat des Bezirkes Potsdam unternommen würden. Des Weiteren würden die Prämien für Gemeinden, die ihr Ablieferungssoll für landwirtschaftliche Erzeugnisse erfüllten, häufig zu formal und wettbewerbshemmend verteilt. 
Dokument 37: Dreizehnter Bericht des Vorsitzenden des Rates des Bezirkes Potsdam über die Durchführung der Verwaltungsreform im Bezirk Potsdam, 30. August 1952 (Auszug)

Der Bericht skizziert die weiterhin bestehenden Schwierigkeiten bei der Besetzung der Kreistage und Räte der Kreise. Der Rat des Bezirkes Potsdam habe sich außerdem angesichts mangelhafter Ernteerträge entschlossen, in eine ausgewählte Maschinenausleihstation eine Kontrollbrigade zu senden, deren Erkenntnisse dann ,im gesamten Bezirk ein Veränderung“ herbeiführen sollten.

Dokument 38: Protokoll der ersten Tagung des provisorischen Bezirksvorstandes des Bezirksausschusses Cottbus der Nationalen Front des demokratischen Deutschland, 30. August 1952 (Auszug)

Der Bezirksvorstand betont, dass die Propagierung der neuesten Note der sowjetischen Regierung „zu einer breiten, anhaltenden Aufklärungsarbeit in den nächsten Wochen und Monaten“ führen müsse. Dafür liege die Hauptlast ,auf den Schultern der mittleren Funktionäre“. Außerdem sei angesichts der Notwendigkeit, trotz der Bildung der Streitkräfte den Fünfjahrplan zu erfüllen, der „Mobilisierung der örtlichen Reserven“ größere Aufmerksamkeit zu schenken.

Dokument 39: Schreiben der Koordinierungs- und Kontrollstelle für die Arbeit der Verwaltungsorgane an den Vorsitzenden des Rates des Bezirkes Potsdam, 2. September 1952 (Auszug)

Die Koordinierungs- und Kontrollstelle ermahnt den Rat des Bezirkes Potsdam, alle Planstellen rasch zu besetzen, die Kreise wirksamer anzuleiten sowie Vertragsgerichte einzurichten, die den „Fehlern, Mängeln und Schwächen im Ablauf des wirtschaftlichen Lebens“ entgegenwirken müssten.

Dokument 40: Vierzehnter Bericht des Vorsitzenden des Rates des Bezirkes Potsdam über die Durchführung der Verwaltungsreform im Bezirk Potsdam, 8. September 1952

Der Bericht meldet die Konstituierung sämtlicher Kreistage im Bezirk Potsdam sowie eine erfolgreiche Schulung der Abgeordnete des Bezirkstages. Zudem werden Mitarbeitern der Koordinierungs- und Kontrollstelle ,große Unklarheiten“ bei der Instruktion der Bezirksfunktionäre vorgeworfen. Die mangelnde Bereitstellung von Dienstgebäuden hemme weiterhin „die Arbeit der Kreise“.

Dokument 41: Beschluss des Ministerrats der DDR über die „Aufstellung der Haushalte der Bezirke“ für das Jahr 1952, 12. September 1952

Der Beschluss listet die Einnahmen und Ausgaben sämtlicher Bezirke (ohne Ost-Berlin) für die Monate September bis Dezember 1952 auf und mahnt an, die ,,von der Staatlichen Stellenplankommission festgelegten Lohn- und Gehaltsfonds“ einzuhalten. 
Dokument 42: Fünfzehnter Bericht des Vorsitzenden des Rates des Bezirkes Potsdam über die Durchführung der Verwaltungsreform im Bezirk Potsdam, 14. September 1952 (Auszug)

Der Bericht schildert die Bemühungen des Rates des Bezirkes Potsdam, „die Erfassung von Kartoffeln zu beschleunigen" und die Kreise besser anzuleiten. Die Schulung der Haus- und Straßenvertrauensleute sei erfolgreich, da sie nun erst erführen, „was ihre Aufgaben sind“. Die neuen Methoden setzten sich bei den Staatsfunktionären nur langsam durch, und man bitte für die Behebung von Unwetterschäden erneut um „Unterstützung von Seiten der Regierung der DDR“.

Dokument 43: „Stellenplanbesetzung“ des Rates des Bezirkes Potsdam, 16. September 1952

Die tabellarische Aufstellung weist 30 unbesetzte Stellen in den Abteilungen des Rates des Bezirkes Potsdam auf, zugleich aber auch 22 Stellen über dem Plansoll von 53 Stellen beim technischen Personal.

Dokument 44: Bericht der Abteilung Staatliche Organe der Bezirksleitung der SED Potsdam ,über die Arbeit des Rates des Bezirks Potsdam“, 18. September 1952

Der sehr ausführliche Bericht analysiert detailliert die Arbeit der Staatsfunktionäre auf Bezirksund Kreisebene im Bezirk Potsdam. Dabei wird u. a. die unterschiedliche Auslastung der Stellenpläne kritisiert und eine regelmäßige Durchführung von Arbeitsbesprechungen angemahnt.

Dokument 45: Protokoll einer Besprechung, „über die Abgabe des Vermögens der ehemaligen Landesregierung Brandenburg“", 19. September 1952

Es werden rechtliche und finanzielle Folgen der Gebäudeübertragung an den Rat des Bezirkes Potsdam erörtert. Insbesondere der Komplex Heinrich-Mann-Allee 103 erfordere eine personalintensive Verwaltung, die bisher nicht langfristig gewährleistet sei.

Dokument 46: Thesen aus ,dem Referat des Herrn Staatssekretärs Eggerath auf der Konferenz der Vorsitzenden und Sekretäre der Räte der Bezirke“" in Potsdam, 23. September 1952

Werner Eggerath skizziert die nächsten Aufgaben der Räte der Bezirke. Er fordert eine ,allseitige Verbesserung der Arbeitsweise“ und bekräftigt die Schlüsselstellung des Sekretärs als „,das organisatorische Zentrum für die Arbeit des Rates“. Insgesamt erwartet er ein wachsendes Arbeitspensum von den Staatsfunktionären. Sie sollten ,zur selbständigen Arbeit“ erzogen werden und zugleich empfänglicher für verbindliche Vorgaben werden.

\section{Dokument 47: Arbeitsbericht der Abteilung Kader beim Rat des Bezirkes Potsdam} für das III. Quartal 1952, 3. Oktober 1952 (Auszug)

Der Bericht beschreibt die Aufgaben der Abteilung Kader im unmittelbaren Umfeld der Bezirksbildung zwischen Juli und September 1952. Als wesentliches Feld habe sich „Anleitung der Kaderleiter der Kreise“ erwiesen, um Tendenzen zu unterbinden, „den neuen Kreisen nur 
zweitrangige Kräfte zu vermitteln“. Die statistische Auswertung zeige u. a. zu niedrige Anteile von Frauen und Jugendlichen bei den Angestellten des Rates des Bezirkes.

Dokument 48: Bericht des Sekretärs des Rates des Bezirkes Cottbus ,über die weitere Demokratisierung des Aufbaus und der Arbeitsweise der Organe der Staatsmacht im Bezirk Cottbus“, 14. Oktober 1952 (Auszug)

Der Sekretär beurteilt in seinem umfangreichen Bericht die administrative Umgestaltung im Bezirk Cottbus rückblickend als insgesamt erfolgreich, auch wenn etwa bei der Besetzung der Abteilungsleiterstellen im Bezirk und in den Kreisen ,ernste Schwächen“ aufgetreten seien. Die personelle Zusammensetzung der inzwischen aufgelösten Bezirkskommission sei unbeständig gewesen, sodass ihre Arbeit ,völlig ungenügend gewesen“ sei.

Dokument 49: Schreiben der Koordinierungs- und Kontrollstelle für die Arbeit der Verwaltungsorgane an den Vorsitzenden des Rates des Bezirkes Potsdam über die „Verteilung der Geschäfte bei den Räten der Kreise“, 17. Oktober 1952

Da in den Kreisen des Bezirkes Dresden ,den Abteilungsleitern z. T. abteilungsfremde Sachgebiete unterstellt“ worden seien, listet das Schreiben ,die Abteilungen, selbständigen Referate und selbständigen Sachgebiete bei den Räten der Kreise" auf.

Dokument 50: Vorlesung des stellvertretender Leiter der Abteilung staatliche Verwaltung des Zentralkomitees der SED, Willi Barth, an der Parteihochschule „Karl Marx“", 21. Oktober 1952 (Auszug)

Willi Barth liefert eine ausführliche Begründung für die abgeschlossene Bildung der Bezirke, deren Einteilung wie im Fall Cottbus ,,vornehmlich nach ökonomischen Gesichtspunkten“" vorgenommen worden sei. Neuartige Einrichtungen wie die ständigen Kommissionen, der Sekretär des Rates oder die „doppelte Unterstellung“ der regionalen Verwaltung hätten eine übergeordnete Bedeutung auch im Hinblick auf die Systemkonkurrenz. Die „Demokratisierung des Staatsapparates“ trage daher zum „Anwachsen der nationalen Befreiungsbewegung im Westen" Deutschlands bei.

Dokument 51: Bericht der Abteilung Leitende Organe der Partei und der Massenorganisationen des Zentralkomitees der SED über die LDP, 26. Januar 1953

Der Bericht konstatiert für die LDP ,eine zunehmende Verschärfung der Widersprüche in ihren Reihen“. Ihre „fortschrittlichen Kräfte“ müssten unterstützt werden, ohne dass eine „Verwischung des Charakters der LDP als bürgerliche Partei“ erfolge. Eine rückläufige Mitgliederentwicklung zeige eine „Interessenlosigkeit“ in der LDP, und die Arbeit von LDP-Mitglieder in den Staatsorganen sei „mit wenigen Ausnahmen sehr formal“. 
Dokument 52: „Rahmen-Qualifizierungsmerkmale für die Mitarbeiter der Plankommissionen der Räte der Bezirke“ des Ministeriums des Innern der DDR, 1. Februar 1953

Die Vorschrift des Ministeriums des Innern umreißt die Aufgaben der Plankommission bei den Räten der Bezirke und leitet daraus differenzierte Qualifizierungsmaßnahmen für die einzelnen Funktionsträger ab.

\section{Dokument 53: Statistische Übersicht der Kaderabteilung des Rates des Bezirkes Frankfurt (Oder) über die Beschäftigtenstruktur der Bezirksverwaltung Frankfurt (Oder), 2. April 1953}

Die Übersicht schlüsselt die Staatsfunktionäre des Rates des Bezirkes Frankfurt (Oder) u. a. nach sozialer Herkunft, Alter, Geschlecht, Bildungsstand, Parteizugehörigkeit auf. Es wird eine Zunahme politisch zuverlässiger Mitarbeiter registriert, aber auch „ernste Mängel und Schwächen“ bei der Stellenplandisziplin. Die Zusammenarbeit mit den Mitgliedern des Rates des Bezirkes hänge stark von persönlichen Faktoren ab, werde aber auch davon beeinflusst, dass sich der Vorsitzende des Rates „noch viel zu viel mit Aufgaben beschäftigt, die eigentlich seine Stellvertreter zu machen hätten“.

Dokument 54: Beschluss des Büros der Bezirksleitung der SED Potsdam ,über die Massenarbeit in der Woche vom 24.6. bis 29.6.1954“, 1. Juli 1954 (Auszug)

Der Beschluss resümiert die bisherigen Kampagnen gegen die in Westeuropa geplante „Europäische Verteidigungsgemeinschaft" im Bezirk Potsdam und leitet daraus zukünftige Propagandamaßnahmen ab. Es sei bisher nicht gelungen, ,das Bündnis der Arbeiter mit den werktätigen Bauern in jeder Hinsicht fest und unerschütterlich zu machen“. Jugendversammlungen wie auch „Klein- und Kleinstversammlungen“ seien jedoch erfolgreich.

Dokument 55: Einschätzung der Arbeit der Organisations-Instrukteur-Abteilungen im Bezirk Cottbus durch das Ministerium des Innern der DDR, 9. November 1954 (Auszug)

Der umfangreiche Bericht sieht die Org.-Instrukteur-Abteilungen im Bezirk Cottbus ,in der Mehrzahl voll arbeitsfähig“, stellt aber ,,in fast allen Kreisen des Bezirkes“ eine ,übermäßige Fluktuation“ der Mitarbeiter fest. Ein Mangel sei, dass die Instrukteure meistens nur mündlich über ihre Arbeit berichteten. Auch hätten sich die Org.-Instrukteur-Abteilungen bisher kaum „für die Erfüllung des Volkswirtschaftsplanes“ eingesetzt, etwa ,indem sie durch eine wesentliche Verbesserung der politischen Massenarbeit die Aktivität der Werktätigen förderten“.

Dokument 56: Rede des Vorsitzenden des Rates des Bezirkes Rostock, Hans Warnke, auf der 21. Tagung des Zentralkomitees der SED, 13. November 1954 (Auszug)

Hans Warnke fasst vor dem ZK der SED seine bisherigen Erfahrungen als Vorsitzender des Rates des Bezirkes Rostock zusammen. Vor allem die willkürlichen Interventionen der Ministerien seien ein großes Problem. Die „doppelte Unterstellung“ führe dazu, dass Ministerien die Abteilungen des Rates des Bezirkes „,nach wie vor als nachgeordnete Dienststellen“ betrachteten. 
Zugleich sei eine starke Arbeitsüberlastung der Staatsfunktionäre in den Bezirken und Kreisen festzustellen. Es sollte geprüft werden, ob die Schwierigkeiten nicht durch ,eine tiefgreifende Änderung der Struktur“ der betreffenden Organe sowie durch eine personelle Verstärkung der Gemeinden behoben werden könnten.

Dokument 57: Schreiben des Vorsitzenden des Rates des Bezirkes Potsdam, Josef Stadler, an das Staatssekretariat für Innere Angelegenheiten beim Ministerium des Innern der DDR über die „Einschätzung der bisherigen Erfahrungen der Arbeit der Bevollmächtigten und Instrukteure“", 2. Juni 1955 (Auszug)

Josef Stadler berichtet über die Arbeit der politischen Instrukteure in den überwiegend landwirtschaftlich geprägten Kreisen des Bezirkes Potsdam. Wichtig für den Erfolg sei, dass die Instrukteure „einen genauen Überblick über die Struktur ihrer Gemeinden“ hätten. Die Werbung „werktätiger Einzelbauern“ für den Eintritt in eine Landwirtschaftliche Produktionsgenossenschaft sei insgesamt schwierig.

Dokument 58: Protokoll einer „,Sitzung der Arbeitsgruppe Strukturfragen örtliche staatliche Organe“6, 23. Juli 1957 (Auszug)

Die Arbeitsgruppe erörtert Möglichkeiten der „Veränderung der Arbeitsweise und Struktur der örtlichen Organe der staatlichen Verwaltung“. Neben der Klärung der Aufgabenverteilung zwischen dem Vorsitzenden des Rates und seinem Stellvertreter sowie der Existenzberechtigung der „Kontrollstellen bei den Vorsitzenden der Räte der Bezirke und Kreise“ werden die Funktion neu einzurichtender Wirtschaftskommissionen sowie eine stärkere Einbeziehung von Mitgliedern der Blockparteien bei der Stellenbesetzung behandelt.

Dokument 59: Beschlussvorlage der Hauptabteilung für Angelegenheiten der örtlichen Räte des Ministeriums des Innern für das Politbüro des Zentralkomitees der SED ,über die Aufgaben und die Struktur der Plankommissionen bei den Räten der Kreise“, 12. Dezember 1957

Die Beschlussvorlage bestimmt detailliert die Zusammensetzung und Aufgabenstellung der Plankommissionen auf Kreisebene. Neben die „Ausarbeitung von Entwicklungsprogrammen“ sowie „Perspektiv- und Jahresvolkswirtschaftsplänen“ tritt u. a. die „operative Kontrolle der Planerfüllung in Zusammenarbeit mit den Fachorganen der Räte der Kreise“ sowie die „Unterstützung der Räte der Städte und Gemeinden bei der Aufstellung und Durchführung der Stadtund Dorfpläne“.

Dokument 60: Analyse der Hauptabteilung für Angelegenheiten der örtlichen Räte des Ministeriums des Innern ,über die Kadersituation im Jahre 1958“،, 9. März 1959

Die umfangreiche statistische Analyse stellt die Personalveränderungen in den Bezirken denjenigen auf der zentralen Regierungsebene der DDR gegenüber. Sowohl die Bildung einer „Kaderreserve“ als auch die „politische und fachliche Qualifikation“ der Staatsfunktionäre seien noch immer unbefriedigend, auch wenn in beiden Bereichen Erfolge erzielt würden. Insgesamt müsse man sich in den Bezirken weiter auf die „Überwindung des bürgerlichen Einflusses im 
Staatsapparat durch eine konsequente und systematische klassenmäßige Stärkung in den Organen der Staatsmacht" konzentrieren.

Dokument 61: Auswertung einer Beratung Otto Grotewohls mit den Vorsitzenden der Räte der Bezirke bei einer Dienstbesprechung von Ratsmitgliedern und Abteilungsleitern des Rates des Bezirkes Potsdam, 19. Juli 1960

Die Auswertung paraphrasiert Äußerungen Otto Grotewohls, der auf der Beratung die Arbeit der Staatsorgane insgesamt ,sehr kritisch“ eingeschätzt habe. Noch immer würde ängstlich vermieden, „die Beschlüsse der Partei auf die Staatspraxis“ umzuformulieren. Es hätte nun aber eine neue Phase begonnen, in der „die Diktatur des Proletariats offen und klar durchgesetzt werden" müsste.

Dokument 62: „Hinweise“ der SED-Bezirksleitung Potsdam für ein „Seminar mit den Bürgermeistern und Parteisekretären“ aus den „Randorten“ des Bezirkes Potsdam, 26. November 1960

Die Hinweise formulieren inhaltliche Vorgaben für die politische Schulung kommunaler Staatsund Parteifunktionäre aus den an West-Berlin grenzenden Gemeinden des Bezirkes Potsdam. Zentral sei, den Funktionären zu vermitteln, ,wie eine höhere Qualität in der Arbeit der Organe der Staatsmacht erreicht werden“ könne. Um dies zu erreichen, müsse jeder Schritt ,in engster Verbindung mit den Werktätigen“" erfolgen. 


\section{Dokumente 1952-1960}

\section{Dokument 1: Berichtigter Beschluss des Politbüros der SED über die „,Verbesserung der Arbeit des Staatsapparates“, 28. März 1952 225}

1) Beim Ministerrat wird der Stellvertreter des Ministerpräsidenten, Genosse Rau, als Mitglied des Politbüros verantwortlich gemacht für die Koordinierung und die Kontrolle der Durchführung der Beschlüsse durch die wirtschaftlichen Ministerien. ${ }^{226}$ Genosse Rau ist persönlich verantwortlich für Industrie und Verkehr. Ein Hauptabteilungsleiter ist verantwortlich für Landwirtschaft, ein Hauptabteilungsleiter ist verantwortlich für Außenhandel, Innenhandel und Handel und Versorgung. $\mathrm{Zu}$ diesem Zweck wird ein besonderer Apparat gebildet, der dem Genossen Rau untersteht.

2) Für die Koordinierung und Kontrolle der Durchführung der Beschlüsse auf dem Gebiete der Wissenschaft, der Volksbildung und der Kunst wird beim Ministerrat Minister Wandel verantwortlich gemacht. ${ }^{227}$

3) Es wird ein Staatssekretär beim Ministerrat eingesetzt, der die Landesregierungen, Kreisräte und sonstige kommunale Behörden anleiten und kontrollieren soll. ${ }^{228}$ Die Abteilung innere Verwaltung beim Innenministerium wird aufgelöst.

4) Diese Genossen unterstehen parteimäßig direkt dem Politbüro und werden von ihren jetzigen Staatsfunktionen freigestellt.

5) Beim Zentralkomitee wird eine außenpolitische Abteilung geschaffen.

6) Das Sekretariat wird beauftragt, dem Politbüro Vorschläge zu machen für einen Staatssekretär für die Anleitung der Staatsorgane in den Ländern und Kreisen und für einen Staatssekretär für Volksbildung.

[BArch, DY 30/IV 2/2/204, Bl. 12]

225 Berichterstatter des Beschlusses war Walter Ulbricht (1893-1973), seit Oktober 1949 stellvertretender Ministerpräsident der DDR und seit Juli 1950 Generalsekretär der SED; vgl. Müller-Enbergs, Wer war wer, S. 868, sowie grundsätzlich Frank, Ulbricht.

226 Heinrich Rau (1899-1961) war seit 1950 Vorsitzender der Staatlichen Plankommission; vgl. Müller-Enbergs, Wer war wer, S. 682.

227 Paul Wandel (1905-1995) war seit Oktober 1949 Minister für Volksbildung, vgl. Müller-Enbergs, Wer war wer, S. 887.

228 Staatssekretär in der neu geschaffenen „Koordinierungs- und Kontrollstelle für die Arbeit der Verwaltungsorgane beim Ministerpräsidenten der DDR“"wurde Werner Eggerath (1900-1977), zu diesem Zeitpunkt Ministerpräsident des Landes Thüringen; vgl. Niemann/Herbst, SED-Kader, S. 162. 


\section{Dokument 2: Beschlussvorlage für das Sekretariat des Zentralkomitees der SED über „Maßnahmen zur Änderung der staatlichen Struktur der Deutschen Demokra- tischen Republik“6, 24. April 1952}

Die staatlichen Organe haben in zunehmendem Maße ihre Arbeitsweise verbessert. Die Anwendung neuer Arbeitsmethoden trug wesentlich zur Entfaltung des demokratischen Lebens bei und festigte die Verbundenheit insbesondere der örtlichen Organe des Staates mit der Bevölkerung zur gemeinsamen Lösung der staatlichen Aufgaben.

Trotz der Erfolge darf nicht übersehen werden, dass die Leistungen der staatlichen Organe mit der stürmischen Initiative der Bevölkerung in der Lösung der Aufgaben nicht Schritt halten. Es hat sich gezeigt, dass breiteste Kreise der Bevölkerung durchaus Verständnis für die Schwierigkeiten zeigen, die die staatlichen Organe insbesonders bei der Erfüllung der Wirtschaftspläne zu überwinden haben. Die Bevölkerung hat aber kein Verständnis für den noch tief eingewurzelten Bürokratismus in vielen staatlichen Organen. Gerade im Kampf um die Überwindung der Schwierigkeiten fordert die Bevölkerung insbesondere in den Städten und Gemeinden, dass sie mitarbeiten darf, dass sie herangezogen wird zu der Lösung der staatlichen Aufgaben. Die Bevölkerung hat in vielen Kreisen, Städten und Gemeinden insbesondere bei der Ausarbeitung und der Erfüllung der Pläne der Kreise und Gemeinden ihre Schöpferkraft bewiesen. Es gilt, diese Initiative, die Schöpferkraft der Bevölkerung schneller zu entfalten und für den wirtschaftlichen Aufbau einzusetzen.

Das aber erfordert nicht nur in den Großstädten, sondern im gesamten Gebiet der Deutschen Demokratischen Republik eine noch engere Bindung in der Zusammenarbeit zwischen den staatlichen Organen und der Bevölkerung, um so den staatlichen Organen und ihren Mitarbeitern besser zu ermöglichen, den Arbeitsablauf ständig zu überprüfen, mit den Produktionsstätten der Bevölkerung in engster Verbindung zu stehen und um insbesonders aufmerksam die Beschwerden und Vorschläge der Bevölkerung zu beachten, aus denen sich die wertvollsten Anregungen für die Verbesserung der Arbeitsweise der staatlichen Organe ergeben.

Die weitere und schnellere Entfaltung dieses demokratischen Lebens wird jedoch in der gegenwärtigen Periode unserer Entwicklung durch die bestehende gebietliche staatliche Struktur behindert. Die Überwindung dieser alten feudalen Gliederung, die Schaffung einer staatlichen Struktur entsprechend der heutigen politischen und wirtschaftlichen Entwicklung ist deshalb eine Forderung der Bevölkerung an den Staatsapparat.

Zur Beseitigung dieser Hemmungen der weiteren Demokratisierung und damit des schnelleren wirtschaftlichen Aufschwungs ist es erforderlich, anstelle der bisherigen fünf Länderorgane 13 auf Landesbasis gegliederte demokratische Bezirksorgane zu schaffen und eine weitere Aufgliederung von insbesondere großen Kreisgebieten herbeizuführen. Dabei ist darauf zu achten, dass die Grenzen der Bezirke und Kreise entsprechend den politischen, wirtschaftlichen und verkehrstechnischen Zweckmäßigkeiten festgelegt werden. 
Deshalb wird vorgeschlagen:

1.) Das Gebiet der Deutschen Demokratischen Republik wird der Gliederung nach Ländern entsprechend in folgende Bezirke aufgeteilt:
1. Bezirk Sachsen-Dresden
20 Kreise
1169 Gemeinden
2. Bezirk Sachsen-Chemnitz
22 Kreise
613 Gemeinden
3. Bezirk Sachsen-Leipzig
12 Kreise
670 Gemeinden
4. Bezirk Sachsen-Anhalt-Halle
20 Kreise
813 Gemeinden
5. Bezirk Sachsen-Anhalt-Magdeburg
20 Kreise
911 Gemeinden
6. Bezirk Thüringen-Erfurt
17 Kreise
1013 Gemeinden
7. Bezirk Thüringen-Gera
13 Kreise
777 Gemeinden
8. Bezirk Brandenburg-Potsdam
12 Kreise
739 Gemeinden
9. Bezirk Brandenburg-Frankfurt
14 Kreise
755 Gemeinden
10. Bezirk Brandenburg-Oranienburg 229
8 Kreise
425 Gemeinden
11. Bezirk Mecklenburg-Schwerin
15 Kreise
771 Gemeinden
12. Bezirk Mecklenburg-Rostock
9 Kreise
403 Gemeinden
13. Bezirk Mecklenburg-Neubrandenburg
13 Kreise
624 Gemeinden

Diese Bezirksgliederung baut sich auf eine enge Verbundenheit der historischen Entwicklung dieser Gebiete mit den neu entstandenen politischen, wirtschaftlichen und verkehrstechnischen Gegebenheiten auf.

2.) Die Ausarbeitung einer genauen Abgrenzung dieser vorgeschlagenen Bezirke und Kreise erfolgt durch eine zentrale Kommission, bestehend aus:
Genossen Anton Plenikowski, ${ }^{230}$
Genossen Hans Warnke, ${ }^{231}$
Genossen Werner Eggerath, ${ }^{232}$
Genossen Ernst Lange, ${ }^{233}$
Genossen Klaus Sorgenicht. ${ }^{234}$

229 Anstelle eines Bezirks Oranienburg wurde im Süden Brandenburgs der neue Bezirk Cottbus gebildet, der auch erhebliche Teile Sachsens und Sachsen-Anhalts umfasste; vgl. Mielke, Auflösung, S. 73.

230 Anton Plenikowski (1899-1971) war seit 1946 Leiter der Abteilung Staatliche Verwaltung beim ZK der SED; vgl. Müller-Enbergs, Wer war wer, S. 663.

231 Hans Warnke (1896-1984) war seit Oktober 1949 Staatssekretär im Ministerium des Innern der DDR und wurde im August 1952 Vorsitzender des Rates des Bezirkes Rostock; vgl. Niemann/ Herbst, SED-Kader, S. 505.

$232 \mathrm{Zu}$ Werner Eggerath vgl. Dok. 1, Anm. 228.

233 Ernst Lange (1905-1971) war seit 1948 stellvertretender Vorsitzender der Zentralen Kommission für Staatliche Kontrolle beim Ministerrat der DDR; vgl. Müller-Enbergs, Wer war wer, S. 500.

234 Klaus Sorgenicht (1923-1999) war seit 1951 Hauptabteilungsleiter im Ministerium des Innern der DDR; vgl. Müller-Enbergs, Wer war wer, S. 807. 
Diese Kommission wird beauftragt, die Abgrenzung der Bezirke und Kreise in Besprechungen mit dem Minister des Innern des Landes ${ }^{235}$ und dem 2. Landessekretär ${ }^{236}$ festzulegen.

$\mathrm{Zu}$ diesen Besprechungen sind jeweils für die bestimmten Bezirke und Kreise die Genossen Landräte (die Genossen Stellvertreter der Landräte, soweit Landräte nicht der Partei angehören) sowie die 2. Kreissekretäre hinzuzuziehen.

Die Besprechungen sind so durchzuführen, dass der Plan der Gliederung am 2. Mai vorliegt.

3.) Nach Festlegung der bezirklichen Aufgliederung und Festlegung der Kreise wird für jeden Bezirk eine Arbeitskommission gebildet. Die Zusammensetzung dieser Kommission bestimmt die zentrale Kommission nach Rücksprache mit dem Minister des Innern des Landes und dem 2. Landessekretär.

Diese Kommission legt genau die Bezirks- und Kreisgrenzen fest.

4.) Die zentrale Kommission arbeitet den Struktur- und Stellenplan für die Bezirke und Kreise aus.

Unter Mitwirkung des Genossen Glaser als Leiter der Abteilung Leitende Parteiorgane wird ein genauer Plan über die Verwendung der bisherigen leitenden Funktionäre der Landesregierungen ausgearbeitet sowie ein Plan über die Besetzung der leitenden Funktionen des Partei- und Staatsapparates in den Bezirken.

Bei den Bezirkskommissionen wird in gleicher Weise eine Kaderkommission einen Plan über die Besetzung der leitenden Funktionen des Partei- und Staatsapparates in den Kreisgebieten des Bezirkes ausarbeiten.

Die Pläne sind bis zum 15. Mai dem Sekretariat vorzulegen.

5.) Eine besondere Kommission unter der verantwortlichen Leitung des Genossen Ernst Lange wird unmittelbar die durch diese Maßnahme freiwerdenden Gebäude der Landesregierungen in den bisherigen Landeshauptstädten feststellen. Vom Ministerium des Innern der Republik wird der Genosse Danneberg dieser Kommission angehören. Diese Kommission fährt in jede Landeshauptstadt und sorgt nach Rücksprache mit dem Minister des Innern dafür, dass diese Gebäude der einheitlichen zentralen Verwendung zur Verfügung stehen.

Diese Maßnahme erfolgt nach Festlegung der Struktur der Bezirke und Kreise.

6.) Die durch diese Maßnahme erforderliche Struktur der staatlichen Organe darf nicht zu einer Erhöhung der Stellenpläne der staatlichen Organe der Bezirke und Kreise gegenüber den bisherigen Stellenplänen der Länder und Kreise führen. Durch Maßnahmen

235 Minister des Innern im Land Brandenburg war seit 1949 Bruno Lentzsch (1903-1972); vgl. MüllerEnbergs, Wer war wer, S. 507.

236 2. Landessekretär der SED in Brandenburg war seit 1947 Kurt Seibt (1908-2002); vgl. Niemann/ Herbst, SED-Kader, S. 454. 
zur weiteren Demokratisierung muss erreicht werden, dass gegenüber dem bisherigen Stellenplan weitere Einsparungen von Stellen schon in diesem Jahre erzielt werden.

7.) Die Bezeichnung der örtlichen staatlichen Organe wird wie folgt festgelegt:
1. für den Bezirk
a) Bezirkstag
2. für den Kreis
b) Rat des Bezirkes
3. für die Stadt
a) Kreistag
b) Rat des Kreises
3. für die Stadt a) Stadtverordnetenversammlung
b) Rat der Stadt
4. für die Gemeinde
a) Gemeindevertretung
b) Rat der Gemeinde

8.) Der Termin für die Neuwahl der Bezirks- und Kreisorgane wird noch festgelegt.

Die Bezirkstage und Kreistage setzen sich aus den Abgeordneten der Landtage und Kreistage zusammen, die ihren Wohnsitz in dem betreffenden Bezirks- bzw. Kreisgebiet haben. Dabei ist zu prüfen, inwieweit bis zur Erreichung der gesetzlich vorgesehenen Anzahl von Kreistagsabgeordneten zusätzlich Abgeordnete durch den Kreistag zu berufen sind. Die neuen Kandidaten werden durch die Blockparteien bzw. Massenorganisationen dem Kreisausschuss der Nationalen Front benannt.

Die gleiche Regelung ist bezüglich der Bezirkstage zu treffen.

Die zentrale Kommission arbeitet unter Hinzuziehung des Genossen Hans Seigewas$\operatorname{ser}^{237}$ (Nationalrat) einen Plan aus, in dem auch die Anzahl der Abgeordneten der Bezirkstage festzulegen ist.

Dieser Plan ist gleichfalls bis zum 2. Mai dem Sekretariat vorzulegen.

Mit der Aufnahme der Tätigkeit der Bezirks- und Kreistage sind von diesen nach dem Beispiel der Stadtbezirksorgane ständige Kommissionen für bestimmte Arbeitsgebiete zu berufen.

9.) Die zentrale Kommission macht bis zum 2. Mai dem Sekretariat Vorschläge über die Maßnahmen, die aus diesen Beschlüssen für den Erlass von Gesetzen erforderlich sind.

[BArch, DY 30/IV 2/13/50, sechs Bl., nicht foliiert]

237 Hans Seigewasser (1905-1979) war seit Mai 1950 stellvertretender Vorsitzender des Nationalrates der Nationalen Front; vgl. Müller-Enbergs, Wer war wer, S. 790. 
Dokument 3: Beschluss des Sekretariats des Zentralkomitees der SED zur Bildung der Bezirke und der neuen Kreise, 30. Mai 1952

1. Es wird ein zentrales Organisationskomitee zur Durchführung des Beschlusses über die Neugliederung der Bezirke und Kreise geschaffen. Die Kommission setzt sich zusammen:

Genossen Eggerath ${ }^{238}$ - Vorsitzender

Genossen Plenikowski ${ }^{239}$

einem Vertreter der Abteilung Leitende Organe der Partei und der Massenorganisation beim ZK

Genossen Hans Warnke, Staatssekretär im Innenministerium ${ }^{240}$

Genossen Fritz Lange, Vorsitzender der Staatlichen Kontrollkommission ${ }^{241}$

Genossen Willy Rumpf ${ }^{242}$

dem stellvertretenden Vorsitzenden des FDGB und

dem stellvertretenden Vorsitzenden der FDJ.

2. Der staatliche Apparat und jede Massenorganisation bildet für jeden Bezirk und jeden Kreis, dessen Grenze verändert oder der neu gebildet wird, ein Organisationskomitee.

3. In den Ländern ist eine Kommission für den Bezirk der Landeshauptstadt in ähnlicher Zusammensetzung zu bilden. Der Vorsitzende dieser Kommission ist der bisherige Ministerpräsident des Landes. Die Kommissionen für die Bezirke sind so zusammenzusetzen, dass die künftigen leitenden Funktionäre diesen Organisationskommissionen angehören. Die Bezirkskommissionen sind vom Sekretariat des Zentralkomitees zu bestätigen. Die Vorsitzenden der Kommissionen sind durch das Politbüro zu bestätigen.

4. Die zentrale Kommission beginnt ihre Arbeit sofort. Sobald die Organisationskommissionen der Bezirke zusammengesetzt sind, sind ihnen auf einer zentralen Besprechung die Richtlinien für die Arbeit zu geben.

5. Genosse Ulbricht wird beauftragt, als Stellvertreter des Ministerpräsidenten ein Schreiben an den Innenminister und an Genossen Eggerath zu richten mit den Ersuchen, die notwendigen Maßnahmen zu ergreifen, um im Interesse einer besseren Arbeit des staatlichen Apparates in den Ländern und Kreisen und der engeren Verbin-

$238 \mathrm{Zu}$ Werner Eggerath vgl. Dok. 1, Anm. 228.

$239 \mathrm{Zu}$ Anton Plenikowski vgl. Dok. 2, Anm. 230.

$240 \mathrm{Zu}$ Hans Warnke vgl. Dok. 2, Anm. 231.

241 Fritz Lange (1898-1981) war seit 1949 Vorsitzender der Zentralen Kommission für Staatliche Kontrolle beim Ministerrat der DDR; vgl. Müller-Enbergs, Wer war wer, S. 500.

242 Willy Rumpf (1903-1982) war seit 1949 Staatssekretär im Ministerium für Finanzen der DDR; vgl. Müller-Enbergs, Wer war wer, S. 721. 
dung mit der Bevölkerung die Schaffung von Bezirken und die Verkleinerung einiger Kreis durchzuführen. In drei Wochen [ist] im Block der antifaschistisch-demokratischen Parteien zu dieser Frage Stellung zu nehmen.

6. Die zentrale Kommission für Staatliche Kontrolle wird beauftragt:

a) mit Genossen Rumpf Richtlinien für die Übergangsregelung in den Fragen der Steuerabführung auszuarbeiten.

b) mit Genossen Streit ${ }^{243}$ und dem stellvertretenden Ministerpräsidenten Scholz ${ }^{244}$ Richtlinien für die Übergangsregelung in den Fragen der Ablieferung und Erfassung der landwirtschaftlichen Produkte auszuarbeiten.

c) für alle übrigen Fragen entsprechende Regelungen mit den zuständigen Ministerien vorzubereiten.

7. Die Stellenpläne für den Rat der Bezirke und den Rat der Kreise sind dem Sekretariat des ZK vorzulegen.

[BArch, NY 4090/432 (Nachlass Otto Grotewohl), Bl. 1]

Dokument 4: Protokoll einer Sitzung der Unterkommission Struktur- und Stellenpläne, 4. Juni 1952

\section{Anwesend:}

Werner Eggerath, Vorsitz ${ }^{245}$

Sorgenicht ${ }^{246}$

Manneberg 247

Geiss $^{248}$

Radelt

\section{Tagesordnung:}

1.) Aufgaben der Kommission

2.) Ausarbeitung einer Grobstruktur der Bezirke und Kreise.

243 Hermann Streit (1909-1996) war zu diesem Zeitpunkt Staatssekretär für Erfassung und Aufkauf landwirtschaftlicher Erzeugnisse im Ministerium für Handel und Versorgung der DDR; vgl. MüllerEnbergs, Wer war wer, S. 834.

244 Paul Scholz (1902-1995) war seit 1950 Minister für Land- und Forstwirtschaft der DDR; vgl. Müller-Enbergs, Wer war wer, S. 760.

$245 \mathrm{Zu}$ Werner Eggerath vgl. Dok. 1, Anm. 228.

$246 \mathrm{Zu}$ Klaus Sorgenicht vgl. Dok. 2, Anm. 234.

247 Werner Manneberg (1923-2000) war seit Februar 1952 Instrukteur der Abteilung Staatliche Organe des ZK der SED; vgl. Niemann/Herbst, SED-Kader, S. 327.

248 Willi Geiss (*1911) war zu diesem Zeitpunkt Leiter der staatlichen Stellenplankommission der DDR; vgl. Baumgartner, Biographisches Handbuch, S. 214. 
Am Anfang der Sitzung wurde festgestellt, dass in den Bezirken und Kreisen keine Unterkommissionen zu bilden sind.

\section{Zu 1.)}

Die Kommission sieht ihre Aufgabe darin, für die Bezirke und Kreise einen Struktur- und Stellenplan auszuarbeiten, der mit einem Minimum von Kräften und mit dem geringsten Kostenaufwand die höchstmöglichen Resultate erzielen muss.

Ausgangspunkt der Arbeit ist

a) die Übersicht über die Stellenpläne und Mittel der Landkreisverwaltungen (in der Anlage beigefügt) und

b) über die Stellenpläne und Mittel der Landesregierung.

\section{Zu 2.)}

\section{Grobstruktur der Bezirke}

\section{[1.] Vorsitzender}

Dem Vorsitzenden obliegt die Anleitung der gesamten Verwaltung. Zu seinem Aufgabenbereich gehören:

a) Personal und Schulung

b) Beschwerdestelle

c) Förderung der Intelligenz

d) Kontrollorgan unter besonderer Berücksichtigung von Landwirtschaft und Erfassung, sowie Auswertung örtlicher Organe.

Die Bezirke müssen zu einem anleitenden und kontrollierenden Organ gemacht werden und daher ist es zweckmäßig, dass sich der gesamte Apparat nur in Abteilungen gliedert.

\section{[2.] Abteilungen der Bezirke}

1.) Planung und Materialversorgung

2.) Land-, Forst- und Wasserwirtschaft einschließlich Erfassung

3.) Industrie - Handwerk - Verkehr einschließlich Gewerbe der Arbeit

4.) Aufbau

5.) Arbeit und Berufsausbildung einschließlich Sozialwesen

6.) Versorgung

7.) Gesundheitswesen

8.) Volksbildung

9.) Kunstangelegenheiten

10.) Innere Verwaltung
a) Archiv
b) Amt zum Schutze des Volkseigentums
c) Personenstandswesen
d) Kirchenfragen
e) Rechtsstelle

11.) Allgemeine Verwaltung 
12.) VS-Abteilung

13.) Vermessung

14.) Finanzen

15.) Information

16.) Jugendfragen und Leibesübungen

Für die Bezirke sind sechs Bezirksräte vorgesehen, denen folgende Abteilungen unterstehen:

I. Innere Verwaltung, Allgemeine Verwaltung, VS-Abteilung, Vermessung, Information, Jugend

II. Finanzen, Planung

III. Gesundheit, Arbeit und Berufsausbildung, einschließlich Sozialwesen

IV. Volksbildung, Kunstangelegenheiten

V. Industrie-Handwerk-Verkehr einschließlich Gewerbe, Aufbau

VI. Land-, Forst- und Wasserwirtschaft, Versorgung.

Die Eingruppierung der Vorsitzenden soll nach E 4, bei Halle, Magdeburg und Dresden eventuell nach E 3 erfolgen.

Die Bezirksräte sollen in die Gruppe E 6 eingestuft werden.

Der Bezirksrat der Inneren Verwaltung nach E 5.

\section{Grobstruktur der Kreise:}

\section{[1.] Landrat}

Den Landräten unterstehen folgende Abteilungen:

a) Personal und Schulung

b) Förderung der Intelligenz nur in Ausnahmefällen, d. h. dort wo sich die Schwerpunkte der Industrie befinden.

c) VS-Bearbeiter

\section{[2.] Abteilungen der Kreise}

1.) Planung und Materialversorgung

2.) Land-, Forst- und Wasserwirtschaft einschließlich Erfassung

3.) Industrie-Handwerk-Verkehr einschließlich Gewerbe

4.) Aufbau

5.) Arbeit und Berufsausbildung einschließlich Sozialwesen

6.) Versorgung

7.) Gesundheitswesen

8.) Volksbildung und Kunstangelegenheiten

9.) Innere Verwaltung

a) Allgemeine Verwaltung

b) Archiv

c) Volkseigentum

d) Personenstandswesen 
e) Rechtsstelle

f) Information

g) Jugendfragen und Leibesübungen

10.) Vermessung

11.) Finanzen

Den Kreisräten unterstehen folgende Abteilungen:

I. Innere Verwaltung, Allgemeine Verwaltung, Vermessung, Information, Jugendfragen und Leibesübungen

II. Finanzen, Planung und Materialwirtschaft

III. Gesundheit, Arbeit und Berufsausbildung, einschließlich Sozialwesen

IV. Volksbildung, Kunstangelegenheiten

V. Industrie-Handwerk-Verkehr einschl. Gewerbe, Versorgung

VI. Land-, Forst- und Wasserwirtschaft einschl. Erfassung

In kleinen Kreisen kann II. und IV. zusammengelegt werden.

Die weitere Arbeit ist folgende:

Ausarbeitung einer Feinstruktur der Bezirke und Kreise.

Der Genosse Geiss wird bis Dienstag, den 10.6.1952, die Geschäftsverteilungspläne für die Bezirke und Kreise vorlegen.

[BArch, DO 1/26099 (Ministerium des Innern), Bl. 98-100]

\section{Dokument 5: Anlage zum Protokoll einer Sitzung des Sekretariats des Zentralkomi- tees der SED, 26. Juni 1952}

Der Ministerrat erlässt folgende Richtlinien für die Personalpolitik im Staatsapparat und der volkseigenen Wirtschaft:

Das MdI wird beauftragt, allen Organen für die Durchführung dieser Richtlinien die erforderliche Anleitung zu geben und die ständige Kontrolle durchzuführen.

1. Die weitere Entwicklung und Festigung der DDR verlangt, dass alle Mitarbeiter des Staatsapparates und in der Verwaltung der volkseigenen Wirtschaft die erforderlichen Qualifikationen besitzen, um die ihnen im Rahmen des Fünfjahrplanes gestellten große Aufgaben zu erfüllen.

Voraussetzungen für die Beschäftigung als Mitarbeiter in dem Staatsapparat und in der Verwaltung der volkseigenen Wirtschaft:

Aus der besonderen Rolle des Staatsapparates bei der Verwirklichung der Ziele unserer Regierung ergibt sich, dass die Tätigkeit in dem Staatsapparat und in der Verwaltung sowie in der Leitung der volkseigenen Wirtschaft, eine gesellschaftliche Funktion und des- 
halb mit der Übernahme besonderer Verantwortung und besonderen Pflichten verbunden ist.

Allen Mitarbeitern wird zur Pflicht gemacht, ihre Arbeit auf der Grundlage unserer Verfassung und unserer demokratischen Gesetze durchzuführen. Sie sind verpflichtet, ihr demokratisches Staatsbewusstsein ständig weiter zu entwickeln. Bei jedem Mitarbeiter muss das Staatsbewusstsein darin zum Ausdruck kommen, dass er vorbehaltlos die Gesetze unserer Regierung verwirklicht, sich aktiv für die Einheit Deutschlands, für die Erhaltung des Frieden und für unverbrüchliche Freundschaft mit der Sowjetunion und den Ländern der Volksdemokratien sowie allen friedliebenden Kräften der Welt einsetzt. Sie müssen bereit sein, aktiv an der bewaffneten Verteidigung der DDR teilzunehmen. Von allen Mitarbeitern des Staatsapparates und den Verwaltungen der volkseigenen Wirtschaft wird ein einwandfreies moralische Verhalten bei der Arbeit und im persönlichen Leben, enge Verbundenheit mit der werktätigen Bevölkerung, demokratische Wachsamkeit und ständige Bemühungen um die Förderung des gesellschaftlichen Fortschritts verlang. Die Mitarbeiter müssen ständig ihre Fachkenntnisse erweitern und neue Arbeitsmethoden entwickeln, wozu jeder aus den Erfahrungen der Sowjetunion für sein Arbeitsgebiet lernen muss.

\section{Maßnahmen zur ständigen Verbesserung der Zusammensetzung der Verwaltung.}

Die Zusammensetzung unseres Staatsapparates muss die Struktur unserer Bevölkerung zum Ausdruck bringen. Daher sind Aktivisten und Betriebsarbeiter, werktätige Frauen, Jugendliche und Angehörige der fortschrittlichen Intelligenz, die moralisch und fachlich geeignet sind und sich in ihrer Arbeit und in den gesellschaftlichen Organisationen als zuverlässige Demokraten bewährt haben, stärker als bisher zu den Arbeiten der Verwaltungen heranzuziehen. Ihrer Forderung ist hierbei größte Aufmerksamkeit zu widmen. Das gilt im gleichen Umfang für die Heranziehung der Land- und Forstarbeiter und der Söhne und Töchter der werktätigen Bauern.

\section{Verantwortung für die Personalpolitik}

Die Minister und Staatssekretäre mit eigenem Geschäftsbereich und die Leiter von Dienststellen und Betrieben sind in ihrem Aufgabenbereich (einschließlich nachgeordneter Dienststellen), für die Durchführung der Personalpolitik auf der Grundlage der vorliegenden Richtlinien voll verantwortlich. Hierbei ist ihnen der Personalleiter der wichtigste Mitarbeiter, die für die richtige Anwendung dieser Richtlinien verantwortlich gemacht wird.

Die Personalpolitik ist eine ständige Aufgabe aller bewusst tätigen Mitarbeiter, insbesondere aber der leitenden Kräfte. Diese haben aus ihrer besonderen Kenntnis der Mitarbeiter, die sie durch ihre tägliche Arbeit mit ihnen gewinnen, dem Leiter der betreffenden Institution Vorschläge für neu zu besetzende Stellen zu machen, sie auf entwicklungsfähige Kräfte hinzuweisen und ihre Vorschläge für den Besuch von Verwaltungs- und Fachschulen, Kursen usw. zur Qualifizierung zu unterbreiten. 
Die Auswahl der Vorschläge zum Besuch von Lehrgängen aller Art ist mit der größten Sorgfalt vorzunehmen, wobei besonders Frauen und Jugendliche zu berücksichtigen sind. Für jeden Lehrgangsteilnehmer ist vorher die Perspektive für den Einsatz nach Absolvierung der Schule konkret festzulegen. Alle Absolventen der Lehrgänge sind in ihrer weiteren Entwicklung zu beobachten und zu fördern.

Die Hauptaufgabe in der Personalpolitik besteht darin, dass die Entwicklung aller Mitarbeiter in Zusammenarbeit mit den entsprechenden Stellen planmäßig gelenkt und beschleunigt wird. Dazu ist ein klarer Überblick über Leistungen, Fähigkeiten, Neigungen und Herkunft jedes Einzelnen erforderlich, der eine allseitige Einschätzung ermöglicht.

Diese umfassende Kenntnis über jeden Mitarbeiter muss dazu beitragen, das Eindringen von Agenten im Staatsapparat zu verhindern. Dazu gehört ferner, mit allen zu Gebot stehenden Mitteln jeden Mitarbeiter zur höchsten Wachsamkeit zu erziehen.

Die Leiter der Dienststellen sind dafür verantwortlich, dass durch eine sorgfältige Auswahl der Menschen als Mitarbeiter im Staatsapparat und der Verwaltungen, durch das richtige Kennenlernen derselben, ihren Einsatz entsprechend ihren Fähigkeiten am richtigen Arbeitsplatz, durch die konkrete Festlegung und Förderung ihrer Entwicklung, ein entschiedener Kampf zu Beseitigung der Fluktuation geführt wird.

\section{Prinzipien der Nomenklatur}

Um die Durchführung einer einheitlichen Personalpolitik entsprechend den vorliegenden Richtlinien zu gewährleisten und auch um die Verantwortung aller Leiter für ihre nachgeordneten Dienststellen auszuübende Anleitung und Kontrolle zu verstärken, ist der Grundsatz der Nomenklatur in allen Zweigen des Staatsapparates und der volkseigenen Wirtschaft anzuwenden.

Als Nomenklatur wird der Personenkreis bezeichnet, dessen Einstellung, Umgruppierung, Versetzung und Entlassung der vorherigen Einwilligung der übergeordneten Dienststelle (Nomenklaturstelle) bedarf. Verstöße gegen dieses Prinzip sind disziplinarisch zu bestrafen. Der Umfang der Nomenklatur der Ministerien und Staatssekretariate mit eigenem Geschäftsbereich und Ämter der Regierung der DDR bedarf der vorherigen Zustimmung des MdI, ebenso wie der Umfang der Nomenklatur der nachgeordneten Organe und Verwaltungen, der vorherigen Zustimmung der Leiter der Fachministerien bzw. der vorgeordneten Dienststellen bedarf.

Eine Veränderung des Umfanges der Nomenklatur erfordert ebenfalls die entsprechende Zustimmung. Die Entwicklung der zur Nomenklatur gehörenden Beschäftigten ist sowohl von dem Leiter der Arbeitsstelle des Betreffenden, als auch vom Leiter der Nomenklaturstelle besonders sorgfältig zu beachten. Der Nomenklaturstelle sind daher unaufgefordert laufend alle hierfür erforderlichen Angaben zu machen. 
Das MdI hat entsprechende Anleitung für die Aufstellung von Nomenklaturen zu geben.

\section{Nomenklatur des MdI der DDR}

a) Die Nomenklatur des MdI umfasst alle Hauptabteilungsleiter, persönliche Referenten, Personalleiter und Abteilungsleiter der Ministerien, Staatssekretariate mit eigenem Geschäftsbereich und Ämter der Regierung der DDR, sowie der Präsidial- und Privatkanzlei des Präsidenten der DDR und des Sekretariats der Volks- und Länderkammer.

b) Aus den Bezirken die Vorsitzenden und Mitglieder des Bezirksrates und die Personalleiter.

c) Eine Änderung oder Erweiterung dieses Personenkreises kann auf Vorschlag des MdI vom Ministerrat vorgenommen werden.

\section{Einspruchsrecht des MdI}

a) Die Anweisung und Einspruchsbefugnis des MdI der DDR bei Einstellungen und Entlassungen erstreckt sich auf die gesamte staatliche Verwaltung und volkseigene Wirtschaft.

b) Erhebt das MdI Einspruch, so ist die Einstellung, Entlassung usw. sofort rückgängig zu machen, auch wenn es sich dabei um Meinungsverschiedenheiten handelt, die den Geschäftsbereich mehrerer Ministerien berühren und somit der Regierung zur Beratung und Beschlussfassung zu unterbreiten sind.

\section{Berichterstattungspflicht}

Die Leiter der Dienststellen sind verpflichtet, auf Anforderung ihrer übergeordneten Dienststellen oder des MdI der DDR, mindestens vierteljährlich über die Ergebnisse der Personalpolitik in ihrem Arbeitsbereich zu berichten und dabei die nach einheitlichen Gesichtspunkten aufzustellende Personalstatistik und die Analyse zu dieser einzureichen.

\section{Mitteilungspflicht}

Die Einstellung und Entlassung aller Angestellten der Ministerien, Staatssekretariate mit eigenem Geschäftsbereich und Ämter der Regierung der DDR sowie sonstige Veränderungen, die sich auf diesen Personenkreis beziehen, sind dem MdI, Hauptabteilung Personal, unverzüglich anzuzeigen. 


\section{Aufgaben der Hauptabteilung Personal des MdI der DDR}

Im Rahmen der durch den Ministerrat festgelegten Verantwortlichkeit des Ministeriums des Innern für die Einhaltung der Richtlinien der Personalpolitik im Staatsapparat und der volkseigenen Wirtschaft ergeben sich für das Ministerium des Innern, Hauptabteilung Personal, folgende Aufgaben:

a) Die Hauptabteilung Personal kontrolliert in allen Organen des Staatsapparates und der volkseigenen Wirtschaft die Einhaltung der personalpolitischen Richtlinien, die vom Ministerrat erlassen wurden. Die Hauptabteilung Personal hat darauf zu achten, dass die soziale Zusammensetzung im Staatsapparat - gemäß der Struktur unserer Bevölkerung - ständig verbessert wird und muss hierfür allen Organen die notwendige Anleitung geben. Hierbei gilt es, besonders auf die Förderung der Frauen und Jugendlichen, der Aktivisten aus den volkseigenen Betrieben sowie der wissenschaftlichen und technischen Intelligenz zu achten.

b) Die Hauptabteilung Personal ist verantwortlich für die Ausarbeitung grundsätzlicher Richtlinien in allen Fragen der Personalpolitik für den gesamten Staatsapparat und der volkseigenen Wirtschaft. Die Hauptabteilung Personal muss sich das hierfür notwendige Material durch ständigen Einsatz von Kaderinstrukteuren zur Untersuchung dieser Probleme im Staatsapparat und der volkseignen Wirtschaft erarbeiten. Die Vorschläge des Ministeriums des Innern, Hauptabteilung Personal sind dem Ministerrat zur Beschlussfassung zu unterbreiten.

Die Hauptabteilung Personal erlässt die erforderlichen Anweisungen für eine einheitliche, unbürokratische Personaltechnik und gibt hierzu einheitliche Arbeitsmittel (Entwicklungskartei usw.) heraus.

c) Die Personalstatistik für den gesamten Staatsapparat und die volkseigene Wirtschaft wird von dem MdI, Hauptabteilung Personal, geführt und regelmäßig mit den entsprechenden Schlussfolgerungen ausgewertet.

d) Die Nomenklatur des MdI, Hauptabteilung Personal, erfasst aus den Regierungsdienststellen der DDR alle

Hauptabteilungsleiter bzw. Verwaltungsleiter

Abteilungsleiter

Persönliche Referenten der Minister, Staatssekretäre und Leiter von Ämtern

Leiter der zentralen Verschlusssachenabteilung

Angestellten, die im Auftrag der Regierung im Ausland tätig sind (Missionen und

Handelsvertretungen)

aus den Bezirken alle

Vorsitzenden-Bezirksräte und Personalleiter.

Dieser Personenkreis wird von der Hauptabteilung Personal kaderpolitisch betreut. Ebenso werden für diese die Personalakten von ihr geführt. 
Außerdem führt das MdI Hauptabteilung Personal die Personalakten der Minister, Staatssekretäre und Leiter der Ämter. Das MdI Hauptabteilung Personal bestätigt den Umfang der Nomenklaturen der Ministerien, Staatssekretariate und Ämter.

e) Bei der Einstellung von Spezialisten aus Westdeutschland in den Staatsapparat und die volkseigene Wirtschaft werden diese durch die Hauptabteilung Personal des MdI überprüft und bestätigt.

f) Die Registratur des MdI, Hauptabteilung Personal, führt über alle Angestellten der Regierungsdienststellen eine Suchkartei, die ständig auf dem Laufenden zu halten ist. Ferner ist in der Registratur eine Sicherungskartei zu führen, die alle Personen erfasst, welche aus politischen oder kriminellen Gründen aus dem Staatsapparat entfernt wurden.

Die zur Durchführung dieser Aufgaben notwendigen Verfügungen und Anweisungen des Ministers, Staatssekretärs bzw. der Hauptabteilung Personal des MdI der DDR sind bindend für alle Organe des Staatsapparates und der volkseigenen Wirtschaft.

[BArch, DY 30/J IV 2/3/304, Bl. 26-32]

Dokument 6: Beschluss des Sekretariats des Zentralkomitees der SED „für die Überleitung der Staatlichen Organe in die neuen Bezirke und Kreise“, 3. Juli 1952

Die Reorganisation des Staatsapparates in die Bezirks- und Kreisverwaltungen muss nach folgenden Grundsätzen vorbereitet und durchgeführt werden.

1.) Die Vorbereitung und Durchführung der Reorganisation hat so zu erfolgen, dass kein Bürger und Betrieb der Deutschen Demokratischen Republik Schaden erleidet.

2.) Alle Anordnungen sind so zu treffen, dass die jetzigen Staatlichen Organe ihre Funktionen solange auszuüben haben, bis die neuen Bezirks- und Kreisorgane ihre Tätigkeit aufnehmen können.

3.) Die Durchführung der Reorganisation hat entsprechend dem vom Sekretariat des Zentralkomitees der SED genehmigten Struktur- und Stellenplänen in den Bezirken und Kreisen zu erfolgen.

Das Prinzip der strengsten Sparsamkeit ist anzuwenden. Eine Erhöhung der genehmigten Haushaltsmittel für das Jahr 1952 (Landeshaushalt) darf nicht erfolgen.

4.) Alle sich in der Vorbereitung und Durchführung der Reorganisation ergebenden Maßnahmen haben nach dem Prinzip der strengsten Einhaltung von Sicherheitsmaßnahmen zu erfolgen. 
5.) Die Reorganisation wird in folgenden Etappen durchgeführt:

1. Die Bezirksräte (Leitung der Staatlichen Organe im Bezirk) sind zu bilden bis zum 1.8.1952

2. Die Bildung der Bezirksorgane muss abgeschlossen sein am 15.8.1952

3. Die Kreisräte (Leitung der Staatlichen Organe im Kreis) sind zu bilden bis zum 1.9.1952

4. Die Kreisorgane müssen die Reorganisation beenden am 15.9.1952

5. Der Abschluss der gesamten Reorganisation der Staatlichen Organe in den Bezirken und Kreisen muss beendet sein am 30.9.1952

Für die Reorganisation des Staatsapparates wird folgendes Organisationsprinzip vorgeschlagen:

1.) Die auf Grund der Direktive des ZK am Sitz der Landeshauptstädte und in den Bezirksstädten bereits gebildeten Kommissionen werden von der Zentralen Kommission angeleitet und kontrolliert.

2.) Die Bezirkskommissionen haben folgende Aufgaben:

1. Die Räte in den Bezirken und Kreisen sowie die Organisationskomitees bei den Bezirks- und Kreisorganen entsprechend der von den einzelnen Ministerien und Staatssekretariaten erlassenen Direktive anzuleiten und zu kontrollieren;

2. für die Einhaltung der festgesetzten Fristen zu sorgen;

3. sie haben zu kontrollieren, dass alle Gemeinden entsprechend der neuen Struktur der Bezirke erfasst und von den entsprechenden Sachgebieten des Staatsapparates betreut werden.

4. sie sind dafür verantwortlich, dass die entsprechenden Kader für die neu zu bildenden Bezirksorgane im Einvernehmen mit den Kaderabteilungen der SED besetzt werden.

5. Sie sind dafür verantwortlich, dass die Übergabe der Planungsunterlagen, Haushaltmittel, Materialien, Akten usw. rechtzeitig vorbereitet wird und ordnungsgemäß unter Anwendung von Übergabeprotokollen vor sich geht.

6. Bei der Vorbereitung der zu treffenden Übergabe- und Übernahmemaßnahmen haben die Bezirkskommissionen zu beachten, dass keine Materialien in falsche Kanäle gelangen, die Wachsamkeit verstärkt wird und Sicherungsmaßnahmen getroffen werden.

3.) Die Genossen Minister und Staatssekretäre bei der Regierung der DDR, deren Fachgebiete bis in die Bezirke und Kreise gehen, sind für die Reorganisation ihres Fachgebietes voll verantwortlich.

Sie erlassen unter Anleitung der Zentralen Kommission für Staatliche Kontrolle für die Reorganisierung ihres Fachgebietes für die Bezirke und für die Kreise je eine Direktive. 
Diese Direktive muss enthalten, welche Maßnahmen zu einem bestimmten Termin durchzuführen sind.

Die Direktive hat genau festzulegen:

1. für die Bezirke

2. für die Kreise

wer für die Durchführung bestimmter Maßnahmen verantwortlich ist.

4.) Zur Durchführung dieser Direktive wird unter Anleitung des Ministers oder Staatssekretärs bei den betreffenden Ministerien oder Staatssekretariaten ein Organisationsstab gebildet.

Dieser Organisationsstab hat folgende Aufgaben:

1. darüber zu wachen, dass alle Maßnahmen so getroffen werden, dass die Versorgung der Bevölkerung und der Betriebe auf allen Gebieten reibungslos weiter vonstatten geht;

2. der jeweilige Organisationsstab hat die bei den Landesregierungen vorhandenen Ministerien oder Hauptabteilungen anzuleiten, damit ihr Fachgebiet für die neu zu bildenden Bezirke und Kreisorgane entsprechend der vom Sekretariat des ZK der SED beschlossenen Struktur- und Stellenpläne ordnungsgemäß aufgebaut werden kann;

3. der jeweilige Organisationsstab hat darüber zu wachen, dass bei den Landesregierungen, Ministerien und Hauptabteilungen bzw. -verwaltungen die für die Bezirke abzugebenden Pläne, Materialien usw. an die Bezirksorgane ordnungsgemäß übergeben werden;

4. vorsorglich muss durch den jeweiligen Organisationsstab gesichert werden, dass bei den einzelnen Ministerien bzw. Hauptabteilungen der Landesregierungen sofort nach der erfolgten Übergabe an die Bezirksorgane eine Abwicklungsstelle verbleibt, die am 30.9.1952 ihre Tätigkeit beendet.

5. Unter Leitung des Vorsitzenden des Rates des Bezirkes ist in den neu zu bildenden Bezirksorganen ein Organisationskomitee zu schaffen. Diesem Komitee gehören die sechs Bezirksräte an.

Jeder der Bezirksräte ist voll verantwortlich für den Aufbau seiner Fachgebiete in den Bezirksorganen.

Die Organisationskomitees bei den Bezirksorganen haben dafür zu sorgen, dass für die einzelnen Fachgebiete die Übernahme von Planungsunterlagen, Haushaltmitteln, Parteien und Akten gesichert ist.

Sie haben die Aufgabe, dafür zu sorgen, dass zum festgelegen Zeitpunkt die Arbeit reibungslos aufgenommen wird.

5.) In den alten und neuen Kreisorganen wird ein Organisationskomitee gebildet, das für die Reorganisation der Staatlichen Organe im gesamten Kreisgebiet verantwortlich ist.

Dieses Organisationskomitee steht unter Leitung des Landrates und setzt sich aus den Kreisräten zusammen. 
Die Anleitung erfolgt durch das Organisationskomitee des Bezirkes.

Die Organisationskomitees in den Kreisen arbeiten nach den Direktiven der einzelnen Ministerien oder Staatssekretariate, damit das entsprechende Fachgebiet in dem Kreisorgan aufgebaut werden kann.

Das Organisationskomitee in den Kreisorganen hat die Aufgabe, den Aufbau der einzelnen Fachgebiete der Staatlichen Organe, die Übergabe und Übernahme von Materialien, Karteien, Akten, Plänen usw. entsprechen den gegebenen Terminen zu sichern.

6.) Die Organisationskomitees in den Bezirken und Kreisen haben bis in den Direktiven festgelegten Sicherungsmaßnahmen zu treffen. Die persönliche Verantwortung der einzelnen Verwaltungsfunktionäre für die Übergabe und Übernahme ist genau festzulegen.

Durchzuführende Transporte von Karteien, Materialien Unterlagen usw. sind von diesen Verantwortlichen persönlich zu begleiten.

7.) Regelmäßige Besprechungen in allen Organisationskomitees sind durchzuführen und Arbeitspläne für je eine Woche aufzustellen.

Eine dreitätige Berichterstattung ist von unten nach oben zu sichern.

8.) Die Genossen der Staatlichen Kontrolle werden beauftragt, die Vorbereitung und durchzuführende Reorganisation zu kontrollieren und auftretende Schwierigkeiten beseitigen zu helfen.

[BArch, NY 4090/432 (Nachlass Otto Grotewohl), Bl. 66-72]

\section{Dokument 7: Aufstellung für den Bezirk Potsdam, 3. Juli 1952 249}

Einwohnerzahl: 1.274.354

Abgeordnete entsprechend dem Schlüssel: 82

\begin{tabular}{|l|c|c|c|c|}
\hline $\begin{array}{l}\text { Partei und } \\
\text { Massen- } \\
\text { organisa- } \\
\text { tionen }\end{array}$ & $\begin{array}{c}\text { Anzahl der } \\
\text { Abgeordneten } \\
\text { entsprechend } \\
\text { dem Schlüssel } \\
\text { der Volkswahlen }\end{array}$ & $\begin{array}{c}\text { Anzahl der } \\
\text { Abgeordneten } \\
\text { nach neuem } \\
\text { Vorschlag }\end{array}$ & $\begin{array}{c}\text { bei den Massen- } \\
\text { organisationen zu } \\
\text { berücksichtigen } \\
\text { bzw. bereits } \\
\text { vorhanden }\end{array}$ & $\begin{array}{c}\text { Differenz } \\
\text { zwischen dem } \\
\text { alten Schlüssel } \\
\text { und dem neuen } \\
\text { Vorschlag }\end{array}$ \\
\hline SED & 15 & 16 & & +1 \\
\hline CDU & 12 & 9 & & -3 \\
\hline LDP & 10 & 8 & & -2 \\
\hline NDPD & 5 & 8 & & +3 \\
\hline DBD & 5 & 7 & & +2 \\
\hline
\end{tabular}

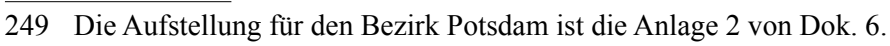




\begin{tabular}{|l|c|c|c|c|}
\hline FDGB & 9 & 9 & $\begin{array}{c}1 \text { NDPD, } \\
\text { parteilos, 1 CDU }\end{array}$ & \\
\hline FDJ & 7 & 7 & 1 parteilos & \\
\hline DFD & 7 & 7 & 1 CDU & \\
\hline KB & 4 & 4 & & \\
\hline VVN & 3 & 3 & & \\
\hline VdgB & 3 & 2 & 1 DBD & -1 \\
\hline KG & 2 & 2 & & \\
\hline zusammen: & & $\mathbf{8 2}$ & $\mathbf{6}(\mathbf{3 8})$ & \\
\hline
\end{tabular}

Die absolute Mehrheit ist gegeben, insgesamt 44 Genossen.

Begründung: Seit der Volkswahl 1950 hat sich die führende Rolle der Arbeiterklasse entscheidend gefestigt und die Bedeutung der Sozialistischen Einheitspartei Deutschlands als dem Vortrupp der deutschen Arbeiterklasse bei der Erfüllung der politischen, wirtschaftlichen und kulturellen Aufgaben wesentlich erhöht. Die Parteiorganisationen im Bezirk Potsdam haben sich inzwischen zahlenmäßig und in ihrer Aktivität gesteigert, wobei besonders die Industriezentren Hennigsdorf, Brandenburg, Potsdam, Wildau und Kirchmöser zu berücksichtigen sind.

Die LDP und CDU traten in den Kreisen des Bezirkes Potsdam als Organisationen immer weniger in Erscheinung. Besonders bei der Organisierung der Verteidigung unserer Heimat leisteten beide Parteien keine nennenswerte Unterstützung. In vielen Orten haben sich die Parteiorganisationen völlig aufgelöst, fast überall verminderte sich die Mitgliederzahl. Aus allen Kreisen wird gemeldet, dass die Mitarbeit in der Nationalen Front sehr nachgelassen hat und dass die Realisierung der im Block gefassten Beschlüsse fast ganz den übrigen Parteien und Massenorganisationen überlassen bleibt.

Es wird daher die Verminderung der Mandate bei der LDP von 10 auf 8 und bei der CDU von 12 auf 9 vorgeschlagen.

DBD und NDPD: Für diese beiden Parteien schlagen wir eine Erhöhung der Mandate vor, und zwar bei der DBD von 5 auf 7 und bei der NDPD von 5 auf 8. Zahlenmäßig und in der Aktivität sind diese beiden Parteien gewachsen.

Die NDPD setze sich besonders bei der Aufklärung innerhalb der Nationalen Front ein, während die Bedeutung der DBD durch die großen Aufgaben bei der Demokratisierung des Dorfes gestiegen ist. Durch ihre Überzeugungsarbeit unter den Bauern half sie mit, gute Ablieferungsergebnisse zu erzielen.

FDGB: In der Fraktion des FDGB sind bereits drei gewählte Abgeordnete vorhanden, von denen einer der NDPD, einer der CDU angehört und einer parteilos ist. 
DFD: Bei der Abgeordneten, die der CDU angehört, handelt es sich um eine bereits gewählte Landtagsabgeordnete.

VdgB: Der Struktur des Bezirks Potsdam entsprechend werden für die VdgB zwei Mandate für ausreichend gehalten.

[BArch, NY 4090/432 (Nachlass Otto Grotewohl), Bl. 78]

Dokument 8: Aufstellung für den Bezirk Cottbus, 3. Juli $1952^{250}$

Einwohnerzahl: 705.152

Abgeordnete entsprechend dem Schlüssel: 66

\begin{tabular}{|l|c|c|c|c|}
\hline $\begin{array}{l}\text { Partei und } \\
\text { Massen- } \\
\text { organisa- } \\
\text { tionen }\end{array}$ & $\begin{array}{c}\text { Anzahl der } \\
\text { Abgeordneten } \\
\text { entsprechend } \\
\text { dem Schlüssel } \\
\text { der Volkswahlen }\end{array}$ & $\begin{array}{c}\text { Anzahl der } \\
\text { Abgeordneten } \\
\text { nach neuem } \\
\text { Vorschlag }\end{array}$ & $\begin{array}{c}\text { bei den Massen- } \\
\text { organisationen zu } \\
\text { berücksichtigen } \\
\text { bzw. bereits } \\
\text { vorhanden }\end{array}$ & $\begin{array}{c}\text { Differenz } \\
\text { zwischen dem } \\
\text { alten Schlüssel } \\
\text { und dem neuen } \\
\text { Vorschlag }\end{array}$ \\
\hline SED & 12 & 13 & & +1 \\
\hline CDU & 9 & 7 & & -2 \\
\hline LDP & 8 & 6 & & -2 \\
\hline NDPD & 4 & 6 & & +2 \\
\hline DBD & 4 & 6 & & +2 \\
\hline FDGB & 7 & 7 & & \\
\hline FDJ & 6 & 6 & 1 parteilos & \\
\hline DFD & 6 & 6 & & \\
\hline KB & 3 & 3 & 1 NDPD & \\
\hline VVN & 3 & 2 & & \\
\hline VdgB & 2 & 2 & 1 DBD & \\
\hline KG & 2 & 2 & & \\
\hline zusammen: & $\mathbf{6 6}$ & $\mathbf{6 6}$ & & \\
\hline
\end{tabular}

Absolute Mehrheit ist gegeben, insgesamt 37 Genossen.

Begründung: Durch die vorhandenen Industriezentren im Bezirk Cottbus ergibt sich die Tatsache, dass sich die Arbeiterklasse hier besonders konzentriert. Die Industriezentren im Süden des Bezirks werden weiterhin durch die aus den Ländern Sachsen und Sachsen-Anhalt hinzukommenden Industriezentren verstärkt. Entsprechend der sich in den letzten Jahren stark entwickelten Parteiorganisationen in diesem Bezirk und der vorhan-

250 Die Aufstellung für den Bezirk Cottbus ist die Anlage 3 von Dok. 6. 
denen Industriezentren halten wir die Verstärkung der SED um einen Abgeordneten für notwendig.

Bei der CDU und LDP schlagen wir vor, die Abgeordnetenzahl zu vermindern, da sich in den letzten Jahren gezeigt hat, dass beide Parteien immer weniger in Erscheinung treten und besonders in der augenblicklichen Situation des verstärkten Kampfes um den Friedensvertrag und die Einheit Deutschlands nicht die notwendige Aktivität zeigen. Ihre Mitarbeit in der Nationalen Front muss im Allgemeinen als schwach angesprochen werden. Sie konzentriert sich zu stark auf die Unterbringung ihrer Mitglieder in bestimmten Funktionen.

Im Süden des Bezirks ist festzustellen, dass die LDP gegenüber der CDU, trotz ihrer geringeren Mitgliederzahl, aktiver als die CDU ist. Im Norden des Bezirks ist das Verhältnis umgekehrt, sodass sich im Allgemeinen im Bezirk beide Parteien die Waage halten.

Dem gegenüber haben die NDPD und DBD in den letzten Jahren ihren Einfluss verstärkt und eine gute Aktivität entwickelt. Beide Parteien leisten eine gute Mitarbeit innerhalb der Nationalen Front. Im antifaschistisch-demokratischen Block tragen sie mit Verantwortung bei der Festigung unserer antifaschistisch-demokratischen Ordnung und bei der Durchsetzung der Politik unserer Regierung.

Aus diesem Grunde schlagen wir vor, beide Parteien stärker zu berücksichtigen.

[BArch, NY 4090/432 (Nachlass Otto Grotewohl), Bl. 79]

Dokument 9: Aufstellung für den Bezirk Frankfurt (Oder), 3. Juli $1952^{251}$

Einwohnerzahl: 641.985

Abgeordnete entsprechend dem Schlüssel: 64

\begin{tabular}{|l|c|c|c|c|}
\hline $\begin{array}{l}\text { Partei und } \\
\text { Massen- } \\
\text { organisa- } \\
\text { tionen }\end{array}$ & $\begin{array}{c}\text { Anzahl der } \\
\text { Abgeordneten } \\
\text { entsprechend } \\
\text { dem Schlüssel } \\
\text { der Volkswahlen }\end{array}$ & $\begin{array}{c}\text { Anzahl der } \\
\text { Abgeordneten } \\
\text { nach neuem } \\
\text { Vorschlag }\end{array}$ & $\begin{array}{c}\text { bei den Massen- } \\
\text { organisationen zu } \\
\text { berücksichtigen } \\
\text { bzw. bereits } \\
\text { vorhanden }\end{array}$ & $\begin{array}{c}\text { Differenz } \\
\text { zwischen dem } \\
\text { alten Schlüssel } \\
\text { und dem neuen } \\
\text { Vorschlag }\end{array}$ \\
\hline SED & 12 & 13 & & +1 \\
\hline CDU & 8 & 7 & & -1 \\
\hline LDP & 8 & 6 & & -2 \\
\hline NDPD & 4 & 5 & & +1 \\
\hline DBD & 4 & 5 & & +1 \\
\hline
\end{tabular}

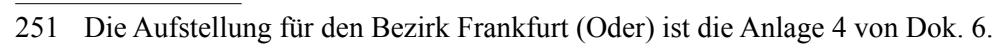




\begin{tabular}{|l|l|l|l|l|}
\hline FDGB & 7 & 7 & & \\
\hline FDJ & 6 & 6 & & \\
\hline DFD & 6 & 6 & parteilos & \\
\hline KB & 3 & 3 & & \\
\hline VVN & 2 & 2 & & \\
\hline VdgB & 2 & 2 & 1 DBD & \\
\hline KG & 2 & 2 & & $+\mathbf{+ 3}$ \\
\hline zusammen: & $\mathbf{6 4}$ & $\mathbf{6 4}$ & & $\mathbf{- 3}$ \\
\hline
\end{tabular}

Die absolute Mehrheit ist gegeben, insgesamt 39 Genossen.

Begründung: Erhöhung der Mandate der SED von 12 auf 13. Durch die in diesem Bezirk entstandenen Industriezentren haben sich die Parteiorganisationen stark entwickelt und leisten eine aktive Arbeit.

Auch in den Kreisen mit landwirtschaftlichem Charakter sind die Parteiorganisationen der SED gewachsen und sind die führende Kraft bei der Erfüllung der Pläne und bei der Mobilisierung der Bevölkerung für den Friedenskampf.

Herabsetzung der Mandate der CDU von 8 auf 7. Es hat sich gezeigt, dass die CDU nicht so mitgearbeitet hat, wie es in der gegenwärtigen politischen Situation erforderlich ist.

Die CDU-Parteiorganisationen bestehen zum Teil nur auf dem Papier, leisten keine aktive Mitarbeit in der Nationalen Front und treten immer weniger in Erscheinung.

Herabsetzung der Mandate der LDP von 8 auf 6. Die Arbeit der LDP hat in den letzten Jahren immer mehr nachgelassen. An Mitgliederstärke ist diese Partei in den einzelnen Kreisen des Bezirks Frankfurt (Oder) bedeutend schwächer geworden, auch ihr Einfluss bei der Bevölkerung ist mehr und mehr zurückgegangen.

Die Mitarbeit in der Nationalen Front seitens der LDP ist als völlig ungenügend zu bezeichnen.

Ihre Parteiorganisationen bestehen ebenfalls z. T. nur formal auf dem Papier, leisten keine Arbeit und treten immer weniger in Erscheinung.

Erhöhung der Mandate der NDPD und DBD von je 4 auf 5. Beide Parteien haben sich seit der Volkswahl sehr stark entwickelt. Sie leisten eine gute Mitarbeit bei allen zu lösenden Aufgaben und arbeiten aktiv in der Nationalen Front des demokratischen Deutschland 
mit. In den einzelnen Kreisen sind die NDPD und DBD nach der SED die stärksten Parteien. Ihr Einfluss bei der Bevölkerung hat sich ebenfalls vergrößert.

[BArch, NY 4090/432 (Nachlass Otto Grotewohl), Bl. 80]

Dokument 10: Vorlage des stellvertretenden Leiters der Abteilung Staatliche Verwaltung des Zentralkomitees der SED, Willi Barth, ${ }^{252}$ für das Politbüro über die „Grundsätze der Gesetzesvorlagen über die Neuorganisation im Staatsapparat", 5. Juli $1952^{253}$

Alle Maßnahmen, die zur Neuorganisation des Staatsapparates durchgeführt werden, stehen in Übereinstimmung mit der Verfassung, die der Demokratisierung unseres Staatsapparates den Weg ebnet. Eine Änderung des Textes der Verfassung ist nicht notwendig. Es erscheint zweckmäßig, in der Begründung der Neuorganisation das Hauptgewicht nicht gegen die Länder zu richten. Das Hauptgewicht ist vielmehr auf die Notwendigkeit einer weiteren Demokratisierung des Staatsapparates zu legen. Im Zuge dieser weiteren Demokratisierung verändern die Länder ihre Verwaltungsorganisationen. Die Länder bleiben als territoriale Einheiten bestehen. Die Tatsache, dass gewisse Teile der Verfassung (Art. 109ff. „Republik und Länder“) nicht mehr den mit der Neuorganisation erreichten Zustand unserer Staatsstruktur widerspiegeln, macht eine Aufhebung dieses Teiles der Verfassung nicht notwendig. Die Weiterexistenz der Länderkammer lässt sich unter dem Gesichtspunkt rechtfertigen, dass die grundlegende Gliederung der Republik in Länder nicht aufgehoben ist. ${ }^{254}$

Es wird empfohlen, die Länderverfassungen formell nicht aufzuheben. Es lässt sich juristisch der Standpunkt vertreten, sie seien gegenstandslos geworden. ${ }^{255}$

\section{Vorschlag:}

Die Maßnahmen zur Neuorganisation des Staatsapparates werden von oben durch die Volkskammer beschlossen. Dabei wird betont, dass die weitere Demokratisierung erforderlich macht:

a) eine Neugliederung der Kreise nach wirtschaftlichen Gesichtspunkten. Dazu werden entsprechende Veränderungen der Ländergrenzen vorgenommen.

b) Bildung von Bezirken.

252 Zu Willi Barth (1899-1988) vgl. Müller-Enbergs, Wer war wer, S. 42.

253 Das Dokument enthält handschriftlichen Anmerkungen, die sehr wahrscheinlich vom Ministerpräsidenten der DDR, Otto Grotewohl, stammen.

254 Handschriftlich am Rand des Absatzes: „Keine grundsätzliche Beseitigung der Länder, nur: Veränderung der Verwaltungspraxis; also: bleibt auch Länderkammer“.

255 Handschriftlich am Rand des Absatzes: „Keine Schranken für Einheit“. 
Der Landtag legt durch Gesetz fest:

a) welche Kreise im Einzelnen neu gebildet werden,

b) welche Kreise zu welchen Bezirken zusammengefasst werden,

c) die Zustimmung zur Änderung der Ländergrenzen durch Volkskammergesetz (Art. 110 Abs. II)

d) die Abgeordneten der Landtage setzen ihre Tätigkeit in den Bezirkstagen fort,

e) die Funktionen der Landesregierung gehen auf die Bezirksverwaltungen über.

\section{Begründung dieses Vorschlags:}

Die Regierung der Republik und die Volkskammer treten als entscheidende Kraft für die Neuorganisation des Staatsapparates hervor. Dieser Vorschlag hat den großen Vorteil, dass hier die politische Bedeutung der Neuorganisation als Schritt zur Vertiefung unserer Demokratie von der Regierung in der Volkskammer und damit vor dem ganzen deutschen Volk dargelegt wird. Das ist sehr bedeutsam, weil für den weiteren Ausbau der neuen Struktur, insbesondere für die Frage, die neuen Kreis- und Bezirksorgane arbeitsfähig zu machen, hier die entscheidenden Gesichtspunkte gegeben würden. Das wäre zugleich die Einleitung einer großen ideologischen Kampagne für den Ausbau von organisatorischen Formen, die die Mitarbeit der Bevölkerung sicherstellen. ${ }^{256}$

Dieser Vorschlag hat ferner den Vorteil, dass die Landtage bei der Durchführung der Neuorganisation weitgehend herangezogen werden. Die Regierung der Republik und die Volkskammer legen die entscheidenden politischen Richtlinien fest (Notwendigkeit der Neubildung der Kreise und der Bildung on Bezirken). Die Landtage führten dann die Neubildung der Kreise und die Bildung von Bezirken faktisch durch. ${ }^{257}$

\section{Vorschlag: 258}

Die Maßnahmen zur Neuorganisation des Staatsapparates werden von oben durch die Volkskammer beschlossen. Dabei wird betont, dass die weitere Demokratisierung erforderlich macht:

a) die Neubildung von Kreisen unter Veränderung der Landesgrenzen (der Volkskammerbeschluss führt hiernach die Kreise im Einzelnen auf),

b) die Bildung von Bezirken (der Volkskammerbeschluss zählt im Einzelnen die Bezirke auf und legt die Aufteilung der Kreise auf die Bezirke fest).

256 Handschriftlich am Rand des Absatzes: „Führung DDR; Plan erzwingt die Neuregelungen von der DDR“.

257 Handschriftlich am Rand des Absatzes: ,alle Beschlüsse a) Volkskammer b) Landtage mit 2/3 Mehrheit fassen".

258 Handschriftlich: „Nein!“ - Der gesamte Text des zweiten Vorschlags ist einmal quer durchgestrichen. 
Der Landtag beschließt durch Gesetz:

a) die Zustimmung zur Änderung der Landesgrenzen durch Volkskammergesetz (Art. 110 Abs. II),

b) die Abgeordneten der Landtage setzen ihre Tätigkeit in den Bezirkstagen fort,

c) die Funktionen der Landesregierung gehen auf die Bezirksverwaltung über.

\section{Begründung dieses Vorschlags:}

In ihm kommen dieselben Gesichtspunkte zum Ausdruck wie in dem 1. Vorschlag, mit dem Unterschied, dass die Landtage in weiterem Maße als nach dem 1. Vorschlag ausgeschaltet werden, indem die Bildung der Kreise und Bezirke durch die Volkskammer selbst erfolgt. Es würde hier die verfassungsrechtliche Schwierigkeit vorhanden sein, dass nach der Demokratischen Kreisordnung die Änderung von Kreisgrenzen Hoheitsrecht des Landes ist. Es wäre aber vertretbar, dass im Zuge dieser Neuorganisation die Volkskammer von sich aus diese Neufestsetzung der Kreisgrenzen bestimmt.

\section{Begründung:}

Entsprechend dem erteilten Auftrag wurde die bestehende Gliederung der Verwaltung in Gemeinden, Kreise und Länder sowie die Struktur der Organe der Gemeinden, Kreise und Länder einer kritischen Analyse unterworfen. Die Untersuchung wurde unter dem Gesichtspunkt vorgenommen, zu erforschen, ob die gegenwärtig bestehende territoriale Gliederung noch den realen ökonomischen Verhältnissen entspricht und ob bei der gegenwärtigen Struktur der Verwaltung, insbesondere in den Kreisen und Ländern, diese noch geeignet ist, die Aufgaben zu bewältigen, die ihnen durch die Gesetze und Verordnungen der Deutschen Demokratischen Republik auferlegt sind.

Diese Frage reifte in den letzten Jahren heran und ihre Lösung wurde immer dringender. Die Bewältigung der wachsenden Aufgaben, die von unserem demokratischen Staat im Zuge des kulturellen und wirtschaftlichen Aufbaus gestellt werden, stellen an die Organe des Staatsapparates erhöhte Anforderungen. Dies gilt insbesondere für die örtlichen Organe des Staates, deren Funktion die Durchführung der Gesetze und Verordnungen der Republik ist.

Die bestehende territoriale Gliederung insbesondere der Kreise und die bestehende Struktur der Verwaltung der Kreise und Länder hat sich als veraltet erwiesen. Bei ihrem Aufbau wurde im Wesentlichen an die Tradition der Weimarer Republik angeschlossen, wobei die diktatorischen Elemente des alten ${ }^{259}$ Staatsapparates beseitigt wurden. Die tiefgreifenden Veränderungen, die sich bei uns vollzogen haben, haben indes bisher in der Gliederung und Struktur der Verwaltung nicht ihre Berücksichtigung gefunden. Es muss festgestellt werden, dass der Staatsapparat, seine Gliederung und Struktur, hinter unserer

259 Handschriftlich eingefügt: „Hitlerschen“. 
gesellschaftlichen Entwicklung, insbesondere der Aufgabenstellung des Fünfjahrplanes, zurückgeblieben ist. Das muss sich notwendig hemmend auswirken. Der Staatsapparat kann die große schöpferische Kraft nicht entfalten, deren er bedarf, um der Bevölkerung zu helfen, die Aufgaben des Fünfjahrplanes zu erfüllen.

Angesichts der gegenwärtigen Gliederung und Struktur ist der Staatsapparat nicht in der Lage, die beiden entscheidenden Aufgaben durchzuführen, die vor ihm stehen:

die genaue Durchführung der Gesetze und Verordnungen der Deutschen Demokratischen Republik sicherzustellen

und des weiteren

die organisatorischen Formen zu schaffen, die die Mitarbeit der breiten Schichten der Bevölkerung an der Durchführung der Gesetze und damit an der Politik unseres demokratischen Staates gewährleisten.

Strikte Einhaltung der demokratischen Gesetzlichkeit und allseitige Entwicklung der Demokratie sind die notwendigen Voraussetzungen für die Erfüllung der großen Aufgaben des kulturellen und wirtschaftlichen Aufbaus, die vor unserem Staate stehen.

Die Landtage und Kreistage bestehen und arbeiten heute noch im Wesentlichen in den Formen des alten parlamentarischen Betriebes. Sie treten nur zu den Sitzungen zusammen, wirken aber bei der Durchführung der Gesetze und Verordnungen nicht operativ mit, Ihre Verbindung mit den breiten Schichten der Bevölkerung ist nur sehr locker und gewährleistet nicht die Heranziehung der Massen zur Lösung der staatlichen Aufgaben.

Die Kreise sind zu groß. Sie können nicht die ihnen übertragenen Aufgaben, die strikte Durchführung der Gesetze und Verordnungen zu gewährleisten, erfüllen. Die örtlichen Staatsorgane haben die volle Verantwortung für die strikte Durchführung der Gesetze und Verordnungen. Die Bürgermeister, selbst der kleinsten Gemeinden, haben wichtige staatspolitische und ökonomische Aufgaben. Wegen der Größe der meisten Kreise kann ihnen nicht die notwendige Anleitung und Hilfe gegeben werden.

Aber auch die Anleitung, Hilfe und Kontrolle der Kreise durch die Landesregierungen hat sich als völlig unzureichend erwiesen. Die Zahl der anzuleitenden Kreise ist zu groß, die Wege bis zur Kreisverwaltung zu weit. Hierdurch wird, anstatt operativ anzuleiten, bürokratisch verfahren, Rundschreiben erlassen und so die Entwicklung faktisch dem Selbstlauf überlassen.

Der Vorschlag für die neue Einteilung und Struktur berücksichtigt die ökonomischen Veränderungen und die neue Aufgabenstellung an die örtlichen Organe der Staatsmacht. Er befähigt diese Organe operativ die Durchführung der Gesetze und Verordnungen anzuleiten und die Massen zur Mitarbeit zu mobilisieren. 
Der Vorschlag geht in der folgenden Richtung: Die Gemeinden bleiben in ihrer jetzigen Form bestehen. Zur besseren Anleitung, Hilfe und Kontrolle sind die meisten Kreise verkleinert. Dadurch wird eine intensive Anleitung, Hilfe und Kontrolle der Bürgermeister und Räte der Gemeinden gewährleistet, was in der bisherigen Form nicht sichergestellt war.

Damit auch die Kreise aktiver in die Entwicklung eingreifen können, muss auch diesen eine bessere Anleitung und Hilfe zuteil werden. Deshalb sieht der Vorschlag vor, dass die den Landesregierungen obliegende Verpflichtung zur Anleitung, Hilfe und Kontrolle durch Bezirksorgane ausgeübt wird. Das von den Landesregierungen erfasste Territorium ist zu umfassend, eine operative Anleitung ist kaum möglich und wird auch faktisch nicht durchgeführt.

Die Festigung der demokratischen Gesetzlichkeit erfordert die strikte Durchführung der Gesetze und Verordnungen durch alle Organe des Staatsapparates. Dies ist Richtschnur der Tätigkeit der neu zu schaffenden Organe der Bezirke, Kreise und Gemeinden. Dabei haben die Bezirke den Kreisen und die Kreise den Gemeinden in der Durchführung ihrer Aufgaben zu helfen und die Innehaltung der Gesetze zu kontrollieren.

Das Neue in unserer demokratischen Entwicklung, die Massen des Volkes zur Mitarbeit bei der Durchführung der Aufgaben zu mobilisieren, verlangt auch eine Änderung der Tätigkeit der Vertretungskörperschaften in den Gemeinden, Kreisen und Bezirken. Bisher haben diese Vertretungskörperschaften sich darauf beschränkt, Gesetze und Verordnungen zu erlassen - es muss indes auch ihre Funktion sein, für die Durchführung der Gesetze und Verordnungen Sorge zu tragen. Die Erfahrungen, die hinsichtlich der Tätigkeit der jüngst geschaffenen ständigen Kommissionen bei den Stadtbezirken in den Großstädten und in einigen Städten und Gemeinden vorliegen, zeigen einen Weg für die neue Form der Arbeit der Volksvertretungen und sind eine Form unserer demokratischen Entwicklung.

Durch die ständige Kommission der Vertretungskörperschaft, der diese Anleitung, Hilfe und Kontrolle bei der Durchführung der Gesetze und Verordnungen obliegt, ist die operative alltägliche Zusammenarbeit zwischen der Vertretungskörperschaft, den Verwaltungsorganen und der Bevölkerung sichergestellt. Dies ist eine Form, die die Heranziehung der Massen zur aktiven Mitwirkung bei der Durchführung der Gesetze und Verordnungen sicherstellt.

Dies ist zugleich der Weg zur Überwindung des alten parlamentarischen Betriebes, dessen Grundübel die Teilung zwischen dem Erlass von Gesetzen und Verordnungen auf der einen - der Durchführung auf der anderen Seite war. Das Parlament sah als seine ausschließliche Befugnis den Erlass der Gesetze an und überließ die Durchführung der Verwaltung. Es ist vielmehr die Funktion der Volksvertretungen selbst, gestützt auf die breiten Massen der Bevölkerung und diese zur aktiven Mitwirkung heranziehend, um so an 
der Durchführung der Gesetze und damit an der Verwirklichung der Politik unseres Staates mitzuwirken.

So wird unsere demokratische Entwicklung in ein höheres Stadium treten.

[BArch, NY 4090/432 (Nachlass Otto Grotewohl), Bl. 81-88]

Dokument 11: Erster Bericht des Vorsitzenden des Organisations-Komitees für den Bezirk Potsdam, Rudolf Jahn, ${ }^{260}$ über den ,Stand der Vorbereitungsarbeiten für die Verwaltungsreform im Bezirk Potsdam“, 17. Juli 1952 ${ }^{261}$

a) Territoriale Fragen sind sowohl im Bezirk als auch in den einzelnen Kreisen des Bezirkes klar. Es gibt keinerlei Schwierigkeiten und ungeklärte Fragen.

Die vom Land Mecklenburg angeforderten Unterlagen für die Kreise Westprignitz und Prenzlau sowie Teile des Kreises Templin sind an Mecklenburg übergeben worden. Für die kleinen Teile, die der Bezirk Potsdam aus dem Land Sachsen-Anhalt erhält, haben wir ebenfalls die von uns angeforderten Unterlagen von Sachsen-Anhalt erhalten.

b) Kaderfragen auf der Verwaltungsebene sind noch nicht restlos geklärt. Für den Bezirksrat ist der 1. Vorsitzende und der Stellvertreter (Inneres) klar und vom Politbüro bestätigt. Für die weiteren Bezirksräte liegen Vorschläge vor, die vom Sekretariat der Landesleitung aber noch nicht vom Politbüro bestätigt. Für die weiteren Bezirksräte liegen Vorschläge vor, die vom Sekretariat der Landesleitung aber noch nicht vom Politbüro bestätigt wurden. Es hindert vor allen Dingen die noch nicht restlos vorhandene Klarheit über die künftige Struktur den endgültigen Abschluss.

Für die Kreisräte liegen ebenfalls vom Sekretariat der Landesleitung bestätigte Vorschläge für den Vorsitzenden des Kreisrates und Stellvertreter (Inneres) vor. Bei einigen wenigen Fällen ist noch nicht endgültig entschieden. Die Entscheidung fällt jedoch in den nächsten Tagen, auch in Bezug auf die anderen Kreisräte.

c) Gebäudefragen für den Bezirk Potsdam sind vom Sekretariat der Landesleitung bestätigt und zur endgültigen Bestätigung der zentralen Gebäudekommission in Berlin vorgelegt. Für die Regelung der Gebäudefragen für die Kreise des Bezirkes Potsdam

260 Rudolf (Rudi) Jahn (1906-1990) war seit 1949 Ministerpräsident des Landes Brandenburg und im Sommer 1952 ursprünglich als künftiger Vorsitzender des Rates des Bezirkes Potsdam vorgesehen. Er wurde dann aber im August 1952 Vorsitzender des Rates des Bezirkes Dresden; vgl. Niemann/ Herbst, SED-Kader, S. 256.

261 Die hier abgedruckten Berichte des Potsdamer Organisationskomitees (Dok. 11, 13, 24, 25, 26, 28, $31,32,34,36,37,40$ und 42) waren an die von Werner Eggerath geleitete Koordinierungs- und Kontrollstelle für die Arbeit der Verwaltungsorgane beim Ministerpräsidenten der DDR gerichtet. 
liegen ebenfalls von der Gebäudekommission des Landes konkrete Vorschläge vor, die nur noch durch die Bezirkskommission am 19.7.52 bestätigt werden müssen.

d) Bezirks- und Kreistage für den Bezirk Potsdam sind nach den bisher vorliegenden Direktiven klar und vom Sekretariat der Landesleitung bestätigt. Nach den vorliegenden Informationen wird sich jedoch hier noch vieles ändern, nachdem über die künftige Regelung Klarheit sein wird, die wir durch den Besuch des zentralen Instrukteurs am 17.7. erwarten.

e) Überleitung. Die Bezirkskommission Potsdam ist verantwortlich für die Aufarbeitung und Überleitung aus der Landesregierung in die drei Bezirke des Landes. Die Genossen Minister resp. Genossen Hauptabteilungsleiter in den Ministerien mit bürgerlichen Ministern, haben vom Ministerpräsidenten Anweisung und Anleitung erhalten, Vorbereitungsarbeiten zu treffen und die bisher geleisteten Vorarbeiten in Einklang zu bringen mit den Direktiven, die ihnen von ihren Ministerien oder Staatssekretariaten der Regierung der DDR zugehen. Sie haben bis zum 18.7.52 einen konkreten Arbeitsplan mit Terminen und Verantwortlichen dem Ministerpräsidenten vorzulegen, nach welchem die Aufarbeitung, Überleitung und Abwicklung vor sich gehen soll. Erst im nächsten Bericht am Montag, den 21.7.52 kann hier über Schwierigkeiten und Probleme berichtet werden, die im Republiksmaßstab noch geklärt werden müssen.

f) Schwierigkeiten und Unklarheiten sind insofern noch vorhanden, als noch keine restlose Klarheit über die künftige Struktur und die Aufgaben der Bezirks- und Kreisräte vorliegt, dass die bisherige Direktive nach all dem was man hört, sich noch in einigen Dingen Änderungen ergeben werden. Auch der immer noch nicht vorhandene Stellenplan - der ja nun am 19.7.52 von Berlin abgeholt werden soll - behindert die Vorbereitungsarbeiten.

[BLHA, Rep. 401, Nr. 58, Bl. 1-2]

Dokument 12: Bericht an den Leitinstrukteur ${ }^{262}$ für das Land Brandenburg über
den „Instrukteureinsatz Verwaltungsreform im Land Brandenburg“, 18. Juli 1952

Am 17.7.52 um 12 Uhr sprach ich in Potsdam beim Statistischen Landesamt vor. Dem Kollegen Schuster wurde die Direktive des Statistischen Zentralamtes übergeben und die damit verbundenen Aufgaben besprochen.

262 Der Leitinstrukteur für das Land Brandenburg, Schulz, koordinierte die einzelnen Instrukteure, die vom Ministerrat der DDR in den Ländern für den Übergang jedes einzelnen Ressorts in die Bezirksstrukturen eingerichtet wurden. Eine Aufstellung sämtlicher Instrukteure enthält das Dok. 14, zu den Instrukteuren des Ministeriums für Justiz der DDR vgl. Dok. 22. 
Von Seiten des Landesamtsleiters waren anhand der Informationen, die auf der zweitägigen Tagung in Berlin gegeben wurden, die Abteilungen angewiesen worden, eine genaue Bestandsaufnahme der im Landesamt vorhandenen Papiere durchzuführen. Zur Zeit läuft diese Arbeit noch.

Darüber hinaus hat die Amtsleitung mit den für die Bezirke als Leiter vorgesehenen Kollegen Ettlinger und Wierick den Personenkreis festgelegt, der für die weitere Arbeit in den Bezirken in Frage kommt. Eine Rücksprache mit diesen Kollegen findet in der nächsten Woche statt.

Anlässlich einer Rücksprache des Kollegen Schuster bei der für die Bezirke eingesetzten Gebäudekommission wurde festgestellt, dass diese Kommission den Raumbedarf des Statistischen Dienstes völlig übersehen hatte. Auf Grund dessen sah sich Kollege Schuster genötigt, einen Bedarf von zehn Räumen je Bezirksamt und drei Räumen je Kreisamt anzumelden.

Da alle Instrukteure um 15 Uhr zu einer Besprechung beim Ministerpräsidenten des Landes geladen waren, wurde lediglich nur mit dem Landesamt für den 18.7. um 8 Uhr morgens eine erneute Besprechung mit allen verantwortlichen Kollegen festgelegt.

Bei der Besprechung beim Ministerpräsidenten wurde die Aufgabenstellung noch einmal ganz allgemein aufgezeigt und darüber hinaus festgelegt, dass täglich um 17 Uhr Instrukteure zu einem Erfahrungsaustausch und zur Berichterstattung zusammen zu kommen haben. Die erste Besprechung dieser Art findet am 18.7.52 statt.

Am 18.7. 8 Uhr fand die festgelegte Besprechung beim Landesamt statt. Nachdem auch hier die Aufgabenstellung nochmals durchgesprochen wurde, wurde für die kommende Woche ein Arbeitsplan ausgearbeitet, in dem die einzelnen Kollegen mit verantwortlichen Aufgaben betraut wurden.

Im Laufe dieser Besprechung kam noch folgendes zur Ausdruck:

Um die Erledigung der laufenden und mit der Reorganisation verbundenen Arbeiten zu gewährleisten, können Urlaubsansprüche über den Rahmen der festgelegten Urlaubsliste keine Berücksichtigung finden. Da aber mit der Auflösung des Landesamtes noch Urlaubsansprüche abzugelten sind, muss dafür Sorge getragen werden, dass die zur Entlassung kommenden Kollegen noch anschließend ihren Urlaub nehmen können (Klärung in der Haushaltsabteilung notwendig).

Außerdem ist zentral ein genauer Termin festzulegen, bis zu dem die Länder verpflichtet sind, das Material derjenigen Kreise und Gemeinden zu übergeben, die nunmehr zu einem Bezirk eines anderen Landes kommen. Von Bedeutung für die rechtzeitige Über- 
gabe der Materialien an die zu übernehmenden Kreise ist die umgehende Zustellung der gedruckten Gemeindeverzeichnisse.

Weiter ist im Laufe der nächsten Tage noch folgende Frage zentral zu klären:

Bisher wurde die Herausgabe von statistischen Zahlen von der Zustimmung des Ministerpräsidenten abhängig gemacht. Mit der Aufnahme der Arbeit in den Bezirken wird diese Stelle nicht mehr zur Verfügung stehen und es muss geklärt werden, wir für die Genehmigung zuständig ist.

Im Anschluss an diese Besprechung ist geplant, einige Abteilungen des Landesamtes zu überprüfen, inwieweit die angesetzten Arbeiten durchgeführt und termingerecht erledigt werden.

Über den Verlauf der heutigen Besprechung beim Ministerpräsidenten wird in dem nächsten Bericht berichtet werden. ${ }^{263}$

[BLHA, Rep. 401, Nr. 58, Bl. 63]

Dokument 13: Zweiter Bericht des Vorsitzenden des Organisations-Komitees für den Bezirk Potsdam, Rudolf Jahn, ${ }^{264}$, über den Stand der Durchführung der Verwaltungsreform für die Bezirke Cottbus, Potsdam und Frankfurt (Oder)“, 20. Juli 1952 (Auszug)

\section{1.) Gebäudefragen}

Durch die Anordnung der Zentralen Kommission vom 19.7.52, in der untersagt wird, bei der Unterbringung der neuen Bezirks- und Kreisverwaltungen auf Wohnraum zurückzugreifen, werden sowohl bei den Bezirksverwaltungen in Cottbus und Frankfurt als auch in einer Reihe von Kreisen erhebliche Schwierigkeiten bei der Unterbringung der einzelnen Verwaltungen auftreten. Aus diesem Grunde werden vor allem bei einigen Kreisen Baracken aufgestellt werden. [...]

\section{2.) Bezirksräte und Bezirkstage}

Über die Zusammensetzung der Bezirksräte und Bezirkstage für alle drei Bezirke des Landes Brandenburg wurde in einer Sitzung des Landesblocks volle Einigung erreicht. [...] An der personellen Besetzung der Bezirksräte und Bezirkstage wird gearbeitet, so

263 Vgl. Dok. 14.

264 Zu Rudolf Jahn vgl. Dok. 11, Anm. 260. 
dass am Dienstag, den 22.7.52, die gesamte Liste dem Sekretariat der Landesleitung zur Bestätigung vorliegt.

Die Vorbereitungen für die Durchführung der ersten Sitzungen der Bezirkstage am 29.7.52 und der ersten Sitzung der Bezirksräte am 30.7.52 sind in allen drei Bezirken begonnen.

\section{3.) Bezirksverwaltung}

Die Feinstruktur und der entsprechende Stellenplan für den Aufbau der Bezirksverwaltungen traf am 19.7. von der Stellenplankommission der Zentralen Kommission für Staatliche Kontrolle ein. Auf der Aufstellung der Struktur- und Stellenpläne für alle drei Bezirke mit den entsprechenden Tätigkeitsmerkmalen wird z. Zt. gearbeitet, ebenso an der personellen Besetzung des Stellenplanes und der Mittelberechnung.

Zu klären wäre noch eine Frage. Im ersten Nachtrag zum Strukturplan wird davon gesprochen, dass bei den Bezirksverwaltungen eine Staatliche Plankommission gebildet werden muss mit einem Vorsitzenden, in dessen Arbeitsbereich alle Fragen der Wirtschaftsplanung und Materialversorgung liegen. Soll dieser Vorsitzende der Plankommission genauso wie die anderen Abteilungsleiter einem Stellvertreter des Vorsitzenden unterstellt werden oder steht er außerhalb dieser Regelung? Die schnelle Klärung dieser Frage wäre sehr erwünscht.

\section{4.) Überleitung}

Alle Ministerien und Hauptabteilungen der Regierung des Landes Brandenburg haben von den Übergeordneten Ministerien bzw. Staatssekretariaten der Regierung der DDR ihre Überleitungsvorschriften erhalten. Die für die Länder vorgesehenen Instrukteure sind im Laufe des 18.7.52 eingetroffen und haben unter Anleitung und Kontrolle des Instrukteurs der Zentralen Koordinierungs- und Kontrollstelle für die Arbeit der Verwaltungsorgane ihre Arbeit aufgenommen. Die festgelegte Sitzung mit den Mitgliedern der drei Bezirkskommissionen hat am 18.7. stattgefunden.

Die Org.-Kommissionen in den Ministerien und Hauptabteilungen der Landesregierung Brandenburg haben entsprechend den Überleitungsvorschriften nach einem Plan ihre Arbeit ebenfalls in Angriff genommen.

\section{5.) Schwierigkeiten und Unklarheiten}

Hier verweise ich zunächst noch einmal auf den letzten Satz zum Punkt 3 Bezirksverwaltungen. Außerdem wird mir von meiner Hauptabteilung Wirtschaftsplanung gesagt, dass es folgende Unklarheiten gibt: 
„Die Fachministerien des Landes erhalten aus den Fachministerien der DDR Anweisungen, nach denen sie ca. Mitte August Übersichten über den Planvorschlag 1953 für das Land geben sollen. Durch diese Anweisungen entsteht Konfusion, da die bisherigen Anweisungen der Staatlichen Plankommission die Erarbeitung der Planvorschläge für 1953 nach der neuen Struktur vorsehen. Da die neuen Bezirksräte ab 1. August arbeiten sollen, ihre Organe ab 15.8.52, müssten die den Betrieben und Kreisen gegebenen Fristen für die Aufstellung des Planvorschlages 1953 wesentlich gekürzt werden, wenn sie überhaupt ihre Planvorschläge noch bis zu einer arbeitsfähigen Landesregierung bringen wollen. Das ist mit Rücksicht auf die Qualität des Planes nicht zu verantworten.“

Des Weiteren bitte ich um Mitteilung, ob sich in Bezug auf das Amt für Reparationen etwas geändert oder ob das Amt für Reparationen weiterhin im Landesmaßstab in derselben Form wie jetzt seine Arbeit weiter leistet. Für diesen Fall und auch für die Frage der Abwicklungskommissionen fehlt dann allerdings noch eine Klärung in Bezug auf die Finanzierung dieser Arbeit. Es müsste also dann ein kurz befristeter Stellenplan festgelegt werden.

[BLHA, Rep. 401, Nr. 58, Bl. 4-5]

Dokument 14: Bericht des Leitinstrukteurs ${ }^{265}$ für das Land Brandenburg, „über den Stand der Durchführung der Verwaltungsreform für die Bezirke Cottbus, Potsdam und Frankfurt (Oder)“, 21. Juli 1952 (Auszug)

1.) An der ersten Besprechung im Land Brandenburg, die am 17.7.52 um 15 Uhr beim Ministerpräsidenten stattfand, nahmen folgende Instrukteure teilt:

$\begin{array}{ll}\text { Ministerium der Finanzen } & - \text { Paulitz } \\ \text { Ministerium für Land- und Forstgut } & - \text { Becker } \\ \text { Ministerium für Volksbildung } & - \text { Kaste } \\ \text { Ministerium für Arbeit } & - \text { Voß } \\ \text { Ministerium für Gesundheitswesen } & - \text { Stettiner } \\ \text { Ministerium für Handel und Versorgung } & - \text { Schaumburg } \\ \text { Staatliche Plankommission } & - \text { Neser } \\ \text { Staatliche Verwaltung fürMaterialversorgung } & - \text { Wilke } \\ \text { Amt für Information } & - \text { Schulze } \\ \text { Statistisches Zentralamt } & - \text { Spiller } \\ \text { Staatliche Kommission für Kunstangelegenheiten } & - \text { Krüger } \\ \text { Staatssekretariat für Berufsausbildung } & - \text { Thode } \\ \text { Staatssekretariat für Nahrungs- und Genussmittelindustrie } & - \text { Bartels } \\ \text { DVA. } & - \text { Fischer }\end{array}$

265 Vgl. Dok. 12, Anm. 262. 
Bis heute ist noch eingetroffen Ministerium für Aufbau Kollege Bönicke. Die Kollegin Voß vom Ministerium für Arbeit wurde am 19.7. von ihrer Dienststelle abberufen. Sie soll am 21.7.52 durch den Kollegen Zwiekirsch vertreten werden.

2.) Bereits vor unserem Eintreffen waren die Kommissionen gebildet und arbeiteten, desgleichen die Unterkommissionen. Org.-Komitees wurden in folgenden Ministerien und Hauptabteilungen gebildet: Ministerium des Innern, Ministerium der Finanzen, Ministerium für Land- und Forstwirtschaft, Ministerium für Volksbildung, Ministerium für Arbeit, Ministerium für Gesundheitswesen, Handel und Versorgung, Wirtschaftsplanung, Amt für Information, Statistisches Zentralamt, Landesverwaltung für Kunstangelegenheiten, Berufsausbildung und Aufbau.

3.) In der Durchführung der Aufgaben der Reorganisation wirkt sich erschwerend aus, dass von den Fachministerien bisher nur folgende Direktiven hier vorliegen:

1. Amt für Information

2. Abteilung für Kunstangelegenheiten

3. Generalstaatsanwaltschaft

4. Jugendfragen

5. Staatliche Plankommission

6. Sozialversicherung

7. Statistisches Zentralamt

Das gleiche gilt für die neuen Gemeindeverzeichnisse (Broschüre des Statistischen Zentralamtes), die unverzüglich den Instrukteuren und Fachministerien der Landesregierung zugeleitet werden müssen.

Im Erfahrungsaustausch mit den Leitinstrukteuren der Fachministerien wurden Widersprüche in den Direktiven der verschiedenen Fachministerien festgestellt, deren Klärung schnellstens zentral erfolgen muss. Z. B. bei der Staatlichen Plankommission und dem Ministerium für Land- und Forstwirtschaft oder Plankommission und Statistisches Zentralamt. Nähere Angaben darüber beinhalten die Berichte der Instrukteure in den Fachministerien.

In der dem Ministerpräsidenten zugestellten Direktive des MdI der DDR werden abweichend von unserer Terminologie ständig Bezeichnungen wie „Innere Verwaltung“, „Bezirks- und Kreisräte für Inneres“, „Referat für Kirchenfragen bei der inneren Verwaltung“, „Leiter Abteilung Schutz des Volkseigentums“ usw. verwendet.

Um Irrtümer zu vermeiden, ist es notwendig, diese Direktiven nochmals zu überarbeiten und der allgemeinen Terminologie anzupassen.

Schwierigkeiten entstehen in einzelnen Fällen durch kurzfristige Einstellungen in die VP. Es wird vorgeschlagen, dass sich die Werbekommission wegen des Einstellungstermins mit den zuständigen Personalabteilungen abstimmt, damit die Durchführung der Reorganisation nicht gefährdet wird.

Dem Prinzip der Sparsamkeit widersprechen einige Direktiven der Fachministerien, die besagen, dass sämtliches Inventar auf die Bezirke verteilt und dahin überführt werden soll. Da in vielen Fällen die Räte der Bezirke in Gebäuden untergebracht wer- 
den, die z. Zt. von anderen Verwaltungen benutzt werden, welche jetzt Gebäude in der Landeshauptstadt erhalten, wird vorgeschlagen, dass Mobiliar nur in solchen Fällen überführt werden darf, wo dieses am neuen Sitz nicht vorhanden ist.

4.) Alle Instrukteure wurden angewiesen, die eingeleiteten Maßnahmen auf ihrem Fachgebiet zu überprüfen, die gestellten Aufgaben mit der Direktive abzustimmen und einen Arbeitsplan bis zum 26.7. aufzustellen, nach dem sie die Fachministerien und Hauptabteilungen anleiten und kontrollieren.

5.) Besprechung mit dem Innenminister, Fragen der Grenzkreise betreffend.

Die aufgrund der Anweisung des Ministers Zaisser ${ }^{266}$ vom 4.7.52 zu bildenden Landes- und Kreiskommissionen für den Grenzkreis Westprignitz bestehen und arbeiten. Die Landeskommission berichtet termingemäß an die zentrale Regierungskommission. Weitere Kommissionen sind in anderen Kreisen nicht gebildet worden.

Besondere Schwierigkeiten bei der weiteren Bewirtschaftung der frei gewordenen Bauernwirtschaften bestehen nicht. Die Einbringung der Ernte erscheint gesichert. $[\ldots]$

6.) Zur Frage der personellen Veränderungen betont Innenminister, Kollege Lentzsch, ${ }^{267}$ dass an ihn keine Weisungen oder Listen von der zentralen Kommission gelangt sind. Er habe das auf telefonische Anfrage bereits mitgeteilt. Die operative zentrale Kommission hat die Listen an die Landesleitung der Partei Brandenburg gegeben. Erst vor einigen Tagen hat er daher die Listen mit den personellen Veränderungen erhalten. Die werden z. Zt. in der Personalabteilung vom Kollegen Maier überprüft. Innenminister Lentzsch wurde nochmals auf die Notwendigkeit der unbedingten Einhaltung der arbeitsrechtlichen Bestimmungen hingewiesen.

Zur Frage der Wasserversorgung im Raum von Berlin erklärte er, dass diese bei allen genannten Objekten gesichert ist, wo das noch nicht geschehen ist, kann sofort bei eintretendem Bedarf unsere Wasserversorgung in Aktion treten.

7.) Innenminister Kollege Lentzsch kritisierte die schlechte Verwaltungsarbeit der Koordinierungs- und Kontrollstelle für die Arbeit der Verwaltungsorgane. Es kommt häufig vor, dass unsere Schreiben ohne Datum und ohne Aktenzeichen abgesandt werden, z. B. das über die personellen Veränderungen.

Die Anweisung des Ministeriums für Staatssicherheit vom 4.7.52 ist von diesem als GVS, von uns aber nur als vertraulich versandt worden. Da aus der GVS nicht zu ersehen war, ob der Inhalt auch den Landräten mitgeteilt worden ist, habe er unser Schrei-

266 Wilhelm Zaisser (1893-1958) war seit 1950 Minister für Staatssicherheit; vgl. Müller-Enbergs, Wer war wer, S. 946.

267 Zu Bruno Lentzsch vgl. Dok. 2, Anm. 235. 
ben vertraulich an den Kreis Westprignitz weitergegeben. Damit habe er, wenn auch nicht formal, so aber sachlich gegen die Bestimmungen über GVS verstoßen.

Mit den Erfordernissen der Wachsamkeit ist es nicht vereinbar, dass wir den Landräten direkt Weisungen erteilen, ohne die Landesregierung zu verständigen. Die Landräte fragen bei der Landesregierung zurück, ehe sie die Weisungen durchführen. Oftmals können die Landesregierungen keine Auskunft geben, weil sie selbst die Schreiben nicht kennen. Unter drei von den Landräten eingesandten Schreiben der letzten Zeit befand sich eine Fälschung mit der Unterschrift des Staatssekretärs Rumpf.

Die hier kritisierten Mängel müssen sofort beseitigt werden.

8.) Von der Landesleitung der Partei wurde dem Ministerpräsidenten mitgeteilt, dass von zentraler Stelle eine Änderung der Termine in Aussicht genommen ist, die sich auch in der Aufgabenstellung wesentlich auswirken wird. Z. B. sei beabsichtigt, die Reorganisation der Kreise noch durch die Landesregierung durchzuführen und die Überleitung in die Bezirke erst nach der Reorganisation der Kreise.

Auf meine Weisung wird im Staatsapparat an den bisher gestellten Terminen festgehalten, solange nicht von dort Gegenteiliges mitgeteilt wird.

[BLHA, Rep. 401, Nr. 58, Bl. 50-52]

Dokument 15: Aktennotiz des Staatssekretärs im Ministerium des Innern der DDR, Hans Warnke, ${ }^{268}$ zur „Begründung für die territoriale Einteilung““, 21. Juli 1952

Bei der territorialen Einteilung sind wir davon ausgegangen, die Kreise zu verkleinern und die Kreis- und Bezirkseinteilung nach ökonomischen und verkehrspolitischen Gesichtspunkten und auch so vorzunehmen, dass die verschiedenen Verwaltungen nach der gleichen Einteilung ihre Struktur vornehmen können. Aus diesen Gründen ist das ganze Küstengebiet zum Bezirk Rostock zusammengefasst. Das ist geschehen, damit die Organe der Seepolizei nur mit einer Verwaltungsstelle zu tun haben. Die Bezirkseinteilung an der Demarkationslinie ist so vorgenommen, dass von den 14 Bezirken nur vier mit Fragen der Demarkationslinie zu tun haben. Ebenso haben von den 14 Bezirken nur vier mit den Fragen der Staatsgrenze mit Polen etwas zu tun. Bei der Einteilung in Bezirke um Berlin herum sind die Kreise so gelegt, dass die Bevölkerung zu den Bezirksorten kommen kann, ohne über Berlin zu fahren. Darum sind die Kreise Templin und Prenzlau zum Bezirk Neubrandenburg genommen und der Kreis Perleberg zum Bezirk Schwerin. Auch der Kreis Bernau ist zum Bezirk Frankfurt genommen anstatt zu Potsdam.

$268 \mathrm{Zu}$ Hans Warnke vgl. Dok. 2, Anm. 231. 
Im Bezirk Rostock sind die beiden Kreise Grevesmühlen und Wismar geografisch und verkehrsmäßig günstiger nach Schwerin gelegen als nach Rostock. Trotzdem sind sie nach ernster Diskussion im Politbüro zu Rostock genommen.

Wismar ist neben Rostock die wichtigste Hafen- und Werftstadt. Sie musste schon deshalb mit nach Rostock verlegt werden.

Der Kreis Grevesmühlen hat gleichfalls einen Küstenstreifen von über $40 \mathrm{~km}$. Dort stehen die gleichen Fragen der Ordnung an der Küste, der Uferbefestigungen, der Ordnung in den Badeorten, und es sind dort z. Zt. 30 Fischer, die in zwei Genossenschaften zusammengeschlossen sind. Weil die Bahnverbindung, die Straßenverbindung und Autobusverbindung immer günstiger nach Wismar als nach Schwerin lag, ist als die größte Stadt für den sonst Agrarbezirk Grevesmühlen Wismar anzusehen. Die Bahnverbindung aus dem Kreise Grevesmühlen nach Wismar ist günstiger als nach Schwerin.

Bezirk Schwerin ist vorwiegend Agrargebiet. Es ist neu hinzugekommen der Kreis Perleberg, einmal um dadurch das Gebiet an der Demarkationslinie ganz in die Verwaltung Schwerin zu bringen, und zum anderen, weil die Verbindung von Perleberg mit Schwerin eine günstigere ist. Die Struktur von Perleberg ist gleich der Struktur der übrigen Kreise des Bezirks Schwerin. Die beiden Kreise Templin und Prenzlau sind zum Bezirk Neubrandenburg gekommen, weil sie verkehrsmäßig nach Neubrandenburg günstiger liegen, insbesondere aber damit die Bevölkerung, wenn sie mit der Bahn nach Potsdam will, nicht gezwungen ist, durch Berlin zu fahren.

In Sachsen-Anhalt sind nur zwei Bezirke gebildet, weil die geografische Lage schwer eine neue Bezirksstadt finden lässt. Darum sind die Kreise Liebenwerda, Herzberg und Jessen aus dem bisherigen Land Sachsen-Anhalt herausgenommen.

Das Land Thüringen ist in drei Bezirke geteilt, wobei der Bezirk Suhl ein nur kleiner Bezirk mit acht Kreisen und 550.000 Einwohnern wird. Wenn dieser Bezirk nicht gebildet wird, wird der Bezirk Erfurt zu groß. Außerdem sind die Verkehrsverhältnisse wegen des Thüringer Waldes derart, dass die Vergrößerung des Bezirks Suhl schwer war.

Bei der Bildung der Bezirke Gera und Chemnitz hat es eine Diskussion gegeben, um die Textilindustrie unter eine Verwaltung zu bekommen, einen weiteren Bezirk Plauen zu bilden. Es ist davon abgesehen, weil das eigentliche Textilgebiet sich ausdehnt bis in den Kreis Gera hinein, aber auch um Chemnitz herum. Es wären doch nicht die entscheidenden Textilbetriebe unter eine Verwaltung gebracht worden. Es stand die Frage, dann die Kreise um Plauen herum nach Gera einzugliedern. Auch davon ist abgesehen, weil damit das gewünschte Ziel, die Textilindustrie unter eine Verwaltung zu bringen, nicht erreicht wird. 
Es war für den Bezirk Chemnitz entscheidend, dass die Steinkohle in einem Bezirk vereinigt wird. Die Kohle liegt in den Kreisen Stolberg, Ölsen, Zwickau, aber auch in diesen Kreisen und in den Kreisen nördlich davon liegt starke Textilindustrie, sodass eine Trennung zwischen einem Steinkohlen- und einem Textilbezirk schwer möglich war.

Es ist der neue Bezirk Cottbus gebildet worden, weil in diesem Gebiet die Braunkohle besonders liegt. Weil die zukünftigen Hauptbraunkohlegebiete in Lübben und Lübbenau liegen und mit den Kohlengebieten um Senftenberg-Doberlug-Kirchhain zusammengehören, müssen diese Gebiete zusammengefasst werden. Aber auch in Hoyerswerda und in Weißwasser liegen Braunkohlengebiete, sodass auch diese beiden Kreise und das Gebiet um Ruhland aus dem Lande Sachsen dem neuen Bezirk Cottbus eingegliedert werden mussten. In diesem Bezirk liegen auch die neuen Brikettfabriken wie in Tattendorf und auch das neue Braunkohlenverhüttungskombinat in Lauchhammer.

In der beiliegenden Anlage sind die Grenzkreise mit der Zahl der Gemeinden und Einwohner ersichtlich. Daraus ist zu ersehen, dass die Grenzkreise in der Frage der Zahl der Gemeinden über dem Durchschnitt der übrigen 194 Kreise liegen, in der Frage der Einwohner unter dem Durchschnitt. Die bisherige Kreiseinteilung ergibt, dass zu einem Kreis 81 Gemeinden mit 118.000 Einwohnern zählten.

Die neue Einteilung ergibt als Durchschnitt 50 Gemeinden mit 70.000 Einwohnern. Der Durchschnitt der Grenzkreise ergibt 61 Gemeinden mit 54.000 Einwohnern.

Im Einzelnen ist dazu folgendes zu sagen:

Der Kreis Grevesmühlen ist um ca. 40 Gemeinden verkleinert, und zwar durch die Bildung des neuen Kreises Gadebusch. Eine Verkleinerung durch Bildung des Kreises Schönberg ist diskutiert, müsste aber abgelehnt werden, weil Schönberg zu nahe an der Demarkationslinie liegt.

Der Kreis Hagenow ist der größte Kreis in Bezug auf Gemeinden in der DDR. Es ist in mehreren Sitzungen über diese Frage mit den Mecklenburger Genossen diskutiert. Eine andere Einteilung ist wegen der Lage nicht möglich.

Die größte und wichtigste Stadt ist Boizenburg mit seiner Werft und seiner Plattenfabrik. Boizenburg liegt unmittelbar an der Zonengrenze und kommt deshalb als Kreisstadt nicht in Frage. Der nächst größere Ort ist Zarenthin, liegt ebenfalls unmittelbar an der Zonengrenze. Der Ort Wittenburg ist eine kleine Stadt mit 6.840 Einwohnern.

Bei der Benennung von Wittenburg als Kreisstadt könnte dies nur ein kleiner Kreis mit ca. 15-20 Gemeinden werden, oder es müsste die Bevölkerung, wenn sie zur Kreisstadt will, über die bisherige Kreisstadt Hagenow fahren. Das ist unzweckmäßig. Es ist des- 
halb vorgeschlagen, die Kreisverwaltung dieses Kreises besonders zu stärken, damit sie ständig Instrukteure in den entlegenen Orten für ein festes Gebiet einsetzen kann.

Auch der Kreis Ludwigslust mit 82 Gemeinden und 72.000 Einwohnern ist sehr groß. Die nächst größere Stadt ist Dömitz, liegt direkt an der Interzonengrenze. Die Stadt Cleve liegt nördlich von Ludwigslust, kann also auch keine entscheidende Erleichterung bringen, Grabow liegt noch $5 \mathrm{~km}$ von Ludwigslust entfernt, kann auch keine Erleichterung bringen. Lenzen wiederum liegt an der Demarkationsgrenze.

Der Kreis Ludwigslust ist um einige Orte vergrößert worden. Damit ist erreicht, dass der Kreis Perleberg verkleinert ist und keine Orte an der Demarkationslinie zu betreuen hat.

Der Kreis Salzwedel hat 70 Gemeinden mit 54.000 Einwohnern. Ein anderer größerer Ort liegt im Kreise nicht. Salzwedel selbst liegt nur $5 \mathrm{~km}$ von der Zonengrenze entfernt.

Auch im Kreis Haldensleben ist kein größerer Ort, der als Kreisstadt in Frage käme.

Der Kreis Nordhausen mit 69 Gemeinden und 126.000 Einwohnern ist verhältnismäßig sehr groß, aber auch dort ist kein großer Ort, wo eine Kreisverwaltung untergebracht werden kann. Der bisherige Kreis Heiligenstadt ist geteilt in Worbis und Heiligenstadt. Eine weitere Einteilung lässt sich nicht vornehmen.

Der Kreis Mühlhausen gilt auch als Grenzkreis, hat aber nur fünf Orte an der Grenze zu liegen.

Der Kreis Eisenach lässt sich deshalb schwer teilen, weil die beiden größeren Orte Kreuzburg und Bad Berka unmittelbar an der Zonengrenze liegen und der größte Teil der Einwohner in Eisenach selbst wohnt.

Der Kreis Bad Salzungen mit 83 Gemeinden und 88.000 Einwohnern ist ernstlich besprochen worden. Es sind die verschiedenen Varianten erörtert, um auch diesen Kreis zu verkleinern. Wegen der Verkehrsverbindungen, die durch den Thüringer Wald bedingt sind, lässt sich auch hier eine Verkleinerung des Kreises nicht mehr vornehmen.

Dasselbe trifft zu für den Kreis Meiningen, wonach Untermaßfeld wegen der dortigen äußerst angespannten Gebäudefrage wegen des großen Werkes keine Verwaltung eingerichtet werden kann und Römhild zu nahe an der Grenze liegt.

Der Kreis Hildburghausen ist gleichfalls ernstlich besprochen, aber er ist mit 96 Gemeinden und 67.000 Einwohnern immer noch ein verhältnismäßig großer Kreis. Aber auch hier lässt sich keine Teilung vornehmen, weil die größeren Orte in der 5-km-Zone liegen. 
Der Kreis Saalfeld hat nur vier Orte im Grenzgebiet zu liegen. Der Kreis Plauen hat gleichfalls nur vier Orte im Grenzgebiet. Der Kreis Oelsnitz ist mit 75 Gemeinden noch ein verhältnismäßig großer Kreis. Aber auch hier lässt sich eine Teilung schwer durchführen, weil der größte Ort Bad Elster im 5-km-Streifen liegt und Adorf 6 km.

[BArch, DY 30/IV 2/13/50, Bl. 258-262]

Dokument 16: Protokoll einer Besprechung der Instrukteure der Fachministerien mit den Vorsitzenden der Bezirkskommissionen, 23. Juli 1952

Im ersten Punkt galt es festzustellen, welche Schwierigkeiten die Instrukteure der Fachministerien bei der Durchführung ihrer Reorganisationsaufgaben haben.

\section{Instrukteur des Finanzministeriums}

In der Landesfinanzdirektion kann wegen Fehlen des Strukturplanes die Arbeit nicht termingemäß durchgeführt werden. Es besteht eine Tendenz der Fluktuation, der man nicht entgegentreten kann, weil man nicht weiß, wen man auf welche Stelle setzt. Nach Angabe des Finanzministeriums kommt der Strukturplan erst Ende der Woche.

\section{Instrukteur des Staatssekretariats für Nahrungs- und Genussmittelindustrie}

Hier steht die Frage genau wie im Finanzministerium. So weit bekannt, ist der Strukturplan bis heute noch nicht diskutabel.

Der Ministerpräsident forderte die Instrukteure der Fachministerien auf, ihm bis morgen Vormittag im Telegrammstil einen kurzen Bericht über außerdem vorhandene Schwierigkeiten zu geben, damit die Besprechung durch die Diskussion über diesen Punkt nicht unnötig hinausgezögert werden muss.

Der Instrukteur des Staatssekretariats für Erfassung und Aufkauf teilt mit, dass sich die Hauptabteilung Erfassung u. Aufkauf von ihren Kreisdienststellen Drei-Tagesmeldungen über den Stand der Erfassung geben lässt, d. h. über den Stand der Erfüllung des Volkswirtschaftsplanes, um danach die Aufteilung auf die Bezirke und Gemeinden vornehmen zu können.

Der Ministerpräsident äußert dazu, dass es nicht sein darf, dass jede Kreisabteilung alle drei Tage einen Sonderkurier nach Potsdam schickt, sondern dass man hier koordinieren muss zwischen den einzelnen Fachabteilungen, sodass nur ein Sonderkurier nötig ist.

Die Genossin Instrukteurin der Staatlichen Plankommission erklärt, dass aus der Hauptabteilung Wirtschaftsplanung ca. elf Genossen und Kollegen sich für den Dienst in 
der Volkspolizei gemeldet haben, die teilweise für wichtige Funktionen in den Bezirken vorgesehen sind. Dadurch ist die reibungslose Durchführung der Reorganisation nicht gewährleistet.

Die Instrukteure wurden vom Ministerpräsidenten aufgefordert, an die Vorsitzenden der Bezirkskommissionen zu melden, welche Kollegen in den Bezirken für welche Funktionen vorgesehen sind. Das Sekretariat der Landesleitung wird dann von Fall zu Fall entscheiden über den weiteren Einsatz, da es politisch falsch wäre, wenn man die Werbung für die VP während der Zeit der Reorganisation grundsätzlich vernachlässigen würde.

Der Leitinstrukteur Genosse Schulz stellte die Frage, welche Vorsitzenden der Bezirkskommissionen bzw. Unterkommissionen und Vorsitzenden der Org.-Komitees anwesend sind.

a) Potsdam Vorsitzender der Bezirkskommission und Sekretär Vorsitzender der Unterkommission territoriale Fragen

b) Cottbus Vorsitzender der Gebäude- und Überleitungskommission

c) Frankfurt Vorsitzende der Gebäude- und Überleitungskommission

Außerdem fragte er, was getan wurde, damit am 30.7.52 der Rat des Bezirkes seine Arbeit aufnehmen kann.

Bis zum 28.7.52 ist von den Vorsitzenden der Org.-Komitees zu berichten, ob und inwieweit die Bestätigung

a) der Abgeordneten und

b) der Räte der Bezirke geklärt ist.

c) Was wurde zur Popularisierung der Abgeordneten getan?

\section{Überleitungsfragen}

Wo werden die einzelnen Fachabteilungen untergebracht?

Diese Frage ist an die Instrukteure zu beantworten, damit diese sie an ihre Fachministerien weitergeben können.

$\begin{array}{ll}\text { Potsdam } & \text { Heinrich-Mann-Allee } 107 \\ \text { Cottbus } & \text { Neuer Markt } 5 \\ \text { Frankfurt } & \text { Im jetzigen Gebäude der Kreisverwaltung Große Scharrnstraße }\end{array}$

Nach einer breiten Diskussion über die Aufgaben der Überleitungskommission wurde herausgearbeitet, dass es nicht Aufgabe der Überleitungskommission sein kann, den gesamten Umzug zu organisieren, sondern dass es ihre Aufgabe ist, durch Stichproben in den Fachministerien festzustellen, inwieweit die Überleitung vorbereitet ist. 
Bis zum 29.7.52 haben die Vorsitzenden der Bezirke einen festliegenden Umzugsplan an den Leitinstrukteur - Genosse Schulz - zu geben.

\section{Kaderfragen}

Was wurde getan, um die fehlenden Kader in den Bezirken zu ersetzen und was wurde zur Unterbringung der in Potsdam verbleibenden Kader getan?

Ministerpräsident: Über die Kader, die unter die Nomenklatur der Landesleitung fallen, entscheidet die Partei.

Außerdem hat die Hauptabteilung Personal des Innenministeriums mit den Personalleitern der Ministerien gesprochen, dass alle freiwerdenden Kader gemeldet werden, sodass man über den Einsatz dieser Menschen verfügen kann.

Die Kaderfragen für die Besetzung der Bezirke und Kreise wird man nicht alle in Potsdam klären können. Man muss sich die Kräfte an der Basis suchen.

Kräfte, die nach der Reorganisation keine Verwendung mehr finden, werden der Abt. Arbeitskraft zur Verfügung gestellt.

Abschließend stellt der Ministerpräsident fest, dass eine Besprechung in diesem Rahmen unfruchtbar ist. Der Genosse Leitinstrukteur soll sich für bestimmte zu behandelnde Fragen die jeweils zuständigen Genossen heranholen. Außerdem ist es notwendig, dass für zu behandelnde Fragen bestimmte Vorschläge gemacht werden, sodass nicht die Gefahr besteht, dass die Diskussion abwegig und planlos verläuft.

[BLHA, Rep. 401, Nr. 58, Bl. 53-54]

Dokument 17: Direktive der Koordinierungs- und Kontrollstelle für die Arbeit der Verwaltungsorgane beim Ministerpräsidenten der DDR „für die Vorbereitung der Durchführung der konstituierenden Sitzung des Bezirkstages“", 24. Juli 1952

\section{Vorbereitung der Sitzung}

1.) Die Einberufung der konstituierenden Sitzung des Bezirkstages hat gemäß dem Beschluss des Ministerrates der Regierung der Deutschen Demokratischen Republik vom 24.7.1952 durch die Bezirkskommission zu erfolgen. Die erste Sitzung des Bezirkstages ist in der Zeit vom 29.7. bis spätestens 5.8.1952 in der Bezirksstadt durchzuführen. 
2.) Die Einberufung soll so erfolgen, dass alle Abgeordneten des Bezirkstages eine schriftliche Einladung unter Bekanntgabe des Tagesordnungsvorschlages durch den Vorsitzenden der Bezirkskommission erhalten. Außerdem ist eine Bekanntmachung über die Einberufung des Bezirkstages in der Presse notwendig.

3.) Die Teilnahme an der konstituierenden Sitzung des Bezirkstages ist eine Ehre und erfolgt durch besondere Einladung. Die Einladung ergeht vom Vorsitzenden der Bezirkskommission an die besten und verdientesten Bürger, insbesondere Aktivisten, Meisterbauern, verdiente Lehrer und Ärzte, Wissenschaftler, Künstler sowie Vertreter der Parteien und Massenorganisationen. Zur Popularisierung der Beschlüsse des Bezirkstages ist ebenfalls die Presse und möglichst auch der Rundfunk einzuladen.

4.) Für jeden Abgeordneten des Bezirkstages ist folgendes Material vorzubereiten und in der Sitzung auszuhändigen:

a) Die Tagesordnung der Sitzung

b) Das Gesetz der Volkskammer über die weitere Demokratisierung des Aufbaus und der Arbeitsweise der staatlichen Organe in den Ländern der Deutschen Demokratischen Republik vom 23.7.1952. ${ }^{269}$

c) Die Verordnung der Regierung der Deutschen Demokratischen Republik über den Aufbau und die Arbeitsweise der staatlichen Organe des Bezirkes und des Kreises, ${ }^{270}$

d) das Gesetz des Landtages über die weitere Demokratisierung des Aufbaus und der Arbeitsweise der staatlichen Organe im Land vom 25.7.1952 271

5.) Der Vorsitzende der Bezirkskommission ist dafür verantwortlich, dass für die Durchführung der Sitzung des Bezirkstages die erforderlichen technischen Kräfte zur Verfügung gestellt werden.

269 Das „Gesetz über die weitere Demokratisierung des Aufbaus und der Arbeitsweise der staatlichen Organe in den Ländern der Deutschen Demokratischen Republik" vom 23. Juli 1952 ist abgedruckt in Dokumente 1949-1961, S. 99-101, sowie im Gesetzblatt der DDR, Teil I, 1952, S. 613-614.

270 Die „Ordnung über den Aufbau und die Arbeitsweise der staatlichen Organe der Bezirke“ vom 24. Juli 1952 ist abgedruckt in Dokumente 1949-1961, S. 101-104, sowie im Gesetzblatt der DDR, Teil I, 1952, S. 621-623, die entsprechende Ordnung für die Kreise vom selben Tag in ebd., S. $623-625$.

271 Das „Gesetz über die weitere Demokratisierung des Aufbaus und der Arbeitsweise der staatlichen Organe im Lande Brandenburg“" ist unter dem Datum 24. Juli 1952 abgedruckt in Akten und Verhandlungen, Bd. 3, S. 437-438. Die ausführliche Begründung des Gesetzes durch brandenburgischen Ministerpräsidenten, Rudolf Jahn, findet sich ebd., S. 439-444, sowie auszugsweise in Dokumente 1949-1961, S. 104-106. 


\section{Tagesordnung}

Die Tagesordnung für die konstituierende Sitzung des Bezirkstages wird vom Vorsitzenden der Bezirkskommission vorgeschlagen. Sie muss in der Sitzung durch den Bezirkstag bestätigt werden. Es wird folgende Tagesordnung vorgeschlagen:

1.) Eröffnung der konstituierenden Sitzung des Bezirkstages durch den ältesten Abgeordneten.

2.) Wahl des Tagungsvorsitzenden und zweier Stellvertreter aus der Mitte der Abgeordneten.

3.) Beschlussfassung über die Tagesordnung.

4.) Referat eines Abgeordneten des Bezirkstages über die Notwendigkeit der weiteren Demokratisierung des Aufbaues und der Arbeitsweise der staatlichen Organe sowie Begründung der Vorschläge für den Rat des Bezirks und für die ständigen Kommissionen.

5.) Vorstellung und Wahl des Rates des Bezirks:
a) des Vorsitzenden
b) der fünf Stellvertreter
c) des Sekretärs
d) der Mitglieder

6.) Wahl der ständigen Kommissionen des Bezirkstages sowie Bestimmung deren Vorsitzenden:
a) Haushalt
b) Landwirtschaft und ländliches Bauwesen
c) Gesundheitswesen und Sozialfürsorge
d) Volksbildung
e) Handel
f) Verkehr
g) Wohnungswesen und Kommunalwirtschaft
h) Kulturelle Massenarbeit
i) Örtliche Polizei und Justiz
k) Industrie

7.) Rede des Vorsitzenden des Rates des Bezirkes.

8.) Beschlussfassung über die Erteilung eines Auftrages an den Rat des Bezirkes auf Ausarbeitung eines Arbeitsplanes und Vorlage dieses Arbeitsplanes in der nächsten Sitzung des Bezirkstages. 


\section{Erläuterung zur Tagesordnung:}

\section{Zu Punkt 1)}

Der älteste Abgeordnete muss ermittelt und rechtzeitig benachrichtigt werden. Der älteste Abgeordnete verliest die Namen der Abgeordneten des Landtages, die im Bezirkstag ihre Tätigkeit als Volksvertreter fortsetzen; die Namen der von dem Ausschuss der Nationalen Front des Bezirks benannten Abgeordneten, deren Nominierung die Zustimmung der Werktätigen gefunden hat. Anschließend stellt er die Konstituierung des Bezirkstages fest.

\section{Zu Punkt 2)}

Die Wahl des Tagungsvorsitzenden und der zwei Stellvertreter muss vorbereitet werden.

\section{Zu Punkt 5)}

Zunächst erfolgt die Wahl des Rates in seiner Gesamtheit. Anschließend werden der Vorsitzende, die fünf Stellvertreter und der Sekretär für ihre Funktionen besonders bestimmt. Die Abstimmung ist offen.

\section{Zu Punkt 6)}

Alle Mitglieder der ständigen Kommissionen werden aus der Mitte des Bezirkstages gewählt. Aus den Mitgliedern des Rates sollen keine Abgeordneten in die Kommission gewählt werden. Die Vorsitzenden jeder einzelnen Kommission sind besonders bei der Wahl zu bestimmen.

\section{Popularisierung der Beschlüsse des Bezirkstages}

1.) In der Zeit zwischen dem 1. und 10.8.1952 ist eine Lektion für alle Abgeordneten des Bezirkstages zu organisieren mit dem Thema:

„Demokratisierung des Aufbaus und der Arbeit der örtlichen Organe der Staatsgewalt."

Verantwortlich für die Durchführung dieser Lektion sind die Vorsitzenden der Räte der Bezirke.

2.) Im Anschluss an die Lektion berichten alle Abgeordneten nach einem vom Rat des Bezirkes in Verbindung mit dem Ausschuss der Nationalen Front aufzustellenden Plan in den Aufklärungslokalen der Nationalen Front über das Gesetz der Volkskammer, die Verordnung der Regierung, den Beschluss des Landtages und die Bildung des Bezirkstages.

3.) In Verbindung mit der Presse ist dafür Sorge zu tragen, dass die Abgeordneten des Bezirkstages und die Mitglieder des Rates des Bezirkes, insbesondere die Helden der Arbeit, Aktivisten, Meisterbauern, Wissenschaftlicher, Künstler und andere popularisiert werden.

[BLHA, Rep. 401, Nr. 70, Bl. 202-204] 
Dokument 18: Direktive der Koordinierungs- und Kontrollstelle für die Arbeit der Verwaltungsorgane beim Ministerpräsidenten der DDR „für die Durchführung der konstituierenden Sitzung des Rates des Bezirkes“, 24. Juli 1952

A) Die konstituierende Sitzung des Rates des Bezirkes findet nicht später als zwei Tage nach der ersten Sitzung des Bezirkstages, in der der Rat des Bezirkes gewählt wird, statt.

B) Die Einberufung der Sitzung des Rates des Bezirkes erfolgt durch den Vorsitzenden.

C) Als Tagesordnung wird empfohlen:

1.) Eröffnung der 1. Sitzung des Rates durch den Vorsitzenden.

2.) Bekanntgabe der vom Vorsitzenden des Rates vorgenommenen Aufteilung der Aufgabengebiete (Abteilungen und Einrichtungen) auf den Vorsitzenden, jedem der fünf Stellvertreter und dem Sekretär.

(Hierzu wird anliegende Aufteilung vorgeschlagen).

3.) Beratung von Aufgaben, die vom Rat des Bezirkes zu lösen sind:

a) Schulung der Abgeordneten des Bezirkstages und Popularisierung der Beschlüsse in der Bevölkerung.

b) Aufbau der Abteilungen und Einrichtungen des Rates und Übernahme der Aufgabengebiete von den Organen der früheren Landesregierung bis zum 15.8.1952

c) Vorbereitung von Maßnahmen für die Überleitung der Aufgaben auf die neu gegliederten Kreise.

d) Festlegung von Maßnahmen zur Sicherung der Einbringung der Ernte und der Erfüllung der Erfassungspläne.

4.) Beschluss über die Vorbereitung des Arbeitsplanes des Rates des Bezirkes zur Vorlage vor dem Bezirkstag.

D) Über den Verlauf der Sitzung des Rates ist ein Protokoll anzufertigen, in dem die Beschlüsse des Rates genau formuliert sein müssen. Das vom Vorsitzenden und Sekretär zu unterzeichnende Protokoll ist an die Koordinierungs- und Kontrollstelle für die Arbeit der Verwaltungsorgane in zweifacher Ausfertigung einzusenden.

\section{[Anlage: Aufteilung der Aufgabengebiete]}

\section{Vorsitzender:}

Plankommission

Abt. Kader

Abt. Jugendfragen und Sport

Förderung der Intelligenz

Kirchenfragen 


\section{Sekretär:}

Org.-Instrukteur-Abteilung

Abt. Information

Abt. Allgemeine Verwaltung

Abt. Vermessung

Rechtsstelle

Staatliches Eigentum

Personenstandswesen

Archiv

VS-Stelle

Stellvertreter:

Abt. Finanzen

Stellvertreter:

Abt. Industrie

Abt. Aufbau

Abt. Kommunale Wirtschaft

Abt. Verkehr

\section{Stellvertreter:}

Abt. Landwirtschaft

Abt. Erfassung und Aufkauf

Abt. Handel und Versorgung

\section{Stellvertreter:}

Abt. Arbeit und Berufsausbildung

Abt. Gesundheitswesen

\section{Stellvertreter:}

Abt. Kunst und kulturelle Massenarbeit

Abt. Volksbildung

Die Verteilung der Aufgabengebiete darf nicht schematisch erfolgen. Sie muss den örtlichen Verhältnissen angepasst werden, jedoch ist dabei zu beachten, dass die hier angegebenen Aufgabengebiete für den Vorsitzenden und den Sekretär nicht den Stellvertretern übertragen werden. Lediglich das Referat Kirchenfragen kann einem geeigneten Stellvertreter übergeben werden.

[BLHA, Rep. 401, Nr. 70, Bl. 205-206] 
Dokument 19: „Beschlussvorlage für die Präsidiumssitzung der Nationalen Front des demokratischen Deutschland vom 29.7.1952“, 24. Juli 1952

\section{Zum Tagesordnungspunkt 1: Bestätigung der neuen Bezirkstagsabgeordneten für die Bezirke Potsdam, Frankfurt (Oder) und Cottbus}

1. Das Präsidium bestätigt die vorgeschlagenen Abgeordneten für die Bezirkstage Potsdam, Frankfurt, Cottbus.

2. Die Mitglieder des Präsidiums veranlassen über ihre Landessekretariate, dass die Mitglieder ihrer Parteien und Organisationen, die als Abgeordnete in den Bezirkstagen Potsdam, Frankfurt, Cottbus tätig sind, sich den Kreisausschüssen der Nationalen Front im Monat August wöchentlich zweimal für Abhaltung von Sprechstunden mit ihren Wählern in den Aufklärungslokalen der Ausschüsse der Nationalen Front zur Verfügung stellen.

3. Das Landessekretariat wird beauftragt, den Kreisausschüssen entsprechende Anleitung zu geben. Die Kreissekretariate der Nationalen Front werden verpflichtet, einen Plan zu erarbeiten, in welchem Aufklärungslokal die Abgeordneten ihres Kreises ihre Sprechstunden mit der Bevölkerung durchführen.

Für diese Durchführung dieser Aufgaben ist verantwortlich das Landessekretariat.

\section{Zum Tagesordnungspunkt 2: Bericht über den Stand des Bodenreform-Baupro- gramms im Lande Brandenburg}

4. Zur Unterstützung der Planerfüllung des Bodenreform-Bauprogramms beschließt das Präsidium des Landesausschusses Brandenburg der Nationalen Front des demokratischen Deutschland:

Die Kreise Prenzlau, Ostprignitz, Ruppin, Angermünde, Templin, Westhavelland, Seelow und Oberbarnim werden in der Durchführung des Bodenreform-Bauprogramms vom Landesausschuss der Nationalen Front des demokratischen Deutschland und seinem Präsidium schwerpunktmäßig bearbeitet. Dazu sind folgende Aufgaben durchzuführen:

Die Kreisvorstände der Kreisausschüsse nehmen sofort in den nächsten Tagen bis spätestens 6.8.1952 einen Bericht des Landrates über den Stand der Erfüllung des Bodenreform-Bauprogramms des Kreises entgegen. Die Kreisvorstände beschließen daraufhin auf der Grundlage des Beschlusses des Präsidiums des Landesausschusses Brandenburg der Nationalen Front des demokratischen Deutschland vom 29.7. und des Ministerrats- 
beschlusses 4/52 Maßnahmen zur Aktivierung der Ortsausschüsse, der Entfaltung der gegenseitigen Hilfe, der Solidaritätshilfe der Bauarbeiter zu den Bauern, der Patenschaftshilfe von Nachbargemeinden, in denen das Bodenreform-Bauprogramm durchgeführt wird, und der Nutzbarmachung von örtlich vorhandenen Materialien. An diesen Kreisvorstandssitzungen nehmen Mitglieder des Präsidiums des Landesausschusses Brandenburg der Nationalen Front des demokratischen Deutschland teil und zwar für den Kreis Prenzlau

Kreis Ruppin

Kollege Nuß (FDJ)

Kreis Templin

Kollege Lohrisch (NDPD)

Kreis Angermünde

Kollege Pech (DBD)

Kreis Ostprignitz

Kollege Neddermeyer (VdgB) (BHG)

Kreis Westhavelland

Kollege Bombach ${ }^{272}$ (FDGB)

Termin: 15.8.1952

Kollege Seibt (SED)

Verantwortlich: 1. Landessekretär.

5. Das Landessekretariat der Nationalen Front des demokratischen Deutschland Brandenburg wird beauftragt, einen politisch-ideologischen Plan zur Mobilisierung aller Bevölkerungsschichten, verbunden mit Solidaritätsaktionen, vor allem in den Schwerpunkten des Landes zur Durchführung des Bodenreform-Bauprogramms aufzustellen. Das hat zu geschehen mit den Stellen der Verwaltung und den Vertretern der Parteien und Massenorganisationen.

Dieser Plan ist dem Präsidium des Landesausschusses der Nationalen Front des demokratischen Deutschland bis zum 10.8.1952 vorzulegen.

Hierbei sind besonders die Erfahrungen des Oderbruchhilfsprogramms auszuwerten. Verantwortlich: Kollege Klose und Kollege Cabbe.

6. Das Sekretariat des Landesausschusses wird beauftragt, in Durchführung der politischen Aufgaben das Argumentationsmaterial zur Durchführung des BodenreformBauprogramms, insbesondere zur verstärkten Anwendung der Naturbauweise in der gesamten Schulungsarbeit mit zum Inhalt zu nehmen.

Termin für die Behandlung des ersten Argumentationsmaterials in der Schulungsarbeit bis zum 15.8.1952.

In Zusammenarbeit mit der Landesregierung sind laufende Hinweise für die Argumentationen den Kreisausschüssen zu geben.

Verantwortlich: Landessekretariat der Nationalen Front.

7. Das Landessekretariat wird beauftragt, den Kreissekretariaten der Schwerpunktkreise ständige Anleitung zu geben und die Kontrolle der Beschlüsse durchzuführen. Mit den Kreissekretariaten der Nationalen Front ist monatlich ein Erfahrungsaustausch über den Stand des Bodenreform-Bauprogramms durchzuführen.

272 Erich Bombach (1908-1985) war zu diesem Zeitpunkt 1. Vorsitzender des Landesvorstandes des FDGB Brandenburg; vgl. Baumgartner, Biographisches Handbuch, S. 72. 
8. Die ersten Kreissekretäre der Kreisausschüsse der Nationalen Front der genannten Kreise geben monatlich den Kreisvorständen einen kritischen Bericht über den Stand des Bodenreformbauprogramms. Zu diesem Tagesordnungspunkt ist der Landrat und der Verantwortliche für das Bodenreformbauprogramm aus der Verwaltung hinzuzuziehen.

9. Die Durchführung des Bodenreform-Bauprogramms in den Kreisen Prenzlau und Ostprignitz erfordert besondere Maßnahmen, da z. Zt. nicht genügend Bauarbeiter im Kreis vorhanden sind. Um die Durchführung des Bodenreform-Bauprogramms zu gewährleisten, ist dort die Entfaltung der Solidaritätshilfe von erstrangiger Bedeutung. Um diese wichtige Aufgabe durchzuführen, ist es erforderlich, für die Kreise Prenzlau und Ostprignitz eine Instrukteurbrigade aus folgendem Personenkreis zusammenzustellen:

1) Leiter der Instrukteurbrigade: ein Instrukteur des Landesausschusses,

2) ein Vertreter der Landesregierung, Abt. Aufbau,

3) ein Instrukteur von der VdgB (BHG) und dem FDGB.

Die Instrukteurbrigade nimmt die Arbeit am 4.8.1952 auf.

10. Die Landesvorstände der Industriegewerkschaften und Gewerkschaften werden durch den Landesvorstand des FDGB angeleitet, dass ihre Kreisvorstände die gemeinsame Direktive des Bundesvorstandes des FDGB und des Büros des Präsidiums des Nationalrates der Nationalen Front des demokratischen Deutschland über die Verbesserung der Mitarbeit der Gewerkschaften in der Nationalen Front des demokratischen Deutschland schnellstens verwirklichen. Die besondere Hilfe des FDGB für die Durchführung des Bodenreform-Bauprogramms liegt in der Hilfe der Betriebe gegenüber den werktätigen Bauern auf der Grundlage der in der gemeinsamen Direktive unter Abschnitt IV vorgeschlagenen Freundschaftsverträge mit den Ortsausschüssen der Nationalen Front des demokratischen Deutschland.

Das Präsidiumsmitglied, Kollege Bombach, gibt dem Präsidium bis zum 15.8.1952 einen Überblick darüber

a) wie viel Freundschaftsvorträge wurden in den sechs Schwerpunktkreisen von den dort vorhandenen Betrieben mit den Ortsausschüssen abgeschlossen,

b) wie hat sich diese Hilfe bei der Durchführung des Bodenreform-Bauprogramms in der Solidaritätshilfe bemerkbar gemacht.

11. Der Plan zur Enttrümmerung der Kreise muss im unmittelbaren Zusammenhang mit dem Bodenreform-Bauprogramm zur Durchführung gebracht werden. Die bei der Enttrümmerung gewonnenen Materialien ermöglichen eine schnellere Durchführung des Bodenreform-Bauprogramms. Die Aufgabe der Ausschüsse der Nationalen Front des demokratischen Deutschland ist hierbei, die Bevölkerung für die Durchführung von Solidaritätsaktionen durch ihre Überzeugungsarbeit zu gewinnen. Aus diesem Grunde müssen sie einen ständigen Überblick über den Stand der Enttrümmerung im Kreise haben. 
Die Kreissekretariate und die Kreisvorstände der Kreisausschüsse der Nationalen Front des demokratischen Deutschland lassen sich regelmäßig von dem Kreisrat für Aufbau in der Kreisverwaltung über die Erfüllung des Enttrümmerungsplans berichten und beschließen Maßnahmen für die Mobilisierung der Bevölkerung zu Solidaritätsaktionen.

Verantwortlich: Kreisvorsitzender.

\section{Zum Tagesordnungspunkt 3: Vorbereitung der Landesausschusstagung im Monat August.}

12. Das Präsidium beschließt, den Landesausschuss am Freitag, dem 29.8.1952 zusammenzurufen. Das Landessekretariat wird beauftragt, dem Präsidium in seiner nächsten Sitzung den Plan für die Durchführung der Landesausschusstagung zu unterbreiten. Mit den Bundesausschussmitgliedern ist sofort Verbindung aufzunehmen, um sie für die Mitarbeit bei der Durchführung der Kreiskonferenzen im Monat August zu gewinnen.

Verantwortlich: 1. Landessekretär.

[BLHA, Rep. 401, Nr. 58, Bl. 301-304]

Dokument 20: Bericht an den Leitinstrukteur ${ }^{273}$ des Landes Brandenburg über den
„Instrukteureinsatz Verwaltungsreform Land Brandenburg“،, 28. Juli 1952 (Aus-
zug)

Gemäß Arbeitsplan für die Zeit vom 21. bis 26.7.52 fand am 21.7. eine Aussprache mit den Kollegen des Statistischen Landesamtes statt, die für die neuen Bezirke oder Kreisämter vorgesehen waren. Von den Befragten haben sich 15 für die Übersiedlung entschieden. Die anderen Kollegen wurden gebeten, bis Ende der Woche eine Stellungnahme abzugeben. Darüber hinaus haben sich fünf Kollegen für den Dienst bei der Volkspolizei gemeldet.

Mit der Gebäudekommission fand eine kurze Aussprache statt. Es konnte lediglich die Zustimmung erreicht werden, dass das Bezirksamt Potsdam in den Räumen des Landesamtes Potsdam verbleiben soll, um somit eine enge Verbindung mit der Hollerith-Abteilung zu haben. ${ }^{274}$ Jedoch ist hierfür die Zustimmung der zentralen Kommission noch erforderlich. Für die Bezirke steht die Entscheidung nach wie vor noch aus.

273 Vgl. Dok. 12, Anm. 262.

274 Das von dem US-Amerikaner Herman Hollerith Ende des 19. Jahrhunderts entwickelte, auf Lochkarten basierende Datenverarbeitungsverfahren bildete bis in die 1970er Jahre die wesentliche Grundlage für statistische Arbeiten auch in der DDR. 
Am 22.7. fand die im Arbeitsplan festgelegte Dienstbesprechung statt. [...]

Die für den 23.7. festgelegten Arbeitsbesprechungen der Abteilung mussten vertagt werden, da von Seiten des Ministerpräsidenten ein Gemeinschaftsempfang der Übertragung der Volkskammersitzung angeordnet war. Anschließend sollte eine Belegschaftsversammlung stattfinden, auf der der Amtsleiter verpflichtet war, die Verwaltungsreform noch einmal anzusprechen und zu erläutern. Die Arbeitsbesprechungen wurden auf Grund dessen für den 24. und 25.7. festgelegt.

Nachdem kurzfristig der Gemeinschaftsempfang abgesagt wurde, und die Belegschaftsversammlung wegen der Dienstreise des Amtsleiters verschoben werden musste, war ich nochmals bemüht, von der Gebäudekommission etwas Näheres zu erfahren. Leider waren konkrete Auskünfte nicht zu erreichen. Am Abend des 23.7. fand um 20.00 Uhr eine Besprechung beim Ministerpräsidenten Jahn mit allen Leitinstrukteuren und Vorsitzenden der Kommissionen statt. Die für uns sehr wichtige Frage der Gebäude und des Zeitpunkts der Überführung konnte auch hier nicht geklärt werden. Es war lediglich möglich, den Leitinstrukteuren einige organisatorische Fragen zu erläutern. Hier muss noch gesagt werden, dass das Fehlen der Struktur- und Stellenpläne, die bei den anderen Ministerien schon vorliegen, sich hindernd für die Arbeit bemerkbar machen.

Am 24.7. wurde Bezirk Cottbus gemeinsam mit dem Kollegen Wierick als zukünftiger Leiter des Bezirksamtes aufgesucht. Es war uns leider nur möglich, personelle Fragen und Fragen des Inventars zu klären, da, wie schon gesagt, über die Gebäude keine Entscheidung vorlag.

Anschließend wurden die Kreise Hoyerswerda und Liebenwerda aufgesucht. Hierbei handelt es sich um Kreise, die von Sachsen bzw. Sachsen-Anhalt in den Bezirk Cottbus übergehen. Der Zweck unseres Besuchs war, zunächst einmal Kontakt mit den Kreisen aufzunehmen, um darüber hinaus Kenntnis über die personelle Besetzung und das Inventar zu bekommen.

Im allgemeinen wurde festgestellt, dass sich auch in den Kreisen nunmehr eine gewisse Beunruhigung feststellen lässt, die durch das Fehlen der Stellenpläne wesentlich beeinflusst wird, da niemand weiß, wie in Zukunft die Kreisämter weiter personell besetzt werden.

Am 25.7. wurde gemeinsam mit dem Kollegen Ettlinger der Bezirk Frankfurt (Oder) aufgesucht. Hier fand auf Veranlassung der zentralen Kommission genauso wie in Cottbus eine Zusammenkunft der verschiedenen Kommissionsmitglieder des Bezirks mit der zentralen Kommission statt. Für uns war lediglich die eine Feststellung zu treffen, dass auch hier die Entscheidung über die Gebäude noch aussteht. Die Arbeit der Bezirkskommissionen war bisher noch sehr schleppend, da konkretere Anweisungen bisher fehlten. Lediglich die Gebäudekommission hat ihre entsprechenden Vorschläge eingereicht, während 
die Übergabekommission erst am Tage vorher die Direktiven erhalten hat und infolgedessen ihre Arbeit noch nicht aufnehmen konnte.

Für den Bezirk Frankfurt hängt die Umsiedlung davon ab, inwieweit es möglich sein wird, für die Kreisverwaltung, die nach Fürstenberg umziehen soll, die erforderlichen Räume zu beschaffen. Wie uns mitgeteilt wurde, ist ein Vorschlag nach Berlin gereicht worden, für die Kreisverwaltung in Fürstenberg Baracken aufzustellen, da andere Räume nicht zur Verfügung stehen.

Anschließend wurden die Kreise Freienwalde und Bernau besucht, um auch hier lediglich personelle Fragen und Fragen des Inventars durchzusprechen. Eine Anleitung der Kreise über den Rahmen der im Protokoll festgelegten Aufgaben ist leider nicht möglich, da eine Stellungnahme des Statistischen Zentralamtes über die weiteren Behandlungen des Materials noch aussteht.

Am 26.7. fand nochmals im Landesamt eine Besprechung mit dem Personalleiter statt, um die Frage der Übersiedlung einzelner Kollegen nochmals durchzusprechen. Hierbei musste festgestellt werden, dass die Arbeitsbesprechung in den einzelnen Abteilungen keine weiteren Zustimmungen zur Umsiedlung ergeben haben. Insgesamt haben sich nunmehr 20 Kolleginnen und Kollegen zur Umsiedlung bereit erklärt, 38 waren sich noch nicht recht klar darüber, 23 sind zur Entlassung vorgesehen, während der Rest und die 25 Kollegen der Hollerith-Abteilung in Potsdam verbleiben sollen.

Von den 20 zur Umsiedlung bereiten Kollegen gehen drei in den Bezirk Cottbus und sieben nach Frankfurt (Oder), während die anderen für die verschiedenen Kreise vorgesehen sind. Dadurch ergibt sich, dass die Leiter der Bezirksämter sich noch sehr stark mit der personellen Besetzung ihres Amtes zu beschäftigen haben.

Im Anschluss an diese Besprechung wurden die Abteilungsleiter nochmals befragt, inwieweit die übertragenen Aufgaben durchgeführt sind. Die für die Bezirke und Kreise einzurichtenden Mappen mit Rundschreiben und Beschlüsse der Regierung liegen am 31.7. termingemäß vor. Das Mobiliar ist inventarmäßig erfasst und für die Bezirke aufgeteilt. Nach Anordnung des Ministerpräsidenten soll das Mobiliar so wenig wie möglich transportiert werden, sondern in erster Linie soll auf vorhandenes Mobiliar in den Bezirken zurückgegriffen werden. Da aber zweifelhaft ist, dass in den Bezirken Möbel vorzufinden sind, wurde schon wie anfangs gesagt, die Aufteilung listenmäßig durchgeführt. Die Aufgliederung des im Landesamt vorhandenen Materials ist entsprechend der Vorschläge des Landesamts ebenfalls am 31.7. beendet, sodass, wenn andere Anweisungen des Statistischen Zentralamtes nicht gegeben werden, das Landesamt mit dem 1.8.52 zur Überführung bereit ist. 
Von Seiten der Buchhaltung wurde noch die Frage aufgeworfen, inwieweit dieselbe auf die Bezirke umzustellen sei und dass gegebenenfalls dann noch Karteikarten zu beschaffen seien.

Hiermit ist der gestellte Arbeitsplan in seinen wesentlichen Punkten erfüllt worden.

Es muss lediglich noch gesagt werden, dass über diesen Arbeitsplan hinaus täglich beim Hauptinstrukteur um 17.00 Uhr ein Erfahrungsaustausch stattfand. Hier war den Kollegen Instrukteuren die Möglichkeit gegeben, Zweifelsfragen zu klären.

Die dem Landesamt zur Verfügung gestellten 600 vorläufigen Gemeindeverzeichnisse wurden nach Rücksprache mit dem Ministerpräsidenten Jahn dem Ministerium des Innern zwecks weiterer Verteilung zugeleitet.

[BLHA, Rep. 401, Nr. 58, Bl. 64-67]

Dokument 21: Direktive des Ministeriums für Justiz der DDR ,über die Überleitung der Justizverwaltung und den neuen Gerichtsaufbau“, 31. Juli 1952

I.

1.) Für die grundsätzliche Ausarbeitung aller Maßnahmen zur Strukturveränderung in der Justiz ist im Ministerium der Justiz ein Organisationsstab gebildet worden. Die Leitung dieses Stabes hat der Staatssekretär Dr. Toeplitz. ${ }^{275}$ Sein Stellvertreter ist der Persönliche Referent des Ministers. Weitere Mitglieder des Organisationsstabes sind: Die Leiter und je ein weiterer Mitarbeiter der Hauptabteilungen I und II, der Personalleiter, der Leiter der Schulungsabteilung, der Leiter der Allgemeinen Verwaltung, der Haushaltsreferent und der Organisations-Instrukteur.

2.) Zur Anleitung der ab 1.8.52 in den bisherigen Ländern eingesetzten Brigaden und der Arbeit der Bezirksverwaltungen der Justiz ist im Ministerium eine zentrale Brigade gebildet worden. Die Leitung der Brigade hat Frau Ganske. Der Brigade gehören weiter die Abteilungsleiter Klühsendorf und Werk an, ferner als Stellvertreter die Kollegen Paetzold, Glück und Küster.

3.) Ab 1.8.52 werden in den bisherigen Ländern Brigaden zur operativen Durchführung der gesamten Strukturänderung, zur Verwirklichung der Stellenpläne und der Kaderbewegung, zur Unterbringung und Ausstattung der Bezirksverwaltungen und Gerichte

275 Heinrich Toeplitz (1914-1998) war seit 1950 Staatssekretär im Ministerium für Justiz der DDR; vgl. Müller-Enbergs, Wer war wer, S. 858. 
gebildet. Zusammensetzung: Hauptabteilungsleiter, Personalleiter, Leiter der Abteilung Rechtsprechung, Haushaltsreferent.

Die Hauptabteilungsleiter der Länder berichten alle 3 Tage Frau Ganske telefonisch über die geleistete Arbeit und auftretende Schwierigkeiten.

\section{Justizverwaltung}

1.) Ab 1.8.52 beginnt der Aufbau der Justizverwaltungen der Bezirke. Diese stehen auBerhalb der Organisation des Rates des Bezirkes und der allgemeinen Bezirksverwaltung. Sie sind unmittelbar dem Ministerium der Justiz unterstellt. Bis zum 15.8.52 muss der Aufbau der Bezirksverwaltungen der Justiz und die Übernahme der Geschäfte und Unterlagen der bisherigen Landesjustizverwaltungen abgeschlossen sein.

2.) Die Bezirksverwaltungen der Justiz gliedern sich in drei Abteilungen:

a) Rechtsprechung, Kontrolle und Statistik: Der Schwerpunkt dieser Abteilung wird in der Kontrolle der künftigen Kreisgerichte liegen. Sie wird zu diesem Zweck mit der erforderlichen Zahl von Inspekteuren besetzt.

b) Kader: In dieser Abteilung werden die bisher getrennten Personal- und Schulungsaufgaben zusammengefasst.

c) Haushalt und Verwaltung: Diese Abteilung bearbeitet die Haushaltfragen der Justiz im Bezirk, sowie die Aufgaben der allgemeinen Verwaltung.

3.) Für die Aufgabenstellung der Bezirksverwaltungen der Justiz ist der Grundsatz maßgebend, dass die Leiter der Gerichte nur die Verwaltungsfunktionen behalten werden, welche die Arbeit ihres eigenen Gerichts betreffen. Alle anderen Verwaltungsfunktionen, die bisher bei den Leitern der Gerichte lagen, werden auf die Bezirksverwaltungen der Justiz übergeleitet.

4.) Nach einer Entscheidung des Ministeriums der Finanzen der DDR wird der gesamte Justizhaushalt der Bezirke in den Republikhaushalt übernommen. Über die zukünftige Bearbeitung der Haushaltfragen und die Abgrenzung der Funktionen der Abteilungen Haushalt und Verwaltung der Bezirksverwaltungen gegenüber dem Ministerium der Justiz ergeht eine besondere Anweisung.

\section{Gerichte}

1.) Mit Wirkung vom 1.9.52 wird die neue Gerichtsverfassung in Kraft treten. Damit fallen die Oberlandesgerichte fort. An die Stelle der Land- und Amtsgerichte treten Bezirksgerichte in den neuen Bezirken und Kreisgerichte in den neuen Kreisen. In den dezentralisierten Großstädten erhält jeder Stadtbezirk ein eigenes Kreisgericht.

2.) Zur Vorbereitung der neuen Gerichtsorganisation ist sofort mit der Auswahl der Gebäude und ihrer Einrichtung zu beginnen. Nach der Bestätigung der Struktur- und 
Stellenpläne der neuen Gerichte durch die Staatliche Stellenplankommission werden diese Pläne den Länderbrigaden und den Leitern der Bezirksverwaltungen der Justiz unverzüglich zugestellt, damit die Kaderbewegung durchgeführt werden kann.

\section{Freiwillige Gerichtsbarkeit}

Die freiwillige Gerichtsbarkeit wird ab 1.9.52 von den Gerichten getrennt. Beurkundungen, Nachlasssachen, und Vormundschaftssachen zu Gunsten von Erwachsenen werden auf Staatliche Notariate übergeleitet, die bei den Kreisgerichten eingerichtet werden und unmittelbar der Bezirksverwaltung der Justiz unterstehen. In den dezentralisierten Großstädten wird nur je ein Stadtnotariat eingerichtet. Die übrigen Aufgaben der freiwilligen Gerichtsbarkeit werden auf die fachlich zuständigen Verwaltungen übergeleitet. Hierüber und über die Errichtung der Staatlichen Notariate ergeht eine besondere Anweisung.

[BArch, DY 30/IV 2/13/51, Bl. 225-226]

\section{Dokument 22: Nachtrag zur Direktive des Ministeriums für Justiz der DDR vom 31. Juli 1952, ohne Datum}

Die Durchführung der Reorganisation der Justizverwaltung in den Ländern wird verantwortlich von den bisherigen Hauptabteilungsleitern der Hauptverwaltung Justiz vorgenommen:

für das Land Mecklenburg

für das Land Brandenburg

für das Land Sachsen-Anhalt

für das Land Sachsen

für das Land Thüringen die Hauptabteilungsleiterin Grävenrath der Hauptabteilungsleiter Utech

der Hauptabteilungsleiter Gebhardt der Hauptabteilungsleiter Dr. Grafe der Hauptabteilungsleiter Spranger

In den bisherigen Hauptverwaltungen der Länder ist eine Abwicklungsstelle zu bilden, für die zwei Personen verantwortlich die Abwicklung durchführen. Mit der Abwicklung sind nur Mitarbeiter zu beauftragen, die bereits für die weitere Tätigkeit im Bezirk übernommen sind. Die Besoldung ab 1.9.1952 muss aus dem Justiz-Bezirkshaushalt erfolgen. Zentrale Mittel stehen nicht zur Verfügung. Die Abwicklungsstellen haben spätestens mit dem 30. September 1952 ihre Tätigkeit einzustellen.

Dem Einsatz von Instrukteuren bzw. Brigaden in den Bezirken hat vor der Aufnahme der Instruktionstätigkeit eine Besprechung mit dem Leitinstrukteur der Regierungskommission im Bezirk voranzugehen. 
Leitinstrukteur für den Bezirk Potsdam ist der Kollege Schulz

in Vertretung der

für den Bezirk Cottbus

für den Bezirk Frankfurt

für den Bezirk Dresden

für den Bezirk Leipzig

für den Bezirk Chemnitz

für den Bezirk Halle

für den Bezirk Magdeburg

für den Bezirk Erfurt

für den Bezirk Gera

für den Bezirk Suhl

für den Bezirk Schwerin

für den Bezirk Rostock

für den Bezirk Neubrandenburg
Kollege Altmann

Kollege Perschke

Kollege Kiesche

Kollege Gschwandner

Kollege Schlicht

Kollege Leidert

Kollege Kelle

Kollege Volkmann

Kollege Oelpke

Kollege Jatzke

Kollege Söhnel

Kollege Kereit

Kollege Thomas

Kollege Radonski

Für die Übergabe von Akten sowie sämtliche andere Materialien sind die Behördenleiter der betreffenden Dienststellen voll verantwortlich (Für die Abgabe der Behördenleiter der abgebenden Dienststelle und für die Übernahme der Behördenleiter der übernehmenden Dienststelle). Besonders wird darauf hingewiesen, dass für die Sicherheit der Materialienübergabe verantwortliche Mitarbeiter bestellt werden. Die Übergabe und Übernahme ist protokollarisch festzuhalten.

Die Bezirksjustizverwaltungen werden angewiesen, möglichst bald den Postverkehr aufzunehmen.

Ferner sind die Anforderungen für Hausmeister, Pförtner, Betriebsschutz, Heizer und Putzfrauen listenmäßig durch den Bezirk an das Ministerium der Justiz der Deutschen Demokratischen Republik zwecks Bestätigung durch die Zentrale Stellenplaninspektion schnellstens einzureichen.

Die Anforderungen für das vorstehend genannte Personal hat bei Zusammenlegung mehrerer Dienststellen im gleichen Gebäude durch die Dienststelle zu erfolgen, die mit der Gebäudeverwaltung beauftragt ist.

[BLHA, Rep. 401, Nr. 71, Bl. 158] 
Dokument 23: Schreiben des brandenburgischen Innenministers, Bruno Lentzsch, ${ }^{276}$ an den Ministerpräsidenten des Landes Brandenburg, Rudolf Jahn, ${ }^{277}$ zur , ̈̈berleitung und Übernahme der Arbeit des Staatsapparates in den Bezirken“, 2. August 1952

Um eine geordnete Überleitung und eine sofortige Weiterführung der Arbeit in den Bezirken zu garantieren, ist folgendes notwendig:

Die Kollegen Minister lassen sich von ihrem Personalleiter die Liste aller neuen Abteilungsleiter für die ihr Ministerium betreffenden Aufgabengebiete in den Bezirken Potsdam, Cottbus und Frankfurt geben. Die Kollegen Minister bzw. die bisherigen Hauptabteilungsleiter nehmen den Personenkreis zusammen und führen die Kollegen in ihr Aufgabengebiet ein. Dabei ist zu beachten, dass vor allen Dingen die dringendsten Probleme eingehend behandelt werden, um z. B. in der Durchführung des BodenreformBauprogramms, in der Materialversorgung oder im Gesundheitswesen in der Seuchenbekämpfung usw. die Betreffenden konkret über die Lage in ihren Bezirken zu informieren. Da die Verwaltung bereits im Umzug begriffen ist, bitte ich diese Besprechung so schnell wie möglich zu organisieren.

[BLHA, Rep. 401, Nr. 58, Bl. 136]

Dokument 24: Fünfter Bericht des Vorsitzenden des Organisations-Komitees für den Bezirk Potsdam über den Stand der Durchführung der Verwaltungsreform für die neuen Bezirke des ehemaligen Landes Brandenburg, Potsdam, Cottbus und Frankfurt (Oder), 4. August 1952

Den Bezirksräten Cottbus und Frankfurt (Oder) sind am Sonnabend, dem 2. August 1952, $11.00 \mathrm{Uhr}$, die Akten übergeben und in die Bezirke transportiert worden.

Die Übergabe und Überführung in die oben genannten Bezirke ist ohne Störung verlaufen.

Der Bezirksrat Frankfurt (Oder) ist, wie wir feststellten, noch nicht arbeitsfähig, da ein großer Teil der Mitarbeiter sich noch in Potsdam befindet. - Heute, Montag, den 4. August 1952, 12.00 Uhr, fährt ein Omnibus nach Frankfurt (Oder), um die in Zukunft dort tätigen Angestellten zur neuen Arbeitsstätte zu bringen.

Die erste Abteilungsleiterbesprechung findet am Dienstag, dem 5. August 1952, um 8.30 Uhr in Frankfurt (Oder) statt.

276 Zu Bruno Lentzsch vgl. Dok. 2, Anm. 235.

277 Zu Rudolf Jahn vgl. Dok. 11, Anm. 260. 
Bis jetzt waren noch keine Fahrzeuge in Frankfurt (Oder), sodass die schon dort anwesenden Mitarbeiter nicht einsatzfähig waren. Es ist Anweisung erteilt worden, sofort Fahrzeuge in die Bezirke zu überführen.

Die Übergabe der Akten für den Bezirk Potsdam findet heute um 15.00 Uhr statt. - Von demselben Zeitpunkt weg arbeiten die Abteilungsleiter in ihren neuen Gebäuden, wo heute ebenfalls die Aufteilung vorgenommen wurde.

In Potsdam fand heute eine Abteilungsleiterbesprechung statt, bei der zur Frage der Übergabe der Akten und der Arbeiten für die nächsten Tage Stellung genommen wurde.

Der Stand der Überleitung im Bezirk Cottbus ist derselbe wie in Frankfurt (Oder).

Der Umzug der einzelnen bisherigen Verwaltungsdienststellen in ihre neuen Bezirke geht seit Freitag, dem 1. August 1952, vor sich. - Schwierigkeiten treten bei der Schaffung der neuen Kreise in allen drei Bezirken auf, und zwar handelt es sich um die Aufstellung der Baracken. Laut der Beschlüsse der Gebäudekommissionen sind für die drei Bezirke in folgenden Kreisen Baracken vorgesehen:

$\begin{array}{lll}\text { Bezirk Frankfurt (Oder): } & \begin{array}{l}\text { in Fürstenberg } \\ \text { in Strausberg }\end{array} & \text { 2 Baracken mit je 20 Räumen } \\ & \text { 2 Baracken mit je 20 Räumen } \\ \text { in Beeskow } & \text { 2 Baracken mit je 20 Räumen } \\ \text { Bezirk Potsdam: } & \text { in Gransee } & \text { 6 Baracken mit je 20-25 Räumen } \\ & \text { in Pritzwalk } & \text { 3 Baracken mit je 20-25 Räumen } \\ \text { in Oranienburg } & \text { 2 Baracken mit je 20-25 Räumen } \\ \text { Bezirk Cottbus: } & & 6 \text { Baracken mit je 20 Räumen }\end{array}$

Bei der Zentralen Kommission, Herrn Ernst Lange, wurde beantragt, die Genehmigung der dafür benötigten Mittel aus einsparten Geldern des Landes Brandenburg zu erteilen. Diese Summe würde etwa 800.000 bis 1.000 .000 DM betragen.

Ebenso treten dergestalt Schwierigkeiten bei allen Bezirken auf, weil das Staatssekretariat Materialversorgung bis jetzt die Materialanforderungen noch nicht bestätigt hat.

[BLHA, Rep. 401, Nr. 58, Bl. 12] 
Dokument 25: Sechster Bericht des Vorsitzenden der Bezirkskommission Potsdam, Curt Wach, ${ }^{278}$,über den Stand der Durchführung der Verwaltungsreform im Bezirk Potsdam“, 7. August 1952 (Auszug)

Das Org.-Komitee des Bezirkes Potsdam hat täglich eine Sitzung, in der alle Fragen, die im Laufe des Tages ungeklärt bleiben, besprochen und Entscheidungen getroffen werden. Die Überleitung der Akten ist nunmehr auch für den Bezirk Cottbus abgeschlossen.

Die Angestellten der Bezirksverwaltungen arbeiten in ihren neuen Gebäuden. Dabei wurde allerdings festgestellt, dass Schwierigkeiten dergestalt auftreten, indem zu viel Angestellte in den einzelnen Zimmern sitzen. Das hat nichts mit Raummangel zu tun, sondern ist durch die Tatsache zu verzeichnen, dass einmal ein Teil der Angestellten, welche für die Bezirke Cottbus und Frankfurt (Oder) bestimmt waren, plötzlich verweigern, in diesen Bezirken zu arbeiten; ${ }^{279}$ zum anderen gibt es einen Teil Menschen, die in den drei Bezirksverwaltungen nicht aufgenommen werden können - für die zum Teil noch keine andere Beschäftigung festgelegt ist - oder solche, die zur Entlassung kommen, aber die Entlassungsschreiben erst am 15. August 1952 bekommen. Diese Menschen wirken nicht fördernd auf die Arbeit der Angestellten im Bezirk Potsdam, sondern führen teilweise eine negative Diskussion mit den im Bezirk verbleibenden Angestellten.

Es ist erforderlich, dass auf diesem Gebiet eine Klärung herbeigeführt wird. - Der vom Unterzeichneten gemachte Vorschlag, beim Erfahrungsaustausch bei der ehemaligen Landesleitung der Partei am heutigen Tage, alle diejenigen Angestellten, welche nicht im Bezirk Potsdam beschäftigt werden und noch keinen Urlaub hatten, vorerst in Urlaub zu schicken, fand die Zustimmung aller Beteiligten. Dadurch ist zu erwarten, dass ein großer Teil der überflüssigen Angestellten aus den Büroräumen von hier verschwinden.

Mit den Kräften, die für die anderen Bezirke vorgesehen waren und bisher abgelehnt haben, nach dort zu gehen, wird im Laufe des heutigen Tages noch besonders gesprochen.

An Abteilungsleitern sind im Bezirk Potsdam noch nicht bestätigt: Abt. Jugendfragen, Förderung der Intelligenz, Industrie, Aufbau und Land- und Forstwirtschaft.

Am Dienstag, den 6. August 1952 fand eine Besprechung mit allen bisherigen Landräten und den Vorsitzenden der neu zu wählenden Kreise statt. [...]

278 Curt Wach (1906-1974) war zugleich Vorsitzender des Rates des Bezirkes Potsdam; vgl. Niemann/ Herbst, SED-Kader, S. 498.

279 In Brandenburg gab es bei der Versetzung bisheriger Landesbediensteter in die beiden neuen Bezirksstädte Frankfurt (Oder) und Cottbus besonders große Schwierigkeiten, da in beiden Städten die Voraussetzungen für Wohnen und Arbeiten denkbar ungünstig waren. Noch am 29. August 1952 waren in der Bezirksverwaltung Cottbus nur 70,3 \%, in Frankfurt gar nur 62,8 \% der Stellen besetzt - das zweitschlechteste Ergebnis im Vergleich aller DDR-Bezirke. Anfang September 1952 waren etwa in Potsdam bereits 95,7 \% der Planstellen besetzt; vgl. Hajna, Länder, S. 159-162. 
$\mathrm{Zu}$ bemerken ist dazu, dass es noch zwei Kreise gibt, in denen bis heute die Vorsitzenden dieser Kreis noch nicht vorhanden und bestätigt sind. Aufgrund dieser Tatsache wurde heute das Bezirkskomitee der Partei angesprochen und darauf hingewiesen, dass dies sofort nachgeholt werden muss.

Zur Reorganisation in den Kreisen ist folgendes festzustellen:

Die Tatsache, dass von Seiten der DDR noch keine Freigabescheine für die zu erstellenden Baracken vorhanden sind, bringt bestimmte Schwierigkeiten mit sich und birgt die Gefahr in sich, dass der Termin nicht eingehalten werden kann.

Wir bitten in dieser Frage um Unterstützung der Zentralen Regierungskommission.

Ebenso erschwerend wirkt sich die Tatsche aus, dass die Struktur- und Stellenpläne noch nicht in unserem Besitz sind. Dadurch treten ständig Schwierigkeiten auf, weil die bisherigen Kreisräte oder Stadtverwaltungen, die im Zuge der Bildung der Bezirksräte schon aus den bisherigen Gebäuden herausmüssen, mit sämtlichen Angestellten einziehen wollen und dann die vorgesehenen Gebäude nicht ausreichen. Auch in dieser Beziehung erbitten wir schnellste Hilfe von Seiten der Zentralen Kommission.

$\mathrm{Zu}$ der Stimmung im Bezirk Potsdam wird folgendes ermittelt: In den Grenzgemeinden von Westberlin wird vom Gegner die Behauptung aufgestellt, dass die Reorganisation nur deswegen durchgeführt wird, um die Möglichkeit zu haben, einen Sperrgürtel von $5 \mathrm{~km}$ in diesem Gebiet errichten zu können und alle dort wohnenden Menschen müssen ihre Gebäude und Wohnungen verlassen. - Aufgrund dieser Feststellung wurde angeordnet, dass sofort in Verbindung mit der Nationalen Front in diesen Gemeinden Versammlungen durchgeführt werden, um die Gerüchte des Gegners zu zerschlagen.

Bezirkstag: Der Bezirkstag im Bezirk Potsdam konstituiert sich nunmehr am Freitag, dem 8. August 1952, um 15.00 Uhr. Alle Vorbereitungen dafür sind getroffen. [...] - Dasselbe trifft für die erste Sitzung des Bezirksrates zu. Eine Stunde nach Beendigung der Sitzung des Bezirkstages wird mit dieser Sitzung begonnen.

Um Zeit und Finanzmittel zu sparen, wurde die Schulung der Abgeordneten für die durchzuführenden Versammlungen auf Sonnabend, dem 9. August 1952, $9.00 \mathrm{Uhr}$, festgelegt.

Die Nationale Front hat für den Bezirk Potsdam einen Terminplan erarbeitet, sodass in allen Kreisen des Bezirkes Potsdam anschließend in den Aufklärungs- und anderen Versammlungslokalen mit den Abgeordneten Versammlungen durchgeführt werden.

[BLHA, Rep. 401, Nr. 58, Bl. 18] 
Dokument 26: Siebter Bericht des Vorsitzenden der Bezirkskommission, Curt Wach, ${ }^{280}$,über den Stand der Durchführung der Verwaltungsreform im Bezirk Potsdam", 11. August 1952

Am Freitag, dem 8. August 1952, fand die Sitzung des Bezirkstages für den Bezirk Potsdam statt.

Von den Abgeordneten fehlten 17, die zum größten Teil wegen Krankheit oder Urlaub entschuldigt waren.

Der Verlauf der Tagesordnung war reibungslos. - Die Wahlen erfolgten einstimmig. - Die beiden gehaltenen Referate wurden beifällig aufgenommen.

Nach der konstituierenden Sitzung trat der Bezirksrat zu seiner ersten Sitzung zusammen. Vom Vorsitzenden wurde das Aufgabengebiet verteilt und vier Vorlagen, welche zur Beschlussfassung eingebracht waren, wurden einstimmig angenommen. Besondere Beachtung verdient dabei die Vorlage über die Mobilisierung aller Kräfte für die Einbringung der Ernte, Ziehen der Schälfurche, Zwischenfruchtanbau und der Erfassung. - Ebenso wurde beschlossen, den Auftrag des Bezirkstages schnellstens durchzuführen, nämlich einen Arbeitsplan für August und September aufzustellen. Einstimmig wurde auch der Beschluss gefasst, dass zur Unterstützung der Kreise je zwei vom Vorsitzenden, seinen Stellvertretern und seinem Sekretär überprüft und angeleitet werden.

Am Sonnabend, dem 9. August 1952, fand die Schulung der Abgeordneten statt. Das Lektorenmaterial wurde zur Grundlage dieser Schulung genommen. Dabei wurde an praktischen Beispielen aufgezeigt, wie in den Zusammenkünften mit der Bevölkerung die Wichtigkeit der Verwaltungsreform und die neuen Maßnahmen, die in diesem Zusammenhang eingeleitet werden, zu erläutern sind. Von allen Anwesenden wurde zum Ausdruck gebracht, dass mit der bisherigen Tätigkeit der Abgeordneten Schluss gemacht werden soll und dass die Abgeordneten eine ständige Verbindung mit den schaffenden Menschen herbeiführen werden.

Ebenfalls am Sonnabend, dem 9. August 1952, fand eine Abteilungsleiterbesprechung statt. In dieser wurde der Beschluss gefasst, dass alle Abteilungen mit neuen, den jetzigen Verhältnissen entsprechenden Arbeitsmethoden an die Aufgaben herangehen. - Weiter wurde beschlossen, dass bis Montag, dem 11. August 1952, von jeder Abteilung ein im Kollektiv erarbeiteter Arbeitsplan abgegeben wird, um aus diesen Abteilungs-Arbeitsplänen einen Gesamt-Arbeitsplan für den Rat des Bezirkes Potsdam zu schaffen.

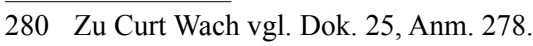


Am Montag, dem 11. August 1952, fand eine Besprechung der 1. Kreissekretäre, der bisherigen Landräte sowie der für die neu zu bildenden Kreise vorgesehenen Vorsitzenden der Räte statt. In dieser Zusammenkunft wurde vom Vorsitzenden des Rates des Bezirkes auf alle Fragen der Überleitung und der organisatorischen Maßnahmen, die in den Kreisen getroffen werden müssen, eingegangen. Insbesondere wurde auch hier wieder auf die Notwendigkeit der schnellen Erledigung der Beschwerden der Bevölkerung sowie der ständigen Überprüfung der Ernteeinbringung, der Erfassung und der Versorgung der Bevölkerung hingewiesen. In regem Erfahrungsaustausch konnten bisher noch nicht geklärte Fragen ihre Erledigung finden.

Ebenfalls am Montag, dem 11. August 1952, trat die Bezirkskommission zusammen und nahm Stellung zu der Beschaffung der notwendigen Baracken. Die Kommission beschloss neben anderen Maßnahmen, die Zentrale Kommission auf die ernste Situation, in der sich das gesamte Land befindet, hinzuweisen. (Siehe beiliegendes Protokoll.) ${ }^{281}$

Nach Eingang der Struktur und Stellenpläne für die Kreise wurde sofort die Besetzung der neuen Kreise besprochen und Maßnahmen beschlossen, dass von den nicht übernommenen Mitarbeitern der ehemaligen Landesregierung sowie der bisherigen Kreise versucht wird, einen Teil derselben in die neuen Kreise zu bringen.

[BLHA, Rep. 401, Nr. 58, Bl. 21]

Dokument 27: Sitzungsprotokoll der Bezirkskommission Potsdam, 11. August $1952^{282}$

Verhandelt wurde über die Frage der Schaffung von Baracken.

Der Bezirkskommission wurde bekannt gegeben, dass zwar die Millionen DM, die für diese Baracken benötigt werden, aus Reserven vorhanden sind und auch die Genehmigung für die Verwendung vorliegt, dass aber von Seiten der DDR bis jetzt die Freigabe von Kontingent-Scheinen für das Material versagt wurde. - Auch die Rücksprache, die Herr Lentzsch ${ }^{283}$ heute mit dem Staatssekretär Eggerath ${ }^{284}$ hatte, verlief negativ, da derselbe von diesen Schwierigkeiten, die auf diesem Gebiete im Lande Brandenburg bestehen, nicht informiert war. Er wollte sich mit Ernst Lange ${ }^{285}$ in dieser Frage in Verbindung setzen.

\footnotetext{
281 Vgl. Dok. 27.

282 Das Sitzungsprotokoll ist eine Anlage zum Dok. 26.

283 Zu Bruno Lentzsch vgl. Dok. 2, Anm. 235.

$284 \mathrm{Zu}$ Werner Eggerath vgl. Dok. 1, Anm. 228.

$285 \mathrm{Zu}$ Ernst Lange, vgl. Dok. 2, Anm. 233.
} 
Nach dieser Diskussion beschließt die Kommission folgendes:

Der Rat des Bezirkes wird beauftragt, sofort folgende Maßnahmen zu veranlassen:

1. Mit den Bau-Unionen der Bezirke Verhandlungen aufzunehmen, um zu versuchen, von diesen Bau-Unionen eine oder einige Baracken zu kaufen.

2. In Zusammenarbeit mit der Abteilung Forst soll versucht werden, eine Überprüfung vorzunehmen, ob nicht dringend benötigtes Holz vorhanden ist, was schnellstens zum Bau von Baracken verwandt werden könnte.

Ungeachtet dieser Maßnahme werden der Zentralen Kommission die entstandenen Schwierigkeiten - die jetzt kurz vor der Reorganisierung der Kreise ernste Formen annehmen - berichtet mit dem Antrag, sich ebenfalls mit dieser Frage zu beschäftigen.

Als weiterer Punkt wurde behandelt die Frage der Überleitung, insbesondere der Parteien und Organisationen.

Der Vertreter des FDGB gab die Erklärung ab, dass bei ihnen diese Überleitung am 15. August 1952 beginnt und am 15. September 1952 abgeschlossen sein wird. Darunter ist $\mathrm{zu}$ verstehen, dass die Wahlen vorgenommen werden, sodass ab 1. Oktober 1952 in den Bezirken der FDGB seine Tätigkeit aufnimmt.

Der Vertreter der FDJ gab bekannt, dass mit dem heutigen Tage die Landesleitung der FDJ aufgelöst ist. Die Reorganisation beginnt am 20. August 1952 und endet am 15. Oktober 1952. Dann von sämtlichen Einheiten die Wahlen vorgenommen werden, dann die Kreisdelegiertenwahlen stattfinden, sodass die Arbeit in den Bezirken von der FDJ durch die Bezirksleitung am 15. Oktober aufgenommen wird.

Bei allen Parteien, so wurde festgestellt, ist die Überleitung durchgeführt.

Ebenso wird in den Kreisverwaltungen nach den Direktiven die Überleitung vorgenommen.

Herr Seibt ${ }^{286}$ führte aus, dass die bisherige Popularisierung noch ungenügend ist und dass mit allen Mitteln versucht werden muss, eine bessere Popularisierung der Verwaltungsreform in allen Orten des Bezirkes durchzuführen.

$286 \mathrm{Zu} \mathrm{Kurt} \mathrm{Seibt,}$ seit August 1952 1. Sekretär der SED-Bezirksleitung Potsdam, vgl. Dok. 2, Anm. 236. 
Insbesondere wurde darauf hingewiesen, sollen nunmehr die Abgeordneten des Bezirkstages nach der am Sonnabend, dem 9. August 1952, durchgeführten Schulung durch die Nationale Front für die Aufklärung eingesetzt werden.

[BLHA, Rep. 401, Nr. 58, Bl. 22]

Dokument 28: Achter Bericht des Vorsitzenden des Rates des Bezirkes Potsdam,
Curt Wach, ${ }^{287}$,über den Stand der Durchführung der Verwaltungsreform im Bezirk
Potsdam“, 14. August 1952

In Bezug auf die Gebäudefrage ist es nunmehr gelungen, einen Teil der benötigten Baracken im Lande Brandenburg festzustellen und zu erwerben, sodass für den Bezirk Cottbus keinerlei Schwierigkeiten mehr bestehen. Es ist zu erwarten, dass bis zum 15. August 1952 diese bis jetzt dringendste Frage von uns gelöst wird. - Schwierigkeiten gibt es in der Gebäudefrage täglich, weil - nachdem nunmehr die Struktur- und Stellenpläne im Besitz der einzelnen Verwaltungen, Organisationen und Institutionen sind - sich ein wesentliches anderes Bild ergeben hat, als vordem vorauszusetzen war.

Zur Überleitung in den Kreisen wird folgendes festgestellt:

Um eine genaue Garantie zu haben, dass die mündlichen Beratungen, die wir mit den Vorsitzenden der Kreise oder, wo ein solcher noch nicht vorhanden ist, mit einem anderen Mitglied des Org.-Komitees durchgeführt haben, auch wirklich nach der Direktive vorgenommen wird, wurde in jeden Kreis ein Instrukteur geschickt, um helfend und anleitend in den Kreisen zu wirken. Diese Instrukteure wurden vor der Entsendung in die Kreise besonders zusammengefasst und geschult. - Bis zum 15. August 1952 liegt ein genauer Bericht von dem Stand der Überleitungen in den Kreisen vor.

Für die Kreise Jüterbog und Brandenburg werden die Vorbereitungen getroffen, damit beide als erste den Kreistag durchführen können.

Besondere Beachtung wurde der Ernteeinbringung, Erfassung und Versorgung der Bevölkerung im Bezirk gewidmet. Durch Operativ-Einsätze und durch Zuhilfenahme breiter Schichten der Bevölkerung gelang es, in den Kreisen Nauen und Ostprignitz gute Beispiele zu schaffen. Es gilt, diese Ergebnisse in den nächsten Tagen zu verbreitern und dort, wo noch Rückstände vorhanden sind, dieselben schnellstens aufzuholen. ${ }^{288}$

$287 \mathrm{Zu}$ Curt Wach vgl. Dok. 25, Anm. 278.

288 In der frühen DDR wurden Ablieferungssolls für landwirtschaftliche Produkte festgelegt. Demnach mussten Betriebe mit mehr als 20 ha Nutzfläche über 85 \% ihrer Erträge zu niedrigen Erfassungspreisen an die 1949 gebildeten „Volkseigenen Erfassungs- und Aufkaufbetriebe“ (VEAB) liefern, während kleinere Betriebe lediglich knapp 50 \% abzuliefern hatten. Diese gerade für große Betriebe 
Trotz aller Bemühungen ist keine Möglichkeit gegeben, durch die Nationale Front einen Überblick zu erhalten, wie viel Aufklärungsversammlungen bis jetzt durchgeführt wurden. - Aus einem Teil der Berichte der Abgeordneten ist zu erkennen, dass überall solche Versammlungen durchgeführt werden, ohne dass sie im Bezirksmaßstab von Seiten der Nationalen Front registriert wurden. Um einen genauen Überblick zu bekommen, wurden die Instrukteure, welche zur Anleitung in die Kreise gegangen sind, beauftragt, bis zum 15.8. darüber Mitteilung zu machen, wie viel solche Versammlungen bisher durchgeführt wurden und wie viel noch durchgeführt werden. - Die Bevölkerung begrüßt die Maßnahmen der Regierung und stellt auf allen Gebieten konkrete Fragen oder erteilt Wähleraufträge an die Abgeordneten.

Über die Arbeit des Rates des Bezirkes selbst ist folgendes zu berichten:

Es ist außerordentlich schwer, die bisherigen Angestellten der Landesregierung zu bewegen, von den alten Arbeitsmethoden abzukommen. Immer wieder versuchen sie, mit den bisherigen Methoden die Probleme zu lösen. Die ständigen und sehr langen Sitzungen, die anberaumt werden, lassen es auch dem Vorsitzenden des Rates des Bezirkes nicht zu, richtige Anleitungen zu geben. - Dasselbe ist bei den Vorsitzenden der Kreise zu verzeichnen. Auch werden Anordnungen gegeben, die unnötige Belastung bedeuten und keinen Erfolg haben bzw. wieder zurückgezogen werden müssen. - Zum Beispiel wurde am Montag, dem 11. August 1952, vom Leitinstrukteur Schulz der Auftrag erteilt, für Donnerstag, dem 14. August 1952, die Vorsitzenden der Kreise zusammenzurufen, damit sie von einem Instrukteur, der wichtige Fragen zu besprechen hatte, unterrichtet werden können. Dieser Instrukteur, welcher zur Sicherung der Vermögenswerte hier erscheinen sollte, war für Dienstag angesagt, doch bis heute ist er hier noch nicht eingetroffen, sodass die Einladungen dann kurzfristig widerrufen werden mussten.

Die 2. Sitzung des Rates des Bezirkes Potsdam wurde heute, am 14. August 1952, durchgeführt. Sie umfasst folgende Tagesordnung:

1. Sicherung der Einbringung der Ernte

Bericht stellvertretender Vorsitzender, Kollege Beer,

2. Ablieferung landwirtschaftlicher Produkte

Bericht stellvertretender Vorsitzender, Kollege Beer,

ruinöse Ablieferungspflicht wurde streng überwacht und Verstöße wurden hart bestraft, weshalb viele Bauern gerade in dieser Zeit die DDR verließen; vgl. Kotsch, Brandenburg, S. 274-277. 
3. Beschlussfassung über die Erteilung einer Vollmacht an die Org.-Komitees der Kreise durch den Vorsitzenden des Rates des Bezirkes, Kollege Wach.

[BLHA, Rep. 401, Nr. 58, Bl. 23-24]

\section{Dokument 29: Stenografisches Protokoll der ersten Besprechung Otto Grotewohls ${ }^{289}$ und Werner Eggeraths ${ }^{290}$ mit den Vorsitzenden und Sekretären der Räte der Be- zirke, 15. August 1952 (Auszug)}

Eggerath: [...] Uns war die Aufgabe gestellt, bis zum 15. August die Überleitung in den Bezirken so weit durchzuführen, dass die neuen Organe in den Bezirken die Arbeit fast in der Hand haben sollten. Ich glaube, gerade der heutige Tag ist dazu angetan, um eine Bilanz über unsere bisherige Arbeit zu ziehen und festzustellen, wo Mängel und Schwächen aufgetreten sind, wo es Unklarheiten gibt, um dann zu beraten, was unmittelbar eingeleitet werden muss, um die zweite Phase erfolgreich in Angriff zu nehmen und zu beenden, d. h. die Überleitung in den Kreisen in der vorgeschriebenen Zeit so durchzuführen, dass es zu keinerlei Erschütterungen auf irgendeinem Gebiet der staatlichen Arbeit kommt. [...]

Durch Beschluss des Sekretariats des ZK waren in jedem Bezirk Bezirkskommissionen zu bilden. Diese Bezirkskommissionen sollten in einer bestimmten Zusammensetzung arbeiten, hatten bestimmte Aufgaben. Sie sollten u. a. den ganzen Prozess anleiten, kontrollieren und vor allen Dingen die Vorbereitungen in den Kreisen so treffen, dass dort die Arbeit ohne ernstliche Erschütterungen durchgeführt werden konnte. Heute müssen wir feststellen - und das ist eine sehr ernste Feststellung -, dass es uns nicht gelungen ist, diese Bezirkskommissionen zum Arbeiten zu bringen. Obwohl die verantwortlichen Funktionäre nach Berlin geholt wurden, um ihnen die Aufgaben zu erläutern, obwohl in der Direktive zur Überleitung noch einmal die Aufgabe konkretisiert war, obwohl die zentralen Kommissionen arbeiten müssen, können wir heute feststellen, dass die Kommissionen ihre Aufgabe nicht erfüllt haben, und daraus herleitend sind eine ganze Reihe von Fehlern, Mängeln und Schwächen festgestellt. [...]

Wir müssen erkennen, dass es jetzt darum geht, diese neuen Organe, die die höchsten Organe der Staatsgewalt darstellen, die außerordentliche Vollmachten haben, und die praktisch zum Ausdruck bringen, dass die Werktätigen die Leitung des Staates in die Hand nehmen, zu solchen arbeitenden Körperschaften zu machen, dass sich in ihnen der Wille der Werktätigen widerspiegelt und sie den Willen der Werktätigen durchführen. [...]

289 Zur Rolle Otto Grotewohls (1894-1964), seit Oktober 1949 Ministerpräsident der DDR, bei der Bildung der Bezirke vgl. Hoffmann, Grotewohl, S. 412-421.

$290 \mathrm{Zu}$ Werner Eggerath vgl. Dok. 1, Anm. 228. 
Der Bezirkstag ist das höchste Organ und wählt sich als vollziehendes und verfügendes Organ den Rat des Bezirks. Der Rat ist ein Teil des Bezirkstages, und niemand soll glauben, dass die Arbeit des Bezirkstages und die Arbeit der Ständigen Kommissionen dem Selbstlauf überlassen werden darf. Der Rat muss hier das organisierende Element darstellen für die Tätigkeit des Bezirkstages, für die Tätigkeit der Abgeordneten, für die Tätigkeit der Ständigen Kommissionen. Der Rat muss den Abgeordneten helfen, ganz planmäßig, ganz systematisch ihre Tätigkeit so zu organisieren, dass jeder Abgeordnete für ein bestimmtes Wirkungsfeld verantwortlich ist, dass man unter bestimmten Bedingungen vielleicht auch zwei Abgeordnete für ein bestimmtes Gebiet verantwortlich macht, dass der Abgeordnete dort regelmäßig Gesetze, Beschlüsse usw. erläutert, erklärt und die Durchführung sofort an Ort und Stelle organisierend unterstützt. Der Abgeordnete muss regelmäßig seine Sprechstunden durchführen. Er muss sich das Vertrauen der Wähler erarbeiten. Es ist eine Sache des Rates, die vielen Wünsche, Beschwerden, Hinweise, Vorschläge, die aus der Bevölkerung an die Abgeordneten herangetragen werden, zusammenzufassen, zu systematisieren, zu analysieren, auszuwerten und für die Arbeit sowohl des Bezirkstages und der Ständigen Kommissionen als auch des Rates und seines Apparates so zu verwenden, dass diese Hinweise, Vorschläge usw. in der Praxis Berücksichtigung finden. Kurzum, der Rat muss diese Arbeit organisieren und muss sie vor allen Dingen so organisieren, dass der einzelne Abgeordnete die Unterstützung sieht und immer größere Freude an dieser Arbeit empfindet, weil er weiß, dass seine Arbeit sehr sorgfältig ausgewertet wird.

Aber das, was ich jetzt kurz umriss, ist nur eine Seite der Tätigkeit des Bezirkstages und der Abgeordneten. Die andere Seite ist meiner Meinung nach genauso bedeutungsvoll, und hier müssen wir sehr schnell zu einer Tätigkeit kommen, die die ganze Arbeit befruchtet. Das ist die Tätigkeit der Ständigen Kommissionen. In dieser Frage gibt es außerordentlich große Unklarheiten, und leider war es uns bis heute noch nicht möglich, diese Instruktion für die Arbeit der Ständigen Kommissionen dem Ministerrat vorzulegen. Die Schuld liegt nicht bei uns. Aber diese Organisierung der Tätigkeit der Abgeordneten in den Ständigen Kommissionen wird für die ganze weitere Entwicklung von außerordentlich großer Bedeutung sein.

Im Strukturplan sind bisher zehn Ständige Kommissionen vorgesehen. Das bedeutet, dass praktisch jeder Abgeordnete, soweit er nicht Mitglied des Rats ist, in einer solchen Kommission entsprechend seinen Kenntnissen, entsprechend seinen Fähigkeiten auf bestimmten fachlichen Gebieten, entsprechend seinen Neigungen arbeitet. Unter keinen Umständen darf man diese Ständigen Kommissionen irgendwie mit den Ausschüssen, die wir bisher in den Landtagen hatten, gleichsetzen. [...]

Die Hauptaufgabe der Ständigen Kommissionen besteht eben darin, die breiten Massen der Werktätigen in die unmittelbare Mitarbeit bei der Gestaltung des Staates einzubeziehen. Dem Rat des Bezirkes erwachsen bei der Bildung und bei der Arbeit der Kommissionen Aufgaben, die außerordentlich kompliziert sind. Denn er muss erstens einmal 
erreichen, dass diese Kommissionen eine wirkliche Tätigkeit in Verbindung mit der Bevölkerung erreichen, dass sie sich ein Aktiv bilden von bestimmten Persönlichkeiten, die in einer würdigen Form eingeladen und berufen werden, im Aktiv dieser oder jener Kommission zu arbeiten, sie müssen den Arbeitsprozess dieser Kommission organisieren, dass er mit dem Arbeitsplan des Rates, mit dem Arbeitsplan des Bezirkstages übereinstimmt und somit ein kontinuierlicher Arbeitsprozess gesichert wird, der es möglich macht, die Grundfragen zu behandeln und systematisch nacheinander eine Grundfrage nach der andern zu behandeln und zu beraten, und zwar so nach einer sorgfältigen Vorbereitung, dass ein Beschluss, der auf diesem Gebiet gefasst wird, ein Arbeitsprogramm für eine Zeitspanne darstellt. [...]

Das Entscheidende ist, dass wir die Arbeit dieser Ständigen Kommissionen in die Richtung prinzipieller Untersuchungen und der Ausarbeitung von Vorschlägen für die Verbesserung der Lage auf diesem bestimmten Gebiet bringen und dadurch eine außerordentlich günstige Arbeitsgrundlage für den Rat und auch für den Bezirkstag schaffen. Hier ist aber besonders wichtig, dass der Rat die Arbeit der Ständigen Kommissionen dauernd beobachtet, dauernd auswertet. Denn in der Arbeit der Ständigen Kommissionen werden doch sehr viele kritische Gesichtspunkte an die Mitarbeiter in den Ständigen Kommissionen herangebracht, sehr viele Hinweise gegeben, die der Rat mit seinem Apparat vollständig übersehen wird. Denn es ist ja jetzt eine Kontrolle der Massen, die sich entwickelt, die Arbeit der Ständigen Kommissionen dauernd zu überprüfen, dauernd auszuwerten und für die Arbeit des Apparates auszunutzen. Das ist eine sehr wichtige Aufgabe des Rates. [...]

Ich habe vorhin schon darauf hingewiesen, dass die Zusammenfassung der Arbeit der Abgeordneten, die Zusammenfassung der Arbeit der Ständigen Kommissionen des Bezirkstages nur möglich ist, wenn der Rat selbst einen sorgfältig durchdachten Arbeitsplan hat, der abgestimmt ist auf den Arbeitsplan dieser Institution. Das bedeutet, dass der Rat und die einzelnen Abteilungen nach einem Arbeitsplan arbeiten müssen, sie in bestimmten Abständen bestimmte Schwerpunkte der Arbeit gründlich untersuchen, die Ergebnisse der Untersuchungen sich verdichten zu einem Bericht und die Schlussfolgerungen, die daraus hergeleitet werden, sich verdichten zu einem Beschluss. [...]

Hier möchte ich etwas sagen zur Rolle des Sekretärs. Auch hier gibt es außerordentlich große Unzulänglichkeiten. Es gibt eine Vorstellung, als ob der Sekretär irgendwie ein besserer Schriftführer wäre. Wir haben keine sehr großen Ausführungen darüber gemacht. Aber die Tatsache, dass heute auf der ersten Dienstbesprechung neben den Vorsitzenden auch die Sekretäre eingeladen sind, zeigt die Wichtigkeit der Rolle des Sekretärs.

Welches ist die Aufgabe des Sekretärs? Der Sekretär ist der zentrale Punkt in diesem so breiten Arbeitsprozess, den wir jetzt organisieren, an dem Tausende und Zehntausende Menschen beteiligt sind, diesem planmäßigen Arbeitsprozess. Der Sekretär des Rates wird derjenige sein, der jetzt nach der gegebenen politischen Linie die Arbeit organisiert und die Arbeit des Bezirkstages, die Arbeit der Ständigen Kommissionen, die Arbeit der 
Abgeordneten mit der Arbeit der Abteilungen auf der Grundlage des vom Rat beschlossenen Arbeitsplanes organisiert und koordiniert, das viele Nebeneinanderarbeiten beseitigt und einen einheitlichen Arbeitsprozess organisiert mit dem Grundsatz: Höchste Steigerung der Arbeitsproduktivität eines jeden einzelnen Mitarbeiters, Höchstmaß an Sparsamkeit der Verausgabung von Mitteln des Staates.

Der Sekretär muss der Mittelpunkt dieses Arbeitsprozesses sein. Das bedeutet nicht, dass er irgendwie die Verantwortlichkeit der Stellvertreter des Vorsitzenden einengt. Im Gegenteil: Er wird Signale geben, wenn in irgendeiner Abteilung die Arbeit nicht in Ordnung geht. Jetzt haben wir eine Fülle von Signalen, wie schlecht gearbeitet wird und wie schlecht gearbeitet wurde. Wir haben solche Beispiele, dass es in ganzen Gebieten keine Organisierung des Nachtdrusches, dass es keine Rodepläne gibt, dass die Anbaupläne in Frühkartoffeln und mittelfrühen Kartoffeln nicht mit den tatsächlich bebauten Flächen übereinstimmen. Der Sekretär wird in Zukunft mit Hilfe der Arbeit der Abgeordneten der Ständigen Kommissionen in der Lage sein, auf die Arbeit der einzelnen ganz anders einzuwirken, als es bisher der Fall war. Er wird dann dem Rat Signale geben, wenn diese Abteilung schlecht arbeitet, oder wenn irgendwelche kritischen Gesichtspunkte auftreten, oder wenn der Stellvertreter des Vorsitzenden seiner Pflicht der Anleitung und Kontrolle nicht genügt. Der Sekretär wird die Aufgabe haben, anstelle der vielfach planlosen Arbeit, der Nebeneinanderarbeit der vielen Abteilungen und Hauptabteilungen, wie wir es $\mathrm{zu}$ verzeichnen hatten, nunmehr einen systematischen und kontinuierlichen Arbeitsprozess zu organisieren. $[\ldots]$

Um diese Arbeit erfolgreich organisieren und die Aufgaben, die gemeinsam gestellt sind, erfolgreich lösen zu können, ist dem Sekretär ein wichtiges Instrument in die Hand gegeben: nämlich die Org.-Instrukteur-Abteilung. Ich muss feststellen, dass trotz der verschiedenen Hinweise auf die bedeutungsvolle Aufgabe der Org.-Instrukteur-Abteilung bei den verschiedensten Anlässen [...] jetzt ersichtlich ist, dass man dem Aufbau dieser Abteilung eine sehr geringe Aufmerksamkeit widmet, dass man keine sorgfältige Auswahl der Mitarbeiter vornimmt, Gelegenheitsmaßnahmen einleitet, nicht systematisch an den Aufbau dieser Abteilungen herangeht, oder es zeigt sich auch schon in vielen Fällen, dass man die Aufgaben dieser Abteilungen unterschätzt, indem man ihnen technische Aufgaben zuweist, wie die Organisierung von Kontrollen bei den Bezirkstagen, das Scheiben von Einladungen usw. [...]

Was sind ihre Aufgaben?

1. Mit Hilfe der Org.-Instrukteur-Abteilung wird der Rat die Arbeit der Abgeordneten registrieren, das Wesentliche zusammenstellen, systematisieren. Diese Abteilung wird die Kritik, die Hinweise aus der Bevölkerung für die Arbeit der übrigen Abteilungen des Rates auswerten. Diese Abteilung wird die Arbeit der Ständigen Kommissionen dauernd beobachten und das Material zur Information des Rates in dieser oder jener Frage zusammenstellen, wird das Material bei Zusammenstellung von Berichten zur 
Verfügung stellen, das durch die Abgeordneten, durch die Ständigen Kommissionen bei einer guten Arbeit stetig zufließt. Das ist die eine Seite.

2. Die Org.-Instrukteur-Abteilung wird als Instrument des Rates in der Hand des Sekretärs die Arbeit der einzelnen Abteilungen und Einrichtungen ganz systematisch nach dem Arbeitsplan, der vom Rat bestätigt ist, überprüfen, wird die Erfahrungen auswerten, verallgemeinern, wird kritische Hinweise geben; kurzum: wird die Arbeit des Apparates ganz systematisch verbessern, wird dahin arbeiten, dass nicht nur jede Abteilung planmäßig, nach einem sorgfältig durchdachten Arbeitsplan arbeitet, sondern dass auch jeder Mitarbeiter nach seinem persönlichen Arbeitsplan arbeitet, der ein Teil des Abteilungsarbeitsplanes ist. Das ist die zweite Aufgabe.

Die dritte Aufgabe ist - das ist eine sehr bedeutungsvolle Aufgabe - die Organisierung der Komplexuntersuchungen, wozu die Org.-Instrukteur-Abteilung die qualifiziertesten Mitarbeiter aus den einzelnen Abteilungen, dann eine Anzahl Abgeordnete, Fachleute, Spezialisten zusammenzieht, um in Zusammenarbeit mit dem FDGB und mit anderen Organisationen - zum Beispiel der VdgB - einen Kreis in seiner Gesamtheit von allen Seiten zu durchleuchten, und wissenschaftlich zu untersuchen: wo liegen die Ursachen einer ganzen Reihe von Erscheinungen. Das Ergebnis dieser Untersuchungen gibt dann die Möglichkeit, Schlussfolgerungen für die Arbeit auf allen Arbeitsgebieten in allen Kreisen zu ziehen. Oder aber diese Org.-Instrukteur-Abteilung organisiert Zweiguntersuchungen, zum Beispiel des gesamten Handels im Bezirk oder gesamten Gesundheitswesens im Bezirk. Wohlgemerkt: Die Abteilung führt sie nicht selbst durch, sie organisiert diese Untersuchung. Mit Hilfe von Abgeordneten, mit Hilfe von ehrenamtlichen Mitarbeitern, mit Hilfe der Arbeiter aus den Betrieben wird ein bestimmter Zweig von oben bis unten gründlich durchleuchtet, und es ist dann möglich, für eine Verbesserung der Arbeit auf diesem Gebiet Schlussfolgerungen zu ziehen. [...]

Ich möchte noch einen anderen Komplex ganz ernst behandeln: Das ist die Frage der Anleitung der Kreise. Wir wissen, dass das in der Vergangenheit eines der schwierigsten und am wenigsten gelösten Probleme war. Ich brauche nicht die Ausführungen von Walter Ulbricht zu zitieren. Aber ich glaube, jetzt wird es entscheidend davon abhängen, ob wir eine solche Anleitung der Kreise organisieren, damit in den Kreisen die Überleitung von der Apparatarbeit in die Massenarbeit gesichert wird; denn der Kreis ist doch weit mehr mit den Massen verbunden, und die Anleitung des Kreises bezüglich der Gemeinden und Städte ist doch unerhört wichtig. Wir können die Kreise nur fähig machen, ihre Aufgabe zu lösen, wenn wir eine systematische Anleitung von Bezirk und Kreis sichern.

Es wird sich notwendig machen, dass die einzelnen Räte der Bezirke mindestens einmal im Monat auf die Tagesordnung ihrer Beratung den Bericht eines Vorsitzenden eines Rates des Kreises setzen. Aber dieser Bericht darf nicht den Charakter haben wie die Berichte in der Vergangenheit, dass man eine Einladung schickt: Sie werden gebeten, einen Bericht zu geben, und lässt es dann darauf ankommen. Ein solcher Bericht muss von 
Seiten des Rates des Bezirkes gründlich vorbereitet sein. Der Rat des Bezirkes muss sich schon vorher mit den Einzelheiten der Lage in diesem Kreise befassen, und wenn dann der Vorsitzende des Rates des Kreises seinen Bericht gibt, dann muss der Rat des Bezirkes in der Lage sein, ihm zu antworten; ihm nicht nur diese und jene Mängel vor Augen zu führen, sondern ihm auch aufzuzeigen, wie sie abgestellt werden können. In dieser Berichterstattung eines Vorsitzenden müssen wir dann eine Anzahl anderer Vorsitzenden von Räten der Kreise zuziehen, damit die Berichterstattung und die Behandlung des Berichts gleichzeitig auch eine konkrete Anleitung für die anderen Kreise wird. Der augenblickliche Stand in dieser Beziehung ist außerordentlich unbefriedigend. Wir können uns nicht mehr solange mit Einrichtungen usw. beschäftigen. Es gilt in den nächsten Tagen die Leitung der Kreise straff in die Hand zu nehmen und dort die äußersten Anstrengungen zu machen, damit sie bis zu dem Tage, wo die Überleitung beginnt, ein Höchstmaß von Aktivität entwickeln, schon gewisse Reserven schaffen, damit die Tage, wo die eigentliche Überleitung durchgeführt wird, was einen gewissen Ausfall an Arbeit bringt, keine Auswirkungen haben werden. [...]

Ich möchte jetzt noch eine Frage behandeln, die auch an mich gerichtet wurde, nämlich die Frage der staatlichen Aufsicht. Darüber gibt es große Unklarheiten. Was ist die staatliche Aufsicht? Ich habe vorhin schon gesagt, dass den Räten außerordentlich große Vollmachten gegeben wurden, also den Organen der Staatsgewalt, die in den Händen der Werktätigen liegen. Ich bin überzeugt davon, dass die Sache der Werktätigen in den Händen der Werktätigen selbst in guten Händen liegt. Zu diesen Vollmachten gehört auch die staatliche Aufsicht über zentral geleitete Organisationen. Darunter fallen auch die Eisenbahn, die Post, das Fernmeldewesen, die zentral geleiteten Betriebe und alle anderen zentralen Einrichtungen. Aber wie sieht hier die staatliche Kontrolle aus? Ich glaube, niemand von uns denkt daran, dass jetzt ein Mitglied des Rates berechtigt ist, zur Eisenbahn zu gehen, wenn ihm irgendetwas nicht passt, und irgendeine Weiche umzustellen, weil er lieber möchte, dass der Zug anders fahren soll. Es ist ganz selbstverständlich, dass wir nicht in die Verantwortlichkeit des Betriebsleiters eingreifen dürfen, sodass dieser sagen kann: Dafür trage ich nicht mehr die Verantwortung; denn es ist der Rat gewesen, der mich gezwungen hat! Wohl aber hat der Rat in Zukunft das Recht, einen Betriebsleiter vor den Rat zu zitieren und ihm zu erklären: Wir sind mit diesen und jenen Erscheinungen nicht einverstanden; wir sind nicht zufrieden damit, dass der Berufsverkehr dort so schlecht durchgeführt wird; wir verlangen eine Abänderung, und zwar bis zu einem bestimmten Termin! Der Rat ist berechtigt, in Zukunft jeglichen Leiter einer solchen Institution auch darauf aufmerksam zu machen, dass nach seiner Meinung das und das geändert werden muss, und wenn dann der Leiter dem nicht folgt, so ist der Rat berechtigt und verpflichtet, der Regierung über diese Zustände Mitteilung zu machen. Der Rat ist also auch verpflichtet, den leitenden Institutionen Signale zu geben, wenn unten irgendetwas nicht in Ordnung ist. Wenn diese Frage noch nicht klar sein sollte, so bitte ich, sie in der Diskussion noch einmal zu stellen, dann werden wir sie noch einmal im Einzelnen behandeln. 
In Verbindung damit möchte ich noch auf etwas hinweisen, was noch immer sehr störend wirkt. Wir müssen uns entsprechend der neuen Lage auch an die neue Terminologie gewöhnen. Immer noch liest man „Sitzung des Bezirksrats“, immer noch hört man: „Der stellvertretende Vorsitzende“" und ähnliche Ausdrücke. Wir wollen das ganz klar sehen. Es kommt nicht von ungefähr, dass wir sagen ,der Rat des Bezirkes“. Der Rat des Bezirkes ist eine Körperschaft mit außerordentlich großen Vollmachten, aber das Mitglied des Rates, der Bezirksrat - so nennen wir ihn - ist nur eine Person, deren Vollmachten sehr beschränkt sind, und deshalb müssen wir ganz klar sagen: der Rat des Bezirkes, der Rat des Kreises. Wir sollen auch nicht sprechen vom stellvertretenden Vorsitzenden, sondern der Stellvertreter des Vorsitzenden. Wir sollten auch nicht sprechen von der „Reform“, obwohl das im Beschluss der II. Parteikonferenz festgelegt ist. Man soll heute sehen, es geht um weit mehr als um eine Verwaltungsreform. Der Ausdruck „Reform“ rennt einfach in diese Richtung, dass es sich um eine strukturelle Veränderung handelt. Es handelt sich aber um eine große politische Veränderung, und deshalb sprechen wir von einer ,weiteren Demokratisierung“. Ich bitte deshalb, auch diesen Hinweis zu beachten und in Zukunft die Terminologie zu ändern. [...]

Nun möchte ich zu einer anderen Frage übergehen. Ich habe schon eingangs gesagt: Der Aufbau des Sozialismus ist keine Kleinigkeit. Aufbau des Sozialismus - das bedeutet eine unerhörte Verschärfung des Klassenkampfes. Aufbau des Sozialismus unter den Bedingungen des gespaltenen Deutschlands bedeutet zusätzliche Schwierigkeiten, bedeutet Erhöhung der Wachsamkeit, Schaffung der Voraussetzungen zur Verteidigung unserer Errungenschaften. Das ist alles nicht so einfach, und deshalb ist es notwendig, dass der Staat straff geleitet wird. Das muss sich auch in der Zuverlässigkeit der Berichterstattung ausdrücken. Die übergeordnete Leitung muss sich auf einen Bericht von unten hundertprozentig verlassen können. Sie muss wissen, dass nur solche Fragen vor der übergeordneten Leitung gestellt werden, die man aus eigenen Kräften nicht lösen kann. Sie muss wissen, dass die Berichte zuverlässig sind, damit sie schnell und sicher reagieren kann. Aber zu dieser straffen Leitung des Staates gehört auch, dass die übergeordnete Leitung stets im Bilde sein muss über die Situation im Territorium, für welches sie verantwortlich ist. [...]

Wir brauchen eine schnellere Berichterstattung von unten nach oben, um schnell reagieren zu können, und müssen deshalb eine Berichterstattung organisieren, die kurz und präzise die Situation darlegt. Unter Umständen genügen zwei Sätze eines Berichtes eines Rates eines Kreises, dass keine besonderen Vorkommnisse sind. Aber wenn wichtige Erscheinungen da sind, wie das Zurückbleiben in der Schälfurche oder der Anbauplan wird aus dem und dem Grunde nicht erfüllt, die MAS Soundso fällt aus, weil kein Treibstoff vorhanden ist, dann muss das in zwei oder drei Sätzen klar sein. Dann hat der Rat des Bezirkes am Berichterstattungstag eine Übersicht über die Lage, und dort, wo der Rat eines Kreises gesagt hat: es ist nichts Besonderes, muss der Rat beruhigt sein und sagen: damit brauchen wir uns nicht beschäftigen. So müssen wir diese kurze und präzise Berichterstattung über die Situation, über besondere Erscheinungen von unten nach oben organisieren, ohne dass wir viel Papier beschreiben und dort große Kurierdienste in Bewegung 
setzen. Hier bei mir muss zweimal in der Woche ein klares Bild über die Lage in der Republik vorliegen, damit ich in der Lage bin, dem Ministerpräsidenten über die Lage drauBen Bericht zu erstatten. [...]

Jedenfalls müssen wir heute feststellen, dass die Räte der Bezirke im allgemeinen gesehen noch nicht so arbeitsfähig sind, dass sie den gesamten Arbeitsprozess in die Hand nehmen können. Das ist eine sehr ernste Feststellung. Das muss in wenigen Tagen überwunden werden, und nicht nur mit apparatmäßigen Mitteln, sondern auch, indem wir jetzt Hilfe mobilisieren. Versorgungsfragen - das sind Fragen, die jeden Einzelnen berühren. Ernte, Erfassung, Aufkauf - das sind Fragen, die jeden Einzelnen berühren. Ziehung der Schälfurche - das ist eine sehr ernste Frage, denn davon hängt schon der Ertrag des nächsten Jahres ab. Die Räte der Bezirke müssen also in den nächsten Tagen eine fieberhafte Tätigkeit entwickeln und alle Kräfte mobilisieren, um auf diesem Gebiet aufzuholen. Ich will dazu jetzt keine Einzelvorschläge machen. - Das ist die eine Seite.

Gleichzeitig und trotz der Kompliziertheit allein dieser Aufgabe, das Zurückbleiben zu überwinden und die Abteilungen zu einem wirklichen Arbeitsschwung zu bringen, müssen wir in den Kreisen die Voraussetzungen schaffen, dass die Überleitung schnell, zügig und ohne irgendwelche nachteiligen Wirkungen in der Versorgung, im Finanzwesen, also in der Steuereinziehung, oder auf irgendeinem anderen Gebiet durchgeführt wird. Das ist keine Kleinigkeit, man soll das nicht unterschätzen. Dazu bedarf es der Mobilisierung großer Kräfte. Die Räte der Bezirke müssen diese Kräfte mobilisieren. Sie sind für die Überleitung in den Kreisen verantwortlich. Es ist unmöglich, das hier von uns aus zu dirigieren oder zu lenken. Wir können Hilfe geben, wo es möglich ist; aber diese Möglichkeiten sind beschränkt.

Es zeigt sich jetzt, dass eine große Anzahl von Fragen sehr oberflächlich behandelt wurde. Die Fragen der Unterbringung, die Gebäudefragen z. B. sind in einer ganzen Anzahl von Kreisen sehr oberflächlich behandelt worden. Eine Reihe von Vorsitzenden traten vorgestern auf mich zu und wiesen mir nach, dass sie überhaupt keine Möglichkeit sehen, mit dem neu aufzubauenden Apparat irgendwie unterzukommen. Und jetzt entwickelt sich etwas Eigenartiges, wiederum typisch apparatmäßig Hilfe von oben erwartend: eine Flut von Anträgen auf Bereitstellung von Baracken. Ganze Barackenstädte werden nach den Plänen, die uns eingereicht werden, entstehen. Kein Mensch macht sich Gedanken darüber, wo das Geld herkommen soll, macht sich Gedanken darüber, ob es überhaupt so viele Baracken gibt. Aber das Entscheidende sieht man nicht: die Mobilisierung der örtlichen Reserven. Ein ganz kleines Beispiel: Hier sitzt Ernst Lange, stellvertretender Vorsitzender der Zentralen Kommission für Staatliche Kontrolle. Er erzählte mir heute Morgen, dass es in Fürstenberg einen großen Sturm gegeben hat: Wir können das neue Organ nicht aufbauen, wir brauchen vier Baracken, sonst können wir nicht arbeiten, und dann wurden einige Maßnahmen gemacht, dann spricht man mit einer Gruppe von Arbeitern, und da sagt ein Arbeiter: Aber da stehen doch drei Baracken, die könnt ihr doch nehmen. Von den vier Baracken waren also schon drei vorhanden. 
Man muss also mit Entschiedenheit gegen eine solche meiner Meinung nach opportunistische Tendenz angehen, dass von oben die Bereitstellung von vielen Millionen, die Bereitstellung von funkelnagelneuen Baracken in einer Anzahl, welche alle Vorstellungen übersteigt, erwartet wird. Man muss damit Schluss machen, man muss die örtlichen Reserven mobilisieren, man muss an die Arbeiter der Betriebe herangehen, man muss an die Bevölkerung herangehen, und man wird dann auch Möglichkeiten schaffen. [...]

Dann gibt es noch etwas anderes, worauf ich hinweisen möchte. Es gibt Tendenzen, wonach in Zukunft nur noch Mitglieder der SED verantwortliche Positionen im Staatsapparat besetzen dürfen. Man muss gegen diese sektiererischen Tendenzen auftreten. Vorgestern wurde uns z. B. berichtet, dass im Kreis Herzberg strikt gesagt worden ist: Abteilungsleiter nur noch Mitglieder der SED. Ich habe schon eingangs gesagt: Die Politik der Zusammenfassung aller aufbauwilligen, aller patriotischen Kräfte bleibt dieselbe, unsere Blockpolitik wird beherrschend für unsere Politik bleiben. Ich bitte, auch hier dem Gegner nicht das Material für seine Hetze gegen uns zu liefern und solche sektiererischen Tendenzen entschieden zu bekämpfen.

Es geht nun darum, dass wir erstens das Zurückbleiben auf den verschiedenen Gebieten jetzt energisch beseitigen, zweitens, dass wir durch eine gute Beratung mit den verantwortlichen Funktionären auf allen Linien in den zukünftigen Kreisen eine planmäßige, systematische Arbeit einleiten, damit diese neuen Kreisorgane möglichst schnell und in einer ganz kurzen Frist der Überleitung arbeitsfähig werden, und zwar so arbeitsfähig werden, dass sie schon vom Vertrauen der Bevölkerung getragen sind. Das sind die zwei Hauptaufgaben, die ich Ihnen heute aufzeigen möchte, zwei schwierige und sehr komplizierte Aufgaben, weil die Räte der Bezirke im Augenblick noch nicht so arbeitsfähig sind. $[\ldots]$

Ministerpräsident Grotewohl: [...] Wir haben uns bis heute - und das ist genau nach dem Kalender gemacht - mit den Fragen des organisatorischen Aufbaus beschäftigt. Aber dabei hat sich herausgestellt, dass die eigentliche Arbeit, für die wir organisieren, - denn wir organisieren nicht um des Organisierens willen - zu kurz gekommen ist. Es ist in den Bezirken nicht gelungen, neben dieser anfallenden großen organisatorischen Arbeit die wirkliche wirtschaftliche, kulturelle und politische Arbeit kontinuierlich in dieser Entwicklung zu halten. Wir sind mit der praktischen Arbeit zurückgefallen, sie ist zu kurz gekommen. [...]

Unsere II. Parteikonferenz hat beschlossen, wir wollen mit dem Aufbau des Sozialismus beginnen. Auf der II. Parteikonferenz wurde das Grundgesetz des Sozialismus, so wie es Stalin uns gelehrt hat und wie es der marxistisch-leninistischen Auffassung entspricht, zu Grunde gelegt. Ich will es hier wiederholen, damit es uns völlig klar ist. Das von Stalin formulierte Grundgesetz des Sozialismus lautet: 
„Sicherung der maximalen Befriedigung, der ständig wachsenden materiellen und kulturellen Bedürfnisse der gesamten Gesellschaft durch das ununterbrochene Wachstum und die Vervollkommnung der sozialistischen Produktion auf der Basis der höchsten Technik." 291

Genossen, in diesem Zitat von Stalin und in dieser Feststellung haben wir die ganze Zielsetzung unserer Arbeit. Wenn man jedes dieser Worte genau überlegt: die maximale Befriedigung der ständig wachsenden materiellen und kulturellen Bedürfnisse der Gesellschaft, so zeigt sich uns, dass der Aufbau des Sozialismus nicht irgendein konstanter Vorgang ist, sondern ein ewig wachsender und immer größer werdender Vorgang und Prozess. Wenn also das Wachstum der maximalen Bedürfnisse vorhanden ist, das, was sich aus den ständig wachsenden materiellen und kulturellen Ansprüchen der Gesellschaft ergibt, so bedeutet es, dass unsere Aufgabe nicht gering ist und infolgedessen in einem ständigen Wachstum und in einer ständig größer werdenden Aufgabe beim Aufbau verankert ist. Und wenn darin gesagt wird, dass die Vervollkommnung der sozialistischen Produktion auf der Basis der höchsten Technik sich zu vollziehen hat, so reißt dieser Satz, Genossen, ganze Probleme vor uns auf, mit denen wir fertig werden müssen, die wir lösen müssen, wenn das Grundgesetz des Aufbaus des Sozialismus verwirklicht werden soll.

Wenn wir also diese Auffassungen zugrunde legen, dann müssen wir uns klar sein, dass wir mit den altherkömmlichen Auffassungen von Verwaltung innerhalb eines Staates überhaupt nicht mehr zurechtkommen, dass man sich von diesen Auffassungen völlig freimachen muss und dass wir begreifen müssen, dass unsere mächtigste Waffe zur Erfüllung dieser Aufgaben die Staatsmacht ist. Wir haben die Staatsmacht aus ihrer eigenen Gebundenheit der Länder nicht nur wegen eines historischen Vorganges gelöst, weil es keine Fürstenhäuser, keine Könige von Sachsen und keine Großherzöge von Mecklenburg usw. mehr gibt, sondern weil einfach mit dieser Struktur diese neue Aufgabe nicht mehr zu erfüllen ist, und mit der Lösung der Struktur Kräfte frei werden, die wir zur Entwicklung der Staatsmacht brauchen.

Die Aufgaben unsers Staates sind ja vollkommen klar auf unserer II. Parteikonferenz niedergelegt. Es sind nur drei Punkte, Genossen, die im gegenwärtigen Augenblick alles in sich zusammen vereinigen:

291 Vgl. Stalin, Probleme, S. 49: „Existiert ein ökonomisches Grundgesetz des Sozialismus? Ja, es existiert. Was sind die wesentlichen Merkmale und Forderungen dieses Gesetzes? Die wesentlichen Merkmale und Forderungen des ökonomischen Grundgesetzes des Sozialismus könnte man ungefähr folgendermaßen formulieren: Sicherung maximaler Befriedigung der ständig wachsenden materiellen und kulturellen Bedürfnisse der gesamten Gesellschaft durch ununterbrochenes Wachstum und ununterbrochene Vervollkommnung der sozialistischen Produktion auf der Basis der höchsten Technik.“ 
1. Die Brechung des Widerstandes der gestürzten und enteigneten Großkapitalisten und Großagrarier, die Liquidierung ihrer Versuche zur Restaurierung ihrer Macht.

2. Punkt: Organisierung des Aufbaues des Sozialismus mit Hilfe des Zusammenschlusses aller Werktätigen um die Arbeiterklasse.

3. großer Punkt, zu dem ich einiges sagen werde: Schaffung der bewaffneten Streitkräfte der Deutschen Demokratischen Republik zur Verteidigung unserer Errungenschaften und zur Sicherung unserer Errungenschaften.

Wer schwach ist, wird überrannt. Und da wir viele große und einflussreiche Gegner haben, müssen wir stark werden, wenn wir alles, was wir getan haben und noch zu tun gedenken, lebensfähig erhalten wollen. Eine vollkommen klare Zielsetzung, die für unsere ganze Verwaltung gilt und die Grundlage bildet. Die Zusammensetzung der neuen Organe soll die Voraussetzung für eine solche Staatsmacht bilden. Nun Genossen, diese Staatsmacht, die wir bilden, sieht anders aus als die, die wir bisher gehabt haben. Warum? Wir haben bisher neben dem Fünfjahrplan gewissermaßen mit den Prinzipien der Weimarer Regierungsmethodik so herunter verwaltet. Manchmal mehr schlecht als recht. Mit dieser Methodik geht das nicht mehr. Lenkung der Wirtschaft und Aufbau des Sozialismus ist nicht durch einen Staatsapparat allein möglich, sondern nur durch die engste Verbindung mit dem Volk, durch die allerengste Verbindung mit den Volksräten der Bezirke.

Bezirkstag, Räte der Kreise und Kreistage sind wichtige Einrichtungen. Aber die allerwichtigste Einrichtung sind die Ständigen Kommissionen. Und darin liegt das grundsätzlich Neue unserer Verwaltung. Wir müssen auch den Begriff einer Kommission in Zukunft mit einem ganz anderen Inhalt ausfüllen, als wir das bisher getan haben. Bisher hatte man so die Vorstellung: Wenn man in einer Beratung nicht richtig zum Ziele kommen konnte, setzte man Kommissionen ein.

\section{(Zwischenruf Jahn: ${ }^{292}$ Begräbnis erster Klasse!)}

Diese hat Beratungen und Vorschläge gemacht. Diese Kommissionen, Genossen, sind nicht solche Einrichtungen, sondern Einrichtungen der operativen Arbeit. [...] Arbeiten sollen die Kommissionen, und aus den praktischen Erfahrungen, die an den jeweiligen Stellen, für die sie bestimmt sind, gesammelt wurden, sollen die Anregungen und Vorschläge für die vollziehenden Organe gegeben werden. Was sie sich in den Schulen erarbeitet, was sie sich in den Krankenhäusern erarbeitet, was sie sich an den Wirtschaftsstellen erarbeitet, fassen sie zu wirklich praktischen Vorschlägen, die fundiert sind, mit allen in Frage kommenden Leuten zusammen und bringen sie in diese Verwaltung und schaffen damit einen neuen Blutkreislauf. Es wird nicht mehr von oben herunter beschlossen und

292 Zu Rudolf Jahn vgl. Dok. 11, Anm. 260. 
verwaltet, sondern es wird jetzt von der Basis aus ein Kreislauf geschaffen. Man arbeitet nicht so herunter und auch nicht so von unten herauf, sondern es ist ein Kreislauf der Verwaltung. Die Erfahrungen des praktischen Lebens laufen in die Verwaltung hinein, werden dort verarbeitet und gehen von dort in konkreten Anweisungen und Veränderungen der stabilen Verhältnisse wieder zurück. [...]

Solange wir die Menschen nur zusammenholen zum Quatschen, wie es an vielen Stellen bisher gewesen ist, verlieren die Leute natürlich die Lust, wollen sie gar nicht mehr. Aber wenn sie erst spüren, dass ihre Arbeit einen wirklich tatsächlichen Sinn bekommt, dass sie nicht nur an Dingen herumreden, sondern dass sie neue Vorschläge gestalten, dass sie das alles neu machen, dann werden sie auch eine ganz andere Freude entwickeln, eine solche Freude, wie sie aus dem Bericht von Eggerath ersichtlich war, wie wir sie aus den Erfahrungen der Sowjetunion kennengelernt haben. Unsere Leute sind nicht anders als die sowjetischen Genossen. Es fehlt ihnen nur die Erfahrung, es fehlen die Voraussetzungen. Es fehlt ihnen die Entwicklung, und diese müssen durch diese neuen Organe geschaffen werden. Darum ist diese Veränderung unserer Staatsapparatur geschaffen. [...]

Das ist eine große Erziehungsarbeit. Es ist vollkommen klar: Das morgen zu erreichen, wäre Irrsinn. Aber wir müssen begreifen, wo unsere Aufgabe liegt, um richtig heranzugehen, um richtig zu gestalten.

Der zweite Punkt ist: Das Volk soll also handeln, soll auf dieser Basis zu Hunderttausenden zur direkten Arbeit herangezogen werden. Und seht, Genossen, diese beiden Elemente einer solchen Verwaltungsarbeit sind die Elemente einer Volksdemokratie. Demokratie und Handeln in der Demokratie! Aus dem Reden herauskommen zum Gestalten! Das Volk handelt, und es handelt mit demokratischen, das heißt in seiner Gesamtheit eingesetzten Kräften. Das ist es, was wir meinen, wenn wir in unserem Beschluss gesagt haben, wir legen die Grundlagen oder entwickeln die Grundlagen einer Volksdemokratie. Darum haben wir die Gewaltenteilung der alten Staatsauffassungen in der Verwaltung beseitigt. Es gibt keine Teilung mehr, sondern das Volk steht unmittelbar jetzt daran. [...]

Dazu gehört Enthusiasmus. Der ist auch damit bei jedem verbunden, wenn er an dieses große Ziel und an seine Verwirklichung denkt. Aber dieses Ziel besteht nicht nur aus Begeisterung und aus Enthusiasmus, sondern es besteht aus tausend kleinen Aufgaben. Es setzt sich zusammen aus tausendfältigen Arbeiten, die gar nicht mehr so begeisternd aussehen, wenn sie gemacht werden. Zu denen gehört etwas anderes: Fleiß, Zähigkeit, Ausdauer und Gewissenhaftigkeit. [...] Unsere Aufgabe ist es, die Menschen davor zu bewahren, dass sie in Praktizismus versinken. Wir müssen ihnen in unserer neuen Arbeit, in unserem neuen Arbeitsstil klarmachen, dass die Begeisterung für den Sozialismus und für das große Ziel keinerlei Gegensätzlichkeit zu Gewissenhaftigkeit für die kleine Aufgabe darstellt. [...] Wenn diese Dinge so zueinander gebracht werden, und die Bewusstseinsbildung unserer Verwaltung weiter entwickelt wird, dann schaffen wir die Voraussetzungen, die wir haben müssen, um zu einem bolschewistischen Arbeitsstil zu kommen. [...] 
Nun will ich auf einen Gesichtspunkt hinweisen, der unsere Verwaltungsarbeit sicher sehr bald sehr spürbar erreichen wird: Unser Gesetz vom 23. Juli 1952 über die weitere Entwicklung der Demokratie hat natürlich nicht nur eine Wirkung und Bedeutung für die Deutsche Demokratische Republik, sondern selbstverständlich auch für die Arbeiterklasse im Westen Deutschlands, für die Bauern in Westdeutschland, die mit großem Interesse verfolgen werden, was sich hier vollzieht; ob das richtig oder falsch ist, was wir hier machen, ob Erfolge oder Misserfolge dabei herauskommen. Aber auch noch eine zweite Gruppe ist durch dieses Gesetz in Bewegung gesetzt: Die Monopolisten und die von uns ausgerückten Junker und die im Westen vorhandenen Elemente des gleichen Kalibers haben natürlich sofort gespürt, dass ein solches Gesetz doch Auswirkungen nach sich zieht, dass für den Bestand dieser kapitalistischen Gesellschaftsordnung, für die Privilegien der Monopolisten und der Junker eine außerordentlich scharfe Wendung eintreten wird. Die nehmen nichts widerspruchslos hin. Es ist ganz klar, dass wir in Zukunft mit einer erheblichen Verschärfung des Klassenkampfes rechnen müssen. Die Kräfte, die aus den eigenen Elementen innerhalb der Deutschen Demokratischen Republik in dieser Beziehung in Freiheit gesetzt werden, werden vermutlich nicht so stark und gefährlich sein wie die Kräfte, die von außerhalb, vom Westen nach uns hinein filtriert werden, die Saboteure, die Diversanten, die Unterbrechung unserer Arbeit, der Versuch von Terror. Wir haben nicht aus lauter Vergnügen in den letzten Wochen diese Prozesse veranstaltet, sondern um der Öffentlichkeit zu zeigen, was überhaupt vorgeht. Das ist ein Lehrvorgang, der unseren Genossen die Zuspitzung des Klassenkampfes klarmachen soll und die Notwendigkeit der weiteren Steigerung unserer Wachsamkeit, der Wachsamkeit in der Verwaltung, Wachsamkeit im ganzen Volk, Wachsamkeit in der Wirtschaft. Die Sicherung unserer Aufbauarbeit ist nicht nur eine polizeiliche oder juristische Angelegenheit - das sind nur die Mittel, mit denen wir zuschlagen -, sondern es ist eine Arbeit unseres ganzen Volkes. Ich bitte die Genossen, in den Bezirken von vornherein in dieser Richtung die Arbeit richtig zu entwickeln, damit hier keine Einschläferung vorkommen kann. [...]

Unsere Arbeit darf in den Räten des Bezirks und auch nachher in den Kreisen nicht im Kampf um die Stühle und Schreibtische, um das Telefon, um die Automobile und die Aktenschränke bestehen, sondern sich in erster Linie auf die Fortführung unserer sachlichen Arbeit ausrichten. Ich kann mir denken, dass es Wochen geben kann, in denen ihr so improvisieren müsst in Bezug auf den persönlichen Luxus des Verwaltungszimmers, wie wir es 1945 mussten.

\section{(Zustimmung)}

Wenn wir es anders machen, begehen wir einen großen Fehler. Seid überzeugt, Eure Verwaltungsräume kommen alle noch in Ordnung, - bestimmt! - auch die Aktenstapel, die jetzt noch in großen Haufen in den Zimmern liegen oder von Automobilen verloren werden, auf der Landstraße liegen und von anderen aufgesucht werden, sie finden alle noch ihren richtigen Platz. Aber es ist unverzeihlich, wenn wir durch die Beschäftigung mit 
solchen Dingen wichtige Aufgaben vernachlässigen, und wir haben wichtige Aufgaben vernachlässigt. Es ist höchste Zeit, dass wir beginnen, das zu beseitigen. [...]

Eggerath: [...] Ich bitte nun zur Diskussion zu schreiten. Vielleicht ist es zweckmäßig, falls es Fragen gibt, die noch nicht geklärt sind, dass zunächst diese Fragen ganz knapp und präzis gestellt werden und dass wir dann in die eigentliche Diskussion eintreten. [...]

Vertreter des Bezirks Frankfurt: ${ }^{293}$ Die VVEAB führt bei uns im Bezirk Frankfurt Massenkündigungen durch, weil der Finanzplan überzogen ist, z. B. im Kreis Angermünde allein 80 Kündigungen. Wir sind der Meinung, dass das in der großen Aktion, die wir jetzt bei uns durchführen, unmöglich ist, dass dieser Apparat geschwächt wird.

Eine andere Frage: Das Eisenhüttenkombinat Fürstenberg hat die Versorgung wie Berlin. Bei unserer Kreisverwaltung, die wir in Fürstenberg aufbauen, sind es jetzt schon 30 Angestellte, die in das Eisenhüttenkombinat abgezogen wurden, weil die Kollegen natürlich diese günstigen Voraussetzungen wahrnehmen. Hier treten also bestimmte Schwierigkeiten ein. Ist es möglich, hier für die ganze Stadt Fürstenberg eine Änderung vorzunehmen? Das trifft auch für die Entlohnung zu.

(Eggerath: Welche Veränderung ist gemeint?)

- Die Ortsklassen sind gemeint. Die Entlohnung ist im Eisenhüttenkombinat nach A, bei uns in der Kreisverwaltung, die wir aufbauen, nach C. [...]

Manneberg $^{294}$ (Cottbus): ${ }^{295}$ Ich möchte fragen, wieweit jetzt über die Bezeichnung unserer Organe endgültig entschieden ist, ob wir uns also „Rat des Bezirks Cottbus - Land Brandenburg“ oder nur „Rat des Bezirks Cottbus“ bezeichnen [sic!]. Dann möchte ich noch fragen: Erfolgt die Herstellung der Siegel zentral oder bleibt uns das überlassen?

Eggerath: Was sagt das Landtagsgesetz darüber?

\section{(Zuruf: Land.)}

Geyer: ${ }^{296}$ Es soll heißen: Bezirk Dresden, in Klammern Land Sachsen. Nicht etwa ein Briefkopf, wo oben steht „Land Sachsen“ und darunter Bezirk Dresden. „Land Sachsen“ kommt nur in Klammern. Es ist ja ein absterbender Körperteil.

293 Der Redner ist namentlich nicht identifizierbar.

294 Im Original „Massenberg“.

295 Zu Werner Manneberg, seit August 1952 Vorsitzender des Rates des Bezirkes Cottbus, vgl. Dok. 4, Anm. 247.

296 Fritz Geyer (1888-1966) war seit 1950 als Staatssekretär Leiter der Regierungskanzlei der DDR; vgl. Baumgartner, Biographisches Handbuch, S. 221, sowie Hoffmann, Grotewohl, S. 397. 
Eggerath: Wir setzen also den Bezirk zuerst: zum Beispiel Bezirk Gera, Thüringen, und im Einzelnen: der Rat des Bezirks oder der Bezirkstag Gera, Thüringen.

\section{(Widerspruch)}

Wir haben doch wichtigere Dinge zu besprechen und sollten uns nicht im Einzelnen mit diesen kleinen Punkten abgeben. Das wird sich alles schon einspielen. Heute wollen wir grundsätzliche Fragen klären. [...]

Adolphs (Leipzig): ${ }^{297}$ Ich möchte zunächst etwas zu der Frage der Bezirkskommissionen sagen. Ich möchte einleitend bemerken, dass wir in Leipzig in einer schlechten Situation waren, weil wir erst ungefähr zehn Tage vor dem Stattfinden des Bezirkstages mit dieser Funktion beauftragt wurden und nicht alle Unterlagen, die wichtig sind, erhalten haben. Die Tatsache, dass eine solche Bezirkskommission geschaffen werden muss, habe ich, glaube ich, erst drei Tage vor Stattfinden des Bezirkstages erfahren, und da wurde mir seitens der Instrukteure mitgeteilt, dass diese Bezirkskommission in erster Linie die Aufgabe hat, die ideologische Vorarbeit zu leisten und die ideologische Arbeit zu organisieren - und damit Schluss. Ich habe mich dann erkundigt. Eine Direktive war nicht aufzutreiben. Ich habe lediglich die Zusammensetzung der Bezirkskommission erfahren. Es sind meistens Genossen, die in Dresden wohnen. Es stand nun die Frage: was praktisch tun? Wir haben in Zusammenarbeit mit der Partei den Bezirkstag vorbereitet, und ich glaube, im Allgemeinen auch politisch nicht schlecht vorbereitet. Das kommt darin zum Ausdruck, dass 1.600 Gastdelegierte aus den Betrieben an dem Bezirkstag teilnehmen. Jeder Kreis hat mindestens 25 Delegierte aus Betrieben, MAS und Produktionsgenossenschaften entsandt. Wir haben einen solchen Widerhall gehabt, dass den Bezirkstag etwa 700 Telegramme und Grußbotschaften mit Selbstverpflichtungen und mit bestimmten Aufträgen an den Bezirkstag erreichten. Es gibt eine ganze Reihe Betriebe, vor allem auch Großbetriebe, die fordern, dass die Abgeordneten ideologisch die Patenschaft über die Betriebe übernehmen.

Ich muss sagen, nach dem, was ich heute über die Bedeutung der Bezirkskommission gehört habe, ergibt sich ein vollkommen anderes Bild. Obwohl ich bereits im zweiten Bericht auf diese Tatsachen hingewiesen habe, dass wir nicht recht wissen, was die Bezirkskommission machen soll, wäre es doch zweckmäßig gewesen, von hier aus zu reagieren; denn wir schreiben ja unsere Berichte und melden unsere Fehler, Schwächen und Mängel, damit sie schnell abgestellt werden.

(Eggerath: Es ist sehr scharf reagiert worden. Du warst aber nicht da.)

297 Karl Adolphs (1904-1989) war seit August 1952 Vorsitzender des Rates des Bezirkes Leipzig; vgl. Niemann/Herbst, SED-Kader, S. 85. 
- Ich bin die ganze Zeit da gewesen.

(Eggerath: Die Bezirkskommissionen haben einen sehr scharfen Brief aufgrund des Beschlusses der Zentralen Kommission bekommen.)

Der Bezirkstag und auch die Durchführung der Lektion waren gut. Ausspracheabende am zweiten Tage in Leipzig waren ebenfalls sehr erfolgreich. Aber dann entstand eine Lücke. Die Frage war: was weiter? Ich bin der Meinung, die entscheidende Frage ist, dass jeder Abgeordnete sich dessen bewusst sein muss, nicht nur durch die Referate, die auf dem Bezirkstag gehalten werden, und durch die Lektion, die bei uns Professor Kröger gehalten hat, ${ }^{298}$ sondern dass er auch durch die Praxis fühlen muss, dass er nicht mehr ein Landtagsabgeordneter alten Stils ist, sondern dass Aufgaben an ihn gestellt werden. Es stellte sich heraus, dass angesichts der Beschwerden - es waren rund 700 bis 800 Beschwerden, die allein über die Stadtverwaltung Leipzig eingegangen sind - am anderen Tage eine ganze Anzahl Abgeordnete, vor allem bürgerliche Bezirkstagsmitglieder, von sich aus die Initiative ergriffen und der Stadtverwaltung Leipzig Anweisung gaben, der Frau Sowieso einen Bezugsschein auszustellen usw. Wir haben sofort eingegriffen und gesagt, so geht das auf keinen Fall, und wir haben in einer Sitzung der stellvertretenden Vorsitzenden diese Frage behandelt und sind dazu gekommen, den Oberbürgermeister zu der nächsten Ratssitzung zu laden, ihm dort von der Nationalen Front die Liste mit allen Beschwerden zu überreichen und ihn zu beauftragen, innerhalb von acht Tagen die wichtigsten Fälle zu klären bzw. dem Bezirksamt Bericht zu erstatten. Diese Vereinbarung wurde mit dem Org.-Komitee der Partei getroffen. [...]

Es stellte sich heraus, dass unsere ständigen Kommissionen, die wir zur ersten Sitzung eingeladen haben, zum Teil nicht wussten, was sie tun sollen, zum Beispiel die Kommission für Polizei und Justiz. Sie hat ihre Sitzung gehabt, aber praktisch ohne nennenswertes Ergebnis. Wir haben auch noch nicht gewusst - das sage ich ganz offen -, wie diese Aktivs gebildet werden sollen und welche entscheidende Rolle der Rat des Bezirks zu spielen hat im Zusammenhang mit der Organisierung der ständigen Kommissionen, der Arbeit der ständigen Kommissionen und der Schaffung der Aktivs. Selbst dann, wenn oben noch nicht eine vollkommene Klarheit darüber geschaffen war, hätte man uns meiner Meinung nach doch gewisse Hinweise geben können: Geht jetzt weiter vor, indem ihr meinetwegen auf dem Gebiet der Wirtschaft und dem Gebiet des kulturellen Lebens euch umschaut, damit die ersten Aktivs für die ständigen Kommissionen gebildet werden. Das ist bei uns noch nicht geschehen. Aber wir werden es aufgrund der heutigen Aussprache sofort in Angriff nehmen.

298 Herbert Kröger (1913-1989) war zu diesem Zeitpunkt Dekan der Juristischen Fakultät der Deutschen Verwaltungsakademie in Forst Zinna und hielt im Sommer 1952 in vielen Bezirken Vorträge über die Aufgaben der Abgeordneten in den neu gebildeten Bezirks- und Kreistagen; vgl. Kröger, Bedeutung, sowie Baumgartner, Biographisches Handbuch, S. 440. 
Mit der Nationalen Front ist ein Plan ausgearbeitet worden, wonach die Abgeordneten bis Ende des Monats fünf bis sechs Ausspracheabende im Bezirk durchzuführen haben. Ein Teil Abgeordnete hat bereits diese Ausspracheabende durchgeführt. Es zeigt sich, dass diese Ausspracheabende durchweg von der Bevölkerung sehr stark besucht sind und das Interesse für die weitere Demokratisierung sehr groß ist. Aber wir müssen uns hier noch unterhalten: Wie ist das Aktiv bei der Ständigen Kommission gedacht? Soll lediglich ein großes Aktiv gebildet werden oder wird es nicht so sein, dass wir bei bestimmten Kommissionen eine Unterabteilung haben werden - was eine Gesamtzusammenfassung nicht ausschließt - oder dass wir Aktivs bilden werden, die eine bestimmte Aufgabe durchführen, und wenn diese bestimmte Aufgabe durchgeführt ist, dann ist ihre Arbeit erledigt? Wie gesagt, darüber herrscht bei uns noch Unklarheit. Ich weiß nicht, inwieweit wir heute diese Frage noch klären können. [...]

Brasch: ${ }^{299}$ Ich möchte zwei Fragen anschneiden: Die erste betrifft die Arbeit der Bezirkskommissionen. Nach dem Brief, den Genosse Eggerath geschrieben hat, kann man nicht feststellen, dass wir den Schwerpunkt auf die Arbeit in der Bezirkskommission gelegt haben. Es gibt gewisse objektive Schwierigkeiten, die z. B. darin bestehen, dass die Bezirkskommission Cottbus sich insgesamt fünfmal geändert hat, und nie wieder dieselben Menschen zusammengekommen sind. Entweder von der Seite der Partei, des Staatsapparates oder der Massenorganisationen. Aber das hatte Auswirkungen, die man jetzt nicht unterschätzen darf. Vor dem Stattfinden des Bezirkstages ist - wenn man die Sache objektiv betrachtet - sehr wenig Aufklärungsarbeit gemacht worden. Es gibt heute noch Menschen, die in unserem Bezirk nicht wissen, wohin sie gehören, zumindest bis zum Stattfinden des Bezirkstages nicht. Das wird sich jetzt mit dem Erscheinen einer einheitlichen Presse unserer Partei verbessern. [...]

Es bleibt jetzt zu fragen, nachdem faktisch, wenn auch nicht gewählte, so doch arbeitende Sekretariate der Partei bestehen, in denen letzten Endes die Genossen der staatlichen Verwaltung mitarbeiten und zu denen auch die Genossen der Massenorganisationen zu bestimmten Fragen herangezogen werden, inwieweit man auf diese Bezirkskommission in der Form, wie sie bisher bestehen sollte, noch weiter diesen entscheidenden Wert legen muss. Dass der Vorsitzende dieser Bezirkskommission nicht der erste Sekretär der Partei, sondern der Vorsitzende des Rates des Bezirkes ist, ist nach meiner Meinung in der gegebenen Situation, wo die Landesleitungen aufgelöst sind und die Bezirksleitungen der Partei bestehen, nicht mehr notwendig.

Ich habe aber noch eine zweite Frage: Ich habe an den Genossen Eggerath geschrieben, worauf ich noch keine Antwort bekommen habe. Es ist die Frage: Wie verhält es sich mit der Anleitung durch die zentralen Ministerien der Republik an den Bezirk? Wir haben

299 Horst Brasch (1922-1989) war seit 1952 Sekretär des Rates des Bezirkes Cottbus; vgl. Niemann/ Herbst, SED-Kader, S. 130. 
z. B. die Erscheinung, dass der Vorsitzende des Rates des Bezirkes einen dringenden Auftrag von Staatssekretär Malter ${ }^{300}$ bekommt, bis heute festzustellen, wie viel Einzelverträge auf den verschiedensten Gebieten in welcher Höhe abgeschlossen sind. Vor einigen Tagen bekam der Stellvertreter des Vorsitzenden unter der Bezeichnung „Bezirksrat für Landwirtschaft" die Aufforderung des Ministers für Landwirtschaft, er hat hier zu einer Sitzung zu erscheinen. In einer Vorbesprechung, die wir vor etwa einem Monat hatten, brachte Genosse Sorge nicht zum Ausdruck, dass das nicht mehr der richtige Weg ist. Ich bin der Auffassung, dass neben all den Fehlern, die wir in der mangelnden Aufklärung der Mitarbeiter gemacht haben, diese Aufklärung nach oben in den verschiedenen Ministerien nicht vernachlässigen können, die jetzt anfangen, den Stellvertretern, dem Sekretär, dem Vorsitzenden Aufträge zu erteilen und nicht den Weg gehen, den sie gehen müssen, nämlich über die Abteilungsleiter. Das hängt mit der Arbeit der Instrukteure der Fachministerien zusammen. Es gibt drei Fragen, mit denen sie mich laufend belästigen: Erstens sind sie nicht einverstanden mit dem Stellenplan. Das sah so aus: Am Freitag kam der Stellenplan für die Kreise. Der Instrukteur der Verwaltung Materialversorgung kam zu mir und sagte: Wie viel Stellen haben wir im Kreis? Ich sage: In der Plankommission sind soundso viel. Darauf sagte er, ich will mich in Berlin beschweren.

\section{(Zuruf: Wie hieß er?)}

- Er ist von Materialversorgung.

Die zweite Frage ist, dass sie Räume und Autos fordern, damit die Abteilungen arbeiten können. Soviel Autos, wie sie fordern, hat es nicht einmal in der Landesregierung gegeben. Sie sorgen aber nicht dafür, dass die Arbeitsweise der alten Landesregierung liquidiert und eine neue Arbeitsweise eingeführt wird. Sie klären ihre Mitarbeiter nicht auf. Der Genosse aus Leipzig sagte schon: Wir haben Abteilungsleiter, die vorher keine Abteilungsleiter waren. Was ist die Aufgabe der zentralen Instrukteure? Mit uns zusammen diesen Menschen schnellstens zu helfen, ihnen zu zeigen, wie man die Arbeit organisiert!

(Zuruf: Wird der zentrale Instrukteur auch angeleitet?)

- Er wird auch angeleitet. Er ist jede Woche einmal zwei Tage in Berlin. Er arbeitet mit dem Instrukteur des Genossen Eggerath zusammen, bekommt Anweisungen, die er mehr oder weniger durchführt. Sie führen ein gewisses Eigenleben. Man kann dafür nicht nur allein diese Menschen verantwortlich machen, sondern man muss die Ursache auch bei der Arbeit der zentralen Ministerien in der Frage der Überleitung sehen. Sie wissen nicht, mit welchen Schwierigkeiten das verbunden ist, welche Probleme auftreten. Deshalb verstehen sie auch nicht genügend, ihren Instrukteuren die entsprechende Anleitung zu

300 Friedel Malter (1902-2001) war seit 1950 Staatssekretärin im Ministerium für Arbeit und Berufsbildung der DDR; vgl. Müller-Enbergs, Wer war wer, S. 549. 
geben. Unter der Leitung des Instrukteurs, der von der Koordinierungsstelle kam, sind wir zu einer Regelung gekommen, die sie zumindest zum Arbeiten gebracht hat, dass sie uns in den Kreisen helfen.

Das wird zum mindesten im Haus und im Kreis einige Hilfe bedeuten. Ich bitte, dass das auch mit besprochen wird, da sonst die Arbeit praktisch behindert wird.

Vors.: Ich bin für solche Diskussionsbeiträge, die eine große Unterstützung für mich sind, sehr dankbar. Es wird ein unerhört harter Kampf entbrennen, nicht der Minister und Staatssekretäre, aber bis die einzelnen Ministerien oder Staatssekretariate begriffen haben, was eigentlich los ist.

(Zuruf: Auch der Minister und Staatssekretäre!)

- Ich würde das nicht mal so in den Vordergrund stellen. [...]

Wach $^{301}$ (Potsdam): ${ }^{302}$ Die Ursachen für die Schwierigkeiten liegen einmal darin begründet, dass ein Teil der alten Landräte, die nicht wieder eingesetzt werden, weil sie das schon wissen, nicht die notwendige Initiative entwickeln. In dem ganzen alten Apparat der Kreisleitung gibt es aber ebenso die Tendenz, sich nicht mehr auf die Gebiete zu konzentrieren, die sie später nichts mehr angehen, weil sie wissen, sie gehen zum anderen Kreis. Sie kümmern sich nur um das Gebiet, das den zukünftigen Kreis ausmacht, wo sie praktisch dann arbeiten.

Die andere Frage ist die, dass man in den einzelnen Räten der Bezirke versucht, die Erfassung mit den alten Methoden weiterzutreiben. Die Abteilungsleiter stellen sofort, wenn irgend etwas hängt, die Frage: Wir müssen die Erfassungskontrolleure hinausschicken. Diese gehen dann aber praktisch als Gendarmen hinaus und treiben bei den werktätigen Bauern ein. Wir haben uns bemüht, auf diesem Gebiet sofort eine andere Linie hineinzubringen. Der Abteilungsleiter für Ankauf und Erfassung, mit dem wir vor einigen Tagen gesprochen und ihm gesagt haben, dass es gilt, die Erfassung jetzt nur mit ideologischer Aufklärung der Bauern durchzuführen, war vollkommen dagegen eingenommen und war der Meinung, dass das zu keinem Erfolg führen könne. Wir haben gesagt: Entweder Du beginnst, deine Arbeitsweise zu ändern, oder wir müssen mit der Partei sprechen, dass wir einen anderen Abteilungsleiter bekommen. Darauf hat er einiges mitbekommen. So haben wir im Kreise Nauen, wo wir am meisten hängen und der Landrat nicht wieder eingesetzt wird, in der schlechtesten Gemeinde, nachdem wir ohne jeden Druck dort gearbeitet haben, nur mit ideologischen Mitteln, etwas erreicht. Die Bauern sollen in Nauen empfangen werden und wollen mir dort am Sonntag das gesamte Getreide übergeben. Ohne dass

301 Im Original „Macht“.

302 Zu Curt Wach vgl. Dok. 25, Anm. 278. 
eine Strafe angedroht wurde, konnte man die Bauern überzeugen, dass wir das Getreide haben müssen.

Wir haben auch mit unseren zukünftigen Vorsitzenden, soweit sie vorhanden waren, gesprochen, dass die alten Methoden grundlegend überwunden werden müssen. Genosse Barnick in Großprignitz steht in der Kartoffelbersorgung [sic!] an der Spitze und hat sein Soll schon übererfüllt. Als ich ihn vorgestern anrief, wir brauchten noch mehr Kartoffeln, sagte er sofort zu, dass er sie noch beschafft. Wir haben an einigen Beispielen gezeigt, wie man ideologisch mit den Bauern sprechen und arbeiten soll. Der Genosse geht ins schlechteste Dorf, wo noch viele Großbauern sind, und diskutiert in einer Brigade mit den Bauern. Am Abend macht er eine Versammlung der gesamten Dorfbevölkerung. Er hat seinen Wirtschaftsstrafabteilungsmann dort und erklärt, was sie in der Diskussion am Tage festgestellt haben, dass die werktätigen Bauern bereit sind abzuliefern. Aber einige Bauern, die schon voriges Jahr nicht erfüllt haben, wollen es auch heute nicht. „Ich kann als Landrat die Strafe festlegen, aber nachdem wir auf dem Wege zum Sozialismus sind, sollt ihr die Strafe festlegen; wenn ihr wollt, dass sie nicht bestraft werden, und wisst, was für Auswirkungen das hat, sollt ihr sie nicht bestrafen." Das ganze Dorf, das anwesend war, nimmt Stellung, stellt die Anträge und bestimmt, dass die Höhe der Strafe für die Bauern festgelegt wird. Der Landrat hat das sofort angenommen, weil die Strafe mindestens 50 \% höher lag, als er sich selber vorgestellt hat. Das Ergebnis: In wenigen Tagen haben etwa sechs bis acht umliegende Gemeinden zügig abgeliefert, nur weil man dort die werktätigen Menschen des ganzen Dorfes ideologisch bearbeitet hat. Wir haben die Schlussfolgerungen daraus gezogen, und nicht der Landrat, sondern das Dorf hat gestraft.

Wir haben noch einige andere solche Dinge gemacht und finden dabei, dass wir den Abgeordneten nicht schematisch, sondern an praktischen Beispielen gezeigt haben, wie man es machen muss. [...] Es gilt also, einen dauernden Erfahrungsaustausch mit den Abgeordneten herbeizuführen, damit sie erfahren, welche Probleme draußen stehen, wie der Gegner versucht, die Ausspracheabende zu torpedieren, damit man den Abgeordneten soviel Rückgrat gibt, dass sie wissen, wie sie draußen diskutieren müssen.

Dann wird immer wieder vergessen, die gewählten Hausobleute stärker heranzuziehen, um die neuen Verwaltungsmethoden durchzuführen. Ich hatte vor zwei Tagen eine Versammlung, die, geografisch gesehen, nicht gerade gut vorbereitet war, aber sonst gut. Die Menschen haben dort ganz offen ihre Sorgen vorgebracht und erwarten, dass wir jetzt praktisch zum Verhalten der Verwaltungsorgane Stellung nehmen. Aber nicht nur das kam zum Ausdruck, sondern eine ganze Reihe von Vorschlägen. Man hat sich mit dem Problem der Stromabschaltung beschäftigt. Dort wurde aber nicht nur die Frage gestellt, warum der Strom abgeschaltet wird, sondern die Menschen haben selbst Vorschläge gemacht, wie man das ändern könne. Wenn auch die Vorschläge im einzelnen nicht richtig waren und nicht so durchführbar sind, so waren es doch wertvolle Hinweise. Die Leute haben jetzt gesagt: Wir können unserer Industrie helfen und selber die Zeit der Stromabschaltung verkürzen, wenn wir in unserem Haushalt endlich nur so viel Strom 
verbrauchen, wie wir wirklich gebrauchen müssen, und sie stellten dann die Frage, dass der Hausobmann mit den Familien der Hausgemeinschaft darüber sprechen soll. Dieser stellte die verkehrte Forderung, dass man einfach die Sicherung herausdrehen solle. Das ist natürlich verkehrt. Aber wenn man den Gedanken aufgreift und jetzt die Frage stellt, so wird durch den Obmann in der Hausgemeinschaft eine Diskussion darüber herbeigeführt und man stellt häuser- oder straßenweise fest, dass z. B. in einem Haus im Monat 400 kW verbraucht werden. Dann wird man einen Plan aufstellen, wie man diese Zahl vermindern kann, aber nicht durch Herausdrehen von Sicherungen, sondern indem man mit den Menschen spricht und so erreicht, dass sie sich mit dem Problem beschäftigen, die unseren Plan betreffen usw. [...]

[BArch, NY 4090/401 (Nachlass Otto Grotewohl), Bl. 1-155; hier Bl. 2-41, 55-60, 96-99 und 109-115]

Dokument 30: Direktive der Koordinierungs- und Kontrollstelle für die Arbeit der Verwaltungsorgane ,zur Durchführung des Gesetzes über die weitere Demokratisierung des Aufbaus und der Arbeitsweise der staatlichen Organe in den Ländern der Deutschen Demokratischen Republik vom 23.7.1952“, 16. August 1952

Die weitere Demokratisierung des Staatsapparates muss nach folgenden Grundsätzen vorbereitet und durchgeführt werden:

1.) Die Vorbereitung und Durchführung der weiteren Demokratisierung des Staatsapparates hat so zu erfolgen, dass kein Bürger und Betrieb der Deutschen Demokratischen Republik Schaden erleidet.

2.) Alle Anordnungen sind so zu treffen, dass die jetzigen staatlichen Organe ihre Funktionen so lange auszuüben haben, bis die örtlichen Organe der Staatsgewalt der Bezirke und Kreise ihre Arbeit aufnehmen können.

3.) Der Aufbau der örtlichen Organe der Staatsgewalt hat nach den genehmigten Struktur- und Stellenplänen zu erfolgen. Das Prinzip der strengsten Sparsamkeit ist anzuwenden; eine Erhöhung der genehmigten Haushaltmittel für das Jahr 1952 (Landeshaushalt) darf nicht erfolgen.

4.) Die Vorbereitung und Durchführung der weiteren Demokratisierung des Staatsapparates hat unter der strengsten Einhaltung von Sicherheitsmaßnahmen zu erfolgen.

5.) Die weitere Demokratisierung des Staatsapparates wird in folgenden Etappen durchgeführt:

a) Die konstituierende Sitzung der Bezirkstage ist in der Zeit vom 29.7. bis spätestens 5.8.52 durchzuführen. 
b) Die konstituierende Sitzung der Räte der Bezirke hat in der Zeit vom 29.7. bis 7.8.52 zu erfolgen.

c) Der Aufbau der Abteilungen bei den Räten der Bezirke muss am 15.8.1952 abgeschlossen sein.

d) Die Kreistage haben ihre konstituierende Sitzung in der Zeit vom 25. bis 30.8.1952 durchzuführen.

e) Die konstituierende Sitzung der Räte der Kreise hat spätestens am 1.9.1952 zu erfolgen.

f) Der Aufbau der Abteilungen bei den Räten der Kreise hat bis zum 15.9.1952 zu erfolgen.

g) Bis 30.9.1952 müssen alle Maßnahmen zur weiteren Demokratisierung des Staatsapparates (Bildung der örtlichen Organe der Staatsgewalt) abgeschlossen sein.

Zur Bildung der örtlichen Staatsorgane in den Kreisen verweisen wir auf die Direktive über die Vorbereitung der Arbeit der staatlichen Organe in den Kreisen der Koordinierungs- und Kontrollstelle für die Arbeit der Verwaltungsorgane - Hauptabteilung örtliche Organe.

Für die weitere Demokratisierung des Staatsapparates ist folgendes Organisationsprinzip anzuwenden:

1. Unter der Verantwortung des Leiters der Koordinierungs- und Kontrollstelle für die Arbeit der Verwaltungsorgane arbeitet eine Zentrale Regierungskommission.

Die Zentrale Regierungskommission ist für die Vorbereitung, Durchführung, Anleitung und Kontrolle aller Maßnahmen, die mit der weiteren Demokratisierung des Staatsapparates in Verbindung stehen, verantwortlich. Insbesondere leitet die zentrale Regierungskommission die Bezirkskommissionen an und kontrolliert deren Arbeit.

2. In den Bezirken sind Bezirkskommissionen zu bilden, die die Verantwortung für alle Maßnahmen der weiteren Demokratisierung des Staatsapparates in ihrem Territorium tragen. Die Bezirkskommissionen haben folgende Aufgabe:

a) Sie haben die Org.-Komitees bzw. Räte der Bezirke und Kreise entsprechend der von den zentralen Dienststellen der Regierung der Deutschen Demokratischen Republik erlassenen Direktive anzuleiten und zu kontrollieren.

b) Für die Einhaltung der festgesetzten Termine zu sorgen.

c) Zu kontrollieren, dass alle Gemeinden entsprechend der neuen Struktur der Bezirke erfasst und von den entsprechenden Sachgebieten des Staatsapparates betreut werden.

d) Sie sind dafür verantwortlich, dass die entsprechenden Kader für die zu bildenden Organe der örtlichen Staatsgewalt ausgewählt und eingesetzt werden.

e) Sie sind dafür verantwortlich, dass die Übergabe der Planungsunterlagen, Haushaltmittel, Materialien, Akten usw. rechtzeitig vorbereitet wird und ordnungsgemäß unter Anwendung von Übergabeprotokollen und Lageberichten vor sich geht. 
f) Bei der Vorbereitung der betreffenden Übergaben und Übernahme haben die Bezirkskommissionen zu beachten, dass keine Materialien in falsche Kanäle gelangen, die Wachsamkeit verstärkt wird und Sicherungsmaßnahmen getroffen werden.

3. Die Minister, Staatssekretäre und Leiter der Dienststellen der Regierung der Deutschen Demokratischen Republik, deren Fachgebiete sich bis in die Bezirke und Kreise erstrecken, sind für die Reorganisation ihres Fachgebietes voll verantwortlich.

Sie erlassen unter Anleitung der Zentralen Kommission für Staatliche Kontrolle für die Reorganisation ihres Fachgebietes für die Bezirke und für die Kreise je eine Direktive.

Diese Direktive muss enthalten, welche Maßnahmen zu bestimmten Terminen getroffen werden müssen.

Die Direktive hat genau festzulegen:

a) für die Bezirke

b) für die Kreise

wer für die Durchführung bestimmter Maßnahmen verantwortlich ist.

4. Zur Durchführung dieser Direktive wird unter Anleitung des Ministers, Staatssekretärs oder Leiters der Dienststelle der Regierung der Deutschen Demokratischen Republik ein Organisationsstab gebildet.

Der Organisationsstab hat folgende Aufgaben:

a) darüber zu wachen, dass alle Maßnahmen so getroffen werden, dass die Versorgung der Bevölkerung und der Betriebe auf allen Gebieten gesichert ist.

b) die bei den Landesregierungen vorhandenen Ministerien oder Hauptabteilungen anzuleiten, damit deren Fachgebiete in den zu bildenden Organen der Staatsgewalt in den Bezirken und Kreisen auf der Grundlage der bestätigten Struktur- und Stellenpläne ordnungsgemäß aufgebaut werden können.

c) darüber zu wachen, dass die Ministerien und Hauptabteilungen der Landesregierungen die Pläne, Materialien usw. ordnungsgemäß an die entsprechenden Abteilungen der Räte der Bezirke bzw. Räte der Kreise übergeben werden.

d) dafür zu sorgen, dass bei den einzelnen Ministerien bzw. Hauptabteilungen der Landesregierungen sofort nach der Überleitung der Aufgaben auf die Bezirksorgane eine Abwicklungsstelle eingerichtet wird.

Die Abwicklungsstellen haben ihre Tätigkeit spätestens am 30.9.1952 zu beenden.

e) Die Organisationsstäbe haben der Koordinierungs- und Kontrollstelle für die Arbeit der Verwaltungsorgane Bericht zu erstatten.

5. Für den Aufbau der örtlichen Organe der Staatsgewalt in den Bezirken sind Organisationskomitees zu schaffen. Die Organisationskomitees der Bezirke setzen sich aus den künftigen Vorsitzenden, Stellvertretern und Sekretären der Räte der Bezirke zusammen. 
Das Organisationskomitee des Bezirkes ist für den Aufbau der Räte der Bezirke voll verantwortlich.

Die Organisationskomitees der Bezirke haben dafür zu sorgen, dass für die einzelnen Fachgebiete die Übernahme von Planungsunterlagen, Haushaltsmitteln, Karteien und Akten gesichert ist. Die Organisationskomitees der Bezirke tragen die Verantwortung für die termingerechte Aufnahme der Arbeit der Räte der Bezirke und Kreise.

Die Organisationskomitees bzw. Räte der Bezirke haben den Aufbau der Organe zu kontrollieren.

6. Für die bisherigen und künftigen Kreisorgane ist ein Organisationskomitee zu bilden, das für die Durchführung der weiteren Demokratisierung des Staatsapparates im gesamten Kreisgebiet verantwortlich ist.

Das Organisationskomitee des Kreises setzt sich zusammen aus den künftigen Vorsitzenden, Stellvertretern und Sekretäre der Kreise.

Die Anleitung des Organisationskomitees der Kreise erfolgt durch das Organisationskomitee des Bezirkes bzw. durch den Rat des Bezirkes.

Die Organisationskomitees der Kreise arbeiten nach den Direktiven der Dienststellen der Regierung der Deutschen Demokratischen Republik, damit das entsprechende Fachgebiet bei den künftigen Räten der Kreise aufgebaut werden kann.

Die Organisationskomitees der Kreise haben die Aufgabe, den Aufbau der einzelnen Fachgebiete der örtlichen Organe der Staatsgewalt in den Kreisen, die Übergabe und Übernahme von Materialien, Karteien, Akten, Plänen usw. entsprechend den festgesetzten Terminen zu sichern.

7. Die Organisationskomitees bzw. Räte der Bezirke und die Organisationskomitees der Kreise haben die in den Direktiven der Dienststellen der Regierung der Deutschen Demokratischen Republik festgelegten Sicherungsmaßnahmen zu treffen. Die persönliche Verantwortung der einzelnen Verwaltungsfunktionäre für die Übergabe und Übernahme ist genauestens festzulegen.

Durchzuführende Transporte von Karteien, Materialien, Unterlagen usw. sind von diesen Verantwortlichen persönlich zu begleiten.

8. Regelmäßige Besprechungen in allen Organisationskomitees sind durchzuführen und Arbeitspläne für je eine Woche aufzustellen.

Die Berichterstattung ist von unten nach oben zu sichern.

9. Die Organe der Staatlichen Kontrolle werden beauftragt, die Vorbereitung und Durchführung über die weitere Demokratisierung des Staatsapparates zu kontrollieren und auftretende Schwierigkeiten beseitigen zu helfen.

[BLHA, Rep. 401, Nr. 71, Bl. 190-195] 
Dokument 31: Neunter Bericht des Vorsitzenden des Rates des Bezirkes Potsdam über die Durchführung der Verwaltungsreform im Bezirk Potsdam, 18. August 1952 (Auszug)

Zur Versorgung der Bevölkerung mit Kartoffeln wurde am Sonnabend, dem 16. August 1952, folgende Veranlassung getroffen:

Alle Vorsitzenden der Kreise des Rates des Bezirkes Potsdam erhielten Mitteilung und Anweisung, schnellstens das Kartoffel-Roden verstärkt durchzuführen. - Ein Teil der Betriebe wurde angesprochen, sodass zur Unterstützung der werktätigen Bauern Rode-Kolonnen aus den Betrieben und Verwaltungs-Dienststellen eingesetzt werden.

Wie uns aus dem Kreis Ostprignitz mitgeteilt wurde, ist das auferlegte Soll für Sonntag weit übererfüllt worden.

Nach dem von uns Veranlassten sind wir der Meinung, dass bis Mitte der Woche sämtliche Früh- und ein großer Teil der mittelfrühen Kartoffeln gerodet werden können.

Mit der VVEAB wurde am Sonnabend, dem 16. August 1952, ebenfalls noch Rücksprache genommen, und zwar bezüglich des Transportes. Dieser kann als gesichert betrachtet werden.

In diesem Zusammenhang möchten wir auf folgendes hinweisen:

Der Oberbürgermeister der Stadt Potsdam beschwert sich heute darüber, dass er laut eine Anordnung des Ministeriums für Handel und Verordnung der DDR täglich von 6.00 bis 8.00 Uhr mündlich über den täglichen Verkauf, täglichen Bestand und was an Kartoffeln angeliefert wurde, berichten muss. - Außerdem hat er aufgrund unseres Beschlusses alle drei Tage beim Rat des Bezirkes Potsdam die gleichen Fragen zu beantworten und Mitteilung über den Stand der Versorgung zu machen.

Zur Ablieferung von Getreide wurde, um den Nachtdrusch besser vorwärts zu bringen, von Seiten des Rates des Bezirkes Potsdam in der Nacht vom Sonnabend zum Sonntag (16. zum 17.8.) ein Beispiel geschaffen. 40 der Staatsfunktionäre, darunter zwei Stellvertreter des Vorsitzenden des Rates des Bezirkes, führten in der Gemeinde Zeestow, Kreis Nauen, bei Neubauern den Nachtdrusch durch, und zwar mit folgendem Ergebnis: 300 Ztr. ausgedroschenes Getreide, das bedeutet zugleich eine Verbesserung der Getreideablieferung der Gemeinde um 12 \%. Die Stimmung in dieser Gemeinde ist eine ausgezeichnete. - Vom Landesverband der CDU wird mir soeben mitgeteilt, dass sie ebenfalls - aufgrund der Anregung des Rates des Bezirkes Potsdam - vom Sonnabend zum Sonntag Nachtdrusch durchgeführt haben und ihren Kreisverbänden die Anweisung erteilten, gleichfalls den Nachtdrusch zu fördern. 
Zur Vorbereitung der Kreistagssitzungen wurde von den einzelnen Instrukteuren, die laut Beschluss des Rates des Bezirkes für die Kreise eingesetzt sind, mitgeteilt, dass die Vorbereitungen zur Zufriedenheit durchgeführt sind und der Durchführung der Kreistage nichts mehr im Wege stehe.

Schwierigkeiten gibt es beim Rat des Bezirkes auf folgendem Grunde:

Zur Erledigung der Umzüge nach Westberlin oder Westdeutschland war bis jetzt eine Stelle in der Hauptabteilung Wirtschaftsplanung verantwortlich. Nach einer Direktive des innerdeutschen Handels wird dort festgestellt, dass die Bearbeitung dieser Angelegenheiten ab 15.8.1952 nicht mehr vom Innerdeutschen Handel vorgenommen wird, sondern von der Abteilung Inneres. Beim Rat des Bezirkes aber gibt es keine solche Abteilung, auch ist im Stellenplan keine Stelle dafür vorgesehen. Das bedeutet, dass diese Angelegenheiten jetzt nicht schnell und ordnungsgemäß erledigt werden, sondern eine Stockung eintritt. Wir bitten in dieser Frage jetzt um klare Entscheidung, von welcher Stelle aus diese Dinge in Zukunft zu bearbeiten sind. [...]

Das Unwettergebiet im Kreis Zauch-Belzig wurde am Sonntag, dem 17. August 1952 von dem Vorsitzenden des Rates des Bezirkes Potsdam aufgesucht und festgestellt, dass durch den Einsatz von über 700 Personen ein großer Teil der Schäden - das trifft besonders auf die Telefon-, Licht- und Starkstromleitungen zu - bereits beseitigt ist. - Ebenso konnte das durch die Windhose weit geschleuderte Getreide wieder aufgestellt werden.

Die Stimmung in diesem Gebiet ist zufriedenstellend. Besonders haben es die Angehörigen der Volkspolizei verstanden, ihre der Bevölkerung gebrachte Hilfe mit einer politischen Aufklärung zu verbinden, indem sie am Abend mit der Dorfbevölkerung Ausspracheabende durchführten und zugleich mit ihren Kulturgruppen Kulturprogramme zur Aufführung brachten. - Ungünstig wirkte sich aus, dass ein Teil der Staatsfunktionäre vor Beendigung der gesetzlichen Dienstzeit die Arbeitsstätte in den Dörfern verlassen haben.

In wenigen Tagen sind wir in der Lage, einen genauen Bericht über die Höhe der entstandenen Schäden zu übersenden.

[BLHA, Rep. 401, Nr. 58, Bl. 26 und 29]

Dokument 32: Zehnter Bericht des Vorsitzenden des Rates des Bezirkes Potsdam über die Durchführung der Verwaltungsreform im Bezirk Potsdam, 21. August 1952 (Auszug)

[...] Zur Einbringung der Ernte und Ablieferung des Getreidesolls wurden die in der letzten Sitzung des Rates des Bezirkes beschlossenen Maßnahmen verstärkt durchgeführt. In einigen zurückhängenden Kreisen wurden Instrukteure des Staatsapparates eingesetzt, die 
dort mit den Parteien und Organisationen und der Nationalen Front die Kreiskommissionen bei der schnellen Beendigung der Getreideernte und zügigen Erfassung unterstützen. Das trifft besonders auf die Kreise Zossen und Königs Wusterhausen zu.

Die Lage im Unwettergebiet, Kreis Zauch-Belzig, hat sich insofern verändert, dass die Hilfskräfte, die wir gestellt hatten, zurückgezogen werden konnten. Die Stimmung bei der gesamten Bevölkerung dieses Gebietes ist ausgezeichnet. - Ein genauer Abschlussbericht auch über die Höhe des entstandenen Schadens können wir Ende der Woche überreichen. Wir bitten, zu erwägen, ob es möglich ist, eine finanzielle Unterstützung für die Hinterbliebenen des während des Unwetters umgekommenen Einwohner aus diesem Gebiet sowie für die Familienangehörigen der im Krankenhaus liegenden Verletzten zu gewähren.

Schwierigkeiten gibt es immer noch bei der Beschaffung von Baracken und Gebäuden. Aus diesem Grunde wurden auch heute wieder Instrukteure in die Kreise gesandt, die sich nur mit der Beschaffung von Baracken zu beschäftigen haben.

Wie wir schon gestern Herrn Sorgenicht ${ }^{303}$ telefonisch mitteilten, ist die Lage in Bezug auf Treibstoff außerordentlich ernst. Eine Überprüfung, die ich auf diesem ganzen Gebiet vornahm, zeigt allerdings, dass man in der Vergangenheit die Kontingente besonders für die Parteien und Organisationen leichtsinnig erhöht hat. Auch könnte meines Erachtens nach auf allen Gebieten eingespart werden. Das wird sich allerdings nicht sofort auswirken, sodass die ernste Lage, in der wir uns befinden, bestehen bleibt.

[BLHA, Rep. 401, Nr. 58, Bl. 30]

Dokument 33: Bericht der Abteilung Information des Rates des Bezirkes Potsdam, 21. August 1952

Wir haben im Rahmen unserer Friedens- und Planpropaganda die Bildung und Arbeitsaufnahme des Bezirkstages und des Bezirksrates Potsdam durch die am 20. August erfolgte Herausgabe von

a) 200.000 Flugblättern und

b) 18.000 Plakatstreifen

unterstützt. Der Verteilerschlüssel zu diesen Materialien ist aus dem Beiblatt ersichtlich. Die Verteilung erfolgt über die Sekretäre der Kreisräte bzw. der Kreis-Org.-Komitees durch das System der Straßen- und Hausvertrauensleute. Gleichzeitig ist durch den Sekretär des Bezirksrates in Zusammenarbeit mit uns hierzu eine Anweisung an die Räte der Kreise gerichtet worden, was konkret mit diesem Material zu tun ist.

303 Zu Klaus Sorgenicht vgl. Dok. 2, Anm. 234. 
Diese Maßnahme hat bis Ende des Monats ein weiteres Bekanntwerden der Organisation bzw. der Struktur des Bezirksrates unter der Bevölkerung zur Folge. Jedoch ist auch das nach unserer Meinung noch nicht ausreichend. Da jetzt die Bildung der Kreisräte beginnt, sollten auch diese ein ähnliches Material zur Popularisierung derselben im Kreismaßstab herausbringen. Wenn in wenigen Wochen die Bildung der Kreisräte eine vollständige und endgültige ist, dann empfiehlt es sich bei der Herausgabe eines beabsichtigten Propaganda- und Agitations-Materials für den Bezirk Potsdam damit in geeigneter Form eine erneute Propagierung der ersten verantwortlichen Personen des Bezirksrates und der Kreisräte zu verbinden. Je stärker die Popularisierung dieser Staatsfunktionäre erfolgt, umso mehr werden diese selbst bestrebt sein, Beispiele neuer Verwaltungsarbeit zu schaffen, die wir systematisch publizieren.

In diesem Zusammenhang teile ich mit, dass in der Berliner Zeitung ,Nacht-Express“ am Freitag eine Sonderseite über die neue Arbeitsweise der Verwaltung erscheint, zu der wir Material auch aus dem Bezirk Potsdam geliefert haben. Desgleichen planen wir, in den nächsten Tagen eine Bild- und Text-Reportage über die Sprechstunden der Mitglieder unseres Bezirksrates herzustellen, die von derselben Zeitung gebracht wird.

Ich lenke weiterhin die Aufmerksamkeit darauf, dass es notwendig ist, die vom 29. August bis 30. September 1952 im Nachbarbezirk Cottbus stattfindende FünfjahrplanAusstellung auch im Bezirk Potsdam zu propagieren. Diese Ausstellung des AfI $^{304}$ der DDR, die ein Groß-Objekt darstellt, wird in Cottbus letztmalig gezeigt. An der zum Ziel gestellten Besucherzahl von 200.000 Personen müssen wir uns nach sorgfältiger Berechnung mit einem Kontingent von etwa 32.000 Menschen aus dem Bezirk Potsdam (einschl. der Schulen) beteiligen. Die Werbung für den Ausstellungsbesuch müsste vor allem in den Südkreisen unseres Bezirkes, namentlich in den industriellen Schwerpunkten der Kreise Brandenburg/Havel, Stadtkreis Potsdam, Königs Wusterhausen, Jüterbog, Luckenwalde, Zossen und Belzig betrieben werden. Wir haben diese Werbung schon jetzt mit einer Verbreitung von 3.900 Plakaten und 47.500 Handzetteln in diesen Kreisen begonnen. Außerdem erwarten wir noch die Lieferung von 20 bis 25.000 illustrierten Blättern mit Bildern aus dieser Ausstellung.

Eine solche großzügige Werbung für den Besuch der Ausstellung in Cottbus kann natürlich nur auf der Grundlage einer Planvorlage erfolgen, die hierzu von der Bezirksleitung der Partei angenommen wird. Wir beabsichtigen, eine solche Vorlage auszuarbeiten und vom Sekretär der Bezirksleitung der Partei beschließen zu lassen. Nur auf dieser Basis kann die Werbung in den genannten Kreisen begonnen werden, deren konkrete Formen mit den Leitenden Organen der Partei, des FDGB, der VdgB, des DFD, der FDJ und der Nationalen Front festzulegen sind. Es müssen natürlich erhebliche Anstrengungen

304 Zum „Amt für Information“ beim Ministerpräsidenten der DDR, das als Pressestelle der Regierung fungierte; vgl. Herbst, So funktionierte die DDR, S. 826-828. 
unternommen werden, um mittels des Einsatzes von Sonderzügen das vorgesehene Besucherkontingent für Cottbus aus dem Bezirk Potsdam aufzubringen. Zu beachten ist dabei, dass das Schwergewicht bei der Werbung auf dem Teil der Bevölkerung liegt, der in der Industrie beschäftigt ist, damit die planmäßige Arbeit auf dem Lande im September nicht gefährdet wird.

Es erscheint mir notwendig, die Entwicklung der kirchenpolitischen Lage im Bezirk Potsdam ins Auge zu fassen. Ich übermittle Ihnen hierzu zunächst aus der Tagung der Außerordentlichen Provinzialsynode der evangelischen Kirche in Berlin-Brandenburg, die am 9. und 10. August stattgefunden hat, anbei einiges Material, dessen Kenntnis erforderlich ist, um nicht überrascht zu sein und um die Lage richtig zu beurteilen.

[BLHA, Rep. 401, Nr. 59, Bl. 70-71]

Dokument 34: Elfter Bericht des Vorsitzenden des Rates des Bezirkes Potsdam über die Durchführung der Verwaltungsreform im Bezirk Potsdam, 23. August 1952 (Auszug)

[...] Zur Versorgung: Dazu kann mitgeteilt werden, dass im Bezirk Potsdam nirgendwo Schwierigkeiten aufgetreten sind. Besonders ist die Belieferung der HO- und Konsumgeschäfte, sowie des Einzelhandels mit Kartoffeln ausreichend.

Die eingeleiteten Maßnahmen zur Rodung der Kartoffeln haben ein gutes Ergebnis gebracht, sodass über den Plan hinaus geliefert werden kann. Die Rodung der Frühkartoffeln kann so gut wie abgeschlossen betrachtet werden, sodass in den kommenden Tagen die Ernte der mittelfrühen Kartoffeln voll einsetzt.

Schwierigkeiten gibt es beim Abtransport der Kartoffeln in die anderen Länder. Zum Beispiel haben Verhandlungen mit Thüringen, dass die dortigen Pendelzüge für den Transport der Kartoffeln eingesetzt werden, zu keinem Erfolg geführt. Auch hat der Bezirk Dresden sein Versprechen, die Kartoffeln mit Lkws von Dresden abzuholen, nicht eingehalten. Das bedeutet Verzögerung und gibt nicht die Gewähr, die Rodekolonnen in den Gemeinden verstärkt zum Einsatz zu bringen.

Von Seiten der DDR wurden Maßnahmen getroffen, die nicht angetan sind, die Arbeit in den Räten der Bezirke zu verbessern. So erhielt der Abteilungsleiter für Landwirtschaft vom Minister Schröder eine Aufforderung, am kommenden Dienstag zu einer Sitzung in Berlin zu erscheinen. ${ }^{305}$ Diese Aufforderung wurde nicht an den Stellvertreter des Vor-

305 Wilhelm Schröder (1913-1967) war seit 1950 Minister für Land- und Forstwirtschaft der DDR; vgl. Müller-Enbergs, Wer war wer, S. 770. 
sitzenden des Rates des Bezirkes gesandt, sondern direkt an den Abteilungsleiter. Durch diese Aufforderungen, die Sitzungen zu besuchen, werden unsere Aufgaben, die wir uns gestellt haben, nicht realisiert werden können.

Ein Fernschreiben erhielten wir gestern - gerichtet an den Rat des Bezirkes Potsdam - in dem die Aufforderung an uns erging, den Abteilungsleiter für Aufbau am Dienstag ebenfalls zu einer Besprechung nach Berlin zu entsenden.

[BLHA, Rep. 401, Nr. 58, Bl. 38]

Dokument 35: Schreiben der Koordinierungs- und Kontrollstelle für die Arbeit der Verwaltungsorgane an den Vorsitzenden des Rates des Bezirkes Potsdam zur „Auflösung der Bezirks- und Kreiskommissionen“", 27. August 1952

Die Zentrale Regierungskommission fasste in ihrer Sitzung am 27.8.52 folgenden Beschluss:

Die Bezirkskommissionen werden mit sofortiger Wirkung aufgelöst. ${ }^{306}$ Die Aufgaben gehen auf die verantwortlichen Organe über.

Die Unterkommissionen bleiben unter Leitung und Verantwortung der Räte der Bezirke bestehen, bis sie ihre Arbeit abgewickelt haben.

Mit der Konstituierung der Kreistage und der Wahl der Räte lösen sich die Kreiskommissionen auf.

Die Unterkommissionen in den Kreisen arbeiten unter Leitung und Verantwortung der Räte der Kreise bis zur Abwicklung ihrer Arbeiten.

Ich bitte Sie, alles Notwendige zu veranlassen und die Vorsitzenden der Org.-Komitees der Kreise bzw. Räte der Kreise entsprechend zu verständigen.

[BLHA, Rep. 401, Nr. 71, Bl. 140]

306 Die Bezirkskommissionen wurden von der Koordinierungs- und Kontrollstelle für die Arbeit der Verwaltungsorgane beim Ministerpräsidenten der DDR bis zu ihrer überstürzten Auflösung als unverzichtbar für die Bezirksbildung eingeschätzt; vgl. insbesondere die Dok. 6 und 29. 
Dokument 36: Zwölfter Bericht des Vorsitzenden des Rates des Bezirkes Potsdam über die Durchführung der Verwaltungsreform im Bezirk Potsdam, 27. August 1952 (Auszug)

Zur Überleitung in den Kreisen ist folgendes zu berücksichtigen: Im neuen Kreis Pritzwalk gibt es insofern Schwierigkeiten, da der Vorsitzende des Rates des Kreises ohne Mitarbeiter ist. Der Stellvertreter, DBD, z. B. weigert sich, seine Arbeit vor dem 1. September aufzunehmen.

Erst gestern, am 26. August 1952, sind die anderen Stellvertreter bestätigt worden, und heute wurde der Vorsitzende, Kollege Utech, verständigt, dass er die Org.-Kommission voll einsetzen muss. - Zur Hilfe und Anleitung wurde heute ein Instrukteur der Kaderabteilung des Rates des Bezirkes nach Pritzwalk geschickt.

Ähnliche Schwierigkeiten gibt es in den Kreisen Gransee und Oranienburg. Bekanntlich wird der Kreis Bernau ein sehr kleiner Kreis und 50 \% des bisherigen Kreises gehen in neue Kreise über. Der bisherige Landrat Wutke verweigert aber die Übergabe von Mobiliar, Schreibmaschinen, Pkws usw. da nach seiner Ansicht er zum Bezirk Frankfurt (Oder) gehört und nichts mit dem Bezirk Potsdam zu tun hat. Mit dem Vorsitzenden des Rates des Bezirkes Frankfurt (Oder) wird sofort Verbindung aufgenommen, um diesen Zustand zu verändern.

Zur besseren Durchführung und Vorbereitung der Kreistagssitzungen wurden am vergangenen Montag (25. August 1952) die vorgesehenen und bestätigten Sekretäre der Kreise zu einer Arbeitstagung zum Rat des Bezirkes Potsdam geladen. Aus vier Kreisen fehlten die Sekretäre, da dieselben noch nicht bestätigt sind. Diese Schulung, die sich über den ganzen Tag erstreckte, zeigte ein positives Ergebnis.

Eine Gefahr besteht darin, dass der Besetzung der einzelnen Stellen laut Stellenplan zu wenig Beachtung beigemessen wird. Deswegen wurden Vertreter der Kaderabteilung des Rates des Bezirkes zur Hilfe und Anleitung in die Kreise entsandt.

Unser Augenmerk wurde gelegt auf die Fragen der Erfassung auf allen Gebieten, insbesondere Besorgniserregung bringt der Stand der Erfassung tierischer Produkte. Die einzelnen Kommissionen sind ständig unterwegs und arbeiten mit Aktivs in den Kreisen. Durch diese aufklärende Tätigkeit unserer Kommissionen und der Aktivs ist auf dem Gebiet der Fleischerfassung seit einigen Tagen eine ansteigende Linie zu erkennen. - Ebenso wurde Wert auf das Durchführen des Druschs und Abliefern des Getreides gelegt.

In der gestern sich konstituierten Blocksitzung wurde zu diesen Fragen ebenfalls Stellung genommen, und der Stellvertreter des Vorsitzenden des Rates des Bezirkes, Herr Beer, erstattete einen Bericht über die Lage. Es wurde eine Entschließung angenommen [...]. - Ebenso wurde dem Antrag des Vorsitzenden des Rates des Bezirkes zugestimmt, dass 
die einzelnen Parteien sofort auf ihre Funktionäre einwirken, dass in den Kreisen und Gemeinden in Blocksitzungen konkrete Beschlüsse gefasst werden, sowie dass jede Partei ihre Mitglieder und Funktionäre auffordert, soweit sie Ablieferungspflichtige sind, vorbildlich zu erscheinen.

Einem weiteren Antrage des Vorsitzenden des Rates des Bezirkes, täglich in allen Zeitungen, die im Bezirk erscheinen, gute und schlechte Beispiele zu veröffentlichen, wurde ebenfalls zugestimmt.

Vom Vorsitzenden des Blockes, Herrn Abgeordneten Seibt, ${ }^{307}$ wurden weitere Vorschläge gemacht, um die Verluste, die auf einigen Gebieten vorhanden sind, schnellstens aufzuholen. Unter dem Kampfziel mit den werktätigen Bauern Sorge zu tragen, dass eine termingemäße Erfüllung geschaffen werden muss, wurde von dem Vorsitzenden des Blockes zusammenfassend über die Arbeiten des Blockes zur Unterstützung des Staatsapparates gesprochen.

Die Wettbewerbskommission, welche die Prämien festgelegt für die Gemeinden, die als erste ihr Soll erfüllt haben, arbeitet im alten Stil und vollkommen formal. So z. B. wurde von ihr zugestimmt, der Gemeinde Vogelsang, aus dem Kreis Templin, eine Prämie von 1.500 DM auszuhändigen, obwohl ihr bekannt war, dass diese Gemeinde nur insgesamt 28 Doppelzentner Getreide zu liefern hat. Die Gemeinde Altes Lager, Kreis Jüterbog, in der sich sieben Neubauern befinden, - Ablieferungssoll 39 Doppelzentner - erhielt ebenfalls 1.500 DM. Dadurch ist eine negative Diskussion in den Kreisen unter den werktätigen Bauern entstanden. Sie sprechen darüber, dass die sogenannten „Blumentopfgemeinden“ die Prämien erhalten und somit die Bedingungen unreal sind, dass es keinen Zweck hat, sich an einem Wettbewerb zu beteiligen. - Es war erst nach längerer Diskussion möglich, die Kommission zu überzeugen, dass es darauf ankommt, durch die Prämierung eine breite Wettbewerbsbewegung auf dem Lande zu entfalten. - Staatssekretär Streit wurde von mir darauf hingewiesen, weil wahrscheinlich in den anderen Bezirken ebenfalls eine solche formale Auslegung der Anordnung vorgenommen wird.

Die am Freitag, dem 22. August 1952, erste durchgeführte Haus- und Straßenvertrauensleute-Versammlung in Potsdam hat - wie aus dem mündlichen Bericht des Oberbürgermeisters der Stadt Potsdam hervorgeht - einen tiefen Widerhall bei den Vertrauensleuten des Staatsapparates gefunden und gute Ergebnisse mit sich gebracht. [...] - Diese Versammlungen werden in den kommenden Wochen im gesamten Bezirk fortgesetzt.

Insgesamt, das wird immer wieder bestätigt, muss festgestellt werden, dass eine große Aufgeschlossenheit unter der werktätigen Bevölkerung vorhanden ist, ferner ist der Wille zur Mitarbeit für die weitere Demokratisierung des Staatsapparates zu verzeichnen.

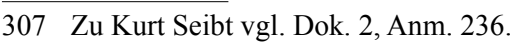


Von der Plankommission wurde darauf hingewiesen, dass auf dem Gebiet des ländlichen Wohnungsbaues Schwierigkeiten entstehen. Dieselben werden von der Deutschen Akademie der Wissenschaften in Berlin, Abteilung Aufbau, gemacht. Zur Bestätigung fügen wir eine Abschrift eines Schreibens der Plankommission an den Vorsitzenden des Rates des Bezirkes Potsdam bei und bitten, dass von Seiten der Koordinierungs- und Kontrollstelle Maßnahmen getroffen werden, dass auch die Aufbauleitung der Deutschen Akademie der Wissenschaft die Richtlinien einhält bzw. dass überprüft wird, wieso es möglich ist, dass die Gebühren für die Projektierung und Bauleitung allein 1/6 der Bausumme ausmachen.

Wie uns heute vom Vorsitzenden des Rates des Kreises Gransee mitgeteilt wurde, hat sich sein Fahrer mit dem Pkw wahrscheinlich nach Westberlin abgesetzt. - Ein genauer Bericht wird in den nächsten Tagen übersandt.

Wir bitten, zu erwägen, ob die Möglichkeit besteht, den Vorsitzenden der Räte der Bezirke sowie den Sekretären und Stellvertretern die Genehmigung zur Führung von dringenden Staatsgesprächen zu erteilen.

[BLHA, Rep. 401, Nr. 58, Bl. 40-40a]

Dokument 37: Dreizehnter Bericht des Vorsitzenden des Rates des Bezirkes Potsdam über die Durchführung der Verwaltungsreform im Bezirk Potsdam, 30. August 1952 (Auszug)

[...] Mit der Konstituierung der Kreise Oranienburg, Kyritz und Pritzwalk am 2. September 1952 haben sich sämtliche Kreise im Bezirk Potsdam konstituiert. - Bei den konstituierenden Sitzungen musste immer wieder festgestellt werden, dass Fehler begangen wurden. Einmal waren es die Referate, die nicht aufeinander abgestimmt waren, zum anderen wurden die Wahlen nicht wie die Direktive besagt, durchgeführt. Und dies alles, obwohl ständig Instrukteure des Bezirkes oder der DDR sich bemühten, die Sitzungen entsprechend der Anweisungen durchzuführen. Dass diese Mängel auftraten, liegt darin begründet, dass gegenwärtig in allen Kreisen zugleich die Kreisdelegiertenkonferenzen stattfinden und dadurch die Partei der Arbeiterklasse bei der Vorbereitung der Kreistagssitzungen nicht die führende Kraft darstellte.

Am Donnerstag, dem 28. August 1952, wurde die 4. Sitzung des Rates des Bezirkes durchgeführt. $\mathrm{Zu}$ dieser Sitzung war eine westdeutsche Delegation, die in Sacrow bei Potsdam zur Erholung ist, als Gast erschienen. Außerdem waren die Leitung der MAS Fröhden sowie der Vorsitzende der Gemeindevertretung der Gemeinde Altes Lager, Kreis Jüterbog, und einige Bauern dieser Gemeinde geladen. Die Ladung vor den Rat des Bezirkes erfolgte deswegen, weil aus diesem Kreis ständig Beschwerden über das Verhalten dieser MAS-Leitung an uns herangetragen wurden. Die Leitung gab einen Bericht, aus dem zu ersehen war, dass an sich alles in Ordnung ist. In Wirklichkeit zeigten die 
werktätigen Bauern auf, welche Schwierigkeiten besonders mit der Leitung der MAS Fröhden beim Drusch usw. zu verzeichnen waren. Sie stellten aber zugleich heraus, dass sie mit den Traktoristen ein gutes Verhältnis haben und dieselben sich bemühten, mit den oftmals schlechten Maschinen den Bauern in jeder Weise zu helfen. Der Leiter dieser MAS, Palluck, war selbst nicht anwesend, da - wie man bekannt gab - derselbe nach Cottbus als politischer Leiter für die MAS abgezogen worden ist.

Es wurde der Protokollbeschluss gefasst, dass zwei Brigaden, bestehend aus Staatsfunktionären und werktätigen Bauern, Traktoristen der MAS, eine Überprüfung zweier MAStationen vornehmen. Das soll zum Ziele haben, die Ursachen der Schwächen der MAStationen aufzuzeigen, um dann im gesamten Bezirk - aufgrund dieser Beispiele - eine Veränderung herbeizuführen. Diese Brigaden werden ihre Arbeit sofort aufnehmen und in einer der nächsten Sitzungen beim Rat des Bezirkes Bericht erstatten bzw. die Ergebnisse ihrer Untersuchungen sämtlichen Leitungen der MA-Stationen mitteilen und in einem Erfahrungsaustausch auswerten.

Zur Aufnahme der Arbeit der neu konstituierten Kreistage kann berichtet werden, dass in allen Kreisen - wenn auch noch nicht mit sämtlichen im Stellenplan vorhandenen Staatsfunktionären, so aber doch mit einem großen Teil - damit begonnen werden kann. Die Personalabteilung des Rates des Bezirkes sowie die Instrukteure der DDR sind in den letzten Tagen ständig in den Kreisen gewesen, um auf diesem Gebiet helfend einzugreifen.

Schwierigkeiten gibt es noch im Kreis Königs Wusterhausen, wo zwar vorläufig die Arbeitsaufnahme möglich ist, aber die Gebäudefragen für die Zukunft noch nicht gelöst sind. Es ist bis jetzt noch nicht möglich gewesen, für die dortige Finanzschule ein entsprechendes Objekt zu finden. In dieses Gebäude, wo bis jetzt die Finanzschule untergebracht war, ist vorgesehen, die Verwaltung einzusetzen.

[BLHA, Rep. 401, Nr. 58, Bl. 42-43]

Dokument 38: Protokoll der ersten Tagung des provisorischen Bezirksvorstandes des Bezirksausschusses Cottbus der Nationalen Front des demokratischen Deutschland, 30. August 1952 (Auszug)

[...] Kollege Münchenhagen: ${ }^{308}$ Wir begrüßen die Initiative des Bezirksvorstandes der Nationalen Front und messen der heutigen Tagung, entsprechend den politischen Ereignissen, eine besondere Bedeutung bei, weil die Beratungen, die wir heute führen und den

308 Walter Münchenhagen $(* 1918)$ war seit August 1952 2. Sekretär der SED-Bezirksleitung Cottbus; vgl. Niemann/Herbst, SED-Kader, S. 361. 
Plan, den wir beschließen, für die jetzigen Ereignisse von größter Bedeutung sind und zwar für die Aufklärungsarbeit unter der Bevölkerung.

Es kommt darauf an, die neue Note der Sowjetregierung ${ }^{309}$ nicht nur in einer kurzen Aufklärungskampagne den Menschen klar zu machen, sondern wir müssen es verstehen, als Bezirksvorstand der Nationalen Front, mit Hilfe dieser Note zu einer breiten, anhaltenden Aufklärungsarbeit in den nächsten Wochen und Monaten zu kommen. Für die nächste Zeit sollte dabei das Bezirkssekretariat der Nationalen Front es sich zur Aufgabe machen, mit Hilfe des provisorischen Bezirksvorstandes und in gemeinsamer Arbeit mit den Gewerkschaften in den einzelnen Orten, Städten und Dörfern, sowie in den Betrieben Versammlungen mit unseren Menschen durchzuführen, um ihnen die neue Not der Sowjetunion zu erklären.

So wäre es zweckmäßig, dass man vor Beginn der Versammlungen Kundgebungen durchführt wie zum Beispiel in Bad Liebenwerda, an der 15.000 Menschen teilgenommen haben. Hier zeigt sich die Aufgeschlossenheit der Bevölkerung. Die Gewerkschaften müssen Versammlungen in allen Betrieben organisieren und Versammlungen, auch im kleinsten Rahmen durchführen. Hierzu müsste sich der Bezirksausschuss der Nationalen Front der Abgeordneten bedienen. Dazu müssen eingesetzt werden die Volkskammer-, Bezirkstags- und Kreistagsabgeordneten, wobei zu empfehlen wäre, dass sich die Volkskammerabgeordneten und namhafte Persönlichkeiten nicht nur auf Kundgebungen sehen lassen und dort sprechen, sondern dass praktisch jeder von uns einen solchen Plan für die nächsten Monate haben muss, der natürlich organisiert werden muss von der Nationalen Front. Der Charakter dieser Versammlungen muss ein anderer werden und nicht so, dass die Hauptlast auf den Schultern der mittleren Funktionäre liegt, die für diese Arbeiten eingesetzt werden, sondern es müssen auch die Spitzenfunktionäre unbedingt eingesetzt werden.

Die Aufklärungsarbeit, die wir jetzt über die neue Note der Sowjetregierung organisieren, ist von größter Bedeutung auch in der Hinsicht, dass ja in den nächsten Wochen der Generalkriegsvertrag vom Bonner Bundestag durchgepeitscht werden soll und im Oktober realisiert. Die Note gibt uns jetzt die Argumentation in die Hand, um den Kampf gegen den Generalkriegsvertrag zu führen. ${ }^{310}$

309 Die Note vom 23. August 1952 war das vierte und letzte Schreiben der sogenannten Stalin-Noten. Die sowjetische Regierung versuchte mit dem Angebot der Bildung eines vereinigten, neutralen Deutschlands, die westliche militärische Integrationspolitik, die die Bundesrepublik Deutschland mit einbezog, zu behindern. Bei dieser letzten Note ging es indes ,nur noch darum, die Schuld am Scheitern einer Friedensregelung mit Deutschland und damit an der endgültigen Teilung Deutschlands dem jeweils anderen aufzubürden"; Ruggenthaler, Stalins großer Bluff, S. 168.

310 „Generalkriegsvertrag“ war die propagandistische Bezeichnung für den Vertrag zur Bildung der „Europäischen Verteidigungsgemeinschaft“, der von der Bundesregierung Ende Mai 1952 unterzeichnet und Anfang Juli 1952 - parallel zur II. Parteikonferenz der SED - im Deutschen Bundestag debattiert worden war; vgl. Staritz, Gründung, S. 9-33. 
Es ist sicherlich damit zu rechnen, dass in absehbarer Zeit aufgrund dieser Note die Volkskammer zusammentritt, um zu dieser Note Stellung zu nehmen. Deshalb wäre jetzt zu überlegen vom Vorstand und vom Sekretariat der Nationalen Front, wie man schon jetzt Vorbereitungen trifft, um Abhörgemeinschaften zu organisieren, um zu erreichen, dass alle Menschen diese Sitzung mit anhören können. Es kommt dann darauf an, dass nach der Volkskammersitzung sich anschließen müssten Tagungen der Bezirkstage, Gemeindevertretungen usw. und dass die Abgeordneten ihre Beschlüsse erläutern.

Es kommt jetzt darauf an, den Aufklärern das notwendige Material in die Hand zu geben. Es muss aufgezeigt werden die neue Seite der Note der Sowjetregierung, nämlich, dass die Sowjetunion jetzt endlich Schluss machen will und daher ihre Forderungen aufgestellt hat. Die gegnerischen Argumente müssen zerschlagen werden. Es ist z. B. so, dass die Hetzpresse im Westen und in Westberlin, sowie der Rias und andere Hetzsender alles versuchen, um die Menschen abzulenken, indem sie sagen, die Reihenfolge, wie sie die Sowjetunion vorschlägt, ist falsch. Sie wollen nicht erst den Friedensvertrag, sondern eine Kommission, die die Untersuchungen führt, ob der Friedensvertrag möglich ist, sodann sollen die Wahlen folgen und danach könne man sich über den Friedensvertrag unterhalten. Hierzu muss man sagen, dass sich diese Kommission zur Überprüfung der Wahlen aufgelöst hat, weil sie einsieht, dass ihr Weiterbestehen zwecklos wäre. In diesem Zusammenhang muss man das Argument benutzen, dass es die Sache der Deutschen selbst ist, zu überprüfen, ob die Voraussetzungen zur Wahl gegeben sind.

Neu an dieser neuen Note ist, dass sie davon spricht, im Gegensatz zu den bisherigen, also klipp und klar ausdrückt, dass der Generalkriegsvertrag ein unverhüllter Kriegspakt ist. Man muss also allen Menschen jetzt klar machen, dass der Generalkriegsvertrag keine Vorteile den Menschen bringt, sondern nichts anderes darstellt als einen Kriegspakt.

Es ist neben der begeisterten Stellungnahme der Bevölkerung interessant, wie die Menschen auf diese Note reagieren. Es ist festzustellen, dass die Behandlung dieser Note ein breites Echo bei unseren Menschen in Westdeutschland und Westberlin findet. Die westbürgerlichen Zeitungen haben sogar kurze Stellungnahmen abgegeben, so z. B. dass alles keinen Zweck hätte, sondern man müsse verhandeln.

Deshalb spielt der Briefverkehr nach Westdeutschland und Westberlin in unsern weiteren Aufgaben eine gewaltige Rolle, denn die Westpresse hat die Note nicht genau wiedergegeben, sondern sie gekürzt.

Soweit mir bekannt, wird Anfang September vom Nationalrat ein neues Weißbuch herausgegeben, das den Generalkriegsvertrag und die Kriegsvorbereitungen in Westdeutschland behandelt. Dieses Buch wird eine große Unterstützung sein für unsere Aufklärungsarbeit. Wir wollen schon jetzt beginnen, Zirkel zu bilden zum Studium des Weißbuches. 
Ebenso spielt eine große Rolle die Sichtwerbung. Alle Parteien und Massenorganisationen müssen ihren Einfluss geltend machen, dass die gesamte Sichtwerbung, auch in den Häusern, eine andere wird. Die jetzige Sichtwerbung muss ausgehen von der zentralen Frage - der neuen Note der Sowjetunion.

Es werden noch weitere Materialien zur Entfaltung der Aufklärungsarbeit herauskommen. Es muss Aufgabe des Sekretariats sein, so zu organisieren, dass diese Dinge schnellstens in die Kreise kommen.

Zum Abschluss möchte ich sagen, dass durch die II. Parteikonferenz der SED die Frage der Wiederherstellung der Einheit Deutschlands durch die Probleme des Aufbaues des Sozialismus etwas in den Hintergrund getreten ist. Die Menschen haben sich begeistert beschäftigt, wie sie den Aufbau des Sozialismus schnellstens verwirklichen, dass aber übersehen wurde, was Ulbricht auf der II. Parteikonferenz sagte, nämlich, dass die Wiederherstellung der Einheit Deutschlands nach wie vor die erste Aufgabe ist. Es ist also unsere Aufgabe, dass wir aus diesem Grunde mit Hilfe der neuen Note der Sowjetunion diese zentrale Frage wieder auf den richtigen Platz rücken müssen und dass alle Aufgaben, die wir durchführen zum Aufbau des Sozialismus, eben dieser Frage dienen muss.

Kollege Manneberg: ${ }^{311}$ Kollege Münchenhagen hat die großen Aufgaben, die vor uns stehen, aufgezeigt. Er sprach insbesondere davon, die Abgeordneten in diese großen Aufgaben mit einzuschalten. Ich denke, es hat sorgfältige Überlegungen gekostet, dass der Ministerrat beschloss, dass die Sprechstunden der Abgeordneten und Versammlungen in den Aufklärungslokalen der Nationalen Front durchzuführen sind. Das heißt, in den Aufklärungslokalen sollen sich die Abgeordneten mit ihren Wählern ständig treffen, um dass [sic!] ihnen die Abgeordneten erläutern die politischen Maßnahmen, die sich ergeben für unser Volk, ihnen erläutern die Gesetze, Verordnungen und Beschlüsse der Volkskammer unserer Regierung. Ich glaube, wir sollten heute erkennen, dass mit der Maßnahme der Demokratisierung unserer Staatsorgane jetzt eine neue Tätigkeit unserer Abgeordneten beginnt. Ich wies in meiner Rede auf dem Bezirkstag darauf hin, dass die Landtage mit ihren Abgeordneten mehr oder weniger repräsentativ arbeiteten, die Spitzenfunktionäre sehr oft in großen Versammlungen sprachen und dass dabei unsere kleineren Städte und Dörfer vernachlässigt wurden. Man darf an dieser Frage, der Einbeziehung der dörflichen Bevölkerung, Kleinstädten usw. nicht vorbeigehen. Man kann diese Menschen nicht auslassen in den planmäßigen Aufgaben im Aufbau des Sozialismus. Hieraus müssen wir die Lehre ziehen, dass auch sehr gute Referenten nicht immer in den Städten sprechen, sondern in erster Linie unten an der Basis zum Einsatz kommen. Man soll die Menschen begeistern für den Kampf zu neuen großen Produktionsleistungen, denn nur diese Produktionsleistungen bringen uns die Voraussetzung für die Stärkung der Deutschen Demokratischen Republik im Kampf um die Einheit Deutschlands. Es kommt darauf an, die

311 Zu Werner Manneberg vgl. Dok. 4, Anm. 247. 
neue Note der Sowjetunion zu verbinden mit einer neuen Kampfbereitschaft in der Erfüllung der Pläne.

Ich begrüße insbesondere, dass ich die Nationale Front die Aufgabe stellt, die Staatsorgane zu unterstützen in ihren Aufgaben in der Landwirtschaft, Einbringung der Ernte, Herbstbestellung usw. Das sind entscheidende Aufgaben, die wir zu lösen haben.

Eine Frage möchte ich noch anschneiden in dem Plan „Die Mobilisierung der örtlichen Reserven“. Um alle diese Aufgaben durchführen zu können, ist es notwendig, trotz der Notwendigkeit der Aufstellung nationaler Streitkräfte die Ziele des Fünfjahrplanes zu erfüllen. Das bedeutet, die Frage der Sparsamkeit zu stellen, Dass wir stärker die Mithilfe der Bevölkerung bei der Durchführung volkswirtschaftlicher Bauten zur Einsparung von Investmitteln organisieren.

Weiter fehlt in dem Plan: „Der Aufbau unserer Hauptstadt Deutschlands, Berlin.“ Diese große Initiative ist noch nicht in den einzelnen Städten zu spüren. Dazu brauchen wir die Hilfe aller patriotischen Kräfte, die, mobilisiert durch die Nationale Front, erkennen, dass Berlin ein schnelleres sozialistisches Berlin wird durch die große Masseninitiative der Bevölkerung. Wir müssen in unserem Bezirk damit anfangen. Je schneller und besser wir den Aufbau des Sozialismus vornehmen und die Aufgaben lösen, die uns zu einem besseren Leben bringen, umso leichter wird es der Bevölkerung in Westdeutschland fallen, sich zu entscheiden, wie sie es haben wollen.

Die Versammlungen zur Aufklärung der Note der Sowjetunion muss man verbinden mit einer konkreten Aufgabenstellung für jede Stadt, jede Gemeinde, jeden Betrieb, jede Institution, um den Menschen den Geist hinauszutragen, dass sie begreifen, dass die neue Note der Sowjetunion nicht abgelehnt werden darf, denn hinter dieser Note steht das gesamte deutsche Volk. Die Sowjetunion setzt sich für die Wahrnehmung unserer Interessen ein, damit wir endlich dazu kommen, was wir seit sieben Jahren fordern, den Friedensvertrag und die Einheit unseres Vaterlandes. [...]

Kollege Mierau: ${ }^{312}$ Ich bin der Meinung, dass die Kollegen Münchenhagen und Manneberg die Bedeutung der Aufgaben, die jetzt vor der Nationalen Front stehen, aufgezeigt haben. Zur Frage der Wasserwirtschaft ist es notwendig, gerade unsere Bevölkerung in der Landwirtschaft zu mobilisieren, dass sie die Erdarbeiten übernimmt, wenn schon die Rohre aus Investmitteln beschafft werden.

Eine entscheidende Frage ist natürlich die verlustlose Einbringung der Ernte. Hier muss auch die Hilfe von Dorf zu Dorf in den Vordergrund gestellt werden.

312 Hans Mierau sprach als Vertreter des Bezirksverbands der „Vereinigung der gegenseitigen Bauernhilfe" (VdgB). 
In unseren Plan muss unbedingt aufgenommen werden die örtlichen Reserven. Jede Organisation muss es sich zur Pflicht machen, diesen Plan und diese Richtlinien des Bezirksausschusses der Nationalen Front zu erläutern, sich dabei aber nicht zu konzentrieren auf die Städte, sondern man muss in erster Linie in das Dorf gehen.

Ich begrüße daher unsere heutige Zusammenkunft. Man muss aber auch erkennen, dass unsere Anleitung nicht nur Anleitung sein darf, wir müssen Kontrollen in den Kreisen durchführen. [...]

Kollege Fleischmann: ${ }^{313}$ Wir wissen, dass sich der Klassenkampf laufend verschärft. Das zeigt sich in letzter Zeit auch in Cottbus. Wir haben eins vergessen, dass ein wichtiger Faktor ist die Bildung der Produktionsgenossenschaften. In Cottbus haben sich drei Produktionsgenossenschaften gebildet. Es hat sich auch gezeigt, dass bereits der Gegner hier arbeitet. [...]

[BArch, DY 6/3470, sieben Bl., nicht foliiert]

Dokument 39: Schreiben der Koordinierungs- und Kontrollstelle für die Arbeit der Verwaltungsorgane an den Vorsitzenden des Rates des Bezirkes Potsdam, 2. September 1952 (Auszug)

Die vorliegenden Berichte über die Arbeit des Rates des Bezirkes Potsdam und über die Lage im Bezirk veranlassen mich, Sie mit allem Ernst auf einige Fragen hinzuweisen und Sie zu bitten, im Rat zu diesen Fragen Stellung zu nehmen und entsprechende Beschlüsse zu fassen.

1. Die Besetzung der Abteilungen beim Rat des Bezirkes ist noch nicht abgeschlossen, obwohl am 15. des Monats die Arbeit voll aufgenommen sein sollte. So fehlen z. B. die Abteilungsleiter für die Abteilungen Aufbau und Örtliche Industrie und Handwerk, sowie der Leiter des Referats Förderung der Intelligenz.

Es ist notwendig, dass in kürzester Frist alle Planstellen besetzt sind.

Die Unterbringung der Mitarbeiter in den Bezirken Cottbus und Frankfurt (Oder) ist völlig ungenügend. Ich empfehle Ihnen daher dringend die Einrichtung eines Wohnungstauschbüros, um auf dem Wege des Tausches eine zusätzliche Unterbringung für die Mitarbeiter in den Bezirken Cottbus und Frankfurt (Oder) zu erreichen.

2. Die Anleitung der Kreise im Bezirk Potsdam muss verbessert werden. Es ist ein sehr ernstes Zeichen, dass die neu zu bildenden Kreise nur ungenügend unterstützt werden

313 Martin Fleischmann sprach für die Bezirksbehörde der Deutschen Volkspolizei Cottbus. 
und die Räte der bestehenden Kreise die besten Mitarbeiter behalten, statt sie helfend beim Neuaufbau der Kreise einzusetzen. Ich weise mit großem Ernst auf die Gefahren hin, die sich ergeben, wenn man hier nicht schnell und helfend eingreift.

3. Ich lenke Ihre Aufmerksamkeit auf die unbefriedigende Behandlung der Beschwerden aus der Bevölkerung sowohl beim Rat als auch in den Abteilungen. Nach vorliegenden Berichten gibt es keine organisierte Kontrolle über die Bearbeitung der Beschwerden. Ich bitte Sie, hier eine Änderung herbeizuführen und Vorsorge zu treffen, dass jede Beschwerde innerhalb einer Woche bearbeitet und dem Beschwerdeführer Nachricht gegeben wird.

4. Der Koordinierungs- und Kontrollstelle für die Arbeit der Verwaltungsorgane wurde bisher nicht die angeforderte Aufstellung über die Zusammensetzung des Bezirkstages, des Rates des Bezirkes und der Ständigen Kommissionen übersandt.

5. Nach vorliegenden Berichten hat der Rat des Bezirkes einige gute Beispiele für die Arbeit der Ständigen Kommission geschaffen. Diese Beispiele sollten in der Presse veröffentlicht werden, damit sie auch den übrigen Bezirken als gute Erfahrungen bekannt werden. Ich bitte Sie, auch der Koordinierungs- und Kontrollstelle für die Arbeit der Verwaltungsorgane von Ihren bisherigen Erfahrungen in der Entwicklung der Arbeit der Ständigen Kommissionen einen eingehenden Bericht zu übersenden. Die Schaffung solcher Beispiele ist auch besonders wichtig, um den Kreisen den Weg zu zeigen.

Nach diesen Hinweisen werfe ich einige Fragen auf, an deren Lösung unverzüglich gegangen werden muss.

1) Der Ministerpräsident hat auf der Konferenz mit den Vorsitzenden und den Sekretären nachdrücklich unterstrichen, dass unverzüglich mit dem Aufbau der Vertragsgerichte in den Bezirken begonnen werden muss.

Diese Vertragsgerichte (Arbitrage) sind für die weitere Entwicklung von außerordentlich großer Bedeutung. Eine ganze Reihe von Fehlern, Mängeln und Schwächen im Ablauf des wirtschaftlichen Lebens sind auf die ungenügende Beachtung der gesetzlichen Bestimmungen über das Vertragswesen zurückzuführen. Für einen Bezirk mit einer solchen wirtschaftlichen Struktur wie der Bezirk Potsdam ist die strikte Einhaltung dieser gesetzlichen Bestimmungen ganz besonders bedeutsam. Ich bitte Sie deshalb, noch im Laufe des Monats dafür zu sorgen, dass die Vorarbeiten eingeleitet werden und bis zum 15. September die personellen Vorschläge ausgearbeitet sind und auch die anderen Voraussetzungen für die Aufnahme der Arbeit dieser wichtigen Institution geschaffen werden.

2) In meinem Schlusswort auf der genannten Konferenz habe ich darauf hingewiesen, dass jeder Bezirk bis zum Oktober einen Plan nach dem Muster des Zwickauer Pla- 
nes ausgearbeitet haben soll. Es besteht kein Zweifel daran, dass diese Kreispläne im nächsten Jahr der Angelpunkt der Arbeit sowohl für die Räte der Kreise als auch der Bezirke sein werden. Es muss aber mit größter Sorgfalt und unter Zugrundelegung der vier Hauptgesichtspunkte des Zwickauer Planes an die Ausarbeitung eines solchen Kreisplanes gegangen werden. Besonders sorgfältig muss die Auswahl eines solchen Kreises erfolgen, um nach einer gründlichen Durcharbeitung aller vorhandenen Möglichkeiten den anderen Kreisen ein Beispiel zu geben. Die von den Räten der Bezirke in gemeinsamer Arbeit mit den politischen Parteien und demokratischen Organisationen ausgearbeiteten Pläne sollen in einer großen Konferenz im Oktober behandelt werden. Es ist unbedingt notwendig, in dieser Frage mit der Bezirksleitung der SED eine gründliche Aussprache durchzuführen.

Ich bitte um Einleitung einer planmäßigen Arbeit.

3) Nachdem im Laufe des Septembers die Räte der Kreise ihre Arbeit konsolidiert haben, macht es sich notwendig, für das 4. Quartal zwei Aufgaben aufzunehmen, die einer gründlichen Vorbereitung bedürfen.

1. soll im Monat November nach einem sorgfältig vorbereiteten Plan eine KomplexUntersuchung eines Kreises in Ihrem Bezirk durchgeführt werden. An diese Untersuchung sollen nicht nur qualifizierte Mitarbeiter der einzelnen Abteilungen, Abgeordnete und Kommissionsmitglieder, sondern auch die gesellschaftlichen Organisationen, die VdgB-BHG, Gewerkschaft usw. (auf dem Wege der Übereinkunft) herangezogen werden, um die Arbeit in diesem Kreis von allen Seiten zu beleuchten. Eine solche Komplexuntersuchung sollte der Vorsitzende des Rates dieses Kreises über die Lage in seinem Kreis als auch über die Arbeit des Rates des Kreises vor dem Rat des Bezirkes Bericht erstatten. Zu dieser Berichterstattung sollen die Vorsitzenden der Räte der anderen Kreise hinzugezogen werden. Der Beschluss des Rates müsste das Arbeitsprogramm für eine bestimmte Zeit darstellen.

2. Angesichts einiger ernster Erscheinungen in der landwirtschaftlichen Produktion, in der Erfassung und dem Aufkauf als auch in der Versorgung mache ich den Vorschlag, in der zweiten Hälfte des Novembers in allen Gemeinden auf die Tagesordnung des Rates und der Gemeindevertretung den Punkt zu setzen: „Was lehrt uns die diesjährige Ernte.“

Der Bericht, der bei der Beratung dieses Tagungsordnungspunktes gegeben wird, muss eine sorgfältige Analyse der gesamten Arbeit, angefangen von der Herbstbestellung des vergangenen Jahres bis zur Herbstbestellung dieses Jahres geben und muss besonders die Fehler, die Mängel und Schwächen der Arbeit aufdecken. Der Beschluss, der gefasst wird, müsste wiederum für die Gemeinde ein Arbeitsprogramm für die nächste Zeit darstellen.

Ende November sollten die Räte der Kreise dieselbe Frage behandeln und die Schlussfolgerungen für die Arbeit auf dem Gebiete der Landwirtschaft, der Erfassung und des Aufkaufs und der Versorgung für den Kreis ziehen. 
Etwa Mitte Dezember soll sich der Rat des Bezirkes mit demselben Thema beschäftigen und die Ergebnisse der Beratungen in den Gemeinden und Kreisen für den Bezirk zusammenfassen und verallgemeinern.

Die Behandlung dieser beiden Fragen wird uns die Möglichkeit geben, eine Reihe Erfahrungen in der Entwicklung der richtigen Methodik einer solchen gründlichen Arbeit zu sammeln. Das ist notwendig, weil im I. Quartal 1953 einige schwierige Aufgaben dieser Art gelöst werden müssen.

Die Regierung wird diese beiden Punkte im Arbeitsplan für das IV. Quartal aufnehmen und wird sich an einigen Untersuchungen beteiligen.

Da solche Arbeitsmethoden mehr und mehr zur Selbstverständlichkeit werden, macht es sich notwendig, die Abteilung Organisation-Instruktion sowohl in den Bezirken als auch in den Kreisen zu wirklich arbeitsfähigen Instrumenten zu machen. Deshalb lenke ich noch einmal Ihre Aufmerksamkeit auf diese Frage. [...]

Ich bitte dringend um Beachtung dieser Hinweise. Die Berichte der eingesetzten Instrukteure zeigen, dass im Allgemeinen nicht mit der notwendigen Energie und Konsequenz an die Realisierung herangegangen wird, weil die politische Bedeutung dieser Verordnung unterschätzt wird. Ich mache Sie darauf aufmerksam, dass dieser Verordnung hier große Bedeutung beigelegt wird.

[BLHA, Rep. 401, Nr. 71, Bl. 146-149]

Dokument 40: Vierzehnter Bericht des Vorsitzenden des Rates des Bezirkes Potsdam über die Durchführung der Verwaltungsreform im Bezirk Potsdam, 8. September 1952

Wir bitten um Entschuldigung, dass wir in dieser Woche nur einen Bericht übersenden. Doch die Tatsache, dass wir einmal mit der Konstituierung der Räte der Kreise beschäftigt waren und auf der anderen Seite unsere ganze Kraft verwandt wurde, um das Soll der Erfassung zu erfüllen, hat ergeben, dass wir nur einen Bericht anfertigen konnten.

Zur Konstituierung der Kreistage: Im Bezirk Potsdam sind jetzt sämtliche Kreistage durchgeführt. Am selben Tage wurden auch die 1. Sitzungen der Räte der Kreise einberufen. - Die letzte Kreistagssitzung fand am 4. September 1952 im Kreis Kyritz statt.

Von Seiten des Rates des Bezirkes wurde im Laufe der Woche die 5. Sitzung des Rates des Bezirkes durchgeführt. Zur Tagesordnung standen die Frage der Erfassung sowie ein Beschluss über die Fertigstellung der Neubauernbauten, zu den gesetzten Terminen. Außerdem wurde durch eine eingehende Begründung und längere Diskussion die als Beschluss eingereichte Vorlage über das Verfahren der Beschwerdeordnung einstimmig angenommen. 
Im Laufe der Woche wurde weiterhin eine Schulung der Abgeordneten des Bezirkstages vorgenommen. An derselben nahm ein Vertreter der Koordinierungs- und Kontrollstelle teil. Dieser Kollege Schiener hat unseres Erachtens nach nicht helfend gewirkt, sondern wie auch ein Teil der Abgeordneten zum Ausdruck brachte, hemmte seine Anwesenheit die Schulung. Er verlangte eine ganz schematische Verlesung der überreichten Lektion. Die Abgeordneten waren damit nicht einverstanden und wünschten, die Lektion durch praktische Beispiele zu bereichern. Im Anschluss an diese Lektion wurden drei Seminare durchgeführt. - Die Vorsitzenden der Räte der Kreise, die an der Lektion teilgenommen hatten, wurden durch den Vorsitzenden zusammengenommen, und es wurde ihnen aufgezeigt, wie sofort - unter Ausscheidung aller Fehler und Mängel, die beim Rat des Kreises aufgetreten sind - die Arbeiten aufgenommen werden sollen. An dieser Besprechung nahm ebenfalls der Vertreter der Koordinierungsstelle, Schiener, teil. Dabei kam zum Ausdruck, dass er bei einigen Fragen große ideologische Schwächen zeigte. Der anwesende Leitinstrukteur Altmann war über das Verhalten des Vertreters der Koordinierungsstelle ebenso empört wie die Vorsitzenden der Räte der Kreise. Solche Vertreter der Koordinierungsstelle wirken keinesfalls helfend, sondern hemmen die angelaufene Arbeit. Zum Beispiel war der Kollege Schiener damit einverstanden, dass die Schulung der Abgeordneten der Kreistage - wie das im Kreis Nauen geschehen ist - in verschiedene Bezirke aufgeteilt und nicht von dem Vorsitzenden, sondern seinen Stellvertretern vorgenommen wird. - Auch in der Frage der Erfassung und anderen Themen zeigte sich, dass der Vertreter der Koordinierungsstelle große Unklarheiten aufweist, und er musste verschiedentlich von Seiten des Vorsitzenden des Rates des Bezirkes revidiert werden.

Zur Gebäudefrage: Dazu ist zu berichten, dass es noch immer einige Schwierigkeiten gibt, die auf die Arbeit der Kreise hemmend wirken. So zum Beispiel im Kreis Königs Wusterhausen. Dort wurde dem stellvertretenden Vorsitzenden der Zentralen Kommission für Staatliche Kontrolle der Vorschlag gemacht, die Grundschule des Finanzministeriums in ein anderes Land zu verlegen. Diese Schule hat eine Kapazität von 160 Personen. Im Land Brandenburg besteht - nachdem Kommissionen wiederholt Prüfungen vorgenommen haben - keine Möglichkeit, diese Schule in anderen Räumen unterzubringen. Es ergibt sich aber daraus die Gefahr, dass der Staatsapparat in Königs Wusterhausen seine Arbeit nicht ordnungsgemäß durchführen kann. - Wir bitten, diese Frage mit dem Finanzministerium zu behandeln und uns Hilfe zu gewähren.

Nicht einverstanden können wir mit dem Beschluss der Zentralen Kommission, die entschieden hat, dass unter anderem auch das Objekt „Obelisk“ der ABF ${ }^{314}$ als Internat zugewiesen wird, sein. In Potsdam gibt es nicht ein einziges Hotel, was außerordentliche Schwierigkeiten mit sich bringt. In dem Objekt „Obelisk“ befindet sich überdies ein Kino, war den Parteien und Organisationen die Möglichkeit geben würde, ihre Aufgaben auf gesellschaftlichem Gebiet zu erfüllen. Dabei muss beachtet werden, dass das Hotel in der

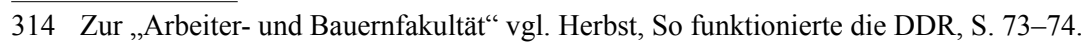


Lennéstr., was bedeutend größer ist, schon der ABF übergeben wurde. Wir bitten (nach Rücksprache mit dem 1. Sekretär der Bezirksleitung der SED), dass dem Bezirk selbst die Möglichkeit gegeben wird, über das Objekt „Obelisk“ zu entscheiden. Die Stellungnahme des stellvertretenden Vorsitzenden der Zentralen Kommission für Staatliche Kontrolle, Ernst Lange, ist unseres Erachtens nach in diesem Falle nicht objektiv.

Zur Arbeit des Rates des Bezirkes der Kreise kann mitgeteilt werden, dass wir besonders in den Kreisen Kyritz, Wittstock und Pritzwalk immer noch Schwierigkeiten haben beim Abtransport des Getreides. Unser Wettbewerb mit dem Bezirk Frankfurt (Oder) ist unreal dadurch, da wir auf dem Gebiet des Abtransportes in diesen oben genannten Kreisen keine Unterstützung erhalten. Es ist eine Tatsache - und das wirkt sich keinesfalls günstig aus - dass in den oben genannten Kreisen alle Kultur- und Tanzsäle mit Getreide belegt werden mussten. Wir bitten auch in diesem Fall um Unterstützung, damit wir in der Lage sind, unseren Plan baldigst zu erfüllen.

Über die Tätigkeit der ständigen Kommissionen des Bezirkes werden wir in den nächsten Tagen einen besonderen Bericht übergeben, in dem wir aufzeigen, wie durch die vorbildliche Arbeit dieser Kommissionen mit weiten Kreisen der Bevölkerung es uns gelungen ist, alle Schichten der werktätigen Bevölkerung zur Mitarbeit an den Aufgaben des Staatsapparates heranzuführen.

Die bisher durchgeführten Versammlungen mit den Haus- und Straßenvertrauensleuten in Potsdam und anderen Orten, wie z. B. Brandenburg/Havel haben außerordentliche Erfolge $\mathrm{zu}$ verzeichnen.

Die nächste Sitzung des Bezirkstages findet am 9. September 1952 statt. Unter anderem steht als Hauptaufgabe die Stellungnahme zur Note der SU. ${ }^{315}$

Wir bitten zu erwägen, ob den Räten der Bezirke nicht insofern eine Erleichterung gegeben werden kann, dass - nachdem nunmehr die Kreise sich konstituiert haben - nicht mehr in der Woche zweimal Berichte an die Koordinierungsstelle zu senden sind, sondern innerhalb einer Woche ein Bericht.

[BLHA, Rep. 401, Nr. 58, Bl. 45-46]

315 Zur Note der Sowjetregierung vom 23. August 1952 vgl. Dok. 38, Anm. 309. 
Dokument 41: Beschluss des Ministerrats der DDR über die „Aufstellung der Haushalte der Bezirke“6 für das Jahr 1952, 12. September 1952

Der Ministerrat nimmt von dem Bericht des Ministeriums der Finanzen über den Abschluss der Haushalte in den Ländern am 31.8.52 Kenntnis und beschließt:

1.) Die Haushaltpläne der Bezirke für die Zeit vom 1.9. bis 31.12 .52 werden in Einnahmen und Ausgaben mit 683,1 Mio. DM laut Anlage bestätigt. ${ }^{316}$

2.) Die Vorsitzenden der Räte der Bezirke werden beauftragt, dem Ministerium der Finanzen bis zum 2. Oktober die Aufteilung der Einnahmen und Ausgaben auf die Einzelpläne und Kapitel mitzuteilen. Dabei sind die Verwaltungskosten entsprechend den von der Staatlichen Stellenplankommission genehmigten Stellenplänen und Lohnfonds einzusetzen.

3.) Das Ministerium der Finanzen wird beauftragt, die von den Bezirken einzureichenden Haushaltpläne dahingehend zu überprüfen, ob die von der Staatlichen Stellenplankommission festgelegten Lohn- und Gehaltsfonds eingehalten wurden. Über die genehmigten Lohn- und Gehaltsfonds hinausgehende Planansätze sind zu sperren. Die sächlichen Verwaltungskosten sind dem neuen Lohn- und Gehaltsfonds anzugleichen.

4.) Soweit sich bei der Durchführung der Haushalte herausstellt, dass die Aufteilung der Haushaltsansätze in den Länderhaushalten für einzelne Aufgaben nicht dem Umfang der Arbeit in den einzelnen Bezirken entspricht, werden die Vorsitzenden der Räte der beteiligten Bezirke ermächtigt, die Aufteilung im Rahmen der Gesamtvolumen zu korrigieren. Wenn eine Einigung nicht erzielt wird, entscheidet das Ministerium der Finanzen endgültig.

5.) Das Ministerium der Finanzen wird beauftragt, dem Ministerrat das System des Haushaltausgleiches der Bezirkshaushalte durch Anteile an den Republiksteuern bis zum 2.10. zur Beschlussfassung vorzulegen.

316 Es handelt sich um einen vergleichsweise geringen Anteil der Bezirkshaushalte im Vergleich zum Gesamthaushalt der DDR. Die Einnahmen und Ausgaben von 683,1 Mio. DM für die vier Monate von September bis Dezember 1952 machen auf das gesamte Etatjahr hochgerechnet eine Summe von 2,0493 Mrd. DM aus. Dies entspricht einem Anteil von nur 6,3\% des Gesamthaushaltes der DDR im Haushaltsjahr 1952, der bei insgesamt 32,470 Mrd. DM lag; vgl. Herwig E. Haase, Staatshaushalt, in: DDR-Handbuch, S. 1280-1296. 
[Anlage:] Haushaltsplan der Bezirke für die Zeit vom 1.9.-31.12.52 in Mio. DM

\begin{tabular}{|c|c|c|c|c|c|c|}
\hline \multirow[t]{3}{*}{ Bezirk } & \multicolumn{4}{|c|}{ Einnahmen } & \multirow[t]{3}{*}{ Ausgaben } & \multirow[t]{2}{*}{$\begin{array}{l}\text { davon Soll- } \\
\text { überschuss } \\
\end{array}$} \\
\hline & $\begin{array}{c}\text { eigene } \\
\text { Einnahmen }\end{array}$ & \multicolumn{2}{|c|}{ Finanzausgleich } & Insgesamt & & \\
\hline & & $\begin{array}{c}\text { über- } \\
\text { nommene } \\
\text { Bestände }\end{array}$ & $\begin{array}{c}\text { aus } \\
\text { Steuer- } \\
\text { anteilen }\end{array}$ & & & \\
\hline Rostock & 2,8 & 2,3 & 13,4 & 18,5 & 18,5 & 2,7 \\
\hline Schwerin & 26,6 & 8,1 & 33,6 & 68,3 & 68,3 & 2,3 \\
\hline $\begin{array}{l}\text { Neubranden- } \\
\text { burg }\end{array}$ & 2,2 & 1,2 & 10,0 & 13,4 & 13,4 & 2,5 \\
\hline Potsdam & 51,5 & $0,3+1,5$ & 62,0 & 115,3 & 115,3 & 4,2 \\
\hline Frankfurt & 2,0 & 0,2 & 13,7 & 15,9 & 15,9 & 2,4 \\
\hline Cottbus & 1,5 & 0,1 & 15,4 & 17,0 & 17,0 & 2,3 \\
\hline Magdeburg & 5,1 & 7,3 & 17,7 & 30,1 & 30,1 & 3,7 \\
\hline Halle & 41,8 & 16,9 & 43,4 & 102,1 & 102,1 & 6,3 \\
\hline Erfurt & 51,6 & $19,5+12,0$ & 20,9 & 104,0 & 104,0 & 6,1 \\
\hline Gera & 1,8 & 1,9 & 7,5 & 11,2 & 11,2 & 0,6 \\
\hline Suhl & 1,2 & 1,6 & 5,7 & 8,5 & 8,5 & 0,5 \\
\hline Dresden & 58,1 & $3,9+18,8$ & 20,0 & 100,8 & 100,8 & 4,8 \\
\hline Leipzig & 6,9 & 2,5 & 28,6 & 38,0 & 38,0 & 4,2 \\
\hline Chemnitz & 5,2 & 2,1 & 32,7 & 40,0 & 40,0 & 5,3 \\
\hline zusammen & 258,3 & $67,9+32,3$ & 324,6 & 683,1 & 683,1 & 47,9 \\
\hline
\end{tabular}

\section{Begründung}

1.) Nach $\S 5$ des Gesetzes über die weitere Demokratisierung des Aufbaus und der Arbeitsweise der staatlichen Organe in den Ländern der Deutschen Demokratischen Republik sind die durch das Gesetz vom 19.7.52 über den Staatshaushaltsplan 1952 (Gesetzblatt Seite 483) für die Haushalte der Länder bestätigten Einnahmen und Ausgaben vom Ministerrat auf die Bezirke aufzuteilen.

2.) Die in der Vorlage enthaltenen Summen für die Einnahmen und Ausgaben der Bezirke für die Zeit vom 1.9.-31.12.52 werden durch den Bericht über den Abschluss der Haushalte der Länder zum 31.8.52 begründet:

\begin{tabular}{|c|c|c|}
\hline a) Die eigenen Einnahmen der Länder betragen & & \\
\hline nach dem Haushaltsgesetz & 600,1 & Mio. DM \\
\hline die Ist-Erfüllung per 31.8. beträgt & 341,8 & Mio. DM \\
\hline Der Rest bleibt auf die Bezirke aufzuteilen & 258,3 & Mio. DM \\
\hline $\begin{array}{l}\text { Wie aus der Anlage der Vorlage hervorgeht, ist diese Einnahme } \\
\text { auf die neuen Bezirke verteilt worden. }\end{array}$ & & \\
\hline
\end{tabular}




\begin{tabular}{|c|c|c|c|}
\hline $\begin{array}{l}\text { b) Die Ausgaben einschließlich des für das Jahresende } \\
\text { vorgesehenen Überschusses in Höhe von } 47,9 \text { Mio. DM } \\
\text { betragen für die Länder nach dem Haushaltgesetz }\end{array}$ & & 1650,1 & Mio. DM \\
\hline die Ist-Erfüllung der Ausgaben beträgt & & 985,0 & Mio. DM \\
\hline bleibt auf die Bezirke aufzuteilen & & 665,1 & Mio. DM \\
\hline $\begin{array}{l}\text { In den Ländern Sachsen-Anhalt und Thüringen } \\
\text { sind aber bereits zusätzlich ausgegeben worden für } \\
\text { Kartoffelkäferbekämpfung }\end{array}$ & & 18,0 & Mio. DM \\
\hline $\begin{array}{l}\text { Wie aus der Anlage zur Vorlage hervorgeht, wurden } 683,1 \\
\text { Mio. DM auf die neuen Bezirke aufgeteilt. In dieser Summe ist } \\
\text { der für das Jahresende vorgesehene Überschuss in Höhe von } \\
\text { 47,9 Mio. DM enthalten. }\end{array}$ & & 683,1 & Mio. DM \\
\hline \multicolumn{4}{|l|}{$\begin{array}{l}\text { Von der im Gesetz vorgesehenen Verwaltungskosteneinsparung } \\
\text { von } 16 \text { Mio. DM sind bis zum } 31.8 .52 \text { in den Ländern } 10 \\
\text { Mio. DM realisiert und an die Finanzministerien abgeführt } \\
\text { worden. }\end{array}$} \\
\hline \multicolumn{4}{|l|}{$\begin{array}{l}\text { c) Die Auswirkung der Bildung der Bezirke auf den } \\
\text { Finanzausgleich Republik/Länder. }\end{array}$} \\
\hline $\begin{array}{l}\text { Im Haushaltsgesetz ist vorgesehen, dass die Länder aus } \\
\text { Anteilen an Steuern der Republik Zusendungen in Höhe von } \\
\text { 1.049,9 Mio. DM erhalten. }\end{array}$ & & $1.049,9$ & Mio. DM \\
\hline $\begin{array}{l}\text { Für die Zeit vom 1.1.-31.8. = } 8 \text { Monate standen den Ländern } \\
\text { danach zu }\end{array}$ & 699,9 & & Mio. DM \\
\hline $\begin{array}{l}\text { Zugeführt wurden den Ländern aufgrund des Ist-Aufkommens } \\
\text { der Steuern }\end{array}$ & 743,4 & & Mio. DM \\
\hline $\begin{array}{l}\text { Aufgrund des tatsächlichen Steueraufkommens steht nach dem } \\
\text { Gesetz den Ländern das Mehraufkommen voll zu }\end{array}$ & & 43,5 & Mio. DM \\
\hline Soll für die Länder aufgrund des Aufkommens bis 31.8 . & & $1.093,4$ & Mio. DM \\
\hline \multicolumn{4}{|l|}{$\begin{array}{l}\text { Finanzausgleich entsprechend dem Abschluss der Länder zum } \\
\text { 31.8. und der Haushalte der Bezirke }\end{array}$} \\
\hline 1) die Einnahmen der Länder & 643,2 & & Mio. DM \\
\hline $\begin{array}{l}\text { 2) von den Bezirken übernommene Bestände und von den } \\
\text { Kreisen zurückzuzahlende Vorschüsse }\end{array}$ & 100,2 & & Mio. DM \\
\hline insgesamt 1) u.2) & 743,4 & & Mio. DM \\
\hline \multirow[t]{2}{*}{$\begin{array}{l}\text { 3) Finanzausgleiche Republik/Bezirke zum Ausgleich der } \\
\text { Bezirkshaushalte }\end{array}$} & 324,6 & & Mio. DM \\
\hline & & $1.068,0$ & Mio. DM \\
\hline
\end{tabular}




\begin{tabular}{|l|l|l|l|}
\hline $\begin{array}{l}\text { Die Zuwendungen der Republik, die die Länder bisher erhalten } \\
\text { haben, zuzüglich der Zuwendungen, die zum Ausgleich der } \\
\text { neuen Bezirkshaushalte erforderlich sind, sind um } \\
\text { geringer, als den Ländern und Bezirken nach dem }\end{array}$ & 25,4 & Mio. DM \\
$\begin{array}{l}\text { Haushaltsgesetz zustehen. Diese Minderausgabe der Republik } \\
\text { muss bereitgehalten werden, um notfalls den Ausgleich der neu } \\
\text { aufzustellenden Kreishaushalte zu ermöglichen. }\end{array}$ & & & \\
\hline
\end{tabular}

[BArch, C-20 I/3-135, Bl. 19-23]

\section{Dokument 42: Fünfzehnter Bericht des Vorsitzenden des Rates des Bezirkes Pots- dam über die Durchführung der Verwaltungsreform im Bezirk Potsdam, 14. Sep- tember 1952 (Auszug)}

[...] Im Laufe der Woche wurde auch eine Sitzung des Rates des Bezirkes durchgeführt. In dieser Sitzung stand im Vordergrund der Bericht über die einzuleitenden Maßnahmen, um die Erfassung von Kartoffeln zu beschleunigen; ebenso alle anderen tierischen und pflanzlichen Produkte, wo wir im Rückstand sind, schnellstens aufzuholen. Dabei konnte berichtet werden, dass dort, wo mit den werktätigen Bauern gemeinsam der Kampf gegen die sabotierenden Großbauern geführt wird, entscheidende Erfolge zu verzeichnen sind.

Neben dieser Ratssitzung tagte das Bezirksernte- und Erfassungsaktiv in Beratung mit werktätigen Bauern. Auch hier wurden entscheidende Maßnahmen zur Verbesserung der Erfassung und der Bildung von Rodekolonnen gefasst.

Die Räte der Kreise haben zwar ihre Arbeit begonnen, jedoch beschäftigen sie sich noch zu viel mit den inneren Angelegenheiten der Kreise selbst. Aus diesem Grunde fasste der Rat des Bezirkes auch den Beschluss, zur Anleitung und Unterstützung für jeden Kreis einen Stellvertreter oder Abteilungsleiter verantwortlich zu machen.

Die Schulungen bzw. Versammlungen mit den Haus- und Straßenvertrauensleuten wurden im Bezirk fortgesetzt. Alle diese Versammlungen sind überaus zahlreich besucht. Die Vertrauensleute bringen zum Ausdruck, dass sie nun erst wissen, was ihre Aufgaben sind, da sich bis jetzt niemand um sie bemüht hat. In allen diesen Versammlungen wird von ihnen verlangt, dass die Versammlungen regelmäßig durchgeführt werden und dass die Gesetze und Verordnungen der DDR mit ihnen eingehend besprochen werden. - Viele Hinweise werden in den Versammlungen vorgebracht; aber auch die Bereitschaft, dem Staatsapparat in seinen Arbeiten zu unterstützen.

Wir werden nach Abschluss der ersten Versammlungswelle einen umfassenden Bericht überreichen, aus dem zu ersehen ist, welche wertvolle Unterstützung der Bezirk bzw. die Kreise durch die Straßen- und Hausvertrauensleute erhalten. 
$\mathrm{Zu}$ den Arbeiten des Rates des Bezirkes selbst ist Folgendes zu bemerken: Ohne Zweifel ist eine Veränderung in der Arbeitsweise der einzelnen Abteilungen festzustellen. Trotzdem ist in der Betrachtung der Tätigkeit der Abgeordneten und der Tätigkeit der Angestellten des Staatsapparates ein wesentlicher Unterschied festzustellen. Während die Abgeordneten sowie auch die Kommissionen mit ihren Aktivs begeistert mit neuen Methoden - unter Hinzuziehung von breiten Schichten der Bevölkerung - ihre Arbeiten durchführen, ist dies bei den Angestellten des Staatsapparates keinesfalls in diesem Maße vorhanden. Die Diskussion über ungenügende Stellenpläne und dergleichen mehr überwiegt in einigen Abteilungen jede Anregung weniger Angestellter, mit neuen Methoden die Einbeziehung breiter Schichten der Bevölkerung in die Arbeit des Staatsapparates herbeizuführen. - Dasselbe gilt auch für die Kreise im Bezirk.

$\mathrm{Zu}$ der vor kurzem gemeldeten Unwetterkatastrophe in Belzig wurde uns vom Rat dieses Kreises die Aufstellung über die Sachschäden, die finanziell gedeckt werden müssen, eingereicht.

Danach ergibt sich folgendes Bild:

7.952,50 DM Selbstfinanzierung aus Haushalts- und Finanzplänen von Schulen, VEBetrieben und VE-Gütern. Eigenfinanzierung der Kirche.

18.000,00 DM bringen die Betroffenen selbst auf,

11.300,00 DM werden von den Versicherungsanstalten des Landes Brandenburg gezahlt,

57.000,00 DM können von den werktätigen Bauern, besonders Neubauern, nicht aufgebracht werden und mussten deshalb vom Staat bereitgestellt werden.

Wir hatten in einem unserer vorhergehenden Berichte gebeten, dass uns in dieser Frage Unterstützung von Seiten der Regierung der DDR gegeben wird. Wir möchten - nachdem nun die Gesamtaufstellung der Sachschäden feststeht - diese Bitte hiermit wiederholen.

[BLHA, Rep. 401, Nr. 58, Bl. 47-48] 
Dokument 43: „Stellenplanbesetzung“ des Rates des Bezirkes Potsdam, 16. September $1952^{317}$

\begin{tabular}{|c|c|c|c|c|}
\hline Abteilung & $\begin{array}{c}\text { Soll lt. } \\
\text { Stellenplan }\end{array}$ & Ist & & Nicht besetzte Planstellen \\
\hline Leitung & 15 & 14 & & persönlicher Referent \\
\hline Abt. Kader & 12 & 12 & & \\
\hline Abt. Plankommission & 38 & 35 & & 3 sonstige Angestellte \\
\hline Abt. Org. Instrukteur & 13 & 11 & & 2 sonstige Angestellte \\
\hline Abt. Information & 9 & 9 & & \\
\hline Abt. Allgemeine Verwaltung & 7 & 7 & & \\
\hline Abt. Vermessung & 4 & 3 & & Leiter der Abteilung \\
\hline Abt. Finanzen & 29 & 29 & & \\
\hline $\begin{array}{l}\text { Abt. Finanzen } \\
\text { Unterabt. Abgaben }\end{array}$ & 41 & 41 & & \\
\hline Abt. Industrie & 37 & 36 & & Abteilungsleiter \\
\hline Abt. Aufbau & 13 & 12 & & $\begin{array}{l}\text { Abteilungsleiter } \\
{[\text { wickelt } a b]}\end{array}$ \\
\hline Abt. Verkehr & 12 & 11 & & $\begin{array}{l}\text { sonstiger Angestellter } \\
{[\text { Sachbearbeiter }} \\
\text { Landschaftsgestaltung] }\end{array}$ \\
\hline Abt. kommunale Wirtschaft & 3 & 3 & & \\
\hline Abt. Erfassung und Aufkauf & 11 & 11 & & \\
\hline Abt. Handel und Versorgung & 22 & 21 & $\begin{array}{l}\text { [wird 1 } \\
\text { gestrichen] }\end{array}$ & sonstige Angestellte \\
\hline $\begin{array}{l}\text { Abt. Arbeit und Berufsaus- } \\
\text { bildung }\end{array}$ & 39 & 38 & & Berufsschulinspizient \\
\hline Abt. Volksbildung & 28 & 26 & $\begin{array}{l}\text { [wird 1 } \\
\text { gestrichen] }\end{array}$ & 2 sonstige Angestellte \\
\hline Abt. Land und Forst & 67 & 57 & $\begin{array}{l}\text { [wird } \\
\text { gestrichen }]\end{array}$ & $\begin{array}{l}1 \text { Abteilungsleiter } \\
7 \text { sonstige Angestellte } \\
2 \text { Stenotypisten }\end{array}$ \\
\hline Abt. Kunst & 9 & 9 & & \\
\hline Abt. Jugendfragen & 4 & 4 & & \\
\hline Abt. Gesundheitswesen & 35 & 33 & & $\begin{array}{l}2 \text { sonstige Angestellte } \\
\text { [1 Arzt u. 1 Sachbearbeiter] }\end{array}$ \\
\hline $\begin{array}{l}\text { Abt. Förderung der Intelli- } \\
\text { genz }\end{array}$ & 5 & 4 & & Leiter \\
\hline $\begin{array}{l}\text { Abt. Rechtsstaat, Kirchen- } \\
\text { fragen }\end{array}$ & 4 & 4 & & \\
\hline Abt. Staatliches Eigentum & 8 & 7 & & 1 sonstiger Angestellter \\
\hline Abt. Verschluss & 3 & 3 & & \\
\hline
\end{tabular}

317 Handschriftliche Hinzufügungen sind kursiv in eckigen Klammern gesetzt. 


\begin{tabular}{|l|r|r|l|l|}
\hline Abt. Personenstandswesen & 1 & 1 & & \\
\hline Abt. Archiv & 1 & 1 & & \\
\hline Abt. Bevölkerungspolitik & 2 & 2 & & \\
\hline BGL & 2 & - & & $\begin{array}{l}\text { Vorsitzender } \\
1 \text { Stenotypist }\end{array}$ \\
\hline & 474 & 444 & & 30 \\
\hline Technisches Personal & 53 & 75 & & \\
\hline & $\mathbf{5 2 7}$ & $\mathbf{5 1 9}$ & & \\
\hline
\end{tabular}

[BLHA, Rep. 401, Nr. 84, Bl. 330]

Dokument 44: Bericht der Abteilung Staatliche Organe der Bezirksleitung der SED Potsdam ,über die Arbeit des Rates des Bezirks Potsdam“, 18. September 1952

\section{1.) Beurteilung der Arbeitsaufnahme der Abteilungen.}

Die Arbeitsaufnahme der einzelnen Abteilungen beim Rat des Bezirks erfolgte sehr unterschiedlich.

Einige Abteilungen konzentrierten sich sofort auf das Neue und versuchten, mit neuen Methoden die Arbeit zu organisieren.

Die Mehrzahl der Abteilungen konnte sich aber von dem Alten, Bestehenden noch nicht trennen.

Es traten teilweise Diskussionen auf, dass auf Grund des geringen Stellenplanes die Aufgaben nicht zu lösen wären und die Anleitung seitens des Rates ungenügend sei. ${ }^{318}$

Dementsprechend war auch die Arbeitsorganisation innerhalb der einzelnen Abteilungen eine unterschiedliche.

Nicht alle Abteilungen sind z. Zt. im Besitz von Arbeitsplänen und haben auch nicht genügend Übersicht über die augenblickliche Situation, auch in den Kreisen.

Eine gute Arbeit leistet die Abteilung Handel und Versorgung. Sie hat Arbeitspläne für den Monat September und für das IV. Quartal; es besteht hier eine gute Übersicht über die Lage in den Kreisen. Die Abteilung arbeitet operativ. 
Täglich werden Arbeitsbesprechungen durchgeführt und im Kollektiv die wichtigsten Aufgaben durchgesprochen.

Eine ungenügende Arbeit wird in der Plankommission geleistet. Hier erfolgt keine konkrete Anleitung für die Mitarbeiter durch den Abteilungsleiter. Der Planvorschlag 1953 beweist, dass man keineswegs kämpferisch genug an die Erfüllung und Übererfüllung der Kontrollziffern herangegangen ist.

Besondere Schwächen in der Arbeit treten auch bei den Abteilungen Aufbau und Industrie auf. Dies zeigte sich besonders bei einer Tagung mit den Vertretern aus den Kreisen am 4.9.1952, wo die Mitarbeiter dieser Abteilungen eine vollkommen desorganisierte Arbeitstagung zustande brachten und die gestellten Probleme Abschluss der Bauleistungsverträge, Bauwirtschaftsplan, angefangene Bauobjekte und Aufstellung freiwerdender Arbeitskräfte nicht geklärt werden konnten, da die Leitung dieser Beratung diese Probleme nicht beherrschte.

Die Arbeit der Org.-Instrukteur-Abteilung ist z. Zt. auch noch ungenügend, weil die Besetzung mangelhaft ist und auch die Qualifikation der Org.-Instrukteure nicht ausreicht, die Aufgaben zu lösen.

Eine Veränderung wird in kürzester Frist so erfolgen, dass aus den einzelnen Abteilungen Fachinstrukteure in die Org.-Instrukteur-Abteilung versetzt werden und der Stellenplan voll besetzt wird.

Um die Arbeit der Abteilungen zu verbessern, ist es notwendig, die guten Methoden, die von einzelnen Abteilungen angewandt werden, in Dienstbesprechungen und Arbeitsbesprechungen zu verallgemeinern und insbesondere großen Wert auf die Kontrolle der Arbeitspläne und auf die Auswertung der Anleitung, die vom Sekretär des Rates in den Dienstbesprechungen den einzelnen Abteilungen gegeben wird, zu legen; denn es tritt bis jetzt die Erscheinung auf, dass diese Anleitung nicht von den Abteilungsleitern bis zu jedem Mitarbeiter der Abteilung getragen wird.

\section{2.) Beurteilung der Abteilungsleiter, ob sie den Aufgaben gewachsen sind.}

Der Genosse Westphal, Leiter der Org.-Instrukteur-Abteilung, ist seinen Aufgaben nicht gewachsen. Er versteht es nicht, seine Mitarbeiter schwerpunktmäßig anzusetzen und verliert sich in Kleinigkeiten. Er entwickelt nicht genügend Eigeninitiative und geht nicht entschlossen an die übertragenen Aufgaben heran.

Genosse Singula, Leiter der Materialversorgung, zeigt in seiner Arbeit ebenfalls Schwächen. Er versucht, diese nicht durch bessere Arbeitsorganisation zu überwinden, sondern hat die Absicht, seine Funktion aufzugeben und nach Berlin, Deutscher In- und Außenhandel, zu gehen. 
Die Bezirksleitung lehnt die Freistellung ab.

Der Genosse Neumann, Abteilungsleiter Erfassung und Aufkauf, der fachlich seinen Aufgaben gerecht wird, zeigt kein Parteibewusstsein. Z. B. hat er an einem Sonnabend sein Parteidokument einem Kraftfahrer übergeben und ist mit der S-Bahn durch Westberlin nach Hause gefahren, damit er unter allen Umständen um 13.00 Uhr zu Hause ist.

Der Genosse Poppen, Leiter der Plankommission, der eine gute fachliche Qualifizierung besitzt, überträgt sein Wissen ungenügend auf seine Mitarbeiter und leitet sie nur mangelhaft an.

Der Genosse Dittrich, Leiter der Abteilung Allgemeine Verwaltung, ist seinen Aufgaben nicht annähernd gewachsen, er hat keinerlei Übersicht in seinem Aufgabengebiet und es ist vorgesehen, ihn durch einen anderen geeigneten Genossen zu ersetzen.

Gute Arbeit haben bisher die Abteilungsleiter Genosse Dr. Schaumann, Handel und Versorgung, Genosse Otto Westphal, Finanzen, und Genosse John, Volksbildung, gezeigt.

Sie verstehen es, die neuen Methoden auf ihre Mitarbeiter zu übertragen und haben in ihren Abteilungen eine ausgezeichnete Arbeitsorganisation und eine vollkommene Übersicht über die Lage in den Kreisen.

\section{3.) Sitzungen des Bezirksrates.}

Seit der Konstituierung des Rates haben sieben Sitzungen stattgefunden, denen insbesondere die Fragen der weiteren Demokratisierung des Staatsapparates und die Maßnahmen für die Überleitung der Aufgaben auf die neuen Kreise, die Schulung der Abgeordneten des Bezirksrates, die Hilfe für die Produktionsgenossenschaften, die Arbeit der ständigen Kommissionen, die Bearbeitung der Beschwerden, das Neubauern-Bauprogramm, Vorschläge für den Volkswirtschaftsplan 1953 und die Arbeit der Maschinenausleihstationen behandelt wurden.

Insgesamt sind bisher 15 Ratsbeschlüsse gefasst und angenommen worden.

Der Arbeitsplan des Rates des Bezirks wird wöchentlich in den Sitzungen des Rates auf seine Erfüllung kontrolliert, dadurch, dass die verantwortlich gemachten Kollegen über die Durchführung ihrer Aufgaben im Rat berichten.

\section{4.) Sprechstunden der Mitglieder des Rates und Bearbeitung der Beschwerden.}

Die Sprechstunden des Vorsitzenden des Rates, des Sekretärs und der Stellvertreter finden im laufenden Turnus täglich von 
$9.00-12.00$ und von $16.00-19.00 \mathrm{Uhr}$ statt,

sonnabends von $9.00-12.00$ und von $13.00-16.00 \mathrm{Uhr}$.

Durch die Presse sind diese Sprechstunden popularisiert worden, und es ist ein reger Besuch zu verzeichnen.

Es ist in Vorbereitung, nicht nur bekannt zu geben, wann die Sprechstunden stattfinden, sondern wöchentlich zu veröffentlichen, wer in den Sprechstunden anzutreffen ist.

In der Zeit vom 1.-15.9.52 waren insgesamt 114 Besucher in den Sprechstunden. 118 Beschwerden wurden vorgebracht, davon sind bis jetzt 57 erledigt worden.

Die mündlich vorgebrachten Beschwerden werden nach jeder Sprechstunde protokollarisch festgehalten und jedes Protokoll wird über den Sekretär des Rates dem Abteilungsleiter der Org.-Instrukteur-Abteilung weitergeleitet, der die Erledigung der Beschwerden kontrolliert.

Nach abschließender Bearbeitung der Beschwerden wird ein zweites Protokoll gefertigt, aus dem klar zu ersehen ist, ob und wie die Beschwerden geklärt wurden.

Auch dieses Protokoll wird über den Sekretär der Org.-Instrukteur-Abteilung zugeleitet. Die Org.-Instrukteur-Abteilung kontrolliert also anhand der Protokolle die Bearbeitung der Beschwerden.

Die bisher durchgeführten Sprechstunden haben einen guten Anklang bei der Bevölkerung gefunden und alle vorgebrachten Beschwerden wurden bisher unbürokratisch und schnell erledigt (soweit berechtigt).

Der Rat des Bezirks hat für die Bearbeitung der Beschwerden am 4.9.52 eine Beschwerdeordnung beschlossen.

\section{5.) Die Arbeit der ständigen Kommissionen des Bezirkstages.}

Besonders hervorgehoben werden muss die Arbeit der Kommission für Landwirtschaft und ländliches Bauwesen. Sie hat es verstanden, ihre Aufgabe unter Heranziehung weiter Kreise der Bevölkerung zu lösen.

So konnte der Vorsitzende der Kommission, der Neubauer Lindner, über seine Tätigkeit in der Gemeinde Tietzow, Kreis Nauen, berichten, dass infolge der schlechten Besetzung der Gemeindeverwaltung Mängel in der Ablieferung von pflanzlichen und tierischen Produkten zu verzeichnen waren. Durch Heranziehung der Massenorganisationen wurde es möglich, diese Fehler zu beseitigen. 
Auf einem großbäuerlichen Grundstück wurden Rennpferde gezüchtet, statt Nutzvieh. Das Grundstück, das einem Westberliner gehört, wurde auf Grund dieser Kontrollmaßnahmen unter Sequester gestellt.

Von den zehn bestehenden Kommissionen haben bis auf die Kommission für Justiz- und Volkspolizeifragen alle ihre Arbeit aufgenommen.

Eine gute Arbeit wurde von den Kommissionen für Landwirtschaft und ländliches Bauwesen, Industrie und Handwerk und kulturelle Massenarbeit geleistet.

Die Kommissionen befassen sich in erster Linie mit den im Arbeitsplan des Rates des Bezirkes festgelegten Schwerpunkten.

Die Kommissionen Industrie und Handwerk, kulturelle Massenarbeit, Volksbildung, Gesundheitswesen und Sozialfürsorge arbeiten bereits nach konkreten Arbeitsplänen.

Die Kommission für Landwirtschaft und ländliches Bauwesen hat Richtlinien ausgearbeitet für die Arbeit der Kommission in den Kreistagen, die eine gute und konkrete Anleitung darstellen.

Als negatives Beispiel gegenüber der Arbeit der Kommission für Landwirtschaft und ländliches Bauwesen muss die Arbeit der Kommission für Verkehr angesehen werden. Sie hat es bisher nicht verstanden, ihre Arbeit in enger Verbindung mit der Bevölkerung durchzuführen. Dieser Kommission liegt weder ein Arbeitsplan vor noch hat sie bisher konkrete Beschlüsse mit Festlegung von Terminen und Verantwortlichkeit gefasst.

\section{6.) Wie erfolgt die Anleitung der Kreise durch den Rat des Bezirks?}

Von allen Kreisen wird begrüßt und für gut befunden die Anleitung durch den Vorsitzenden, Genossen Wach, und den Sekretär, Genossen Grünewald, in den 14-tägigen Arbeitskonferenzen mit den Vorsitzenden und Sekretären der Räte der Kreise, die bereits dreimal stattgefunden haben und in denen sie ganz genaue Richtlinien für die Durchführung ihrer Schwerpunktaufgaben in seminaristischer Form erhalten. Z. B. am 18.9. äußerten die Sekretäre der Räte der Kreise im Anschluss an ihre Beratung, die folgende Tagesordnung hatte:

1. Aufgaben des Sekretärs,

2. Bericht über die Arbeitsaufnahme der Kreise, dass solche Beratungen für sie die beste Anleitung ist und sie wünschen, dass diese Beratungen systematisch durchgeführt werden.

Mangelhaft aber ist noch die Anleitung durch einzelne Abteilungen, denn die Mitarbeiter der Bezirksverwaltung, die in die Kreise kommen, wenden immer noch die alte Methode des Feststellens der Mängel, aber nicht der operativen Veränderung an. 
Die Vorsitzenden der Räte der Kreise beklagen sich außerdem über das Überlaufen mit Instrukteuren. So waren z. B. an einem Tag in Königs Wusterhausen 15 Instrukteure des Rates des Bezirks und der Regierung der DDR anwesend.

Die von den einzelnen Fachabteilungen durchgeführten Arbeitsberatungen mit den Vertretern aus den Kreisen zeigen teilweise noch ein schlechtes Niveau und sind mangelhaft vorbereitet.

Außerdem beklagen sich die Kreisräte, dass sie zu oft und nicht an dem bestimmten Konferenztag (Donnerstag) zu Besprechungen nach Potsdam geholt werden.

\section{Arbeit der Kreisverwaltungen.}

\section{1.) Wie ist die Besetzung der Kreise, welche Schwierigkeiten sind bei der Unterbrin- gung aufgetreten, wo liegen die Ursachen dieser Schwierigkeiten, wer trägt die Verantwortung dafür?}

Schwierigkeiten traten auf in Zossen, wo bis zum 1.11.52 neue massive Baracken errichtet werden; mit dem Bau wurde bereits begonnen. Bis dahin verbleiben einige Abteilungen in den alten Gebäuden in Mahlow.

In Pritzwalk ist das Gebäude an Größe ausreichend, jedoch sind die Räume nicht heizbar. Dem Rat des Kreises sind Mittel zum Ausbau der Räume zur Verfügung gestellt worden; die Arbeiten sind bereits im Gange.

Der Rat des Kreises Brandenburg/Land hat z. Zt. seinen Sitz im Hotel „Zum Bären“, welches aber nicht ausreichend ist.

Die sogenannte Klosterkaserne, die z. Zt. von sowjetischen Freunden benutzt wird, wird jetzt dem Rat des Kreises zur Verfügung gestellt. Nach Renovierung, etwa 4-5 Wochen, zieht der Rat des Kreises um.

Die Unterbringung des Rates des Kreises Königs Wusterhausen ist völlig ungenügend. Ein Teil ist in dem ehemaligen Blindenheim, die Abt. Arbeit im Bahnhofhotel und einige andere Abteilungen noch in Mahlow untergebracht.

Es war vorgesehen, die Finanzschule freizumachen, was jedoch von Regierungsstellen in Berlin abgelehnt wird.

Der Rat des Bezirks hat sich bisher ungenügend eingeschaltet und den Rat des Kreises in dieser Frage nicht ausreichend unterstützt. 
In Gransee besteht die Schwierigkeit bei der Unterbringung des Rates des Kreises darin, dass die vorgesehenen sechs Baracken nicht sofort geliefert worden sind und jetzt erst zwei aufgebaut werden.

Der Rat des Bezirks hatte versprochen, diesen Mangel sofort zu beseitigen, seitdem sind einige Wochen vergangen.

Durch das Eingreifen der Staatlichen Kontrolle sind diese ersten zwei Baracken jetzt geliefert.

In den übrigen Kreisen bestehen keine besonderen Raumschwierigkeiten.

\section{2.) Sind in allen Kreisen zwei Kreisratssitzungen durchgeführt worden, welche Grundprobleme sind dort behandelt worden?}

Außer im Kreis Ruppin und Oranienburg ist bei allen Räten die 2., 3. bzw. 4. Ratssitzung durchgeführt worden.

Die Räte der Kreise beschäftigen sich in allen Kreisen mit den gleichen Problemen, z. B. Demokratisierung des Staatsapparates, Arbeitsplan, Ernteeinbringung, Erfassung und Aufkauf, Popularisierung der Note der Sowjetunion, Herbstbestellung und mit der Arbeit der Abgeordneten und der Kommissionen der Kreistage.

$\mathrm{Zu}$ diesen Schwerpunkten wurden auch bei allen Räten des Kreises entsprechende Beschlüsse gefasst, z. B. in Jüterbog zur Ernteeinbringung.

Der Rat gab gute Anleitung und Hilfe. Dadurch hat sich der Stand der Getreideablieferung in den letzten zehn Tagen von 55 auf $75 \%$ erhöht.

Eine ganze Anzahl von Kreisen befasste sich außerdem noch mit folgenden Punkten: Werbung für die Volkspolizei, Bildung von Rodegemeinschaften, Anleitung der Hausund Straßenvertrauensleute, Durchführung des Neubauern-Bauprogramms, Wohnraumlenkung, devastierte Betriebe und der Erarbeitung des Kreisplanes.

\section{3.) Einschätzung der Arbeit der Kreisverwaltungen insgesamt und der Arbeit der Abteilungen eines Kreises.}

Wie lösen sie ihre Aufgaben, haben sie einen Überblick über die Situation in ihrem Kreis, welche Schwächen und Mängel traten auf?

Arbeitsmethode und Arbeitsweise der Räte der Kreise ist unterschiedlich. Während z. B. Zossen, Belzig, Brandenburg/Land, Rathenow und Kyritz versuchten, mit neuen Methoden zu arbeiten, insbesondere jetzt in der Frage der Ablieferung und der Herbstbestellung, 
haben sich die übrigen Kreise nicht genügend von der bürokratischen Verwaltungsarbeit, vom Schreibtisch, gelöst.

In den Kreisen Luckenwalde, Königs Wusterhausen, Wittstock und Potsdam/Land haben die Räte der Kreise noch einen ungenügenden Überblick über die Lage im Kreis und geben den Bürgermeistern keine systematische, operative Anleitung, weil sie sich von den Dingen treiben lassen und nicht planmäßig arbeiten. Sie ersticken fast in ihren Aufgaben, weil sie es noch nicht verstanden haben, die Mitarbeiter und insbesondere die breiten Massen der Bevölkerung zur Lösung der vielen Aufgaben heranzuziehen.

Auch wird noch die Rolle und die Bedeutung der Betriebsparteiorganisation bei den Räten der Kreise unterschätzt.

Das kommt z. B. darin zum Ausdruck, wenn der Genosse Grundhoff, Vorsitzender des Rates des Kreises Königs Wusterhausen, nicht an den Mitgliederversammlungen teilnimmt oder wenn er unentschuldigt bei den Kreisleitungssitzungen fehlt.

Auf Beschluss des Sekretariats der Bezirksleitung muss sich die Kreisleitung in allen Kreisen jeden Tag über den Stand der Getreideschlacht und der Kartoffelversorgung von unseren Genossen im Rat berichten lassen.

Die angegebenen Zahlen in Königs Wusterhausen sind aber so unterschiedlich und offensichtlich falsch, dass man daraus schließen muss, dass der Rat des Kreises überhaupt keinen Überblick über die Ablieferung und Erfassung hat.

Eine schlechte Methode ist es auch in Königs Wusterhausen, wenn schon die ersten Beschlüsse der Ratssitzungen nicht realisiert werden, wie z. B. der Beschluss Nr. 5 über die Aufstellung von Wochenarbeitsplänen - oder wenn der Rat des Kreises nicht weiß, ob und wo die Abgeordneten Sprechstunden durchgeführt haben.

Es ist trotzdem zu erkennen, dass in allen Kreisen etwas Neues in der Arbeit im Entstehen ist, dass sie sich auf das Neue konzentrieren, wie es z. B. der Rat des Kreises Rathenow macht. Hier hat der Rat des Kreises eine sehr gute operative Anleitung und Hilfe für die junge Produktionsgenossenschaft Schönholz gegeben, der eine beharrliche Aufklärungsarbeit vorausging. Brigaden und Verwaltung haben den werktätigen Bauern in Schönholz geholfen bei der Erarbeitung ihrer Pläne und helfen jetzt bei der Ausarbeitung der Normen.

$\mathrm{Zu}$ den Ratssitzungen werden hier ständig die besten Menschen aus dem Kreis hinzugezogen und mit ihnen gemeinsam die Aufgaben beraten.

In Königs Wusterhausen ist der Sekretär des Rates des Kreises der Meinung gewesen, dass Gäste nur zu konstituierenden Sitzungen eingeladen werden. Er äußerte sich zu 
einem Mitarbeiter der Kreisleitung etwa folgendermaßen: „In der Ratssitzung hast Du doch gar nichts zu suchen!“

\section{4.) Wie ist die Arbeit der Kommissionen des Kreistages?}

Im Kreis Potsdam/Land haben sich bereits alle Kommissionen konstituiert.

Die Kommission für Landwirtschaft und ländliches Bauwesen hat sich als besonderen Punkt die Hilfe für die Produktionsgenossenschaft Groß-Glienicke gestellt.

In fast allen Kreisen hat bisher nur die Kommission für Landwirtschaft und ländliches Bauwesen mit der Arbeit begonnen.

In Ruppin arbeitet noch keine Kommission.

Die Kommission beschäftigt sich mit der Frage der Ablieferung der Herbstbestellung, der Kartoffelrodung und mit der Aufstellung des Arbeitsplanes.

Die Frage des Aktivs bei den Kommissionen ist noch nicht entsprechend seiner Bedeutung berücksichtigt worden.

In Belzig und Gransee haben außerdem die Kommission für Handel und Versorgung mit der Arbeit begonnen. Hier gaben die Sekretäre jeder Kommission in der ersten Sitzung Anleitung für ihre Arbeit. Es muss erreicht werden, dass an den Sitzungen der Kommission die Abteilungsleiter des Rates teilnehmen.

[BLHA, Rep. 401, Nr. 84, Bl. 332-341]

Dokument 45: Protokoll einer Besprechung ,über die Abgabe des Vermögens der ehemaligen Landesregierung Brandenburg“, 19. September 1952

Es wurde vereinbart, dass das Grundstück Friedrich-Ebert-Straße 79/81 an den Rat der Stadt als überwiegende Nutznießerin ab 1. September 1952 übergeben wird. Das Übergabeprotokoll wird von der Abteilung Allgemeine Verwaltung gefertigt und dem Kollegen Paulitz vorgelegt.

Das Gebäude Friedrich-Ebert-Straße 32 wird an die Bezirksjustizverwaltung übergeben, und benachrichtigt, dass dieselbe einen Mietvertrag mit der Versicherungsanstalt (Eigentümerin des Hauses) abschließt ab 1. August 1952, da seit dem Tage die Bezirksjustizverwaltung das Haus nutzt.

Das Gelände Heinrich-Mann-Allee 107 wird vom Rat des Bezirkes Potsdam genutzt. Haus 8 wird vom Deutschen Roten Kreuz genutzt, der Justizneubau von der 
Medizinischen Fachschule, Haus 14 vom Werbebüro der Volkspolizei und Haus 2 vom Bezirksstaatsanwalt. Für diese Dienststellen wurden Nutzungsverträge vorbereitet.

Das Verwaltungsgelände Heinrich-Mann-Allee 103 gehörte zur Verwaltung der ehemaligen Landesregierung Brandenburg. Nach der Auflösung der Landesregierung wurde das Gelände vom Rat des Bezirkes übernommen. Der Stellenplan (14 Kollegen) liegt in Berlin zur Genehmigung vor. Die Verwaltung ist zur Zeit unbesetzt. Von der Stellenplaninspektion, Kollege Schmude, wurde vorgeschlagen, bis Ende des Jahres mit dem zu bestätigenden Stellenplan das Gelände zu verwalten, dann ab 1. Januar 1953 dazu überzugehen, entweder einen volkseigenen oder Dienstleistungsbetrieb zu errichten, da der Stellenplan sicherlich befristet sein wird (1. Dezember 1952). Das würde bedeuten, dass alle Dienststellen auf dem Verwaltungsgelände Heinrich-Mann-Allee 103 Miete zahlen müssten.

Folgende Dienststellen sind untergebracht:

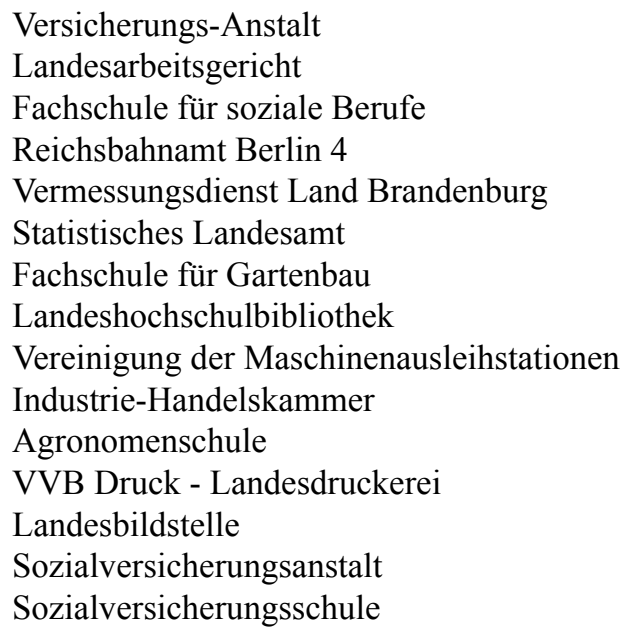

In der Besprechung wurde zum Ausdruck gebracht, dass eine eigene Verwaltung (Dienstleistungsbetrieb) die Verwaltung in der Heinrich-Mann-Allee 103 verteuern würde. Weiterhin ist zu bemerken, dass das Gelände des Rates des Bezirkes mit diesem Gelände Heinrich-Mann-Allee 103 durch die Fernheizung und Telefonanlage, ca. 60 Hausanschlüsse, verbunden ist. Also müsste der Rat des Bezirkes Potsdam anteilige Bewirtschaftungskosten zahlen. Es wurde in der Besprechung zum Ausdruck gebracht, dass es das günstigste wäre, dieses Gelände Heinrich-Mann-Allee 103 durch den Rat des Bezirkes zu verwalten, und den in Berlin vorliegenden Stellenplan unbefristet genehmigen sollte.

Die Materialeinplanung für 1953 ist bereits beim Rat des Bezirkes erfolgt. Bis zur endgültigen Klärung wurde gleichfalls vorgeschlagen, die Haushaltmittel Werterhaltungs- und 
Unterhaltungskosten wie Strom, Heizung usw. im Haushaltplan 1953 beim Rat des Bezirkes vorzusehen.

[BLHA, Rep. 401, Nr. 58, Bl. 137]

Dokument 46: Thesen aus ,dem Referat des Herrn Staatssekretärs Eggerath ${ }^{319}$ auf der Konferenz der Vorsitzenden und Sekretäre der Räte der Bezirke“" in Potsdam, 23. September 1952

\section{Die wichtigsten Aufgaben der nächsten Zeit:}

Nachdem jetzt die Struktur der örtlichen Organe der Staatsgewalt in den Bezirken und Kreisen den ökonomischen und politischen Verhältnissen unter den Bedingungen des Aufbaus des Sozialismus angepasst und die Überleitung der Aufgaben abgeschlossen ist, ergibt sich

1. die Notwendigkeit der allseitigen Verbesserung der Arbeitsweise auf allen Gebieten. Dabei gilt es insbesondere das Niveau der organisatorischen Arbeit auf die Höhe der politischen Aufgaben zu heben.

2. Es gilt ferner, von der administrativen Arbeit des Apparates loszukommen und bei der Durchführung der großen Aufgaben die Werktätigen in die Leitung des Staats einzubeziehen, d. h. die Massenarbeit allseitig zu organisieren.

3. Die Räte der Bezirke müssen die Anleitung der Räte der Kreise qualifizieren, weil diese unmittelbar an der Basis den Kampf um die Verwirklichung der Pläne organisieren müssen.

\section{Verbesserung der Arbeit der Bezirkstage und der Abgeordneten:}

1. Durchführung einer persönlichen Aussprache mit jedem Abgeordneten durch den Vorsitzenden und Sekretär.

2. Überprüfung der Funktionen einzelner Abgeordneter, gegebenenfalls Entlastung.

3. Verbesserung der Sitzungen des Bezirkstages:

a) Schlussmachung mit den häufigen Sitzungen,

b) Tagesordnung mindestens vier Wochen vorher festlegen,

c) ständige Kommissionen beschäftigen sich in dieser Zeit mit den auf der Sitzung des Bezirkstages zu lösenden Fragen (Durchführung von Untersuchungen, Vorbereitung von Korreferaten oder Vorschlägen, Vorbereitung von Diskussionsbeiträgen).

d) Der Rat, die Abteilungen und insbesondere die Org.-Instrukteur-Abteilung müssen die Beschlussvorschläge und Berichte gründlich vorbereiten und eine Woche

319 Zu Werner Eggerath vgl. Dok. 1, Anm. 228. 
vor der Sitzung die Beschlussvorschläge den Abgeordneten zustellen, damit diese noch ausreichend Zeit zum Studium haben.

e) Die Teilnahme von Gästen an den Sitzungen des Bezirkstages muss ebenfalls vorbereitet werden, die an den zu behandelnden Fragen interessiert sind.

4. Die Wirkungsbereiche der einzelnen Abgeordneten müssen nach individueller Aussprache mit ihnen noch einmal überprüft und eventuell neu festgelegt werden. Der Bezirkstag fasst hierüber Beschluss. Auch die Mitglieder des Rates müssen einen ständigen Wirkungsbereich haben.

5. Die Sprechstunden der Abgeordneten in ihrem Wirkungsbereich gründlicher vorbereiten, höchstens zweimal im Monat eine Sprechstunde jedes Abgeordneten. Technische Hilfsmittel (Blocks) den Abgeordneten zur Verfügung stellen. Nationale Front leitet nicht die Organisierung der Sprechstunden, sondern unterstützt sie. Verantwortlich für die Vorbereitung der Sprechstunde der Rat der Gemeinde.

\section{Arbeitsweise des Rates des Bezirkes:}

1. Der Vorsitzende des Rates des Bezirkes bestimmt auf der Grundlage der Beschlüsse des Bezirkstages und der Gesetze und Verordnungen die politische Linie der Arbeit des Rates. Demzufolge kann er sich nicht in Kleinigkeiten verlieren, sondern muss sich auf die Lösung der Schwerpunkte im Bezirk konzentrieren. Er trägt dafür Sorge, dass im Rat des Bezirkes Maßnahmen und Direktiven beschlossen werden, die die Abteilungen befähigen, die Schwerpunktaufgaben durchzuführen und für sie die Arbeitsgrundlage für einen längeren Zeitraum darstellt. Der Vorsitzende lässt sich ständig von den Stellvertretern und vom Sekretär berichten, wie die Abteilungen die Beschlüsse durchführen. Der Vorsitzende überzeugt sich durch persönliche Informationen in den Gemeinden, Betrieben und durch Abhaltung von Sprechstunden von der Durchführung der vom Rat gefassten Beschlüsse.

2. Der Sekretär ist das organisatorische Zentrum für die Arbeit des Rates. Auf diese Weise sichert er die Durchführung der politischen Linie. Durch ständiges Studium der Arbeitsorganisation in den Abteilungen mit Hilfe der Org.-Instrukteur-Abteilung hilft er durch Anwendung von Kritik und Selbstkritik ständig die Arbeit verbessern. Durch seine Hand gehen alle Berichte und Beschlussvorschläge für den Rat.

Er verhindert, dass schlecht vorbereitete Berichte und Beschlussvorlagen dem Rat zugeleitet werden und gibt den Abteilungen Hinweise zur Verbesserung ihrer Arbeit.

Vom Rat gefasste Beschlüsse werden durch den Sekretär den entsprechenden Abteilungen bzw. Räten der Kreise zugeleitet. Mit Hilfe der Org.-Instrukteur-Abteilung organisiert er die Arbeit der ständigen Kommissionen, unterstützt sie bei der Auswertung ihrer Arbeit und wirkt darauf hin, dass sich zwischen den Abteilungen und den ständigen Kommissionen eine gute Zusammenarbeit entwickelt.

Er leitet die Arbeiten zur Vorbereitung und Auswertung der Sitzungen der Bezirkstage und kontrolliert die Durchführung der Sprechstunden sowie die Behandlung der Beschwerden. 
3. Die Stellvertreter leiten die ihnen unterstellten Abteilungen in ihrer Arbeit an, ohne den Abteilungsleitern die Verantwortung für die Durchführung der ihnen obliegenden Aufgaben abzunehmen. Sie kontrollieren ständig die Durchführung der Schwerpunktaufgaben und halten vom Vorsitzenden und vom Rat die Fragen der täglichen Arbeit fern, indem sie die Abteilungen zu einer verantwortungsbewussten Arbeit erziehen. Sie beraten mit den Abteilungsleitern in regelmäßigen Dienstbesprechungen die Fragen der Arbeit und koordinieren die Arbeit der ihnen unterstellten Abteilungen (das trifft insbesondere für die operative Arbeit zu).

4. Die Räte sollen sich von dem Grundsatz Lenins leiten lassen: „Lieber weniger - aber besser zu arbeiten“. Das bedeutet, dass die Räte nach einem genau festgelegten Arbeitsplan systematisch hintereinander alle Schwerpunktaufgaben beraten und wissenschaftlich ausgearbeitete Beschlüsse bzw. Direktiven beschließen, die die Grundlage für die Arbeit auf bestimmten Gebieten für längere Zeit darstellen.

\section{Zur Arbeit der Abteilungen des Rates des Bezirkes:}

1. Erziehung der Kader in den Abteilungen zur selbständigen Arbeit und zur Hebung der persönlichen Verantwortung (Ausarbeitung von Geschäftsverteilungsplänen sowie Kontrolle der Realisierung derselben)!

2. Abkehr von der sporadischen Arbeit, dafür mehr planmäßige und wissenschaftliche Arbeit.

3. Volle Verantwortung der Abteilungsleiter für ihre Kader und deren Qualifizierung.

4. Organisierung einer guten Zusammenarbeit mit den ständigen Kommissionen - jedoch keine Über- oder Unterordnung.

5. Verbesserung der Anleitung der Kreise durch Organisierung von Komplex- und Zweiguntersuchungen mit dem Ziel, gute Beispiele der Arbeit zu schaffen und die Erfahrungen zu verallgemeinern.

\section{Organisierung der Massenarbeit über die ständigen Kommissionen:}

1. Die Direktive des Ministerrates über die Arbeit der Aufgaben der ständigen Kommissionen muss gründlich studiert und den Abgeordneten erläutert werden. Hierzu dient besonders auch die dritte Lektion. Direktive gibt kein Rezept für alle Arbeitsmethoden und -formen der ständigen Kommissionen, sondern nur allgemeine Grundsätze. Kommissionen müssen unter Anleitung ihre Arbeit selbst organisieren;

2. denn die Kommissionen sind kein Anhängsel des Rates und seiner Abteilungen. Jedoch muss der Rat die Arbeit ständig unterstützen und die guten Erfahrungen auswerten. 


\section{Die Org.-Instrukteur-Abteilung:}

1. Eingehendes Studium der vom Ministerrat beschlossenen Direktive über die Arbeit der Org.-Instrukteur-Abteilung. ${ }^{320}$

2. Ausarbeitung von Arbeitsplänen, die vom Rat zu beschließen sind. Dabei Berücksichtigung der von uns gegebenen Hinweise zur Durchführung von Komplexuntersuchungen und zur Anleitung der Aktion „Was lehrt und die diesjährige Ernte?“

3. Organisierung einer richtigen Arbeitsweise der Org.-Instrukteur-Abteilung in den Kreisen durch die Org.-Instrukteur-Abteilung beim Rat des Bezirkes.

4. Schnellste kadermäßige Besetzung der freien Planstellen.

\section{Sprechstunden sowie Bearbeitung der Beschwerden:}

1. Jeder Rat des Bezirkes beschließt eine Direktive über Arbeit der Beschwerden. Diese muss mit allen Mitarbeitern durchdiskutiert werden.

2. Die Frist für die Beantwortung der Beschwerden soll nicht mehr als eine Woche betragen.

3. Die Org.-Instrukteur-Abteilung kann nicht jede Beschwerde bearbeiten, sondern kontrolliert die Bearbeitung der Beschwerden durch die Abteilungen.

4. Der Rat muss in bestimmten Zeitabständen den Eingang und die Bearbeitung der Beschwerden analysieren und daraus die Schlussfolgerungen für die Arbeit ziehen.

[BLHA, Rep 401, Nr. 71, Bl. 106-109]

\section{Dokument 47: Arbeitsbericht der Abteilung Kader beim Rat des Bezirkes Potsdam für das III. Quartal 1952, 3. Oktober 1952 (Auszug)}

Die zweite Parteikonferenz der SED fasste den historischen Beschluss, mit dem Aufbau des Sozialismus in der Deutschen Demokratischen Republik zu beginnen.

Eines der wichtigsten Instrumente beim Aufbau des Sozialismus ist der Staatsapparat, wie Walter Ulbricht das ausführte.

Die Volkskammer erließ daraufhin das Gesetz vom 23. Juli 1952 über die weitere Demokratisierung des Aufbaues und der Arbeitsweise der staatlichen Organe in den Ländern der Deutschen Demokratischen Republik.

320 Die Direktive ,für die Arbeit der Organisations-Instrukteur-Abteilungen bei den Räten der Bezirke und Kreise" vom 18. September 1952 ist abgedruckt in Dokumente 1949-1961, S. 110-111, sowie im Gesetzblatt der DDR, Teil I, 1952, S. 875-876. 
Auf Grund dieses Gesetzes stellte sich die Kaderabteilung des Bezirkes Potsdam folgende Schwerpunktaufgaben im III. Quartal 1952:

1. Einsatz der Kader der bisherigen Landesregierung in den neu gebildeten Bezirken und Kreisen.

2. Auswahl von Bestätigungen der Kaderleiter für die Kreise des Bezirkes Potsdam.

3. Hilfe und Anleitung der Kaderleiter der Kreise in Bezug auf die Kaderbesetzung der Räte der Kreise.

4. Neuorganisierung der Zirkel der Staatspolitischen Schulung im Bezirk und in den Kreisen, Auswahl und Bestätigung der Zirkelleiter.

Dieser Schwerpunktarbeitsplan wurde nicht in all seinen Punkten erfüllt.

Die Aufteilung der Kader für die Bezirke und Kreise wurde ohne Schwierigkeiten und termingemäß durchgeführt. Dagegen bereitete die Unterbringung der übrigen Kräfte, die nicht in den Bezirken und Kreisen untergebracht werden konnten, größere Schwierigkeiten, sodass sich die Kaderabteilung noch bis Ende September mit der Unterbringung einiger Kräfte beschäftigen musste.

Die Auswahl der Kaderleitungen konnte ebenfalls termingemäß erreicht werden. Jedoch zeigt sich heute schon, dass in einigen Kreisen an die Auswahl nicht mit dem nötigen Ernst herangegangen wurde. So müssen u. a. die Kaderleiter in den Kreisen Potsdam/ Land, Oranienburg, Gransee und Wittstock ausgewechselt werden. Unsere Aufgabe im IV. Quartal wird es sein, hierfür fähigere Kaderleiter einzusetzen. Die Bestätigung der Kaderleiter durch uns steht noch aus, weil die gesellschaftlichen Organisationen bisher noch nicht Stellung dazu genommen haben.

Den Kaderleitern in den Kreisen wurde in zweimaligen Arbeitsberatungen Hilfe und Anleitung gegeben. Es wurden im Laufe des Monats August und September sämtliche Kreise persönlich besucht, um auftretende Schwierigkeiten zu beseitigen.

In einigen alten Kreisen, wie z. B. Neuruppin, trat die Tendenz auf, den neuen Kreisen nur zweitrangige Kräfte zu vermitteln. Das konnte durch unser Eingreifen verhindert werden.

Die Neuorganisierung der Zirkel im Bezirk und in den Kreisen wurde durchgeführt, sodass die innerbetriebliche Schulung am 1. Oktober aufgenommen werden konnte.

In einigen Kreisen fehlen noch die Schulungsbeauftragten, wie z. B. in Wittstock, in Zossen usw.

In Kyritz wurde der Schulungsbeauftragte für andere Arbeiten einsetzt und die innerbetriebliche Schulung konnte hier am 1. Oktober nicht anlaufen. Es wurde veranlasst, dass der Schulungsbeauftragte sofort seine Arbeit aufnimmt und der erste Schulungstag 
nachgeholt wird. Die Bestätigung der Zirkellehrer konnte erst im geringen Masse vollzogen werden.

Im Bezirk ergaben sich noch besondere Schwierigkeiten in der Form, dass nicht alle Personalunterlagen der ehemaligen Ministerien ordnungsgemäß übergeben wurden, sodass heute noch nachgeforscht werden muss wo die Personalakten geblieben sind.

Einen großen Teil der Arbeitszeit wurde benötigt um den vielen Anforderungen nach Beurteilungen der ehemaligen Landesregierung Brandenburg nachzukommen.

Das hemmte unsere eigentlichen Aufgaben.

\section{Analyse der Statistik.}

Die Statistik beim Rat des Bezirkes zeigt uns, dass der Anteil der Frauen mit 48,7 \% zu gering ist.

Vor allen Dingen wurde nicht darauf geachtet, dass bei der Besetzung des Bezirks Frauen in leitende Stellungen eingesetzt wurden. Der Anteil der Mitarbeiter die ihrer sozialen Herkunft nach Arbeiter sind beträgt 52,7 \%.

Vor allen Dingen ist der Anteil der Bauern zu gering. Er beträgt 5,2 \%.

Auch der Anteil der Jugendlichen mit 22,6 \% ist zu niedrig. Das liegt jedoch daran, dass der größte Teil der männlichen Jugendlichen zur Volkspolizei ging. Der Anteil der ehemaligen Kriegsgefangenen aus der Sowjetunion mit $13 \%$ ist gegenüber dem Anteil der Kriegsgefangenen aus kapitalistischen Ländern mit 11,2 \% zu gering. Als ausreichend zu bezeichnen ist der prozentuale Anteil der Mitglieder der SED mit 56,9 \%. Demgegenüber steht der Anteil der Parteilosen mit 36,1\%.

Bei den Kriegsgefangenen aus kapitalistischen Ländern handelt es sich zwar nur um kurzfristige Gefangenschaften, trotzdem müssen wir im IV. Quartal unser schärfstes Augenmerk darauf richten, diesen Anteil herabzudrücken.

Die Zahl der offenen Planstellen mit 28 ist seit dem Stichtag, dem 15.9.1952 weiter verringert worden. Eine endgültige Besetzung kann erst erfolgen, nachdem der bestätigte Stellenplan hier vorliegt. Bedenklich ist, dass bereits im Monat September die Fluktuation erneut einsetzte, so schieden z. B. im Monat September 19 Kollegen aus. Die Gründe des Ausscheidens sind langfristiger Schulbesuch, Übernahme in die Leitungen gesellschaftlicher Organisationen und in wenigen Fällen falscher Einsatz bei der Besetzung des Rates des Bezirkes. Demgegenüber wurden 16 Neueinstellungen vorgenommen. 


\section{Analyse der Räte der Kreise.}

Die Zahl der offenen Planstellen mit rund $20 \%$ ist darauf zurückzuführen, dass die Kreise am Stichtag, den 15.9.1952, noch in der Umorganisierung begriffen waren. Die Besetzung hat sich nach den neuesten Meldungen wesentlich gebessert. Es gibt allerdings noch einige Schwerpunkte wie z. B. Gransee, Königs Wusterhausen, Jüterbog.

Der Anteil der Mitarbeiter die ihrer sozialen Herkunft nach Arbeiter waren, beträgt $61,3 \%$, was als gut zu bezeichnen ist.

Dagegen könnte der Anteil der Bauern mit 7,9 \% höher sein.

Der Gesamtanteil der Frauen mit rd. $47 \%$ ist ebenfalls noch zu gering. Der Anteil der Jugendlichen beträgt $26,9 \%$.

Der Anteil der ehemaligen sowjetischen Kriegsgefangenen mit 11,5\% ist zu gering, gegenüber dem Anteil der Kriegsgefangenen aus den kapitalistischen Ländern mit $15 \%$. Hier gilt es im IV. Quartal unbedingt eine Verbesserung zu erreichen.

Der Anteil der Frauen und Jugendlichen in leitenden Stellungen konnte bei der Reorganisation nicht verbessert werden. Im Gegenteil trat eine Verschlechterung ein.

\section{Analyse der kreisangehörigen Städte.}

Der Anteil offenen Planstellen beträgt $11 \%$.

Der Anteil der Frauen mit 54,3 \% kann als ausreichend bezeichnet werden. Mitarbeiter die ihrer sozialen Herkunft nach Arbeiter waren sind 54,7 \% beschäftigt.

\section{Bauern 6,3\%.}

Der Anteil der Mitglieder der SED beträgt 40,9 \% und ist gegenüber dem Anteil der Parteilosen mit 41,5\% entschieden zu gering.

Desgleichen der Anteil der Mitarbeiter die in sowjetischer Kriegsgefangenschaft mit $6 \%$ gegenüber denen der kapitalistischen Länder mit $10 \%$. Auch der Anteil der Jugendlichen mit 19,4 \% muss als zu gering bezeichnet werden. Es gilt im IV. Quartal hier besonders einzugreifen um jenes zu verändern. 


\section{Analyse der kreisangehörigen Gemeinden.}

Der Anteil der offenen Planstellen beträgt $9 \%$.

Der Anteil der Frauen 50,1 \% und der Anteil der Mitarbeiter die ihrer sozialen Herkunft nach Arbeiter sind 50,3 \%. Der Bauern 14,9\%. Was durchweg als nicht ausreichend bezeichnet werden kann. Schlecht ist hier auch die politische Zugehörigkeit der SED mit $39,8 \%$ gegenüber den parteilosen mit 49,4\%. Die Jugendlichen mit ihrem Anteil von $17 \%$ sind ebenfalls entschieden zu gering.

Mitarbeiter aus sowjetischer Kriegsgefangenschaft sind 6,3\% gegenüber denen aus kapitalistischen Ländern mit 10,2 \% zu wenig.

\section{Analyse der Räte der Stadtbezirke.}

Die Analyse der in Potsdam neu gebildeten Stadtbezirke ergibt:

Anteil der Frauen 58,3\%

Anteil der Jugendlichen 16,55\%

Der Mitarbeiter die ihrer sozialen Herkunft nach Arbeiter waren 53,6 \%

Der Bauern 4,6\%

Mitglieder der SED 31,7\%

Parteilose 57,3 \%

Mitarbeiter mit sowjetischer Kriegsgefangenschaft 9,6\%

mit westlicher Gefangenschaft 10,5\%.

Abschließend zu der Analyse und zur Statistik muss gesagt werden, dass die kein reales Bild gibt, da inzwischen die Räte der Kreise voller besetzt wurden und die Statistik der kreisangehörigen Städte und Gemeinden durch die Reorganisation auch zu wünschen übrig lässt. Die Kreise waren am Stichtag den 15.9.1952 noch nicht in der Lage, eine wirklich hundertprozentige reale Statistik insbesondere der kreisangehörigen Gemeinden aufzustellen. Es gilt nun die in der Analyse aufgezeigten Schwächen und Mängel im IV. Quartal entschieden zu bekämpfen, um eine bessere Zusammensetzung des gesamten Staatsapparates zu erreichen. Die wichtigste Aufgabe wird es sein, die Räte der Kreise voll zu besetzen und dabei besonderes Gewicht auf die Einstellung von Frauen und Jugendlichen zu legen. Die Kaderleiter in den Kreisen sind zum großen Teil neu. Auf die Anleitung dieser Kaderleiter muss ich unser Schwergewicht legen.

Es gilt vor allen Dingen, auch den Anteil der SED-Mitglieder zu heben und der Mitarbeiter, die in sowjetischer Kriegsgefangenschaft waren. Dagegen muss ein konsequenter Kampf geführt werden gegen das Ansteigen der Mitarbeiter, die in den kapitalistischen Ländern in Kriegsgefangenschaft waren. 
Die Analyse wird der Gegenstand einer ernsthaften Beratung mit allen Kaderleitern des Bezirkes Potsdam sein.

Die Kaderleiter der Kreise sind angewiesen, für das III. Quartal einen Arbeitsbericht nicht einzureichen. Aus diesem Grunde kann eine nähere Stellungnahme dazu nicht erfolgen. Es erfolgte auch keine Meldung aus den Kreisen über eingestellte Betriebsarbeiter. Beim Rat des Bezirkes wurden Betriebsarbeiter im Laufe der Monate August und September nicht eingestellt.

Über die Kaderentwicklung kann ebenfalls kein genaues Bild gegeben werden. Wohl wurden eine Anzahl Mitarbeiter die bisher bei der Landesregierung oder in den Kreisen weniger qualifizierte Funktionen inne hatten, als Abteilungsleiter in den neuen Räten der Bezirke und Kreise eingesetzt. Jedoch ist es auch vorgekommen, dass Mitarbeiter, die bisher höhere Funktionen hatten, in niedrigere eingesetzt wurden.

Im Berichtsquartal endete der sechste Hauptlehrgang der Grundverwaltungsschule Plaue und der vierte Hauptlehrgang der Grundverwaltungsschule Gransee. Die Schüler wurden fast ausschließlich in ihrer alten Dienststelle wieder eingesetzt. Die Unterlagen befinden sich bei der Deutschen Verwaltungsakademie „Walter Ulbricht“ und werden von dort weiter bearbeitet.

\section{Kaderreserven}

Die Mitarbeiter der Kaderabteilungen im Bezirk und in den Kreisen waren mit der Reorganisation und den damit verbundenen technischen Arbeiten voll in Anspruch genommen, sodass an der Bildung einer Kaderreserve noch nicht herangegangen werden konnte.

\section{Schwerpunkte für den Arbeitsplan im IV. Quartal.}

1. Hilfe und Anleitung, sowie Kontrolle der Kaderabteilung der Kreise in Bezug auf die Kaderbesetzung und Maßnahmen zur Verbesserung der kaderpolitischen Zusammensetzung.

2. Anleitung der Kaderabteilungen der Kreise in technischer Hinsicht, zur ordnungsgemäßen Anlegung und Vervollständigung der Personalakte, Entwicklungskartei und der Statistischen Kartei.

3. Anleitung und Kontrolle der Schulungsbeauftragten der Kreise sowie Fortsetzung der Auswahl und Bestätigung der Zirkellehrer. [...]

[BLHA, Rep. 401, Nr. 73, fünf Bl., nicht foliiert] 
Dokument 48: Bericht des Sekretärs des Rates des Bezirkes Cottbus, Horst Brasch, ${ }^{321}$ ,über die weitere Demokratisierung des Aufbaus und der Arbeitsweise der Organe der Staatsmacht im Bezirk Cottbus“،, 14. Oktober 1952 (Auszug)

\section{Die Schaffung der staatlichen Organe im Bezirk und in den Kreisen}

Auf Vorschlag der II. Parteikonferenz nahm die Volkskammer der Deutschen Demokratischen Republik am 23. Juli 1952 das Gesetz über die weitere Demokratisierung des Aufbaus und der Arbeitsweise der staatlichen Organe in den Ländern der Republik an. Im Zuge der Durchführung dieses Gesetzes wurde der Bezirk Cottbus mit 14 Landkreisen und 781 Städten und Gemeinden gebildet [...]. Im Bezirkstag, seinen ständigen Kommissionen, dem Rat des Bezirkes, den Kreistagen, den ständigen Kommissionen derselben und in den Räten der Kreise arbeiten 696 Werktätige mit, davon 586 Abgeordnete und 110 Mitglieder der ständigen Kommissionen der Kreise oder Mitglieder der Aktivs der ständigen Kommissionen des Bezirkstages.

\section{Verlauf der Aktion}

Die Demokratisierung wurde in drei Etappen durchgeführt. Die erste Etappe bis Mitte Juli diente der Vorbereitung. Das Territorium wurde festgelegt, die Auswahl der Abgeordneten erfolgte, Gebäude für die neuen Dienststellen wurden gesichert und Maßnahmen der Überleitung wurden getroffen.

In der zweiten Etappe, die vom Zeitpunkt der Veröffentlichung bis zum 15. August dauerte, wurden der Bezirkstag, der Rat des Bezirkes und die ständigen Kommissionen gebildet. In dieser Etappe wäre es vor allem auf eine breit angelegte Aufklärung der Bevölkerung über die neuen Maßnahmen angekommen. Schließlich wurden der Aufbau der Abteilungen des Rates des Bezirkes und die Vorbereitungen zur Konstituierung der Kreistage, der Räte der Kreise und der ständigen Kommissionen durchgeführt.

Die dritte Etappe bis 15.9. diente der Bildung der Kreistage, ihrer ständigen Kommissionen und der Räte der Kreise sowie dem Aufbau der Abteilungen in den Räten der Kreise.

\section{Die Führung der Aktion}

Bereits Mitte Juni wurde auf Beschluss des Politbüros von der Landesleitung der Partei eine Bezirkskommission zur Leitung der Aktion gebildet. Diese setzte sich wie folgt zusammen:

321 Zu Horst Brasch vgl. Dok. 29, Anm. 299. 
Vorsitzender war der künftig als Vorsitzender des Rates des Bezirkes vorgesehene Genosse.

Mitglieder waren die Genossen, die als 1. und 2. Sekretäre der Bezirksleitungen der Partei vorgeschlagen waren.

Ferner die als 1. Sekretär der FDJ und als Vorsitzender des FDGB im Bezirk vorgesehenen Genossen.

Es gehörten der Kommission an

die Vorsitzenden der Unterkommissionen für Territoriale Fragen - Genosse Ziemainz Kaderfragen - Genosse Hermann

Bezirkstag u. Kreistage - Genosse Mielisch

Gebäudefragen - Genosse Siegmeyer

Überleitung - Genosse Siegmeyer

Ende Juli wurden in der Partei, im Staatsapparat und in den Massenorganisationen Org.Komitees geschaffen.

Die gleichen Kommissionen, Unterkommissionen und Org.-Komitees wurden in allen Kreisen gebildet.

\section{Die Durchführung der Aktion im Bezirk Cottbus}

Die Unterkommissionen leisteten eine schnelle und konkrete Arbeit. Das Territorium wurde rasch abgegrenzt. Fehler sind dabei nur unwesentlich gemacht worden. Die Zusammensetzung des Bezirkstages und der Kreistage konnte termingemäß abgeschlossen werden. Hierbei trat allerdings ein entscheidender Fehler auf. Die 1950 gewählten Kreistagsabgeordneten wurden bei der Zusammensetzung der Kreistage ungenügend beachtet und in vielen Fällen zugunsten eines neuen politischen Schlüssels nicht mehr in die Kreistage aufgenommen. Es gab hierbei jedoch auch eine objektive Schwierigkeit. Bei Beibehaltung der gesetzlich festgelegten Zahl der Abgeordneten und Beibehaltung aller alten Mandate war es nicht immer möglich, die Räte der Kreise politisch, sozial und fachlich entsprechend den Notwendigkeiten zusammenzusetzen. Es machte sich notwendig, die Zahl der Abgeordneten in einigen Kreisen zu erhöhen, z. B. Spremberg von 30 auf 40.

Weniger erfolgreich verlief die Auswahl von Kadern für die Abteilungsleiter des Rates des Bezirkes und der Räte der Kreise. Es gab eine Reihe von ernsten Schwächen. So fehlt z. B. im Kreis Luckau bis heute noch der Stellvertreter des Vorsitzenden des Rates des Kreises, den unsere Partei zu benennen hat, damit fehlt auch ein Abgeordneter. Es fehlen im Rat des Bezirkes bis zum heutigen Tage die von der Partei bestätigten Abteilungsleiter für Volksbildung, Gesundheitswesen, Erfassung und Aufkauf, Verkehr. In den Kreisen unterschätzte man bei den Kadervorschlägen die Rolle der Sekretäre. Das zeigte sich z. B. in 
den Kreisen Forst und Jessen. Die als Sekretäre gewählten Genossen sind schwächer als die Stellvertreter des Vorsitzenden, die von der Partei benannt werden.

Bei der Besetzung mit Abteilungsleitern unterschätzte man in den Kreisen die Rolle und Bedeutung der drei wichtigsten Abteilungsleiter Kader, Plankommission und Org.-Instrukteure. So haben z. B. die Kreise Forst und Weißwasser bis heute noch keine Leiter der Abteilung Org.-Instrukteure. In den Kreisen Cottbus, Weißwasser und Guben fehlen noch immer die Leiter der Abteilung Kader.

Die Gebäudefragen wurden im Wesentlichen gelöst. Allerdings hatte die Gebäude-Unterkommission keinen genauen Überblick über die Zahl und den Umfang der unterzubringenden Stellen, sodass heute noch an diesen Fragen gearbeitet werden muss.

In den Kreisen Jessen, Weißwasser, Finsterwalde und Luckau gibt es noch immer Schwierigkeiten mit der Unterbringung von Dienststellen. Ungenügend wurde von der Möglichkeit Gebrauch gemacht, nicht ortsgebundene Dienststellen zu verlegen.

Ungenügend war anfänglich auch die Ausnutzung örtlicher Reserven in Baracken. Die Kommission kümmerte sich nicht um die Sicherung des Inventars, sodass auch hier später erhebliche Verzögerungen eintraten. Es wurde verfehlt, dieser Unterkommission den Auftrag zu erteilen, Maßnahmen zur Unterbringung der Mitarbeiter in Wohnungen, Zimmern und Ledigenheimen zu erteilen.

Die Unterkommission für Überleitung ist niemals aktiv in Erscheinung getreten. Sie kümmerte sich weder um Transporte von Akten und Möbeln, noch um die Sicherung der Planunterlagen, vor allem aus Dresden und Halle. Ihre Aufgaben wurden durch das Org.-Komitee in der Verwaltung übernommen.

Es muss zur Arbeit der Unterkommissionen gesagt werden, dass sie, teilweise durch Schweigepflicht bedingt, zum Teil aber auch fehlerhafte Arbeit zu isoliert arbeiteten. Kaderfragen, territoriale Fragen und Gebäudefragen wurden sogar oftmals ohne Hinzuziehung der am besten informierten Genossen beschlossen. So trat z. B. bei der Auswahl der Abgeordneten die Tatsache ein, dass nach der ersten Sitzung des Bezirkstages zwei Abgeordnete fehlten. Eine Abgeordnete war zu jung, ein anderer Abgeordneter war gar nicht befragt worden.

Völlig unzureichend war die Aufklärung der Bevölkerung über die Beschlüsse der II. Parteikonferenz und über das Gesetz zur Demokratisierung der staatlichen Organe. Zwar war die Nationale Front beauftragt, dafür zu sorgen, dass sich die neuen Abgeordneten des Bezirkstages und der Kreistage vor der Konstituierung der Bevölkerung vorstellten. Die Aktion wurde jedoch weder richtig organisiert noch kontrolliert. Es haben nicht mehr als zehn neue Bezirkstagsabgeordnete solche Versammlungen durchgeführt. Auch die von der Nationalen Front organisierten Versammlungen nach der Konstituierung wurden nur zu einem kleinen Teil durchgeführt, da sie oftmals ohne Wissen der Sprecher organisiert wurden. Vor 
allem konzentrierte sich die Versammlungskampagne zu sehr auf den Kreis Cottbus. Inzwischen sind in Auswertung der Sitzung des Bezirkstages und der Kreistage über die Note der Sowjetunion vom 23.8. zur Deutschlandfrage eine erhebliche Anzahl von Versammlungen durchgeführt worden. ${ }^{322}$ Ein genauer Überblick besteht jedoch darüber noch nicht, da die Berichterstattung der Abgeordneten sehr schleppend vor sich geht. Es muss festgestellt werden, dass die Popularisierung des Gesetzes völlig ungenügend ist. Auch die Arbeit der Presse und der Abteilung Information wiesen diesbezüglich ernste Mängel auf.

Abschließend muss einiges zur Arbeit der Bezirkskommission gesagt werden. Ihre Arbeit war völlig ungenügend. Es gab keinen Arbeitsplan, kaum eine Kontrolle der Beschlüsse. Die Sitzungen waren unregelmäßig und oft ohne Tagesordnung. Selten nur waren alle Mitglieder anwesend. Die Frage der Aufklärung und der Mobilisierung der Massen wurde niemals besprochen. Die Nationale Front und die Presse wurden nicht informiert. Die Kreiskommissionen wurden nicht angeleitet. Mit der Schaffung der Org.-Komitees im Staatsapparat hörte entgegen den Instruktionen des ZK die Bezirkskommission auf zu funktionieren.

Eine der Ursachen für diesen Zustand ist die Unbeständigkeit in der Führung der Kommission. Der Wechsel hat folgendes Bild:

$\begin{array}{llll} & \text { als 1. Sekretär der Partei } & \text { 2. Sekretär } & \text { Vorsitzender des Rates } \\ \text { Ende Juni } & \text { Grüneberg }^{323} & \text { Samtlebe } & \text { Brasch }^{324} \\ \text { Anfang Juli } & \text { Seibt }^{325} & \text { Kisling } & \text { Wach }^{326} \\ \text { Mitte Juli } & \text { Seibt } & \text { Langner } & \text { Wach } \\ \text { Ende Juli } & \text { Seibt } & \text { Langner } & \text { Holweger }^{328} \\ \text { Anfang August } & \text { Bruk }^{329} & \text { Münchenhagen } & \text { Manneberg }^{331}\end{array}$

322 Zur Note der Sowjetregierung vom 23. August 1952 vgl. Dok. 38, Anm. 309.

323 Gerhard Grüneberg (1921-1981) war bis Juli 1952 Sekretär der SED-Landesleitung Brandenburg und wurde im folgenden Monat 1. Sekretär der SED-Bezirksleitung Frankfurt (Oder); vgl. Niemann/Herbst, SED-Kader, S. 212.

324 Zu Horst Brasch vgl. Dok. 29, Anm. 299.

325 Zu Kurt Seibt, bis Juli 1952 2. Sekretär der SED-Landesleitung Brandenburg, vgl. Dok. 2, Anm. 236.

326 Zu Curt Wach vgl. Dok. 25, Anm. 278.

327 Margarete Langner (1906-1992) war bis Juli 1952 Sekretär für Kultur in der SED-Landesleitung Brandenburg und wurde im folgenden Monat 2. Sekretär der SED-Bezirksleitung Potsdam; vgl. Niemann/Herbst, SED-Kader, S. 299.

328 Erhard Holweger (1911-1976) war Ende Juli 1952 für eine Woche Vorsitzender des Rates des Bezirkes Rostock und wurde dann wegen einer Parteistrafe nicht in diesem Amt bestätigt; vgl. Niemann/Herbst, SED-Kader, S. 248. Sein kurzzeitiger Einsatz in Brandenburg bleibt unklar; vgl. Kotsch, Brandenburg, S. 55.

329 Franz Bruk (1923-1996) war von August 1952 bis August 1953 1. Sekretär der SED-Bezirksleitung Cottbus; vgl. Niemann/Herbst, SED-Kader, S. 135.

330 Zu Walter Münchenhagen, von August 1952 bis September 1954 2. Sekretär der SED-Bezirksleitung Cottbus, vgl. Dok. 38, Anm. 308.

331 Zu Werner Manneberg vgl. Dok. 4, Anm. 247. 
Eine weitere Ursache ist, dass das Sekretariat der Landesleitung zu lange die Fäden in seiner Hand behielt, anstatt dieselben verantwortungsvoll auf die Bezirkskommissionen zu übertragen. Die Hauptursache ist jedoch die Unterschätzung der Bedeutung der Demokratisierung und die ungenügende Beachtung der Richtlinien des Zentralkomitees, vor allem in der Frage der Popularisierung der Maßnahmen durch die Genossen in der Bezirkskommission.

Es muss jedoch auch festgestellt werden, dass die operative Anleitung der Bezirkskommissionen und Org.-Komitees durch die zentralen Stellen des ZK und der Regierung ungenügend war.

\section{Die Arbeit der staatlichen Organe im Bezirk und in den Kreisen}

Der Bezirkstag konstituierte sich am 11.8.1952. Es waren 58 Abgeordnete anwesend. Acht Abgeordnete fehlten durch Krankheit oder Urlaub entschuldigt, zwei Abgeordnete fehlten aus den auf der Vorseite genannten Gründen. Der Rat des Bezirkes, bestehend aus 14 Mitgliedern, und die ständigen Kommissionen wurden gewählt.

Am 10.9. hielt der Bezirkstag seine zweite Sitzung ab. Es wurde zur Note der Sowjetunion zur Deutschlandfrage vom 23.8.1952 Stellung genommen. ${ }^{332}$ Ein Beschluss wurde über Fragen der Erfassung angenommen und der Arbeitsplan des Rates des Bezirkes für das IV. Quartal angenommen. An dieser Sitzung nahmen 60 Abgeordnete teil. Diese Sitzung war, was die Diskussion zu den Fragen der Erfassung und des Arbeitsplanes betrifft, ungenügend vorbereitet. Für die Abgeordneten wurden laut zentraler Anweisung bisher drei Schulungen durchgeführt. Die Beteiligung war wie folgt:

1. Schulung am 8.8.1952 über ,die Bedeutung des Gesetzes über die weitere Demokratisierung des Aufbaus und der Arbeitsweise der staatlichen Organe in den Ländern der DDR vom 23.7.1952 und die Aufgaben der Abgeordneten der Bezirks- und Kreistage." - 42 Abgeordnete waren anwesend.

2. Schulung am 4.9.1952 über „Wie verwirklichen die Beschlüsse der II. Parteikonferenz der SED über die weitere Demokratisierung des Aufbaus und der Arbeitsweise der staatlichen Organe und ihre Durchführung den Grundsatz der Lenkung des Staates durch die Werktätigen?“ - 48 Abgeordnete waren anwesend.

3. Schulung am 11.10.1952 über ,Wie arbeiten die ständigen Kommissionen der Bezirks- und Kreistage?“ - 32 Abgeordnete waren anwesend.

Eine Reihe von Abgeordneten haben überhaupt noch nicht an der Schulung teilgenommen, darunter die führenden Genossen unserer Partei.

332 Zur Note der Sowjetregierung vom 23. August 1952 vgl. Dok. 38, Anm. 309. 
Ein entscheidender Mangel ist, dass der Bezirkstag für 1952 kein Arbeitsprogramm hat, das zeigt, womit sich der Bezirkstag in seinen Sitzungen, durch seine ständigen Kommissionen, durch die Tätigkeit der einzelnen Abgeordneten und mit Hilfe des Rates beschäftigen wird.

Unterschiedlich ist die Tätigkeit der einzelnen Abgeordneten. Es gibt hervorragende Beispiele, die zeigen, wie das Neue allmählich zum Durchbruch kommt. Zu Abgeordneten, die bereits ein enges Verhältnis zur Bevölkerung hergestellt haben, gehören die Genossen Kopetschke, Bestla, Handtke, Dietus, Schütte, Weißkopf.

Der Genosse Kopetschke schuf sich in seinem Wirkungsbereich, das nach seinen Wünschen und entsprechend seiner Tätigkeit festgelegt wurde, ein Aktiv, mit dessen Hilfe er schon Einiges veränderte. Z. B. veranlasste er, dass ein Straßenbauvorhaben, das wegen Brennstoffmangel eingestellt werden sollte, aufrechterhalten wurde, indem man anstatt Lkws Grubenzüge für den Transport von Schotter einsetzte.

Der Genosse Handtke zeigt in seinen Berichten, wie er mit Hilfe des Rates der Gemeinde und des Rates des Kreises die Ursachen mannigfaltiger Beschwerden beseitigte.

Im krassen Gegensatz hierzu stehen die Abgeordneten Nobis (LDP) und Kernchen (LDP). In ihren Berichten wird nur nach Diäten, Benzin usw. gefragt. Kernchen gab sogar Anweisungen an Bürgermeister, die den Interessen von Großbauern dienten. Die Abgeordnete Fera-Ina Wenk (NDPD) lebt in Kyritz (Bezirk Potsdam) und erscheint außer zu Bezirkstagssitzungen nicht. Sie nimmt auch sonst ihre Pflichten als Abgeordnete nicht wahr.

Mit dem 15.10.1952 liegen die Wirkungsbereiche der Abgeordneten fest und auch der Termin der Sprechstunden.

Ungenügend ist noch die Hilfe der Abteilung Org.-Instrukteure für die Abgeordneten. Bisher wurden noch zu wenig Aussprachen mit den Abgeordneten durchgeführt. Die Tätigkeit der Abgeordneten wird ungenügend kontrolliert, sodass kein voller Überblick über ihre Tätigkeit besteht.

Aus der bisherigen Übersicht geht hervor, dass die meisten Beschwerden der Bevölkerung in den Sprechstunden und Versammlungen der Abgeordneten betrafen: Wohnungsfragen, Versorgung mit Gemüse und Arbeitskleidung, Arbeit der Handelsorgane, Versorgung mit Viehfutter, schlechte Arbeit der MAS. Es erweist sich, dass die Abgeordneten noch $\mathrm{zu}$ sehr mit anderen gesellschaftlichen Funktionen belastet sind. Beispiel hierfür sind die Genossen Wuttke und Kuppke, die je 14 andere Funktionen bekleiden. 


\section{Die ständigen Kommissionen}

Zur Anleitung der Arbeit der ständigen Kommissionen nahm das Org.-Komitee der Bezirksleitung der Partei Mitte August einen Rahmenplan an. Dieser wurde zur Grundlage der Berichte der Abteilungsleiter des Rates des Bezirkes gemacht, die diese auf den ersten Sitzungen der ständigen Kommissionen gaben.

Dieser Weg war jedoch falsch und nicht erfolgreich. Der Plan war am grünen Tisch entworfen. Ein weiterer Mangel war, dass der Plan nicht den Vorsitzenden der ständigen Kommissionen zugestellt worden war. Erst ein Erfahrungsaustausch der Vorsitzenden der ständigen Kommissionen und die Hilfe bei der Ausarbeitung von Arbeitsplänen (Mitte September) brachte den wirklichen Beginn der Tätigkeit der Kommissionen. Die dritte Schulung und die Durcharbeitung der vorläufigen Direktive über die Arbeit der ständigen Kommissionen brachte weitere Klarheit. ${ }^{333}$

Die ständigen Kommissionen für Verkehr, Gesundheitswesen, Handel, örtliche Industrie, kulturelle Massenarbeit, Volksbildung und Wohnungswesen haben sich Aktivs geschaffen und die Arbeit begonnen. Die ständige Kommission für Verkehr z. B. hat für ihre Arbeit in Lauchhammer ein Aktiv von 30 Spezialisten und Werktätigen.

Völlig unbefriedigend ist die Tätigkeit der ständigen Kommissionen für Landwirtschaft und für örtliche Volkspolizei und Justiz. Auch hier zeigt sich die ungenügende Arbeit der Abteilung Org.-Instrukteure bei der Anleitung und Hilfe für die Kommissionen. Das Verhältnis zwischen den ständigen Kommissionen und den Fachabteilungen ist noch nicht gut. Die Abteilungen versuchen, die Kommissionen zu bevormunden. Auch der Rat des Bezirkes hat sich der Hilfe der ständigen Kommissionen noch nicht bedient. Ungenügend verstehen die Abgeordneten noch ihre Tätigkeit als Abgeordnete mit der eines Mitglieds der ständigen Kommission zu verbinden.

\section{Rat des Bezirkes}

Der Rat des Bezirkes hat seit dem 12.8.1952 neun Sitzungen durchgeführt. In diesen hat er zu den wichtigsten wirtschaftlichen Fragen - wie Ernte, Erfassung, Investplan, Haushaltsplan, Erfüllung des Steueraufkommens, Versorgung der Bevölkerung - Stellung genommen. Dadurch sind eine Reihe von Erfolgen erzielt worden. Ein gutes Beispiel richtiger Arbeit wurde in Cottbus mit der Massenmobilisierung zur Erfüllung des Abgabenplanes geschaffen. Erfolgreich waren auch die Beratungen zur Frage der Unterstützung der Produktionsgenossenschaften und zur Förderung der sorbischen Bevölkerung.

333 Die Direktive „über die Aufgaben und Arbeit der ständigen Kommissionen“ vom 18. September 1952 ist abgedruckt in Dokumente 1949-1961, S. 107-109, sowie im Gesetzblatt der DDR, Teil I, 1952, S. 873-875. 
In der Arbeit des Rates gibt es noch ernste Schwächen. Die Sitzungen sind nicht gut genug vorbereitet, daher werden improvisierte und vorher nicht mit der Bezirksleitung vereinbarte Beschlüsse gefasst. Der Rat wird durch die ungenügende Arbeit der Stellvertreter noch mit zu viel Kleinigkeiten belastet, was dazu führte, dass auf den ersten acht Sitzungen 263 Beschlüsse gefasst wurden. Es ist bei dieser Fülle von Beschlüssen unmöglich, eine wirkliche Kontrolle durchzuführen. Die vom Rat den Abteilungen gestellten Termine sind oft nicht zu verwirklichen, was den Schlendrian in der Arbeit nach sich zieht. Der Rat ist noch kein Kollektiv. Die Mitglieder des Rates nehmen noch ungenügenden Anteil an der Arbeit mit Ausnahme der Genossen Kopetschke und Wuttke. Der Genosse Vorsitzender, die Genossen Stellvertreter und der Sekretär bemühen sich ungenügend um die ehrenamtlichen Ratsmitglieder. Die Stellungnahme zu kulturellen und sozialen Fragen ist noch ungenügend. Der Rat verfügt trotz aller Bemühungen noch nicht über die nötige Übersicht. Ungenügend ist schließlich bei den Ratsbeschlüssen die Einbeziehung der Massen in ihre Verwirklichung und Kontrolle. Entscheidende Mängel sind der Praktizismus der Genossen im Rat, die ungenügende Qualifizierung der Stellvertreter und Abteilungsleiter durch die Genossen Manneberg und Brasch sowie die schlechte Arbeit der Betriebsparteiorganisation.

\section{Die Arbeit der Abteilungen des Rates des Bezirkes}

Die Abteilungen sind zu $93 \%$ besetzt. Die Arbeit der Abteilungen ist das schwächste Glied in der Tätigkeit der staatlichen Organe. Abgesehen von einigen Erfolgen wie z. B. die Schaffung eines Beispiels der Abteilung Industrie zur Anwendung neuer Arbeitsmethoden in den Ziegeleien der örtlichen Industrie oder das bereits erwähnte Beispiel der Abteilung Finanzen bei der Aufbringung der Steuerrückstände verläuft die Arbeit noch stark im Stil der Landesregierung. Es wird administrativ gearbeitet und nicht schöpferisch geleitet.

Trotz vorhandener Arbeitspläne wird planlos und improvisiert gearbeitet. Das Prinzip der Einbeziehung der Massen in die Lösung der staatlichen Aufgaben wird fast ebenso wenig angewandt wie die Aufklärung der Bevölkerung über getroffene Maßnahmen. Ungenügend ist das Studium der Beschlüsse der Partei und Regierung sowie des Rates des Bezirkes.

Ungenügend ist die Beachtung des Volkswirtschafts- und Haushaltsplanes durch die Fachabteilungen. Ausgesprochen schlecht ist die Anleitung der entsprechenden Abteilungen in den Kreisen. Operative Einsätze und Tagungen in Cottbus sind in den wenigsten Fällen gründlich vorbereitet. Die Maßnahmen sind nicht genug organisatorisch geplant. Eine Kontrolle über eingeleitete Maßnahmen wird kaum durchgeführt.

Die Rolle und Bedeutung des Rates ist den meisten Mitarbeitern noch unklar. Eine entscheidende Ursache für diese Schwächen ist die mangelhafte Arbeit der Stellvertreter des Vorsitzenden mit den ihnen unterstellten Abteilungen. Daran tragen nicht zuletzt die 
Genossen Manneberg und Brasch, die die Stellvertreter nicht genügend kontrollieren und sie sogar übergehen, Schuld. Es kommt hinzu, dass die Mitarbeiter ungenügend zur Lösung der Aufgaben mobilisiert werden. Partei- und Gewerkschaftsorganisatoren beschäftigen sich noch nicht mit den Fragen der Arbeitsorganisation.

\section{Arbeit in den Kreisen}

Die noch ungenügende Arbeit des Rates des Bezirkes wirkt sich natürlich auf die Kreise aus. Hier ist vor allem die Arbeit der Räte und der ständigen Kommissionen völlig unbefriedigend. Es gibt fast nirgends Aktivs der ständigen Kommissionen. Arbeitspläne der ständigen Kommissionen sind nur teilweise vorhanden.

In einige Kreisen haben sich die ständigen Kommissionen noch nicht konstituiert. Die Räte arbeiten meist losgelöst von der Partei. Sie beschäftigen sich nicht mit den Hauptfragen und sind meist noch nicht zum Zentrum der staatlichen Aufgaben geworden. Die Abteilungen sind zu 88 \% besetzt. Die Qualifizierung der Mitarbeiter durch die Abteilungen des Rates des Bezirkes reicht nicht aus, um sie zu befähigen, ihre Aufgaben zu lösen. Von 198 im Plan vorgesehenen Abteilungsleitern sind 178 Stellen besetzt. In den Kreisen Guben, Cottbus, Weißwasser fehlen sogar die Abteilungsleiterkader. [...]

[BLHA, Rep. 801, Nr. 136, Bl. 39-45]

Dokument 49: Schreiben der Koordinierungs- und Kontrollstelle für die Arbeit der Verwaltungsorgane an den Vorsitzenden des Rates des Bezirkes Potsdam über die „Verteilung der Geschäfte bei den Räten der Kreise“, 17. Oktober 1952

Vom Rat des Bezirkes Dresden wird uns mitgeteilt, dass in den Kreisen den Abteilungsleitern z. T. abteilungsfremde Sachgebiete unterstellt wurden. So sind z. B. den Leitern der Org.-Instrukteur-Abteilungen das Personenstandswesen, der Bearbeiter für Information, der Beauftragte für Staatliches Eigentum, die Rechtsstelle und sehr oft die Abteilung Allgemeine Verwaltung zugeordnet.

Dieser offensichtliche Fehler resultiert in erster Linie daraus, dass die von der Stellenplaninspektion herausgegebenen Feinstruktur- und Stellenpläne für die Kreise z. T. eine sehr unübersichtliche Gliederung aufweisen und nicht in allen Fällen die Unterscheidung zwischen den Abteilungen und den ihnen zugehörigen Sachgebieten andererseits erkennen lassen.

Da dieser Mangel der Feinstruktur- und Stellenpläne auch bei den Räten der Kreise in den übrigen Bezirken Unklarheiten hervorgerufen haben wird, halten wir es für notwendig, in Erläuterung der Pläne eine genaue Übersicht über die Abteilungen, selbständigen Referate und selbständigen Sachgebiete bei den Räten der Kreise zu geben. 
Abteilungen:

Plankommission (mit den Rechten einer Abteilung)

Kader

Org.-Instrukteur-Abteilung

Allgemeine Verwaltung

Vermessung

Finanzen

Aufbau

Land- und Forstwirtschaft

Erfassung und Aufkauf

Arbeit und Berufsausbildung

Gesundheitswesen

Volksbildung

Örtliche Industrie und Handwerk

Handel und Versorgung

Kreiskomitee für Körperkultur (mit den Rechten einer Abteilung)

Selbständige Referate:

Verkehr und kommunale Wirtschaft

Kunst und kulturelle Massenarbeit

\section{Selbständige Sachgebiete:}

Rechtsstelle

Information

Staatliches Eigentum

Personenstandswesen

Archiv

VS

Jugendfragen.

Die Verteilung der Geschäfte auf die einzelnen Mitglieder des Rates erfolgt in der Weise, dass dem Vorsitzenden, den Stellvertretern und dem Sekretär sowohl Abteilungen als auch selbständige Referate und selbständige Sachgebiete direkt unterstellt werden. Wir verweisen in diesem Zusammenhang auf unsere Empfehlungen für die Verteilung der Geschäfte auf den Vorsitzenden, die Stellvertreter und den Sekretär des Rates des Kreises. Danach wurde von uns folgende Verteilung der Aufgabenbereiche vorgeschlagen:

Vorsitzender:

Plankommission, Kader, Jugendfragen.

\section{Stellvertreter:}

Land- und Forstwirtschaft, Erfassung und Aufkauf, Handel und Versorgung. 


\section{Stellvertreter:}

Finanzen, Verkehr u. kommunale Wirtschaft, Aufbau, Arbeit und Berufsausbildung, örtliche Industrie u. Handwerk

\section{Stellvertreter:}

Gesundheitswesen, Volksbildung, Kunst und kulturelle Massenarbeit, Komitee für Körperkultur.

\section{Sekretär:}

Org.-Instrukteur-Abteilung, Rechtsstelle, Information, Staatliches Eigentum, Personenstandswesen, Archiv, Allgemeine Verwaltung, Vermessung, VS.

In Auswertung des Beispiels aus dem Bezirk Dresden empfehlen wir Ihnen, die Verteilung der Geschäfte bei den Räten der Kreise Ihres Bezirkes hinsichtlich ihrer Richtigkeit überprüfen zu lassen und bitten Sie, bei festgestellten Fehlern die entsprechenden Maßnahmen zur Berichtigung zu treffen.

[BLHA, Rep. 401, Nr. 71, Bl. 59-60]

Dokument 50: Vorlesung des stellvertretender Leiter der Abteilung staatliche Verwaltung des Zentralkomitees der SED, Willi Barth, ${ }^{334}$ an der Parteihochschule „Karl Marx", 21. Oktober 1952 (Auszug)

Das Thema meiner Ausführungen ist die weitere Demokratisierung des Aufbaus und der Arbeitsweise der örtlichen Organe der Staatsgewalt in der Deutschen Demokratischen Republik. [...]

Wir wollen nicht vergessen hervorzuheben, dass die Maßnahmen zur weiteren Demokratisierung entwickelt wurden aufgrund eines Studiums der Struktur und der Arbeitsweise der staatlichen Organe in der Sowjetunion durch eine Studienkommission von Partei- und Staatsfunktionären aus der Deutschen Demokratischen Republik. ${ }^{335}$

Diese wertvollen Erfahrungen befähigten uns, entsprechend der konkreten Situation in der Deutschen Demokratischen Republik die richtigen Schlussfolgerungen zu ziehen. Die Durchführung der uns von der II. Parteikonferenz gestellten Aufgaben wird wesentlich erleichtert durch die Ergebnisse des XIX. Parteitages der KPdSU. [...]

$334 \mathrm{Zu}$ Willi Barth vgl. Dok. 10, Anm. 252.

$335 \mathrm{Zu}$ dieser Studienkommission gehörten u. a. Werner Eggerath (vgl. Dok. 1, Anm. 228), Fritz Lange (vgl. Dok. 3, Anm. 241) und Fritz Geyer (vgl. Dok. 29, Anm. 296). Ihre mehrwöchige Reise in die Sowjetunion endete am 6. Juli 1952, also zu einem Zeitpunkt, als die Grundlinien und viele Details der Bezirksbildung bereits festgelegt waren; vgl. Foitzik, Sowjetische Kommandanturen, S. 24. 
Genosse Walter Ulbricht stellte in seinem Bericht auf der II. Parteikonferenz der Staatsmacht folgende entscheidende Aufgaben:

1. Brechung des Widerstandes der gestürzten und enteigneten Großkapitalisten und Großagrarier, Liquidierung aller ihrer Versuche, die Macht des Kapitals wieder herzustellen;

2. Organisierung des Aufbaues des Sozialismus mit Hilfe des Zusammenschlusses aller Werktätigen um die Arbeiterklasse;

3. Schaffung der bewaffneten Streitkräfte der Deutschen Demokratischen Republik zur Verteidigung der Heimat gegen die äußeren Feinde zum Kampf gegen den Imperialismus.

Die weitere Demokratisierung der örtlichen Organe der Staatsgewalt beinhaltet noch folgende Prinzipien:

Maximale Vereinfachung des Staatsapparates und strengste Sparsamkeit, die Beseitigung seiner überlebten und überflüssigen Glieder, die Verbesserung der Arbeitsmethoden, die Herstellung einer engeren untrennbaren Verbindung der zentralen Organe mit den unteren Organen, ihre maximale Heranführung an das Volk und die breiteste Einbeziehung der Werktätigen in die Leitung des Staates.

Wir haben wiederholt festgestellt, dass die Deutsche Demokratische Republik die Basis im Kampf um die Herstellung der demokratischen Einheit Deutschlands ist. Während wir in der Deutschen Demokratischen Republik die weitere Demokratisierung unter den eben genannten Prinzipien durchführen, macht im Westen unserer Heimat der Staatsapparat in immer stärkerem Maße von den brutalen faschistischen Unterdrückungsmethoden Gebrauch.

Die wachsende Aktivität der Militärclique und der faschistischen Elemente ist eine Tatsache, und sie streben eine Regierung der Militärdiktatur unter dem Schutz der amerikanischen Bajonette an.

Wir werden mit der weiteren Demokratisierung des Staatsapparates in der Deutschen Demokratischen Republik das Anwachsen der nationalen Befreiungsbewegung im Westen unserer Heimat, den Kampf der Werktätigen für ihre Rechte, für die Beseitigung der Bonner Kriegstreiber stärkstens unterstützen. [...]

Der ganze schwerfällige Apparat der Länder, die Regierungen, VEAB, HO, MAS, Landesfinanzdirektionen usw. wurden aufgelöst.

Das Gebiet der Deutschen Demokratischen Republik ist jetzt bekanntlich in 14 Bezirke eingeteilt. Die Einteilung geschah vornehmlich nach ökonomischen Gesichtspunkten. Von der Notwendigkeit dieser Maßnahme zeugt folgendes Beispiel: 
Im Bezirk Cottbus liegt das Kohlenrevier Senftenberg und die Großkokerei Lauchhammer. Das Kohlenrevier Senftenberg und die Großkokerei Lauchhammer sind eng miteinander verbunden. Viele tausend werktätige Menschen arbeiten in diesen wichtigen Betrieben an der Erfüllung und Übererfüllung des Planes. Viele Probleme sind damit verbunden. Denken wir z. B. an den Verkehr und Transport, die Versorgung, Wohnungsfragen, Sozial- und Gesundheitswesen, kulturelle Betreuung usw. Alle diese Aufgaben müssen unter Leitung des Staates gemeinsam mit den Werktätigen gelöst werden.

Das Kohlengebiet Senftenberg lag bisher im Land Brandenburg und ein Teil davon im Land Sachsen. Lauchhammer lag im Lande Sachsen-Anhalt, d. h. unter Leitung von drei schwerfälligen und komplizierten Landesregierungen. Wenn die zuständigen Ministerien in diesem Kohle- und Industriegebiet Probleme der Produktion oder Versorgung zu lösen hatten, und für die letzten Endes in der Durchführung die Landesregierungen verantwortlich waren, so musste das betreffende Ministerium mit drei Landesregierungen verhandeln, also in Potsdam, in Dresden und in Halle. [...]

Nach diesen Gesichtspunkten wurden also die 14 Bezirke geschaffen, die nicht zu umfangreich sind und im Durchschnitt 12 bis 15 Kreise umfassen. Der größte Bezirk ist Magdeburg mit 21 Kreisen, der kleinste Bezirk Suhl mit sieben Kreisen.

Auch die Kreise waren zu groß. Sie umfassten Hunderte und mehr Gemeinden. So z. B. der Landkreis Jena-Stadtroda mit 118 Gemeinden. Das hinderte den Rat des Kreises, die Gemeinden konkret anzuleiten, und führte dazu, dass die Gesetze und Verordnungen der Regierung, die Beschlüsse der Landtage und Landesregierungen ebenso der Kreistage und Räte der Kreise in ihrer konsequenten Durchführung bis in die Gemeinden nur mangelhaft und ungenügend kontrolliert werden konnten. Dasselbe trifft zu für die Kreisleitungen der Partei.

Es wurden statt der früheren 121 Landkreise 194 Landkreise geschaffen. Jeder Kreis umfasst im Durchschnitt 50 Gemeinden. Dadurch wird ein klarer Aufbau des Staatsapparates und seine weitere Demokratisierung gesichert. Die leitende Rolle der zentralen Organe wird verstärkt und steigert die Verantwortlichkeit, Ordnung und Disziplin in der Arbeit der unteren Organe.

Vor allem wird die operative Anleitung und Kontrolle der Durchführung von Beschlüssen und Anweisungen übergeordneter Organe erleichtert. Selbstverständlich sind damit die Länder als solche nicht liquidiert, sondern wir sprechen z. B. von dem Bezirk Suhl im Lande Thüringen. [...]

Nach der neuen Struktur sind die obersten Organe der Staatsgewalt in den Bezirken und Kreisen die Bezirks- bzw. Kreistage. Zu den Aufgaben der Bezirks- und Kreistage gehört, den Schutz der staatlichen Ordnung in ihrem Bereich zu gewährleisten. Sie schützen die Rechte der Bürger und mobilisieren und unterstützen sie auf jede Weise in ihrem Kampf 
um die Festigung der demokratischen Errungenschaften. Sie sind in ihrem Bereich für die Lenkung und Leitung des wirtschaftlichen und sozial-kulturellen Aufbaues voll verantwortlich. Sie sind verantwortlich für die Anleitung ihrer vollziehenden und verfügenden Organe und nehmen die Berichte des Rates des Bezirkes bzw. Kreises über seine Arbeit entgegen und kontrollieren seine Tätigkeit. Die Bezirks- und Kreistage bestätigen den kulturellen und wirtschaftlichen Aufbauplan des Bezirkes bzw. Kreises; sie bestätigen den Haushalt, beraten Fragen von allgemeiner staatlicher, bezirklicher bzw. kreislicher Bedeutung und unterbreiten den übergeordneten Organen Vorschläge zu diesen Fragen.

Die Beschlüsse des Bezirks- bzw. Kreistages sind verbindlich für alle ihm untergeordneten und sich in seinem Bereich befindlichen Organe der Staatsgewalt.

Sie können von der Volkskammer aufgehoben werden, soweit sie ungesetzlich sind. Die Regierung der Deutschen Demokratischen Republik kann die Durchführung der Beschlüsse des Bezirkstages einstweilen aussetzen. Die Beschlüsse des Kreistages können vom Bezirkstag und von der Volkskammer der Deutschen Demokratischen Republik aufgehoben werden. Der Rat des Bezirkes und der Ministerrat können die Durchführung der Beschlüsse des Kreistages einstweilen aussetzen. Der Bezirks- bzw. Kreistag fasst Beschlüsse und erlässt Entscheidungen im Rahmen der Rechte, die durch die Verfassung, durch Gesetze und Verordnungen der Deutschen Demokratischen Republik den örtlichen Organen übertragen worden sind.

Diese straffe Gliederung des Staatsaufbaues und die genaue Abgrenzung der Verantwortlichkeit wird jeder Genosse begreifen, wenn er einmal die Gesetze der vergangenen Landtage überprüft. Er wird feststellen, dass die verschiedensten Probleme in jedem Land anders behandelt wurden und die Einheitlichkeit der Staatsführung nicht gegeben war. [...]

Der Vorsitzende des Rates des Bezirkes bzw. Kreises beruft die Sitzungen des Bezirksbzw. Kreistages ein. Zu Beginn einer jeden Sitzung wählt der Tag zu seiner Leitung einen Vorsitzenden und zwei Stellvertreter.

Das ist neu. Bisher gab es bekanntlich den Landtagspräsidenten und den Kreistagsvorsitzenden als ständige Vorsitzende dieser Volksvertretungen. Die direkte Verantwortung des Vorsitzenden des Rates des Bezirkes bzw. Kreises für die Vorbereitung und Einberufung der Sitzungen ist deshalb möglich, weil der Vorsitzende des Rates, die Stellvertreter und die weiteren Mitglieder auch Mitglieder des Tages sein müssen, was bisher nicht immer der Fall und nicht gesetzlich verankert war. Damit sind die Überreste der Trennung von Legislative und Exekutive beseitigt worden. Das Exekutivorgan ist ein Teil der Legislative. $[\ldots]$

Die Erfahrungen, die wir bis jetzt bei der Durchführung der weiteren Demokratisierung gemacht haben, zeigen, dass die Entwicklung und Aufgabenstellung für die ständigen Kommissionen noch die größten Schwächen aufweist. Die Hauptursache für diese 
Schwächen sind die Unklarheiten über die Aufgaben der ständigen Kommissionen, ihre Rechte und Pflichten. Bisher gab es Ausschüsse bei den Landtagen, bei den Kreistagen und Gemeindevertretungen. Diese setzten sich aus Abgeordneten und Bürgern zusammen, die von den Parteien oder den Massenorganisationen benannt wurden. Diese Ausschüsse behandelten meist Einzelfragen, wie Anträge in sozialen Fragen, Gewerbezulassungen oder Konzessionsentzüge, Grundstücksfragen usw. Bei Untersuchungen durch Brigaden des ZK stellte sich heraus, dass diese Ausschüsse sehr unregelmäßig oder überhaupt nicht arbeiteten. Es ist bekannt, dass die Ausschüsse des Kreistages Frankfurt (Oder) bis auf drei überhaupt keine Sitzungen durchgeführt haben. Gearbeitet hat nur der Verkehrsausschuss regelmäßig. Allerdings war die einzige Tätigkeit die monatliche Verteilung von Autoreifen und Benzinmarken.

Die ständigen Kommissionen sind Organe des Bezirks- bzw. Kreistages. Ihnen obliegt es, die Bezirks- und Kreistage bei der Durchführung ihrer Aufgaben zu unterstützen und breite Kreise der Werktätigen in die Leitung des Staates einzubeziehen. [...]

Die erste wichtigste Aufgabe der ständigen Kommissionen ist es, ein breites Aktiv politisch bewusster und erfahrener Bürger um sich zu scharen. Zu diesen Aktivs werden die Besten berufen: Nationalpreisträger, Helden der Arbeit, Aktivisten, Meisterbauern, Vorsitzende von Produktionsgenossenschaften, Spezialisten und Facharbeiter auf allen Gebieten usw.

Die ständigen Kommissionen haben folgende Rechte:

a) Die Tätigkeit der entsprechenden Abteilungen des Rates sowie andere Einrichtungen ihres Aufgabenkreises zu studieren;

b) aus diesen Abteilungen und Einrichtungen die erforderlichen Dokumente einzusehen;

c) Mitteilungen der Abteilungsleiter des Rates des Bezirkes bzw. Kreises und der Verantwortlichen der übrigen staatlichen Einrichtungen entgegenzunehmen;

d) den Bezirkstagen bzw. Kreistagen Vorschläge über die Verbesserung der Arbeit ihrer Abteilungen und Einrichtungen zu unterbreiten und über diese Fragen in den Sitzungen der Bezirks- bzw. Kreistage und der Räte der Bezirke bzw. Kreise Stellung zu nehmen;

e) den Bezirks- bzw. Kreistagen und den Räten der Bezirke bzw. Kreise konkrete Vorschläge über die Verbesserung der Arbeit auf den ihnen anvertrauten Aufgabengebieten zu unterbreiten;

f) die ständigen Kommissionen haben das Recht, auf den Sitzungen der Räte der Bezirke bzw. Kreise und den Bezirks- bzw. Kreistagen mit Referaten oder Korreferaten zu der Tagesordnung aufzutreten, die die Tätigkeitsgebiete ihrer Kommissionen betreffen;

g) bei dem Studium der Arbeit der Abteilungen oder Einrichtungen ihres Fachgebietes haben die ständigen Kommissionen nicht das Recht, in die Tätigkeit dieser Stellen einzugreifen, deren Weisungen aufzuheben oder abzuändern, ihnen Auflagen zu erteilen usw. Die ständigen Kommissionen arbeiten Vorschläge zur Beseitigung festge- 
stellter Mängel und zur Verbesserung der Arbeit aus und leiten diese je nach Wichtigkeit und Dringlichkeit dem Rat des Bezirkes bzw. Kreise oder dem Bezirks- bzw. Kreistag zur Beschlussfassung zu.

Sie treten mindestens einmal im Monat zusammen. Es kommt in der Arbeit der ständigen Kommissionen darauf an, dass sie das Studium der Tätigkeit der staatlichen Organe gründlich vornehmen, das heißt, dass sie die Ursachen, die Methoden, die zu den Erfolgen in der Arbeit führen, feststellen und für ihre Verallgemeinerung Sorge tragen. Ebenso dürfen die ständigen Kommissionen nicht nur bestehende Mängel feststellen, sondern es kommt darauf an, dass sie die Ursachen, die zu diesen Mängeln führten, ergründen, um dem Rat des Bezirkes bzw. Kreises oder dem Bezirks- oder Kreistag Vorschläge zu unterbreiten, auf welchem Wege diese Mängel beseitigt werden können.

Es ist klar ersichtlich, dass die Tätigkeit der ständigen Kommissionen und ihrer Aktive viel umfassender, viel verantwortlicher ist als die der bisher bestehenden Kommissionen und Ausschüsse. Bereits die ersten Anfänge ihrer Arbeit zeigen, wie aufgeschlossen und wie bereitwillig die Werktätigen in den Aktivs mitwirken und welche großen verantwortlichen Aufgaben sie gelöst haben bzw. noch lösen wollen. [...]

Im Bezirk Potsdam hat die Kommission für Landwirtschaft und ländliches Bauwesen, die von Ernst Lindner, dem Vorsitzenden der Produktionsgenossenschaft Neuheim, geleitet wird, bereits die Überprüfung des Kreises Nauen, der als schlechtester Kreis in der Erfassung und im Aufkauf landwirtschaftlicher Produkte galt, abgeschlossen. Tagelang diskutierte die Kommission und das Aktiv mit den werktätigen Bauern, die ihre Unzufriedenheit darüber zum Ausdruck brachten, dass sich bisher niemand um die offensichtliche Sabotage der Großbauern bei der Ablieferung gekümmert habe. Die werktätigen Bauern gaben selbst Hinweise, wie man die Großbauern zur besseren Erfüllung ihrer Ablieferungspflichten veranlassen müsse. In einer öffentlichen Versammlung mussten die Großbauern vor der ganzen Bevölkerung Rechenschaft über ihr Verhalten ablegen. [...]

Es erwächst besonders den Bezirks- und Kreisleitungen der Partei die Aufgabe, durch ständige Hilfe und Anleitung die Tätigkeit der ständigen Kommissionen und ihrer Aktivs rascher zur Entfaltung zu bringen, um die staatlichen Organe auf ein höheres organisatorisches und politisches Niveau zu heben und sie dadurch zu stärken und zu festigen.

Dabei gilt es, die Erfahrungen aus der Sowjetunion, welche von der Studienkommission gesammelt wurden, zu verallgemeinern, die Weisung des Genossen Stalin bei uns zu verwirklichen. [...]

Der Rat gewährleistet den Schutz der staatlichen Ordnung und trägt dazu bei, die Verteidigungsfähigkeit des Landes zu stärken, die Einhaltung der Gesetze und den Schutz der Rechte der Bürger gewährleisten. Der Rat des Bezirkes leitet den kulturellen und wirt- 
schaftlichen Aufbau in seinem Bereich. Zu seinen Aufgaben gehört die Bestätigung seines Haushalts, die Leitung der Tätigkeit der ihm unterstellten staatlichen Organe.

Sehr große Aufmerksamkeit müssen die Räte der Bezirke und Kreise der richtigen Bearbeitung und Erledigung der Beschwerden und Vorschläge der Bevölkerung widmen. Darüber hinaus sind sie dafür verantwortlich, dass die Bevölkerung die Möglichkeit besitzt, die Mitglieder des Rates in regelmäßigen Abständen sprechen zu können, um ihre Kritik, ihre Sorgen, ihre Vorschläge den Verantwortlichen unmittelbar vortragen zu können. Das ist eine der wichtigsten Aufgaben, die zwar bisher auch schon bestand, aber sehr unterschiedlich und zum Teil sehr nachlässig durchgeführt wurde.

Wir erinnern uns an die Feststellungen der vom Sekretariat des ZK eingesetzten Brigade im Landkreis Seelow, wo die Beschwerden und Vorschläge der Bevölkerung derartig missachtet wurden, dass der damalige Landrat Götz sofort seiner Funktion enthoben wurde. Tiefgreifende Veränderungen mussten im Apparat des Rates des Kreises vorgenommen werden. Die an Sabotage grenzende Missachtung der berechtigten Beschwerden der Bevölkerung und die vom Sekretariat beschlossenen Maßnahmen können die Genossen im „Neuen Deutschland“ vom 6. Juli 1952 nachlesen. ${ }^{336}[\ldots]$

Zur Durchführung der großen Aufgaben stehen den Räten der Bezirke 20 Abteilungen als vollziehende und verfügende Organe zur Verfügung. Neu ist das Prinzip der doppelten Unterstellung. Nach dem Prinzip der doppelten Unterstellung sind die Fachabteilungen einerseits dem Rat des Bezirkes bzw. Kreises unterstellt und andererseits den entsprechenden Fachministerien und Staatssekretariaten der Regierung der Deutschen Demokratischen Republik bzw. die des Kreises den entsprechenden Fachabteilungen des Rates des Bezirkes. So zum Beispiel ist die Finanzabteilung eines Bezirkes gleichzeitig dem Rat des Bezirkes und dem Finanzministerium der Deutschen Demokratischen Republik unterstellt. Genauso ist im Kreis die Kreisfinanzabteilung dem Rat des Kreises und der Finanzabteilung des Rates des Bezirkes unterstellt.

Die außerordentlich große Bedeutung des Prinzips der doppelten Unterstellung besteht darin, dass es die Zentralisation der staatlichen Leitung mit einer maximalen Entwicklung der Initiative der örtlichen Organe und der schöpferischen Tätigkeit der werktätigen Massen verbindet.

Die doppelte Unterstellung besteht nicht darin, dass die Ministerien und Staatssekretariate mit eigenem Geschäftsbereich die Räte der Bezirke mit unsinnigen Aufträgen belasten und durch Rundschreiben die Arbeit behindern. [...]

336 Vgl. „Neues Deutschland“ vom 6. Juli 1952, S. 4: „Für Landrat Götz war es ,unmöglich“. Bericht der Kommission des Sekretariats des ZK der SED zur Untersuchung von Missständen im Kreis Seelow". 
Noch einige Worte zu den Aufgaben des Sekretärs, dessen Funktion bei uns neu ist.

Der Sekretär muss ein politisch und fachlich erfahrener und qualifizierter Funktionär sein, um die vielgestaltigen Aufgaben zu meistern.

Ihm obliegt die Koordinierung der gesamten Arbeit, ohne dabei die Verantwortlichkeit des Vorsitzenden, seiner Stellvertreter oder Abteilungsleiter einzuschränken. Die Ausarbeitung des Arbeitsplanes des Rates liegt ebenfalls in seinen Händen sowie die Vorbereitung der Sitzungen des Rates und der Beschlussvorlagen. Das heißt, der Sekretär ist dafür verantwortlich, Überschneidungen im Apparat zu vermeiden, die Arbeit zwischen den einzelnen Abteilungen abzustimmen und das organisatorische Niveau der Arbeit des Rates und seiner Abteilungen ständig zu heben.

Von ihm wird die Einhaltung der Gesetzlichkeit, die Durchführung der Beschlüsse kontrolliert.

Zu seinem Arbeitsbereich gehört die Unterstützung der Abgeordneten in ihrer Tätigkeit in den ständigen Kommissionen, Sprechstunden und die Qualifizierung der Abgeordneten durch regelmäßige Schulungen. Es darf nicht so sein wie beim Rat des Bezirkes Halle, wo der Vorsitzende, Genosse Bruschke, ${ }^{337}$ den Sekretär zu seinem persönlichen Referenten machen will.

Zur Durchführung all dieser Aufgaben stehen dem Sekretär einige Abteilungen zur Verfügung: Die Abteilung Information, die Rechtsstelle, Abteilung Staatliches Eigentum, Abteilung Allgemeine Verwaltung und Abteilung Vermessung. [...]

Hierbei hat die Org.-Instrukteur-Abteilung beim Rat des Bezirkes und Kreises eine große Bedeutung. Um die Durchführung der Gesetze und Verordnungen zu studieren, die Methoden und Formen der Arbeit, führt die Org.-Instrukteur-Abteilung Komplexund Zweigkontrollen durch. Eine Komplexuntersuchung umfasst alle Einrichtungen eines Kreises oder einer Gemeinde, wobei die Zweigkontrolle sich nur auf ein bestimmtes Gebiet erstreckt, so z. B. in einem Kreis nur die Einrichtungen des Gesundheitswesens oder der Volksbildung untersucht. Die Org.-Instrukteur-Abteilung zieht zu solchen Untersuchungen die qualifiziertesten Mitarbeiter der entsprechenden Abteilungen mit hinzu und in vielen Fällen werden sich die ständigen Kommissionen und ihre Aktivs daran beteiligen.

337 Werner Bruschke (1898-1995) war von August 1952 bis November 1954 Vorsitzender des Rates des Bezirkes Halle; vgl. Niemann/Herbst, SED-Kader, S. 135. 
Wir haben schon viele Brigadeeinsätze durchgeführt, unzählige Instrukteurseinsätze sind bereits erfolgt, doch meist stellten diese einen bestimmten Zustand fest, und in vielen Fällen wurde auch dieser Zustand zum positiven verkehrt, aber nicht mehr.

Die Erfahrungen aus der Sowjetunion lehren uns, dass eine Komplex- oder Zweiguntersuchung immer die Ursachen der bestehenden Zustände ergründet, um daraus Schlussfolgerungen für die gesamte Arbeit zu ziehen. [...] Bei den Räten der Bezirke und Kreise wird es Aufgabe der Org.-Instrukteur-Abteilungen sein, geduldig und unerbittlich die neuen und besseren Arbeitsmethoden zu verallgemeinern und den Kampf gegen das Alte in der Arbeit ständig zu führen.

Die Org.-Instrukteur-Abteilung hilft den Abgeordnete, den ständigen Kommissionen und ihren Aktivs bei der Durchführung ihrer verantwortlichen Tätigkeit. Sie hilft ihnen dadurch, dass sie ihnen bestimmte Materialien, die in der Arbeit benötigt werden, zur Verfügung stellt. Sie registriert die Wähleraufträge, die die Abgeordneten in ihren Sprechstunden erhalten, und überwacht die Einhaltung der Termine. Sie lenkt und leitet die Entfaltung der Organisations-Massenarbeit. Allein aus dieser kurzen Darstellung der Aufgaben der Org.-Instrukteur-Abteilungen wird jedem Genossen klar, dass die Mitarbeiter dieser so wichtigen Abteilung politische und fachlich qualifizierte Funktionäre sein müssen, um den Anforderungen, die an sie gestellt sind, gerecht zu werden. Aufgabe der Parteileitungen wird es sein, die Arbeit der Org.-Instrukteur-Abteilungen genauestens zu verfolgen und aktive Unterstützung zu geben. [...]

Die Zusammenarbeit des Blocks der antifaschistisch-demokratischen Parteien bewährte sich erneut in gemeinsamer Arbeit aller Parteien und Massenorganisationen bei der Durchführung des Gesetzes über die weitere Demokratisierung des Aufbaus und der Arbeitsweise der staatlichen Organe in den Ländern der Deutschen Demokratischen Republik.

Die Organe unserer demokratischen Staatsgewalt entfalten ihre Tätigkeit auf dieser Grundlage der Zusammenarbeit aller demokratischen Parteien und Massenorganisationen. Sie sind zu einer aktiven Tätigkeit berufen, um den Willen der werktätigen Bevölkerung zu verwirklichen, der in den Gesetzen und Verordnungen unseres Staates seinen Ausdruck findet.

Fortschrittliche Vertreter der DBD, der NDPD, der CDU, der LDP sowie der Massenorganisationen haben in den Organen der Staatsgewalt in den Bezirken und Kreisen verantwortliche Funktionen übernommen und arbeiten im Staatsapparat mit.

Viele Mitglieder und Funktionäre dieser Parteien und Massenorganisationen sind zusammen mit vielen Parteilosen in den Bezirkstagen, Kreistagen und Gemeindevertretungen als gewählte Vertreter des Volkes tätig. Jeder Abgeordnete, soweit er nicht Mitglied des Rates ist, arbeitet in einer der ständigen Kommissionen. [...] 
Es besteht die Möglichkeit, dass einige Genossen die Ausführlichkeit, mit der ich das Neue in der weiteren Demokratisierung behandelte, übertrieben finden. Es ist aber unverkennbar, dass die Schwächen im Staatsapparat im Wesentlichen darauf zurückzuführen sind, dass die Organe der Partei, insbesondere die Kreisleitungen sich in der Vergangenheit wenig mit diesen Problemen beschäftigt haben. [...]

Es ist eine Tatsache, dass bei den Parteiaktivtagungen in den Kreisen, wo die Beschlüsse des 8. Plenums des ZK behandelt wurden, und wo sich Genosse Walter Ulbricht sehr ausführlich mit der führenden Rolle [der Partei] im Staatsapparat beschäftigte, ${ }^{338}$ in sehr vielen Parteiaktivtagungen dieser Teil der Rede und Beschlüsse deshalb ungenügend behandelt wurde, weil die Genossen sich mit diesen Problemen nicht genügend beschäftigten.

Auf der Parteiaktivtagung in Chemnitz war ich selbst und musste das Gleiche feststellen. In den meisten Kreisen gehörte der damalige Landrat zum Sekretariat der Kreisleitung der Partei. Das war der sogenannte Experte für die Probleme des Staatsapparates für das Kreissekretariat der Partei. Der 1. Kreissekretär glaubte, dass alle diese Probleme dem Landrat überlassen werden könnten.

Als dann, wie z. B. in Frankfurt (Oder), in einer Sekretariatssitzung der Partei die vom Sekretariat des ZK nach diesem Kreis [Seelow] entsandte Brigade den wirklichen, unhaltbaren Zustand der Arbeit der staatlichen Organe erklärte und die entsprechenden Beschlüsse fassen ließ, erkannte der 1. Sekretär zum ersten Mal die wirkliche Lage in diesem Kreis. Das Sekretariat erkannte ferner, dass der Genosse Landrat nur deshalb so schludrig und gewissenlos arbeiten konnte, weil sich das Sekretariat nicht um die Probleme kümmerte und dadurch nicht anleiten, führen und kontrollieren konnte. [...]

Obwohl in einer großen Zahl von Delegiertenkonferenzen in den Kreisen und Bezirken, die vor kurzem abgeschlossen wurden, die Aufgaben der Partei in der Führung und Anleitung des Staatsapparates behandelt wurden, obwohl festzustellen ist, dass die Durchführung der weiteren Demokratisierung des Aufbaues und der Arbeitsweise der staatlichen Organe einer großen Anzahl von Funktionären der Partei im Kreis und der Gemeinde die Wichtigkeit dieser Aufgabe vor Augen führte und eine gute Arbeit der Parteileitungen bei der Durchführung dieser Aufgaben zu verzeichnen war, werden wir die noch vorhandenen Schwächen nur beseitigen, wenn die Organe der Partei sich intensiv mit den Problemen des Staatsapparates beschäftigen und die Parteiorganisationen in allen Organen der Staatsmacht besser als bisher anleiten. [...]

[BArch, DY 30/IV 2/215, Bl. 8-41]

338 Die 8. Tagung des ZK der SED vom 21. bis 23. Februar 1952 hatte u. a. die Zielstellung formuliert, den demokratischen Zentralismus ,innerhalb der bestehenden staatlichen Strukturen weiter auszudehnen“, ohne dabei bereits eine umfassende Neugestaltung der regionalen Verwaltung zu erörtern; Mielke, Auflösung, S. 66. 


\section{Dokument 51: Bericht der Abteilung Leitende Organe der Partei und der Massenor- ganisationen des Zentralkomitees der SED über die LDP, 26. Januar 1953}

Die Lage in der LDP ist gekennzeichnet durch eine zunehmende Verschärfung der Widersprüche in ihren Reihen bis hinauf zum Parteivorstand. Beschleunigt und verschärft wird dieser Zerfallsprozess durch die Verwirklichung der Beschlüsse der II. Parteikonferenz der SED, durch die Beschlüsse der Leipziger Konferenz der Parteibeauftragten der LDP hierzu, sowie durch die Entlarvung und den Ausschluss des ehemaligen Mitvorsitzenden Hamann und der Dresdener Gruppe. ${ }^{339}$

In der LDP treten drei Hauptgruppierungen in Erscheinung:

1.) Es gibt vereinzelte fortschrittliche Kräfte unter Funktionären und Mitgliedern (vorwiegend Angestellte des Staatsapparates), die dem planmäßigen Aufbau der Grundlagen des Sozialismus zustimmen. Diese Kräfte versuchen, wenn auch schwach, die Politik ihrer Partei auf die richtigen Fragen zu orientieren.

2.) Die zweite Gruppe verhält sich schwankend. Sie erfasst breite Kreise der Mitglieder und weicht offenen Stellungnahmen zu den Vorgängen in ihrer Partei aus. Große Teile dieser schwankenden Elemente sprechen bereits ihr Misstrauen zu den im Politischen Ausschuss gefassten Beschlüssen aus und fordern Untersuchung durch den Hauptausschuss.

Besonders gefährlich ist die Tatsache, dass diese Gruppe von den feindlichen Kräften stark beeinflusst und als Stütze für deren feindliche Diskussion benutzt wird.

Ein Beispiel hierfür sind die Vorkommnisse in Dresden.

3.) Die dritte Gruppe nimmt offen gegen die Maßnahmen der Regierung Stellung, diskriminierte unsere Partei und „kritisiert“ ihren eigenen Parteivorstand bis zum offenen Misstrauen. Ihre Einflussnahme auf die schwankenden Elemente wird von Dr. Loch, ${ }^{340}$ Täschner ${ }^{341}$ und deren Anhänger dadurch begünstigt, dass sich diese bei jeder Gelegenheit revolutionärer Phrasen bedienen, die nicht dazu beitragen, die bürgerlichen Menschen in ihrer Partei für die Politik der Regierung zu gewinnen.

Die reaktionären Kräfte gehen, wie das am Beispiel in Dresden klar sichtbar wurde, zur illegalen Gruppenbildung über und versuchen in zunehmenden Maße, stärkeren Einfluss in den verschiedenen Parteileitungen zu erhalten. Besonders stark tritt diese

339 Karl Hamann (1903-1973) war seit Februar 1949 Ko-Vorsitzender der LDP und wurde im Oktober 1949 Minister für Handel und Versorgung der DDR. Beide Funktionen verlor er im Dezember 1952, als er wegen „Sabotage“ verhaftet wurde; vgl. Müller-Enbergs, Wer war wer, S. 308.

340 Hans Loch (1898-1960) war seit Dezember 1952 Vorsitzender der LDP und bereits seit Oktober 1949 Minister der Finanzen; vgl. Müller-Enbergs, Wer war wer, S. 531.

341 Herbert Täschner (1916-1984) war von 1950 bis 1954 Generalsekretär der LDP; vgl. Müller-Enbergs, Wer war wer, S. 842. 
Gruppe in den Bezirken Dresden, Chemnitz, Leipzig, Halle und Magdeburg auf. In diesen Bezirken ist eine besondere Konzentration von Großbauern, Unternehmern usw. in den Reihen der LDP zu verzeichnen.

Die Interessenlosigkeit der Mitglieder zeigt sich unter anderem darin, dass im Monat November 1952 nur 3,4 \% der Mitgliedschaft der LDP an den monatlichen Parteiversammlungen teilnahmen. Die Missbilligung breiter Kreise der Mitglieder zu den „Leipziger Beschlüssen“ kann man auch an den Parteiabgängen feststellen.

Während im Zeitraum von zwölf Monaten d. h. vom 31.7.1951 bis 31.7.1952 12.217= 6,2 \% Mitglieder ausschieden, also der Mitgliederbestand von 156.764 auf 144.547 absank, betrugen die Abgänge im Zeitraum von fünf Monaten nach der II. Parteikonferenz d. h. vom 31.7. - 20.12.52 8.947= ebenfalls 6,2\%, ${ }^{342}$ wodurch der Mitgliederstand auf 135.601 absank.

Die starken Abgänge führten bereits zu Auflösung einer Reihe von LDP-Ortsgruppen.

Die soziale Zusammensetzung der LDP ergab am 20.12.1952 folgendes Bild:

\begin{tabular}{|l|r|l|}
\hline Arbeiter & 14.469 & $=10,68 \%$ \\
\hline z. Zt. Arbeiter & 1.983 & $=1,40 \%$ \\
\hline Behörden Angestellte & 25.435 & $=18,77 \%$ \\
\hline sonstige Angestellte & 22.289 & $=16,45 \%$ \\
\hline Bauern bis 20 ha & 14.458 & $=10,67 \%$ \\
\hline Bauern über 20 ha & 2.328 & $=1,73 \%$ \\
\hline Unternehmer bis 50 Beschäftigte & 2.560 & $=1,91 \%$ \\
\hline Unternehmer über 50 Beschäftigte & 239 & $=0,19 \%$ \\
\hline Handwerker bis 10 Beschäftigte & 10.126 & $=7,40 \%$ \\
\hline Selbständige Kaufleute & 7.708 & $=5,70 \%$ \\
\hline Freie Berufe & 5.564 & $=4,11 \%$ \\
\hline Hausfrauen & 14.923 & $=11,01 \%$ \\
\hline Sonstige (Schüler, Studenten, Rentner) & 13.519 & $=9,98 \%$ \\
\hline
\end{tabular}

Betrachtet man die Mitarbeit der Mitglieder der LDP auf den verschiedensten Gebieten, so ergibt sich folgendes Bild:

Die Arbeit der Staatsfunktionäre und Abgeordneten ist mit wenigen Ausnahmen sehr formal.

Die Arbeit in den Blockausschüssen ist ebenfalls formal. Ihre Vertreter sind meist bei den Sitzungen anwesend und stimmen den Beschlüssen zu. Sie unternehmen jedoch nichts, um ihre Mitglieder für deren Durchführung zu mobilisieren. Wiederholt wurden von LDP-Mitgliedern Blockbeschlüsse verletzt.

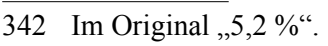


Die Mitarbeit in den Ausschüssen der Nationalen Front und den Friedenskomitees ist von allen Blockparteien die schwächste. Meist arbeiten nur solche Funktionäre mit, die auf Grund ihrer beruflichen oder politischen Stellung (Vorsitzende, Bürgermeister usw.) sich dieser Arbeit nicht entziehen können. nach den Angaben der LDP arbeiten $6.442=4,7 \%$ ihrer Mitglieder in den Ausschüssen der Nationalen Front und nur 2.088 $=2 \%$ in den Friedenskomitees mit.

Aufgliederung der Betriebsgruppen der LDP nach dem Stand vom 20.11.1952:

\begin{tabular}{|c|c|c|}
\hline VEB & 168 & Mitglieder 2.528 \\
\hline SAG & 13 & Mitglieder 614 \\
\hline Privatbetriebe & 49 & Mitglieder $\quad 445$ \\
\hline Verwaltungen & 678 & Mitglieder 9.336 \\
\hline Schulen & 438 & Mitglieder 4.758 \\
\hline Sonstige & 91 & Mitglieder 1.042 \\
\hline Insgesamt: & 1.437 & Mitglieder 18.723 \\
\hline
\end{tabular}

Zur Frage der Betriebsgruppenarbeit ist festzustellen, dass die Leitung der LDP fast keine Anstrengungen macht, neue Betriebsgruppen zu gründen.

\section{Schlussfolgerungen:}

1) Die LDP muss ihre Arbeit stärker als bisher auf die Fragen des Kampfes um den Frieden und die Einheit Deutschlands orientieren.

2) Die LDP soll besser als bisher auf ihre Mitglieder einwirken, damit sie die Gesetze unseres Staates einhalten.

3) Der Einfluss reaktionärer Elemente ist bei der Neuwahl ihrer Vorstände, die zur Vorbereitung ihres Parteitages (April 1953) stattfinden, weitgehendst unwirksam zu machen. Dabei muss darauf geachtet werden, dass keine Verwischung des Charakters der LDP als bürgerliche Partei erfolgt.

4) Der Sektor „Befreundete Organisationen“ hat eine stärkere Kontrolle der Politik des Vorsitzenden der LDP, Dr. Loch, und des Generalsekretärs, Täschner, durchzuführen.

[BArch, NY 4090/504 (Nachlass Otto Grotewohl), Bl. 63-66] 
Dokument 52: „Rahmen-Qualifizierungsmerkmale für die Mitarbeiter der Plankommissionen der Räte der Bezirke“ des Ministeriums des Innern der DDR, 1. Februar 1953

Die Plankommissionen der Räte der Bezirke leiten auf der Grundlage der Direktiven der Staatlichen Plankommission und der Beschlüssen der Räte der Bezirke die Ausarbeitung der Perspektiv-, Jahres- und Quartalspläne für die Entwicklung des wirtschaftlichen und kulturellen Lebens in den Bezirken und üben die Kontrolle über die Durchführung dieser Pläne aus.

Die Plankommissionen der Räte der Bezirke erfüllen diese Aufgabe durch

1) die Ausarbeitung eigener Planentwürfe aufgrund exakter Untersuchungen der einzelnen Zweige des wirtschaftlichen und kulturellen Lebens und ihre Vorlage beim Rat des Bezirkes.

2) die Ausarbeitung klarer Direktiven für die Ausarbeitung und Durchführung der Perspektiv-, Jahres- und Quartalspläne durch die Fachabteilungen der Räte der Bezirke und die Plankommissionen der Räte der Kreise.

3) die Vorlage der von den Fachabteilungen der Räte der Bezirke und von den Plankommissionen der Räte der Kreise ausgearbeiteten Perspektiv-, Jahres- und Quartalspläne mit der volkswirtschaftlichen Beurteilung durch die Plankommission des Rates des Bezirkes beim Rat des Bezirkes zur Entscheidung.

4) die Bearbeitung von Einzelproblemen der Entwicklung des wirtschaftlichen und kulturellen Lebens im Bezirk aufgrund von Aufträgen der Staatlichen Plankommission, von Beschlüssen des Rates des Bezirkes und aus eigener Initiative.

5) die systematische Kontrolle aufgrund schwerpunktmäßiger Kontrollprogramme, der gründlichen Auswertung des statistischen Materials und periodischer Analyse sowie der ständigen Beachtung der sich aus der Entwicklung des gesellschaftlichen Lebens in der DDR ergebenden Erfordernisse.

Die Erfüllung dieser Aufgaben verlangt von den Vorsitzenden der Plankommissionen der Räte der Bezirke und ihren Mitarbeitern die Erkenntnis des Charakters unseres Staates als Arbeiter- und Bauernmacht und der sich daraus ergebenden Konsequenzen, Kenntnis der Verfassung der DDR und der demokratischen Gesetze, die gründliche Kenntnis der Wirksamkeit der ökonomischen Gesetze und der Methoden ihrer Ausnutzung im Interesse der Arbeiter- und Bauernmacht und einen umfassenden Überblick über die wirtschaftliche und soziale Struktur des Bezirkes. 
Aus der Aufgabenstellung der Plankommissionen der Räte der Bezirke und den allgemeinen Voraussetzungen für die Erfüllung dieser Aufgaben ergibt sich folgender Rahmen für die Qualifikationsmerkmale der einzelnen Mitarbeiter der Plankommissionen:

\section{Vorsitzender der Plankommission.}

Qualifikationsmerkmale: Solide Kenntnis der politischen Ökonomie und der Wirtschaftspolitik, Überblick über die gesamte Struktur der Volkswirtschaft der DDR sowie die Kenntnis der Grundlegenden wirtschaftspolitischen Aufgaben der einzelnen Wirtschaftszweige.

Praktische Erfahrungen zumindest in einem bedeutenden Zweig der Wirtschaft.

Gründliches Wissen über die methodischen Fragen der Planung und der Statistik.

Genaue Kenntnis des wirtschaftlichen und kulturellen Lebens des Bezirkes und seiner Entwicklungsmöglichkeiten.

Gute organisatorische Fähigkeiten und Fähigkeiten zur Kaderentwicklung.

Strenge Parteilichkeit bei der Durchführung aller Aufgaben. Rücksichtslosigkeit gegen jeden Opportunismus und ständige Kritik der eignen Arbeit.

Qualifizierungsmöglichkeiten: Wirtschaftswissenschaftlichen Vollstudium bzw. Fernstudium an der Hochschule für Planökonomie, Bezirksparteischule.

\section{Mitarbeiter der Plankoordinierung:}

Qualifikationsmerkmale: Kenntnis der Politökonomie, der gesamten Planungsmethodik und der Statistik sowie der Struktur des Bezirkes.

Gute organisatorische Fähigkeiten.

Einblick in die volkswirtschaftliche Bilanzierung wie auch in die betriebliche Planung.

Praktische Erfahrung.

Qualifizierungsmöglichkeiten: Wirtschaftswissenschaftliches Vollstudium bzw. Fernstudium an der Hochschule für Planökonomie, Kreisparteischule.

\section{Mitarbeiter des Plangebietes Finanzen und Haushalt.}

Qualifikationsmerkmale: Gründliche Kenntnisse auf dem Gebiet der Finanzwirtschaft der volkseigenen Betriebe und des Staatshaushaltes.

Praktische Erfahrung im Rechnungswesen des Betriebes.

Qualifizierungsmöglichkeiten:

Fernstudium an der Hochschule für Planökonomie oder für Finanzwirtschaft.

\section{Mitarbeiter des Plangebietes Arbeitskräfte, Produktivität, Löhne, Berufsausbil- dung und Arbeitsschutz.}

Qualifizierungsmerkmale: Gründliche Kenntnis der Betriebswirtschaft und ihrer Verschiedenheiten in den einzelnen Wirtschaftszweigen.

Längere praktische Erfahrung in der Produktion.

Qualifizierungsmöglichkeiten: Fernstudium an der Hochschule für Planökonomie. Gewerkschaftsschule. 


\section{Mitarbeiter des Plangebietes Investitionen, Generalreparaturen, Lizenzen und Werterhaltung.}

Qualifizierungsmerkmale: Gründliche Kenntnis der Probleme des volkswirtschaftlichen Reproduktionsprozesses, der Struktur der Volkswirtschaft und der Aufgaben der einzelnen Zweige.

Guter Überblick über die Kapazitätslage und über die Ausrüstungs- und Materialfragen. Kenntnis der Probleme des Staatshaushaltes.

Praktische Erfahrung im Betrieb.

Qualifizierungsmöglichkeiten: Fernstudium an der Hochschule für Planökonomie.

\section{Mitarbeiter in der Regionalen Planung}

Qualifizierungsmerkmale: Überblick über die Struktur der gesamten Volkswirtschaft, Kenntnis der Verflechtung des Bezirkes mit der Volkswirtschaft, der Struktur des Bezirkes, der Wirtschaftsgeografie und der Standortfragen.

Kenntnisse über die Entwicklungsmöglichkeiten der einzelnen Zweige und Kreise.

Praktische Erfahrungen.

Qualifizierungsmöglichkeiten: Fernstudium an der Hochschule für Planökonomie.

\section{Mitarbeiter des Plangebietes Örtliche Industrie, Genossenschafts- und Hand- werksbetriebe.}

Qualifizierungsmerkmale: Spezielles Wissen über die Industrieplanung; möglichst ingenieurtechnische Kenntnisse.

Gute Kenntnisse der Kapazitätsfragen und des Bedarfs von industriellen Erzeugnissen.

Überblick über die Struktur des Bezirkes und seine Verflechtung mit der Volkswirtschaft. Erfahrungen aus der Tätigkeit im Industriebetrieb.

Qualifizierungsmöglichkeiten: Fernstudium an der Technischen Hochschule.

\section{Mitarbeiter des Plangebietes Kommunalwirtschaft.}

Qualifizierungsmerkmale: Spezielle Kenntnisse der Haushalts- und Finanztechnik und der Aufgaben der Dienstleistungs- und Versorgungsbetriebe sowie der kommunalen Einrichtungen.

Qualifizierungsmöglichkeiten: Praktische Tätigkeit in der Kommunalwirtschaft einer größeren Stadt.

\section{Mitarbeiter des Plangebietes Landwirtschaft.}

Qualifizierungsmerkmale: Spezielle Kenntnisse der landwirtschaftlichen Produktion und vollständige Klarheit über die Bündnispolitik zwischen der Arbeiterklasse und den werktätigen Bauern.

Praktische Erfahrung in MTS oder VEG.

Qualifizierungsmöglichkeiten: Landwirtschaftsschule. Kreisparteischule. 


\section{Mitarbeiter des Plangebietes Warenumsatz und Warenbereitstellung.}

Qualifizierungsmerkmale: Kenntnis der Aufgaben und der Struktur des Handels, der Kaufkraftproblematik und der Bedarfsfragen.

Praktische Handelstätigkeit (staatlicher oder genossenschaftlicher Handel)

Qualifizierungsmöglichkeiten: Fernstudium an der Hochschule für Planökonomie oder Hochschule für Handel.

\section{Mitarbeiter des Plangebietes örtlicher Verkehr.}

Qualifizierungsmerkmale: Spezielle Kenntnis der verschiedenen Transportprobleme und des Zusammenwirkens der einzelnen Transportsysteme sowie ihre Rolle in der Gesamtwirtschaft.

Qualifizierungsmöglichkeiten: Praktische Tätigkeit im Verkehrswesen.

12. Mitarbeiter des Plangebietes Kulturelle Entwicklung, Kunst, Jugend und Sport. Qualifizierungsmerkmale: Kenntnis der Rolle der kulturellen Fragen im gesellschaftlichen Leben und der Aufgaben auf dem Gebiet der kulturellen Entwicklung.

Qualifizierungsmöglichkeiten: praktische Tätigkeit als Kulturfunktionär.

\section{Mitarbeiter des Plangebiets Gesundheits- und Sozialwesen.}

Qualifizierungsmerkmale: Kenntnis der Rolle des Gesundheits- und Sozialwesens in der Volkswirtschaft und der auf diesem Gebiet zu lösenden Aufgaben.

Qualifizierungsmöglichkeiten: Praktische Tätigkeit auf dem Gebiet des Gesundheits- und Sozialwesens.

\section{Mitarbeiter des Plangebietes Forschung und Technik.}

Qualifizierungsmerkmale: Kenntnisse der Struktur und Entwicklungsaufgaben in der gesamten Volkswirtschaft, vor allem der Industrie.

Praktische Tätigkeit in der Industrie, Ingenieur-technische Kenntnisse.

Qualifizierungsmöglichkeiten: Fernstudium an der Technischen Hochschule.

\section{Mitarbeiter des Gebietes Materialplanung.}

Qualifizierungsmerkmale: Materials- und Ausrüstungskenntnisse, Kenntnisse der Materialbilanzierung; der Bedarfsermittlung und der Materialverbrauchsnormen.

Ingenieur-technische Kenntnisse.

Praktische Tätigkeit in der Industrie.

Qualifizierungsmöglichkeiten: Fernstudium an der Technischen Hochschule.

\section{Mitarbeiter des Gebietes Materialverteilung.}

Qualifizierungsmerkmale: Spezielle Material- und Ausrüstungskenntnisse.

Qualifizierungsmöglichkeiten: Praktische Tätigkeit in der Industrie. 


\section{Mitarbeiter des Gebietes Innere und örtliche Reserven.}

Qualifizierungsmerkmale: Kenntnis der Methoden zur Materialeinsparung und der Organisierung der Erfassung von Reserven.

Qualifizierungsmöglichkeiten: Praktische Tätigkeit in der Industrie.

\section{Mitarbeiter auf dem Gebiet des Innerdeutschen Handels.}

Qualifizierungsmerkmale: Spezialkenntnisse über die Funktion des Innerdeutschen Handels.

Qualifizierungsmöglichkeiten: Praktische Tätigkeit in der Produktion oder im Großhandel.

\section{Mitarbeiter auf dem Gebiet der Regierungsaufträge.}

Qualifizierungsmerkmale: Spezialkenntnisse der Verteilung von Material und Ausrüstungen nach volkswirtschaftlichen Gesichtspunkten.

Praktische Erfahrung in der Industrie bzw. im Großhandel.

Qualifizierungsmöglichkeiten: Kreisparteischule.

Die Vorsitzenden der Plankommissionen der Räte der Kreise müssen den Qualifikationsmerkmalen eines Mitarbeiters der Plankoordinierung der Plankommission des Rates des Bezirkes entsprechen.

Die Qualifikationsmerkmale für die Mitarbeiter der Plankommissionen der Räte der Kreise sind aus denen der entsprechenden Mitarbeiter der Plankommission des Rates des Bezirkes abzuleiten.

Die Staatliche Plankommission hat die Qualifizierung der Planungskader der örtlichen Staatsorgane auf breiter Grundlage eingeleitet. Dazu dient vor allem der Fernunterricht und das Fernstudium an der Hochschule für Planökonomie.

Die Staatliche Plankommission erwartet von allen Planungskadern der örtlichen Staatsorgane die Teilnahme am Fernunterricht, soweit sie noch nicht die notwendigen Voraussetzungen zur Aufnahme eines Fernstudiums besitzen.

[BArch, DO 1/26055, Bl. 51-57]

Dokument 53: Statistische Übersicht der Kaderabteilung des Rates des Bezirkes Frankfurt (Oder) über die Beschäftigtenstruktur der Bezirksverwaltung Frankfurt (Oder), 2. April 1953

Der Rat des Bezirkes Frankfurt hatte mit dem Stichtag 15.3.1953 eine Sollzahl von insgesamt 462 Planstellen. Davon sind besetzt 422 Planstellen $=91,3 \%$ 
Im Vergleich zum IV. Quartal 1952 haben sich:

\section{Planstellen}

erhöht um 8 auf 462
Zahl der besetzten Stellen

zurückgegangen um 2 auf 422

Die Besetzung ist um 1,8\% gefallen

\begin{tabular}{|l|r|l|r|}
\hline Genehmigte Planstellen & & Besetzte Planstellen \\
\hline $\begin{array}{l}\text { Vorsitzender, Sekretär und Stellvertreter } \\
\text { unverändert }\end{array}$ & 7 & $\begin{array}{l}\text { Vorsitzender, Sekretär und Stellvertreter } \\
\text { unverändert }\end{array}$ & 7 \\
\hline $\begin{array}{l}\text { Abteilungsleiter zurückgegangen um 2 } \\
\text { auf }\end{array}$ & 19 & $\begin{array}{l}\text { Abteilungsleiter zurückgegangen um 2 } \\
\text { auf }\end{array}$ & 17 \\
\hline $\begin{array}{l}\text { Oberreferenten und Referenten erhöht } \\
\text { um 5 auf }\end{array}$ & 185 & $\begin{array}{l}\text { Oberreferenten und Referenten unverän- } \\
\text { dert }\end{array}$ & 144 \\
\hline Sachbearbeiter erhöht um 5 auf & 100 & Sachbearbeiter erhöht um 7 auf & 107 \\
\hline $\begin{array}{l}\text { Übrige Angestellte erhöht um 2 auf } \\
\text { Uän }\end{array}$ & 185 & $\begin{array}{l}\text { Übrige Angestellte zurückgegangen um } \\
\text { 4 auf }\end{array}$ & 85 \\
\hline $\begin{array}{l}\text { Technische Angestellte zurückgegangen } \\
\text { um 2 auf }\end{array}$ & 66 & $\begin{array}{l}\text { Technische Angestellte zurückgegangen } \\
\text { um 3 auf }\end{array}$ & 62 \\
\hline & $\mathbf{4 6 2}$ & & $\mathbf{4 2 2}$ \\
\hline
\end{tabular}

Der Rückgang der Abteilungsleiter ist darauf zurückzuführen, dass die Abteilungen Informationen und Vertragsgericht nicht mehr zum Rat des Bezirkes Frankfurt gehören.

Der Rückgang der besetzten Planstellen Abteilungsleiter wird damit begründet:

Abteilung Erfassung und Aufkauf, Kollege Pansegrau wurde fristlos entlassen, wegen falsche politische Auslegung der Gesetze der DDR und Desorganisation der Abteilung. Des Weiteren Kommunale Wirtschaft - Abteilungsleiter Kollege Lange wurde zur Stalinstadt als Stellvertreter des Vorsitzenden versetzt.

In der Spalte Sachbearbeiter sind Mitarbeiter aufgeführt, welche zu Referenten entwickelt werden, sodass eine planmäßige Qualifizierung gewährleistet ist. Zum Beispiel soll die Kollegin Buhl in der Plankommission zur Referentin entwickelt werden.

\begin{tabular}{|c|c|}
\hline $\begin{array}{l}\text { Soziale Herkunft: } \\
\text { (ohne technisches Personal) } \\
\text { Stand vom 15.12.1952 }\end{array}$ & $\begin{array}{l}\text { Soziale Herkunft: } \\
\text { (ohne technisches Personal) } \\
\text { Stand vom 15.3.1953 } \\
\end{array}$ \\
\hline Arbeiter $52 \%$ & zurückgegangen um $0,6 \%$ auf $51,4 \%$ \\
\hline Klein- und Mittelbauern 4,2 \% & erhöht um $1,4 \%$ auf $5,6 \%$ \\
\hline Großbauern $1,7 \%$ & unverändert $1,7 \%$ \\
\hline Angestellte $16,2 \%$ & zurückgegangen um $1,2 \%$ auf $15,0 \%$ \\
\hline Beamte $11,4 \%$ & zurückgegangen um $0,4 \%$ auf $11,0 \%$ \\
\hline Gewerbetreibende (bis 10 Beschäftigte) $12,8 \%$ & erhöht um $0,2 \%$ auf $13,0 \%$ \\
\hline Gewerbetreibende (über 10 Beschäftigte) $0,3 \%$ & erhöht um $0,3 \%$ auf $0,6 \%$ \\
\hline Freie Berufe und sonstige $1,4 \%$ & erhöht um $0,3 \%$ auf $1,7 \%$ \\
\hline
\end{tabular}


Der Rückgang in der Rubrik Arbeiter ist darauf zurückzuführen, dass den durch die Demokratisierung nach Frankfurt (Oder) versetzten Mitarbeitern nicht genügend Wohnraum zur Verfügung gestellt werden konnte, sodass [infolge] persönlicher und familiärer Gesundheitsschäden eine Rückführung an den Wohnort erforderlich war. Zum Beispiel Kollege Schröder, Hauptsachbearbeiter in der Abteilung Finanzen, musste aufgrund seines Gesundheitszustandes nach seinen Wohnort im Bezirk Potsdam zurück.

Des Weiteren wurden drei Mitarbeiter den Nationalen Streitkräften, bzw. der Deutschen Volkspolizei zur Verfügung gestellt.

Die Erhöhung der Klein- und Mittelbauern wirkt sich positiv insbesondere auf die Abteilung Landwirtschaft aus. Es muss deshalb nach wie vor die soziale Herkunft in Bezug auf Arbeiter für das folgende Quartal größere Beachtung finden. Durch das Herauslösen von zwei Abteilungen (Vertragsgericht und Information) ist in der umseitig angeführten Gegenüberstellung sowie in fast allen nachfolgenden Zusammenstellungen eine prozentuale Veränderung zu verzeichnen. Z. B. schieden im I. Quartal 29 Mitarbeiter aus, soziale Herkunft - Arbeiter. Dagegen wurden 36 Mitarbeiter eingestellt mit der sozialen Herkunft - Arbeiter.

\begin{tabular}{|l|l|}
\hline Leitende Angestellte bis Abteilungsleiter \\
\hline $\begin{array}{l}\text { Soziale Herkunft } \\
\text { Stand vom } 15.12 .1952\end{array}$ & $\begin{array}{l}\text { Soziale Herkunft } \\
\text { Stand vom } 15.3 .1953\end{array}$ \\
\hline Arbeiter $85 \%$ & zurückgegangen um $10,0 \%$ auf $75,0 \%$ \\
\hline Klein- und Mittelbauern 3,8 \% & erhöht um $0,4 \%$ auf $4,2 \%$ \\
\hline Großbauern 3,8\% & erhöht um $0,4 \%$ auf $4,2 \%$ \\
\hline Angestellte 3,7\% & erhöht um $4,5 \%$ auf $8,2 \%$ \\
\hline Beamte 3,7 \% & erhöht um $0,5 \%$ auf $4,2 \%$ \\
\hline Gewerbetreibende (über 10 Beschäftigte) entfällt & erhöht um $4,2 \%$ auf $4,2 \%$ \\
\hline
\end{tabular}

Der Rückgang in der Rubrik Arbeiter ist darauf zurückzuführen, dass hier besonders einige leitenden Angestellten wegen nicht richtiger Auslegung der Gesetze, Abteilungsleiter Erfassung und Aufkauf, Kollege Pansegrau, sowie krimineller Vergehen, Abteilungsleiter Allgemeine Verwaltung Kollege Vater ihrer Funktion enthoben wurden, sowie qualifizierte Mitarbeiter für leitende Tätigkeiten übergeordneter Dienststellen abgegeben wurden. Zum Beispiel Kollege Weigmann, Abteilungsleiter Information zum ZK unserer Partei, Kollege Leimbach, Oberreferent Finanzen, zum Ministerium der Finanzen.

Die Veränderung in der Rubrik Angestellte ist durch die Einstellung des Stellvertreters des Vorsitzenden, Kollege Zaiger, begründet.

Die prozentuale Veränderung bei den Großbauern und Beamten ist in dem oben angeführten Absatz begründet. 


\begin{tabular}{|l|l|}
\hline $\begin{array}{l}\text { Soziale Herkunft bis 1945 } \\
\text { Stand vom } 15.12 .1952\end{array}$ & $\begin{array}{l}\text { Soziale Herkunft bis 1945 } \\
\text { Stand vom } 15.3 .1953\end{array}$ \\
\hline Arbeiter $16,7 \%$ & erhöht um $0,5 \%$ auf $17,2 \%$ \\
\hline Klein- und Mittelbauern $0,6 \%$ & unverändert $0,6 \%$ \\
\hline Großbauern $0,6 \%$ & unverändert $0,6 \%$ \\
\hline Angestellte $43,5 \%$ & unverändert $43,5 \%$ \\
\hline Beamte $1,4 \%$ & unverändert $1,4 \%$ \\
\hline Gewerbetreibende (bis 10 Beschäftigte) $2,5 \%$ & zurückgegangen um $0,8 \%$ auf $1,7 \%$ \\
\hline Gewerbetreibende (über 10 Beschäftigte) $0,0 \%$ & erhöht um $0,3 \%$ auf $0,3 \%$ \\
\hline Freie Berufe und sonstige $2,5 \%$ & zurückgegangen um $0,3 \%$ auf $2,2 \%$ \\
\hline Polizei u. Berufssoldaten $3,6 \%$ & erhöht um $0,6 \%$ auf $4,2 \%$ \\
\hline Schüler und Studenten $28,6 \%$ & zurückgegangen um $0,3 \%$ auf $28,3 \%$ \\
\hline
\end{tabular}

Hier ist zu erkennen, dass die soziale Stellung - Arbeiter - erhöht werden konnte, dagegen die Rubriken Kleinbauern bis Beamte unverändert blieben und im Wesentlichen eine Erhöhung der Rubrik Polizei und Berufssoldaten um 0,6 \% zu verzeichnen ist. Zu bemerken ist hierzu, dass keine Konzentration in den einzelnen Abteilungen vorhanden ist. Für das II. Quartal muss daher hier besondere Aufmerksamkeit geschenkt werden. Insbesondere der Rückgang der Schüler und Studenten muss wieder aufgeholt und verstärkt werden.

\begin{tabular}{|l|l|}
\hline Leitende Angestellte bis Abteilungsleiter \\
\hline $\begin{array}{l}\text { Soziale Stellung bis } \mathbf{1 9 4 5} \\
\text { Stand vom } 15.12 .1952\end{array}$ & $\begin{array}{l}\text { Soziale Stellung bis 1945 } \\
\text { Stand vom } 15.3 .1953\end{array}$ \\
\hline Arbeiter 34,6 \% & erhöht um 7,1 \% auf $41,7 \%$ \\
\hline Klein- und Mittelbauern entfällt & entfällt \\
\hline Großbauern 3,8 \% & erhöht um $0,4 \%$ auf $4,2 \%$ \\
\hline Angestellte 38,5\% & Rückgang um 9,4 \% auf $29,1 \%$ \\
\hline Beamte entfällt & entfällt \\
\hline Gewerbetreibende (bis 10 Beschäftigte) entfällt & entfällt \\
\hline Freie Berufe und sonstige 3,8 \% & erhöht um $0,4 \%$ auf $4,2 \%$ \\
\hline Polizei u. Berufssoldaten $3,8 \%$ & erhöht um $4,5 \%$ auf $8,3 \%$ \\
\hline Schüler und Studenten $15,5 \%$ & Rückgang um 3,0 \% auf $12,5 \%$ \\
\hline
\end{tabular}

Hier gelang [...] uns bei den leitenden Angestellten eine weitere Steigerung in der Rubrik Arbeiter. Dagegen wurde auch hier die Rubrik Polizei und Berufssoldaten erhöht. Diese Veränderung der Prozentzahl ergab sich außerdem durch den Abgang von zwei Abteilungen. Im Wesentlichen ist dazu zu sagen, dass es sich um gute qualifizierte Mitarbeiter handelt, welche durch Besuch von gesellschaftlichen Schulen günstige Voraussetzungen für ihre Tätigkeit mitbringen. Z. B. Kollege Hoppe, Bezirksenergiebeauftragter in der Abteilung Industrie, soziale Herkunft Arbeiter, Mitglied unserer Partei. Eine Erhöhung darf jedoch auch hier im II. Quartal nicht erfolgen. Besondere Aufmerksamkeit muss den 
Jugendlichen in leitenden Stellungen gegeben werden, da auch hier ein Teil für Funktionen nach übergeordneten Dienststellen sowie zur Volkspolizei abgegeben wurden.

\begin{tabular}{|l|l|}
\hline $\begin{array}{l}\text { Altersaufgliederung } \\
\text { Stand vom } 15.12 .1952\end{array}$ & $\begin{array}{l}\text { Altersaufgliederung } \\
\text { Stand vom } 15.3 .1953\end{array}$ \\
\hline bis 25 Jahre $32,6 \%$ & Rückgang um $7,3 \%$ auf $25,3 \%$ \\
\hline $26-30$ Jahre $19,5 \%$ & erhöht um $0,7 \%$ auf $20,2 \%$ \\
\hline $31-40$ Jahre $23,1 \%$ & erhöht um $3,0 \%$ auf $26,1 \%$ \\
\hline $41-50$ Jahre $13,4 \%$ & erhöht um $1,3 \%$ auf $14,7 \%$ \\
\hline $51-60$ Jahre $9,8 \%$ & erhöht um $1,9 \%$ auf $11,7 \%$ \\
\hline über 60 Jahre $1,6 \%$ & erhöht um $0,4 \%$ auf $2,0 \%$ \\
\hline
\end{tabular}

\section{Leitende Angestellte bis Abteilungsleiter}

\begin{tabular}{|l|l|}
\hline $\begin{array}{l}\text { Altersaufgliederung } \\
\text { Stand vom } 15.12 .1952\end{array}$ & $\begin{array}{l}\text { Altersaufgliederung } \\
\text { Stand vom } 15.3 .1953\end{array}$ \\
\hline bis 25 Jahre $15,5 \%$ & Rückgang um $11,3 \%$ auf $4,2 \%$ \\
\hline $26-30$ Jahre $19,2 \%$ & Rückgang um $2,5 \%$ auf $16,7 \%$ \\
\hline $31-40$ Jahre $43,3 \%$ & Rückgang um $0,6 \%$ auf $41,7 \%$ \\
\hline $41-50$ Jahre $11,5 \%$ & erhöht um $13,5 \%$ auf $25,0 \%$ \\
\hline $51-60$ Jahre $3,8 \%$ & erhöht um $4,5 \%$ auf $8,3 \%$ \\
\hline über 60 Jahre $7,7 \%$ & Rückgang um $3,6 \%$ auf $4,1 \%$ \\
\hline
\end{tabular}

Insgesamt haben wir 91 Jugendliche (politische Mitarbeiter ohne technisches Personal), davon:

\begin{tabular}{|l|l|}
\hline Stand vom 15.12.1952 & Stand vom 15.3.1953 \\
\hline insgesamt 117 Jugendliche & insgesamt Rückgang um 26 auf 91 Jugendliche \\
\hline davon 70 weibliche Jugendliche $=60 \%$ & Rückgang um 11 auf 59 Jugendliche $=64,8 \%$ \\
\hline davon 47 männliche Jugendliche $=40 \%$ & Rückgang um 15 auf 32 Jugendliche $=35,2 \%$ \\
\hline
\end{tabular}

\section{Leitende Angestellte bis Abteilungsleiter}

\begin{tabular}{|l|l|}
\hline insgesamt 4 Jugendliche $=15,5 \%$ & Rückgang um 3 auf 1 Jugendliche $=4,2 \%$ \\
\hline davon 1 weibliche Jugendliche $=25,0 \%$ & Rückgang um 1 auf 0 Jugendliche \\
\hline davon 3 männliche Jugendliche $=73,0 \%$ & Rückgang um 2 auf 1 Jugendliche \\
\hline
\end{tabular}

Im II. Quartal müssen wir unser besonderes Augenmerk darauf legen, dass die Zahl der Jugendlichen wieder erhöht wird, damit durch den Abzug von Jugendlichen bzw. durch das Älterwerden der Mitarbeiter, die Lücke geschlossen wird.

Hier ist bei den leitenden Angestellten eine Abteilungsleiterin Mittelstädt jetzt über 25 Jahren [sic!], der Abteilungsleiter Kommunale Wirtschaft, Kollege Lange, versetzt 
nach Stalinstadt, sowie der Abteilungsleiter für Information Kollege Weigmann, versetzt zum ZK unserer Partei.

Eingestellt wurden 18 Jugendliche, entlassen bzw. versetzt 21 Jugendliche.

\section{Frauen}

\section{Leitende Angestellte bis Abteilungsleiter}

\begin{tabular}{|l|l|}
\hline $\begin{array}{l}\text { Altersaufgliederung } \\
\text { Stand vom 15.12.1952 }\end{array}$ & $\begin{array}{l}\text { Altersaufgliederung } \\
\text { Stand vom 15.3.1953 }\end{array}$ \\
\hline 2 Frauen $=100 \%$ Mitglieder der SED & Rückgang um 1 auf 1 Frau \\
\hline
\end{tabular}

Hier musste die Abteilungsleiterin Handel und Versorgung, Kollegin Uber, ihrer Funktion enthoben werden, Grund: mangelnde Qualifikation. Es gilt nach wie vor, Frauen zu leitenden Angestellten zu qualifizieren.

\section{Angestellte ohne technisches Personal}

\begin{tabular}{|l|l|}
\hline Stand vom 15.12.1952 & Stand vom 15.3.1953 \\
\hline 144 Frauen $=40 \%$ davon: & erhöht um 3 auf $147=40,9 \%$ davon: \\
\hline 51 Frauen $=35,4 \%$ Mitglied der SED & Rückgang um 1 auf $50=34 \%$ SED \\
\hline 13 Frauen $=19,1 \%$ Mitglied Blockpartei & unverändert $13=8,8 \%$ \\
\hline 80 Frauen $=55,5 \%$ parteilos & erhöht um 4 auf $84=57,2 \%$ parteilos \\
\hline
\end{tabular}

Hier gelang es uns, den Stand vom 15.12.1952 ungefähr auf derselben Höhe zu halten bzw. bietet das II. Quartal die Möglichkeiten, den Anteil der Frauen als Mitglieder der SED zu verändern, da Neuanträge anlässlich des Todes des Genossen Stalin für die Aufnahme in die Partei vorliegen. Z. B. Kollegin Pelz, Sachbearbeiterin Materialversorgung, oder Kollegin Meißner, Referentin für Heimerziehung in der Abteilung Volksbildung.

Weiterbildung nach 1945 der Angestellten ohne technisches Personal

\begin{tabular}{|l|l|}
\hline Stand vom 15.12.1952 & Stand vom 15.3.1953 \\
\hline Verwaltungsgrundschule 5,5\% & erhöht um $0,1 \%$ auf $5,6 \%$ \\
\hline Landesverwaltungsschule $4,2 \%$ & Rückgang um $0,3 \%$ auf $3,9 \%$ \\
\hline Kurzlehrgang der DVA $1,7 \%$ & Rückgang um $0,6 \%$ auf $1,1 \%$ \\
\hline Ein-Jahr-Lehrgang $0,3 \%$ & unverändert $0,3 \%$ \\
\hline Zwei-Jahr-Lehrgang $1,7 \%$ & Rückgang um $0,9 \%$ auf $0,8 \%$ \\
\hline Fernstudium DVA 3,3 \% & Rückgang um $0,2 \%$ auf 3,1 \% \\
\hline Gesellschaftliche Schulung über 3 Monate $6,4 \%$ & Rückgang um $1,1 \%$ auf $5,3 \%$ \\
\hline Gesellschaftliche Schulung über 6 Monate $1,4 \%$ & erhöht um $0,8 \%$ auf $2,2 \%$ \\
\hline
\end{tabular}




\section{Weiterbildung nach 1945 leitende Angestellte bis Abteilungsleiter}

\begin{tabular}{|l|l|}
\hline Stand vom 15.12.1952 & Stand vom 15.3.1953 \\
\hline Verwaltungsgrundschule $0,0 \%$ & unverändert \\
\hline Landesverwaltungsschule 3,8 \% & erhöht um $0,4 \%$ auf $4,2 \%$ \\
\hline Kurzlehrgang der DVA $7,7 \%$ & Rückgang um 3,1 \% auf $8,4 \%$ \\
\hline Ein-Jahr-Lehrgang 3,8\% & \\
\hline Zwei-Jahr-Lehrgang $15,4 \%$ & Rückgang um 7,1\% auf 8,3\% \\
\hline Fernstudium DVA 23,0 \% & erhöht um $10,3 \%$ auf 33,3 \% \\
\hline Gesellschaftliche Schulung über 3 Monate 3,8\% & unverändert 3,8 \% \\
\hline Gesellschaftliche Schulung über 6 Monate 3,8\% & erhöht um $0,4 \%$ auf $4,2 \%$ \\
\hline
\end{tabular}

Aus den o. a. Zahlen ersehen wir, dass 62,2 \% von den leitenden Angestellten eine fachlich und gesellschaftspolitische Qualifikation über drei Monate besitzen, bzw. am Fernstudium der DVA teilnehmen. Von den sonstigen Angestellten sind es 22,3\% über drei Monate. Der Rückgang der Mitarbeiter, welche an einem 2-Jahr-Lehrgang DVA teilgenommen haben, erklärt sich durch die Versetzung des Abteilungsleiters Kommunale Wirtschaft, Kollege Lange, der sich als stellvertretender Vorsitzender der Stalinstadt qualifizieren konnte. Z. Zt. befinden sich sieben Mitarbeiter DVA, zwei Mitarbeiter Verwaltungsschule, vier Mitarbeiter auf gesellschaftlichen Schulen. Das Anlaufen der neuen Staatspolitischen Schulen, sowie die Fachschulungen der einzelnen Abteilungen außerhalb der Arbeitszeit bieten günstige Voraussetzungen einer weiteren Qualifikation unserer Mitarbeiter.

Parteizugehörigkeit nach 1945 der Angestellten ohne technisches Personal

\begin{tabular}{|l|l|}
\hline Stand vom 15.12.1952 & Stand vom 15.3.1953 \\
\hline Parteilos $34 \%$ & erhöht um $0,7 \%$ auf $34,7 \%$ \\
\hline SED $55,7 \%$ & Rückgang um $1,0 \%$ auf $54,7 \%$ \\
\hline CDU $2,2 \%$ & unverändert $2,2 \%$ \\
\hline LDP $2,5 \%$ & erhöht um $0,3 \%$ auf $2,8 \%$ \\
\hline NDP $3,1 \%$ & unverändert $3,1 \%$ \\
\hline DBD $2,5 \%$ & unverändert $2,5 \%$ \\
\hline
\end{tabular}

Parteizugehörigkeit nach 1945 der leitenden Angestellten bis Abteilungsleiter

\begin{tabular}{|l|l|}
\hline Stand vom 15.12.1952 & Stand vom 15.3.1953 \\
\hline Parteilos entfällt & entfällt \\
\hline SED $85,5 \%$ & erhöht um $2,0 \%$ auf $87,5 \%$ \\
\hline CDU entfällt & entfällt \\
\hline LDP $3,8 \%$ & erhöht um $0,4 \%$ auf $4,2 \%$ \\
\hline NDP $3,8 \%$ & erhöht um $0,4 \%$ auf $4,2 \%$ \\
\hline DBD $3,9 \%$ & erhöht um $0,2 \%$ auf $4,1 \%$ \\
\hline
\end{tabular}


Die hier aufgeführte Zahlen ergeben das Ziel, welches wir uns im IV. Quartal stellten. Durch Neueinstellung von Schreibkräften erhöhte sich zwar die Zahl der parteilosen Mitarbeiter, dagegen wurden bei der SED ein Rückgang von 1 \% verzeichnet, der durch bedingte Entlassungen, z. B. Kollege Vater, Abteilungsleiter Allgemeine Verwaltung, wegen krimineller Vergehen, bzw. durch Abgang guter Kräfte in andere Funktionen notwendig wurde (Stalinstadt und ZK).

\section{Kriegsgefangenschaft der Angestellten}

\begin{tabular}{|l|l|}
\hline Stand vom 15.12.1952 & Stand vom 15.3.1953 \\
\hline Sowjetunion $12,5 \%$ & unverändert auf $12,5 \%$ \\
\hline Kapitalistische Länder $13,6 \%$ & erhöht um $1,7 \%$ auf $15,3 \%$ \\
\hline
\end{tabular}

Kriegsgefangenschaft der leitenden Angestellten bis Abteilungsleiter

\begin{tabular}{|l|l|}
\hline Stand vom 15.12.1952 & Stand vom 15.3.1953 \\
\hline Sowjetunion $30,4 \%$ & Rückgang um $5,4 \%$ auf $25,0 \%$ \\
\hline Kapitalistische Länder $11,5 \%$ & erhöht um $13,5 \%$ auf $25,0 \%$ \\
\hline
\end{tabular}

Auf Grund unserer systematischen Kaderauswahl gelang es uns, den Anteil der Mitarbeiter, welche in sowjetischer Gefangenschaft waren auf den alten Stand zu halten. Der Rückgang bei leitenden Angestellten ist auf Entlassungen und Erkrankungen einiger Mitarbeiter zurückzuführen, z. B. mussten der Stellvertreter des Vorsitzenden, Kollege Johanson, und der Abteilungsleiter Industrie, Kollege Moeller, wegen Tbc-Erkrankung ausscheiden.

Leitende Mitarbeiter schieden durch Krankheit bzw. Versetzung aus, welche in sowjetischer Gefangenschaft waren, dagegen wurde ein Stellvertreter, Kollege Zaiger, der Abteilungsleiter Plankommission, sowie der Abteilungsleiter Allgemeine Verwaltung mit britischer Gefangenschaft neu eingestellt, letzterer in den letzten sechs Wochen.

\section{Ehemalige Offiziere und Feldwebel}

\begin{tabular}{|l|l|}
\hline Stand vom 15.12.1952 & Stand vom $\mathbf{1 5 . 3 . 1 9 5 3}$ \\
\hline Offiziere $3,6 \%$ & erhöht um $0,3 \%$ auf $3,9 \%$ \\
\hline Feldwebel $6,4 \%$ & erhöht um $0,3 \%$ auf $6,7 \%$ \\
\hline
\end{tabular}

Ehemalige Offiziere und Feldwebel der leitenden Angestellten bis Abteilungsleiter

\begin{tabular}{|l|l|}
\hline Stand vom 15.12.1952 & Stand vom 15.3.1953 \\
\hline Offiziere $2=7,7 \%$ & erhöht um $0,6 \%$ auf $8,3 \%$ \\
\hline Feldwebel $5=19,2 \%$ & erhöht um $5,8 \%$ auf $25,0 \%$ \\
\hline
\end{tabular}


Der Zugang von Offizieren ist insofern zu erklären, als dass der Abteilungsleiter Landwirtschaft, Kollege Else (Zwei-Jahr-Lehrgang DVA), eingestellt worden ist. Des Weiteren wurden einige Feldwebel, welche jedoch verteilt in den einzelnen Abteilungen arbeiten, neu eingestellt.

Dieselben gehören bis auf den Stellvertreter des Vorsitzenden, Kollege Zaiger, der SED an. Die ehemaligen NSDAP-Mitglieder weisen einen unveränderten Stand von 5,8 \% auf.

Zusammenfassend wäre zu sagen, dass einer der größten Schwerpunkte im I. Quartal die Besetzung der Planstellen der leitenden Angestellten sowie der selbstständigen Referatsleiter war, so musste der Abteilungsleiter der Allgemeinen Verwaltung (Vater) wegen krimineller Vergehen entlassen werden. Ein Grund der späten Entdeckung seiner Vergehen ist jedoch auch in der Kaderabteilung zu suchen, weil noch nicht vollständig sämtliche Personalakten studiert werden konnten und die Arbeit sporadisch durchgeführt wurde. Die Kaderabteilung beschäftigt sich oft mit Suchen von Stenotypistinnen, Organisierung von Einsetzungen usw. Mit den letzten Arbeiten muss deshalb in der Kaderabteilung sofort Schluss gemacht werden, damit die Direktive unseres Ministerrates [ausgeführt] wird.

Wie in der Analyse ersichtlich, konnte trotz prozentualen Rückganges in der sozialen Herkunft eine Verbesserung erzielt werden, indem 29 Mitarbeiter zwar ausschieden, dafür aber 36 Mitarbeiter in der sozialen Herkunft Arbeiter eingestellt wurden. Bei den Neueinstellungen leitender Mitarbeiter waren alle in ihrer sozialen Herkunft Arbeiter, z. B. Plankommission Kollege Syring, Abteilung Industrie Kollege Altwig, lediglich der Stellvertreter des Vorsitzenden Kollege Zaiger ist seiner Herkunft nach Angestellter. Er wurde auf Vorschlag seiner Partei (NDPD) für den an Tbc erkrankten Vorgänger, Kollegen Johanson, eingesetzt.

Die Gesetze zur Förderung und Qualifizierung der Jugend und der Frauen konnten in einigen Fällen gut verwirklicht werden. So konnte z. B. eine Stenotypistin der Plankommission, Kollegin Buhl, zur Referentin entwickelt werden. Der Kollege Adler, Oberreferent bei der Plankommission, hat die Patenschaft für ihre weitere Qualifikation übernommen. So wurde auch unter anderem die Kollegin Ackermann aus der Abteilung Finanzen, die vorher dort als Buchhalterin tätig war, nach Beendigung eines 5-monatigen Lehrganges an der Verwaltungsschule in das Referat Vermögen versetzt, um in der Perspektive als Betriebsprüferin Verwendung zu finden.

Trotz einiger Erfolge muss nach wie vor in den folgenden Quartalen der Entwicklung der Frauen und Jugendlichen größere Aufmerksamkeit geschenkt werden.

Als Grundlage hierfür wird die gut angelaufene Staatspolitische Schulung bilden. Noch nicht genügend angelaufen ist jedoch die fachliche Schulung außerhalb der Arbeitszeit. Außer dem Staatssekretariat für Inneres sowie dem Ministerium für Land und Forst und der Finanzen hat noch kein anderes Ministerium oder Staatssekretariat mit der 
Herausgabe von Richtlinien und Prospekten über die Durchführung dieser Fachschulungen eine Anleitung gegeben.

Zur Frage Stellenplandisziplin: Die beim Rat des Bezirkes Frankfurt durchgeführte Überprüfung durch die Stellenplankommission zeigte ernste Mängel und Schwächen auf und gibt gleichzeitig Hinweise, wie diese Mängel behoben werden können. Durch die weitere Demokratisierung des Staatsapparates gab es bei der Gründung des Rates des Bezirkes selbstverständlich in einigen Stellenplanfragen objektive Schwierigkeiten, die erkannt werden müssen und deren Auswirkungen sich noch bis heute erstrecken.

In diesem Zusammenhang muss zwecks Verbesserung unserer Arbeit auf Mängel und Schwächen der Stellenplaninspektion in Berlin hingewiesen werden. In solchen Fällen, wie die Beispiele aufzeigen, kann die Stellenplandisziplin auf keinen Fall eingehalten werden.

1. Die schriftliche Bekanntgabe, dass das Amt für Information aufgelöst wird, erhielten wir so spät, dass die Kaderabteilung nicht mehr in der Lage war, die gesetzlich einzuhaltenden Kündigungsfristen durchzuführen. Es handelte sich hier meistens um vierwöchentliche Kündigungen.

Somit wurden wir gezwungen, diese Kollegen auf andere Planstellen zu setzen und von dort zu bezahlen. Hinzu kommt noch, dass sich ein Kollege auf der Akademie für Staats- und Rechtswissenschaft befindet, und wo wir jetzt nicht wissen, aus welcher Planstelle er jetzt bezahlt werden soll. Es ist klar, dass sich einige Abteilungsleiter in dieser Beziehung sträuben, die Bezahlung anzuweisen.

2. Durch den Vorsitzenden des Rates des Bezirkes, dem Kollegen Peplinski, erfuhr die Kaderabteilung, dass die Bezirksverwaltung der MTS als Abteilung beim Rat des Bezirkes ab 28.2.53 angeschlossen wurde. Bis heute hat die Kaderabteilung noch keinerlei Anweisung von Seiten der Stellenplankommission. Wie der Kollege Vorsitzende sagt, ist die Eingliederung der MTS in den Rat des Bezirkes ein Ministerratsbeschluss.

3. Der Beschluss des Präsidiums des Ministerrates über die sofortige Bildung von Brennstoffbevollmächtigen, z. B. beim Rat des Bezirkes mit den Planstellen I und III und bei den Kreisen mit der Planstelle II (Referent), wurde ebenfalls nicht durch die Stellenplaninspektion als amtlich bekannt gegeben. Obgleich vom Vorsitzenden des Rates des Bezirkes seit langem ein Antrag, diese Planstellen aus unserem Volumen zu nehmen, an die Stellenplankommission gestellt wurde, ist bis heute noch keinerlei Nachricht eingegangen. Das bedeutet, dass praktisch trotz Beschlusses des Ministerrates noch kein Brennstoffbevollmächtigter arbeiten kann.

4. Dasselbe ist bei den Veränderungen der Bodenschätzer zu verzeichnen. Eine Anordnung des Ministeriums für Finanzen besagt, dass sämtliche Bodenschätzer aus den 
Kreisen bzw. Bezirken herausgelöst werden und zentralen Dienststellen unterstellt werden. Auch hier erhielten wir keinerlei Anweisung von der Zentralen Stellenplankommission.

5. Mitte März dieses Jahres erschien beim Vorsitzenden des Rates des Bezirkes, der Hauptabteilungsleiter von der Hauptabteilung Reparationen Berlin und gab bekannt, dass wir uns sofort mit der Bildung einer Abteilung Reparationen (eine Planstelle I und eine Planstelle IV) zu beschäftigen hätten. Er hatte bereits konkrete Anweisungen der Regierung der Deutschen Demokratischen Republik mit. In der Zwischenzeit hat bereits der Ministerrat, wie der Kollege Peplinski der Kaderabteilung mitteilt, ${ }^{343}$ die Bildung einer Abteilung Reparationen beschlossen.

Auch hier ist von Seiten der Stellenplankommission keinerlei Stellenplannachtrag und Mittelzuwendungen eingegangen. Im Gegenteil, sie wissen von nichts.

6. In der vergangenen Woche bekamen von der Stellenplaninspektion Frankfurt einige Kreise die Nachricht, dass die Abteilung Handel und Versorgung ab 1.4.53 eine gekürzte Planstellenzahl besitzt. Das bedeutet, dass die Mittel für die gekürzten Planstellen ab 1.4.53 nicht mehr zur Verfügung stehen. Z. B. trifft das für den Kreis Angermünde von über zehn Kollegen zu.

Die Stellenplaninspektion hat hierbei das Gesetz der Arbeit vollkommen außer Acht gelassen. Es ist klar, dass die Kollegen eine 14-tägige Kündigungszeit bzw. vier-wöchentliche Kündigungszeit haben. Infolgedessen ging von uns die Anweisung heraus, die durch die Stellenplankürzung notwendig gewordene Kündigung sofort durchzuführen, dabei aber das Kündigungsrecht auf keinen Fall zu verletzen, sondern zu beachten.

Diese eben angeführten Beispiele sollen aufzeigen, mit welchen großen Schwierigkeiten wir zu kämpfen haben, um tatsächlich eine gute Stellenplandisziplin einhalten zu können. Es ist einfach unverantwortlich, wenn die einzelnen Fachministerien oder Staatssekretariate mit eigenem Geschäftsbereich in Stellenplanangelegenheiten selbständige Entscheidungen treffen, ohne die Zentrale Stellenplaninspektion davon in Kenntnis zu setzen.

Obgleich nun Fehler und Mängel in der Stellenplandisziplin vorhanden waren, und durch die o. a. Beispiele notgedrungen noch vorhanden sind, muss gesagt werden, dass Mittelüberschreitungen, sei es in Form von Lohn oder Gehalt sowie Leistungsstufen, in keiner Weise eingetreten sind und dass auch nach wie vor keine eintreten werden. In Zukunft wird eine strengere Stellenplandisziplin eingehalten werden. Vorauszusetzen dafür ist aber gleichzeitig eine Verbesserung der Arbeitsweise der übergeordneten Organe, insbesondere der zentralen Stellenplaninspektion.

343 Franz Peplinski (1910-1991) war seit August 1952 Vorsitzender des Rates des Bezirkes Frankfurt (Oder); vgl. Niemann/Herbst, SED-Kader, S. 383. 
Betr. Beschlussvorlage: Der Rat des Bezirkes hat bereits im ersten Monat seines Bestehens über die Kaderarbeit Beschlüsse gefasst, in denen z. B. alle Abteilungsleiter verantwortlich gemacht wurden für die Heranziehung und Qualifizierung ihrer Kader. Im Bezirk Frankfurt steht insbesondere z. Zt. im Vordergrund die Besetzung freier Bürgermeisterstellen sowie die Herauslösung unqualifizierter bzw. feindlich zur DDR eingestellte Bürgermeister.

Aus den oben kurz angeführten Gründen wurde vom Rat der Beschluss Nr. 12/53 gefasst, kaderpolitische Überprüfungen durchzuführen und auf diese Lehrgänge neue Kader für die Bürgermeisterfunktionen zu entwickeln. Für die weitere Qualifizierung von bereits eingesetzten Bürgermeistern sind 14-tägige Internatslehrgänge durchzuführen.

Für den Monat Mai ist im Terminplan des Rates des Bezirkes geplant, dem Rat einen Bericht zu geben über die Auswertung der Analyse vom ersten Quartal 1953 über die Kaderund Schulungsarbeit. In diesem Bericht werden dem Rat Beschlüsse zur Verbesserung der Kaderarbeit vorgeschlagen werden.

Wie verwirklichen der Dienstellenleiter (Vorsitzender) und die anderen leitenden Funktionäre die ihnen obliegende Verantwortlichkeit für die Kaderarbeit?

Die Zusammenarbeit mit dem Kollegen Peplinski: Noch immer muss festgestellt werden, dass der Kollege Vorsitzende sich noch viel zu viel mit Aufgaben beschäftigt, die eigentlich seine Stellvertreter zu machen hätten. Dies trifft hauptsächlich zu für Erfassung und Aufkauf, Landwirtschaft, Handel und Versorgung. Die Qualifikation einiger Stellvertreter, wie z. B. des Kollegen Pech und Fritz, ist nicht gut. Das hat zur Folge, dass der Kollege Vorsitzende gezwungen wird, sich mit Arbeiten zu beschäftigen, die seine Stellvertreter durchführen könnten und er dafür seine Aufgaben vernachlässigt. Nicht immer erkennt auch er die neuen Aufgaben der Kaderabteilung. Sonst dürfte es nicht vorkommen, dass die Kaderabteilung beauftragt wird, gegen die personalpolitischen Richtlinien zu verfahren, d. h. allerlei Einsätze zusammenzustellen, für irgendwelche Zwecke Stenotypistinnen zu suchen und gar selbst die Kader zu suchen.

Die wenigen Mitarbeiter der Kaderabteilung vernachlässigen dadurch die Anleitung und Kontrolle beim Rat des Bezirkes sowie bei den Räten der Kreise und vernachlässigen ebenfalls die Wachsamkeit.

Es wäre angebracht, wenn sich der Vorsitzende in seiner Dienstbesprechung von einigen leitenden Funktionären berichten ließe, in wieweit die Kaderentwicklung und Qualifizierung der einzelnen Mitarbeiter vorgenommen wird. Ebenfalls wäre eine Kontrolle über die Aufstellung der Entwicklungspläne bei dieser Gelegenheit notwendig. 
Ein gutes Beispiel ist die operative Anleitung des Kollegen Vorsitzenden beim Rat des Kreises Strausberg gewesen. Hier hat der Kollege Vorsitzende in Kaderfragen eingegriffen, kontrolliert und Hinweise zu ihrer Verbesserung gegeben.

Eine hervorzuhebende Leistung vollbrachte er ebenfalls, als das Hochwasser in Oder und Neiße zu einer Katastrophe hätte führen können. Nur durch sein persönliches Eingreifen ist es gelungen, eine Katastrophe größeren Ausmaßes zu verhindern.

In der Durchführung seines Fernstudiums an der Akademie für Staats- und Rechtswissenschaft besteht ebenfalls noch eine Schwäche.

$\mathrm{Zu}$ seinem Gesundheitszustand ist zu sagen, dass er nach wie vor schlecht ist.

Eine Verbesserung seiner familiären Verhältnisse ist eingetreten, nachdem der Kollege Peplinski eine Wohnung in Frankfurt erhalten hat.

Die Zusammenarbeit dem Kollegen Sekretär (Kollege Springer) ${ }^{344}$ hat sich verbessert. Spannungen, die früher zwischen dem Vorsitzenden und dem Sekretär bestanden, sind nicht mehr zu verzeichnen.

Auch der Sekretär führt Arbeiten durch, die nicht die Arbeiten eines Sekretärs des Rates des Bezirkes sind. Dabei vernachlässigt er die ihm unterstellten Fachabteilungen. Er lässt sich ebenfalls noch von Kleinarbeit erdrücken.

Er neigt nach wie vor zu Überspitzungen und Übertreibungen. Bei der Bevölkerung ist er beliebt und hat ebenfalls den größten Zuspruch bei den öffentlichen Sprechstunden. Die ihm übertragenen, zu Recht bestehenden Beschwerden bearbeitet er schnellstens. Familiär lebt er nach wie vor in geordneten Verhältnissen. Er ist Fernstudent an der Akademie für Staats- und Rechtswissenschaft. Nach der nicht bestandenen Zwischenprüfung hält er jetzt sein Fernstudium ein und nimmt regelmäßig an den Konsultationen teil.

Zusammenarbeit mit den übrigen Stellvertretern: Stellvertreter Kollege Fritz, Stellvertreter Kollege Pech, Stellvertreter Kollege Müller, Stellvertreter Kollege Zaiger, Stellvertreter Kollege von Koerber.

Außer dem Kollegen Stellvertreter Müller muss gesagt werden, dass die anderen Stellvertreter sich wenig oder gar nicht verantwortlich fühlen für die Kader der ihnen unterstellten Fachabteilungen.

344 Günter Springer (1922-2013) war seit Juli 1952 Sekretär des Rates des Bezirkes Frankfurt (Oder); vgl. Niemann/Herbst, SED-Kader, S. 465. 
Zusammenarbeit mit den Abteilungsleitern: In der Durchführung von Seminaren der Kaderabteilung mit den Abteilungsleitern bzw. eine erweiterte Parteileitungssitzung, in der nur die Kaderentwicklung und Qualifizierung im Vordergrund stand, haben einige Abteilungsleiter, wie der Kollege Steininger, Abteilung Volksbildung, sowie der Kollege Sinschek, Abteilung Finanzen, gute Schlussfolgerungen daraus gezogen. Die Abteilungsleiter haben zum Teil erkannt, dass nur sie selbst und ihre anderen leitenden Mitarbeiter verantwortlich sein können für die Besetzung der Planstellen sowie für die weitere Qualifizierung und Förderung ihrer Mitarbeiter.

Die Aufstellung von Kaderentwicklungs- und Schulbesuchsplänen ist im Anlauf. Nicht immer versteht es die Kaderabteilung, die einzelnen Fachabteilungen in dieser Frage richtig anzuleiten und zu kontrollieren. Hierbei ergibt sich die dringende Notwendigkeit, die Kaderabteilungen von zweckfremden Arbeiten nun endgültig zu befreien. Je eher dies geschieht, desto schneller wird die Anleitung und Kontrolle bei den einzelnen Fachabteilungen erfolgen können.

Die II. Parteikonferenz der Sozialistischen Einheitspartei Deutschland und das VII. Plenum des ZK der SED stellten uns die Aufgabe, aus jedem Kader einen Meister seines Fachs zu machen. Diesen Grundsatz muss die Kaderabteilung beim Rat des Bezirkes und den Räten der Kreise den Fachabteilungen und besonders den leitenden Funktionären gegenüber streng verfolgen können. Nur dadurch wird es uns gelingen, die Aufgaben, die uns unsere Partei stellt, und wie sie durch die Gesetze der Deutschen Demokratischen Republik ausgedrückt werden, zu erfüllen.

Zusammenarbeit mit der Betriebsparteiorganisation und der BGL: Nach der Neuwahl der Parteileitung und besonders nach dem Einsatz einer Brigade von der Bezirksleitung der SED hat sich die gesamte Arbeit verbessert. Auch in Kaderfragen erhält die Kaderabteilung Unterstützung. Hierzu diente, wie bereits schon erwähnt eine außerordentlich erweiterte Parteileitungssitzung, auf der alle Abteilungsleiter und selbständigen Referatsleiter anwesend waren und in der nur Kaderfragen behandelt wurden.

Auch die Betriebsgewerkschaftsleitung ist nach ihrer Neuwahl arbeitsfähiger. Trotzdem hat die Gewerkschaft beim Rat des Bezirkes noch nicht ihre Hauptaufgaben erkannt. Sie verliert sich in Handwerkerei und ist bis jetzt noch nie der Initiator von Wettbewerben usw. gewesen.

Die Arbeit der Freien Deutschen Jugend hat sich wohl seit dem letzten Quartal weiterentwickelt, doch ist von einem richtigen frohen Jugendleben noch nichts zu spüren.

Zusammenarbeit mit der Bezirksleitung der SED: Die Zusammenarbeit mit der Bezirksleitung der SED, insbesondere mit der Abt. Staatliche Organe, kann als gut bezeichnet werden. Mit der Kaderinstrukteurin, der Genossin Wundke, hält die Kaderabteilung nach wie vor gute Verbindung. 
Kritisch muss aber gesagt werden, dass auch im I. Quartal 1953 zwecks Bestätigung eingereichte Vorlagen noch nicht bearbeitet wurden, da die einzelnen Kreisleitungen die Parteiüberprüfungsunterlagen usw. nur sehr schleppend einreichen. Dies hindert uns, die Bestätigung über die einzelnen Fachminister zu erhalten und dem Bezirkstag zur Bestätigung vorzulegen.

Zusammenarbeit mit der Hauptabteilung Kader des Staatssekretariats für Innere Angelegenheiten: Die Anleitung ist lange nicht ausreichend. Es genügt nicht, jemanden herauszuschicken, der sich noch vorhandene Missstände nur notiert.

Eine gute Anleitung wurde gegeben durch den Kollegen Funk, der selbst bei einer Arbeitstagung der Kaderleiter beim Rat des Bezirkes anwesend war.

Vierteljährliche Zusammenkünfte sind meiner Meinung nach zu wenig. Ich schlage vor beim Staatssekretariat für Innere Angelegenheiten sechs-wöchentliche Zusammenkünfte aller Kaderleiter, um einen Tag lang Erfahrungen auszutauschen.

[BLHA, Rep. 601, Nr. 30, Bl. 6-17]

Dokument 54: Beschluss des Büros der Bezirksleitung der SED Potsdam ,,über die Massenarbeit in der Woche vom 24.6. bis 29.6.1954“, 1. Juli 1954 (Auszug)

Das Ergebnis der Volksbefragung im Bezirk Potsdam zeigt, dass sich die überaus große Mehrheit der Bevölkerung für den Abschluss eines Friedensvertrages, gegen die EVG ausgesprochen hat. ${ }^{345}$

Besonders in den Städten, also dort, wo unsere Arbeiter wohnen, waren die Stimmen für die EVG sehr gering.

Die Volksbefragung lehrt, dass es uns nicht gelungen ist, das Bündnis der Arbeiter mit den werktätigen Bauern in jeder Hinsicht fest und unerschütterlich zu machen. Das zeigt sich darin, dass in einer Reihe von Orten, wo keine oder nur wenig Großbauern leben, werktätige Bauern für die EVG gestimmt haben. Das ist ein Beweis dafür, dass unsere Massenarbeit zur Vorbereitung der Volksbefragung, die einen großen Umfang angenommen hat, noch nicht ausreichte. Es fanden insgesamt 12.087 Versammlungen statt, jedoch ist es uns nicht gelungen, in den 12.477 bestehenden Haus- und Hofgemeinschaften

345 Die seit 1950 konzipierte „Europäische Verteidigungsgemeinschaft“ (EVG) sah eine ,integrierte europäische Armee unter westdeutscher Beteiligung"vor, wurde aber im August 1954 von der französischen Nationalversammlung abgelehnt. Ihr Scheitern beflügelte jedoch die Verhandlungen über die Pariser Verträge, mit deren Ratifizierung die Bundesrepublik im Mai 1955 weitgehend souverän und Mitglied der NATO wurde; vgl. Wolfrum, Bundesrepublik, S. 154-174, Zitat S. 156. 
Versammlungen durchzuführen, sondern lediglich in rund $45 \%$ derselben. Die sich daraus ergebende Schlussfolgerung ist, dass die Massenarbeit qualifizierter durchgeführt werden muss, das heißt, dass alle Bevölkerungsteile angesprochen werden, nicht nur ein Teil.

Die hohe Zahl von Jugendversammlungen, nämlich 1.293, wirkte sich positiv aus, denn die Jugendlichen von 16 bis 18 Jahren haben sich in überwiegendem Maße für den Frieden bekannt.

Die Volksbefragung zeigte aber weiter, dass es uns noch nicht in genügendem Maße gelungen ist, überall Klarheit darüber zu schaffen, was der EVG-Vertrag ist. So gelang es dem Gegner noch am Sonnabend/Sonntag, das Argument zu verbreiten, EVG bedeutet Evangelische Kirchengemeinde, und dadurch bei Christen wenn auch nur einen geringen Einfluss auszuüben.

In der individuellen Aufklärungsarbeit gelang es uns, 85.757 Aufklärer einzusetzen. Jedoch kamen diese erst in den letzten acht Tagen zur breiten Entfaltung. Dabei zeigte sich, dass viele Aufklärer ungenügend qualifiziert waren und dass ferner die Aufklärung blind durchgeführt wurde ohne Kenntnis der konkreten Lage im Aufklärungsgebiet. Häufig wurden Aufklärer aus den Betrieben nicht überzeugt, Aufklärungsarbeit zu leisten, sondern durch Hinweis auf die Parteidisziplin dazu bewegt. Die Folge war, dass sie häufig in der Aufklärung hilflos waren. Daraus gilt es die Schlussfolgerung zu ziehen, dass sich alle Kreise einen genauen Überblick verschaffen, welche Bevölkerungsschichten zu den Volkswahlen aufgeklärt werden müssen, welches die Aufklärer sein werden und wie diese zu schulen sind.

Weiter ist es notwendig, die bestehenden Patenschaften zu überprüfen. Es hat sich in verschiedenen Kreisen gezeigt, dass Verwaltungsbetriebe, wie die DHZ, ihre Patenschaften schlecht durchführten, dass in den Orten hohe Stimmen für die EVG zu verzeichnen waren, während die Orte, wo Produktionsbetriebe Paten waren, die Ergebnisse besser waren.

Ein großer Mangel in der Vorbereitung bei der Volksbefragung war die ungenügende Kenntnis der Situation in den Kreisen. Es zeigte sich in vielen Kreisen, dass die von der Kreisleitung als Schwerpunkt bezeichneten Orte gar keine Schwerpunkte waren. Auch war es nicht richtig, allein von der Einsichtnahme in die Wählerlisten auf Schwerpunkte zu schließen. Viele Orte mit geringer Einsichtnahme haben ein sehr gutes Abstimmungsergebnis gehabt, während Orte mit guter Einsichtnahme ein schlechtes Ergebnis hatten. Alle Kreise müssen die Abstimmungsergebnisse genau analysieren und dementsprechend die Schwerpunkte festlegen.

Bei der Auszählung zeigte sich in verschiedenen Abstimmungslokalen, dass die zuletzt zur Abstimmung gekommenen Bürger, die häufig erst durch Aufklärer aufgefordert werden mussten, in der Mehrzahl für den Friedensvertrag stimmten und dass die EVG- und 
Blanko-Stimmen bereits sehr früh abgegeben wurden. Das ist ein Beweis dafür, dass der Klassengegner eine organisierte Arbeit geleistet hat. Neben Flugblättern und dem Rias gab es in einigen Kreisen auch Flüsterpropaganda.

Die Haltung der Kirche war unterschiedlich. Während viele Pfarrer ,verreisten“, um sich der Abstimmung zu entziehen, traten in vielen Kreisen fortschrittliche Pfarrer auf, die bisher nicht bekannt waren. Im Rahmen der Nationalen Front und der Friedensbewegung müssen diese Pfarrer stärker zur Mitarbeit herangezogen werden. Aber auch mit den negativen Teilen der Pfarrschaft muss weiter gearbeitet werden, denn sie besitzen Einfluss auf ihre Kirchengemeinden.

Die Volksbefragung lenkte die Partei weiter auf die Tatsache, die Blockarbeit weiter zu verbessern und sich mit den Angehörigen der Blockpartei auseinanderzusetzen, die bei der Stimmenauszählung eine negative Haltung bezogen haben. Bei der Auszählung der Stimmen zeigten sich auch verschiedene Bürgermeister in einer Reihe von Kreisen oftmals als staatsfeindlich. Besonders stark war dies in Königs Wusterhausen. Entsprechend dieser Vorkommnisse müssen vom Staatsapparat die entsprechenden Schlussfolgerungen und im Notfall personelle Veränderungen vorgenommen werden.

Weiter zeigte sich, dass die Ausschüsse der Nationalen Front häufig den Aufgaben nicht gewachsen waren. Darum müssen die Kreise endgültig Schluss machen mit der Geringschätzung der Nationalen Front und dort, wo es notwendig ist, personelle Veränderungen vornehmen. Alle Ausschüsse der Nationalen Front sollten zu dem Ergebnis in ihrem Bereich Stellung nehmen und die entsprechenden Schlussfolgerungen ziehen.

Wichtig ist ferner, die Haus- und Hofgemeinschaften zu festigen, um bei der Volkswahl darin feste Stützen zu haben. In einer Reihe von Orten übte die Bevölkerung in den Versammlungen scharfe Kritik an den Missständen bürokratischer Maßnahmen usw. Alle Kreisleitungen müssen gründlich die kritisierten Mängel analysieren und einen Kampf für die Beseitigung derselben führen.

Die Grundorganisationen der Partei haben in der Mehrzahl eine aktive Arbeit entfaltet. Jedoch zeigte sich, dass die von ihnen gefassten Beschlüsse und Arbeitsprogramme nur oft ungenügend verwirklicht wurden. Die Kontrolle der Beschlüsse in Bezug auf die Durchführung derselben ist immer ein schwacher Punkt in der Arbeit. Darum muss auf jeder Mitgliederversammlung die Frage der Verwirklichung der Arbeitsprogramme behandelt werden. Ferner muss sich jede Grundorganisation mit dem Abstimmungsergebnis in ihrem Bereich befassen, vor allem die Arbeit ihrer Aufklärer einer gründlichen Einschätzung unterziehen. Neue Aufklärer müssen ausgewählt und die Patenarbeit verbessert werden.

In der Massenarbeit ist die individuelle Aufklärungsarbeit durchzuführen mit dem Ziel, dass jeder Aufklärer immer dieselben Personen besucht. In den Versammlungen müssen 
Klein- und Kleinstversammlungen die Hauptmethode bilden. Die Tagesordnung ist aus der konkreten Situation festzulegen, z. B. auf dem Dorf zur Zerschlagung des Arguments der freien Wirtschaft und im Betrieb die Steigerung der Massenproduktion usw. [...]

[BLHA, Rep. 401, Nr. 282, Bl. 241-245]

Dokument 55: Einschätzung der Arbeit der Organisations-Instrukteur-Abteilungen im Bezirk Cottbus durch das Ministerium des Innern der DDR, 9. November 1954 (Auszug)

Die Einschätzung hat zur Grundlage:

1. Überprüfung der Arbeit der Org.-Instrukteur-Abteilungen

a) beim Rat des Bezirkes Cottbus,

b) beim Rat des Kreises Forst,

2. Schriftliche Stellungnahmen der Org.-Instrukteur-Abteilungen bei den Räten der Kreise
a) Cottbus-Land,
b) Finsterwalde,
c) Liebenwerda,
d) Spremberg.

I. Besetzung, Arbeitsorganisation und Arbeitsplanung der Org.-Instrukteur-Abteilung, sowie politische und fachliche Qualifikation ihrer Mitarbeiter.

Zu a) Die Org.-Instrukteur-Abteilungen sind gegenwärtig in der Mehrzahl voll arbeitsfähig.

Beim Rat des Bezirkes ist noch eine Planstelle zu besetzen. Es ist ein Genosse vorgesehen, der sich als Beauftragter des Rates des Bezirkes (aus der Abteilung Finanzen) in Vorbereitung der Volkswahlen durch vorbildliche Arbeit ausgezeichnet hat und die Qualifikation für einen Instrukteur besitzt.

In der Org.-Instrukteur-Abteilung beim Rat des Kreises Finsterwalde z. B. arbeiten z. Zt. neben dem Abteilungsleiter vier Instrukteure, zwei Sachbearbeiter und eine Schreibkraft.

Beim Rat des Kreises Forst sind in der Org.-Instrukteur-Abteilung neben dem Abteilungsleiter drei Instrukteure, ein Sachbearbeiter und eine Schreibkraft tätig. Ähnlich ist die Lage bei den übrigen Räten der Kreise, sodass von der Seite der zahlenmäßigen Besetzung her alle Org.-Instrukteur-Abteilungen im Bezirk Cottbus voll wirksam werden könnten. 
Eine starke Auswirkung auf die Tätigkeit der Org.-Instrukteur-Abteilungen im negativen Sinne hat die in fast allen Kreisen des Bezirkes übermäßige Fluktuation. Beim Rat des Bezirkes Cottbus z. B. sind in der Org.-Instrukteur-Abteilung seit der weiteren Demokratisierung im Juli 1952 elf Mitarbeiter tätig gewesen, die heute an anderer Stelle arbeiten. In der Org.-Instrukteur-Abteilung beim Rat des Kreises Spremberg haben im gleichen Zeitraum neun Kollegen gearbeitet, die dann aus den verschiedensten Gründen eine andere Beschäftigung aufnahmen. Die gleichen Erscheinungen sind bei den meisten anderen Kreisen zu verzeichnen (Cottbus-Land-Land, Fluktuation 6, Jessen, Fluktuation 8 usw.)

Relativ konstant blieb die Besetzung der Org.-Instrukteur-Abteilung beim Rat des Kreises Liebenwerda (Fluktuation zwei Mitarbeiter seit 1952). [Ähnlich ist die Lage bei den übrigen Räten der Kreise, sodass von Seiten der zahlenmäßigen Besetzung her alle Org.Instrukteur-Abteilungen im Bezirk Cottbus voll wirksam werden können.] $]^{346}$

Zu b) Eine Ursache für die unterschiedliche Qualität der Arbeit der Org.-Instrukteur-Abteilungen im Bezirk Cottbus ist die sehr abweichende politische und fachliche Qualifikation der einzelnen Mitarbeiter. Die Mitarbeiter der Org.-Instrukteur-Abteilung beim Rat des Kreises Forst, angefangen vom Abteilungsleiter, Genosse Dommaschk, haben bisher weder eine Verwaltungsschule noch eine Schule einer Partei oder Massenorganisation besucht. [...] Entwicklungsgespräche wurden nicht mit allen Mitarbeitern der Org.-Instrukteur-Abteilungen bei den Räten der Kreise geführt.

Zur weiteren Qualifizierung der Mitarbeiter wenden die Leiter der Org.-Instrukteur-Abteilung verschiedene Methoden an:

Beim Rat des Bezirkes wird in der Regel jeder Montagvormittag zum Studium verwandt.

Beim Rat des Kreises Finsterwalde werden wöchentliche Fachschulungen mit Themen wie z. B. „Die Einrichtung der Haus- und Straßenvertrauensleute als Form der Teilnahme der Massen an der Leitung des Staates in der DDR“" usw. durchgeführt.

Die Mitarbeiter der Org.-Instrukteur-Abteilung beim Rat des Kreises Liebenwerda erhalten Aufträge zum Studium bestimmter Artikel, z. B. aus der „Einheit“, dem „Demokratischen Aufbau“ usw. Nach ca. 14 Tagen werden dann - im Anschluss an Arbeitsbesprechungen - Konsultationen darüber abgehalten.

Beim Rat des Kreises Forst finden in Abständen von zwei Wochen ganztägige Schulungen statt (vorläufige Direktive über die Arbeit der Org.-Instrukteur-Abteilung, ${ }^{347}$ Gesetz

346 Der Satz in eckigen Klammern wurde handschriftlich gestrichen.

347 Vgl. Dok. 46, Anm. 320. 
über die weitere Demokratisierung, ${ }^{348}$ Geschäftsverteilungsplan). Auf meinen Hinweis wurden auch die wichtigsten Gesetze, Verordnungen und die Dokumente unserer Partei in den Schulungsplan mit einbezogen.

Meiner Meinung nach sind die Qualifizierungsmöglichkeiten, d. h. die Anzahl der Plätze für die Speziallehrgänge an der Verwaltungsschule Weimar, für die Mitarbeiter der Org.Instrukteur-Abteilungen im Bezirk Cottbus anteilsmäßig zu gering, wenn man den gegenwärtigen Stand der Qualifikation der Kollegen berücksichtigt.

Der Rat des Bezirkes fasste in Auswertung der Vorbereitung und Durchführung der Volkswahl den Beschluss: „Die Räte der Kreise werden verpflichtet, bis 31.12.1954 die Abteilung Org.-Instrukteure durch entsprechende personelle Veränderungen mit Mitarbeitern zu besetzen, die die Qualifikation besitzen, entsprechend ihrer Aufgaben im Auftrage des Rates des Kreises die staatlichen Organe in den Städten und Gemeinden einzuleiten.“

Zu c) In der Grundlinie entspricht die Aufgabenstellung und die Aufgabenverteilung den in den Qualifikationsmerkmalen enthaltenen Gebieten, wobei zu sagen ist, dass einzelne Aufgaben - wie z. B. das ständige Studium der Erfahrungen der Sowjetunion, der Volksdemokratien und der DDR auf dem Gebiet der Leitung durch die Abteilungsleiter oder die regelmäßige Auswertung der Protokolle der Gemeindevertretungen usw. durch die Org.Instrukteure - nicht in allen Fällen konsequent durchgeführt werden.

Zu d) Die überprüften Org.-Instrukteur-Abteilungen arbeiten nach Arbeitsplänen. Grundlage für die Erarbeitung des Quartalsarbeitsplanes der Org.-Instrukteur-Abteilungen sind die Quartalsarbeitspläne der Räte. Eine Ausnahme bildet der Arbeitsplan der Org.-Instrukteur-Abteilung beim Rat des Kreises Forst für das III. Quartal 1954, der früher als der Plan des Rates aufgestellt wurde. Die Entwürfe der Pläne der Abteilungen werden vom Abteilungsleiter erarbeitet und in der Regel in Arbeitsbesprechungen der Abteilungen von alle Mitarbeitern beraten. Die Quartalsarbeitspläne der Org.-Instrukteur-Abteilungen werden von den Räten bestätigt. Eine Ausnahme bildet der Rat des Kreises Finsterwalde.

Die Arbeitsbesprechungen der Org.-Instrukteur-Abteilungen finden in der Regel wöchentlich statt. Gegenstand der Beratung sind neben den politischen Tagesfragen die Arbeiten, die in der nächsten Woche von der Abteilung zu erledigen sind. Die Aufgaben für die einzelnen Mitarbeiter werden festgelegt. Auf dieser Grundlage erarbeiten sich die Kollegen ihren Wochenarbeitsplan.

348 Vgl. Dok. 17, Anm. 269. 
Jeder Org.-Instrukteur berichtet ferner über seine Erfahrungen bei der Lösung der Aufgaben im letzten operativen Einsatz. So werden die Methoden, die sich als die besten erwiesen haben, allen Mitarbeitern übermittelt.

Unregelmäßig wurden die Arbeitsbesprechungen der Abteilungen in der Zeit der Vorbereitung der Volkswahl durchgeführt (bedingt durch den ständigen operativen Einsatz der Org.-Instrukteure). In einigen Kreisen erfolgte eine kurze tägliche Arbeitsberatung. Nicht alle Leiter der Org.-Instrukteur-Abteilungen können die Arbeit ihrer Org.-Instrukteure wirklich real einschätzen, da sie sich bisher nicht ein einziges Mal von deren Herangehen an die Probleme an Ort und Stelle überzeugt haben (Genosse Mehner, Abteilungsleiter beim Rat des Bezirkes, Genosse Dommaschk, Abteilungsleiter beim Rat des Kreises Forst usw.).

Zu e) Die Sekretäre der Räte geben den Org.-Instrukteur-Abteilungen im Allgemeinen eine gute Anleitung, indem sie an deren Arbeitsbesprechungen teilnehmen und dort Hinweise über besondere Probleme geben. Vorbildlich arbeitet in dieser Hinsicht der Genosse Brasch, Sekretär beim Rat des Bezirkes. Er versteht es, stets ausgehend von der politischen Situation, konkrete Ausführungen für die Verbesserung der Arbeit zu machen; er gibt auch laufend Hinweise aus den Besprechungen des Vorsitzenden mit den Stellvertretern.

Dazu kommen die des Öfteren stattfindenden Besprechungen der Sekretäre mit den Leitern der Abteilungen.

Ein schlechtes Beispiel für die Anleitung lieferte der Sekretär des Rates des Kreises Lübben. Dort fanden in der Zeit der Vorbereitung der Volkswahlen nur drei Arbeitsbesprechungen statt, wobei der Sekretär, Genosse Nagel, nur einmal eine halbe Stunde anwesend war.

In Forst beteiligte sich der dort erst seit wenigen Monaten tätige Sekretär, Genosse Köhler, bisher nicht an den Arbeitsbesprechungen der Org.-Instrukteur-Abteilung.

\section{Wie verwirklicht die Abteilung ihre Rolle als Instrument des Rates?}

Zu a) Die Org.-Instrukteur-Abteilungen werden in der Regel mit konkreten Aufträgen von den Räten betraut. So hat die Org.-Instrukteur-Abteilung beim Rat des Bezirkes Cottbus für die Monate November und Dezember folgende Aufgaben zu lösen:

vom 1.-6.11.1954: Überprüfung der Auswertung der Analyse der Volkswahl durch die Räte und leitenden Mitarbeiter. (unter gleichzeitiger Beachtung: welche konkreten Maßnahmen zur Verwirklichung des Wahlprogramms wurden eingeleitet!)

vom 8.-13.11.1954: Überprüfung der Durchführung des Bezirkstagsbeschlusses über die nächsten Aufgaben der örtlichen Organe nach dem IV. Parteitag. 
vom 15.-30.11.1954: Überprüfung der Durchführung der Direktive über die weitere Verbesserung der Arbeitsweise der staatlichen Organe in den Gemeinden in Auswertung der Wahlergebnisse.

vom 1.-31.12. 1954: Durchführung einer Untersuchung der Arbeit des Rates des Kreises Luckau und Auswertung der Untersuchung.

Die Org.-Instrukteur-Abteilung erhielt ferner den Auftrag zur Lösung einiger Sonderaufgaben:

1. Kontrolle des Beschlusses des Rates des Bezirkes vom 23.10.1954 über die kaderpolitische Festigung der Org.-Instrukteur-Abteilungen bei den Räten der Kreise.

2. Überprüfung der Durchführung des Bergbaubeschlusses in der Gemeinde Sedlitz.

3. Überprüfung der Durchführung des Handwerksbeschlusses in Falkenberg.

4. Überprüfung der Arbeit der Org.-Instrukteur-Abteilung beim Rat des Kreises Finsterwalde usw.

Die Org.-Instrukteure des Rates des Bezirkes erhalten von ihrem Abteilungsleiter zur Durchführung ihrer Aufgaben konkrete Hinweise. So enthielt z. B. der Instrukteurauftrag für den oben angeführten Einsatz vom 1. bis 6.11.1954, der in den Kreisen Forst und Spremberg durchgeführt wurde, folgende Punkte:

1. In einer Aussprache mit dem Vorsitzenden, dem Sekretär und dem Leiter der Org.-Instrukteur-Abteilung ist festzustellen, wie die Auswertung des Ergebnisses der Volkswahlen beim Rat des Kreises erfolgt.

2. Es ist zu prüfen, wie die Abteilungsleiter über diese Auswertung informiert sind und welche politische Orientierung sie vom Rat erhalten haben.

3. Wie hat der Abteilungsleiter mit seinen Mitarbeitern die Auswertung vorgenommen und welche politische Orientierung hat er in Verbindung mit den fachlichen Aufgaben seinen Mitarbeitern gegeben?

4. Wie sind die Mitarbeiter in den einzelnen Abteilungen (persönliche Aussprachen führen) über das Ergebnis der Volkswahlen unterrichtet und wie bringen sie diese Kenntnisse mit ihrer täglichen Arbeit in Verbindung (Studie am Arbeitsplatz)?

5. Was hat der Vorsitzende und der Sekretär zur Festigung der Org.-Instrukteur-Abteilung getan? Ziel muss sein: Die besten Mitarbeiter in die Org.-Instrukteur-Abteilungen.

6. Wie ist die Arbeit des Beschwerdeaktivs?

Wie viel Beschwerden aus der Rechenschaftslegung und Kandidatenvorstellung stehen noch offen?

Gibt es eine Einschätzung, auf welchen Gebieten und aus welchen Gemeinden die meisten Beschwerden eingegangen sind.

Wurden die Ursachen ergründet und was wurde zur Beseitigung bestehender Probleme getan. 
Ein Mangel bestand m. E. darin, dass die Org.-Instrukteure des Rates des Bezirkes stets nur mündliche Berichte über ihre Einsätze erstatteten.

Ich halte es für notwendig, dass bei solchen grundsätzlichen Überprüfungen nicht auf die Erarbeitung von schriftlichen Einschätzungen verzichtet werden darf. Nach eingehender Diskussion mit dem Leiter der Org.-Instrukteur-Abteilungen, Genosse Mehner, hat er verfügt, dass bei allen besonders wichtigen Fragen schriftliche Berichte anzufertigen sind; dadurch wird eine gründlichere Auswertung ermöglicht.

Schlechte Beispiele des Zusammenwirkens Rat-Org.-Instrukteur-Abteilung sind in der letzten Zeit aus dem Kreis Forst bekannt geworden. Dort orientierte der Rat bis zum Zeitpunkt der Überprüfung (5.11.1954) die Org.-Instrukteur-Abteilung nicht auf die Schwerpunkte. Es wurde noch nicht an einer gründlichen Auswertung der Volkswahlen gearbeitet. Ohne Zweifel macht sich hier das Fehlen eines Quartalsarbeitsplanes äußerst negativ bemerkbar.

Zu b) Es sind bei der Überprüfung keine Beispiele bekannt geworden, die beweisen, dass die Org.-Instrukteur-Abteilungen sich vorbildlich für die Erfüllung des Volkswirtschaftsplanes, für die Realisierung des Milliardenprogrammes eingesetzt haben, indem sie durch eine wesentliche Verbesserung der politischen Massenarbeit die Aktivität der Werktätigen förderten.

Im Nationalen Aufbauwerk sind die Org.-Instrukteur-Abteilungen völlig unzureichend wirksam geworden. Über gelegentliche Hinweise in Bürgermeisterbesprechungen sind die Org.-Instrukteur-Abteilungen bei den Räten der Kreise in den Fragen des Nationalen Aufbauwerkes im Wesentlichen nicht hinausgekommen.

Stark vernachlässigt wurde die Unterstützung der Ständigen Kommissionen und der Abgeordneten. Bereits im Rat des Bezirkes kommt eine Unterschätzung dieser Seite der Arbeit klar zum Ausdruck. Die Mitarbeiter der Org.-Instrukteur-Abteilung Ristau und Voß haben es bisher versäumt, an den Sitzungen der ihnen zur Unterstützung zugewiesenen Ständigen Kommissionen teilzunehmen.

In den Kreisen zeigen sich in der Regel die gleichen Erscheinungen.

Der Rat des Bezirkes hat diese Mängel erkannt und ist bemüht, sie in Kürze zu beseitigen. Es ist eine Aussprache der Org.-Instrukteur-Abteilung mit den Vorsitzenden der Ständigen Kommissionen für Landwirtschaft und ländliches Bauwesen, Örtliche Industrie und Handwerk, Verkehr und kulturelle Massenarbeit mit dem Ziel einer besseren Zusammenarbeit vorgesehen. 
Zur Verbesserung der Arbeit in den Ständigen Kommissionen ist für die Zeit gleich nach der Wahl des neuen Bezirkstages eine Arbeitstagung mit den Sekretären aller Ständigen Kommissionen geplant.

Vorgesehen ist ferner eine Aussprache mit den neuen Bezirkstagsabgeordneten (Bauern, Handwerker) über ihre künftige Arbeit.

Es gelang mir während des Einsatzes nicht, Beispiele für die Methoden der Aktivierung der Ausschüsse und Kommissionen in den Gemeinden und der Haus- und Straßenvertrauensleute zu finden.

Ferner kann ich nichts Konkretes zu der Frage sagen, welche sichtbaren Veränderungen in Auswertung der Beschwerden, Kritiken und Vorschläge der Werktätigen herbeigeführt wurden. Zur Zeit arbeiten die Beschwerdeaktivs im Bezirk und in den Kreisen weiter, um die Vielzahl der Beschwerden zu erledigen. Danach wird eine abschließende Analyse für eine gründliche Verbesserung der Arbeit des Apparates gezogen.

Zu c) Die Org.-Instrukteur-Abteilungen (sowohl die des Rates des Bezirkes als auch bei den Räten der Kreise) sind meines Erachtens nach bisher zu wenig in der Verbesserung der Gesamtarbeit wirksam geworden. Ohne Zweifel wurden durch den Einsatz der Org.Instrukteur-Abteilungen in den Gemeinden zu den verschiedensten Fragen Veränderungen getroffen, Missstände beseitigt und auch gute Beispiele verallgemeinert. Die Hauptfrage, breiteste Kreise der Werktätigen in die Lösung staatlicher Aufgaben einzubeziehen, ist jedoch bisher noch ungenügend gelöst worden.

Im Ergebnis der Auswertung der Volkswahlen haben einige Org.-Instrukteur-Abteilungen festgelegt, einige Komplexuntersuchungen durchzuführen. Eine fand z. B. zum Zeitpunkt der Überprüfung in der Gemeinde Drachhausen, Kreis Cottbus-Land-Land statt.

Die Org.-Instrukteur-Abteilung des Rates des Bezirkes zog aus der Analyse über die Volkswahlen unter anderem die Schlussfolgerung, in den Kreisen einige Beispiele in Bezug auf die Aktivierung der Tätigkeit der Gemeindevertretungen zu schaffen.

\section{Vorschläge zur Verbesserung der Arbeit der Org.-Instrukteur-Abteilungen.}

Es ist m. E. nach notwendig, eine einheitliche Grundlinie für die fachliche Schulung der Mitarbeiter der Org.-Instrukteur-Abteilungen zu erarbeiten.

Es ist erforderlich, einen größeren Kreis von Mitarbeitern der Org.-Instrukteur-Abteilungen in kürzester Frist die Teilnahme an Speziallehrgängen an der Verwaltungsschule Weimar zu ermöglichen. 
Es ist erforderlich, die Leiter der Org.-Instrukteur-Abteilungen regelmäßig zu Erfahrungsaustauschen zusammenzurufen (Vorschlag: in Abständen von sechs Wochen. - In Cottbus fand die letzte Zusammenkunft vor ca. einen halben Jahr statt).

Es ist erforderlich, dass die Räte es nicht zulassen, dass die Mitarbeiter der Org.-Instrukteur-Abteilungen zu häufig für andere Aufgaben in Anspruch genommen werden (Organisierung von Veranstaltungen, Überwachung des Bürgermeisterurlaubs, Sonderaufträge usw.).

[BArch, DO 1/26059, Bl. 53-60]

Dokument 56: Rede des Vorsitzenden des Rates des Bezirkes Rostock, Hans Warnke, ${ }^{349}$ auf der 21. Tagung des Zentralkomitees der SED, 13. November 1954 (Auszug)

Genosse Walter Ulbricht hat festgestellt, dass der Staatsapparat gegenüber der ökonomischen Entwicklung zurückgeblieben ist. Das ist absolut richtig. Das wurde auch schon früher festgestellt. Die Frage ist, warum sich das noch nicht verbessert hat. Welches sind die Ursachen? Ohne Zweifel ist das politische Niveau, das theoretische, fachliche und politische Wissen der Staatsfunktionäre noch nicht auf der Höhe der Aufgaben angelangt. Aber vielleicht liegt auch eine Ursache in der Struktur, in der Organisation und der Arbeitsweise des Staatsapparates. [...] Ich will diese Frage noch einmal von der Ebene der Bezirke und Kreise erörtern.

Die im Jahre 1952 durchgeführte weitere Demokratisierung der Organe der Staatsgewalt war richtig. Sie hat sich bewährt. Die Einteilung in 14 Bezirke statt in fünf Verwaltungsstellen ermöglichte eine viel bessere Anleitung. Das gleiche ist durch die Verkleinerung der Kreise zu verzeichnen. Aber einiges scheint in den Ministerien noch nicht ganz klar zu sein. Es entwickelt sich etwas, was mir gefährlich zu sein scheint, z. B. im Ministerium für Landwirtschaft. Nach den Prinzipien sind die Fachabteilungen bei den Räten der Bezirke doppelt unterstellt, einmal dem Rat als kollektive Leitung und in fachlicher Beziehung den Fachministern. Dem Landwirtschaftsministerium unterstehen drei Abteilungen, die in den Bezirken sind, und zwar die Abteilung Landwirtschaft, die Abteilung MTS und die Abteilung Verwaltung volkseigener Güter. Das Ministerium betrachtet diese Abteilungen nach wie vor als seine nachgeordneten Dienststellen, denen es Anweisungen in jeder Weise geben kann. Die MTS [und] die Verwaltung volkseigener Güter sind nur formal den Räten unterstellt. Sie sind in jeder Weise nur den Anweisungen des Ministeriums unterstellt. Mir scheint, dass man diesen Zustand dadurch ändern muss, dass die MTS [und]

349 Zu Hans Warnke, seit August 1952 Vorsitzender des Rates des Bezirkes Rostock, vgl. Dok. 2, Anm. 231. 
die Verwaltung volkseigener Güter mit der Abteilung Landwirtschaft zu einer Abteilung zusammengeschlossen werden müssen, und verantwortlich für alle Fragen im Bezirk ist der Leiter der Abteilung Landwirtschaft.

Wie hat sich der jetzige Zustand ausgewirkt? Dazu ein Beispiel: Der Kollege Scholz, der Minister für Landwirtschaft, gibt laufend Anweisungen an den „Stellvertreter des Vorsitzenden“ des Bezirkes, der für Landwirtschaft verantwortlich ist. Er lädt diesen auch zu Besprechungen nach Berlin ein. Dadurch haben wir genau das, was wir nicht haben wollen, nämlich das Dezernatssystem. Der Rat ist ein kollektives Organ, und der Vorsitzende benutzt seine Stellvertreter, damit sie in seinem Auftrage die Anleitung einer Reihe von Fachabteilungen durchführen, da er ja unmöglich in der Lage ist, alle Abteilungen selber anzuleiten. Meines Erachtens kann nur der Ministerpräsident Anweisungen an den Vorsitzenden geben, die Minister haben Hinweise und Anregungen zu geben, aber niemals kann ein Minister Anweisungen an einzelne Ratsmitglieder geben. Im weiteren Verlauf gibt nämlich jetzt der Stellvertreter des Vorsitzenden des Bezirkes ebenfalls Anweisungen an die stellvertretenden Vorsitzenden der Kreise, obwohl er auch entsprechend den Prinzipien unseres Staatsaufbaus dazu kein Recht hat. Manchmal - und das kommt nicht selten vor - ist der Abteilungsleiter für Landwirtschaft, der nach den Prinzipien des Staatsaufbaus für die Arbeiten in der Landwirtschaft verantwortlich ist, nicht von diesen Anweisungen in Kenntnis gesetzt.

Ein anderes Beispiel: Da in den Planvorschlägen auf dem landwirtschaftlichen Sektor, die der Bezirk nach Berlin eingereicht hat, Unklarheiten aufgetreten sind, bestellte sich der Kollege Scholz den stellvertretenden Vorsitzenden beim Rat des Bezirkes und den Planungsleiter der Abteilung Landwirtschaft zu sich und beriet die Fragen. Der Abteilungsleiter Landwirtschaft weiß von dieser Geschichte nichts. Dadurch untergraben wir und verschieben wir die Verantwortung. [...]

Die Genossin Wittkowski hat gestern so ein Beispiel von einem volkseigenen Gut im Bezirk Cottbus, glaube ich, war das, gegeben. ${ }^{350}$ Genossin Wittkowski! Das kommt daher, weil der eine Mann in der Verwaltung volkseigener Güter in Cottbus für alle Bauvorhaben verantwortlich ist, die es in den volkseigenen Gütern im ganzen Bezirk gibt. Hier liegt

350 Hans Warnke vermengte hier zwei Beispiele, die Margarete Wittkowski (1910-1974), zu diesem Zeitpunkt Mitglied des ZK und stellvertretende Vorsitzende der Staatlichen Plankommission, in ihrem Redebeitrag auf derselben ZK-Tagung am 12. November 1954 vorgebracht hatte. In dem volkseigenen Gut Tützpatz in Vorpommern hätten Fehlplanungen bei Erweiterungsbauten zu einer teuren „Investruine“ geführt, und die Baukosten einer Kinderkrippe im südbrandenburgischen Freienhufen seien aufgrund unvollständiger Projektierung um 82.000 DM höher als geplant ausgefallen. Beide Beispiele ließen sich aus Wittkowskis Sicht „,vertausendfachen“ und führten zu Nachforderungen, deren Erfüllung „nur auf Kosten der Schwerindustrie möglich“ sei. Man könne so aber „das Tempo jener Industriezweige - also Kohle, Energie und einiger Zweige der chemischen Industrie - im Jahre 1955 nicht entsprechend steigern“, was dann ,zwangsläufig noch nicht im Jahre 1955, aber dann verschärft im Jahre 1956 und in den folgenden Jahren zu neuen Problemen führen“ müsse; zitiert nach dem stenografischen Protokoll in BArch, DY 30/IV 2/1/136, B1. 150-151. 
auch eine große Gefahr in dieser ganzen Geschichte, nämlich, dass die Verantwortung von unseren Leuten immer nach oben geschoben wird. Es heißt sehr oft, das Ministerium hat das so und so gemacht.

Wir werden auch sehr mit Anordnungen schriftlicher Art überschüttet. Bei einigen war nach dem IV. Parteitag auf diesem Gebiet eine Verbesserung eingetreten. [...] Das Ministerium für Landwirtschaft überschwemmt uns heute aber immer noch, d. h. nicht immer, sondern wieder verstärkt mit Schreiben. Im Monat Oktober dieses Jahres sind in der Abteilung Landwirtschaft 150 Schreiben eingegangen. In der Abteilung MTS 74 Schreiben, in der Abteilung volkseigene Güter 121 Schreiben. Allein in der Zeit vom 4. bis zum 11. November trafen in der Abteilung Landwirtschaft 28 Schreiben vom Ministerium ein. Auch die Besprechungen mit einzelnen Mitarbeitern nehmen von Seiten des Ministeriums überhand. Allein im Monat Oktober waren nur von der Abteilung Landwirtschaft 22 Mitarbeiter in Berlin, von der Verwaltung MTS zehn, von der Verwaltung volkseigener Güter neun Mitarbeiter zu Besprechungen in Berlin. Diese vielen Schreibereien haben zur Folge, dass entsprechend auch diese Anordnungen zum großen Teil als schriftliche Anweisungen an die Kreise und von dort bis an die Gemeinden weitergegeben werden, und letzten Endes landen wieder beim Bürgermeister die Berge von Briefen, die er einfach gar nicht lesen kann. Dazu ist der Bürgermeister faktisch gar nicht in der Lage, wenn er nicht alle seine andere Arbeit liegen lässt. Daraus ergibt sich dann immer wieder die Forderung, wir müssen mehr Personal haben! Ich habe die Frage überprüft, ob das richtig ist, und komme zu dem Ergebnis, dass das nicht richtig ist. Wer kümmert sich alles hauptberuflich um die Landwirtschaft? Das ist erstens die Abteilung Landwirtschaft, die in der Regel 40 Menschen stark ist. Da sind rund 30 Milchprüfer, die dem Zootechniker unterstellt sind. Wir haben schon festgestellt, dass das meistens keine Zootechniker sind. Dann kommen die Viehberater bei der VdgB, und da sind die Agronomen der MTS, die [...] sich um die Fragen der Beratung als Agronomen nicht kümmern, sondern um den Einsatz der Traktoren. Da ist die Deutsche Saatzuchtgesellschaft, da sind die Berater der Zuckerfabriken. Das sind die Erfasser der VEAB, überhaupt der ganze Apparat der VEAB. Da sind andere Organisationen. Das sind insgesamt, die hauptberuflich für die Landwirtschaft in einem Kreis da sind, 400 und mehr Menschen, natürlich nicht einbegriffen die Traktoristen der MTS, die Betriebsleiter und Agronomen der volkseigenen Güter. Aber alle laufen nebeneinander her. Wer fasst diese, ich möchte sagen, Anleitungskräfte für die Landwirtschaft zusammen? Wenn diese Masse Menschen richtig organisiert eingesetzt werden, dann wird es kein Zweifel sein, dass wir die Forderungen des VI. Parteitages besser erfüllen können.

(Bruno Leuschner: Aber Getreide ist zurückgegangen!) $)^{351}$

351 Bruno Leuschner (1910-1965) war seit Mai 1952 Vorsitzender der Staatlichen Plankommission der DDR; vgl. Müller-Enbergs, Wer war wer, S. 521. 
Man sollte bei diesem Zustand ernstlich überprüfen, ob nicht eine tiefgreifende Änderung der Struktur der ganzen landwirtschaftlichen Organe notwendig ist. Meiner Meinung nach muss das wie folgt geschehen: In der Praxis zeigt sich, dass die Räte der Kreise einen stärkeren Einfluss auf die MTS ausüben als die Abteilungen Verwaltung MTS in den Bezirken, was meines Erachtens auch absolut richtig ist. Man sollte die MTS den jeweiligen Räten der Kreise eingliedern. Als unmittelbaren Verbindungsmann zu den MTS müsste ein Verantwortlicher für die Mechanisierung in der Abteilung Landwirtschaft eingesetzt werden. Das müsste natürlich ein qualifizierter Mann sein, der nicht nur die unmittelbare Kontrolle der Arbeit der MTS ausübt.

(Walter Ulbricht: Der sitzt doch in der MTS! Wozu muss er in die Abteilung?)

Mir scheint die Anleitung nur vom Bezirk aus nicht zu genügen, um alle MTS richtig anzuleiten.

(Walter Ulbricht: Ich bin nicht dagegen, dass sie in die Kreise kommen.)

Der Mechanisator sitzt in der MTS, gehört in den Rat des Kreises. Es gibt in den Kreisen immer sieben bis neun MTS. Ich bin der Meinung, dass dieser Mann, der da für die Mechanisierung der Arbeit in den Landwirtschaftlichen Produktionsgenossenschaften verantwortlich ist, auch für die Mechanisierung der Arbeit in den landwirtschaftlichen Produktionsgenossenschaften verantwortlich sein und dort helfen muss. Zur Lösung der gesamten Aufgaben der pflanzlichen Produktion sollte man den besten Agronomen als Kreisagronomen in die Abteilung Landwirtschaft einbauen, der gleichzeitig das Sachgebiet pflanzliche Produktion leitet. Er führt seine Arbeit mit Hilfe der Agronomen der MTS, für die er verantwortlich sein müsste, durch. Außerdem müsste die Anzahl der Agronomen, zumindest ihre Qualität - Genosse Walter Ulbricht hat darauf schon hingewiesen - verstärkt und verbessert werden. Auf dem Gebiet der tierischen Produktion muss das gleiche geschehen. Der Kreis-Zootechniker leitet gleichzeitig das Sachgebiet tierische Produktion an. In jeder MTS müsste ein Ober-Zootechniker eingesetzt werden, dem wiederum die in seinem Bereich arbeitenden Zootechniker und Milchleistungsprüfer unterstehen.

Sinngemäß sollte man mit den volkseigenen Gütern etwas Ähnliches machen. Aber das muss noch gründlicher überprüft werden. Dabei ist natürlich selbstverständlich, dass das Prinzip der doppelten Unterstellung beachtet wird. Dadurch könnten die Abteilungen Verwaltungen MTS und volkseigene Güter in den Bezirken ganz gewaltig eingeschränkt werden. Nach meinem Dafürhalten genügt, dass die Verwaltung MTS in den Bezirken in einer Stärke von 12 bis 14 Menschen weiterhin besetzt sind.

Weiterhin ist es nach meiner Meinung notwendig, eine starke Einschränkung des Personals des Ministeriums für Land- und Forstwirtschaft vorzunehmen und diese Freiwerdenden mit zur Verstärkung der Gemeinden und MTS zu verwenden. 
Ich bin weiterhin der Meinung, dass es unumgänglich notwendig ist, die Gemeinden personell zu verstärken. Bei den Kreisen ist eine Verstärkung nach meinem Dafürhalten nicht erforderlich. Dort sollte man aber auch zurzeit wenigstens keine Einschränkungen vornehmen. Bei der Verstärkung der Gemeinden, womit eine bessere Arbeit verbunden ist, könnte auch - im Moment allerdings langsam aber bestimmt - schon jetzt eine Einsparung bei den Räten der Bezirke erfolgen. Ich bin der Meinung, dass, wenn es uns gelingt, die Arbeit in den Gemeinden und Kreisen zu verbessern, in kürzester Zeit eine Einschränkung der Abteilung Landwirtschaft, die dann zusammengefasst ist mit der Verwaltung MTS und der Verwaltung volkseigener Güter, um mindestens 20 Prozent möglich ist.

Man muss auch die Forderung erheben, [...] die Mastanstalten und auch andere Betriebe wie Tierkliniken den Räten der Bezirke zu unterstellen. Ich möchte nicht empfehlen, sie dem Landwirtschaftsministerium zu unterstellen.

Dass man nun einfach einen bestimmten Prozentsatz von Leuten beim Ministerium für Landwirtschaft streicht, das halte ich nicht für richtig. Ich glaube, man sollte ernsthaft prüfen und soll sehen, was macht diese Abteilung Bauleitung für die volkseigenen Güter, die Bauleitung für die MTS. Auflösen! Weg! Dann passiert gar nichts. Die Arbeit soll draußen in den Kreisen ausgeübt werden. Die kontrollierende und anleitende Aufgabe liegt bei den Bezirken. Hier oben brauchen wir keine solche Abteilung. Diese Kräfte und Menschen haben wir eingespart, um unten in den Gemeinden etwas zu verbessern. So müsste Referat auf Referat durchgearbeitet werden. Dann glaube ich, kommen wir auch auf diesem Gebiet weiter. [...]

Seit Monaten wird an dem Plan 1955 gearbeitet, werden Kontrollziffern gegeben. Sie werden in den Bezirken mit den Fachabteilungen diskutiert, ebenso mit den Kreisen. Das geht jetzt schon monatelang hin und her. Es wird gekämpft um mehr Investitionsmittel usw. Im August dieses Jahres bestätigte das Büro der Bezirksleitung die Kontrollziffern für den Investitionsplan. Aufgrund dessen wird nun der Bezirksplan erarbeitet. Seit Wochen sind hier in Berlin die Fachreferenten der Plankommission der Bezirke, wie man so sagt, zur Abstimmung des Planes. Damit der Plan nun aber auch am Beginn des Jahres anlaufen kann, werden schon vorläufige Zahlen in die Kreise gegeben, damit sie sich danach richten können. Vorgestern wird mir nun mitgeteilt, dass der Plan an einigen Stellen sehr ernst geändert wird. Allein der Investplan für das Wohnungsbauprogramm wird um 26 Prozent gesenkt. Mir ist gesagt worden, die Materialbilanz stimmt nicht. Seit gestern weiß ich, dass das ein bisschen ernster liegt, und die Diskussion hat uns schließlich noch etwas mehr dazu gesagt. Aber, Genossen, ist das denn heute das erste Mal, dass so etwas ist? Ist das nicht immer so? Bringen wir da nicht tausendfache Verärgerung? Könnten wir das nicht verhindern? Das ist doch nicht so leicht, wenn auf einmal der Plan für den Wohnungsbau um 26 Prozent gekürzt wird. [...]

Die verantwortlichen Ministerien müssen alle Aufgaben, die sie im Bezirk durchführen wollen, mit den Räten der Bezirke vorher abstimmen. Aber wie sieht es in der Praxis aus? 
Das Volksbildungsministerium will in Rostock etwas bauen, aber man kommt erst zu uns, wenn das schon beschlossen ist, die ganze Vorbesprechung findet nicht statt. [...]

Ich will noch etwas anderes sagen, [...] auch wenn ich weiß, dass ich wahrscheinlich an dem Programm der gekürzten Wohnungsbauten nicht viel ändern kann. In Rostock ist im vorigen Jahr mit dem Bau von einigen neuen Instituten begonnen worden. Daran wird noch bis 1956 weiter gebaut, bis sie in Betrieb genommen werden. Da ist das hygienische Institut, das medizinische Institut, das agrar-biologische Institut, die schiffbautechnische Fakultät, das nautische Institut und einige andere mehr. Alle bringen Kapazitätserweiterungen mit sich: mehr Studenten, mehr Professoren und mehr Dozenten. Für die Wohnungen hat aber immer die Stadt zu sorgen. Mit der in diesem Jahr nach Rostock erfolgten Verlegung der Verwaltung der Volkspolizei-See, mit der Fertigstellung der Poliklinik und der Institute, die ich eben genannt habe, für Wohnungen dieser neuen Einrichtungen reicht das nicht aus, was wir neu an Wohnungen in Rostock bauen. Was dann noch für die Werftarbeiter übrig bleibt, ist eine andere Frage. [...]

Können die Vorsitzenden der Bezirke und Kreise bei ihren Aufgaben, bei der jetzigen Arbeitsorganisation überhaupt physisch diese Arbeit leisten? - Die Hauptaufgabe des Vorsitzenden sowohl des Bezirks als auch des Kreises ist, er soll den Staatsapparat leiten, er soll den Rat wirklich zu einem Kollektiv entwickeln, kommt er dazu? Ich möchte darauf antworten: Dem Vorsitzenden des Rates des Kreises ebenso wie dem Vorsitzenden des Rates des Bezirks unterstehen direkt - wofür er verantwortlich ist - die Plankommission, die Kaderabteilung, die Abteilung Jugendfragen, der Förderungsausschuss, Fragen der Intelligenz, der Bezirkstierarzt, der Energiebeauftragte, der Schrottbeauftragte. Er ist Vorsitzender des LPG-Beirates; nach dem Gesetz muss der Vorsitzende des Rates [sic!] alle 14 Tage, der Vorsitzende des Bezirks alle vier Wochen diesen LPG-Beirat einberufen. Er ist Vorsitzender der Katastrophenkommission, er ist Vorsitzender der Jagdbehörde, er hat eine Kontrollkommission, er ist Mitglied der Bezirks- bzw. Kreisleitung und damit zu gleicher Zeit Mitglied des Büros dieser Leitungen, er hat in jeder Woche mindestens eine Sitzung des Büros der Kreisleitung, einmal in der Woche muss er mindestens eine Ratssitzung machen, einmal im Monat muss der Vorsitzende des Kreises einen Kreistag durchführen, einmal im Monat muss der Vorsitzende des Kreises zu einer Beratung mit dem Vorsitzenden des Bezirks zusammenkommen, mindestens einmal im Monat muss er mit den Bürgermeistern eine Beratung durchführen, er soll aber auch diese Beratungen und Sitzungen vorbereiten, denn er muss doch dort etwas sagen, er muss doch bei der ganzen Geschichte reden. Er soll sich schließlich auch um die Probleme der anderen Abteilungen kümmern, denn bei dem Vorsitzenden des Rates liegen die Betriebe der örtlichen Wirtschaft, da liegen auch die Baubetriebe. Er muss sich jetzt ernsthaft darum kümmern, ob da die Rechnungsführung schon halbwegs auch nur angefangen hat, ob man sich da schon Gedanken gemacht hat über die wirtschaftliche Rechnungsführung u. a. mehr.

Der Vorsitzende des Kreises als der 1. Staatsfunktionär muss auch Mitglied des Kreisausschusses der Nationalen Front sein. Er muss zum Beispiel auch diesen Monat Mitglied 
des Ausschusses für deutsch-sowjetische Freundschaft sein. Es gibt sogar Menschen, die sagen, ab und zu müsste er sich eigentlich auch mal im Theater oder im Kino sehen lassen. Dann muss er auch studieren.

Einige Vorsitzende der Kreise - und ich persönlich auch - sagen, dass sie Angst darum haben. Ich selber habe wirklich Angst darum, dass ich eines Tages ein Parteiverfahren kriege, weil ich nicht organisiert studiere. Ich fühle selber, wie sehr mir das Wissen fehlt, aber ich weiß nicht, ich werde nicht mehr damit fertig und so gibt es noch einiges mehr.

Ich bin der Meinung, hier muss man einiges ändern. In der Struktur muss dem Vorsitzenden einiges abgenommen werden. Der Vorsitzende darf in den Kreisen oder Bezirken nur folgendes behalten: Die Plankommission, die Kaderabteilung und die Katastrophenkommission, alles andere muss weg. Ich gebe das als Anregung. Man müsste eventuell, um diese kleineren Abteilungen anzuleiten, vielleicht so eine Art Hauptabteilung in den Bezirken einrichten, damit solche Abteilungen auch unter einer größeren Abteilung stehen.

Ich gebe in diesem Zusammenhang den Genossen aus den Ministerien und aus dem Ministerrat noch einen Rat: Fasst nicht fortgesetzt Beschlüsse, in denen steht: dafür ist der der Vorsitzende in den Bezirken und Kreisen persönlich verantwortlich! - Es ist vielleicht notwendig, den Energiebeauftragten, den Schrottbeauftragten, den Tierarzt dem Vorsitzenden für einige Zeit persönlich zu unterstellen. Denn wenn irgendwo etwas brennt jetzt im Augenblick ist die Energieversorgung dran - dann nimmt der Vorsitzende das sowieso in seine Hand, dafür trägt er die Verantwortung für die ganzen Arbeiten im Bezirk.

In Ergänzung dazu möchte ich sagen: Die Verantwortung der Abteilungsleiter muss gehoben werden - ich sagte schon, wie leicht diese Verantwortung dadurch untergraben wird, dass die Abteilungsleiter Gelegenheit haben, alles nach oben abzuschieben, das muss geändert werden. Die Abteilungsleiter tragen die volle Verantwortung gegenüber dem Rat, gegenüber dem Vorsitzenden, aber dieser muss seine Stellvertreter auch wirklich zu verantwortlichen Vorsitzenden machen. Die Stellvertreter müssen wissen, dass sie Vorsitzender sind. Sie haben als Vorsitzende zu entscheiden. Ich glaube, das müssen wir stärker entwickeln, das ist bei weitem noch nicht der Fall.

Dazu gehört auch folgendes: Wie bekommen nun der Vorsitzende und der Stellvertreter ihre Anleitung? Der Vorsitzende bekommt die beste Anleitung dadurch, dass er im Büro der Bezirks- bzw. Kreisleitung mitarbeitet, dass er dort tätig ist. Wenn sich nun der Vorsitzende wirklich mit den Fragen der Leitung beschäftigen kann, dann kann er auch die Stellvertreter anleiten, kann die Probleme stellen, kann auf die Hauptfragen hinweisen usw. Aber genügt nun diese Anleitung, ich glaube nicht. Der Vorsitzende und auch die Stellvertreter brauchen die Anleitung und den Erfahrungsaustausch von den Ministerien bzw. die Vorsitzenden der Kreise von den Bezirken. Mir scheint, das kann man noch etwas verbessern. 
Ich bin seit August 1952 Vorsitzender des Rates des Bezirkes. Wir haben in dieser Zeit rund 125 Ratssitzungen durchgeführt. Noch nie aber hat an einer Ratssitzung ein Minister oder ein Staatssekretär teilgenommen. Es haben bei uns Instrukteure teilgenommen, die sitzen und schreiben. Ich habe einmal das Wort gebraucht: Die Minister regieren durch Anweisungen und dadurch, dass sie ab und zu einmal in Berlin eine Besprechung mit den Fachabteilungen machen und mit Instrukteuren. Mir scheint, das genügt nicht. [...]

Die Vorsitzenden der Bezirke waren in diesem ganzen Jahr zweimal zusammen, aber auf großen Konferenzen mit 300 bis 500 Menschen. Ich glaube, auch diese Anleitung der Vorsitzenden der Bezirke genügt nicht ganz.

Dann komme ich noch zu einer anderen Frage, ich bitte auch, dass das von der zuständigen Stelle überprüft wird. Wir haben zwei Stellen, von denen wir Anleitung bekommen, das ist einmal die Hauptabteilung Örtliche Organe beim Ministerpräsidenten und dann vom Staatssekretariat für Innere Angelegenheiten. Ich empfehle, abschließend einmal zu überprüfen, ob die Aufgaben dieser beiden Abteilungen nicht in ein Staatssekretariat zusammengefasst werden können.

(Walter Ulbricht: Das ist schon beschlossen.) $)^{352}$

Danke schön! [...]

Ich bin weiter der Meinung, dass von dem verantwortlichen Staatssekretär vielleicht zweimal im Jahr durchzuführende größere Konferenzen - mehrmals kann man das nicht machen - und dazu mit den Vorsitzenden der Räte der Bezirke und den Sekretären vielleicht alle vier bis sechs Wochen eine Beratung mit einem Erfahrungsaustausch unter der Leitung des Staatssekretärs durchgeführt werden sollte. [...]

Die Stellvertreter des Vorsitzenden sollen [...] wirklich verantwortlich sein und sich als Stellvertreter des Vorsitzenden fühlen. Dazu scheint mir erforderlich zu sein, dass diese stellvertretenden Vorsitzenden für die einzelnen Fragen von dem zuständigen Minister vielleicht alle zwei bis fünf Monate einmal zusammengenommen werden und dass man sie da nicht so behandelt wie Abteilungsleiter, sondern mit ihnen müssen die Perspektiven, die Hauptfragen der Landwirtschaft, in der örtlichen Industrie, im Verkehr usw. behandelt und untersucht werden.

352 Walter Ulbricht bezieht sich hier offenbar auf politische Entscheidungen, die am 3. Februar 1955 in den „Beschluss des Ministerrates der DDR über die Anleitung und Kontrolle der Räte der Bezirke und Kreise durch den Ministerrat" mündeten. Der Beschluss definierte die Kompetenzen zentraler Regierungsorgane gegenüber den nachgeordneten Bezirks- und Kreisverwaltungen, ohne allerdings die von Hans Warnke angesprochenen informellen Zugriffe unterbinden zu können; der Text des Beschlusses ist abgedruckt in Dokumente 1949-1961, S. 112-113, sowie im Gesetzblatt der DDR, Teil II, 1955, S. 65-66. 
Von den Bezirken bis in die Kreise hinein geht die Anleitung schon besser, weil die Vorsitzenden der Bezirke und seine Stellvertreter häufig ja sogar regelmäßig direkt an den Ratssitzungen in den Kreisen teilnehmen. Dort nehmen sie nicht als einfache Dezernenten teil, sondern als Vorsitzende des Rates des Bezirkes.

Mir scheint, man sollte diesen Vorschlag von der Abteilung Staatliche Organe gemeinsam mit den Genossen der Regierung prüfen. Ich glaube, dass sich dadurch die Arbeit der örtlichen Organe verbessern wird.

(Wilhelm Pieck: Hans, da hast Du aber Deinem Herzen Luft gemacht!) $)^{353}$

[BArch, DY 30/IV 2/13/50, Bl. 451-465] $]^{354}$

Dokument 57: Schreiben des Vorsitzenden des Rates des Bezirkes Potsdam, Josef Stadler, ${ }^{355}$ an das Staatssekretariat für Innere Angelegenheiten beim Ministerium des Innern der DDR über die ,Einschätzung der bisherigen Erfahrungen der Arbeit der Bevollmächtigten und Instrukteure“, 2. Juni 1955 (Auszug)

Zur Arbeit der Bevollmächtigten und Instrukteure im Bezirk Potsdam übersende ich Ihnen nachfolgende Einschätzung:

\section{Zu Punkt 1:}

Die Besetzung der einzelnen Kreise mit Bevollmächtigten und Instrukteuren nach dem Stand vom 1.6.1955 ist folgende:

\begin{tabular}{|l|c|c|c|c|}
\hline Kreis & \multicolumn{2}{|c|}{ Bevollmächtigte } & \multicolumn{2}{c|}{ Instrukteure } \\
\hline & Soll & Ist & Soll & Ist \\
\hline Belzig & 3 & 3 & 23 & 18 \\
\hline Brandenburg & 4 & 3 & 26 & 22 \\
\hline Gransee & 4 & 3 & 23 & 11 \\
\hline Jüterbog & 2 & 2 & 26 & 17 \\
\hline Königs Wusterhausen & 2 & 2 & 20 & 12 \\
\hline Kyritz & 5 & 4 & 34 & 15 \\
\hline Luckenwalde & 2 & 2 & 12 & 12 \\
\hline Nauen & 4 & 3 & 33 & 23 \\
\hline
\end{tabular}

353 Wilhelm Pieck (1876-1960) war seit Oktober 1949 Präsident der DDR; vgl. Müller-Enbergs, Wer war wer, S. 657.

354 Das hier als Vorlage verwendete Typoskript stammt aus den Unterlagen der Abteilung Staatsund Rechtsfragen des ZK der SED und wurde mit dem stenografischen Protokoll der ZK-Tagung (BArch, DY 30/IV 2/1/137, Bl. 126-140) abgeglichen.

355 Josef Stadler (1906-1984) war seit April 1953 Vorsitzender des Rates des Bezirkes Potsdam; vgl. Niemann/Herbst, SED-Kader, S. 467. 


\begin{tabular}{|l|r|r|r|r|}
\hline Neuruppin & 6 & 4 & 35 & 20 \\
\hline Oranienburg & 4 & 3 & 18 & 13 \\
\hline Potsdam & 2 & 2 & 27 & 20 \\
\hline Pritzwalk & 4 & 1 & 36 & 19 \\
\hline Rathenow & 3 & 3 & 22 & 22 \\
\hline Wittstock & 3 & 2 & 17 & 7 \\
\hline Zossen & 3 & 1 & 16 & 9 \\
\hline Gesamt: & $\mathbf{5 1}$ & $\mathbf{3 8}$ & $\mathbf{3 6 6}$ & $\mathbf{2 3 8}$ \\
\hline
\end{tabular}

\section{Zu Punkt 2:}

Überprüft wurden die Kreise Neuruppin, Nauen, Pritzwalk, Zossen, Königs Wusterhausen.

Die Anleitung der Bevollmächtigten in den Landkreisen des Bezirkes Potsdam wird in der Regel einmal wöchentlich durchgeführt, wobei die Tage unterschiedlich gewählt wurden. Zum Beispiel im Kreise Neuruppin sonnabends, Kreis Nauen mittwochs, Kreis Zossen donnerstags. Die Anleitung wird vorgenommen vom 1. Sekretär der Kreisleitung der SED und dem Vorsitzenden des Rates des Kreises. In dieser Anleitung werden die Schwerpunkte der vorhergehenden Bürositzung der Kreisleitung und der Ratssitzung des Rates des Kreises den Bevollmächtigten erläutert, um damit gleichzeitig zu gewährleisten, dass die politischen Aufgaben mit den wirtschaftlichen Aufgaben verbunden werden.

Bei den Instrukteuren erfolgt die Anleitung durch den Bevollmächtigten in einer Arbeitsbesprechung am nächstfolgenden Werktag. Hierzu fasst der Bevollmächtigte die Instrukteure, Zootechniker und die Pflanzenschutztechniker seines MTS-Bereiches zusammen und gibt ihnen die Anleitung für die nächste Woche. So war zum Beispiel die Tagesordnung für die Anleitung der Instrukteure und alle auf dem Gebiete der Landwirtschaft tätigen Funktionäre für alle MTS-Bereiche im Kreise Neuruppin für den 23.5. folgende:

1. Politische Lage

2. Berichterstattung über

a) Plankontrolle in der Viehwirtschaft

b) Anbauplankontrolle

c) Ministerratsbeschluss vom 10.3.55 (Stand des Wettbewerbs)

3. Neue Aufgaben

a) Pflegemaßnahmen, Übernahme von Flächen in persönliche Pflege (Durchsetzung des Leistungsprinzips in der LPG)

b) Wettbewerbsbewegung

c) Kontrollpläne der LPG 
d) Durchsetzung der Erfahrungsaustausche zwischen den LPG zur Verbesserung der Viehwirtschaft

e) Sauenbedeckung

Unter Punkt 1 erläuterten die Polit-Leiter die wichtigsten politischen Ereignisse und verbanden hiermit gleichzeitig die Aufgabenstellung für die politische Arbeit der Instrukteure (Durchführung der Versammlungen zur Erläuterung des Warschauer-Vertrages, Stärkung der Verteidigungsbereitschaft und KVP-Werbung).

\section{Zu Punkt 2 und 3:}

Auch in den anderen Kreisen wurden die Tagesordnungen ähnlich aufgestellt.

Die bisherigen Erfahrungen zeigten, dass, wenn eine planmäßige Anleitung und Kontrolle ausgeübt wird, sich die Arbeit der Bevollmächtigten und Instrukteure auf die Schwerpunkte konzentrierte. In den Kreisen, wo sich die Instrukteure einen genauen Überblick über die Struktur ihrer Gemeinden, über die Arbeit der Ortsparteiorganisationen, des Ortsblockausschusses, der Massenorganisationen und über die Arbeit und Qualitäten des Bürgermeisters verschafften, entwickelte sich ein gutes Verhältnis zwischen den Instrukteuren und den landwirtschaftlichen Produktionsgenossenschaften. In diesen Gemeinden traten die LPG mehr als bisher in den Mittelpunkt.

Auf Grund der gegebenen Anleitung legten die Instrukteure ihr Augenmerk besonders auf die Umbildung der ÖLB in LPG oder Anschluss an schon bestehende LPG. Im Kreis Neuruppin wurde diese Aufgabe jedoch unterschätzt, sodass bis heute noch 15 ÖLB bestehen. In den meisten Kreisen ist die Arbeit der Instrukteure mit den werktätigen Einzelbauern noch sehr schwach entwickelt. Es fehlt ihnen mitunter der Mut und die Erfahrung die einzelnen Fragen in der Verbesserung der pflanzlichen und tierischen Produktion mit den werktätigen Bauern durchzusprechen.

So liegt ein Bericht aus dem Kreis Pritzwalk vor, dass für die bestehenden LPG noch keine werktätigen Einzelbauern zum Eintritt geworben wurden. Zum anderen zeigt aber ein Beispiel des Kreises Neuruppin, dass durch den Einsatz der Instrukteure im MTSBereich Kränzlin bereits 89 Wettbewerbsabschlüsse zur Steigerung der tierischen und pflanzlichen Produktion auf Grund des Ministerratsbeschlusses vom 10.3.55 getätigt wurden. Zusammenfassend kann hierzu gesagt werden, dass die unterschiedliche Qualifikation der Bevollmächtigten und Instrukteure, vor allem auf dem Fachgebiet Landwirtschaft, ausschlaggebend ist für die unterschiedlichen Erfolge in ihrer Arbeit. Zur Verbesserung der Qualifikation werden regelmäßig in Abständen von drei Wochen fachliche Lektionen von der Bezirksleitung der SED für die Bevollmächtigten durchgeführt. An diesem Tag wird gleichzeitig ein Erfahrungsaustausch mit den Bevollmächtigten durchgeführt. Im Arbeitsplan des Rates des Bezirkes für das III. Quartal 1955 ist festgelegt, dass im Schulungsheim Schönhagen im Monat Juli eine Schulung aller Bevollmächtigten des Bezirkes erfolgt. Ein Teil der Bevollmächtigten beteiligen sich am Fernstudium 
für Agrarökonomie. Durch die Volkshochschule der Kreise werden für alle auf dem Gebiet der Landwirtschaft in den MTS-Bereichen tätigen Mitarbeiter im nächsten Semester fachliche Zirkel organisiert.

Die Zusammenarbeit der Bevollmächtigten mit den Leitungen der MTS hat sich nach Überwindung teilweiser Anfangsschwierigkeiten gut entwickelt. Zu Beginn der Einsetzung der Bevollmächtigten kam es in einigen MTS-Bereichen infolge Missverständnissen in der Abgrenzung der Aufgaben beiderseits zu Schwächen in der Zusammenarbeit, die jedoch heute überwunden sind.

Zur vollen Besetzung der noch offenen Stellen der Bevollmächtigten und Instrukteure in den Kreisen wurde durch den Rat des Bezirkes festgelegt, dass unter Verantwortlichkeit der Leiter der Abteilung Innere Angelegenheiten beim Rat des Bezirkes und bei den Räten der Kreise die gebildeten Kommissionen zu aktivieren sind und in Zusammenarbeit mit der Abteilung Kader beim Rat des Bezirkes, sowie den Räten der Kreise dafür zu sorgen ist, dass alle noch offen stehenden Stellen schnellstens besetzt werden.

Für die Kreise mit den meisten Fehlstellen wurden verantwortliche Mitarbeiter der Abteilung Innere Angelegenheiten, Org.-Instrukteur-Abteilung und der Kaderabteilung beauftragt, die Anleitung und Kontrolle für die Besetzung dieser Funktionen auszuüben. In den Kreisen wurde der Abteilungsleiter Innere Angelegenheiten für die volle Besetzung der Planstellen verantwortlich gemacht.

Das bisherige Ergebnis dieser Maßnahmen zeigt, dass in den Kreisen, wo diese Aufgabe 14-tägig in den Ratssitzungen behandelt wurde und der gesamte Rat sich verantwortlich fühlte, der Erfolg nicht aufblieb. Das zeigen uns die Beispiele der Kreise Rathenow, Luckenwalde, Brandenburg und Belzig. [...]

[BArch, DO 1/26184, Bl. 84-88] 


\section{Dokument 58: Protokoll einer „Sitzung der Arbeitsgruppe Strukturfragen örtliche staatliche Organe“6, 23. Juli 1957 (Auszug)}

\section{Anwesend: $: 356$}

Genosse Peplinski, ${ }^{357}$ Staatssekretär

Genosse Opitz, ${ }^{358}$ Hauptabteilungsleiter Ministerium der Finanzen

Genosse Apelt, stellvertretender Arbeitsgruppenleiter (in Vertretung des Genossen Trotz) ZKSK

Genosse Armbrust, ${ }^{359}$ Sektorenleiter ZK

Genosse Jendretzky, ${ }^{360}$ Vorsitzender des Rates des Bezirkes Neubrandenburg

Genosse Springer, ${ }^{361}$ Vorsitzender des Rates des Bezirkes Frankfurt

Genosse Schultz, Sekretär der BPO des Rates des Bezirkes Frankfurt

Genosse Sorgenicht, ${ }^{362}$ Abteilungsleiter ZK kam im Laufe der Sitzung noch hinzu

Genosse Warnke, ${ }^{363}$ Vorsitzender des Rates des Bezirkes Rostock ließ sich entschuldigen, da er z. Zt. zur Kur weilt.

Genosse Peplinski weist einleitend $u$. a. darauf hin, dass es jetzt, nachdem die Thesen über die Vereinfachung des Staatsapparates und die Änderung der Arbeitsweise der Mitarbeiter des Staatsapparates bekannt und veröffentlicht sind, es darauf ankommt, die politisch-ideologische Vorbereitung zu treffen, um die Beschlüsse des 32. Plenums ${ }^{364}$ durchzuführen.

356 Die hier mit in die Edition übernommene Anwesenheitsliste belegt den überdurchschnittlich großen Anteil brandenburgischer Funktionäre in einer wichtigen Arbeitsgruppe auf der zentralen Ebene, die das „Gesetz über die Vervollkommnung und Vereinfachung der Arbeit des Staatsapparates der Deutschen Demokratischen Republik" vom 11. Februar 1958 vorbereitete; vgl. Gesetzblatt der DDR, Teil I, 1958, S. 117-120.

357 Zu Franz Peplinski, ab Oktober 1957 Leiter des Staatssekretariats für die Angelegenheiten der örtlichen Räte im Ministeriums des Innern der DDR, vgl. Dok. 53, Anm. 343.

358 Gerhard Opitz (1924-2013) war seit April 1957 Hauptabteilungsleiter im Ministerium der Finanzen der DDR; vgl. die Einleitung zum Online-Findbuch seines Nachlasses (N 2532) im Bundesarchiv Berlin-Lichterfelde (www.bundesarchiv.de; Zugriff am 1. September 2016).

359 Willi Armbrust (*1924) war zu diesem Zeitpunkt Sektorleiter in der Abteilung für Staats- und Rechtsfragen des ZK der SED; vgl. Baumgartner, Biographisches Handbuch, S. 15.

360 Hans Jendretzky (1897-1992) war seit Dezember 1953 Vorsitzender des Rates des Bezirkes Neubrandenburg; vgl. Niemann/Herbst, SED-Kader, S. 259.

361 Zu Günter Springer, seit November 1956 Vorsitzender des Rates des Bezirkes Frankfurt (Oder), vgl. Dok. 53, Anm. 344.

362 Zu Klaus Sorgenicht vgl. Dok. 2, Anm. 234.

363 Zu Hans Warnke vgl. Dok. 2, Anm. 231.

364 Auf der 32. Tagung des ZK der SED vom 10. bis 12. Juli 1957 wurden „Thesen zur Vereinfachung des Staatsapparates und zur Änderung der Arbeitsweise der Mitarbeiter des Staatsapparates“ beschlossen, die eine Grundlage des Gesetzes ,über die Vervollkommnung und Vereinfachung der Arbeit des Staatsapparates der Deutschen Demokratischen Republik" vom 11. Februar 1958 bildeten; die Thesen sind auszugsweise abgedruckt in Dokumente 1949-1961, S. 41-45. 
Er betont, dass es jetzt darauf ankommt, erst in der Parteiorganisation in diesen Fragen Klarheit zu schaffen und später dann mit allen Mitarbeitern die Probleme zu beraten und mit der ganzen Kraft der Partei die Beschlüsse des 32. Plenums durchzuführen. Er weist darauf hin, dass die Strukturfrage nicht im Vordergrund steht, im Vordergrund steht die inhaltliche Verbesserung der Arbeit und der Arbeitsweise der Mitarbeiter und Organe. Aber die Veränderung und Verbesserung der Arbeitsweise ist ohne die Verbesserung der Struktur nicht möglich. Keinesfalls dürfen jetzt schon eigenmächtige Strukturveränderungen vorgenommen werden, wodurch Unruhe in die Reihen der Mitarbeiter getragen werden könnte.

Das Schwergewicht der Arbeit wird jetzt in den Arbeitsgruppen der Partei liegen, um die Probleme zu untersuchen und auszudiskutieren. Dabei kommt es darauf an, die Fragen und Probleme nicht unnötig zu komplizieren. Es ist notwendig, die wirklich schwierigen Probleme aufzuzeigen.

Genosse Peplinski empfiehlt den anwesenden Genossen ein kurzes Studium der Materialien, die den Anwesenden beim Beginn der Beratung übergeben wurden. Die Kommissionsmitglieder erhielten:

1.) eine schematische Darstellung der Struktur des Bezirkes

2.) eine schematische Darstellung der Struktur des Kreises

3.) einen Entwurf von Grundsätzen für die Veränderung der Arbeitsweise und Struktur der örtlichen Organe der staatlichen Verwaltung

4.) einen Strukturvorschlag mit Bemerkungen für das Aufgabengebiet Bauwesen

5.) Probleme, die bei den Vorschlägen zur Veränderung der Arbeitsweise und der Struktur beachtet werden müssen.

Genosse Peplinski deutet noch auf einige Streitfragen und schwierige Probleme hin, wie sie z. T. in den übergebenen Materialien enthalten sind.

In der sich anschließenden Diskussion wird als erstes Problem die Aufgabenverteilung zwischen dem Vorsitzenden und erstem Stellvertreter des Vorsitzenden des Rates behandelt. Die anwesenden Genossen kommen dabei zu dem Vorschlag, dass das Aufgabengebiet Kader beim Vorsitzenden des Rates verbleiben sollte, weil man damit ansonsten dem Vorsitzenden praktisch die politische Verantwortung nimmt. Die Durchführung der Aufgaben, die das 32. Plenum stellt, macht es notwendig, weiterhin dieses Aufgabengebiet beim Vorsitzenden zu belassen. Im gleichen Zusammenhang wird der Vorschlag unterbreitet, das Aufgabengebiet Kultfragen nicht dem Vorsitzenden, sondern seinem ersten Stellvertreter für Inneres zu übertragen.

Genosse Jendretzky führt zur Begründung dieser Veränderung an, dass es dem Vorsitzenden gegenüber seinem Stellvertreter an Autorität fehlt, wenn ihm das Aufgabengebiet Kader entzogen wird. 
Genosse Peplinski äußert dazu, dass dies bereits in dem ersten Vorschlag der Hauptabteilung enthalten war. Entsprechend den Thesen und den Vorstellungen der Parteikommission soll Inneres der straff gelenkte Apparat sein, in dem alle inneren Angelegenheiten zusammengefasst sind. Es ist z. B. vorgesehen, dass die örtlichen Räte dem Minister des Innern unterstellt werden; das würde zweifellos einige Änderungen des Gesetzes vom 17.1.57 nach sich ziehen. ${ }^{365}$ Es ist erforderlich, das Problem der Zuordnung der Aufgabengebiete Kader und Kultfragen der Parteikommission mit richtigen Beweisen und unserer Stellungnahme vorzulegen.

Als zweites Problem wurde die Auflösung der Kontrollstellen bei den Vorsitzenden der Räte der Bezirke und Kreise diskutiert. Die Meinungen der anwesenden Genossen dazu waren unterschiedlich. Genosse Jendretzky ist z. B. der Meinung, dass es notwendig sein wird, die Kontrollstellen beizubehalten; wenn es auch z. Zt. noch viele Schwächen in der Arbeit der Kontrollstellen gibt, so hat es auf der anderen Seite auch viel Gutes für sich. Z. B. für die Entwicklung der Kader, oder für die Kontrolle der Durchführung der Beschlüsse, insbesondere derer, für die der Vorsitzende des Rates verantwortlich ist. Er begründet das damit, dass die Kontrollstelle der operative Arm des Vorsitzenden ist, womit er die Abteilungsleiter und Stellvertreter des Vorsitzenden zwingt, bestimmte Aufgaben zu lösen. Wenn man trotzdem zur Auflösung der Kontrollstellen kommen sollte, dann muss unbedingt der persönliche Referent bestehen bleiben, weil es für den Vorsitzenden dann etwas schwierig wird, die vielen Aufgaben zu lösen. Insbesondere betrifft das die Vorsitzenden der Räte der Kreise, die z. Zt. keine Planstelle für einen Persönlichen Referenten haben.

Ein weiterer Diskussionspunkt bildet die Frage, warum ein zweiter Stellvertreter des Vorsitzenden des Rates notwendig ist. Mit der Benennung eines zweiten Stellvertreters müsste man auch einen dritten, vierten, und fünften Stellvertreter haben. Deshalb sollte man die Bezeichnung ,zweiter Stellvertreter“ wegfallen lassen. Dazu gaben die Kommissionsmitglieder alle ihre Zustimmung. Die Bezeichnung ,erster Stellvertreter“ soll, wie vorgesehen, bleiben.

Als nächstes Problem steht die Frage der politischen Zugehörigkeit und die Besetzung der Stellvertreter des Vorsitzenden zur Diskussion. Dabei ist notwendig, die Frage zu klären, welche Stellen sollen von unserer Partei und welche von den Blockparteien besetzt werden. Es steht die Frage, was tun die Blockparteien zur Qualifizierung ihrer Mitglieder im Staatsapparat. Die Qualität der meisten Stellvertreter reicht nicht aus. Die Verantwortung für die Qualifizierung der Stellvertreter aus den Blockparteien liegt bei den Blockparteien selbst. Wenn die Qualifizierung eines Stellvertreters nicht vorliegt, gibt es z. B. die Möglichkeit, dass er im Rat verbleibt, aber in einem Fachorgan eingesetzt wird.

365 Das „Gesetz über die örtlichen Organe der Staatsmacht“ ist auszugsweise abgedruckt in Dokumente 1949-1961, S. 117-123, sowie, dort allerdings unter dem Datum 18. Januar 1957, im Gesetzblatt der DDR, Teil I, 1957, S. 65-72. 
Die andere Möglichkeit ist, dass verschiedene Stellvertreter ausscheiden, aber was soll dann mit den Menschen geschehen? Zum anderen, wie können wir diese Frage im Rahmen unserer Blockpolitik klären? Wir können die Blockparteien nicht aus der politischen Verantwortung entlassen. Genosse Jendretzky berichtet, dass beim Rat des Bezirkes Neubrandenburg drei Stellvertreter-Planstellen mit Angehörigen der Blockparteien z. Zt. besetzt sind:

Stellvertreter für Landwirtschaft

DBD

Stellvertreter für örtliche Wirtschaft

LDPD

Stellvertreter für Gesundheitswesen und Arbeit

NDPD

(Die CDU hat ein weiteres Mitglied des Rates)

Nach erfolgter Aussprache kommen die Mitglieder der Arbeitsgruppe zu der Auffassung, dass man die Zahl der Stellvertreter belassen sollte. Für die Besetzung der Planstellen für Angehörige der Blockparteien käme künftig eventuell in Frage:

Stellvertreter für Wirtschaft

Stellvertreter für Landwirtschaft

Stellvertreter für Gesundheitswesen

Einen breiten Raum der Diskussion nahm das Problem der Struktur der Wirtschaftskommission und das Verhältnis der Wirtschaftskommission zum Rat und seinen Fachorganen ein. Im Ergebnis dieser Diskussion wurden im wesentlichen drei Möglichkeiten erwogen.

a) Trennung der Planung von der operativen Tätigkeit. Das entspricht etwa den Vorstellungen, wie sie in der schematischen Darstellung aufgezeigt werden. Dabei wurde insbesondere die Frage der Zuordnung der Abteilung Finanzen diskutiert. Genosse Opitz stellte die Frage, wie der Minister der Finanzen in Zukunft seine wirtschaftliche Tätigkeit ausüben soll, wenn die Abteilung Finanzen nicht mehr dem Ministerrat unterstellt ist und demzufolge der Minister keine Weisungen mehr erteilen kann. Er ist der Auffassung, dass die Abteilung Finanzen dem Stellvertreter für Wirtschaft zugeordnet werden müsste oder, falls Finanzen in die Wirtschaftskommission genommen wird, der Minister der Finanzen weisungsberechtigt gegenüber der Abteilung sein müsste. Zum anderen hat das Ministerium der Finanzen auch Grundsatzfragen zu lösen, z. B. Planungsmethodik usw. Wie soll das künftig an die Fachorgane weitergegeben werden? Die Genossen Jendretzky und Sorgenicht führten aus, dass man die Haushaltplanung und die volkswirtschaftliche Planung voneinander nicht trennen kann. Finanzen muss deshalb unbedingt auch in der Wirtschaftskommission vertreten sein, was eine Zerreißung des Aufgabengebietes Finanzen bedeuten würde. Genosse Sorgenicht betont, dass man nicht von der jetzigen Unterstellungsform ausgehen darf bei der Diskussion dieser Probleme. Die jetzige Unterstellungsform wollen wir ja beseitigen. Weisungen von Leitern zentraler Organe kann es in Zukunft nicht mehr geben, sondern sie kontrollieren nur operativ. Eine andere Frage ist das Problem Inneres, wo wir denselben Innenminister in seiner früheren Stellung schaffen wollen. 
In diesem Zusammenhang wird das Problem diskutiert, welche Beziehungen die Gruppe oder der Sektor in der Wirtschaftskommission zur Abteilung bzw. operativen Gruppe, die dem jeweiligen Stellvertreter untersteht, haben soll. Nach einer längeren Aussprache über diese Frage kam man zu der Auffassung, die Stellvertreter in der Wirtschaftskommission fallen zu lassen und dem Leiter der Gruppe bzw. des Sektors des betr. Fachgebietes in der Wirtschaftskommission gleichzeitig die Funktion des Gruppen- bzw. Abteilungsleiters im Fachorgan des Rates zu übertragen, d. h., dass z. B. der Abteilungsleiter für Landwirtschaft beim Rat gleichzeitig Leiter der Gruppe bzw. des Sektors Landwirtschaft bei der Wirtschaftskommission ist. Er wäre dann also doppelt unterstellt, nämlich einmal dem Stellvertreter des Vorsitzenden des Rates, zum anderen dem Vorsitzenden der Wirtschaftskommission. Der Leiter des Bauamtes wäre z. B. gleichzeitig Leiter des Sektors oder der Gruppe Bauwesen in der Wirtschaftskommission. Damit haben wir die Sache in einer Hand.

Die Stellvertreter des Vorsitzenden des Rates sollten nicht ständiges Mitglied der Wirtschaftskommission sein, sondern nur zu bestimmten Fragen beratend hinzugezogen werden. Sie sollen aber jeweils ein Exemplar der Protokolle über die Sitzungen der Wirtschaftskommission zugestellt erhalten.

b) Auflösung der Aufgabengebiete des Stellvertreters für Wirtschaft und Übernahme in die Wirtschaftskommission, d. h. dass es künftig keinen Stellvertreter für Wirtschaft mehr gibt, dass Planung, Plankoordinierung und operative Kontrolle in die Wirtschaftskommission übernommen wird. Genosse Springer schlägt vor, dass man dann die Sektoren oder Gruppen in der Wirtschaftskommission teilen könnte, z. B. in Planung und operative Durchführung. Im Verlauf der weiteren Diskussion wird die Frage erwogen, weshalb dann noch die Abteilung Landwirtschaft und Handel und die übrigen Gruppen und Abteilungen beim Rat verbleiben sollten. Desgleichen wurde die Frage gestellt, dass, wenn alles in die Wirtschaftskommission aufgenommen wird, sie dann so ein Gebilde wird, die den Rat faktisch aufhebt. Selbst wenn nur die Aufgabenbereiche des Stellvertreters des Vorsitzenden für Wirtschaft in die Wirtschaftskommission übernommen werden, bleibt für den Rat nicht mehr viel übrig.

In diesem Zusammenhang wird auch die Frage aufgeworfen, welche Beziehungen künftig zwischen den neu zu bildenden VVB und der Wirtschaftskommission bestehen sollen. Die neuen VVB werden sich wesentlich von den früheren VVB unterscheiden. Früher war die wirtschaftliche Selbständigkeit der VVB beschränkt. Genosse Armbrust ist der Meinung, dass die im Gesetz vom 17.1.57 formulierten Rechte der örtlichen Organe in dieser Hinsicht erweitert werden müssten. Genosse Peplinski erwähnt, dass es sich eventuell als zweckmäßig erweisen wird, bestimmte Leitbetriebe zu schaffen, dass ferner von den Fachministerien auf die örtlichen Betriebe in Zukunft stärker Einfluss genommen werden muss, insbesondere in Fragen der Technologie und der Arbeitsorganisation. Genosse Jendretzky führt aus, dass es hier gilt, noch eine Frage zu klären. Auf der einen Seite kontrollieren die örtlichen staatlichen Organe die VVB, auf der anderen Seite wird die Wirtschaftskommission für die Erfüllung der Exportaufträge verantwortlich gemacht. 
Genosse Jendretzky erwähnt weiter, dass wir zwar im Bezirk Vorstellungen über die Wirtschaftskommission haben, dass uns diese Vorstellungen aber zentral noch fehlen. Dass es demzufolge notwendig sein wird, eine Abstimmung und Koordinierung vorzunehmen.

c) Beibehaltung der Fachabteilungen bzw. -gruppen auch der Planer und Haushaltsbearbeiter. Dafür sollen die Abteilungsleiter Mitglied der Wirtschaftskommission sein, d. h., dass sich in der Struktur nur wenig verändern würde, dass lediglich die Zusammensetzung der Plankommission bzw. dann Wirtschaftskommission eine Veränderung erfahren würde. Ausgenommen die Abteilung Finanzen, die in die Wirtschaftskommission übergehen würde. Desgleichen ausgenommen die Veränderungen auf dem Gebiet des Bildungswesens, der Kultur, Sport, Gesundheitswesen usw., die nur aus operativen Gruppen beim Bezirk bestehen sollen. Die Planung dieser Aufgabengebiete erfolgte in der Wirtschaftskommission. Genosse Sorgenicht stellte bei dieser Diskussion die Frage, wer dann die Materialversorgung machen sollte. Des Weiteren, wohin der Hauptarchitekt, der ja mit der Städteplanung zu tun hat, hin soll.

Bei diesem Vorschlag werden die Querschnittsabteilungen beigehalten. Das bedeutet, dass große Einsparungen nicht erzielt werden.

Im Verlauf der weiteren Diskussion wurden noch folgende Fragen und Probleme angesprochen: Die Kommission kam zu der einmütigen Auffassung, die Abteilungen Erfassung und Aufkauf und Landwirtschaft zusammen zu legen.

Der Leiter der Gruppe Volksbildung wird künftig der Bezirksschulrat sein. Nach Auffassung der Mitglieder der Arbeitsgruppe ist es nicht erforderlich, dass er Mitglied der Wirtschaftskommission ist. Genosse Sorgenicht betont, dass sich unsere Volksbildung in $\mathrm{Zu}-$ kunft stärker auf die politisch-pädagogisch erzieherische Arbeit orientieren muss. Vom Genosse Jendretzky wird die Frage gestellt, was künftig mit den Kreisbeauftragten der ZKK geschehen soll und welche Aufgaben der Rat des Kreises dabei hat.

Die Mitglieder der Arbeitsgruppe empfehlen der Kommission für staatliche Kontrolle, dass künftig die Kreisbeauftragten der ZKK der örtlichen Volksvertretung vorgestellt und von ihr bestätigt werden.

Desgleichen wird die Frage diskutiert, dass es zur Zeit eine ganze Anzahl von Kontrollorganen gibt, die oftmals losgelöst voneinander arbeiten. In der Zukunft wird es notwendig sein, auch hier eine Koordinierung durchzuführen und eine enge Zusammenarbeit mit den Planungsorganen herzustellen.

Auf eine Anfrage teilt Genosse Opitz mit, dass beim Ministerium der Finanzen einschließlich der Stellenplankommission keine Tätigkeitsmerkmale für die Mitarbeiter beim Rat des Bezirkes bzw. Rat des Kreises vorhanden sind. In der Arbeitsgruppe wird festgelegt, dass Genosse Opitz bis zur nächsten Beratung die Tätigkeitsmerkmale für den Bezirk durch die Stellenplankommission aus dem Bezirk Magdeburg beschafft. 
Genosse Springer erhält von der Arbeitsgruppe den Auftrag, nach den diskutierten Gesichtspunkten (Struktur der Wirtschaftskommission Absatz c) Tätigkeitsmerkmale für die Mitarbeiter beim Rat des Bezirkes Frankfurt auszuarbeiten und möglichst bis zur nächsten Besprechung der Arbeitsgruppe Genosse Peplinski in 12-facher Ausfertigung zu übergeben.

Vom Genosse Sorgenicht wird vorgeschlagen, der Parteikommission am 2.8.57 zwei Probleme vorzulegen:

1) Struktur der Wirtschaftskommission

2) Besetzung der Stellvertreter durch die Blockparteien. [...]

[BArch, DO 1/26087, Bl. 29-36]

Dokument 59: Beschlussvorlage der Hauptabteilung für Angelegenheiten der örtlichen Räte des Ministeriums des Innern für das Politbüro des Zentralkomitees der SED ,über die Aufgaben und die Struktur der Plankommissionen bei den Räten der Kreise“6, 12. Dezember 1957

Die politisch-ökonomische Entwicklung in der Deutschen Demokratischen Republik erfordert die ständige Verbesserung und die weitere Vervollkommnung des Aufbaus und der Arbeitsweise des Staatsapparates. Die staatlichen Organe müssen sich zu wahrhaft sozialistischen Staatsorganen entwickeln und den sozialistischen Aufbau in enger Verbundenheit mit den werktätigen Menschen organisieren.

Die Kreistage leiten als die in ihrem Zuständigkeitsbereich obersten Organe der Staatsmacht im Rahmen ihrer Aufgaben und Rechte auf der Grundlage der Verfassung, der Gesetze und Verordnungen sowie der Beschlüsse übergeordneter Staatsorgane den politischen, wirtschaftlichen und kulturellen Aufbau in ihrem Kreis. Sie verwirklichen die Leitung des sozialistischen Aufbaus insbesondere durch die Beschlussfassung über den Volkswirtschafts- und Haushaltsplan des Kreises sowie durch Beratungen und Beschlüsse, durch die Tätigkeit ihrer ständigen und zeitweiligen Kommissionen, durch die Arbeit ihrer Abgeordneten und die Tätigkeit der Räte als den vollziehend-verfügenden Organen zur Organisierung und Sicherung der Pläne. Die Durchführung der Aufgaben der Kreistage und ihrer Räte ist nur mit Hilfe und in enger Zusammenarbeit mit den Werktätigen möglich, die in Produktionsberatungen, ökonomischen Konferenzen und Beratungen mit den Parteien, der Nationalen Front, den Gewerkschaften, der FDJ und anderen Massenorganisationen zum Ausdruck kommt.

Die planmäßige, operative Leitung der Wirtschaft durch die Kreistage und deren Räte erfordert die Konzentration der Planung und eine höhere Qualität der Arbeit der Planungsorgane bei gleichzeitiger Beseitigung des ressortmäßigen Nebeneinanderarbeitens. 
Die Plankommissionen bei den Räten der Kreise sind daher umzubilden und zu verstärken.

\section{Die Hauptaufgaben der Plankommissionen bei den Räten der Kreise.}

Die Plankommissionen sind Organe der Räte der Kreise. Sie üben ihre Tätigkeit auf der Grundlage und in Durchführung der Gesetze und Beschlüsse der Volkskammer, der Verordnungen und Beschlüsse des Ministerrates sowie der Beschlüsse der Bezirks- und Kreistage und ihrer Räte aus.

Die Ausarbeitung, Durchführung und Kontrolle der Pläne muss unter breitester Mitwirkung der Werktätigen erfolgen, insbesondere in enger Zusammenarbeit mit den Ausschüssen der Nationalen Front, dem Freien Deutschen Gewerkschaftsbund, der VdgB sowie den demokratischen Parteien und Massenorganisationen.

Die Hauptaufgaben der Plankommission sind:

1. Ausarbeitung von Entwicklungsprogrammen auf der Grundlage der ökonomischen Analysen (Ökonomik des Kreises).

2. Auf der Grundlage der Beschlüsse der Kreistage und der Räte der Kreise auszuarbeiten und zu koordinieren

a) die Direktive für die Aufstellung der Perspektiv- und Jahresvolkswirtschaftspläne und des Nationalen Aufbauwerkes,

b) die Vorschläge zu den Perspektiv- und Jahresvolkswirtschaftsplänen,

c) die Perspektiv- und Jahresvolkswirtschaftspläne und des Nationalen Aufbauwerkes auf der Grundlage der staatlichen Aufgaben (einschließlich der Hauptkennziffern für die Volkswirtschaftspläne der Städte, Stadtbezirke und Gemeinden.)

Die Perspektivpläne haben für die einzelnen Gebiete wie Landwirtschaft, Bauwesen, Örtliche und kommunale Wirtschaft usw. die wichtigsten Grundfragen der Perspektive für den wirtschaftlichen und kulturellen Aufbau zu enthalten, um den Werktätigen ein klares Programm für den weiteren Aufbau des Sozialismus in ihrem Kreis zu geben.

Die von den Kreistagen beschlossenen Perspektivpläne bilden die Arbeitsgrundlage für die Plankommissionen.

3. Dem Rat ihre Stellungnahme zu den Entwürfen der Haushaltspläne und zu den Abrechnungen des Haushalts vorzulegen.

4. Ausarbeitung der detaillierten Aufgaben des Volkswirtschaftsplanes in enger Zusammenarbeit mit den Fachorganen für alle Bereiche außer Land- und Forstwirtschaft, Handel und Versorgung und Bauwirtschaft. 
Für die Bereiche Land- und Forstwirtschaft, Handel und Versorgung und Bauwirtschaft legen die Plankommissionen die Hauptkennziffern fest. Auf dieser Grundlage arbeiten die zuständigen Fachorgane ihre detaillierten Pläne aus.

5. Planung der Arbeitskräfte und Löhne sowie der Berufsausbildung. Organisierung der volkswirtschaftlich richtigen Verteilung der Arbeitskräfte.

6. Unterstützung der Räte der Städte und Gemeinden bei der Aufstellung und Durchführung der Stadt- und Dorfpläne. Die Pläne der Städte und Dörfer müssen die systematische Leitung des sozialistischen Aufbaus durch die örtlichen Organe der Staatsmacht gewährleisten.

7. Operative Kontrolle der Planerfüllung in Zusammenarbeit mit den Fachorganen der Räte der Kreise; regelmäßige Auswertung des Standes der Planerfüllung; Ausarbeitung von Analysen über den Stand der Planerfüllung.

8. Planung der Materialversorgung und Verteilung der Kontingente für alle Betriebe und anderen Bedarfsträger in ihrem Zuständigkeitsbereich. Einwirkung auf die zweckmäBigste Verwendung des Materials und der Einführung der fortschrittlichen Technik. Volle Ausnutzung der vorhandenen Kapazitäten, Ausschöpfung örtlicher Rohstoffquellen und anderer örtlicher Reserven.

9. Einwirkung auf die Entwicklung der zentral- und bezirksgeleiteten Wirtschaft durch

- Unterstützung und Kontrolle der Durchführung der Pläne für die zusätzliche Produktion von Massenbedarfsgütern. Erfassung und Verteilung von weiterverwendbaren Abfallmaterialien sowie anderer örtlicher Reserven,

- die Durchführung der Investitionen für soziale, kulturelle und sanitäre Einrichtungen und für weitere Maßnahmen, die sich aus der Entwicklung der zentralen und bezirksgeleiteten Wirtschaft für ihr Gebiet ergeben,

- Unterstützung der Durchführung von zentralen Investitionsvorhaben, Festlegung von Maßnahmen, welche die volkswirtschaftlich richtige Verteilung der Arbeitskräfte und die Berufsausbildung sichern,

- Kontrolle der Durchführung der Arbeitskräftepläne und der Pläne der Berufsausbildung.

10. Einbeziehung des Handwerks und der privatkapitalistischen Industrie in den sozialistischen Aufbau. Förderung der Bildung von Handwerkerproduktionsgenossenschaften sowie der staatlichen Beteiligung an privatkapitalistischen Betrieben. 


\section{Die Zusammensetzung, Struktur und Stellung der Plankommissionen bei den Räten der Kreise}

1. Die Plankommissionen setzen sich zusammen aus:

a) dem Vorsitzenden der Plankommission (Stellvertreter des Vorsitzenden des Rates des Kreises);

b) dem Stellvertreter des Vorsitzenden der Plankommission, der zugleich den Apparat der Plankommission leitet;

c) den Leitern folgender Fachorgane:

aa) Finanzen (der Leiter der Abteilung Finanzen ist zugleich Mitglied der Rates);

bb)Land- und Forstwirtschaft oder der Stellvertreter des Vorsitzenden des Rates für dieses Fachorgan;

cc) örtliche Industrie und Handwerk;

dd) Kreisbauamt (der Leiter des Kreisbauamtes ist zugleich Mitglied des Rates);

ee) Handel und Versorgung;

ff) Lebensmittelindustrie, Erfassung und Aufkauf.

Die Räte der Kreise können entsprechend der Wirtschaftsstruktur des Kreises weitere Leiter der Fachorgane sowie andere leitende Funktionäre z. B. MTS-Direktor usw. zu Mitgliedern der Plankommission berufen bzw. zu den jeweiligen Beratungen hinzuzuziehen.

Die Leiter der Kreisstelle für Statistik haben an den Sitzungen der Plankommission teilzunehmen.

Der Plankommission sollten nicht mehr als 15 Mitglieder angehören. Die Mitglieder der Plankommission werden auf Vorschlag des Vorsitzenden der Plankommission durch die Räte der Kreise berufen und abberufen.

Vom FDGB benannte Vertreter sowie die Kreisbeauftragten der Zentralen Kommission für staatliche Kontrolle haben das Recht, an den Sitzungen der Plankommission teilzunehmen.

2. Dem Stellvertreter des Vorsitzenden des Rates und Vorsitzenden der Plankommission können auf Beschluss des Rates neben der Plankommission weitere Fachorgane unterstellt werden, wie z. B.:

die örtliche Industrie und Handwerk

Kommunale und Wasserwirtschaft ${ }^{366}$

Verkehr

Energie

Arbeit

Die Zuordnung der einzelnen Aufgabenbereiche an die Stellvertreter des Vorsitzenden des Rates beschließen die Räte in eigener Verantwortung. Nach $\S 40$ des Gesetzes

366 Anmerkung im Original: „In größeren Städten kann die Wasserwirtschaft in die Kreisbauämter eingegliedert werden.“" 
über die örtlichen Organe der Staatsmacht vom 17.1.1957 haben sie gegenüber den Leitern dieser Fachorgane sowie den Leitern unterstellter Betriebe und Einrichtungen Weisungsrecht.

Der Apparat der Plankommission gliedert sich in:

a) die Gruppe Perspektivplanung,

b) die Gruppe operative Jahresplanung und Koordinierung

aa) Volkseigene Industrie, Betriebe mit staatlicher Beteiligung, privatkapitalistische Betriebe, Handwerksproduktionsgenossenschaften und Handwerker,

bb) kommunale Wirtschaft und Wasserwirtschaft,

cc) Bauwesen, Baustoffindustrie, Bodenbewegung und Verkehr,

dd)Land- und Forstwirtschaft, Erfassung und Aufkauf und Handel und Versorgung,

ee) Volksbildung, Kultur, Sport, Jugendfragen und Berufsschulwesen,

ff) Gesundheits- und Sozialwesen,

gg) Investitionen und Lizenzen für alle Wirtschaftszweige.

c) Die Gruppe Materialtechnische Versorgung.

3. Die Vorsitzenden der Plankommissionen unterbreiten den Räten zu Beschlussfassung

a) die Direktiven zur Ausarbeitung der Perspektiv- und Jahresvolkswirtschaftspläne. Die Perspektiv- und Jahresvolkswirtschaftspläne und das Nationale Aufbauwerk.

b) Die Analysen und Maßnahmen zur Erfüllung der Pläne.

c) Vorschläge über Maßnahmen in der operativen Plandurchführung, die eines Beschlusses des Kreistages oder ihrer Räte erfordern.

Der Vorsitzende der Plankommission ist dem Rat des Kreises für die Arbeit der Plankommission verantwortlich und rechenschaftspflichtig.

Der Vorsitzende der Plankommission hat das Recht, von den im Zuständigkeitsbereich liegenden Betrieben Organen und Einrichtungen, die dem Rat des Kreises nicht unterstellt sind, Auskünfte im Rahmen der Kompetenzen des Rates des Kreises zu verlangen, ausgenommen sind davon Spezialfragen, über die besondere Vorschriften bestehen.

Der Vorsitzende der Plankommission hat gegenüber der Kreisstelle für Statistik Weisungsbefugnis in Fragen der Sammlung und Auswertung von statistischen Ergebnissen des Kreises.

[BArch, DO 1/26087, Bl. 176-182] 
Dokument 60: Analyse der Hauptabteilung für Angelegenheiten der örtlichen Räte des Ministeriums des Innern „über die Kadersituation im Jahre 1958“،, 9. März 1959

\section{Besetzung von Planstellen}

Die Zahl der Planstellen verringerte sich um 13,0\%

davon örtliche Räte um 7,4 \%

davon Regierungsdienststellen um $41,1 \%$

Die Zahl der unbesetzten Planstellen ist unwesentlich angestiegen.

\begin{tabular}{|c|c|c|c|}
\hline \multicolumn{2}{|c|}{ Stand unbesetzte Stellen } & \multicolumn{2}{|c|}{ davon } \\
\hline & & Örtliche Räte & $\begin{array}{c}\text { Regierungsdienst- } \\
\text { stellen }\end{array}$ \\
\hline 1957 & $4,5 \%$ & $3,8 \%$ & $8,5 \%$ \\
\hline 1958 & $5,3 \%$ & $\begin{array}{c}4,6 \%=4465 \text { Plan- } \\
\text { stellen unbesetzt }\end{array}$ & $\begin{array}{c}10,1 \%=389 \text { Plan- } \\
\text { stellen unbesetzt }\end{array}$ \\
\hline
\end{tabular}

davon leitende Mitarbeiter

\begin{tabular}{|l|c|c|c|}
\hline \multicolumn{2}{|c|}{ Stand unbesetzte Stellen } & \multicolumn{2}{|c|}{ davon } \\
\hline & & Örtliche Räte & $\begin{array}{c}\text { Regierungsdienst- } \\
\text { stellen }\end{array}$ \\
\hline 1957 & $4,3 \%$ & $3,5 \%$ & $8,2 \%$ \\
\hline 1957 & $6,0 \%$ & $\begin{array}{c}4,7 \%=863 \text { Plan- } \\
\text { stellen unbesetzt, davon } \\
\text { 336 Bürgermeister }\end{array}$ & $\begin{array}{c}14,4 \%=389 \text { Plan- } \\
\text { stellen unbesetzt }\end{array}$ \\
\hline
\end{tabular}

Das beweist, dass die Anstrengungen um die planmäßige Entwicklung eines ausreichenden Nachwuchses ungenügend sind.

II. Klassenmäßige und politische Zusammensetzung

\begin{tabular}{|l|c|c|c|c|c|c|c|c|}
\hline \multicolumn{2}{|c|}{} & $\begin{array}{c}\text { Soziale } \\
\text { Stellung } \\
\text { Arbeiter }\end{array}$ & $\begin{array}{c}\text { Soziale } \\
\text { Her- } \\
\text { kunft } \\
\text { Arbeiter }\end{array}$ & SED & $\begin{array}{c}\text { ehe- } \\
\text { malige } \\
\text { NSDAP }\end{array}$ & $\begin{array}{c}\text { davon } \\
\text { SED }\end{array}$ & $\begin{array}{c}\text { ehe- } \\
\text { malige } \\
\text { Dienst- } \\
\text { grade }\end{array}$ & $\begin{array}{c}\text { davon } \\
\text { SED }\end{array}$ \\
\hline \multirow{2}{*}{$\begin{array}{l}\text { Örtliche } \\
\text { Räte }\end{array}$} & 1957 & $30,7 \%$ & $61,1 \%$ & $47,0 \%$ & $7,6 \%$ & & $6,5 \%$ & \\
\cline { 2 - 9 } $\begin{array}{l}\text { Zentrale } \\
\text { Organe }\end{array}$ & 1958 & $32,4 \%$ & $63,4 \%$ & $49,1 \%$ & $6,7 \%$ & $45,6 \%$ & $6,4 \%$ & $61,8 \%$ \\
\cline { 2 - 9 } & 1958 & $17,2 \%$ & $58,6 \%$ & $51,1 \%$ & $5,6 \%$ & & $6,9 \%$ & \\
\hline
\end{tabular}


Die höchste Zuwachsrate an produktionserfahrenen Mitarbeitern (Arbeiter der sozialen Stellung nach) zeigen die Räte der Stadtbezirke mit $+4 \%$ wie auch die Räte der Bezirke mit $+3,3 \%$.

Den höchsten Stand besitzen nach wie vor die Räte der Gemeinden mit 44,6 \%, den niedrigsten die Räte der Bezirke mit $26 \%$.

Bei den zentralen Organen zeigen Stand und Zuwachs, dass keine systematische Arbeit zur klassenmäßigen Verstärkung geleistet wurde. Die z. Zt. vorherrschende Methode zur Erhöhung des Anteils der Arbeiterkader ist eine lediglich sorgfältigere Auswahl der jeweils vorliegenden Bewerbungen und Vorschläge. Positiv ist die Verminderung des Anteils ehemaliger Mitglieder der NSDAP und Dienstgrade.

Die beste klassenmäßige Zusammensetzung erreichten auf Bezirksebene

\begin{tabular}{|l|c|c|c|c|c|c|}
\hline & $\begin{array}{c}\text { Soziale } \\
\text { Stellung } \\
\text { Arbeiter }\end{array}$ & Zuwachs & SED & NSDAP & davon SED & $\begin{array}{c}\text { NSDAP } \\
\text { verringert } \\
\text { um }\end{array}$ \\
\hline Magdeburg & $40,7 \%$ & $7,7 \%$ & $65,5 \%$ & $2,2 \%$ & $54,3 \%$ & $2,7 \%$ \\
\hline Gera & $32,2 \%$ & $10,8 \%$ & $67,1 \%$ & $5,4 \%$ & $56,5 \%$ & $2,6 \%$ \\
\hline Halle & $32,0 \%$ & $7,7 \%$ & $62,9 \%$ & $4,9 \%$ & $55,2 \%$ & $2,2 \%$ \\
\hline
\end{tabular}

die schlechteste Zusammensetzung

\begin{tabular}{|l|c|c|c|c|c|c|}
\hline & $\begin{array}{c}\text { Soziale } \\
\text { Stellung } \\
\text { Arbeiter }\end{array}$ & Zuwachs & SED & NSDAP & davon SED & $\begin{array}{c}\text { NSDAP } \\
\text { verringert } \\
\text { um }\end{array}$ \\
\hline Potsdam & $17,6 \%$ & $1,1 \%$ & $53,1 \%$ & $4,4 \%$ & $43,5 \%$ & $1,3 \%$ \\
\hline Schwerin & $19,1 \%$ & $0,9 \%$ & $55,9 \%$ & $6,7 \%$ & $47,2 \%$ & $+0,2 \%$ \\
\hline Cottbus & $19,8 \%$ & $0,9 \%$ & $60,2 \%$ & $3,8 \%$ & $73,3 \%$ & $+0,3 \%$ \\
\hline
\end{tabular}

Auf der Kreisebene erreichten eine gute Zusammensetzung

Bezirk Neubrandenburg mit 36,3\% Arbeitern und einem Zuwachs von 6,7 \%

Bezirk Magdeburg mit 43,2 \% Arbeitern und einem Zuwachs von 4,1 \%

während im Bezirk Schwerin dieser Anteil von 24,4 \% auf 21,8 \% und im Bezirk Suhl von $30,6 \%$ auf $25,7 \%$ sank.

Zur Verstärkung der Bürgermeisterfunktionen durch Industriearbeiter ist in allen Bezirken - außer Cottbus, Schwerin und Suhl - eine, wenn auch allgemein geringe Steigerung erfolgt. An der Spitze stehen hier die Bezirke 


\begin{tabular}{|l|c|l|c|}
\hline Leipzig & Stand $75,9 \%$ & Arbeiter der sozialen Stellung nach, Zuwachs & $0,9 \%$ \\
\hline Halle & Stand $74,0 \%$ & Arbeiter der sozialen Stellung nach, Zuwachs & $0,7 \%$ \\
\hline Neubrandenburg & Stand $68,7 \%$ & Arbeiter der sozialen Stellung nach, Zuwachs & $7,1 \%$ \\
\hline Dresden & Stand $68,3 \%$ & Arbeiter der sozialen Stellung nach, Zuwachs & $0,3 \%$ \\
\hline Karl-Marx-Stadt & Stand $67,9 \%$ & Arbeiter der sozialen Stellung nach, Zuwachs & $2,1 \%$ \\
\hline
\end{tabular}

Der Anteil der „Arbeiter der sozialen Stellung nach“ unter den leitenden Mitarbeitern der Räte der Bezirke hat sich unterschiedlich entwickelt. Insgesamt von 33,8 \% auf 37,8 \% angestiegen, fiel er in den nördlichen Bezirken

Neubrandenburg um 20,8\%

Rostock um 17,9\% und einer Reihe anderer Bezirke um 2-7 \%,

andererseits stieg er stark an in südlichen Bezirken

Erfurt um 24,7 \%

Gera um 19,4\%

Karl-Marx-Stadt um 17,9\%

Halle um 15,3\% und anderen Bezirken um 1-3\%.

In den Kreisen zeigt sich dagegen eine gleichmäßig steigende Tendenz. An der Spitze stehen

\begin{tabular}{|l|l|l|}
\hline Leipzig & mit 42,7\% & Zuwachs 4,3\% \\
\hline Dresden & mit 38,9\% & Zuwachs 0,1\% \\
\hline Karl-Marx-Stadt & mit 37,4\% & Zuwachs 5,3\% \\
\hline Halle & mit 37,2\% & Zuwachs 5,5\% \\
\hline
\end{tabular}

Die höchste Zuwachsrate von 13,2 \% weist dabei Neubrandenburg auf, dem gegenüber sank der Arbeiteranteil bei den Bezirken Schwerin (um 6,6 \%), Frankfurt (um 3,8 \%) und Rostock (um 3,0\%).

Bei den Regierungsdienststellen erreichte den größten Erfolg bei der Verstärkung des Anteils der „Arbeiter der sozialen Stellung nach“ die Regierungskommission für Preise mit einem Zuwachs von 11,4\%. Ihr folgen die Ministerien für Handel und Versorgung mit 4,1 \% und Außenhandel mit 3,4\%. Einen über dem Durchschnitt von $19 \%$ liegenden Stand weisen auf

Oberste Staatsanwaltschaft mit 44,4\%

Ministerium für Auswärtige Angelegenheiten mit 30,6 \%

Ministerium für Justiz mit 30,0 \%

Bemerkenswert ist, dass bei den unter dem Durchschnitt liegenden Regierungsdienststellen der Anteil der Mittelschichten der sozialen Stellung noch relativ hoch ist. 


\begin{tabular}{|l|r|r|r|}
\hline Ministerium für Post und Fernmeldewesen & $31,6 \%$ & dagegen Arbeiter & $8,6 \%$ \\
\hline Ministerium der Finanzen & $15,0 \%$ & dagegen Arbeiter & $12,4 \%$ \\
\hline Ministerium für Gesundheitswesen & $12,8 \%$ & dagegen Arbeiter & $7,3 \%$ \\
\hline Ministerium für Kultur & $11,0 \%$ & dagegen Arbeiter & $10,6 \%$ \\
\hline
\end{tabular}

\section{Bildung einer Kaderreserve}

Bestätigte Kaderreserven liegen vor $=934$

davon für leitende Funktionen $=405$

Aufgliederung:

\begin{tabular}{|l|c|c|c|}
\hline & Kaderreserven & $\begin{array}{c}\text { \% zu Gesamt- } \\
\text { beschäftigtenzahl }\end{array}$ & $\begin{array}{c}\text { Kaderreserven für } \\
\text { leitende Funktionen }\end{array}$ \\
\hline Regierungsdienststellen & 225 & $2,1 \%$ & 104 \\
\hline Bezirke insgesamt & 709 & $0,8 \%$ & 301 \\
\hline davon Räte der Bezirke & 93 & & 34 \\
\hline davon Räte der Kreise & 479 & & 191 \\
\hline davon Räte der Stadtbezirke & 32 & & 6 \\
\hline davon Räte der Städte & 23 & & 63 \\
\hline davon Räte der Gemeinden & 82 & & 7 \\
\hline
\end{tabular}

In den Bezirken verteilt sich die Zahl der Kaderreserven wie folgt:

Sieben Bezirke besitzen eine Kaderreserve für die Räte der Bezirke. An der Spitze stehen:

Erfurt $=42$ Reservekader

Potsdam $=13$ Reservekader

Neubrandenburg $=10$ Reservekader

Alle Bezirke - außer Berlin - besitzen eine solche für die Kreise.

An der Spitze

Erfurt $=110$ Reservekader

Neubrandenburg $=80$ Reservekader

Magdeburg $=49$ Reservekader

Potsdam $=48$ Reservekader

Nur acht Bezirke besitzen eine solche für die Gemeinden. Voran

Potsdam $=18$ Reservekader

Cottbus $=18$ Reservekader

Neubrandenburg $=14$ Reservekader 
Insgesamt gesehen erreichte das beste Ergebnis der Bezirk Erfurt, während Berlin überhaupt keine bestätigten Kaderreserven melden kann.

Die Gesamtergebnisse bei der Schaffung einer Kaderreserve können insgesamt nicht befriedigen, auch wenn berücksichtigt wird, dass diese Angaben nach dem Stand vom 15.12.58 erfolgten.

\section{Stand der politisch-ideologischen und ökonomisch-fachlichen Qualifikation}

Die politische und fachliche Qualifikation wurde erhöht. Die Zahl der Mitarbeiter, die über fünf Jahre im Apparat tätig sind, wurde größer.

Der Anteil der Mitarbeiter mit Hoch- und Fachschulbildung stieg an. Dabei entspricht aber der erzielte Zuwachs und damit das Tempo nicht den zu lösenden Aufgaben.

\begin{tabular}{|l|c|c|c|c|}
\hline & \multicolumn{2}{|c|}{ Örtliche Räte } & \multicolumn{2}{c|}{ Regierungsdienststellen } \\
\hline & Stand 1958 & Zuwachs & Stand 1958 & Zuwachs \\
\hline Hochschulabschluss & $2,7 \%$ & $0,4 \%$ & $15,9 \%$ & $5,2 \%$ \\
\hline Fachschulabschluss & $7,0 \%$ & $0,6 \%$ & $11,2 \%$ & $-0,2 \%$ \\
\hline Hochschulfernstudium & $1,4 \%$ & $0,1 \%$ & $8,0 \%$ & $1,2 \%$ \\
\hline Fachschulfernstudium & $2,8 \%$ & $0,4 \%$ & $3,3 \%$ & $-0,3 \%$ \\
\hline
\end{tabular}

Folgende Gegenüberstellung zeigt das ungenügende Tempo der Qualifizierung:

\begin{tabular}{|c|c|c|c|}
\hline \multicolumn{2}{|c|}{ Örtliche Organe } & Hochschulbildung & Fachschulbildung \\
\hline \multicolumn{2}{|c|}{ Abschluss besitzen } & $2,7 \%$ & $7,0 \%$ \\
\hline \multicolumn{2}{|c|}{ in Ausbildung befindlich } & $\begin{array}{c}1,4 \% \\
\text { Zuwachs } 0,1 \% \\
\text { gegenüber } 1957\end{array}$ & $\begin{array}{c}2,8 \% \\
\text { Zuwachs } 0,4 \% \\
\text { gegenüber } 1957\end{array}$ \\
\hline \multirow{2}{*}{$\begin{array}{l}\text { für } 1959 \\
\text { geplant }\end{array}$} & Fernstudium & $0,4 \%$ & $1,2 \%$ \\
\hline & Direktstudium & $0,5 \%$ & $0,4 \%$ \\
\hline
\end{tabular}

\begin{tabular}{|c|c|c|c|}
\hline \multicolumn{2}{|c|}{ Zentrale Organe } & Hochschulbildung & Fachschulbildung \\
\hline \multicolumn{2}{|c|}{ Abschluss besitzen } & $15,9 \%$ & $11,2 \%$ \\
\hline \multicolumn{2}{|c|}{ in Ausbildung befindlich } & $\begin{array}{c}8,0 \% \\
\text { Zuwachs } 1,2 \% \\
\text { gegenüber } 1957\end{array}$ & $\begin{array}{c}3,3 \% \\
\text { Zuwachs } 0,3 \% \\
\text { gegenüber } 1957\end{array}$ \\
\hline \multirow{2}{*}{$\begin{array}{l}\text { für } 1959 \\
\text { geplant }\end{array}$} & Fernstudium & $0,9 \%$ & $0,6 \%$ \\
\hline & Direktstudium & $0,2 \%$ & $0,05 \%$ \\
\hline
\end{tabular}

Zahl der Mitarbeiter, die zu ihrer Qualifizierung bisher nur Lehrgänge der gesellschaftlichen Organisationen, Verwaltungsschulen und der Deutschen Akademie für 
Staats- und Rechtswissenschaft „Walter Ulbricht“ über zwei Monate (ohne Hoch- und Fachschulbesuch) absolvierten:

\begin{tabular}{|l|c|c|}
\hline & Örtliche Organe & Regierungsdienststellen \\
\hline 1957 & $15,7 \%$ & $12,9 \%$ \\
\hline 1958 & $17,2 \%$ & $14,5 \%$ \\
\hline $\begin{array}{l}1959 \text { Delegierung zu } \\
\text { Verwaltungsschulen geplant }\end{array}$ & $3,4 \%$ & $0,3 \%$ \\
\hline
\end{tabular}

Diese Zahlen beweisen, dass Stand und Entwicklungstempo der Qualifizierung der Mitarbeiter nicht ausreicht, um die geforderte scharfe Wende zur konkreten Leitung der Wirtschaft zu vollziehen.

Das zeigt sich an den folgenden Abteilungen der örtlichen Organe besonders deutlich.

\begin{tabular}{|l|c|c|c|c|}
\hline & $\begin{array}{c}\text { Hochschul- } \\
\text { abschluss }\end{array}$ & $\begin{array}{c}\text { Fachschul- } \\
\text { abschluss }\end{array}$ & im Fernstudium & $\begin{array}{c}\text { Einjahreslehr- } \\
\text { gang DASR }\end{array}$ \\
\hline $\begin{array}{l}\text { Abteilung Land- } \\
\text { und Forstwirt- } \\
\text { schaft }\end{array}$ & $6,5 \%$ & $15,2 \%$ & $8,0 \%$ & $0,4 \%$ \\
\hline $\begin{array}{l}\text { Kreisplankom- } \\
\text { mission }\end{array}$ & $2,0 \%$ & $11,0 \%$ & $4,7 \%$ & $1,0 \%$ \\
\hline Kreisbauämter & $5,2 \%$ & $31,0 \%$ & $3,7 \%$ & $0,3 \%$ \\
\hline
\end{tabular}

\section{Einbeziehung der Frauen in die staatliche Arbeit}

Der Frauenanteil beträgt $\quad 44,8 \%$ in den örtlichen Organen $41,3 \%$ in den zentralen Organen

und ist als gut einzuschätzen. Völlig ungenügend ist der Anteil der Frauen in leitenden Funktionen. Er beträgt: $\quad$ bei den Örtlichen Räten $=4,2 \%$ bei den zentralen Organen $=5,5 \%$.

Die schulische Qualifizierung der leitenden Mitarbeiterinnen in den Regierungsdienststellen weist im Stand gegenüber den männlichen Kollegen kein wesentliches Zurückbleiben auf, ebenso die der Frauen in mittleren Funktionen. Ein Nachhinken zeigt sich aber in der Aneignung ökonomischer Kenntnisse über den Weg des Fachschulstudiums.

Das Schwergewicht muss deshalb auf die Entwicklung der Frauen in leitenden Funktionen gelegt werden, wie auf die Verbesserung des Anteils der Frauen [in] „Arbeiter der sozialen Stellung nach“. Die altersmäßige Gliederung zeigt, dass der Anteil der unbedingt zu qualifizierenden Frauen der Altersgruppe 26-40 Jahre überwiegt (Örtliche Organe $37,8 \%$, Regierungsorgane 38,8 \%). 


\section{Schlussfolgerungen:}

Es ist zu sichern, ausgehend vom Ministerium des Innern, ein straffes System zur Lösung der auf der Partei- und Staatsfunktionärkonferenz im Februar gestellten Aufgaben über die 1. Stellvertreter der Vorsitzenden der Räte der Bezirke und Kreise und bei den zentralen Organen über die für die Kaderarbeit Verantwortlichen. ${ }^{367}$

Die Hauptmethode der Durchsetzung muss die Auswertung und Beispiele, ihre Verallgemeinerung und die konkret kurzfristige Aufgabenstellung sein. Dabei zeigen die vorliegenden Ergebnisse, dass es notwendig ist, sich insbesonders auf folgende Schwerpunkte zu konzentrieren:

1. Überwindung des bürgerlichen Einflusses im Staatsapparat durch eine konsequente und systematische klassenmäßige Stärkung in den Organen der Staatsmacht. Das gilt insbesonders für die in dem Material aufgeführten zurückgebliebenen Organe.

Im Jahre 1959 sind alle noch freien Planstellen zu besetzen und darüber hinaus muss ein Nachwuchs im Umfange von mindestens $10 \%$ des Mitarbeiterstandes herangebildet bzw. seine Qualifizierung eingeleitet werden.

2. Die Hauptaufmerksamkeit ist auf die Auswahl und Qualifizierung eines ausreichenden Nachwuchses vor allem für die leitenden Funktionen in den örtlichen Organen zu richten. Dabei kommt es darauf an, die guten Erfahrungen insbesondere der Bezirke Neubrandenburg, Potsdam und Erfurt auszuwerten und eine straffe Kontrolle der Auswahl der Kader für die Schulen insbesondere der Deutschen Akademie für Staats- und Rechtswissenschaft „Walter Ulbricht“ und den Verwaltungsschulen zu gewährleisten. Über die Probleme muss eine breite Diskussion in der Presse geführt werden. Wichtig ist in diesem Zusammenhang die klassenmäßig richtige Besetzung der Bürgermeisterfunktionen und die Verstärkung der Abteilungen Land- und Forstwirtschaft, der Bauämter und Kreisplankommissionen.

3. Es ist zu sichern, dass die DASR und die Verwaltungsschulen sich weiter entwickeln zu Stätten des praxisverbundenen Erfahrungsaustausches, der erfolgreichsten Methode der sozialistischen Umgestaltung bei gleichzeitiger Erweiterung und Vertiefung der fachlichen und theoretischen Kenntnisse der Lehrgangsteilnehmer. In dieser Richtung ist der Lehrinhalt zu verändern.

4. Es sind stärker die örtlichen Möglichkeiten wie Wochenendlehrgänge, Erfahrungsaustausche, Seminare, Konsultationen, Exkursionen usw. zur Verstärkung der politischen und ökonomisch-fachlichen Kenntnisse der Mitarbeiter des Staatsapparates zu nutzen.

367 Eine Partei- und Staatsfunktionärkonferenz befasste sich vom 25. bis 27. Februar 1959 mit der „,neuen Arbeitsweise der staatlichen Organe“; vgl. Grüneberg, sozialistische Art, sowie Glaeßner, Herrschaft, S. 129-130. 
Prinzip muss weiter sein, dass Mitarbeiter, die über gute politische Kenntnisse und Erfahrungen verfügen, bei denen aber die fachlichen Kenntnisse noch zu schwach sind, Sonderlehrgänge an den Hoch- und Fachschulen besuchen. Es ist erforderlich, dass das Staatssekretariat für das Hoch- und Fachschulwesen dazu die erforderlichen Maßnahmen einleitet.

In den Städten Potsdam, Erfurt und Karl-Marx-Stadt sollen auf der Grundlage des Lehrplanes der DASR die Möglichkeiten der Einführung von Abendschulen geschaffen, danach ausgewertet und verallgemeinert werden.

Zusammen mit dem Ministerium für Land- und Forstwirtschaft und erfahrenen Funktionären der örtlichen Staatsorgane ist das System der Bürgermeisterqualifizierung zu vervollkommnen und zu sichern, dass sich die Bürgermeister ausreichend agrarökonomische Kenntnisse aneignen.

[BArch, DO 1/26405, Bl. 8-14]

Dokument 61: Auswertung einer Beratung Otto Grotewohls mit den Vorsitzenden der Räte der Bezirke ${ }^{368}$ bei einer Dienstbesprechung von Ratsmitgliedern und Abteilungsleitern des Rates des Bezirkes Potsdam, 19. Juli 1960

Vom Genossen Grotewohl wurde auf der Beratung mit den Vorsitzenden der Räte der Bezirke sehr kritisch die staatliche Leitung von der Regierung bis hinunter in die unterste Ebene eingeschätzt.

Sehr ungenügend wurde das Gesetz vom 11.2.1958 verstanden, viel weniger noch in der Praxis angewandt.

Genosse Grotewohl schätzte so ein, dass es daran liegt, dass die Genossen und Kollegen nicht den Unterschied begriffen haben z. B. zwischen der Periode der Entwicklung unserer Republik bis zum V. Parteitag und der Periode danach bis heute, die sich genauer ablesen lässt, wenn man die Präambel des Gesetzes vom 17.1.1957 vergleicht mit der Präambel des Gesetzes vom 11.2.1958. Während wir bis zum V. Parteitag über die so zu bezeichnende Periode der antifaschistischen Demokratie nicht hinauskamen, sind wir nach dem V. Parteitag in die Periode der Durchsetzung der Diktatur des Proletariats eingetreten. Es ist objektiv aus der ganzen historischen und vor allen Dingen ökonomischen Entwicklung und Zielstellung des V. Parteitages, den Sozialismus zum Siege zu führen, zu begründen.

368 Diese Beratung lag offenbar im zeitlichen Umfeld der Ministerratssitzung vom 14. Juli 1960, auf der ein Beschluss ,über die weitere Qualifizierung der Arbeit der Organe des Staatsapparates“ gefasst worden war; eine Mitteilung des Presseamtes des Ministerpräsidenten über diese Beratung ist auszugsweise abgedruckt in Dokumente 1949-1961, S. 81-82. 
Genosse Grotewohl schätzte so ein, dass das Staatswesen bis zum und nach dem V. Parteitag im Widerspruch stand zur politischen und ökonomischen Entwicklung und der Führung der Partei.

Dieser Widerspruch wird besonders deutlich durch die Erkenntnisse des 7. ZK-Plenums. ${ }^{369}$ Das 7. ZK-Plenum forderte von den Genossen und Kollegen im Staatsapparat, den Kampf um eine neue Arbeitsmethodik zu führen. Der Kerngedanke des Gesetzes vom 17.1.1957, das die Rechte und Pflichten der örtlichen Staatsorgane umreißt, spricht vom Aufbau des Sozialismus und einer immer bewussteren Teilnahme der Massen am Aufbau. Es tritt die marxistisch-leninistische Grundidee zutage, dass der Wille des Volkes durch die Volksvertretungen und ihre Organe verwirklicht wird, in dem sich die staatlichen Organe und Volksvertretungen auf die Massenorganisationen und die Nationale Front stützen. Das Gesetz vom 11.2.1958 bringt aber schon einen viel weitergehenden prinzipiellen Gedanken, nämlich die Herrschaft der Arbeiterklasse, die Diktatur des Proletariats, weil das einfach der Objektivität der gesellschaftlichen Entwicklung entspricht und notwendig ist. Dieser Gedanke wird erstmalig Gesetz.

Genosse Grotewohl sagte, es gab nach dem 11.2.1958 und dem V. Parteitag zwischen Partei und Staatsapparat ein Art Katz-und-Maus-Spiel. Das gibt es auch noch heute. Z. B. haben wir ängstlich und peinlich vermieden, die Beschlüsse der Partei umzuformulieren auf die Staatspraxis. Die Blockfreunde haben in den vergangenen Jahren offene Bekenntnisse zur führenden Rolle der Partei abgelegt, doch wurde ein wesentlicher Unterschied zwischen Genossen Stellvertreter und Blockfreund Stellvertreter geführt.

Durch den Genossen Grotewohl wurde hierzu gesagt, dass den Blockfreunden die gleichen Rechte und Pflichten eingeräumt werden wie den Genossen. Die Blockfreunde werden sich ebenso verantwortlich vor der Partei der Arbeiterklasse fühlen wie ein Genosse. Jeder Stellvertreter hat die höchste persönliche Verantwortung. Die Blockfreunde werden überall voll gleichberechtigt hinzugezogen.

Genosse Grotewohl gab, ausgehend von einer Einschätzung der gesamtdeutschen politischen Situation, die Begründung, dass die Diktatur des Proletariats offen und klar durchgesetzt werden muss. In der letzten Zeit sind maßgebende Offiziere in die DDR gekommen und legten Tatsachen über die Blitzkriegspläne auf den Tisch. Dieser Einbruch bis in die Machtorgane des reaktionären imperialistischen westdeutschen Staates wird breiter werden.

Wir müssen darauf hinarbeiten auf das unbedingte Vertrauensverhältnis zwischen Bevölkerung und Staatsorganen. Nur dann werden wir umso wirksamer den Blitzkriegsplänen

369 Die 7. Tagung des ZK der SED vom 10. bis 13. Dezember 1959 hatte sich „nahezu ausschließlich mit agrarpolitischen Fragestellungen“ beschäftigt; Schöne, Frühling, S. 195. 
entgegentreten. Wenn wir uns die Versorgungslage ansehen, dass z. Zt. im Handel Salzmangel besteht und Streichhölzer fehlten und die GHG 6-10 Tage mit der Auslieferung der Waren im Rückstand sind, dann ist es so einzuschätzen, dass wir uns selbst das Misstrauen, die Verärgerung, den Bruch zwischen Staat und Bevölkerung organisieren und das ist direkte Mithilfe zur Durchführung der Blitzkriegspläne. Deshalb vorbildliche Arbeit - weit höheres Verantwortungsbewusstsein. Aufgabe ist Stärkung der DDR, besseres Vertrauensverhältnis zwischen Staatsorganen und Werktätigen herstellen, d. h. nichts anderes, als das Gesetz vom 11.2. durchzusetzen. Die Plandiskussion 1960/1961 mit den Menschen durchzuführen und nicht hinter dem Schreibtisch.

Jeder Staatsfunktionär muss sich Klarheit schaffen über das Verhältnis Regierung, Bezirk, Kreis, Gemeinde von der Seite des Wesenszuges des demokratischen Zentralismus. Es kann keinem Organ gestattet werden, Weisungen nicht durchzuführen.

In den letzten 14 Tagen wurden Sonderbevollmächtigte des Rates des Bezirkes eingesetzt, die sich besonders auf die Arbeit der Kreisräte orientieren sollten, Teilnahme an Kreistagssitzungen usw. Es sollten von den Sonderbevollmächtigten Berichte über die Kreistagssitzungen eingereicht werden, aber bisher liegen nur sechs Berichte vor.

Genosse Grotewohl begründete das so, dass viel Neues entstand. In der Arbeitsmethodik schwanken wir von einem System ins andere. Wir tasten uns zu einer richtigen Arbeitsmethodik, die den neuen Gegebenheiten entspricht.

Durch wissenschaftliche Selbstkritik wurde vom Genossen Grotewohl die Regierungsarbeit eingeschätzt, die darauf hinauslief, unsere Arbeiter und Bauern kämpfen um die Erfüllung der Pläne, aber die staatliche Leitung hält nicht Schritt. Genosse Grotewohl ging darauf ein, dass die Struktur der Regierung nicht mehr in Ordnung ist. Das Politbüro hat beschlossen, dass der Genosse Stoph als Stellvertretender Ministerpräsident an der Seite des Ministerpräsidenten die staatliche Leitung, Koordinierung und konzentrierte Kontrolle zusammenfasst. Es gibt exakte Festlegungen, wer hat was anzuweisen. Weisungen an die Räte der Bezirke ergehen nur über die Fachminister.

Verhältnis Partei - Regierung wird so sein, dass die Beschlüsse des Politbüros in den Ministerrat gehen. Der Ministerrat beratet [sic!], wie werden die Beschlüsse durchgeführt, also von der organisatorischen Seite. Das gleiche trifft auch für die Bezirke zu.

Eine ähnliche Rolle, wie der Genosse Stoph in der Regierung einnimmt, muss der Sekretär des Rates des Bezirkes haben. ${ }^{370}$

370 Willi Stoph (1914-1999) war seit 1954 stellvertretender Vorsitzender des Ministerrates der DDR und wurde Mitte Juli 1960 mit der „Koordinierung und Kontrolle der Durchführung der SED- und Regierungsbeschlüsse im Staatsapparat" beauftragt; vgl. Baumgartner, Biographisches Handbuch, S. 904 . 
Das Politbüro stellte fest, dass viele Kader den Anforderungen nicht mehr gewachsen sind. Die Kader müssen geschult werden. Die Kader aus der Bezirksebene (Ratsvorsitzende) werden durch das ZK mit prinzipiellen Fragen geschult. Die gleiche Aufgabe ist den Büros der Bezirksleitung übertragen worden in Bezug auf die Schulung der Funktionäre und Mitarbeiter des Rates des Bezirkes.

Das Berichtswesen wird verändert. Es ist angewiesen, dass die Festlegungen des Zentralamtes für Statistik, die genehmigt sind, unbedingt beachtet werden müssen. Es darf keine anderen geben als die genehmigten.

Letzte Schlussfolgerung: Kritik und Selbstkritik müssen uns das bewegende Gesetz im Vorwärtsdrängen sein.

Genosse Stoph sagte, es gibt Tendenzen bei Mitarbeitern, die uns hemmen, mit den wir uns auseinandersetzen müssen. Weder die ökonomische Aufgabe, noch ihr Tempo kann man verändern. Den Genossen müssen die Pläne erklärt werden und sie von der Richtigkeit überzeugt werden.

[BLHA, Rep. 401, Nr. 3686, Bl. 136-138]

Dokument 62: „Hinweise“ der SED-Bezirksleitung Potsdam für ein „Seminar mit den Bürgermeistern und Parteisekretären“ aus den „Randorten“ des Bezirkes Potsdam, 26. November $1960^{371}$

Im Seminar ist zu klären, woraus sich die hohen Anforderungen an die Arbeit der Organe der Staatsmacht ergeben.

Die höheren Anforderungen ergeben sich aus dem Kampf um die Sicherung des Friedens, den Sieg des Sozialismus und die Durchführung des Deutschlandplanes des Volkes, woraus den Staatsorganen ständig neue und größere Aufgaben erwachsen.

Diese hohen Anforderungen müssen insbesondere unter den grundlegenden Gesichtspunkten des Hauptinhalts unserer Epoche, des Übergangs vom Kapitalismus zum Sozialismus, von allen Mitarbeitern des Staatsapparates begriffen werden.

371 Das Dokument bezieht sich auf die „Durchführung einer Wochenendschulung mit den Mitgliedern der Arbeitsgruppen Randorte der Kreisleitungen, den leitenden Funktionären der Partei, des Staatsapparates und der Massenorganisationen aus den Randorten und Kreisen Zossen, Oranienburg, Nauen, Potsdam-Land und Potsdam-Stadt am 12./13.11.1960 an der Bezirksparteischule, Klein Machnow"; BLHA, Rep. 530, Nr. 1050, B1. 75. 
Dabei ist herauszuarbeiten, wie eine höhere Qualität in der Arbeit der Organe der Staatsmacht erreicht werden kann und mit welchen Formen der Einsatz der Staatsmacht als Hauptinstrument beim Aufbau des Sozialismus gesichert wird.

1. Herausarbeitung, wie die führende Rolle der Partei in den Organen der Staatsmacht verwirklicht wird.

a) Verschmelzung der Spitzen der Parteiorganisation mit den Spitzen der Staatsmacht

b) Parteibeschlüsse - Grundlage der staatlichen Arbeit

c) Parteigruppen in den gewählten Organen der Staatsmacht

d) über die Grundorganisationen im Staatsapparat

Die konsequente Verwirklichung der Beschlüsse der Partei ermöglicht die Gesetze über die örtlichen Organe der Staatsmacht vom 17.1.1957 und 11.2.1958 voll zur Wirkung zu bringen.

Das tiefe Eindringen in die Beschlüsse der Partei und die schöpferische Anwendung ermöglicht, die noch vorhandene administrative und ressortmäßige Arbeit zu überwinden.

Deshalb ist die gründliche Auswertung und Kontrolle der Parteibeschlüsse in den Parteigruppen der Volksvertretungen, der Räte und in den Grundorganisationen im Staatsapparat mit der ständigen Erziehung der Genossen zur konsequenten Durchführung der Parteibeschlüsse zur Erhöhung der Qualität der staatlichen Leitung von ausschlaggebender Bedeutung.

In diesem Zusammenhang muss die Stellung der Partei im System der Diktatur des Proletariats herausgearbeitet werden, da es darüber noch viele ideologische Unklarheiten gibt.

Beispielargument: Die Partei stellt zu hohe Anforderungen - bzw. die Nichtbeachtung der Parteibeschlüsse. Behandlung wichtiger politischer und ökonomischer Fragen des Ortes in den Volksvertretungen und Räten, ohne vorherige gründliche Beratung in den Ortsparteileitungen.

Die ideologische Hauptfrage der Erziehung der Genossen und Mitarbeiter im Staatsapparat ist die restlose Klärung der führenden Rolle der Partei und die Bedeutung ihrer Beschlüsse sowie die Rolle der Staatsmacht als Hauptinstrument zur Durchsetzung dieser Beschlüsse.

Die Mitarbeiter und Genossen müssen befähigt werden, den Kampf um die Durchführung des Siebenjahrplanes zielstrebig und mit hoher Sachlichkeit und Organisationsfähigkeit zu leiten und zu organisieren. 
Die Aufgaben der Parteigruppen der Volksvertretungen zur Erziehung aller Abgeordneten müssen entsprechend den Aufgaben des Statuts auf ein höheres Niveau gehoben werden. Die Parteigruppe darf zu keiner zweiten Volksvertretersitzung werden. Für die Anleitung sind die Ortsparteileitungen verantwortlich.

2. Ein weiterer wichtiger Faktor zur Erreichung einer hohen Qualität liegt in der ständigen Qualifizierung der Volksvertretungen, der Räte und der Mitarbeiter im Staatsapparat, damit sie in der Lage sind, die wirtschaftlich-organisatorische und kulturell-erzieherische Funktion des Staates voll zu Entfaltung zu bringen.

In diesem Zusammenhang muss die Verantwortung der Volksvertretungen und Räte zur Lösung der Aufgaben des 8. und 9. Plenums sowie der gestellten Aufgaben im Brief des Genossen Walter Ulbricht an die Genossinnen und Genossen der örtlichen Organe der Staatsmacht herausgearbeitet werden.

Ein besonderer Schwerpunkt bildet dabei die Leitung der Entwicklung der landwirtschaftlichen Produktion.

Verhältnis zwischen staatlicher Leitung und innergenossenschaftlicher Demokratie klären.

Um diese Aufgaben zu verwirklichen, ist eine konkrete Arbeitsplanung auf der Grundlage der Beschlüsse der Partei, eine ständige Einschätzung der Klassenkräfte und der Lage im Ort, die seminaristische Aussprache zu aktuell-politischen Fragen und zu wichtigen Beschlüssen der Partei und der Volkskammer, die ständige Erklärung des untrennbaren Zusammenhangs zwischen Politik und Ökonomie, die gründliche Vorbereitung und Auswertung der Tagungen der Volksvertretung unter Mitwirkung der ständigen Kommissionen und breitester Einbeziehung der Bevölkerung sowie die Sicherung der Einheit von Beschlussfassung und Durchführung notwendig.

Als eine wichtige Methode der Leitungstätigkeit ist die Verallgemeinerung der fortgeschrittensten Erfahrungen herauszuarbeiten.

Dabei spielt der Leistungsvergleich eine wichtige Rolle, denn er gibt uns die Möglichkeit, genau die Art und Weise des Herangehens ausfindig zu machen, die zu den besten Ergebnissen führt.

Erfahrungsaustausch der Volksvertretungen Räte und der ständigen Kommissionen untereinander.

3. Entscheidend für eine hohe Qualität in der Arbeit der Staatsorgane ist, dass jeder Schritt nur dann erfolgreich sein wird, wenn er in engster Verbindung mit den Werktätigen erfolgt. 
Die Entfaltung der schöpferischen Mitarbeit der Werktätigen an der Leitung des Staates, die Entwicklung der Initiative zur Lösung der gemeinsamen großen Aufgaben im Kampf um die Sicherung des Friedens, den Sieg des Sozialismus und um die Lösung der nationalen Frage ist eine Lebensfrage unsere sozialistischen Gesellschaftsordnung. Sie ist entscheidend für die Überlegenheit des Sozialismus, für seine Lebenskraft und für seine Wachstumspotenzen.

Das muss zum Inhalt der Arbeit jedes Partei- und Staatsfunktionärs werden. Die Bedeutung der örtlichen Organe der Staatsmacht liegt in ihrer Massenverbundenheit. Die Entwicklung der schöpferischen Fähigkeiten der Menschen, die politisch-ideologische Umwälzung im Denken der Menschen ist der Inhalt des sozialistischen Arbeitsstils der Staatsorgane.

\section{Formen der Einbeziehung der Werktätigen}

Komplex-territoriale Planung, ständige Kommissionen, Aktivs der Kommissionen, Verkaufsstellenausschüsse, HO-Beiräte, Elternbeiräte, Produktionsberatungen, Entwicklung des Wettbewerbs um das schöne sozialistische Dorf usw. sind ständig zu berücksichtigen. Insbesondere müssen sich die Staatsorgane auf die Förderung des Neuen in der Industrie und Landwirtschaft stützen und darauf einen ständigen Einfluss ausüben. Sie müssen die Ergebnisse der Arbeit der sozialistischen Brigaden und Arbeitsgemeinschaften kennen.

Es muss insbesondere herausgearbeitet werden die hohe Verantwortung aller Abgeordneten und Mitarbeiter im Staatsapparat zur vorbildlichen Verwirklichung aller Aufgaben des sozialistischen Aufbaus in der Gemeinde, um die Überlegenheit im Randgebiet zuerst zu beweisen. Dabei spielt die differenzierte Arbeit mit allen Schichten der Bevölkerung eine besondere Rolle.

Die Volksvertretungen und Räte müssen sich in ihrer Arbeit ständig auf die Ausschüsse der Nationalen Front stützen, in der alle Parteien und Massenorganisationen vereint sind.

Besondere Bedeutung hat die Mitarbeit der Arbeiter und der Jugend an der Leitung des Staates, die in fast allen Randorten völlig ungenügend ist.

[BLHA, Rep. 530, Nr. 1050, Bl. 123-127] 



\section{Literaturverzeichnis}

Akten und Verhandlungen des Landtags der Mark Brandenburg. Sitzungsberichte und Verhandlungen der Landtage der Sowjetischen Besatzungszone 1946-1952, 3 Bde., Frankfurt am Main 1992.

Heike Amos: Politik und Verwaltungsorganisation eines zentralistischen Machtapparates. Struktur und Arbeitsweise von Politbüro, Sekretariat, Zentralkomitee und ZK-Fachapparat der SED 1949-1963, Speyer 2002.

Kurt Arlt: Zur Aufstellung militärisch ausgebildeter Polizeiformationen in der SBZ/DDR 1948 bis 1952, in: Peter Nitschke (Hg.): Die deutsche Polizei und ihre Geschichte. Beiträge zu einem distanzierten Verhältnis (= Schriftenreihe der Deutschen Gesellschaft für Polizeigeschichte, Bd. 2), Hilden 1996, S. 207-230.

Rolf Badstübner/Wilfried Loth (Hg.): Wilhelm Pieck - Aufzeichnungen zur Deutschlandpolitik 1945-1953, Berlin 1994.

Andrea Bahr/Sabine Pannen: Soziale Wirklichkeit und regionale Herrschaftspraxis der SED, in: Mitteilungen des Instituts für Parteienrecht 17 (2011), S. 68-79.

Gabriele Baumgartner/Dieter Hebig (Hg.): Biographisches Handbuch der SBZ/DDR 1945-1990. 2 Bde., München u. a. 1996/1997.

Wolfgang Benz: Potsdam 1945. Besatzungsherrschaft und Neuaufbau im Vier-ZonenDeutschland, München 1986.

Christoph Bernhardt: Disparitäten als Tabu. Aspekte räumlich-sozialer Ungleichheit im Sozialismus am Beispiel von Industrieregionen der DDR und Polens, in: Friedrich Lenger/Klaus Tenfelde (Hg.): Die europäische Stadt im 20. Jahrhundert. Wahrnehmung - Entwicklung - Erosion, Köln 2006, S. 307-321.

Frank Betker: „Einsicht in die Notwendigkeit“. Kommunale Stadtplanung in der DDR und nach der Wende (1945-1994) (= Beiträge zur Stadtgeschichte und Urbanisierungsforschung, Bd. 3), Stuttgart 2007.

Wolfgang Blöß: Grenzen und Reformen einer Umbruchgesellschaft. Vom Land Brandenburg zu den Bezirken 1945-1952 (= Veröffentlichungen des Brandenburgischen Landeshauptarchivs, Bd. 66), Berlin 2014.

G. Brunner, Die Verwaltung in der SBZ und DDR, in: Kurt G. A. Jeserich u. a. (Hg.): Deutsche Verwaltungsgeschichte, Bd. 5: Die Bundesrepublik Deutschland, Stuttgart 1987, S. 1218-1283.

Hannsjörg F. Buck: Öffentliche Finanzwirtschaft im SED-Staat und ihre Transformationsprobleme, in: Deutscher Bundestag (Hg.): Materialien der Enquete-Kommission „Überwindung der Folgen der SED-Diktatur im Prozess der Deutschen Einheit“ im 
Deutschen Bundestag (13. Wahlperiode des Deutschen Bundestages), Baden-Baden/ Frankfurt am Main 1999, Bd. III/2, S. 975-1267.

Bundesministerium für innerdeutsche Beziehungen (Hg.): DDR-Handbuch. Dritte erweiterte Aufl., 2 Bde., Köln 1985.

Büro des Ministerrates der Deutschen Demokratischen Republik (Hg.): Gesetzblatt der DDR. Teil I, II und III, Berlin (Ost) 1949-1990.

Stefan Creuzberger: Die sowjetische Besatzungsmacht und das politische System der DDR (= Schriften des Hannah-Arendt-Instituts für Totalitarismusforschung, Bd. 3), Weimar u. a. 1996.

Harald Engler: Stadtplanung und Stadtentwicklung in einer kleinen DDR-Mittelstadt in den Sechziger - und Siebzigerjahren. Das Beispiel Prenzlau, in: Deutschlandarchiv (2009), Heft 2, S. 276-285.

Jan Foitzik: Sowjetische Militäradministration in Deutschland (SMAD) 1945-1949. Struktur und Funktion (= Quellen und Darstellungen zur Zeitgeschichte, Bd. 44), Berlin 1999.

Jan Foitzik (Hg.): Sowjetische Interessenpolitik in Deutschland 1944-1954. Dokumente (= Texte und Materialien zur Zeitgeschichte, Bd. 18), München 2012.

Jan Foitzik (Hg.): Sowjetische Kommandanturen und deutsche Verwaltung in der SBZ und frühen DDR. Dokumente (= Texte und Materialien zur Zeitgeschichte, Bd. 19), München 2015.

Mario Frank: Walter Ulbricht. Eine deutsche Biografie, Berlin 2001.

Thomas Friedrich/Christa Hübner/Herbert Meier/Kerstin Wolf (Hg.): Entscheidungen der SED 1948. Aus den stenographischen Niederschriften der 10. bis 15. Tagung des Parteivorstandes der SED, Berlin 1995.

Geschichte der Sozialistischen Einheitspartei Deutschlands. Abriß, Berlin (Ost) 1978.

Geschichte des Staates und des Rechts der DDR. Dokumente 1945-1949, Berlin (Ost) 1984 [zitiert als: Dokumente 1945-1949].

Geschichte des Staates und des Rechts der DDR. Dokumente 1949-1961, Berlin (Ost) 1984 [zitiert als: Dokumente 1945-1949].

Klaus Geßner/Wladimir W. Sacharow (Hg.): Inventar der Offenen Befehle der Sowjetischen Militäradministration des Landes Brandenburg. Nach der Überlieferung im Staatsarchiv der Russischen Föderation (= Quellen, Findbücher und Inventare des Brandenburgischen Landeshauptarchivs, Bd. 11), Frankfurt/Main 2002.

Gert-Joachim Glaeßner: Herrschaft durch Kader. Leitung der Gesellschaft und Kaderpolitik in der DDR am Beispiel des Staatsapparates (= Schriften des Zentralinstituts für sozialwissenschaftliche Forschung der Freien Universität Berlin, Bd. 28), Opladen 1977. 
Frankdieter Grimm: Geographische Aspekte der Situation und Perspektive der Kreisstädte und Kreise in den mittel- und ostdeutschen Ländern, in: Berichte zur deutschen Landeskunde 65 (1991), Heft 1, S. 83-105.

Gerhard Grüneberg: Auf sozialistische Art leiten, arbeiten und leben. Partei- und Staatsfunktionärkonferenz in Potsdam-Babelsberg 25. bis 27. Februar 1959, Berlin (Ost) 1959.

Karl-Heinz Hajna: Länder - Bezirke - Länder. Zur Territorialstruktur im Osten Deutschlands 1945-1990, Frankfurt am Main u. a. 1994.

Klaus Dietmar Henke: Politik der Widersprüche. Zur Charakterisierung der französischen Militärregierung in Deutschland nach dem Zweiten Weltkrieg, in: VfZ 30 (1982), S. 500-537.

Andreas Herbst u. a. (Hg.): So funktionierte die DDR. Lexikon der Organisationen und Institutionen, 2 Bde., Reinbek 1994.

Dierk Hoffmann u. a. (Hg.): Die DDR vor dem Mauerbau. Dokumente zur Geschichte des anderen deutschen Staates 1949-1961, München 1993.

Dierk Hoffmann: Die DDR unter Ulbricht. Gewaltsame Neuordnung und gescheiterte Modernisierung, Zürich 2003.

Dierk Hoffmann: Otto Grotewohl (1894-1964). Eine politische Biographie (= Quellen und Darstellungen zur Zeitgeschichte, Bd. 74), München 2009.

Thomas Horstmann: Logik der Willkür. Die Zentrale Kommission für Staatliche Kontrolle in der SBZ/DDR von 1948 bis 1958 (= Arbeiten zur Geschichte des Rechts in der DDR, Bd. 3), Köln u. a. 2002.

Matthias Judt (Hg.): DDR-Geschichte in Dokumenten. Beschlüsse, Berichte, interne Materialien und Alltagszeugnisse, Berlin 1997.

Monika Kaiser: Herrschaftsinstrumente und Funktionsmechanismen der SED in Bezirk, Kreis und Kommune, in: Deutscher Bundestag (Hg.): Materialien der Enquete-Kommission „Aufarbeitung von Geschichte und Folgen der SED-Diktatur in Deutschland“ im Deutschen Bundestag (12. Wahlperiode des Deutschen Bundestages), Baden-Baden/Frankfurt am Main 1995, Bd. II/3, S. 1791-1834.

Gerhard Kehrer: Abriss der Entwicklung der Territorialplanung der DDR. Die Raumplanung in der DDR zwischen Anspruch und Wirklichkeit, in: Karl Eckart u. a. (Hg.): Raumplanung und Raumforschung in der DDR (= Schriftenreihe der Gesellschaft für Deutschlandforschung, Bd. 57), Berlin 1998, S. 25-93.

Christoph Kleßmann: Thesen zur Rolle von Zentralismus und Föderalismus in der Bundesrepublik und in der DDR, in: Oliver Janz (Hg.): Zentralismus und Föderalismus im 19. und 20. Jahrhundert. Deutschland und Italien im Vergleich (= Schriften des Italienisch-Deutschen Historischen Instituts in Trient, Bd. 15), Berlin 2000, S. 262-273. 
Detlef Kotsch: Das Land Brandenburg zwischen Auflösung und Wiederbegründung. Politik, Wirtschaft, und soziale Verhältnisse in den Bezirken Potsdam, Frankfurt (Oder) und Cottbus in der DDR (1952 bis 1990) (= Brandenburgische Geschichte in Einzeldarstellungen, Bd. 8), Berlin 2001.

Detlef Kotsch: Karrierewege in Brandenburg nach dem Zweiten Weltkrieg. Entstehung und Etablierung der neuen Eliten in den Jahren 1945-1960, in: Jahrbuch für brandenburgische Landesgeschichte 47 (1996), S. 149-191.

Herbert Kröger: Die Bedeutung des Gesetzes über die weitere Demokratisierung des Aufbaus und der Arbeitsweise der staatlichen Organe in den Ländern der Deutschen Demokratischen Republik vom 23. Juli 1952 und die Aufgaben der Abgeordneten der Bezirks- und Kreistage, Berlin (Ost) 1952.

Christian Kurzweg: Parteiherrschaft und Staatsapparat. Der Bezirk Leipzig 1945/521990, in: Ingrid Grohmann (Hg.): Bewegte sächsische Region. Vom Leipziger Kreis zum Regierungsbezirk Leipzig 1547-2000. Eine Ausstellung des Sächsischen Staatsarchivs Leipzig und des Regierungspräsidiums Leipzig 2001 (= Veröffentlichungen des Sächsischen Staatsarchivs, Reihe C, Bd. 1), Halle/Saale 2001, S. 103-119.

Christian Kurzweg/Oliver Werner: SED und Staatsapparat im Bezirk. Der Konflikt um den Rat des Bezirkes Leipzig 1958/59, in: Michael Richter u. a. (Hg.): Länder, Gaue und Bezirke. Mitteldeutschland im 20. Jahrhundert, Halle (Saale) 2007, S. 255-276.

Peter Joachim Lapp: Der Staatsrat im politischen System der DDR (1960-1971) (= Beiträge zur sozialwissenschaftlichen Forschung, Bd. 9), Opladen 1972.

Peter Joachim Lapp: Der Ministerrat der DDR. Aufgaben, Arbeitsweise und Struktur der anderen deutschen Regierung, Opladen 1982.

Wolfgang Leonhard: Die Revolution entlässt ihre Kinder, Köln 1955.

Wolfgang Leonhard: Im Fadenkreuz der SED. Meine Flucht von der Parteihochschule „Karl Marx“ im März 1949 und die Aktivitäten der Zentralen Parteikontrollkommission, in: VfZ 46 (1998), S. 283-310.

Alf Lüdtke/Peter Becker (Hg.): Akten, Eingaben, Schaufenster - die DDR und ihre Texte. Erkundungen zu Herrschaft und Alltag, Berlin 1997.

Andreas Malycha: Die SED. Geschichte ihrer Stalinisierung 1946-1953, Paderborn u. a. 2000.

Andreas Malycha: Partei von Stalins Gnaden? Die Entwicklung der SED zur „Partei neuen Typs“ in den Jahren 1946 bis 1950, Berlin 1996.

Andreas Malycha: Die SED in der Ära Honecker. Machtstrukturen, Entscheidungsmechanismen und Konfliktfelder in der Staatspartei 1971 bis 1989 (= Quellen und Darstellungen zur Zeitgeschichte, Bd. 102), München 2014.

Heinz Mestrup: Die SED. Ideologischer Anspruch, Herrschaftspraxis und Konflikte im Bezirk Erfurt (1971-1989), Rudolstadt/Jena 2000. 
Henning Mielke: Die Auflösung der Länder in der SBZ/DDR 1945-1952 (= Beiträge zur Wirtschafts- und Sozialgeschichte, Bd. 66), Stuttgart 1995.

Helmut Müller-Enbergs u. a. (Hg.): Wer war wer in der DDR? Zweite aktualisierte Aufl., Berlin 2001.

Mario Niemann: Die Sekretäre der SED-Bezirksleitungen 1952-1989, Paderborn u. a. 2007.

Mario Niemann/Andreas Herbst (Hg.): SED-Kader. Die mittlere Ebene, Biographisches Lexikon der Sekretäre der Landes- und Bezirksleitungen, der Ministerpräsidenten und der Vorsitzenden der Räte der Bezirke 1946 bis 1989, Paderborn u. a. 2010.

Donal O’Sullivan: Stalins „Cordon sanitaire“. Die sowjetische Osteuropapolitik und die Reaktionen des Westens, Paderborn u. a. 2003.

Lothar Person (Bearb.): Bezirkstag und Rat des Bezirkes Potsdam 1952-1990 (Rep. 401). Findbuch zum Bezirkstag und Rat des Bezirkes Potsdam, 2 Bde. (= Quellen, Findbücher und Inventare des Brandenburgischen Landeshauptarchivs, Bd. 30 und 31), Frankfurt am Main 2014.

Protokoll des III. Parteitages der Sozialistischen Einheitspartei Deutschlands. 20. bis 24. Juli 1950, 1.-3. Verhandlungstag, Berlin (Ost) 1951.

Protokoll der Verhandlungen der II. Parteikonferenz der Sozialistischen Einheitspartei Deutschlands. 9. bis 12. Juli 1952 in der Werner-Seelenbinder-Halle zu Berlin, Berlin (Ost) 1952.

Eva Rickmers (Bearb.): Bezirkstag und Rat des Bezirkes Cottbus 1952-1990/91 (Rep. 801). Findbuch zum Bezirkstag und Rat des Bezirkes Cottbus (= Quellen, Findbücher und Inventare des Brandenburgischen Landeshauptarchivs, Bd. 21), Frankfurt am Main u. a. 2007.

Eva Rickmers: Aufgaben und Struktur der Bezirkstage und Räte der Bezirke in der DDR 1952-1990/91 am Beispiel des Bezirkes Cottbus. Eine verwaltungsgeschichtliche Studie (= Quellen, Findbücher und Inventare des Brandenburgischen Landeshauptarchivs, Bd. 22), Frankfurt am Main u. a. 2007.

Peter Ruggenthaler (Hg.): Stalins großer Bluff. Die Geschichte der Stalin-Note in Dokumenten der sowjetischen Führung (= Schriftenreihe der Vierteljahrshefte für Zeitgeschichte, Bd. 95), München 2007.

Willy Sägebrecht: Nicht Amboss, sondern Hammer sein. Erinnerungen, Berlin (Ost) 1968.

Friederike Sattler: Wirtschaftsordnung im Übergang. Politik, Organisation und Funktion der KPD/SED im Land Brandenburg bei der Etablierung der zentralen Planwirtschaft in der SBZ/DDR 1945-52 (= Diktatur und Widerstand, Bd. 5), Münster 2002.

Veit Scheller: Die regionale Staatsmacht. Der Rat des Bezirkes Chemnitz/Karl-MarxStadt 1952-1990 (= Veröffentlichungen des Sächsischen Staatsarchivs, Reihe A, Bd. 12), Halle/Saale 2009. 
Elke Scherstjanoi (Hg.): Das SKK-Statut. Zur Geschichte der Sowjetischen Kontrollkommission in Deutschland 1949 bis 1953, Eine Dokumentation (= Texte und Materialien zur Zeitgeschichte, Bd. 11), München 1998.

Michael F. Scholz: Die DDR 1949-1990 (= Gebhardt Handbuch der deutschen Geschichte, 10. Aufl., Bd. 22), Stuttgart 2009, S. 223-554.

Jens Schöne: Frühling auf dem Lande? Die Kollektivierung der DDR-Landwirtschaft, Berlin 2005.

Hans-Joachim Schreckenbach: Bezirksverwaltungen in den Ländern der ehemaligen Sowjetischen Besatzungszone Deutschlands 1945-1947, in: Jahrbuch für Regionalgeschichte 1 (1965), S. 49-80.

Rudolf Schwarzenbach: Die Kaderpolitik der SED in der Staatsverwaltung. Ein Beitrag zur Entwicklung des Verhältnisses von Partei und Staat in der DDR (1945-1975), Köln 1976.

Josef Stalin, Die ökonomischen Probleme des Sozialismus in der UdSSR, Moskau 1952.

Dietrich Staritz: Die Gründung der DDR. Von der sowjetischen Besatzungsherrschaft zum sozialistischen Staat, dritte erweiterte Aufl., München 1995.

Dieter Stüttgen (Bearb.): Schlesien (= Grundriss zur deutschen Verwaltungsgeschichte 1815-1945, Reich A: Preußen, Bd. 4), Marburg 1976.

Christian Thiem: Die Länderkammer der Deutschen Demokratischen Republik (19491958). Eine verfassungsgeschichtliche Darstellung von der Entstehung bis zur Auflösung (= Schriften zur Verfassungsgeschichte, Bd. 84), Berlin 2011.

Joachim Türke: Demokratischer Zentralismus und kommunale Selbstverwaltung in der sowjetischen Besatzungszone Deutschlands, Göttingen 1960.

Werner Vogel (Bearb.): Brandenburg (= Grundriss zur deutschen Verwaltungsgeschichte 1815-1945, Reich A: Preußen, Bd. 5), Marburg 1975.

Oliver Werner: Die ,Demokratisierung des Staatsapparates“ in der DDR als Beispiel administrativer Mobilisierung (1948 bis 1961), in: ders. (Hg.): Mobilisierung im Nationalsozialismus. Institutionen und Regionen in der Kriegswirtschaft und der Verwaltung des ,Dritten Reiches“ 1936 bis 1945, Paderborn 2013, S. 303-323.

Oliver Werner: Regionale Konstellationen und Mobilisierungsstrategien im „Dritten Reich“ und in der DDR, in: Andreas Kötzing u. a. (Hg.): Vergleich als Herausforderung. Festschrift zum 65. Geburtstag von Günther Heydemann, Göttingen 2015, S. 73-85.

Herbert Wolf u. a.: Der sozialistische Arbeitsstil und die Tätigkeit der Wirtschaftsräte, Berlin (Ost) 1959.

Edgar Wolfrum: Die Bundesrepublik Deutschland 1949-1990 (= Gebhardt Handbuch der deutschen Geschichte, 10. Aufl., Bd. 23), Stuttgart 2005. 


\section{Abkürzungsverzeichnis}

$\begin{array}{ll}\text { ABF } & \text { Arbeiter- und Bauernfakultät } \\ \text { Abs. } & \text { Absatz } \\ \text { Abt. } & \text { Abteilung } \\ \text { AfI } & \text { Amt für Information } \\ \text { Anm. } & \text { Anmerkung } \\ \text { Art. } & \text { Artikel } \\ \text { AVPRF } & \text { Archiv Vnešnej Politiki Rossijskoj Federacii (Archiv der Außenpolitik } \\ & \text { der Russischen Föderation) } \\ \text { BArch } & \text { Bundesarchiv } \\ \text { BdVP } & \text { Bezirksbehörde der Deutschen Volkspolizei } \\ \text { BEL } & \text { Bezirkseinsatzleitung } \\ \text { BGL } & \text { Betriebsgewerkschaftsleitung } \\ \text { BHG } & \text { Bäuerliche Handelsgenossenschaft } \\ \text { Bl. } & \text { Blatt } \\ \text { BLHA } & \text { Brandenburgisches Landeshauptarchiv } \\ \text { BPO } & \text { Betriebsparteiorganisation } \\ \text { bzw. } & \text { beziehungsweise } \\ \text { CDU } & \text { Christlich-Demokratische Union } \\ \text { DASR } & \text { Deutsche Akademie für Staats- und Rechtswissenschaft } \\ \text { DBD } & \text { Demokratische Bauernpartei Deutschlands } \\ \text { DDR } & \text { Deutsche Demokratische Republik } \\ \text { DFD } & \text { Demokratischer Frauenbund Deutschlands } \\ \text { d. h. } & \text { das heißt } \\ \text { DHZ } & \text { Deutsche Handelszentrale } \\ \text { DM } & \text { Deutsche Mark } \\ \text { Dok. } & \text { Dokument(e) } \\ \text { DVA } & \text { Deutsche Verwaltungsakademie } \\ \text { DWK } & \text { Deutsche Wirtschaftskommission } \\ \text { ebd. } & \text { ebenda } \\ \text { EVG } & \text { Europäische Verteidigungsgemeinschaft } \\ \text { FDGB } & \text { Freier Deutscher Gewerkschaftsbund } \\ \text { FDJ } & \text { Freie Deutsche Jugend } \\ \text { GHG } & \text { Großhandelsgesellschaft } \\ \text { GVS } & \text { Geheime Verschlusssache } \\ \text { HO } & \text { Handelsorganisation } \\ \text { KB } & \text { Kulturbund } \\ \text { KG } & \text { Konsumgenossenschaft } \\ \text { km } & \text { Kilometer } \\ & \\ & \end{array}$


Ko.-Ko.-Stelle Koordinierungs- und Kontrollstelle

KPD Kommunistische Partei Deutschlands

KPdSU Kommunistische Partei der Sowjetunion

KVP Kasernierte Volkspolizei

$\mathrm{kW} \quad$ Kilowatt

LDP Liberaldemokratische Partei

LPG Landwirtschaftliche Produktionsgenossenschaft

MAS Maschinen-Ausleih-Station

MdI Ministerium des Innern

m. E. meines Erachtens

MfS Ministerium für Staatssicherheit

MTS Maschinen-Traktoren-Station

NATO North Atlantic Treaty Organization

NDPD Nationaldemokratische Partei Deutschlands

NÖS Neues Ökonomisches System

Nr. Nummer

NSDAP Nationalsozialistische Deutsche Arbeiterpartei

o. a.

ÖLB

oben angeführt(en)

Org.

Örtlicher Landwirtschaftsbetrieb

Organisation(s)

RCChIDNI Rossijskij Centr Chranenija i Izučenija Dokumentov Novejšej Istorii (Russisches Zentrum zur Archivierung und Erforschung von Dokumenten zur Neuesten Geschichte)

Rep. Repositur

SBZ Sowjetische Besatzungszone

SED Sozialistische Einheitspartei Deutschlands

SKK Sowjetische Kontrollkommission

SMA Sowjetische Militäradministration

SMAD Sowjetische Militäradministration in Deutschland

SU Sowjetunion

Tbc Tuberkulose

u. und

u. a. und andere/unter anderem

UdSSR Union der Sozialistischen Sowjetrepubliken

USA United States of America

usw. und so weiter

VdgB Vereinigung der gegenseitigen Bauernhilfe

VE volkseigen(e)

VEAB Volkseigener Erfassungs- und Aufkaufbetrieb (für landwirtschaftliche Erzeugnisse)

VEG Volkseigenes Gut

VfZ Vierteljahrshefte für Zeitgeschichte

vgl. verglichen/vergleiche 


$\begin{array}{ll}\text { VP } & \text { Volkspolizei } \\ \text { VPKA } & \text { Volkspolizeikreisamt } \\ \text { VVB } & \text { Vereinigung Volkseigener Betriebe } \\ \text { VVEAB } & \text { Vereinigung Volkseigener Erfassungs- und Aufkaufbetriebe (für land- } \\ & \text { wirtschaftliche Erzeugnisse) } \\ \text { VVN } & \text { Vereinigung der Verfolgten des Naziregimes } \\ \text { VS } & \text { Verschlusssache(n) } \\ \text { z. B. } & \text { zum Beispiel } \\ \text { ZK } & \text { Zentralkomitee } \\ \text { ZKK / ZKSK } & \text { Zentrale Kommission für Staatliche Kontrolle } \\ \text { z. T. } & \text { zum Teil } \\ \text { Z. Zt. } & \text { zur Zeit }\end{array}$





\section{Personenregister}

Ackermann (Mitarbeiterin der Abteilung Finanzen im Bezirk Frankfurt (Oder)) 247

Adler (Mitarbeiter der Abteilung Plankommission im Bezirk Frankfurt (Oder)) 247

Adolphs, Karl 157

Albrecht, Hans 55

Altmann (stellvertretender Leitinstrukteur für den Bezirk Potsdam) 133, 185

Altwig (Mitarbeiter der Abteilung Industrie im Bezirk Frankfurt (Oder)) 247

Apelt (Mitarbeiter der ZKSK) 275

Armbrust, Willi 275, 279

Bartels (Instrukteur des Staatssekretariats für Nahrungs- und Genussmittelindustrie für das Land Brandenburg) 109

Barth, Willi 8, 9, 10, 23, 26, 37, 66, 73, 99, 222

Becker (Instrukteur des Ministeriums für Land und Forstgut für das Land Brandenburg) 109

Beer (Stellvertreter des Vorsitzenden des Rates des Bezirkes Potsdam) 142, 173

Bestla (Abgeordneter im Bezirkstag Cottbus) 217

Bombach, Erich 125, 126

Bönicke (Instrukteur des Ministeriums für Aufbau für das Land Brandenburg) 110

Brasch, Horst 159, 212, 213, 215, 219 , 220, 259

Bruk, Franz 215

Bruschke, Werner 229

Buhl (Mitarbeiterin der Abteilung Plankommission im Bezirk Frankfurt (Oder)) 240, 247

Bulganin, Nikolai Alexandrowitsch 25
Cabbe (Mitglied des Landessekretariats Brandenburg der Nationalen Front) 125

Danneberg (Vertreter des MdI in der Gebäudekommission) 80

Dietus (Abgeordneter im Bezirkstag Cottbus) 217

Dittrich (Leiter der Abteilung Allgemeine Verwaltung im Bezirk Potsdam) 195

Dommaschk (Leiter der Org.-InstrukteurAbteilung im Kreis Forst) 257, 259

Ebert, Friedrich 38

Eggerath, Werner 8, 13, 25, 26, 28, 29, $30,31,42,61,69,72,77,79,82,83$, $104,139,143,154,156,157,158,159$, $160,161,203,222$

Else (Leiter der Abteilung Landwirtschaft im Bezirk Frankfurt (Oder)) 247

Ettlinger 106, 128

Fischer (Instrukteur der Deutschen Verwaltungsakademie für das Land Brandenburg) 109

Fleischmann, Martin 181

Fritz (Mitglied des Rates des Bezirkes Frankfurt (Oder)) 250, 251

Ganske (Leiterin der Brigade des Ministeriums für Justiz) 130, 131

Gebhardt (Hauptabteilungsleiter Justiz des Landes Sachsen-Anhalt) 132

Geiss, Willi 83, 86

Geyer, Fritz 38, 156, 222

Glaser (Leiter der Abteilung Leitende Parteiorgane) 80

Glück (Mitarbeiter im Ministerium für Justiz) 130

Götz (Landrat im Kreis Seelow) 228

Grafe (Hauptabteilungsleiter Justiz des Landes Sachsen) 132 
Grävenrath (Hauptabteilungsleiterin Justiz des Landes Mecklenburg) 132

Grotewohl, Otto 8, 20, 21, 29, 39, 69, 99, 143, 151, 182, 293, 294, 295

Grundhoff (Vorsitzender des Rates des Kreises Königs Wusterhausen) 200

Grüneberg, Gerhard 215

Grünewald (Sekretär des Rates des Bezirkes Potsdam) 197

Gschwandner (Leitinstrukteur für den Bezirk Dresden) 133

Hamann, Karl 232

Handtke (Abgeordneter im Bezirkstag Cottbus) 217

Hentschel, Paul 55

Hermann (Vorsitzender der Unterkommission Kaderfragen der Bezirkskommission Cottbus) 213

Heyden, Günter 29, 37

Hollerith, Herman 127

Holweger, Erhard 215

Hoppe (Energiebeauftragter im Bezirk Frankfurt (Oder)) 242

Jahn, Rudolf 29, 66, 68, 104, 107, 119 , 128, 129, 130, 134, 153

Jatzke (Leitinstrukteur für den Bezirk Gera) 133

Jendretzky, Hans 275, 276, 277, 278, 279, 280

Johanson (Stellvertreter des Vorsitzenden des Rates des Bezirkes Frankfurt (Oder)) 246, 247

John (Abteilungsleiter Volksbildung im Bezirk Potsdam) 195

Kaste (Instrukteur des Ministeriums für Volksbildung für das Land Brandenburg) 109

Kelle (Leitinstrukteur für den Bezirk Halle) 133

Kereit (Leitinstrukteur für den Bezirk Schwerin) 133

Kernchen (Abgeordneter im Bezirkstag Cottbus) 217
Kiesche (Leitinstrukteur für den Bezirk Frankfurt (Oder)) 133

Kisling (2. Sekretär der Bezirkskommission Cottbus) 215

Klose (Mitglied des Landessekretariats Brandenburg der Nationalen Front) 125

Klühsendorf (Abteilungsleiter im Ministerium für Justiz) 130

Koerber (Mitglied des Rates des Bezirkes Frankfurt (Oder) 251

Köhler (Sekretär beim Rat des Kreises Forst) 259

Kopetschke (Abgeordneter im Bezirkstag Cottbus) 217, 219

Kröger, Herbert 25, 38, 158

Krüger (Instrukteur der Staatlichen Kommission für Kunstangelegenheiten für das Land Brandenburg) 109

Kuppke (Abgeordneter im Bezirkstag Cottbus) 217

Küster (Mitarbeiter im Ministerium für Justiz) 130

Lange, Ernst 25, 79, 80, 135, 139, 150, 186

Lange, Fritz 82, 222

Lange (Leiter der Abteilung Kommunale Wirtschaft im Bezirk Frankfurt (Oder)) 240, 243, 245

Langner, Margarete 215

Leidert (Leitinstrukteur für den Bezirk Chemnitz) 133

Leimbach (Oberreferent Finanzen im Bezirk Frankfurt (Oder)) 241

Lentzsch, Bruno 68, 80, 111, 134, 139

Leuschner, Bruno 46, 265

Lindner, Ernst (Leiter der Kommission für Landwirtschaft und ländliches Bauwesen im Bezirk Potsdam) 227

Lindner (Vorsitzender der Ständigen

Kommission im Bezirk Potsdam) 196

Litwinow, Maxim Maximowitsch 20

Loch, Hans 232, 234 
Lohrisch (Abgeordneter der Nationalen Front für den Kreis Ruppin) 125

Malenkow, Georgi Maximilianowitsch 25

Malter, Friedel 160

Manneberg, Werner 26, 83, 156, 179, $180,215,219,220$

Matern, Hermann 38

Mehner (Leiter der Org.-Instrukteur-Abteilung im Bezirk Cottbus) 259, 261

Meißner (Referentin für Heimerziehung im Bezirk Frankfurt (Oder)) 244

Mielisch (Vorsitzender der Unterkommission Bezirkstag und Kreistage der Bezirkskommission Cottbus) 213

Mierau, Hans 180

Mikojan, Anastas Iwanowitsch 25

Moeller (Leiter der Abteilung Industrie im Bezirk Frankfurt (Oder)) 246

Molotow, Wjatscheslaw Michailowitsch 25

Müller (Mitglied des Rates des Bezirkes Frankfurt (Oder)) 251

Münchenhagen, Walter 176, 179, 180, 215

Nagel (Sekretär beim Rat des Kreises Lübben) 259

Neddermeyer, Robert (Abgeordneter der Nationalen Front für den Kreis Angermünde) 54, 125

Neser (Instrukteurin der Staatlichen Plankommission für das Land Brandenburg) 109

Neumann (Abteilungsleiter Erfassung und Aufkauf im Bezirk Potsdam) 195

Nobis (Abgeordneter im Bezirkstag Cottbus) 217

Nuß (Abgeordneter der Nationalen Front für den Kreis Prenzlau) 125

Oelpke (Leitinstrukteur für den Bezirk Erfurt) 133

Opitz, Gerhard 275, 278, 280

Paetzold (Mitarbeiter im Ministerium für Justiz) 130
Palluck (Leiter der MAS Fröhden) 176

Pansegrau (Leiter der Abteilung Erfassung und Aufkauf im Bezirk Frankfurt (Oder)) 240, 241

Paulitz (Instrukteur des Ministeriums der Finanzen für das Land Brandenburg) 109, 201

Pech (Abgeordneter der Nationalen Front für den Kreis Templin) 125

Pech (Mitglied des Rates des Bezirkes Frankfurt (Oder)) 250, 251

Pelz (Sachbearbeiterin Materialversorgung im Bezirk Frankfurt (Oder)) 244

Peplinski, Franz 37, 46, 248, 249, 250, 251, 275, 276, 277, 279, 281

Perschke (Leitinstrukteur für den Bezirk Cottbus) 133

Pieck, Wilhelm 25, 271

Plenikowski, Anton 23, 24, 25, 26, 32 , $37,38,79,82$

Polak, Karl 26

Poppen (Leiter der Plankommission im Bezirk Potsdam) 195

Puchert, Herbert 51

Radonski (Leitinstrukteur für den Bezirk Neubrandenburg) 133

Rau, Heinrich 77

Ristau (Mitarbeiter der Org.-InstrukteurAbteilung im Bezirk Cottbus) 261

Rumpf, Willy 82, 83, 112

Sägebrecht, Willy 51

Samtlebe (2. Sekretär der Bezirkskommission Cottbus) 215

Schaumann (Abteilungsleiter Handel und Versorgung im Bezirk Potsdam) 195

Schaumburg (Instrukteur des Ministeriums für Handel und Versorgung für das Land Brandenburg) 109

Schiener (Mitarbeiter der Koordinierungsund Kontrollstelle) 185

Schirdewan, Karl 54

Schlicht (Leitinstrukteur für den Bezirk Leipzig) 133 
Schmude (Mitarbeiter der Stellenplaninspektion im Bezirk Potsdam) 202

Scholz, Paul 62, 83, 264

Schön, Otto 55

Schröder (Mitarbeiter der Abteilung Finanzen im Bezirk Frankfurt (Oder)) 241

Schröder, Wilhelm 171

Schultz (Sekretär der BPO des Rates des Bezirkes Frankfurt (Oder)) 275

Schulz (Leitinstrukteur für das Land Brandenburg, später Leitinstrukteur für den Bezirk Potsdam) 30, 105, 117, $118,133,142$

Schulze (Instrukteur des Amts für Information für das Land Brandenburg) 109

Schuster 105

Schütte (Abgeordneter im Bezirkstag Cottbus) 217

Seibt, Kurt 80, 125, 140, 174, 215

Seigewasser, Hans 38, 81

Siegmeyer (Vorsitzender der Unterkommissionen Gebäudefragen und Überleitung der Bezirkskommission Cottbus) 213

Singula (Leiter der Materialversorgung im Bezirk Potsdam) 194

Sinschek (Leiter der Abteilung Finanzen im Bezirk Frankfurt (Oder)) 252

Söhnel (Leitinstrukteur für den Bezirk Suhl) 133

Sokolowski, Wassili Danilowitsch 20

Sorgenicht, Klaus 23, 24, 25, 26, 37, 79, $83,169,275,278,280,281$

Spiller (Instrukteur des Statistischen Zentralamts für das Land Brandenburg) 109

Spranger (Hauptabteilungsleiter Justiz des Landes Thüringen) 132

Springer, Günter 50, 251, 275, 279, 281

Stadler, Josef 45, 75, 271

Stalin, Josef Wissarionowitsch 10, 25, $151,152,227,244$
Steffen, Erwin 42

Steininger (Leiter der Abteilung Volksbildung im Bezirk Frankfurt (Oder)) 252

Stettiner (Instrukteur des Ministeriums für Gesundheitswesen für das Land Brandenburg) 109

Stoph, Willi 37, 295, 296

Streit, Hermann 83, 174

Syring (Mitarbeiter der Abteilung Plankommission im Bezirk Frankfurt (Oder)) 247

Täschner, Herbert 232, 234

Thode (Instrukteur des Staatssekretariats für Berufsausbildung für Ministeriums für das Land Brandenburg) 109

Thomas (Leitinstrukteur für den Bezirk Rostock) 133

Toeplitz, Heinrich 130

Trotz (Mitarbeiter der ZKSK) 275

Tschuikow, Wassili Iwanowitsch 25

Ulbricht, Walter 18, 23, 26, 27, 46, 47, $51,77,82,147,179,206,223,231$, 263, 266, 270, 298

Utech (Hauptabteilungsleiter Justiz des Landes Brandenburg, später Vorsitzender des Rates des Kreises Pritzwalk) 132, 173

Vater (Leiter der Abteilung Allgemeine Verwaltung im Bezirk Frankfurt (Oder)) 241, 246, 247

Volkmann (Leitinstrukteur für den Bezirk Magdeburg) 133

Voß (Instrukteurin des Ministeriums für Arbeit für das Land Brandenburg) 109, 110

Voß (Mitarbeiter der Org.-InstrukteurAbteilung im Bezirk Cottbus) 261

Wach, Curt 68, 69, 136, 138, 141, 143, $161,167,168,171,172,173,174,175$, 181, 184, 190, 197, 215

Wandel, Paul 77

Warnke, Hans 24, 26, 32, 38, 67, 74, 79, $82,112,263,264,270,275$ 
Weigmann (Leiter der Abteilung Information im Bezirk Frankfurt (Oder)) 241, 244

Weißkopf (Abgeordneter im Bezirkstag Cottbus) 217

Wenk, Fera-Ina (Abgeordnete im Bezirkstag Cottbus) 217

Werk (Abteilungsleiter im Ministerium für Justiz) 130

Westphal (Leiter der Org.-InstrukteurAbteilung im Bezirk Potsdam) 194

Westphal, Otto (Abteilungsleiter Finanzen im Bezirk Potsdam) 195

Wierick 106, 128

Wilke (Instrukteur der Staatlichen Verwaltung für Materialversorgung für das Land Brandenburg) 109
Wittkowski, Margarete 264

Wundke (Kaderinstrukteurin der Bezirksleitung der SED Frankfurt (Oder)) 252

Wutke (Landrat in Oranienburg) 173

Wuttke (Abgeordneter im Bezirkstag Cottbus) 217,219

Zaiger (Leiter der Abteilung Plankommission im Bezirk Frankfurt (Oder)) 241, 246, 247, 251

Zaisser, Wilhelm 111

Ziemainz (Vorsitzender der Unterkommission Territoriale Fragen der Bezirkskommission Cottbus) 213

Zwiekirsch (Instrukteur des Ministeriums für Arbeit für das Land Brandenburg) 110 



\section{Ortsregister}

Adorf 116

Altes Lager 174, 175

Angermünde (Kreis) 35, 36, 124, 125, 156,249

Bad Berka 115

Bad Elster 116

Bad Freienwalde 36

Bad Freienwalde (Kreis) 36, 129

Bad Liebenwerda 177

Bad Liebenwerda (Kreis) 36, 113, 128, 256, 257

Bad Salzungen (Kreis) 115

Beeskow 36, 135

Beeskow (Kreis) 36, 53

Beeskow-Storkow (Kreis) 36

Belzig (Kreis) 36, 50, 170, 191, 199, 201, 271, 274

Bernau (Kreis) 36, 112, 129, 173

Boizenburg 114

Brandenburg/Havel 34, 36, 95, 186

Brandenburg/Havel (Kreis) 36, 141, 170, 271

Brandenburg (Land) 9, 11, 13, 14, 15, 16, $18,24,27,28,29,30,33,34,35,36$, $42,50,51,52,57,60,63,66,67,68$, 69, 72, 79, 80, 104, 105, 107, 108, 109, $111,119,124,125,127,132,134,135$, $136,139,141,142,156,185,191,201$, 202, 208, 215, 224, 274

Brandenburg/Land (Kreis) 198, 199

Brandenburg (Mark) 35

Brandenburg (Provinz) 35, 36

Calau (Kreis) 36

Chemnitz/Karl-Marx-Stadt 113, 231, 293

Chemnitz/Karl-Marx-Stadt (Bezirk) 57, $79,113,114,133,188,233,288$

Cleve 115
Cottbus 30, 31, 34, 52, 136, 170, 171, $218,219,263$

Cottbus (Bezirk) 8, 9, 11, 13, 16, 28, 30, $31,32,33,35,36,41,48,52,53,55$, $57,63,66,67,68,71,73,74,79,96$, 107, 109, 114, 117, 124, 128, 129, 133, $134,135,136,141,156,159,170,176$, $181,188,212,213,215,224,256,257$, 258, 259, 264, 287, 289

Cottbus (Kreis) 36, 214, 215, 220

Cottbus-Land (Kreis) 256, 257, 262

Doberlug 114

Dömitz 115

Drachhausen 262

Dresden 157, 224, 232

Dresden (Bezirk) 10, 79, 133, 156, 171, 188, 220, 222, 233, 288

Eberswalde 34

Eberswalde (Kreis) 36

Eisenach (Kreis) 115

Eisenhüttenstadt 34

Erfurt 293

Erfurt (Bezirk) 79, 113, 133, 188, 288, 289, 290, 292

Finsterwalde 36

Finsterwalde (Kreis) 214, 256, 257, 258, 260

Forst 34, 36

Forst (Kreis) 140, 158, 214, 256, 257, $258,259,260,261$

Forst Zinna 158

Frankfurt (Oder) 30, 31, 34, 52, 134, 135, 136, 226, 231, 251

Frankfurt (Oder) (Bezirk) 9, 11, 13, 15, $16,30,31,32,33,35,36,41,44,50$, 52, 53, 55, 63, 66, 67, 68, 74, 79, 97 , $98,107,109,112,117,124,128,129$, 
$133,134,135,136,156,173,181,186$, $188,215,239,241,248,249,251,275$, 288

Freienhufen 264

Fröhden 175, 176

Fürstenberg 36, 135, 156

Fürstenberg (Kreis) 36, 156

Fürstenwalde (Kreis) 36

Gadebusch (Kreis) 114

Gera (Bezirk) 79, 113, 133, 157, 188, 287, 288

Gera (Kreis) 113

Görlitz 35

Grabow 115

Gransee 36, 135, 211

Gransee (Kreis) 33, 36, 173, 175, 199, 201, 207, 209, 271

Grevesmühlen (Kreis) 113, 114

Groß-Glienicke 201

Großprignitz 162

Guben 34

Guben (Kreis) 36, 51, 214, 220

Hagenow 114

Hagenow (Kreis) 114

Haldensleben (Kreis) 115

Halle (Bezirk) 79, 133, 188, 233, 287, 288

Halle/Saale 224

Havelberg (Kreis) 35

Heiligenstadt (Kreis) 115

Hennigsdorf 95

Herzberg 36

Herzberg (Kreis) 113, 151

Hildburghausen (Kreis) 115

Hoyerswerda 35, 114

Hoyerswerda (Herrschaft) 36

Hoyerswerda (Kreis) 36, 128

Jena-Stadtroda (Kreis) 224

Jerichow I (Kreis) 36

Jerichow II (Kreis) 36

Jessen 36

Jessen (Kreis) 113, 214, 257
Jüterbog (Kreis) 36, 141, 170, 175, 199, 209, 271

Kirchhain 114

Kirchmöser 95

Königs Wusterhausen 36

Königs Wusterhausen (Kreis) 36, 169 , 170, 176, 185, 198, 200, 209, 255, 271, 272

Kreuzburg 115

Kyritz 217

Kyritz (Kreis) 36, 175, 184, 186, 199, 207, 271

Lauchhammer 114, 224

Lebus (Kreis) 36

Leipzig 158

Leipzig (Bezirk) 58, 79, 133, 157, 188, 233, 288

Liegnitz (Verwaltungsbezirk) 36

Lübben 114

Lübben (Kreis) 36, 259

Lübbenau 114

Luckau (Kreis) 36, 213, 214, 260

Luckenwalde (Kreis) 36, 170, 200, 271, 274

Ludwigslust 115

Ludwigslust (Kreis) 115

Magdeburg (Bezirk) 35, 79, 133, 188, 224, 233, 287, 289

Mahlow 198

Mecklenburg (Land) 15, 30, 79, 104, 132, 152

Meiningen (Kreis) 115

Mühlhausen (Kreis) 115

Nauen (Kreis) 36, 141, 161, 167, 185, 196, 227, 271, 272, 296

Neubrandenburg 113

Neubrandenburg (Bezirk) 30, 35, 79, 112, 113, 133, 188, 275, 278, 287, 288, 289, 292

Neuheim 227

Neuruppin 24, 28, 272, 273

Neuruppin (Kreis) 36, 207

Niederbarnim (Kreis) 33, 36 
Nordhausen (Kreis) 115

Oberbarnim (Kreis) 36, 124

Oelsnitz (Kreis) 116

Ölsen (Kreis) 114

Oranienburg 24, 28, 33, 36, 79, 135, 272, 296

Oranienburg (Kreis) 33, 36, 173, 175, 199, 207

Ost-Berlin 9, 156, 175, 180, 198, 202, 270, 289, 290

Osthavelland (Kreis) 36

Ostprignitz (Kreis) 35, 36, 124, 125, 126, 141, 167

Perleberg 113

Perleberg (Kreis) 112, 113, 115

Plaue 211

Plauen 113

Plauen (Kreis) 116

Potsdam 12, 15, 19, 30, 31, 33, 34, 36, $52,95,113,116,118,134,135,167$, $170,174,175,185,186,198,203,210$, 224, 293

Potsdam (Bezirk) 9, 10, 11, 13, 15, 16, $24,29,30,31,32,33,35,36,41,42$, $45,48,51,52,53,54,55,56,63,66$, $67,68,69,70,71,72,73,74,75,76$, 79, 94, 95, 96, 104, 105, 107, 109, 112 , $117,124,127,129,133,134,135,136$, $137,138,139,140,141,142,161,167$, $168,169,170,171,172,173,175,181$, $182,184,188,190,192,193,201,202$, 206, 207, 211, 215, 217, 220, 227, 241, 253, 271, 272, 287, 289, 292, 293, 296

Potsdam (Kreis) 272

Potsdam/Land (Kreis) 200, 201, 207

Potsdam (Stadtkreis) 36

Prenzlau (Kreis) 35, 104, 112, 113, 124, 125,126

Preußen (Land) 16, 35

Pritzwalk 36, 135, 198

Pritzwalk (Kreis) 36, 173, 175, 186, 272, 273

Randow (Kreis) 36
Rathenow 34, 272, 274

Rathenow (Kreis) 36, 199, 200

Römhild 115

Rostock 113, 268

Rostock (Bezirk) 74, 79, 112, 113, 133, 188, 215, 263, 275, 288

Rothenburg 35

Rothenburg (Kreis) 36

Ruhland 114

Ruppin (Kreis) 36, 124, 125, 201

Saalfeld (Kreis) 116

Sachsen-Anhalt (Land) 15, 30, 36, 79, 96, 104, 113, 128, 132, 189, 224

Sachsen (Land) 10, 30, 35, 79, 96, 114, $132,152,156,224$

Sacrow 175

Salzwedel 115

Salzwedel (Kreis) 115

Schlesien (Provinz) 35, 36

Schmerwitz 50

Schönberg 114

Schönberg (Kreis) 114

Schönhagen 273

Schönholz 200

Schwedt 34

Schweinitz (Kreis) 36

Schwerin 113

Schwerin (Bezirk) 34, 35, 79, 112, 113, $133,188,287,288$

Sedlitz 260

Seelow (Kreis) 36, 124, 228, 231

Senftenberg 36, 114, 224

Spremberg (Kreis) 36, 213, 256, 257, 260

Stalinstadt 63, 240, 244, 245, 246

Stalinstadt (Kreis) 55

Stolberg (Kreis) 114

Strausberg 36, 135

Strausberg (Kreis) 36, 251

Suhl (Bezirk) 113, 133, 188, 224, 287

Tattendorf 114

Teltow (Kreis) 36, 51

Templin (Kreis) 35, 36, 104, 112, 113, 124, 125, 174 
Thüringen (Land) $15,25,77,79,113$, $132,157,171,189,224$

Tietzow 196

Torgau (Kreis) 36

Tützpatz 264

Untermaßfeld 115

Vogelsang 174

Weimar 258

Weißwasser 36, 114

Weißwasser (Kreis) 214

West-Berlin 29, 62, 63, 76, 112, 113, 137, 168

Westhavelland (Kreis) 36, 124, 125

Westprignitz (Kreis) 35, 104, 111, 112

Wildau 95
Wismar 113

Wismar (Kreis) 113

Wittenberge 34

Wittenberg (Kreis) 36

Wittenburg 114

Wittstock 36

Wittstock (Kreis) 36, 186, 200, 207, 272

Worbis (Kreis) 115

Zarenthin 114

Zauch-Belzig (Kreis) 36, 168, 169

Zeestow 167

Zossen 36

Zossen (Kreis) 36, 51, 169, 170, 198, 199, 207, 272, 296

Zwickau (Kreis) 114 

Mit der Verwaltungsreform vom 23. Juli 1952 gab sich die erst drei Jahre zuvor gegründete DDR eine (staatliche) Verwaltungsstruktur, die bis zur Wende 1989/1990 erhalten blieb. Die faktische Abschaffung der Länder und ihre Neugliederung in 14 Bezirke stellten den tiefgreifendsten Umbau der Staatsorganisation der DDR in all den Jahren ihres Bestehens dar.

Die hier präsentierten 62 Quellen dokumentieren die Bildung und Etablierung der Bezirke in Brandenburg von 1952 bis 1960. Die Beweggründe und konzeptionellen Überlegungen der Initiatoren stehen ebenso im Blickfeld wie die konkreten Maßnahmen und praktischen Probleme des Übergangs von der Länder- zur Bezirksstruktur. Der Fokus richtet sich außerdem auf die Beziehungen zwischen den Instanzen, deren Qualität sich in Kontrollberichten, Verhandlungsprotokollen, intern gehaltenen Einschätzungen und nicht zuletzt in Erfahrungsberichten von Parteiund Staatsfunktionären niederschlug.

Der informelle und interne Charakter dieser Quellen ermöglicht es, die bürokratische Praxis der DDR zu untersuchen und zugleich die Grenzen einer Selbstevaluierung des politischen und administrativen Systems zu erkennen. 